\title{
Technical Analysis of Projects Being Funded by the DOE Hydrogen Program
}

\author{
Final Report
}

\section{Submitted By}

Energetics, Incorporated

In Partial Fulfillment of

Contract DE-FC36-00G010602

February 2006 


\section{Technical Analysis of Projects Being Funded by the DOE Hydrogen Program}

In July 2000, Energetics began a project in which we performed site-visit based technical analyses or evaluations on hydrogen $\mathrm{R} \& \mathrm{D}$ projects for the purpose of providing in-depth information on the status and accomplishments of these projects to the public, and especially to hydrogen stakeholders. In July of 2001, an annual report for Year One of the project was submitted.

During the second year of this project, which was given a three-month extension (July 2001-September 2002) Energetics performed tasks in three different categories: SiteVisit-Based Technical Analysis, In-Depth Analyses, and A Compilation of Site Visit Analyses 1995-2001.

The third year of the report was originally scheduled to receive an increase in funding that would allow Energetics to double our effort. We thus had proposed for Year 3, tasks covering 25 site-visits plus 3 new in-depth analyses and the compilation of all of the rest of the site visits (July 2001 - end of contract). We were awarded the increase, but were then asked to spread the work out over two years. Subsequently, we were given limited funds during Year Three, and then received no money to finish the project. Thus, Year Three consisted of a limited number of site-visit based analyses. In addition, Energetics, with the consent of our contract monitor moved into a more safety analysis focus. The last few projects that were evaluated had to do with safety. (e.g., sensor projects) as well as performing safety assessments of demonstration and research projects. In order to do the latter, several site-visits involved data gathering. That is, visits were made to locations where active demonstrations were being carried out, in order to delve into the types of safety procedures and practices that were being performed in conjunction with the project. From these the plan was to develop a protocol for safety evaluations. The active work on this project ended at the end of September 2003, and the safety work continued via separate funding.

The work performed on the GO contract is summarized below.

\section{Task 1: Site-Visit-Based Technical Analysis}

During the period of the contract, Energetics visited a total of 32 projects that, at the time of the visit were being funded by the Department of Energy (DOE) Hydrogen Program. These projects together with the dates of the site visits are shown in Exhibit 1. The methodology for conducting the evaluations is as follows:

Each project was chosen for technical assessment by the Program (as required by the statement of Work for this Contract). Energetics then conducted a literature review on the subject. This included a review of the last two or three years of Annual Operating Plan submittals, monthly reports, the Annual Review paper, published reviewers' consensus comments from the past few years, publications in journals, and journal publications on the same or similar topics by other researchers. Following completion of the literature 
review, the Principal Investigator (PI) was then contacted, and an on-site visit arranged. A set of topic questions or discussion points was then drawn up based on the literature review, and sent to the PI one to two weeks prior to the visit.

The site-visit itself included a presentation by the PI (formal or informal) on the project and its current status, a tour of the laboratory in which the project is being conducted, preferably including a demonstration of the experimental process (es), and detailed discussions based on the topic questions and on any other items that came out of the tour, demonstration, and presentation. Each on-site visit lasted anywhere from a half-day to over a full day. Following the meeting, Energetics wrote a comprehensive report discussing the project in detail.

Of the 32 site-visits, ten were conducted during Year One of the contract, and the reports for them were included with the first Annual Report, dated July 2001. Fifteen site-visits were conducted during Year Two of the contract, and the corresponding reports for them were included with the second Annual Report, dated December 2002. The remaining seven site visits were conducted during the truncated final period of the contract. Copies of those seven site-visit reports as well as the previous 25 , are attached to this document.

\section{Task 2: In-Depth Analyses}

Energetics performed two in-depth analyses to complement the site visit evaluations. The two in-depth analyses were:

1. Analysis of a Hybrid Hydrogen Production System Using a Solar Reactor and Steam Methane Reformer

\section{Comparative Analysis of Three Compressed Hydrogen Storage Systems}

The plan was to continue doing In-depth Analyses in Year Three., but funding was insufficient. The two in-depth analysis reports were included with the second annual report, and are attached to this report as well.

\section{Task 3: A Compilation of Site Visit Analyses}

During Year Two, Energetics produced a compilation document that contains each sitevisit analysis that we had performed, starting in 1995 (on earlier contracts) through the end of Year One of this project (July 2001). The earlier reports were reformatted to put them into the more streamlined style we had developed. The document also included an introductory section that provided the stakeholder/reader with an overview of the entire series of evaluations to date, including a description of the methodology and also included an afterward that briefly discussed what has happened to some of the projects or project personnel since that particular report was written. 
The Compilation was included in the package with the second annual report, as a separate volume, and was also provided at the same time as a CD ROM in pdf format.

Originally the plan was to provide a second compiled volume including all of the sitevisits from the last two years of this project, but again, this plan was terminated due to the funding shortage. 
Exhibit 1. Table of Projects for Site Visit - Based Technical Analyses

\begin{tabular}{|c|c|c|c|}
\hline Project & $\begin{array}{l}\text { Performing } \\
\text { Organization }\end{array}$ & $\begin{array}{l}\text { Principal } \\
\text { Investigator }\end{array}$ & Date of Site Visits \\
\hline $\begin{array}{l}\text { Dual Bed } \\
\text { Photocatalytic } \\
\text { Water Splitting }\end{array}$ & $\begin{array}{l}\text { Florida Solar } \\
\text { Energy Center }\end{array}$ & Dr. Clovis Linkous & September 22, 2000 \\
\hline $\begin{array}{l}\text { Production of } \\
\text { Hydrogen Through } \\
\text { Electrolysis }\end{array}$ & $\begin{array}{l}\text { Proton Energy } \\
\text { Systems }\end{array}$ & Mr. Rob Friedland & December 7, 2000 \\
\hline Plasma Reformer & $\begin{array}{l}\text { Massachusetts } \\
\text { Institute of } \\
\text { Technology } \\
\end{array}$ & Dr. Leslie Bromberg & December 8, 2000 \\
\hline $\begin{array}{l}\text { Novel Hydrogen } \\
\text { Storage Materials }\end{array}$ & $\begin{array}{l}\text { National Renewable } \\
\text { Energy Laboratory }\end{array}$ & Dr. Mike Heben & February 15,2001 \\
\hline $\begin{array}{l}\text { Maximizing } \\
\text { Photosynthetic } \\
\text { Efficiencies for } \\
\text { Hydrogen } \\
\text { Production }\end{array}$ & $\begin{array}{l}\text { University of } \\
\text { California, Berkeley }\end{array}$ & Dr. Tasios Melis & $\begin{array}{l}\text { February 27-28, } \\
2001\end{array}$ \\
\hline $\begin{array}{l}\text { Reversible Solid } \\
\text { Oxide Fuel Cells }\end{array}$ & $\begin{array}{l}\text { Technology } \\
\text { Management, Inc. }\end{array}$ & $\begin{array}{l}\text { Drs. Robert Ruhl } \\
\text { and Christopher } \\
\text { Milliken }\end{array}$ & March 20, 2001 \\
\hline $\begin{array}{l}\text { Vehicular Hydrogen } \\
\text { Storage Using } \\
\text { Cryogenic } \\
\text { Hydrogen }\end{array}$ & $\begin{array}{l}\text { Lawrence } \\
\text { Livermore National } \\
\text { Laboratory }\end{array}$ & Dr. Salvador Aceves & May 2, 2001 \\
\hline $\begin{array}{l}\text { Hydrogen Internal } \\
\text { Combustion Engine } \\
\text { Research }\end{array}$ & $\begin{array}{l}\text { Sandia National } \\
\text { Laboratories }\end{array}$ & $\begin{array}{l}\text { Dr. Peter } \\
\text { VanBlarigan }\end{array}$ & May 3, 2001 \\
\hline $\begin{array}{l}\text { Thermal } \\
\text { Dissociation of } \\
\text { Methane Using } \\
\text { Solar Coupled } \\
\text { Reactor }\end{array}$ & $\begin{array}{l}\text { University of } \\
\text { Colorado }\end{array}$ & $\begin{array}{l}\text { Dr. Al Weimer } \\
\text { (with Dr. Al } \\
\text { Lewandowski } \\
\text { (NREL) }\end{array}$ & June 13,2001 \\
\hline $\begin{array}{l}\text { Biological } \mathrm{H}_{2} \text { From } \\
\text { Fuel Gases and } \\
\text { Water }\end{array}$ & $\begin{array}{l}\text { National Renewable } \\
\text { Energy Laboratory }\end{array}$ & $\begin{array}{l}\text { Dr. Pin-Ching } \\
\text { Maness }\end{array}$ & July 2-3, 2001 \\
\hline $\begin{array}{l}\text { Gallium Nitride } \\
\text { Integrated } \\
\text { Gas/Temperature } \\
\text { Sensors for Fuel } \\
\text { Cell System } \\
\text { Monitoring for } \\
\text { Hydrogen and } \\
\text { Carbon Monoxide }\end{array}$ & $\begin{array}{l}\text { Peterson Ridge } \\
\text { LLC/ Fluence }\end{array}$ & Dr. Steve Pyke & September 5, 2001 \\
\hline
\end{tabular}




\begin{tabular}{|c|c|c|c|}
\hline $\begin{array}{l}\text { Supercritical Water } \\
\text { Partial Oxidation }\end{array}$ & General Atomics & Mr. Niles Johanson & November 7, 2001 \\
\hline $\begin{array}{l}\text { Hydrogen } \\
\text { Commercialization } \\
\text { for the } 21 \text { st Century }\end{array}$ & $\begin{array}{l}\text { SunLine Services } \\
\text { Group }\end{array}$ & Mr. Bill Clapper & November 27, 2001 \\
\hline $\begin{array}{l}\text { Thermocatalytic } \\
\text { CO2-Free } \\
\text { Production of } \\
\text { Hydrogen From } \\
\text { Hydrocarbon Fuels }\end{array}$ & $\begin{array}{l}\text { Florida Solar } \\
\text { Energy Center }\end{array}$ & Dr. Nazim Muradov & February 11, 2002 \\
\hline $\begin{array}{l}\text { High-Efficiency } \\
\text { Steam Electrolyzer }\end{array}$ & $\begin{array}{l}\text { Lawrence } \\
\text { Livermore National } \\
\text { Laboratory }\end{array}$ & Dr. Quoc Pham & February 20, 2002 \\
\hline $\begin{array}{l}\text { Thermal Hydrogen } \\
\text { Compression }\end{array}$ & Ergenics, Inc. & $\begin{array}{l}\text { Mr. Dave DaCosta/ } \\
\text { Mr. Mark Golben }\end{array}$ & March 19, 2002 \\
\hline $\begin{array}{l}\text { Microchannel } \\
\text { Reforming }\end{array}$ & InnovaTek & Dr. Lloyd Allen & April 17, 2002 \\
\hline $\begin{array}{l}\text { Superadiabatic } \\
\text { Decomposition of } \\
\text { Hydrogen Sulfide }\end{array}$ & $\begin{array}{l}\text { Gas Technology } \\
\text { Institute }\end{array}$ & Dr. Rachid Slimane & April 23, 2002 \\
\hline $\begin{array}{l}\text { Biohydrogen } \\
\text { Production in a } \\
\text { Mixed Culture } \\
\text { Fermenter }\end{array}$ & $\begin{array}{l}\text { Iowa State } \\
\text { University }\end{array}$ & Dr. Shih-wu Sung & August 7, 2002 \\
\hline $\begin{array}{l}\text { New Glass-Ceramic } \\
\text { Proton Conducting } \\
\text { Membrane }\end{array}$ & $\begin{array}{l}\text { Iowa State } \\
\text { University }\end{array}$ & Dr. Steve Martin & August 8, 2002 \\
\hline $\begin{array}{l}\text { Hydrogen } \\
\text { Production Using } \\
\text { Enzymes of the } \\
\text { Pentose Phosphate } \\
\text { Pathway }\end{array}$ & $\begin{array}{l}\text { Oak Ridge National } \\
\text { Laboratory }\end{array}$ & Dr. Barbara Evans & August 14, 2002 \\
\hline $\begin{array}{l}\text { Low-Cost Hydrogen } \\
\text { Production Platform }\end{array}$ & Praxair, Inc. & Mr. Tim Aaron & August 29, 2002 \\
\hline $\begin{array}{l}\text { Codes and } \\
\text { Standards Analysis }\end{array}$ & University of Miami & Dr. Mike Swain & \begin{tabular}{|l|} 
September 5, 2002 \\
\end{tabular} \\
\hline $\begin{array}{l}\text { Heavy Duty Engine } \\
\text { Development }\end{array}$ & NRG Technologies & Dr. Kirk Collier & September 11, 2002 \\
\hline $\begin{array}{l}\text { Hydrogen Storage } \\
\text { in Metal-Modified } \\
\text { Single-Walled } \\
\text { Carbon Nanotubes }\end{array}$ & $\begin{array}{l}\text { California Institute } \\
\text { of Technology }\end{array}$ & Dr. Channing Ahn & September 25, 2002 \\
\hline
\end{tabular}




\begin{tabular}{|c|c|c|c|}
\hline $\begin{array}{l}\text { Advanced } \\
\text { Underground } \\
\text { Vehicle Power and } \\
\text { Control Fuel Cell } \\
\text { Locomotive }\end{array}$ & $\begin{array}{l}\text { Vehicle Projects, } \\
\text { LLC }\end{array}$ & Mr. David Barnes & October 9, 2002 \\
\hline $\begin{array}{l}\text { Biomass Derived } \\
\text { Hydrogen From a } \\
\text { Thermally Ballasted } \\
\text { Gasifier }\end{array}$ & $\begin{array}{l}\text { Iowa State } \\
\text { University }\end{array}$ & Dr. Robert Brown & December 10, 2002 \\
\hline $\begin{array}{l}\text { Complex Hydrides } \\
\text { for Hydrogen } \\
\text { Storage }\end{array}$ & $\begin{array}{l}\text { Florida Solar } \\
\text { Energy Center/ } \\
\text { University of } \\
\text { Central Florida }\end{array}$ & $\begin{array}{l}\text { Dr. Darlene Slattery } \\
\text { (FSEC) } \\
\text { Dr. Michael } \\
\text { Hampton (UCF) }\end{array}$ & March 17-18 2003 \\
\hline $\begin{array}{l}\text { Maximizing } \\
\text { Photosynthetic } \\
\text { Efficiencies for } \\
\text { Hydrogen } \\
\text { Production } \\
\end{array}$ & $\begin{array}{l}\text { University of } \\
\text { California, Berkeley }\end{array}$ & Dr. Tasios Melis & April 9, 2003 \\
\hline $\begin{array}{l}\text { Interfacial Stability } \\
\text { of Thin Film } \\
\text { Hydrogen Sensors }\end{array}$ & $\begin{array}{l}\text { National Renewable } \\
\text { Energy Laboratory }\end{array}$ & Dr. Roland Pitts & May 6-7 2003 \\
\hline $\begin{array}{l}\text { Gallium Nitride } \\
\text { Integrated } \\
\text { Gas/Temperature } \\
\text { Sensors for Fuel } \\
\text { Cell Systems } \\
\text { Monitoring for } \\
\text { Carbon Monoxide } \\
\text { and Hydrogen }\end{array}$ & Fluence & Dr. Stephen Pyke & August 13, 2003 \\
\hline Hydrogen Systems & $\begin{array}{l}\text { SunLine Services } \\
\text { Group }\end{array}$ & Mr. Bill Clapper & August 27, 2003 \\
\hline
\end{tabular}




\section{Attachments:}

32 Site Visit reports as listed in Exhibit 1

2 In-Depth Analysis reports:

1. Analysis of a Hybrid Hydrogen Production System Using a Solar Reactor and Steam Methane Reformer

2. Comparative Analysis of Three Compressed Hydrogen Storage Systems 
Technical Evaluation Report

Project: Solar Photocatalytic Hydrogen Production From Water Using A Dual Bed

Photosystem

Performing Organization: Florida Solar Energy Center, Cocoa, FL

P.I.: Dr. Clovis Linkous

Site-Visit Date: September 22, 2000

Evaluation by: Edward G. Skolnik, Energetics Inc.

\section{Summary:}

The Florida Solar Energy Center (FSEC) is investigating a photoelectrochemical hydrogen production process in which hydrogen production and oxygen production occur in two separate containers linked by a mediator fluid. For several years the FSEC group concentrated on inorganic semiconductor materials, settling on $\mathrm{TiO}_{2}$ to evolve oxygen and InP to evolve hydrogen. Over the past year, FSEC has switched to organic pigmentbased photocatalysts due to instability in the inorganic-based system.

FSEC believes that since these pigments can utilize a wider range of the solar spectrum, they can evolve hydrogen (and oxygen) more efficiently. They also should not be subject to the same instabilities that beset the inorganic materials. FSEC uses ionization potentials as initial screening tools for the pigments, and then continues the downselection process via actual gas evolution experiments.

Gas evolution results to date have been disappointing. The best hydrogen-evolving pigment generated just over 100 microliters of hydrogen after irradiating a $6 \mathrm{~cm}^{2}$ surface of immobilized pigment for six hours with a xenon lamp. This is about 3 orders of magnitude less than theory predicted. Oxygen evolution with its best pigment appeared to be about 4.4 milliliters under the same condition. Subsequent investigation, however, revealed that much of the oxygen was likely coming from photodecomposition of the redox mediator $\mathrm{IO}_{3}{ }^{-}$. The mediator was being photolyzed by ultraviolet radiation that was being transmitted through the new quartz reactor.

Currently, FSEC is trying to regenerate oxygen evolution data using a UV filter to prevent mediator decomposition, and to identify better hydrogen generators. The work also includes improved distribution/immobilization techniques for the photocatalysts and cocatalysts.

I see the following strengths in this project:

- The dual bed method has the potential of lower cost hydrogen production than other photoelectrochemical processes.

- If pigment-based photocatalysts prove successful, there will be many more candidates than with standard semiconductors. If FSEC can start producing acceptable levels of hydrogen, it will likely be easier to "tweak" the system to improve results. 
I see the following weaknesses:

- FSEC does not appear to be producing acceptable levels of hydrogen. Distribution techniques to blend the photocatalyst and cocatalyst as well as to uniformly spread and immobilize the blend must be developed. This is very likely the source of the low levels of hydrogen. However, there is no data that indicates that the pigments themselves are the proper ones.

- The results to date for the entire oxygen-evolution side of the process is flawed. The errors resulted from ultraviolet photolysis of the redox mediator when a (ultraviolet transparent) quartz reactor was used. It was unfortunate that a large amount of data (Exhibit 2) was generated using the quartz reactor.

- The 6-10 acre site needed to produce adequate hydrogen for a refueling station (assuming an 8\% solar conversion efficiency) may make the whole concept unfeasible except under special conditions.

\section{Introduction and Background:}

I visited Dr. Clovis Linkous and his associate Dr. Darlene Slattery at FSEC in Cocoa, FL to observe and discuss their dual bed photoelectrochemical hydrogen production system.

The dual bed photosystem project has been a part of the DOE Hydrogen Program intermittently for the past several years. The premise is that water can best be split into hydrogen and oxygen photoelectrochemically if the two half reactions are physically separated from one another in separate containers, connected by a redox mediator. Thus, each half- system can be tailored to utilize a wider range of the solar spectrum including low energy photons so that they each half can better produce its respective product (hydrogen or oxygen). The two beds also facilitates the separation of the product gasses.

The project has recently shifted from using the inorganic photocatalysts $\mathrm{TiO}_{2}$ (for oxygen evolution) and InP (for hydrogen evolution) to organic pigments. FSEC was concerned about the lack of stability of the inorganic semiconductors, especially InP. In addition, the use of organic pigments will allow one to take advantage of the visible portion of the solar spectrum. While some of our discussion involved general information on the dual bed system, a major portion of the day was spent on the organic pigment concept.

\section{General Discussion:}

FSEC went through a screening process in order to pick the organic pigments best suited to oxidize water and to evolve hydrogen. This involved an investigation of the bandedges of the pigments - looking at the highest occupied molecular orbital and the lowest 
unoccupied orbital for the pigments. Thus, electron affinity and ionization potential (IP) levels are the key parameters.

FSEC is still screening pigments; they want to make sure that they have the best pigments before they scale up. They hope, in FY 2001, to identify the best pigments, and perform a modeling effort to see what their system can do realistically. They believe that they need $8 \%$ efficiency to be successful, and will use the model to develop a sensitivity correlation between that efficiency level and kinetic and design parameters.

Since oxygen evolution $\left(2 \mathrm{H}_{2} \mathrm{O} \rightarrow 4 \mathrm{H}^{+}+\mathrm{O}_{2}+4 \mathrm{e}^{-}\right)$is a more complicated, four electron/mole $\mathrm{O}_{2}$ process compared to the two electron/mole $\mathrm{H}_{2}\left(2 \mathrm{e}^{-}+2 \mathrm{H}^{+} \rightarrow \mathrm{H}_{2}\right)$ process for hydrogen evolution in the other bed, FSEC decided to tackle the oxygen side first.

\section{Oxygen Evolution}

FSEC used IP to chose pigment candidates for oxygen evolution first by conducting a theoretical screening and then measuring IP using ultraviolet photoelectron spectroscopy at the University of Arizona. Based on this, they zeroed in on about twelve different organic pigments, all of which contained fused ring structures with oxygen and nitrogen either in a ring, or attached to a ring. The pigment color comes from the conjugated electrons. These $\pi$ electrons also determine the bandwidth; the more $\pi$ electrons, the smaller the bandwidth. The presence of the "hetero" atom $(\mathrm{O}$ or $\mathrm{N})$ lowers the highest occupied molecular orbital and increases its ability to split water.

FSEC uses a xenon lamp (strong ultraviolet component) to irradiate a vessel with quartz windows to evolve oxygen. Earlier, they had been using a pyrex system. Pyrex, however, filtered out the high energy $(<330 \mathrm{~nm})$ ultraviolet radiation. When they switched to the quartz system, they found that they were irradiating the redox mediator $\left(\mathrm{IO}_{3}{ }^{-}\right)$, causing evolution of oxygen, and giving a falsely high reading of this parameter. They have since inserted an ultraviolet filter, which eliminated the problem. We will address this in more detail later in this report.

Drs. Linkous and Slattery have found that the best oxygen-evolving pigments are based on perylene structures. Perylene is a derivative of anthracene, and contains a high degree of pigment-enhancing conjugated electrons. Specifically, FSEC is considering perylene diimide (generic structure shown) derivatives, and is currently looking at structures containing fluorinated side chains. A fluorinated alkyl side

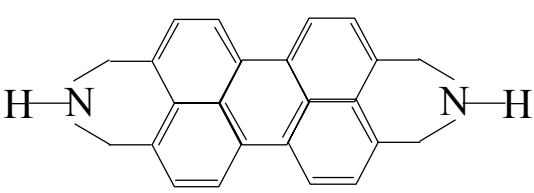

Perylene Diimide Structure chain will increase the conductivity of the pigment by introducing enough molecular disorder to force the $\pi$ electron clouds closer to one another. FSEC is waiting for results of the latest experiments involving the fluorinated system. Dr. Linkous considers this type of study (investigation of side chain effects) as one of the key upcoming tasks that FSEC should be doing. 
While evolution of oxygen is of course important, a demonstration showing high hydrogen evolution efficiency would be a stronger statement.

\section{Hydrogen Evolution}

Early in the pigment selection process, FSEC considered the same pigments for hydrogen evolution as for oxygen evolution, but they were "not the best". Better hydrogen-evolving pigments were found from the photography industry. These are generally soluble, but can be precipitated as barium salts.

One group of materials that FSEC is looking at closely for hydrogen evolution is triaryl methines. These can have colors complementary to the oxygen producers, that is, they don't absorb the same wavelength light. Therefore, one is able to increase efficiency by stacking one bed atop the other.

By changing the positions of the attached halogens and hydroxyl group or the number of sodium sulfonate groups, Dr. Linkous says that they can change the pigment's color (thereby increasing efficiency) without reducing the amount of hydrogen that will be evolved.

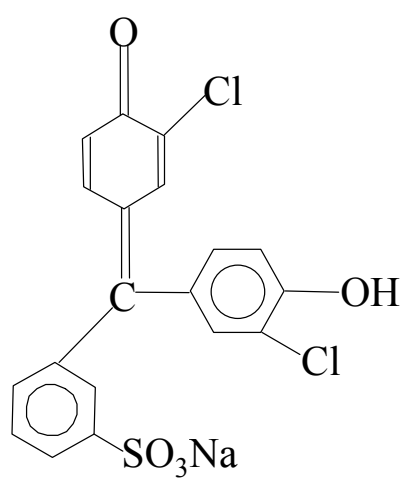

Typical triaryl methine

FSEC, at the time of my visit, had not yet tested this family of pigments for hydrogenevolution. (In fact, much of the earlier work that was done and reported on hydrogenevolving pigments involved a totally different class of materials - phthalocyanine compounds.)

\section{Facility Tour:}

Drs. Linkous and Slattery took me through their photolab where they were running an oxygen evolution experiment. The photocell is a 1-inch diameter, 3 -inch long cylindrical vessel with a "bump" at the top as an oxygen collection area. Lexan (a polycarbonate) is used to immobilize the pigment particles. They soften the Lexan with methylene chloride, and stir in the pigment particles. (Dr. Linkous indicated that they would have to look at scale-up options for this.) The reaction vessel is static (sealed). The pigment is irradiated with a xenon lamp; ultraviolet radiation is filtered out. FSEC runs the oxygen evolving photolysis under an atmosphere of helium, and the hydrogen evolution counterpart under argon.

I was also shown a reactor in which they are fluorinating a perylene diimide. Dr. Linkous indicated that if the fluorinated species does not produce the desired results (a satisfactory oxygen-evolving species), FSEC might next consider a dye-sensitized system next. Alternately, they may want to look at making photoelectrodes (ala NREL and U Hawaii) out of the pigments. It would appear that FSEC may believe that no other options for 
pigment based dual bed photochemistry exist. Dr. Linkous did indicate that they are not "asking for a license to screen pigments forever."

In a separate area, I was also shown a solar simulator that FSEC has recently acquired. It has the power of about one and one-half suns $\left(1.5 \mathrm{~kW} / \mathrm{m}^{2}\right)$. The mixed gas/xenon lamp simulates the entire (middle of the) solar spectrum from the infrared to the ultraviolet. It runs off of a power supply of several hundred amps.

\section{Questions and Answers:}

Prior to our meeting I sent Dr. Linkous a group of questions/discussion topics. In addition to the oral answers provided by Drs. Linkous and Slattery, Dr. Linkous also provided me with written answers. I am therefore reproducing the written answers verbatim (in quotes) and adding comments based both on our verbal discussion (normal type) and on my own interpretation (italics) wherever necessary.

Many of my questions were based on the relatively high reported oxygen yield compared to the hydrogen yield, the apparent emphasis on oxygen evolution to begin with, and the use of ionization potential as a pigment screening tool.

\section{Please discuss how you obtained an $8 \%$ solar to hydrogen efficiency estimate, and a \$13/MMBtu cost for hydrogen based on that efficiency.}

"This was done by making current and future (10 years) estimations of materials costs and combining them with realistic solar conversion efficiencies. The original work appeared in the proceedings of the $12^{\text {th }}$ World Hydrogen Energy Conference. I supplied a few of the numbers, but most of the work was done by Dave Block.

"Assumptions are:

Desert Southwest $\left(6.44 \mathrm{kWh} / \mathrm{m}^{2}\right)$

Glass paneling: $\$ 10 / \mathrm{m}^{2}$

Balance of system to collect $\mathrm{H}_{2}$ and $\mathrm{O}_{2}$ and to hold the cells at the correct latitude tilt angle: $\$ 120 / \mathrm{m}^{2}$. This value is the same as that which is commonly used for photovoltaic systems.

Capital cost is depreciated at $6 \% / y e a r$ over 20 years.

Operating cost/year is taken as $10 \%$ of the initial cost.

Photocatalyst cost: $\$ 50 / \mathrm{g}$ (this gives us plenty of leeway for synthetic intricacy)

Photocatalyst loading: $5 \mathrm{mg} / \mathrm{cm}^{2}$ (actually some of our earlier work would suggest as low as $2 \mathrm{mg} / \mathrm{cm}^{2}$ )

Solar transmission losses (through glass covering and water layer): $11 \%$ and $5 \%$, respectively.

Fixed latitude tilt angle (modules not heliostated).

"The conclusion is that if you can operate a dual bed system at $8 \%$ efficiency, the $\mathrm{H}_{2}$ could be sold at $\$ 13 / \mathrm{MBtu}$. There are literature citings where the conversion efficiency of semiconductor particulates for $\mathrm{H}_{2}$ evolution has been as high as $40 \%$, but that was done with the use of sacrificial electron donors. Our value is based on using water as the ultimate electron donor. In 
the next phase of the project, our task will be to sum the various optimized structural and material attributes of the system to show how the $8 \%$ value can be reasonably achieved."

The $8 \%$ number is a "reasonable guess" based on what other semiconductor photoelectrochemical systems have obtained. Dr. Linkous considers the pigments to be, essentially, semiconductors.

The reference for the Dave Block paper is: "Comparative Costs of Hydrogen Produced from Photovoltaic Electrolysis and from Photoelectrochemical Processes" by D.L. Block, in Hydrogen Energy Progress XII, Proceeding of the $12^{\text {th }}$ World Hydrogen Energy Conference, Buenos Aires, Argentina 21-25 June 1998, J.C. Bolcich and T.N. Veziroglu, Editors, International Association for Hydrogen Energy, pages 185-194.

It should be noted that Dr. Block's analysis assumed the use of the inorganic semiconductors that FSEC was using two years ago, not the organic pigments. It also shows the higher efficiency and lower cost that can be derived from the dual bed process.

\section{Has your previous work shown significant reverse reaction problems? Would you expect this phenomenon to be more or less of a problem with organic pigments?}

"We have run experiments where we stacked the deck toward the reverse reaction as much as possible (continuous $\mathrm{O}_{2}$-purging, high iodide concentration) in order to look at the worst possible case. Even then, we could not halt water-splitting; the rate of $\mathrm{O}_{2}$ consumption was only a small fraction of our measured rates of production. Furthermore, there is no reason to believe that the organics would promote the reverse reaction to any greater extent than the inorganics. If anything, it would be less."

Dr. Linkous uses the term $\mathrm{O}_{2}$-purging to mean adding oxygen, not removing oxygen.

\section{Why do you believe that pigments will work better than semiconductors. What properties of pigments led you to consider them? For what reason did you abandon semiconductors?}

"In our view, the pigments are semiconductors. The properties of semiconductors are enabled by their segregated distribution of filled and empty electronic energy levels. Under these conditions, conductivity must be achieved by creating charge carriers (via injection, heating, or of course light absorption). This is in contrast to metallic conductors where a high density of charge carriers is always present. The arrangement of energy levels and the photoelectrochemical behavior of our pigments are consistent with the definition of semiconductors. While rigorously our pigments might be better classified as photoconductors, the same consideration would have to be applied to $\mathrm{TiO}_{2}$ and many other inorganic photoelectrode materials."

Dr. Linkous indicated that the main difference is between light absorption and conductivity. The pigments will absorb light efficiently with a much thinner surface deposition. However, since the pigment particles are vander Waal's solids rather than crystals they lack the conductivity levels of the inorganic semiconductors. It is important to keep the pigment particles small so as to minimize conductivity losses. 
As to why FSEC is moving away from inorganic semiconductors, there are simply not that many materials out there, according to Dr. Linkous. They were already using what they considered to be the best. Nevertheless $\mathrm{TiO}_{2}$ (anode, oxygen evolution) will always have a limited efficiency due to its narrow bandwith. InP (cathode, hydrogen evolution) has a good bandwidth $(1.1 \mathrm{ev})$, but is not very stable in iodate. The phosphide decomposes in the presence of an electron acceptor. The other high bandwidth inorganic semiconductor, GaAs (1.3 ev) is very unstable in aqueous systems. On the other hand, there are many more organic pigments that can be synthesized and explored.

This may be the crux of the entire matter: there's nowhere new to go with inorganic systems, and the ones used to date are chemically unsatisfactory.

4. In your FY 2000 paper, you presented a plot (Exhibit 1) for experimental vs. calculated ionization potential. You plan to use this as a correction mechanism to determine IP for a series of pigments by a simpler method, thereby screening the pigments. How accurate/reproducible is the plot? (For example, it appears that one data point lies halfway between the least squares line and a line that could be drawn for $y=x$, that is, for IP(exp) = IP(calc).

"Within an analogous series of compounds, the correlation is quite good. An $\mathrm{R}^{2}$ value of $92 \%$ was achieved in this case. The analogous series that we are most interested in consists of those organic pigments that have at least three fused rings and contain oxygen, nitrogen, or both. That may sound restrictive, but actually most of the compounds worth considering fit this description. If somebody suggests a pigment to us, we can run a 25 minute calculation on our p.c. and determine whether it will be good for water-splitting."

Dr. Linkous said that if they went to a different class of compounds, they would have to generate a new correlation curve.

Despite the 0.92 correlation, I was concerned that there were few points and a nontrivial amount of scattering. If we look at Exhibit 1, one of the five points shown is as close to a hypothetical $y=x$ line as it is to the fitted line. It sheds a little doubt on the screening process. (Perhaps a small point, but I wanted to make it).

5. In the FY 2000 paper, you include in your oxygen evolution table (Exhibit 2), an entry for "acrylic blank". You indicate that this may represent background noise and must be subtracted out. Does this mean that only your top four pigments (Perylene Diimide through Perylene TCDA) outperform $\mathrm{TiO}_{2}$ ?

"It turns out we were wrong about the acrylic blank. The acrylic blank value had nothing to do with the acrylic itself. We tested several other polymer substrates and got the same result. We ultimately discovered that the $\mathrm{O}_{2}$ was coming from a direct photolytic reaction between the deep UV part of the Xe lamp spectral distribution and the $\mathrm{IO}_{3}{ }^{-}$redox mediator. Inserting a UV filter in the beam eliminated the effect. It hurt us badly to present that result to the review panel. Now they are speculating that we can't even make $\mathrm{H}_{2}$ using visible wavelength light. They are plainly wrong, and we now have the data to prove it, but it's too late to have any impact on their harsh evaluation. 
"We have gone back and tested some, but not all, of the pigments. Certainly the four that we identified the first time through still outperform $\mathrm{TiO}_{2}$ and will provide plenty of work for us to do."

Given the fact that most of the oxygen evolution was due to $\mathrm{IO}_{3}^{-}$photolysis, it appears that all of the numbers in Exhibit 2 are incorrect. New oxygen evolution rates (or amounts) need to be determined with a UV filter in place for screening purposes. Oxygen evolution is further addressed in the comments to the next question.

6. There appears to be an abundance of data for oxygen evolving pigments, and only a small amount of data for hydrogen-evolving pigments. In addition, the amount of hydrogen formed appears to be less than 1/10 the amount of oxygen on a molar basis. Theoretically, we should be getting twice as much hydrogen as oxygen. Are the differences in the results simply due to different sized reactors, or is there an actual disparity? Are there plans to screen more pigments for hydrogen?

"The UV effect described in the previous question accounts for the disparity. Actually, the rate constants for both reactions appear to be in the same ballpark. From a design and performance standpoint, it is desirable to have similar rate constants for both $\mathrm{O}_{2}$ and $\mathrm{H}_{2}$ evolution. This is especially true for future configurations of the dual bed design, since the photocatalytic layers will be stacked upon one another in a tandem arrangement.

"Yes, we will be screening more pigments for $\mathrm{H}_{2}$. The reason we have emphasized $\mathrm{O}_{2}$ evolution over $\mathrm{H}_{2}$ evolution is that it is the more challenging problem. You need to be able to generate a rather large, positive potential to electrolytically evolve $\mathrm{O}_{2}$ from water. We determined that for any semiconductor substance to oxidatively split water, it should have an ionization potential of at least $7.5 \mathrm{eV}$. As it turned out, most pigments do not have a sufficiently large IP. To look at it another way, it is easy to find other organics that have a large enough IP, but they are poor absorbers of solar radiation. Relatively few of the endless array of organic compounds fulfill the conditions of large IP, visible wavelength absorption, and photochemical stability that we were looking for. Indeed, we deserve some credit for quickly coming up with a short list of pigments on our modest resources.

"In contrast, there are a good many pigments whose electron affinity would indicate they are capable of water reduction to $\mathrm{H}_{2}$. Admittedly, we had spent comparatively little time looking at $\mathrm{H}_{2}$ evolvers going into the annual review meeting. We will certainly spend more time looking at $\mathrm{H}_{2}$ evolution in the next project period."

The answers to the last two questions can be summed up with one comment: The oxygenevolution data were incorrect. Unfortunately it was "wrong the wrong way" - the oxygen evolution numbers were incorrectly too high as opposed to the hydrogen evolution numbers being incorrectly too low. The comments raised by the Review Panel last spring that FSEC was not making enough hydrogen still stand.

\section{Your Annual Review presentation indicated that you planned to look at new membrane impregnation techniques. This task is not evident in your AOP write-up. Has it been abandoned? Do you feel that these techniques would not effect the degree of hydrogen formation?}

"The impregnation technique effort is hidden in the task 3a, "Module Construction-photocatalyst and co-catalyst distribution." We are always looking for better ways of immobilizing the photocatalyst without reducing its activity. The same goes for the co-catalyst. The use of co- 
catalysts has been quite effective in improving gas evolution rates in both photocatalytic modules. Despite the need to work on better distribution techniques, we think one of great advantages of the dual bed approach in comparison to other photoelectrochemical methods is that when we finally develop an active system, it should be relatively easy to scale things up. "

\section{Your results for hydrogen evolution in your FY 2000 paper does not show a comparison to InP. What is the comparison?}

"We did not present data on InP because it is fundamentally unstable in the redox electrolyte that we are using. The initial rates of $\mathrm{H}_{2}$ evolution look impressive, but over the course of a few hours, gas evolution grinds to a halt. At first we thought it was just a photostationary state effect (equalization of forward and reverse reaction rates), but X-ray photoelectron analysis showed convincingly that the phosphide was being oxidized to the oxide $\left(\operatorname{InP} \rightarrow \ln _{2} \mathrm{O}_{3}\right)$ and becoming inactive. Our first inclination was to call it photocorrosion, since many photoelectrodes are plagued with that problem, but ultimately we found that the alkaline iodate solution itself could decompose InP without even turning the light on."

Again we see a potential problem with the iodate - the redox mediator. It produced oxygen in one bed under ultraviolet radiation, and also could have been decomposing the photocatalyst InP in the other bed resulting in a falsely high hydrogen evolution reading. It would appear that stability of the photocatalyst (pigment or inorganic) in the presence of the mediator is a necessary screening procedure.

Dr. Linkous indicated that the InP/iodate reaction only happens in basic solution, and that InP might work in an acidic medium. One possibility might be to use $\mathrm{WO}_{3}$ as the oxygen generator. This could be done in an acidic environment, which would in turn inhibit InP oxidation, thus increasing the value of InP as the hydrogen producing photocatalyst. A group in Switzerland has been looking at $\mathrm{WO}_{3}$ systems. However, Dr. Linkous prefers to stick with the pigment system in an alkaline environment at this time. He says that he believes he can maximize efficiency by stacking the two beds, "one red, one blue." Dr. Linkous said that his goal was to demonstrate the proof of concept of evolving both gases using the same redox electrolyte; they were not focusing on hydrogen.

There may be many scenarios by which one of these systems may work. However, to date, they are not working. There has been no pigment system that has been demonstrated to produce encouraging amounts of hydrogen - or oxygen, for that matter.

\section{You give results for oxygen and hydrogen evolution in units of volume. How large a system is used, and how long must it run to produce these volumes?}

"The samples were $3.0 \mathrm{~cm}$ in diameter, so that the total surface area was $\sim 7.1 \mathrm{~cm}^{2}$. The actual illuminated area was somewhat less; $6 \mathrm{~cm}^{2}$ is probably a good value. Photolysis time is 6 hours. The gas evolution rates from these sample were considerably less than when we use the same photocatalysts as free powders. The thing that really hurt us was the primitive way of admixing the co-catalyst powder. For the inorganic photocatalysts, we distribute the co-catalyst by 
performing a chemical reduction of a metal salt, a sort of electrodeless plating, but with the organics we had early on encountered some problems with this approach, and had gone away from it. In other photocatalytic research projects, we have been fairly successful at making photoactive formulations via direct admixture of powders, but for these experiments, it did not work out as well.“

So, the best reported value for hydrogen evolution in Exhibit 3, 113 micro liters for copper phthalocyanine, is based on $6 \mathrm{~cm}^{2}$ of photolysis area over 6 hours. This is not satisfactory, as Dr. Linkous admits. (He says, that it should be in the 3-5 milliliter range. This is discussed after the next question.) Note that FSEC is now looking at triaryl methines. Oxygen evolution levels, as we have discussed, are undetermined.

Dr. Linkous attributes the low hydrogen evolution rate to the poor method of distributing the photocatalyst. It is necessary to immobilize the powder; if you do not, the two beds would mix. Otherwise they would go with a free powder. There are several things that FSEC can try; they just need time.

This would mean that it could be the distribution process rather than the phthalocyanine - or maybe it's both. I would perhaps try a few distribution experiments first before moving to new materials.

10. Please conceptualize a system where a dual bed photoelectrolytic system is providing hydrogen for, say, a vehicle refueling station. How large would the electrolytic system have to be? How often would you have to replace pigments, mediators, etc.?

"Let's make the following assumptions:

Solar conversion efficiency: $8 \%$

Solar irradiance: $1.0 \mathrm{~kW} / \mathrm{m}^{2}$

Daily insolation: 6 hours at maximum solar irradiance $\left(6 \mathrm{kWh} / \mathrm{m}^{2}\right)$

Tandem cell (stacked) configuration

Station open from 7:00 AM to 9:00 PM

Steady flow of customers (no down time)

Single pumping station (we're not ready for self-serve)

Vehicle refilling time: 5 minutes

Capacity of vehicle fuel tank: four cylinders, 43.8 liters each, 2200 psi.

"As for lifetime performance or replacement costs, all we know at this point is that most of our pigments have shown no degradation after 6 hours.

$$
\begin{aligned}
V & =\text { the volume output of } \mathrm{H}_{2} \text { at } 1.0 \mathrm{~atm} \text { and room temperature per unit area per } \\
\text { day. } & \\
= & (0.08)\left(1.0 \mathrm{~kW} / \mathrm{m}^{2}\right)\left(10^{3} \mathrm{~W} / \mathrm{kW}\right)(1 \mathrm{~J} / \mathrm{W}-\mathrm{s})(1 \mathrm{cal} / 4.184 \mathrm{~J})\left(10^{-3} \mathrm{kcal} / \mathrm{cal}\right) \\
& (1 \mathrm{~mol} / 56.6 \mathrm{kcal})(24.5 \mathrm{~L} / \mathrm{mol})(3600 \mathrm{~s} / \mathrm{hr})(6 \mathrm{hr} / \text { day }) \\
= & 178 \mathrm{~L} \mathrm{H}_{2} / \mathrm{m}^{2} \text {-day }
\end{aligned}
$$




$$
\begin{aligned}
C & =\begin{array}{l}
\text { fuel capacity of each vehicle at same pressure and temperature as stated } \\
\text { above }
\end{array} \\
& =(4 \text { tanks })(43.8 \mathrm{~L} / \text { tank })(2200 / 14.7) \\
& =26,220 \mathrm{~L} \text { (about enough to cruise at highway speeds for } 2 \text { hours }) \\
A & =\text { area required to supply the entire daily station demand for fuel } \mathrm{H}_{2} . \\
& =\frac{(14 \mathrm{hr} / \mathrm{dav})(12 \text { cars } / \mathrm{hr}) \times \mathrm{C}}{\mathrm{V}} \\
& =24,746 \mathrm{~m}^{2}, \text { or } \sim 6 \text { acres }
\end{aligned}
$$

"That's a lot of real estate, but the numbers have little to do with the dual bed technology itself. Rather, it's a reflection of the intensity of sunlight versus the energy consumption of an automobile."

Dr. Slattery added that they are uncertain as to how long a pigment will last. She felt that doing a life test on a material that is just making microliter quantities of hydrogen would be premature. Her "gut feel", however is that the pigments will hold up quite well; these pigments have been used for a number of applications. If holding up means a month or a year, she's not sure.

By way of comparison, let's first use Dr. Linkous' estimate of a potential $8 \%$ efficiency for a $1 \mathrm{~kW} / \mathrm{m}^{2}$ solar irradiance for 6 hours per day. He calculates the production of 178 liters of hydrogen per $\mathrm{m}^{2}$ per day under these conditions. Coincidentally, his bench-scale $\left(6 \mathrm{~cm}^{2}\right.$ active surface area) reactor is also run for six hours. If it also were $8 \%$ efficient and were exposed to $1 \mathrm{~kW} / \mathrm{m}^{2}$ irradiance, it would evolve:

$6 \mathrm{~cm}^{2} \times\left(1 \mathrm{~m}^{2} / 1 \times 10^{4} \mathrm{~cm}^{2}\right) \times 178$ liters $=0.107$ liters $($ or $107 \mathrm{ml})$ hydrogen.

The best data in Exhibit 3 show about three orders-of-magnitude less hydrogen evolution, which can be attributed to less than maximum simulated solar irradiance, less than perfect photocatalyst distribution, and perhaps an inferior photocatalyst. Testing the system using the aforementioned solar simulator might be in order to best approximate irradiance. Addressing distribution is something that FSEC proposes as part of the FY 2001 work. As mentioned earlier, FSEC is already looking at methines for hydrogen evolution.

Dr. Linkous assumed four 2200 psi, 43.8 liter hydrogen tanks aboard an automobile. That works out to $2.34 \mathrm{~kg}$ of hydrogen. (Capacities in the 4-5 $\mathrm{kg}$ range are generally used.) His refueling station services 12 cars an hour for a 14 hour day, or 168 cars/day. This requires a field of dual bed arrays totaling about six acres of surface. (If we use the $4 \mathrm{~kg}$ figure, it comes to a little over 10 acres.)

\section{Other Comments:}


The pigments that are being evaluated are not uncommon, and are in fact, used in the photography industry.

Dr. Linkous indicated that the difference between a "pigment" and a "dye" is similar to the difference between a paint and a stain. Pigments (and paints) contain particles that are insoluble in their carrier, while dyes are soluble. 


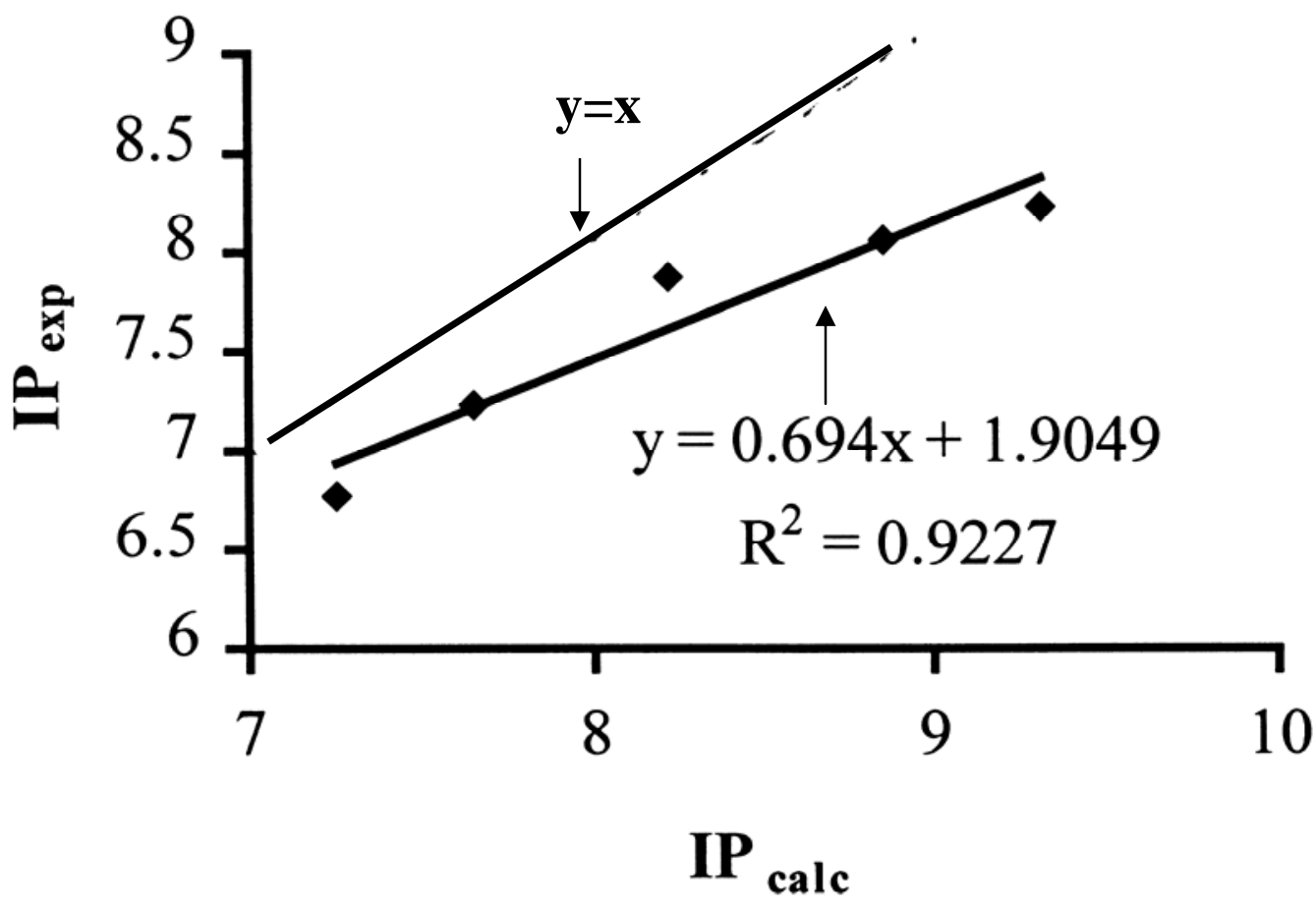

Exhibit 1. Plot of Experimental vs Calculated Ionization Potentials from FSEC Report with a $y=x$ Line Added. 


\begin{tabular}{|c|c|}
\hline \multicolumn{2}{|c|}{} \\
\hline Photocatalyst & $\mathbf{O}_{\mathbf{2}}$ Evolved (ml) \\
\hline Perylene Diimide & 4.4 \\
\hline bis(p-chlorophenyl) DPP & 3.6 \\
\hline Indanthrone & 3.3 \\
\hline Perylene TCDA & 3.2 \\
\hline Pigment Red 177 & 2.6 \\
\hline Indanthrene Yellow & 2.0 \\
\hline Quinacridone & 1.8 \\
\hline Isoviolanthrone & 1.5 \\
\hline Acrylic blank & 1.5 \\
\hline Indigo & 1.4 \\
\hline Dimethoxyviolanthrone & 1.3 \\
\hline TiO ${ }_{2}$ & 1.3 \\
\hline Indanthrene gold orange & 0.9 \\
\hline Indanthrene Black & 0.7 \\
\hline & \\
\hline
\end{tabular}

Exhibit 2. Oxygen Evolution with Various Organic Pigments (from FSEC FY 2000 Report)

\begin{tabular}{|c|c|}
\hline \multicolumn{2}{|c|}{} \\
\hline photocatalyst & $\mathrm{H}_{2}$ evolved $(\mu l)$ \\
\hline CuPc & 113.0 \\
\hline VOPC & 25.6 \\
\hline AlPc-Cl & 16.0 \\
\hline NiPC & 22.6 \\
\hline
\end{tabular}

Exhibit 3. Hydrogen Evolution with Phthalocyanine-based Organic Pigments (from FSEC FY 2000 Report) 
Technical Evaluation Report

Project: Production of Hydrogen Through Electrolysis

Company: Proton Energy Systems, Rocky Hill, CT

P.I.: Rob Friedland

Site-Visit Date: December 7, 2000

Evaluation by: Edward G. Skolnik, Energetics, Inc.

\section{Summary:}

Proton Energy Systems is a small (about 40 people) company located in Rocky Hill, CT, who, in the words of their own Rob Friedland, "exist to make PEMs." They have two major types of products - stand-alone electrolyzers $\left(\mathrm{HOGEN}^{\circledR}\right.$ series) and regenerative fuel cells (UNIGEN ${ }^{\circledR}$ series). There are two concepts for UNIGEN - a box containing one stack that will serve as both an electrolyzer and a fuel cell (unitized system), and a box that will contain two discrete stacks - an electrolyzer stack and a fuel cell stack (discrete system). Presently, Proton is mainly involved with cost reduction of their products and is pursuing this with both DOE and internal funds.

The DOE Hydrogen Program is currently funding only the electrolyzer work. This includes cost-reduction-based improvements on Proton's small HOGEN 40 (6 kW electricity in; produces 40 standard cubic feet per hour (scf/h) of hydrogen) and larger HOGEN 380 (60 kW of electricity in; $380 \mathrm{scf} / \mathrm{h}$ hydrogen). Proton uses a "holistic" approach to cost reduction and is thus addressing cell stack, power conditioning and interfaces, and system costs.

I see the following strengths in the project:

- Proton personnel come from a long history in PEM technology, both electrolyzer and fuel cell. As such, they are well qualified for the present endeavor.

- The cost-reduction-based development that Proton is currently involved in appears to be a sound way to approach the project at this stage.

- The UNIGEN options provide a good potential alternative to battery storage for renewable-based remote power.

I see the following weaknesses in the project:

- The cost targets for the electrolyzer seem to be a little higher than others I have seen. Proton has indicated that the reason for this is that cost estimates by others may be too low. If public monies are being used for development of the electrolyzer, it is in the public's interest to see how the potential market is being impacted by these higher costs.

- While the emphasis on cost reduction is justified, and the approach (discussed in the report) of picking off "the low hanging fruit" is fine, we get very little feeling for how 
big an effort is needed for each of the various electrolyzer parts. We do recognize, however, that some of these data are proprietary.

\section{Introduction and Background:}

I met with four members of the Proton team on December 7, 2000. They included Rob Friedland, Vice President of Operations, who acted as my host; Trent Molter, Vice President of Engineering and Technology; John Speranza, Systems Engineer; and Fred Mitlitsky (formerly of Lawrence Livermore National Laboratory), Director of Advanced Engineering.

Proton was founded in 1996 by former employees of Hamilton Standard looking to develop commercial products derived from the military-based products of their former employer. Proton's products are currently aimed at the industrial gas market and backup power market. Later, as alternative and renewable energy opportunities increase, they plan to include the fuel cell refueling market as well as the renewable and distributed power markets.

The HOGEN 40 is a "real commercial system" now. In the industrial gas market, it replaces cylinders and tube trailers.

We spent several hours discussing the Proton electrolyzer project, going over the questions that I had sent to Mr. Friedland, and taking a tour of the facility.

\section{Questions and Answers:}

I sent Mr. Friedland a set of discussion questions prior to my arrival. The questions were answered by various team members. In addition, I was given a written set of answers for most of the questions. These are reproduced below. The questions are indicated in bold. Written answers are reproduced verbatim in quotes. Answers that came out of our discussion follow the written answers. My comments added to many of the questions during my later analysis and assessment are shown in italics.

\section{$\underline{\text { General Questions }}$}

\section{In Proton's current focus on electrolyzer technology, what efforts are being made to ensure that the new technology will be consistent with regenerative fuel cell technology? How necessary is it for there to be a consistency?}

"Proton defines regenerative fuel cells two different ways. We consider a system with a unitized cell architecture as well as a system with discrete electrolyzer and fuel cell components both to be UNIGEN systems. This is done because the system (i.e. the box) will still make gas and deliver electricity, but the architecture will be determined by the application the box is serving. To this end, the fundamental technology advancements made on the electrolyzer carry over well to 
the regenerative fuel cell. In the discrete component system, the transfer is direct and obvious. In the unitized cell, the basic cell support features, fluids distribution, pressure capability and materials choices all are valuable and consistent.

"Proton's business strategy relies on the fact that much of our technology carries forward into our other products and technologies. That is the essence of PEM technology and a large part of the outside attraction to our story. As for this program specifically, we will not be tracking or forecasting how the technology will work in our regenerative systems."

Technologies that are consistent with electrolyzers and regenerative fuel cells include electrodes and flow field assemblies. High pressure is important for both electrolyzers and regenerative systems, but there is not necessarily a consistency here.

Proton has shown that they can be as efficient with the unitized regenerative system as with the discrete type. They claim performance has been as high with the unitized system as with a discrete electrolyzer or a discrete fuel cell.

It is all an applications issue. In some cases a unitized system makes sense; in others it does not. Mr. Friedland cited backup and uninterruptable power needs as scenarios in which a unitized system would not be applicable. You would want a small electrolyzer, one that could run off of a trickle charge of electricity, but you would want a large fuel cell; when the main power goes off, you need electricity quickly.

The consistency would obviously be greater between electrolyzers and the discrete UNIGEN system, where there is a separate electrolyzer stack.

The question was based on the fact that despite the interest that has been generated about regenerative fuel cells over the past several years, the focus seemed to be moving away from this important area. Seeing some UNIGEN systems, however, and hearing the Proton philosophy on them reassures me that this is not the case.

The UNIGEN discrete system particularly makes a lot of sense; it allows for single nonstack components and for more efficient sizing of stacks.

\section{Why is electrolyzer technology considered the "most difficult and critical link?"}

"As we look at storing energy from renewable sources and having that energy available on demand to meet a varying load requirement, a device is required that can handle input from an intermittent source like renewables, store that energy, and respond like a battery to create that energy on demand. The electrolyzer is one of the only ways to enable that reaction, especially in off-grid applications where alternative fuels are either not available or not easily transported for use.

"The 'difficult' part comes in the fact that the electrolysis reaction is a more difficult reaction to enable, at pressure, than the fuel cell reaction. Few companies have historically been able to manufacture reliable electrolyzers especially at elevated pressures. Much of this can be attributed to the fact that the cell architecture is dramatically different in a PEM electrolyzer than that of a fuel cell, including the type and thickness of membrane and the formulation of the catalysts for the electrodes. 
"The 'critical' part comes from the fact that the key to sustainability in an energy system is for it to work without the need for logistical fuels and constant external involvement and support. The only way we know of to harness solar or wind power and convert it into an alternative form of energy is through electrolysis."

There are not many people working on electrolyzers today. During the '70s and ' $80 \mathrm{~s}$ there was very little work done at all. Very few, according to Proton, have been able to get their "arms around the electrolyzer" since the "50s.

Mr. Friedland added two more facts that make electrolyzers more difficult to deal with than fuel cells: 1) seal technology needs to be more sophisticated because you are "making pressure" and 2) the higher voltage makes for a harsher electrochemical environment.

These are reasonable arguments for continuing to push the electrolyzer side.

3. You indicate that cost-reduction work will be (is being) performed on the cell stack, power conditioning and the renewable interface, and the overall system. What level of cost reductions is being targeted in each area?

In the next few years, power conditioning and system costs will be targeted. That is where there is much "low hanging fruit" to be addressed. One key early target area will be circuit board improvements. Stack cost reductions will come later. After 2005, Proton feels that they will be going into mass production $(10,000-20,000$ units per year). This will lower the costs as well. Of course, costs would be lower still with a million units produced per year, but Proton recognizes that goal as "unrealistic."

Progress to date for cost reduction was presented, but the data are proprietary. Suffice it to say that Proton believes that they are currently beating their goals.

No actual numbers were presented for the cost, or cost reduction, of the major system areas (i.e., stack, power conditioning, etc.). Some numbers were presented for individual materials and components, and these appear in various areas in this report.

4. In your FY2000 Annual Review report you site an overall short term cost target of $\$ 1000 / \mathbf{k W}$ and ten-year cost target of $\$ 500 / \mathbf{k W}$ for hydrogen production using your HOGEN ${ }^{\circledR}$ electrolyzers. Figures 2 and 3 in that paper (reproduced at the end of this evaluation) appear to show the projections in terms of cost per system, that is, cost per $6 \mathrm{~kW}$ for HOGEN 40, and cost per 60kW for HOGEN 380 (assuming I am interpreting it correctly). If this is the case, it appears that you only get to about $\$ 750 / \mathrm{kW}$ by 2010 with the smaller unit, and you may be hitting an asymptote. Do you see small units as viable at this cost of hydrogen?

"In general, it is our belief that the value of being able to scale well to small power levels will allow for some higher pricing, up to $\$ 1000 / \mathrm{kW}$. While we feel that other technical advancements could bring our costs into line with our larger system projections, we are confident that the differences are acceptable, especially in our early entry markets like telecommunications applications. On 
the DOE program, we have contracted with a consulting group to ascertain price levels and offer third party projections of acceptable pricing and competitive analysis with other technologies and have also acquired the latest information from Frost \& Sullivan with regard to the renewable markets."

Proton, perhaps chiding others in the industry, claims that their cost figures are built on actual and projected numbers. They are not based on a "dream." Therefore, their numbers might be higher than those of others who project costs off of a laboratory system.

Proton agrees that the $\mathrm{HOGEN}^{\circledR} 40$ probably will be about $\$ 750 / \mathrm{kW}$ in 2010 , but believes that to be acceptable.

I wonder as to how acceptable the electrolyzer costs actually will be for both the $6 \mathrm{~kW}$ and the $60 \mathrm{~kW}$ system. I have seen numbers more in the $\$ 300-400 / \mathrm{kW}$ range. Perhaps Proton's numbers (as they have stated) are more realistic. If so, the question becomes: how do these higher (or more realistic) numbers affect the potential market?

\section{$\underline{\text { Cell Stack }}$}

This area was discussed in detail during my visit, although no written answers were supplied. Trent Molter led the discussion for Proton.

\section{What methodology will be used for down-selecting components?}

To get started, Proton used a "brute force" approach. This included big tie-rods, machined end plates and spring washers, as well as stainless steel for one (the negative) endplate and aluminum for the other. The important thing was to get it to work. (In the near-term, they will continue to use stainless steel and aluminum plates.) Now, their goal is to reduce materials and labor costs. They are therefore using a modeling effort (using Pro Engineer software) with cost a critical parameter. There is very little trial and error. However, they do expect to use a "bake off" for the final down-selection.

\section{Is the plan to look only at metal endplates, or will you be considering composites as well?}

Yes, Proton is considering composites for the positive (currently aluminum) endplate, but the key driver is not weight, but cost, so they would need an inexpensive composite. They are also considering two component endplates.

We were not referring to weight. Composites would likely be significantly less expensive than machined metal endplates. They also would not suffer from the same corrosion problems that affect metal endplates.

3. Will cast or metal powder materials use the same or similar metal composition as the machined endplates, or will they be different? How will corrosion be addressed? 
For the aluminum side, Proton would like to go with cast material eventually. They envision a spider web design - a thin plate with webs of thicker material. Proton plans on working with people who have casting experience.

Proton recognizes corrosion to be a problem, as are hydrogen embrittlement and material suitability.

In their plans, it seems that Proton will look at anything that will lower costs. Since embrittlement and corrosion issues will eventually affect cost, they will likely address these issues.

\section{What level of cost savings do you anticipate by going away from machined endplates?}

They are looking to cut the cost from about $\$ 900 /$ set of endplates down to about $\$ 200$ $250 /$ set. This includes all parts of the endplates.

\section{Are any modifications planned for the hydrogen electrode?}

Proton wants to modify both electrodes. The plan is to reduce the catalyst loading to increase the potential market by reducing cost. They are looking for a ten-fold decrease in catalyst, from $5-10 \mathrm{mg} / \mathrm{cm}^{2}$ to $0.5-1 \mathrm{mg} / \mathrm{cm}^{2}$. They feel the bigger challenge will be on the oxygen side.

\section{$\underline{\text { Interface }}$}

John Speranza led the discussion for Proton for the interface and system questions.

\section{What types of renewable resources will be considered?}

" $5 \mathrm{~kW}$ Photovoltaics and Wind Turbines will be considered as the base renewables to interface with a HOGEN 40 hydrogen generator."

\section{What is the interface? An AC/DC converter?}

"The interface is a combination of power conversion devices optimized as a fully integrated system to function as the sole power interface to the hydrogen generator. The interface will have the capability to supply DC power to the electrolytic cell stack by converting AC power from the grid, conditioning DC power from a renewable source, or augmenting AC power from the grid with DC power from a renewable source. The diagrams below illustrate two possible applications of such a device: 


\section{Off-Grid Village Power Application}

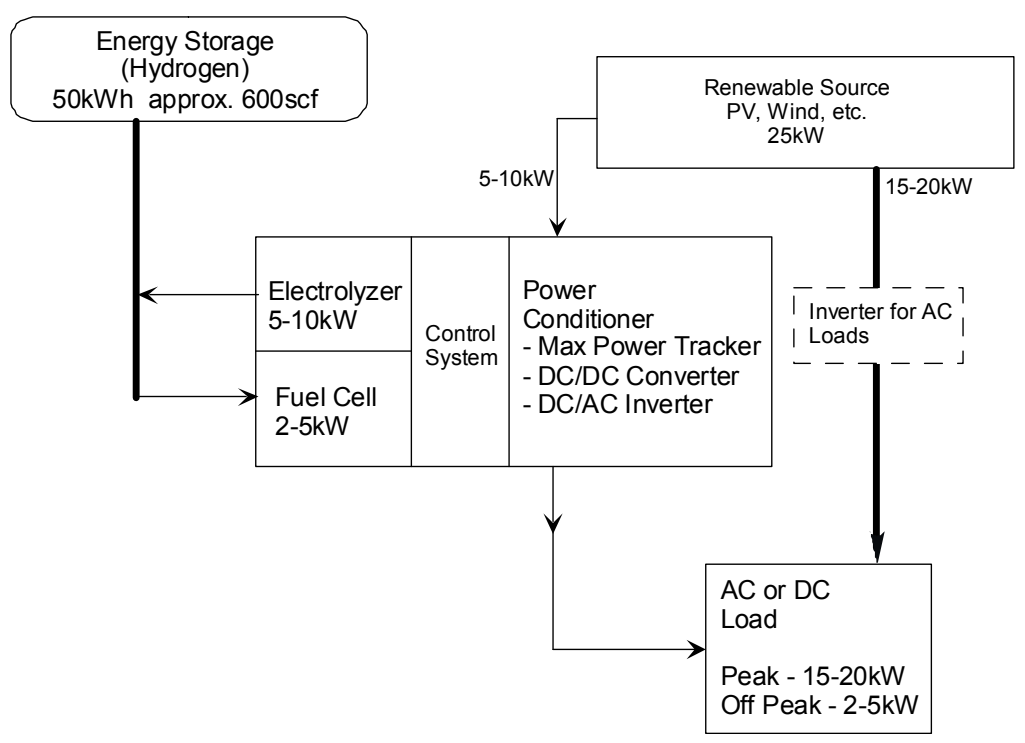

\section{Back Up Power System}

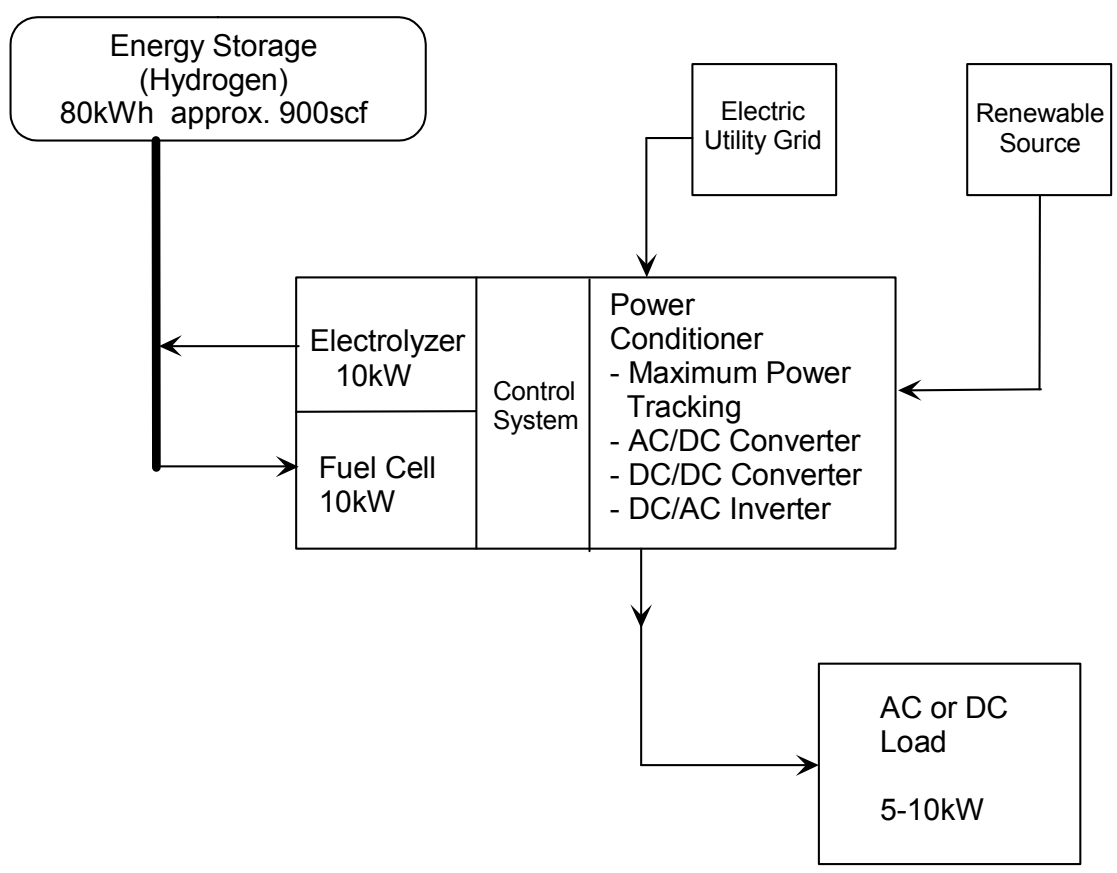


Proton considers off-the-shelf converters to be very inefficient. They want to develop a single integrated component that will work for both grid and non-grid scenarios. The power conditioners need to have the capability to do several things. For instance, the conditioner could have a component that would control PV power tracking and another component that would monitor several different inputs (e.g., PV, hydrogen storage system, grid power if applicable, perhaps even a backup generator for the off-grid system) and switch them on and off as appropriate.

PEM scales down quite well, says Mr. Speranza, and could nicely be used for a small system.

I believe that the off-grid potential for this type of system is quite great. Even a remote, far-removed from "civilization" scenario would work. Some remote villages are looking at using a renewable intermittent resource such as $P V$ or wind to provide power, with a battery or bank of batteries providing storage. A regenerative fuel cell (unitized or discrete) with hydrogen storage similar to the set-up presented by Proton and shown in the first figure above could be a very viable alternative, especially for longer term storage.

An investigation of load profile requirements and/or data for remote locations would be of value in determining how Proton's various HOGENs and UNIGENs would fit.

\section{$\underline{\text { System }}$}

\section{Please explain your manifold-mounting concept.}

"The HOGEN 40 hydrogen generator currently utilizes a considerable amount of stainless steel compression fittings and tubing in the hydrogen fluid management section of the system. While this concept works well and adds flexibility during the prototype and evaluation stages of product development, the materials used are expensive and assembly is labor intensive. The approach of combining multiple fluid junctions into one common manifold needs to be considered as the product enters the production and commercialization phase in order to drive out cost. Machined manifolds will be looked at in both the high-pressure hydrogen side and the low-pressure water side of the generator. Casting those manifolds will be investigated also in order to determine if any cost benefits can be realized through powdered metal fabrication techniques. Welded tube assemblies will also be considered as a possible cost reduction method for these assemblies and may provide an interim solution for present low volume manufacturing."

A manifold is much more cost effective than a series of separate fittings. Mr. Friedland indicated that using a manifold will result in a cost reduction of $30-40 \%$ on materials alone. Labor cost reduction would add to this.

Proton will also be looking at injection molding of plastics as a potential manifold for the low-pressure (water) side of the generator. 


\section{Other Discussion Items:}

- Proton has recently completed a demonstration (partially funded by the Hydrogen Program) of a HOGEN 380 generator as part of a sustainable energy generation project at the Ocotillo Power Plant (Tempe, AZ) owned by Arizona Public Service. Solar energy from a concentrating dish (SunDish ${ }^{\mathrm{TM}}$ ) is fed to a Stirling external heat engine to provide electricity. Additional solar energy is fed to the HOGEN 380 to make hydrogen. This is stored and used to power the Stirling engine during nights and cloudy days. The demonstration is finished, but Proton is still talking to the Dish/Stirling people about further work. Proton also is trying to see if there is any more interest in this at DOE.

- Proton has recently become a member of the California Fuel Cell Partnership. They will be supplying the Partnership with a refueler.

- Proton is currently in a mode in which they are seeking out several partners.

- Proton is currently supporting a remote (off grid) power project where hydrogen will be used for both electricity and fuel. The location and details of this project are currently confidential.

- Among the cost-saving strategies that Proton is employing is the attempt to identify lower cost membranes and catalysts. The current membrane being used is DuPont's Nafion $^{\circledR}$, which costs between $\$ 650-850$ /square meter. Not much lower than it was five years ago! Proton is looking at some non-fluorinated materials. Since electrolysis is more aggressive to a PEM membrane than is fuel cell usage, Proton is looking toward materials that can withstand higher pressure-induced mechanical stresses and a more oxidative condition. The methodology involves starting with the best fuel cell material and then trying to improve it.

This may be one of the more important areas that Proton is addressing. Membrane costs unfortunately continue to be a cost driver.

- Proton is also examining techniques for putting catalysts on the membrane.

- Another cost reduction plan that Proton will be employing will be to minimize the number of mechanical springs. They will use one or two big springs rather than perhaps hundreds of small ones. 


\section{Tour:}

The tour basically consisted of being shown a series of HOGENs and UNIGENs in various states of completion as well as components of both. A HOGEN 380 was pointed out as being the same type as what was used at the Arizona Public Service demonstration. While the system ran very well in Arizona, Proton did point out that it was "babied" - it never got too cold in Tempe, for one thing.

Units that were run under more difficult conditions did have some technical issues mainly life cycle and cell stack problems brought about by large temperature and humidity gradients. These problems caused Proton to step back to smaller units.

Two items were pointed out while looking at an opened HOGEN 380 box: Proton pressurizes the electrical side of the box to keep hydrogen out of it and avoid a potential ignition. Proton is replacing many of their electrical components with a single circuit board. This will result in a reduction in cost from about $\$ 2000$ to about $\$ 250$.

Other systems that I was shown included:

- A test HOGEN 40 that they use to run parametric studies on cell materials, water flow, current density, and load - There is more "balancing" that must be done in an electrolyzer than in a fuel cell.

- Separately, Proton is testing an electrolyzer that will produce hydrogen at 2100 psi.

This may be one of the most important pieces of equipment that Proton is developing.

- A "Chrysalis" electrolyzer, a small 300cc hydrogen generator for gas chromatographs

- Components of a prototype $1 \mathrm{~kW}$ hydrogen/air regenerative fuel cell with discrete electrolyzer and fuel cell stacks

- A $250 \mathrm{~W}$ unitized regenerative hydrogen/oxygen system for EPRI

- A $50 \mathrm{~W}$ unitized regenerative system for NASA - This is meant for zero gravity operation. It uses no pumps, under the premise that fewer components result in higher reliability. Proton has a Phase II Small Business contract with NASA for a $1 \mathrm{~kW}$ follow-on project.

- Several other 4-cell unitized fuel cells 


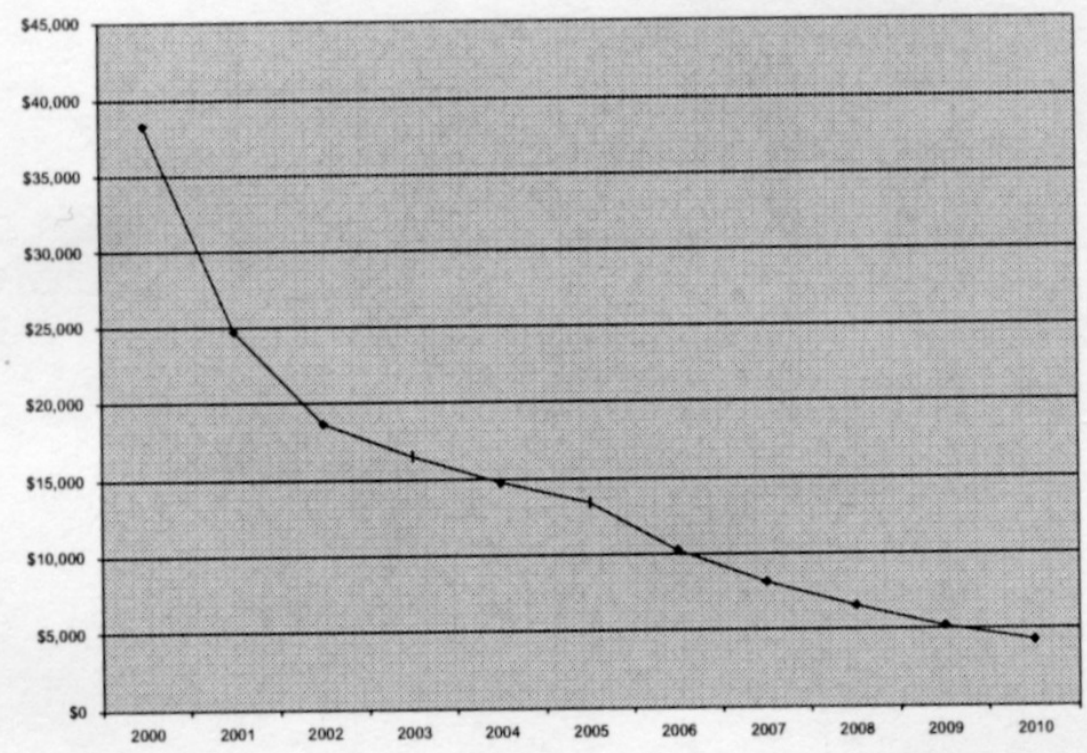

Figure 2 -HOGEN 40 (6kW) Ten Year Cost Projection

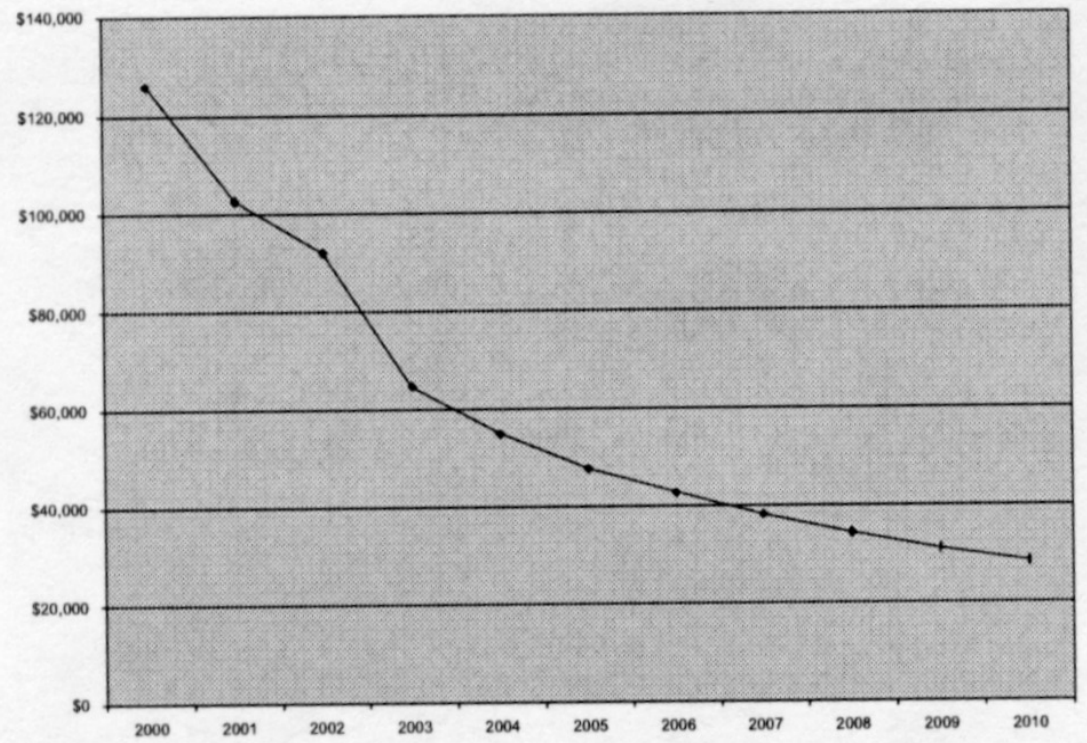

Figure 3 -HOGEN 380 (60kW) Ten Year Cost Projection

Cost Projections from Proton's FY 2000 Annual Review Report 
Technical Evaluation Report

Project: Plasma Reforming

Company: Massachusetts Institute of Technology, Cambridge, MA

P.I.: Dr. Leslie Bromberg

Site-Visit Date: December 8, 2000

Evaluation by: Edward G. Skolnik, Energetics, Inc.

\section{Summary:}

For the past six years, a group of researchers at the Plasma Science and Fusion Center at the Massachusetts Institute of Technology (MIT) have been conducting R\&D on the use of a discharge through a plasma to enable the reforming of gaseous and liquid fossil fuels to produce hydrogen. The process is touted to be more energy efficient than conventional reforming processes, especially on small scale. It can reform both liquid and gaseous fuels, and can be run in ways that can simulate several different conventional reforming methodologies (steam reforming, partial oxidation, pyrolysis).

I see the following strengths in the project:

- The new, non thermal plasmatron that MIT has developed has reduced electrical energy requirements for hydrogen production down to $4 \mathrm{MJ} / \mathrm{kg} \mathrm{H}_{2}$. This is a factor of about 4 better than the best results with the old, high current device and greater than an order of magnitude better than the energy requirements that were being quoted at the time of my 1996 visit.

- The plasma reforming process can provide a compact/convenient configuration as an on-board process.

- Plasma reforming offers the potential of scaling-down more efficiently and cost effectively than conventional reformers; they don't have the same heating requirements as conventional reformers, where size plays a much larger part.

- Costs and efficiencies for diesel reforming using the plasmatron appear potentially to be superior to conventional systems.

- Working with Texaco, BP Amoco, and IMPCO gives the project additional credibility.

I see the following weaknesses in the project:

- In my opinion, the strongest "hook" that this project had to offer was the possibility of reforming methane in a pyrolysis mode, and producing only hydrogen and carbon. This, however, has now been shown to take too much energy to be cost effective.

- The plasma reforming process is producing too much $\mathrm{CO}$. That is, the water shift portion of the reaction does not seem to be working well. This needs to be dealt with. 
- This project has suffered more then most from an on-again, off-again funding situation.

\section{Introduction and Background:}

I visited Drs. Leslie Bromberg and Alex Rabinovich at the Plasma Science and Fusion Center at MIT for the second time. We discussed the progress that they had made on the plasma reforming project, including the development of a new "non-thermal" plasma reformer.

I had first visited this project in 1996 when it was still quite new. At the time, MIT had demonstrated their ability to make hydrogen and were working to develop heat and material balances for the system, and to reduce the input energy. At the time, we saw a potential bonanza for the project if they could efficiently and inexpensively create hydrogen from methane in the pyrolysis mode. Under that condition, the byproduct would be solid carbon, and no gaseous pollutants would be emitted. MIT also felt that the technology lent itself well toward on-board reforming of liquid fuels, which would allow for more or less conventional refueling.

Today, with their two plasmatron designs and their large decrease in the amount of input electricity required, the MIT team sees potential for their plasma reforming technologies in many vehicular and stationary applications.

\section{General Discussion}

\section{$\underline{\text { Applications }}$}

The main feedstocks being evaluated are natural gas and diesel fuel. Dr. Bromberg spoke of using plasma reforming of natural gas in refueling stations, and using diesel fuel for small, decentralized power production and hydrogen production. For on-board systems, Dr. Bromberg proposes the use of plasma reforming of diesel fuel for use in sparkignition engines for emission mitigation. Running in a lean mode will drop $\mathrm{NO}_{\mathrm{x}}$ by two orders of magnitude. In addition, MIT is looking at on-board plasma reforming for auxiliary power units for cars and trucks and as a catalyst regeneration enabler in diesel engines. (For instance, barium carbonate is used to trap $\mathrm{NO}_{\mathrm{x}}$, forming barium nitrate. The reformate can be used to regenerate the carbonate.) MIT has received funding from the DOE Office of Transportation Technologies for its on-board reforming work.

\section{Answers to Questions:}

I sent Dr. Bromberg a set of discussion questions prior to my arrival. These were discussed in detail during my visit. In addition, I was given a written set of answers for most of the questions. These are reproduced below. The questions are indicated in bold. Written answers are reproduced verbatim in quotes. Answers that came out of our 
discussion follow the written answers. My comments added to many of the questions during my later analysis and assessment are shown in italics.

1. What mode are you using to plasma reform diesel fuel (steam reforming, POX, pyrolysis)? What percentage of the hydrogen in diesel fuel becomes molecular hydrogen? What are the byproducts? How will they be dealt with?

"Presently, we are exclusively using partial oxidation, with $\mathrm{O} / \mathrm{C}$ ratios between 1 and 1.8. For diesel, the results are shown in [...Exhibit 1...]. The hydrogen yield is defined as the hydrogen generated divided by the hydrogen content of the fuel. The hydrogen yield can be greater than one because of the water-shifting of the resulting $\mathrm{CO}$. The maximum hydrogen yield in this case is on about 1.8. The ordinate refers to the specific energy consumption, the electrical energy required by the plasmatron divided by the lower heating value of the hydrogen produced. The Old plasmatron refers to the thermal plasmatron that we have investigated in the past, the new plasmatron refers to the nonthermal plasmatron that we have been investigating since the summer of 1999.

"With the plasmatron, we have investigated single stage reforming/water shifting. For diesel, the results for several types of reactors are given in [...Exhibit $2 \ldots]$.

"The empty reactor refers to one where there is no catalyst. The ceramic catalyst is Ni-based steam reforming catalyst on an alumina substrate" (a standard catalyst from United Catalyst.) "The honeycomb catalyst is a rare-earth (Engelhardt proprietary catalyst) on a metallic substrate."

Working with the non-thermal plasmatron, MIT has found that they can reform diesel fuel, (primarily using the partial oxidation approach) obtaining a high rate of conversion to hydrogen with no noticeable soot generation. One problem they are finding is that the $\mathrm{CO}$ concentration remains high even after water shifting. This needs further exploration.

"The best result indicate about a $6 \%$ content of CO. Further water shifting could be accomplished with a low temperature water shift catalyst. Additional CO cleanup (preferential oxidation PROX or methanation) will be required to bring the $\mathrm{CO}$ to acceptable levels for use with a PEM fuel cell."

MIT has not had nearly the success with steam reforming mode and pyrolysis as they did in the partial oxidation mode. Pyrolysis is proving to be too costly, and the steam reforming mode does not seem to work well. It appears that only water shifting works well if water (steam) is present.

There are some problems here. MIT retains far too much $C O$ in the partial oxidation mode. The plasma reformer is supposed to essentially combine the reforming and shifting steps. This is not happening. If we are going to go to a major second process to bring the CO down (we're not talking about just a final purification step), the costs are going to rise - probably unacceptably.

2. Please explain the non-thermal plasmatron concept.

"The non-thermal plasmatron employs a discharge mode with non-equilibrium features allowing operation at much reduced plasma current relative to compact arc plasmatron fuel reformers previously developed at MIT. The discharge is a nonthermal plasma, with electrons at much 
higher temperature than the ions and neutrals, which are at near room temperature. This plasma generates relatively low levels of plasma heating. A low current plasmatron reformer is schematically shown in [...Exhibit $3 \ldots]$.

"Air and fuel are continuously injected in a plasma region provided by a discharge established across an electrode gap. The device operates at atmospheric pressure, with air or air/fuel mixture as the plasma forming gas. Neither electrode is water cooled. A variety of electrode and injection geometries are possible.

"The discharge is continuously broken by the flowing gas, followed by sudden breakdown in another place between electrodes. The discharge breaks and re-ignites at relatively high frequencies, on the order of $2 \mathrm{kHz} . "$

Ion and neutrals temperatures are of the order of a few hundred degrees $\mathrm{C}$ (as opposed to electron temperatures in the 10,000-20,000 C range.) With the standard DC arc plasmatron, the plasma is near equilibrium, and temperatures for the electron, ion, and neutrals are all in the $10,000 \mathrm{C}$ range.

The non-thermal plasmatron runs at low ( $\sim 0.1 \mathrm{amp})$ current; the conventional plasmatron is closer to 20 amps. The non-thermal plasmatron removes the electrode life issue that plagues the conventional plasmatron. The electrodes are hollow, have large surface areas, and do not erode as rapidly as with the high temperature plasmatron. The older plasmatron could be run for about 50 hours, at which time substantial erosion would be noted. The non-thermal plasmatron has not yet shown any signs of erosion. MIT estimates an electrode life of greater than 3000 hours for the new version.

Two generations of the non-thermal plasmatron have been developed. The second possesses a higher power capability - up to $2 \mathrm{~kW}$ vs. $300 \mathrm{~W}$. The lower current, higher voltage device produces a very large spark that is ideal for igniting fuels.

Working with diesel fuel and the non-thermal plasmatron in the laboratory, the researchers find a hydrogen yield of greater than $40 \%$ after 5 seconds (it takes that long to get a sample), and yields of $65-80 \%$ after 90 seconds. Once the system is warmed-up, if the plasmatron is shut off and then restarted, there is no delay in resuming hydrogen generation. Hydrogen is measured with a gas chromatograph. The low-temperature water shift mode is no working well yet.

There is a tremendous decrease in the power requirement for the low temperature plasmatron. This area has shown the most significant progress over the past few years.

3. What do you estimate the total cost of hydrogen production to be (as $\$ / \mathrm{kg}$ ) based on using diesel fuel and the low power plasmatron?

"Using diesel, for a plant on the order of $20000 \mathrm{scfm}$, the cost of the hydrogen generated in on the order of $14 \$ / \mathrm{kg} \mathrm{H}_{2}$. These numbers were extrapolated from a detailed analysis carried out by MIT and BOC on the cost of hydrogen generated from natural gas using a plasma reformer, presented at the Fall Meeting of the American Chemical Society (1999).

"The cost is shown in [...Exhibit $4 \ldots$ ] as a function of the cost of the diesel fuel. 
"It should be stressed that a substantial cost of the hydrogen (on the order of $60 \%$ ) is due to the cost of the fuel. The cost of operating a hydrogen plant is shown in [...Exhibit 5...], for both natural gas and diesel as the hydrocarbon fuel."

$\$ 14 / \mathrm{kg}$ hydrogen is approximately $\$ 123 /$ MMBtu. If one looks at Exhibit 4, it shows costs closer to $\$ 14 / M M B t u$, which I think is what Dr. Bromberg meant, although that would be the cost with \$1/gal diesel fuel. (A gallon of diesel fuel produces approximately 138,000 Btu, so \$7.25/MMBtu diesel produces \$14/MMBtu hydrogen.) The numbers include the use of a separate shift reactor, so they may not be too bad. I think, however, that finding a way to perform the entire reaction with the plasma reformer (as was originally intended) would be valuable.

\section{For natural gas, Dr. Bromberg quoted about \$10/MMBtu hydrogen from about \$4/MMBtu NG.}

4. What do you feel is the maximum rate of hydrogen production that the low power plasmatron can handle?

"Presently, the plasmatron operates efficiently at diesel flow rates between $0.25 \mathrm{~g} / \mathrm{s}$ and $0.5 \mathrm{~g} / \mathrm{s}$ (These numbers approximately represent 10 and $20 \mathrm{~kW}$ of equivalent thermal power).

"We are limited by the experimental facilities in using large flow rates (limited by the air flow in the hood required to dilute the hydrogen and $\mathrm{CO}$ concentration to levels that allows release).

"We are exploring operation at lower flow rates."

This does not really answer the question as to how high a flow rate the plasmatron can handle. The last sentence, however, indicates what types of markets the group is targeting.

5. Please explain the "reaction extension region" that you mention in your AOP submittal. Is it a widening of the plasma region, or actually a second reactor? If the latter, what kind of a reactor?

"The reaction extension region represents the volume immediately following the discharge, where high temperatures due to proper thermal insulation allow completion of the reforming operation. It is not a second reactor."

The reaction extension region can be seen in Exhibit 3, the schematic of the non-thermal plasmatron.

Perhaps if it were a second reactor, it could be tailored to better handle shift reactions.

6. Some of your publications indicate that you generally use standard reforming catalysts for your plasma reforming processes. Have you ever looked at any other catalysts? Does it appear that whatever works best for conventional processes (e.g., steam reforming H.T. water shift, L.T. water shift) also works best with the plasma? 
"We have used Ni-based catalysts (for steam reforming), and water shifting Fe-Cr catalysts that are commercially available (United Catalysts). We have also used rare earth metal catalysts of proprietary nature (Engelhardt)."

With plasma reforming you generally combine several process steps. But apparently not well, based on the remaining CO content of the product.

The Ni-based catalysts are referred to as "ceramic" in Question 1 and Exhibit 2, while the Engelhardt catalysts are referred to as "honeycomb catalyst."

7. Does the non-thermal plasmatron process utilize a catalyst? Is the catalyst different than with the "conventional" plasmatron?

"We have not carried exploration outside "conventional" process catalysts. We have used similar catalysts on both the thermal and nonthermal plasmatrons."

8. You indicate that you will be designing and/or building two pilot plants - one "conventional" and one non-thermal plasmatron based-plant. About what size is each anticipated to be? What will the fuel be? How complete will these systems be? (E.g., will you separate out byproducts, hook the hydrogen up to a fuel cell or store the hydrogen, etc.). What parameters will you be measuring?

"We will be building only a pilot plant based on the nonthermal plasmatron. We will be measuring composition of the reformate, electrical characteristics of the plasmatron as a function of the throughputs, composition and nature of the catalyst.

"We are expecting to generate throughput on the order of $50 \mathrm{~kW}$ thermal equivalent of hydrogen rich gas, with composition that is close to low temperature water shifting.

"The fuel will be diesel and/or natural gas.

"We will not be testing systems for further purification of the hydrogen. These systems are commercially available (such as PSA, pressure swing adsorption)."

MIT appears to be concentrating on the low temperature plasmatron almost exclusively at this juncture.

9. Going back to some of the work you were doing during my visit in 1996: You were examining (or going to examine) the pyrolysis mode reforming of methane. One premise was that potentially, you could get hydrogen and carbon - no $\mathrm{CO}_{2}$. The question was could it be done efficiently and economically. Where did this finally lead? Was this ever tried in the presence of a catalyst?

"We tried extensively to decrease the energy consumption in the pyrolytic conversion of methane. We tried several schemes. The methods explored included:

- Homogeneous reactors

- No preheat

- Preheat 
- Cyclonic soot separation with combined heat exchanger

- Inhomogeneous reactor

- Fluidized bed with charcoal particles

"The results for the different combinations are shown in [...Exhibits 6 and $7 \ldots$ ] as a function of the specific energy input of methane (electrical energy used per mole of methane).

"It was surprising that the results with the fluidized bed reactor were as negative as they turned out to be. It was understood that the fluidized bed was a very good heat transfer mechanism, cooling the gas very efficiently and reducing the yields."

It doesn't appear clear in the written response, but the message seems to be that the fluidized bed being mobile carried the heat away from the plasma lowering hydrogen production efficiency. (Perhaps if the bed were recycled, there wouldn't be as much of a loss.)

"[...Exhibit $8 \ldots]$ shows two of the results without the fluidized bed, one with the lowest specific energy consumption, and the second one with the highest yield. Hydrogen yields were as high as $60 \%$, although at specific energy consumption on the order of $170 \mathrm{MJ} / \mathrm{kg} \mathrm{H}_{2}$. For comparison, the lower heating value of hydrogen is about $120 \mathrm{MJ} / \mathrm{kg}$, less than the electrical power required for the pyrolysis. It was concluded that pyrolysis was impractical due to poor energetics.

"We never tried to do pyrolysis from liquid fuels. Hydrocarbon pyrolysis is being commercially explored for the production of carbon black, where hydrogen is only a by-product of the process."

When we were discussing pyrolysis in 1996, we only spoke of methane since carbon black and hydrogen would be the only products. Pyrolysis of higher hydrocarbons would also probably result in some mixed species.

When MIT tried to run in the pyrolysis mode, their best results came when they used no catalyst. When they ran with an activated carbon catalyst, results were poorer. They never tried metal catalysts. Dr. Bromberg mentioned that they might have gotten better results if they had used a metal catalyst, but they felt that they would have coking problems.

It would have been interesting to have seen some tests with a metal catalyst. Recall that Muradov at FSEC was able to produce hydrogen by pyrolysis with a metal catalyst. It's true that he did have a coking problem, but may have solved it by employing a fluidized bed. The results for the plasma reformer with a fluidized bed and a metal catalyst may have given satisfactory results - lower required energy without coking. Of course, the overly efficient heat transfer abilities of the fluidized bed may have negated the gains.

At any rate, the mass balance came out accurately, and the power consumption numbers are far inferior to those obtained with partial oxidation conditions (by a factor of about 50). The pyrolysis mode for methane plasma reforming does not appear promising. 


\section{Other Discussion:}

MIT is currently building and testing a plasmatron that will be sent to Sandia National Laboratories (CA) to test its ability to reform diesel fuel. Tests will include durability. The plasmatron is planned to be used for the Remote Power project in Alaska. Sandia's Jay Keller has told Dr. Bromberg to just get him the syngas, and Sandia will water shift it. (Recall that the low-temperature plasmatron was having some problems in the low temperature water shift mode.)

Dr. Bromberg recognizes that most of the work that they have done has been geared to non centralized power (distributed generation), be it on board reforming, refueling station sized reforming, or decentralized power production. None of these are conducive toward $\mathrm{CO}_{2}$ sequestration, and therefore don't fit well into the global climate change mitigation arena.

\section{MIT has been and currently is involved in collaborations with several industrial} partners:

- MIT did a project with BOC Gases in which they conceptualized a 20,000 standard cubic feet per hour $(\mathrm{scf} / \mathrm{h})$ hydrogen generation plant, based on the plasmatron. The feedstock was natural gas. Unfortunately, BOC got bought out, and the project is defunct. A schematic for this plant is shown in Exhibit 9.

- $\quad$ MIT is currently looking at higher pressure hydrogen production for BP Amoco. They are trying to produce hydrogen at about 10 bar (approximately $145 \mathrm{psi}$ ).

- They are also involved in some high pressure work with Texaco, in which the feedstock is "real" natural gas, containing about $10 \%$ oxygen.

- MIT will likely do some more work with Texaco that will include shipping a plasmatron to them for a refueling station.

- Finally, MIT is investigating the possibility of a collaboration with IMPCO in the decentralized power arena. IMPCO is interested in refueling stations.

\section{Demonstration/Tour:}

This part of the meeting was shorter and not nearly as involved as most. I basically got a short demonstration of the $2^{\text {nd }}$ generation non-thermal plasmatron. What I saw was two vertically mounted tubes (electrodes) with a space between them. Fuel is injected through the top tube, while air is injected from the side, into the gap, perpendicular to the tubes.

Some of the air is there to atomize the fuel. With atomization there is less, or no, soot.

The plasmatron is powered by a $200 \mathrm{kHz}, 1 \mathrm{~kW}$ power supply. 
The reaction extension zone consists of two sections of catalyst and a heat exchanger.

This is the plasmatron that will be sent to Sandia. 


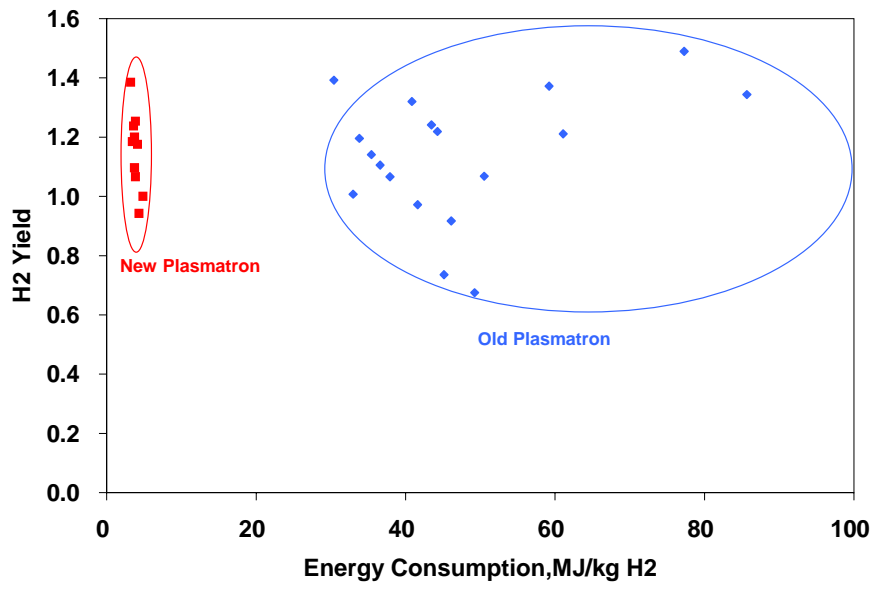

Exhibit 1. Hydrogen Yield vs Energy Consumption for Diesel Reforming 
Exhibit 2. Nonthermal Plasmatron Diesel Reforming

\begin{tabular}{|c|c|c|c|c|c|c|c|c|c|c|c|c|c|}
\hline & \multicolumn{4}{|c|}{ Initial Process Parameters } & \multicolumn{5}{|c|}{ Gas Composition } & \multirow[b]{2}{*}{$\begin{array}{l}\mathrm{C} 2 \mathrm{H} 4 \\
\text { vol. } \%\end{array}$} & \multirow[b]{2}{*}{ H2 Yield } & \multirow{2}{*}{\multicolumn{2}{|c|}{$\begin{array}{l}\text { Power } \\
\text { Consump. } \\
\text { MJ/kg }\end{array}$}} \\
\hline & $\begin{array}{l}\text { Power } \\
\text { kW }\end{array}$ & O/C & $\mathrm{H} 2 \mathrm{O} / \mathrm{C}$ & $\begin{array}{l}\text { Fuel } \\
\text { g/s }\end{array}$ & $\begin{array}{c}\mathrm{H} 2 \\
\text { vol. } \%\end{array}$ & $\begin{array}{l}\text { co } \\
\text { vol. } \%\end{array}$ & $\begin{array}{c}\mathrm{CO} 2 \\
\text { vol. } \%\end{array}$ & $\begin{array}{c}\text { N2 } \\
\text { vol. } \%\end{array}$ & $\begin{array}{l}\mathrm{CH} 4 \\
\text { vol. } \%\end{array}$ & & & & \\
\hline Empty reactor, no water & 0.27 & 1.32 & 0.00 & 0.26 & 14 & 16 & 4.7 & 64 & 0.7 & 0.1 & 0.64 & 56 & 13.2 \\
\hline $\begin{array}{l}\text { Ceramic catalyst, no water } \\
\text { Honeycomb catalyst, no }\end{array}$ & 0.19 & 1.51 & 0.00 & 0.48 & 14 & 17 & 4.7 & 64 & 0.2 & 0.0 & 0.75 & 64 & 4.3 \\
\hline $\begin{array}{l}\text { water } \\
\text { Honeycomb catalyst, with }\end{array}$ & 0.23 & 1.33 & 0.00 & 0.31 & 19 & 21 & 3.3 & 57 & 0.3 & 0.0 & 1.00 & 81 & 6.1 \\
\hline $\begin{array}{l}\text { water ( } 2 \text { excess) } \\
\text { Honeycomb catalyst, with }\end{array}$ & 0.15 & 1.24 & 1.78 & 0.31 & 23 & 17 & 6.2 & 52 & 1.2 & 0.4 & 1.22 & 87 & 3.3 \\
\hline $\begin{array}{l}\text { water ( } 4 \text { excess) } \\
\text { Honeycomb catalyst, with } \\
\text { water } 2 \text { nd generation }\end{array}$ & 0.22 & 1.57 & 4.04 & 0.22 & 21 & 10 & 10.8 & 58 & 0.3 & 0.0 & 1.30 & 72 & 6.3 \\
\hline plasmatron & 0.24 & 1.47 & 3.67 & 0.25 & 23 & 6 & 13.5 & 57 & 0.1 & 0.0 & 1.31 & 60 & 6.0 \\
\hline
\end{tabular}




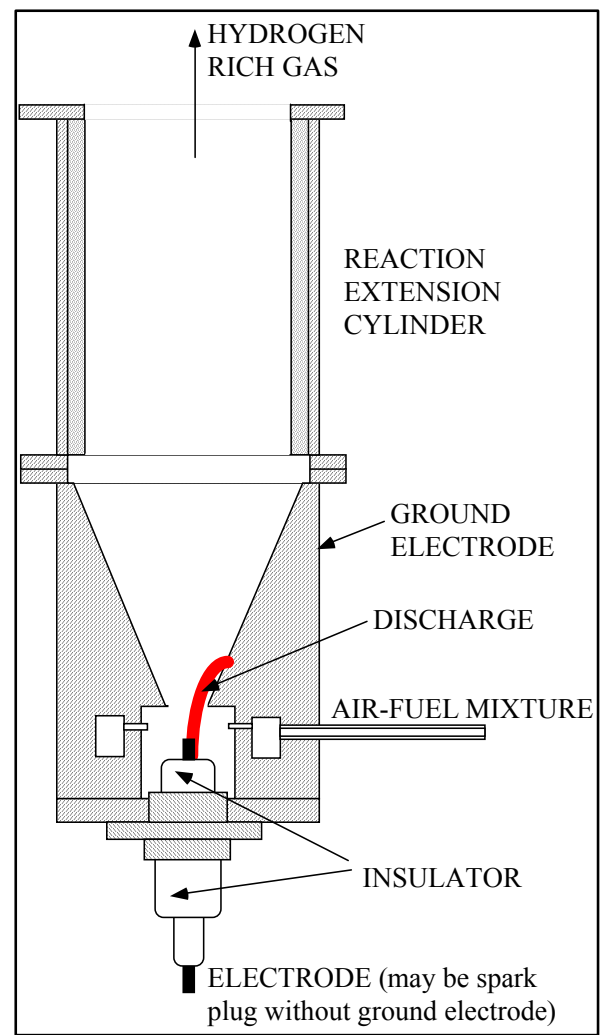

Exhibit 3. Non-Thermal Plasmatron Schematic

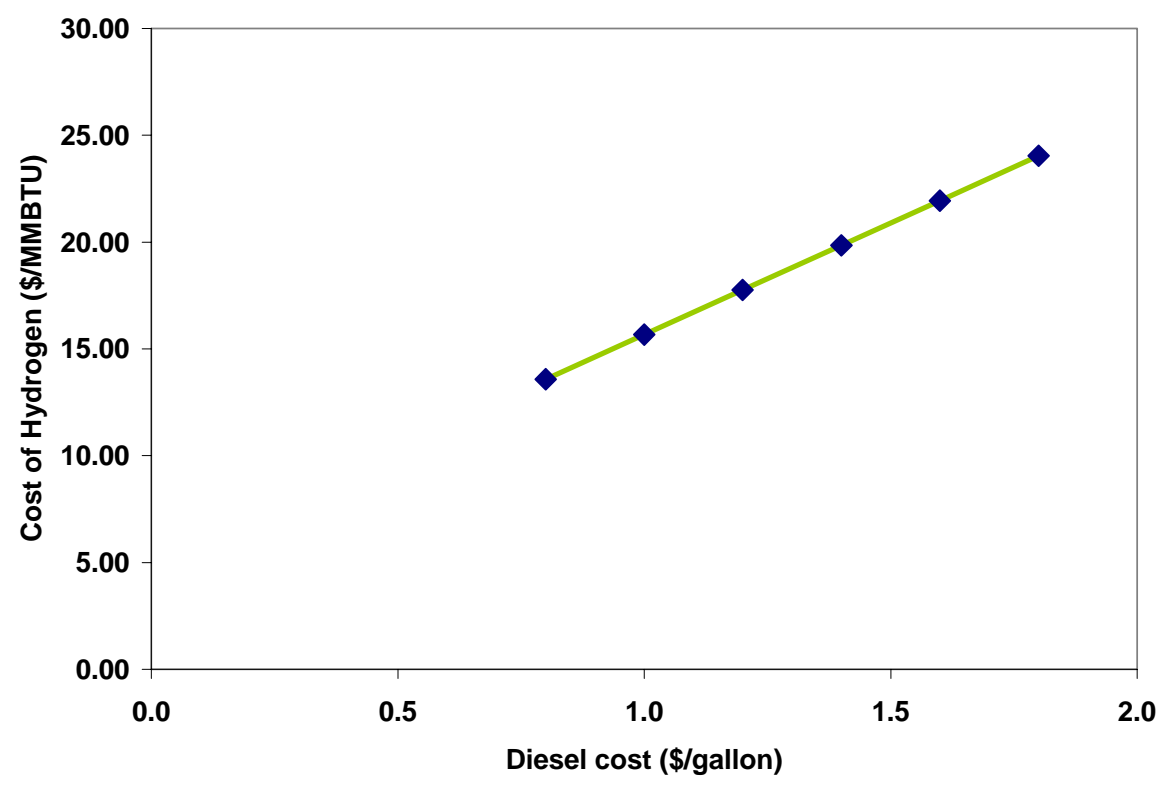

Exhibit 4. Cost of Hydrogen as a Function of the Cost of Diesel Fuel 
Exhibit 5. The Cost of a Hydrogen Producing Plant

\begin{tabular}{|lrr|}
\hline & Natural gas & \multicolumn{1}{c|}{ Diesel } \\
Labor & $\$ 35,000$ & $\$ 35,000$ \\
Catalyst & $\$ 10,000$ & $\$ 10,000$ \\
Power & $\$ 73,636$ & $\$ 156,667$ \\
Fuel & $\$ 221,952$ & $\$ 624,128$ \\
Total Op. + Util. & $\$ 340,588$ & $\$ 825,795$ \\
Total cost Op+util+cap & $\$ 490,558$ & $\$ 1,012,960$ \\
\hline
\end{tabular}

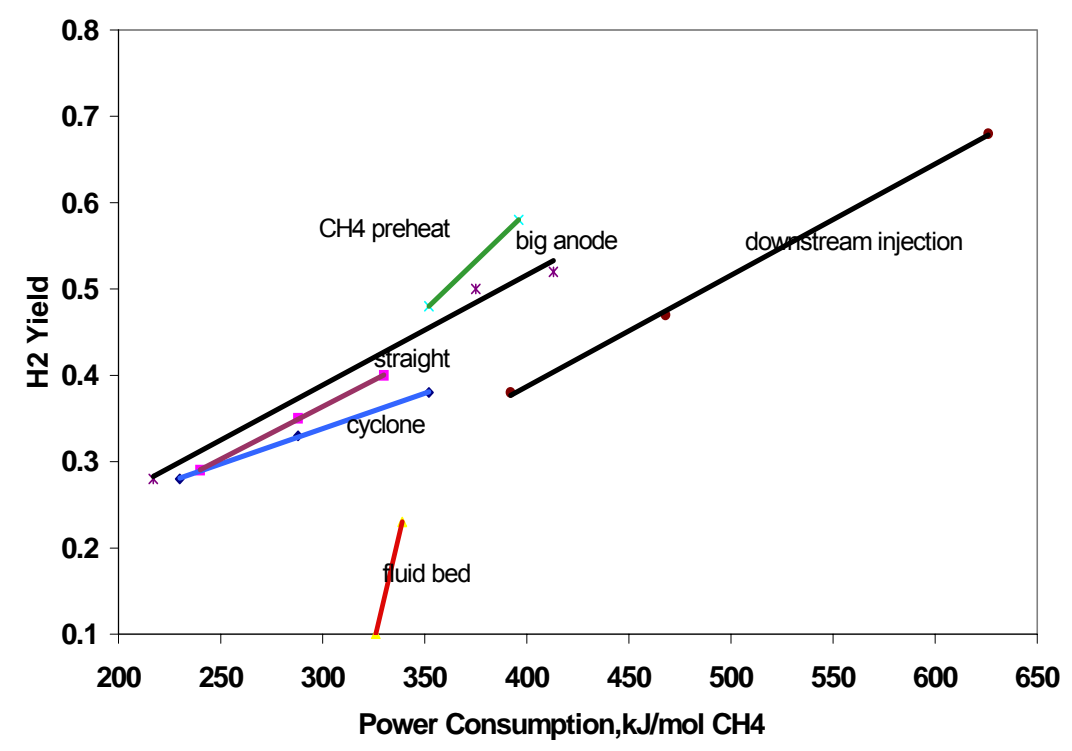

Exhibit 6. Hydrogen Production (Yield) as a Function of Power Consumption for the Pyrolysis of Methane for Different Design Modifications 


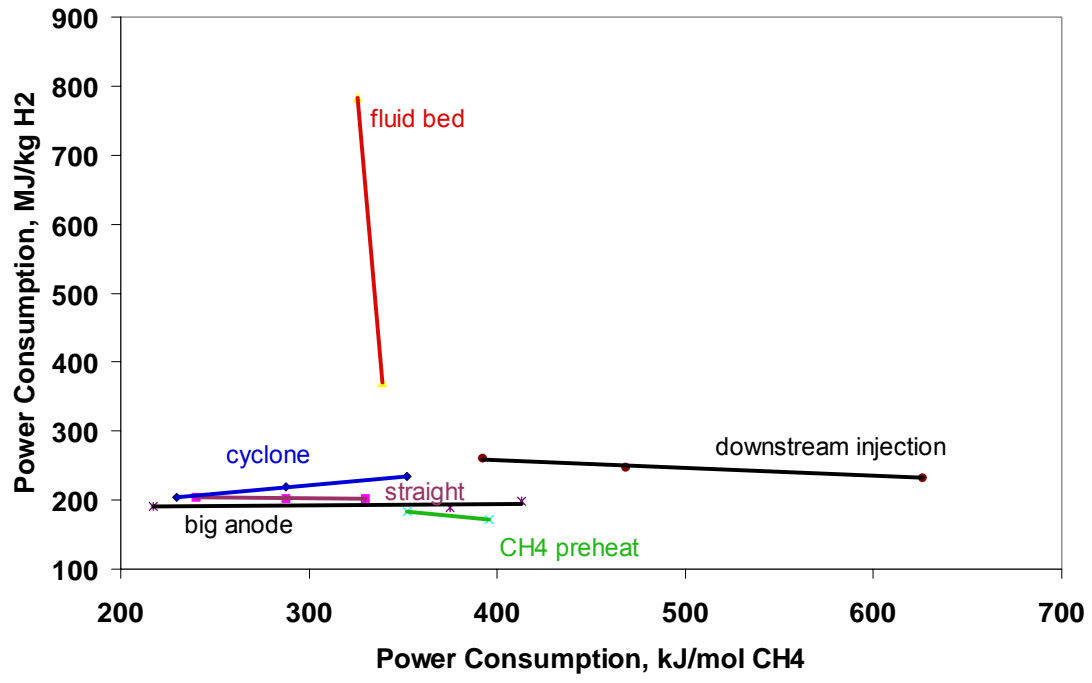

Exhibit 7. Power Consumption Comparison (Hydrogen Produced vs. Methane Used) for the Pyrolysis of Methane, Different Design Modifications. 
Exhibit 8. Pyrolysis of Methane "Best of the Best"

(One Showing Low Power Consumption, and the Other Showing High Hydrogen Yield)

\begin{tabular}{|c|c|c|c|}
\hline \multirow{2}{*}{\multicolumn{2}{|c|}{$\begin{array}{l}\mathrm{CH} 4, \mathrm{~g} / \mathrm{s} \\
\mathrm{N} 2, \mathrm{~g} / \mathrm{s}\end{array}$}} & 0.14 & 0.08 \\
\hline & & 0.29 & 0.29 \\
\hline \multicolumn{4}{|c|}{ OUTPUT } \\
\hline & $\mathrm{H} 2$, vo. $\%$ & 23 & 33 \\
\hline & O2,vol.\% & 0 & 0 \\
\hline & N2, vol. \% & 41 & 54 \\
\hline & $\mathrm{CH} 4$, vol. \% & 28 & 7 \\
\hline & $\mathrm{CO}, \mathrm{vol} . \%$ & 0 & 0 \\
\hline & CO2, vol\% & 0 & 0 \\
\hline & $\mathrm{C} 2 \mathrm{H} 2, \mathrm{vol} \%$ & 4.7 & 3.2 \\
\hline & $\mathrm{C} 2 \mathrm{H} 4, \mathrm{vol} \%$ & 0.66 & 1.16 \\
\hline & C2H6, vol\% & 0.34 & 0.02 \\
\hline & Sum. & 98 & 99 \\
\hline \multicolumn{2}{|c|}{ mass flowrate (g/s) } & 0.43 & 0.37 \\
\hline \multicolumn{2}{|c|}{ volume flowrate, STP $(\mathrm{cm} 3 / \mathrm{s})$} & 543 & 457 \\
\hline \multicolumn{4}{|c|}{ INPUT (g/s) } \\
\hline H2 & & 0.04 & 0.02 \\
\hline C & & 0.11 & 0.06 \\
\hline \multicolumn{2}{|c|}{ Power consump, MJ/kg hydroger } & 169 & 231 \\
\hline \multicolumn{2}{|c|}{$\mathrm{H} 2$, vo. $\%$} & 0.23 & 0.33 \\
\hline \multicolumn{2}{|c|}{ Hydrogen yield } & 0.32 & 0.68 \\
\hline \multicolumn{2}{|c|}{ Specific power, $\mathrm{kJ} / \mathrm{kg}$ total } & 4390 & 8465 \\
\hline \multicolumn{2}{|c|}{ Power consumption, $\mathrm{kJ} / \mathrm{mol} \mathrm{CH} 4$} & 217 & 626 \\
\hline & & & \\
\hline & & & \\
\hline & & & \\
\hline & & & \\
\hline
\end{tabular}




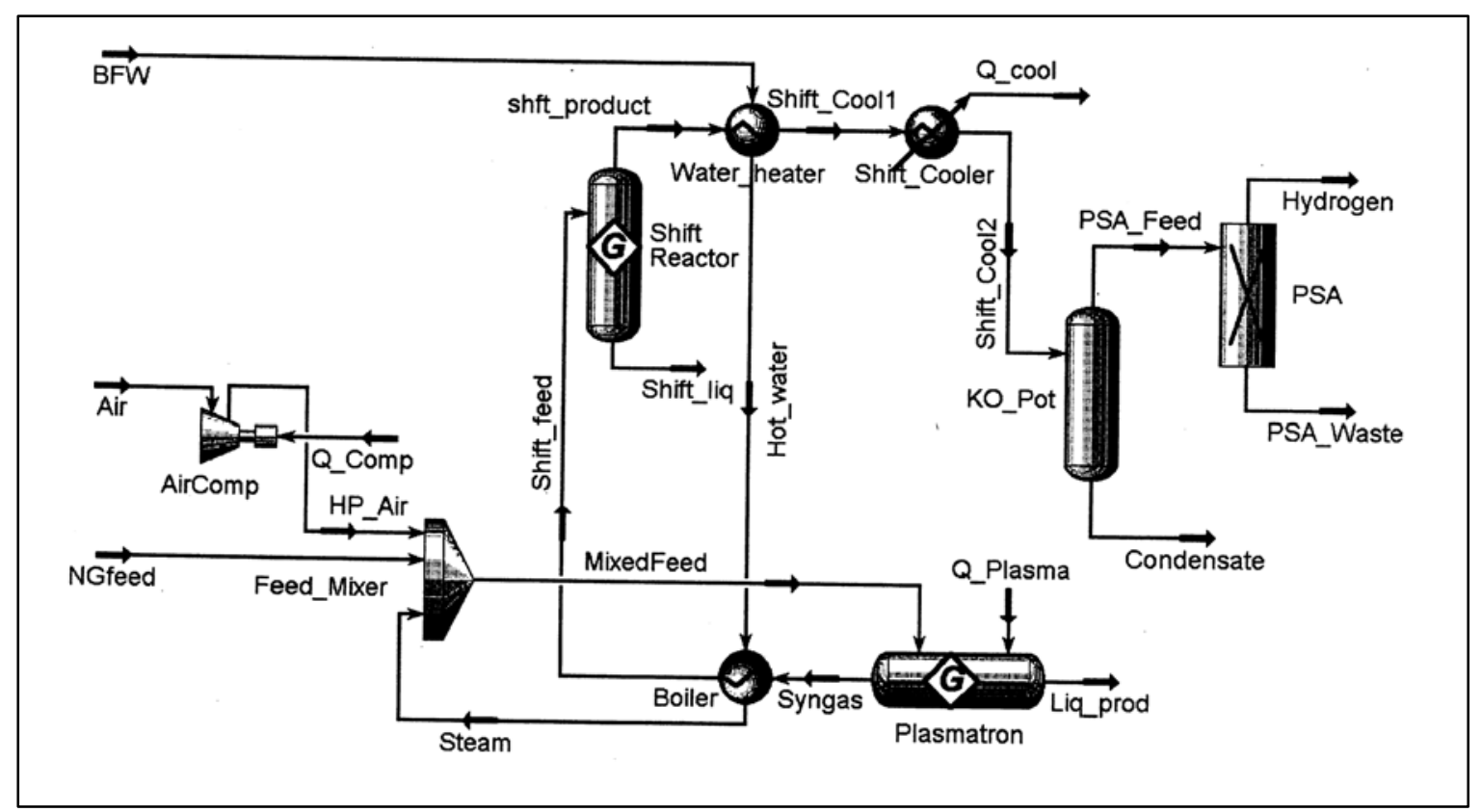

Exhibit 9. Conceptual Design of Plasmatron-Fuel Converter Based Hydrogen Generating Plant (20,000 scf/h plant) 
Technical Evaluation Report

Project: Novel Hydrogen Storage Materials - Carbon Nanotubes

Company: National Renewable Energy Laboratory (NREL), Golden, CO

P.I.: Dr. Mike Heben

Site-Visit Date: February 15, 2001

Evaluation by: Edward G. Skolnik, Energetics, Inc.

\section{Summary:}

The development of a hydrogen storage system based on single-walled nanotubes (SWNT) made of carbon has been going on for about eight years at NREL. The goals are (of course) demonstrated high productivity of nanotubes and high reversible hydrogen adsorption by the nanotubes. While significant progress has been made over the past several years, the project is not yet at the level of results where $6-7 \%$ hydrogen storage (or greater) is demonstrated in gram samples (or greater) of nanotubes.

According to Principal Investigator Dr. Mike Heben, much of the shortcoming (if we want to call it that) is due to the large increase in the level of understanding of SWNT technology over the past couple of years. The two areas of major increases in understanding are 1) in the ability to detect SWNT concentrations accurately, and 2) the realization that SWNT diameter alone does not determine its properties. What this means is that earlier reports of $60-80 \%$ pure nanotubes being produced directly from laser vaporization as earlier reported (both by Dr. Heben and by other researchers who produce SWNTs - albeit not necessarily for hydrogen adsorption) was far too optimistic, being based on inaccurate detection methods. It also means that hydrogen adsorption capability is based on a number of factors, tube diameter being only one. Dr. Heben's research has determined that another key factor is electronic configuration. Some tubes have more or less metallic properties, while others behave more like semiconductors. Furthermore, tubes produced by a particular process do not as previously thought possess a single diameter; they have a range of diameters varying by 5-10 Angstroms. This discovery has both positive and negative implications on the SWNT project as far as the Hydrogen Program is concerned. Negatively, it points out the erroneous nature of earlier nanotube concentration reports. Positively, it appears that it will lead to better understanding of what the pertinent properties of SWNTs as hydrogen storage devices will be.

I see the following strengths in the project:

- There is increased understanding in the nature of SWNTs. This is true in the areas of how to produce nanotubes, how to purify them, and what properties will make them more able to adsorb hydrogen. The more that is known, the better the likelihood of success. (Calling this a "strength" might raise some eyebrows, but seeing that SWNTs are not as uniform as we thought, the knowledge gained is valuable.)

- Having a Cooperative Research and Development Agreement (CRADA) with Honda, and more important, Honda's interest in carbon nanotubes lends a large amount of credibility to the effort. 
- The biggest strength may be in potential. SWNTs represent an alternative (and thus a release from at least perceived safety problems) to compressed hydrogen for physical storage.

I see the following items that need to be addressed:

- Despite all that has been learned in the past few years, SWNT production is still measured in fractions of grams. NREL will need to parlay the recent quantum leap in nanotube technology knowledge (and that is how I would describe it) into a quantum leap in results.

- Switching laser types to the alexandrite laser in the long run might prove to be a positive outcome. (It appears that NREL had no choice, seeing that it was the only laser available that had long pulse options.) The lower hydrogen adsorption numbers presently being reported with this laser, however, is seen as at least a temporary setback. Remember the goal is to increase hydrogen storage capabilities.

- Independent laboratory testing is necessary. As part of this, a methodology for testing needs to be agreed upon by all involved.

The high-risk, high reward potential fits few projects in the Hydrogen Program any better than this one. If this were a basic energy science project, there would be few issues. But it is an applied science project requiring a steady march toward a practical goal. Much is being learned, but progress toward those practical goals is needed.

\section{Introduction:}

I visited the NREL laboratory of Dr. Mike Heben on February 15, 2001 to discuss his SWNT hydrogen storage project. This was the second time that I visited Dr. Heben, the first being in June 1997. We spent a full day going over the progress that the project has made over the past $3 \frac{1}{2}$ years in producing, purifying and cutting nanotubes, and in utilizing these nanotubes for the storage of hydrogen. Included were a tour of the appropriate facilities and a discussion of a series of questions.

Throughout our discussion Dr. Heben stated that much of what we all thought we knew about nanotubes in 1997 was inaccurate. Primarily this dealt with the ability to detect nanotube concentrations and accurately report yield. We also did not understand the mechanisms involved in making nanotubes and thought that using a particular method of nanotube production would result in nanotubes of one, unique diameter. It turns out that yields had been highly overstated, and that nanotubes came in many sizes including distributions of diameters and different electronic properties. We deal with these matters in the Questions and Answers section and the Additional Discussion section below. 


\section{Questions and Answers:}

Prior to our meeting, I sent Dr. Heben a list of questions to be considered during our discussions. These are reproduced together with the result of our discussion below. Some analytical comments are included in italics.

1. Please discuss the various methods you have used in generating SWNTs. Address generation methodology, yield, diameter, uniformity, ease of separation from non-SWNTs, and end-caps (method of removal and ease of removal).

Quite a bit of the information that we were hearing earlier was not entirely accurate. Yields were based on Scanning Electron Microscopy (SEM). These initial assessments were not done rigorously. SEM results showed higher SWNT concentrations than were present in the bulk of the material. These erroneous measurements were not limited to NREL, but were common throughout the industry. It would appear that SWNTs have an affinity for the periphery of a bulk system containing other carbon forms. That would explain the high values from SEM analysis, a process that is surface oriented.

A second major issue is that it was previously believed that method of preparation defined the diameter of SWNTs produced, and that there was a single diameter for all nanotubes made by that process. Dr. Heben now says that each preparation method produces nanotubes over a range of diameters, and that diameters may vary over this range by four or five Angstroms. For both carbon arc nanotubes and laser vaporization nanotubes, the distribution is over the range of 10-14 $\AA$. (Typically nanotubes are between 7 and $20 \AA$ in diameter, for all preparation methods. Tubes smaller than $7 \AA$ cannot exist physically; tubes over $20 \AA$ would tend to collapse.)

Diameter is not the only production issue. Chirality is also important. Looking at two planar arrays of graphite structures as shown in Exhibit 1, if one assumes they can be rolled into tubes along the designated axis, tubes can be formed with an edge having an "armchair" configuration, or a "zigzag" configuration. In addition, tubes can form along some diagonal axis, further complicating the result. (Some configurations are more stable than others, so you do not get all combinations.) As a result, tubes can have widely different properties; some configurations exhibit near metallic qualities, some are more like semiconductors. It all depends on the electronic configurations.

The type of tube can be determined by using different wavelength lasers to excite the tubes.

2. What are the hydrogen uptake levels you have achieved for each of these methods? Please include and differentiate between measured and extrapolated and/or calculated numbers. (For instance, in the early days of your project, you had a low nanotube yield, subjected your entire sample to hydrogen, measured a hydrogen uptake weight, assumed that all of the hydrogen uptake was in the 
nanotubes, and extrapolated a hydrogen weight percentage based on a $100 \%$ nanotube yield.)

The best direct measurement number was 6.5\%. This included metal alloy hydrogen. The $7.2 \%$ was by calculation, subtracting out the metal contribution. This was obtained with the old "YAG" (yttrium-aluminum-garnet) laser. The best values for hydrogen adsorption to date using the new alexandrite laser are about $4 \%$.

This brings up concerns (both real and perceived) about progress. A calculated number is not as persuasive as a measured number. Even though subtracting out a relatively small metal contribution is not the same as extrapolating to $10 \%$ hydrogen adsorption based on 0.05\% SWNT yield (as in the old carbon arc discharge method) it still leaves questions. We address the metal probe used for sonifying the SWNTs in Questions 8 and 9.

The alexandrite laser hydrogen adsorption numbers are not as good as the YAG numbers. Purification of the SWNTs is easier, the tubes may be easier to cut, and eventually the hydrogen numbers may be superior, but right now, as we take a snapshot in time early in 2001, NREL is reporting lower numbers for the new laser.

3. What method do you use to introduce hydrogen into the nanotubes and then to measure hydrogen uptake? What assurances are there that you are measuring hydrogen and not an impurity? (Recall that when the Northeastern University team were measuring hydrogen uptake, there was concern that part or all of their reported results could have been due to water vapor as opposed to hydrogen.)

NREL uses two methods. The first is temperature programmed desorption (TPD). The TPD system is connected to a mass spectrograph (MS). The TPD system is calibrated using calcium hydride. Since no MS peak is seen for $\mathrm{m} / \mathrm{e}=18$ (the mass to charge ratio in mass spectroscopy is generally indicative of the molecular weight of the species $(\mathrm{m})$ divided by the charge (e) with one electron stripped off; thus e is generally equal to one) and water's molecular weight is 18 , and hydrogen's is 2 , (a large $\mathrm{m} / \mathrm{e}=2$ peak is seen), it would appear that there is no water present.

The second method is a pressure/volume/concentration system called a Sievert's apparatus. It can handle much larger samples than the TPD, but samples are difficult to degas.

4. Has any cycling of hydrogen in nanotubes been demonstrated yet? If so, what were the results? (Number of cycles, amount of hydrogen that could be continuously cycled.) Is there anything to indicate that nanotube structures may be compromised by multiple recycling?

About ten cycles have been demonstrated. Over the ten cycles, there was a loss of perhaps $10 \%$ of the hydrogen. 
These results appear to be preliminary, but are of concern as well. Continued decreases could be indicative of SWNT degradation, or of permanent adsorption. However, the loss could also (and perhaps more likely) be metal alloy related. As addressed in Question 9, the metal hydride is not entirely reversible. This would be a much more attractive explanation for cycling losses.

5. You indicated in your FY 2001 AOP submission that you may look at nonSWNT adsorption of hydrogen by carbon structures. What type of materials are you considering (e.g., fullerenes, activated carbon)? What do you see as the potential advantages here?

This was simply offered as an attempt to act as a support service for testing other groups' carbon structures.

Independent testing is of utmost importance in all aspects of hydrogen research.

6. Also in the AOP you indicate that you can make $98 \%$ pure SWNTs that can adsorb about 7 weight percent of hydrogen. What quantity of sample have you been able to produce to date that had these properties?

A single sample only contains about 8-10 mg of SWNTs. Overall, however, NREL has made perhaps $0.5-1 \mathrm{~g}$ of SWNTs with these properties. The few mg samples are all that can be measured by TPD. NREL will use larger samples for volumetric measurements.

7. Your FY 2000 Annual Review report describes a detailed purification process for the SWNTs involving refluxing in nitric acid, drying, and heating/oxidizing. It also describes a sonication process also in nitric acid to cut the SWNTs. Do you foresee similar processes to obtain SWNTs in "production?" Could purification and cutting steps be combined?

NREL expects to develop better cutting and purifying processes. Eventually, there may be one process to do both, but not necessarily so.

Purity of SWNTs can be assessed two different ways. One is the use of Raman spectroscopy to observe high frequency shearing vibration modes. The second is by using thermogravimetric analysis (TGA). First, you react raw SWNTs with nitric acid to oxidize away the metals. (If you don't do this, the metals could act as a "fuse" causing defects to open up in the nanotubes.) Then after removing the metals you run a TGA. Two discrete peaks occur. Non-SWNTs decompose at about $300^{\circ} \mathrm{C}$, while SWNTs do not decompose until $600^{\circ} \mathrm{C}$. Thus, purification consists of SWNTs involves the nitric acid wash to remove metals, and a $550^{\circ} \mathrm{C}$ oxidation step to remove non-SWNT carbon.

So, it appears what Dr. Heben is saying is that if we stick with the laser vaporization process, this will be the purification method. Depending on how often the nanotubes must be replaced, this could be a significant production cost. - But read on. 
Dr. Heben believes that nanotube production using Chemical Vapor Deposition (CVD) may result in tubes that will be sufficiently pure so that a separate purification step can be avoided. More on CVD later.

8. In the same report, you indicated that the sonication probe contained a $\mathrm{Ti} / \mathrm{Al} / \mathrm{V}$ alloy, some of which wound up in the SWNT sample. The 15 wt \% alloy concentration is a very significant amount. While your calculation of $7.2 \%$ hydrogen adsorption by the SWNTs, given a $2.5 \%$ adsorption by the alloy is correct, I am more concerned by the presence of the alloy to begin with. Are there plans to change the cutting technique, change the probe, or include a step in which the SWNTs are separated from the alloy?

NREL is addressing ways of processing the SWNTs that will not introduce metal, and is also investigating the role of the metal. They are looking at different techniques, different probes, and different alloys. In addition, NREL has performed density separations on the metal, and found that they could remove $90 \%$ of the metal particles. Dr. Heben pointed out that these are not production steps; these are analysis steps.

We need to get to production steps.

9. Still on the alloy - under what conditions did you find 2.5 wt $\%$ hydrogen adsorption? This number is better than some hydride numbers at room temperature.

The relatively high hydrogen weight percent for the metal hydride does not relate to a "good" storage system. The metal is in the form of fine particles, and would not easily be made into a hydride bed. In addition, the hydride formation is not entirely reversible. During our meeting, Dr. Heben actually spoke of $3.5 \%$, not $2.5 \%$ hydrogen in the alloy hydride.

The calculation to get to $7.2 \%$ hydrogen on the SWNTs works for $2.5 \%$ hydrogen in the metal - not $3.5 \%$.

The presence of the metal hydride is a likely reason for the inability to recover all of the hydrogen during cycling.

10. You mention a new laser, which give you $50 \%$ SWNTs prior to purification. Are these SWNTs any different than the SWNTs from the old laser (diameter, length, ease of cap removal, etc.)?

The "new" laser is the alexandrite laser. Alexandrite is a doped alumina silicate. Using this laser, chirality and diameter appears to be different. Cap removal appears to be about the same. Right now, NREL is only adsorbing about 4\% hydrogen using the SWNTs made in this manner. (We have already discussed the implications here.) 
The major difference with this laser is that it is a long pulse laser. Most people who try to make nanotubes by laser vaporization generally use short laser pulses using so-called "Qswitching" processes. The trouble with this is that the process causes metal particles to be encapsulated in layers of graphite. This makes purification difficult.

NREL has patented the use of long laser pulsing. The old YAG laser could be used in long pulse mode, but most new lasers cannot be used this way. The new alexandrite laser does have the long pulse capability. The alexandrite laser produces $750 \mathrm{~nm}$ light; the YAG laser was $1064 \mathrm{~nm}$.

\section{What are the biggest challenges for scaling up the system?}

The biggest challenges are obtaining a high quantity of SWNTs in a cost effective manner, and then processing them (i.e., purifying, decapping, and cutting them) to make them accessible to hydrogen. Dr. Heben believes that CVD may be the answer. Dr. Heben is working on a proprietary process that will keep the catalyst clean during continuous nanotube production.

12. If you were asked to put a realistic date on when you believe a nanotube-based hydrogen storage system capable of storing and discharging, say, 6 wt \% hydrogen would become a commercial reality for passenger vehicles, when would that be? How about $8 \%$ ?

This may be difficult to answer. Percentages aside, Dr. Heben sees commercialization to be possible in about 10-12 years.

Perhaps. There are many steps that need to be taken to get the process out of the laboratory, however. Methodology, SWNT yield (quantity), purity, and correlation of good yield/purity with good hydrogen adsorption are still not optimized. And we haven't even begun to talk about packaging and other scale-up issues.

13. I last visited you in June of 1997. At that time, you had recently moved away from arc discharge nanotube production to a laser vaporization method. By so doing, you had increased nanotube yield from the couple of percent range, to the $60-80 \%$ range. (These were the numbers that you told me back in 1997; now it appears that the numbers were actually $20-30 \%$, -- or am I mistaken?) However, you had found that the new nanotubes, having a different diameter, possessed very stable end-caps, and both cap removal and hydrogen adsorption were proving difficult. In the past $3+$ years, what do you consider to be your two or three most significant steps forward? What remains (or has become) your biggest obstacle?

We have already addressed the problem of inaccurate SEM measurements providing erroneously high yields for SWNTs. $20-30 \%$ yields (pre purification) from laser vaporization techniques rather than $60-80 \%$ are correct. 
Dr. Heben identified the following significant steps forward:

i) NREL learning how to purify SWNTs as well as identifying the impurities

ii) Developing a capping/cutting procedure that allows the nanotubes to adsorb 67\% hydrogen

iii) Putting together a CRADA with Honda (it was two years in the making)

iv) Identifying the partial transfer of hydrogen electrons into the $\mathrm{sp}^{3}$ carbon orbitals as the mechanism for hydrogen adsorption.

The biggest obstacles that remain are:

i) Activating large samples and measuring hydrogen adsorption by the traditional Sievert's Apparatus volumetric technique

ii) Developing a methodology that will allow accurate validation by an outside source. It is difficult to degas a sample properly. NREL is currently working with Honda, however, and they may be able to provide the validation.

14. Also in 1997, you had some thoughts about perhaps going back to arc discharge SWNT production based on what appeared to be nanotubes with less stable end caps. At the time, you were collaborating with Prof. Bernier in France, and had mentioned that Bernier was getting 80-90 \% yield of nanotubes. Are you still pursuing carbon arc discharge techniques?

The collaboration ended because of "politics". Bernier's $80-90 \%$ purity numbers were as flawed as everybody else's.

Carbon arc discharge is not likely to be the production method of choice; it is not worth spending time on. The tubes produced are "defective", and contain too much metal. There is also not much processes control compared to other processes. In addition, the high yields are not there. Dr. Heben says there are two techniques still in the running: laser vaporization and CVD. Dr. Heben mentioned that with laser vaporization there is much more control on the type and quantity of the SWNTs than with arc discharge. He says that with laser vaporization he will be able to make "grams a day" in the laboratory.

Grams a day in the laboratory would be a welcome increase. Although up to now much of the production has been based on how large a sample can be measured/tested, a leap in production quantity is sorely needed.

\section{$\underline{\text { Additional Discussion Topics: }}$}

\section{Hydrogen Adsorption Mechanism}

One of the key findings over the past couple of years is the fact that hydrogen adsorption is not necessarily an entirely physical process. Recall that in the past, there was much talk of capillary processes controlling the adsorption of hydrogen. It appears that there is a partial charge transfer occurring from hydrogen to graphite hybrid orbitals. NREL is 
finding this by running Raman spectroscopy tests as well as by thermoelectric transport tests. In the latter, a heat pulse is applied to a site, and the length of time that it takes another site to heat up is measured.

Graphite, in its planar form, possesses $\mathrm{sp}^{2}$ (planar) hybrid orbitals. As the tube is rolledup, it takes on a degree of $\mathrm{sp}^{3}$ (tetrahedral) character. The tighter the roll is (the smaller the tube diameter), the greater the $\mathrm{sp}^{3}$ character and the stronger the attraction to hydrogen. So smaller diameter tubes might hold hydrogen more strongly. Does this mean that they can adsorb more hydrogen, or does it mean that it will be more difficult to recover the hydrogen?

The chirality of the tube also plays a part here. Comparing "zigzag" and "armchair" SWNT configurations (Exhibit 1) means you are pulling carbons into and out of radial and longitudinal positions. (Tube vibration can be seen via Raman Spectroscopy) It also plays into the metal-like vs. semiconductor properties.

So there are a whole series of things that determine how much hydrogen you'll get, and how strongly it will be held. Again, it's good to see that nanotube technology is becoming better understood. It's not good, however, to see how little was known previously. Also, the fact that there are so many factors involved may indicate that it will take a while to sort everything out. NREL will have to determine which SWNTs have what particular hydrogen adsorption and release properties. Perhaps, a Design of Experiments process might help to minimize the number of tests that need to be run. Following this, NREL would need to determine how to control the production of optimum SWNTs.

\section{CVD}

NREL is working with Honda, their CRADA partner, on CVD nanotube production. Much of the information on this process is proprietary between NREL and Honda, but in a simplistic manner, it involves decomposing methane or $\mathrm{CO}$ onto a catalytic surface. Depending on how it is done, one can get a variety of graphite species (SWNTs, multiwall NTs, nanofibers, etc.). Dr. Heben is very excited about the possibilities here, and believes that CVD may eventually become the bulk SNT producer. I am intrigued also, but at the same time I am concerned by the fact that we may be dealing with yet another method with its own set of surprises.

\section{CRADA}

One other issue that Dr. Heben brought up is that at times, the direction necessitated by working with CRADA partner Honda is not aligned with the DOE Program direction. The DOE general goal is (paraphrasing) 'make lots of SWNTs, fill them with lots of hydrogen'. There is not enough money to do this and satisfy the CRADA partner as well. 


\section{Tour of Facilities:}

The tour of NREL's SWNT facilities included revisits of some pieces of equipment visited in 1997, as well as some new additions.

The TPD system utilizes one-milligram samples. Note that it is the limitations of the system as opposed to the lack of material that Dr. Heben claims is the basis for his not demonstrating large volumes of hydrogen storage as yet. The one-mg. samples are placed on platinum foil and heated electronically from $90^{\circ} \mathrm{K}\left(-183^{\circ} \mathrm{C}\right)$ to $1400-1500^{\circ} \mathrm{C}$. Liquid nitrogen is used as the low-temperature reference. As the gas (i.e., hydrogen) comes off, it flows into an MS. Dr. Heben showed me MS plots showing hydrogen $(\mathrm{MW}=2)$ as the only peak. As stated earlier, no water $(\mathrm{MS}=18)$ was observed.

The Sievert's apparatus, used for volumetric measurements can handle markedly larger samples than the TPD system. A known volume of nanotubes is filled stepwise with hydrogen until saturation is reached. The system works well for metal hydrides, but not as well for nanotubes. Degassing is a big problem. Dr. Heben believes that perhaps a new type of measuring system for hydrogen in nanotubes is needed. Measurement of greater than TPD quantities of hydrogen and, more important, nanotube degassing problems pose what I consider to be serious issues for SWNT hydrogen storage. There is no reason to believe that degassing of nanotubes will be easy in the real world if it is difficult to perform in the laboratory. Both Dr. Heben and I concur that it is warranted to connect the Sievert's apparatus to an MS to confirm the identity of hydrogen at greater than TPD quantities.

The old YAG laser for making SWNTs by laser vaporization (actually, two old YAG lasers, including one that I saw in action in 1997) has been retired and replaced by an alexandrite laser. I was given a short demonstration of this laser. It operates in a pulse mode at about $10 \mathrm{~Hz}$ and $0.5-1.0$ Joules per pulse. The pulse width can also be controlled. The carbon target is placed in the center of a tube enclosed in a tube furnace with capabilities up to $1200^{\circ} \mathrm{C}$. (NREL also can use an RF furnace that can heat to $1800^{\circ} \mathrm{C}$.) At very high temperatures, the new laser can make short length SWNTs. The alexandrite laser is more efficient than the YAG laser in making nanotubes, producing perhaps $50 \%$ pure nanotubes as opposed to $20-30 \%$. Hydrogen adsorption, however, is still lagging behind, with the best values for the alexandrite laser-produced SWNTs adsorbing about $4 \%$ hydrogen.

The Raman spectrograph has become a very important measurement tool, being capable of measuring partial charge-transfer of hydrogen electrons into SWNT sp ${ }^{3}$ orbitals. Samples can be degassed, exposed to hydrogen, etc. while Raman spectroscopy tests are being run.

Finally, I was shown an ion mill that is used as a cleansing system, primarily for templates that will be used for CVD. 
Exhibit 1. Planar views of carbon nanotube arrays.

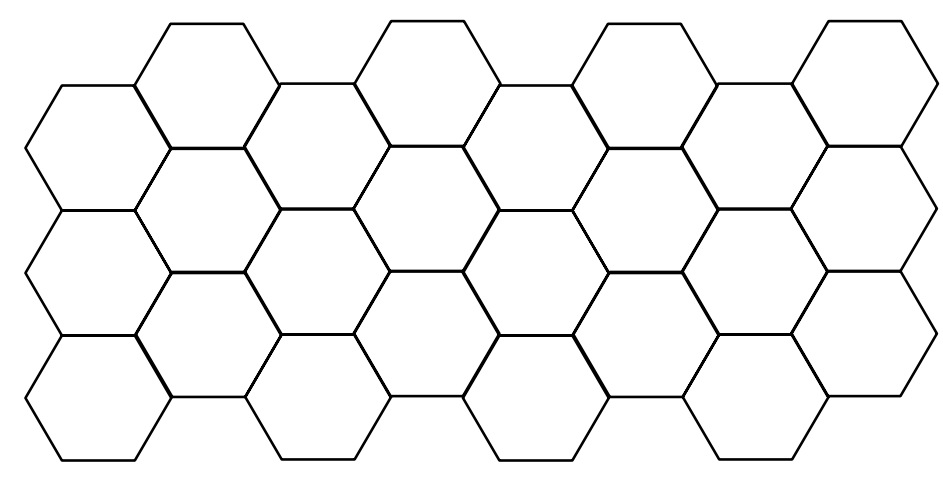

"Armchair"

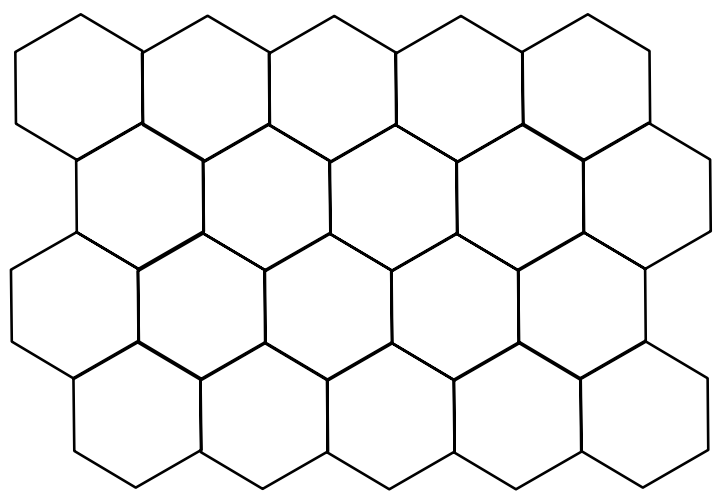

Nanotube Axial Direction

"Zig-zag" 
Technical Evaluation Report

Project: Maximizing Photosynthetic Efficiencies for Hydrogen Production

Company: University of California, Berkeley

P.I.: Dr. Tasios Melis

Site-Visit Date: February 27-28, 2001

Evaluation by: Edward G. Skolnik, Energetics, Inc.

\section{Summary:}

The University of California, Berkeley, Department of Plant and Microbial Biology are part of the DOE Hydrogen Program's multi-lab project to produce hydrogen from sunlight and water by using engineered algae to photobiologically split the water. Specifically, Berkeley is involved in genetically altering the algae to reduce the size of their chlorophyll-based photoreceptors or antennae. Smaller antenna size will lead to more efficient use of incident photons, and therefore an increase in hydrogen production potential.

I see the following strengths in this project:

- Dr. Melis is a recognized expert in chlorophyll antenna size control. His self-built measuring system for antenna size is a marvel of 20-30 year old technology doing the job accurately today. His several methodologies for controlling the antenna size appear to be extremely sound and well thought out.

- Limiting the "footprint" (i.e., increasing the efficiency) of photoreceptors, be they PV panels, photoelectrochemical semiconductors, or algae is a top necessity for making hydrogen from sunlight and water. Antenna size reduction appears to be the way to do it for algae.

- Good progress has been made in identifying/isolating/developing several mutations and transformations of Chlamydomonas reinhardtii that show significant reduction in antenna size. While some of the chl $a$ vs. $b$ work was done earlier, the th- 1 and lutein work is new. The PS I antenna reduction results for th-1 is a step forward.

I have the following concerns:

- There is no data that show how much of an increase in hydrogen per unit area of solar irradiation will occur if the antenna size is reduced by a particular amount - or even to the theoretical limit.

- If Chlamydomonas is not going to be the commercial hydrogen producer, than a transfer to whatever will be should be made. (Dr. Melis believes it will be Dunaliella.) We have to be sure that whatever we learn from Chlamydomonas is representative of what will happen in the real world.

\section{Introduction:}


I visited the laboratory of Dr. Tasios Melis at the University of California, Berkeley, Department of Plant and Microbial Biology to discuss the antenna reduction project. I was accompanied by Dr. Tony San Pietro, Professor Emeritus of Biology, Indiana University. Dr. San Pietro has been associated with the Hydrogen Program's photobiological efforts for several years. Aside from discussions with Dr. Melis (including our usual question and answer sessions) and a tour of the facilities, our roughly day-and-a-half meeting included talking with two of Dr. Melis' associates, Postdoctoral Associate Dr. Sarada Kanakagiri, a molecular geneticist, and Visiting Professor Dr. Tatsuru Masuda, a Molecular Biologist.

\section{Background:}

The chlorophyll receptors in green algae (and other plant) cells that capture sunlight for photosynthesis are quite large. They have evolved this way so that they can capture as many available photons as possible under low-light conditions. Consequently, when they are exposed to bright light, they absorb much more than they can use. Only about $10 \%$ of the photons that are absorbed under bright-light conditions are typically used for photosynthesis; the rest are wasted. For plants that are using light, carbon dioxide and water to make more plant matter, this is not a problem. Plants "don't mind" being inefficient in this way. Being able to survive by efficiently capturing all available photons under low-light conditions is more important. For photobiologists, however, who are trying to grow algae that will photolyze water to make hydrogen, using as many of the available photons as possible under bright-light conditions is more important. It is more likely that these algae will be growing in places with plentiful light. If the excess photons are not absorbed by the large receptors (antennae) on a particular alga cell, they can penetrate the alga matter down to another cell and be absorbed by its antennae, etc. Thus, instead of being wasted, more photons are being used for photosynthesis. That is, sunlight is being used more efficiently. If the photosynthesis is being used to make hydrogen, a larger volume of hydrogen will be produced per plant (note: not per cell).

In order to make the algae more efficient, their antennae must be smaller. With smaller antennae, fewer photons (ideally, only the amount that is needed for photosynthesis) will be absorbed by a single cell, but more cells will become involved as the light can travel deeper into the culture and access other targets. Transforming algae by reducing their antennae size is the research that is being carried out by Dr. Melis and his group. This antenna size-reduction work is meant to be a part of a collaborative effort between Berkeley, the National Renewable Energy Laboratory (NREL), and Oak Ridge National Laboratory (ORNL) to try to develop algae that will efficiently produce hydrogen from sunlight and water.

Dr. Melis' project is now in its fourth year as part of the DOE Hydrogen Program. Even before Dr. Melis was part of the Hydrogen Program, he was involved with Program photobiological workshops. The subject matter for these workshops at the time was that photobiological methodologies were not producing any more than minute quantities of hydrogen. (It was originally recommended by the Photobiology Peer Review panel in 
1997 that Dr. Melis should be invited to bid an antenna reduction project and become part of the photobiology effort.)

During these workshops, Dr. Melis hypothesized that if the organism were deprived of sulfur, "visible" amounts of hydrogen would be produced. Thus, until recently, the Berkeley group was working on two photobiological hydrogen tasks: antenna size reduction, and sulfur deprivation. Currently, the work involves only the antenna size reduction project.

Dr. Melis has over 20 years of experience in manipulating and measuring antenna size, and has over 50 publications on the subject. His work is also supported by the Department of Agriculture, the National Science Foundation (NSF) and by Novartis, a Swiss biological company. The NSF work is being performed in cooperation with the University of Hawaii, and involves the use of biotechnology to pull the State of Hawaii out of its economic slump. The concept of reducing antenna size is almost 30 years old, and the methodology was developed at Berkeley.

\section{General Discussion:}

The algae's photosensitive antennae are made up of several components; the main ones are two forms of chlorophyll, chlorophyll $a$ and chlorophyll $b$ (chl $a$ and $\operatorname{chl} b$ ). Other important components include carotene-derived "xanthophylls" (luteins and/or violaxanthins). The antennae structurally are made up of core and peripheral portions. The core is almost entirely made up of chl $a$, while the trimeric peripheral parts each contain $21 \mathrm{chl} a, 18 \mathrm{chl} b$, and 9 xanthophylls. Dr. Melis mentioned that his laboratory at Berkeley is the only place where chlorophyll type can be measured. A schematic of what an antenna may look like is seen in Exhibit 1. Representations of antennae maximized for low, medium, and high light conditions are shown. The goal of this project is to reduce the antennae to their high light representation. This can be done by removing chl $b$ (as Dr. Melis has done via genetic replacement) and/or lutein (as Dr. Melis is also working on.)

Dr. Melis has also isolated a regulatory mutant (see Question 8) that possesses truncated light harvesting $(t h-1)$ chlorophyll antennae. He is also considering controlling antenna size by slowing down chl $a$ by inhibiting a magnesium chelatase gene (the mechanism for the formation of chl $a$ involves a step in which a precursor is chelated with magnesium) or perhaps another gene.

Dr. Melis discussed the strengths of his laboratory at Berkeley:

- Berkeley is the only place where antenna size can be measured. The reason for this is the presence of the differential spectrophotometer that Dr. Melis developed. (See description in the "Tour" section.) Dr. Melis says that Berkeley is the "sole-source provider" in this regard.

- The laboratory also has a strength in the molecular genetic methods that they use to "transform" any green alga (not only Chlamydomonas). Transformation refers to the 
process by which a new piece of DNA is put into an organism's genetic structure. This is a genetic transformation - not just a mutation.

\section{Questions and Answers:}

I sent Dr. Melis a set of discussion questions prior to my arrival. These were covered thoroughly during my discussion with Dr. Melis and Dr. San Pietro. In addition, I was given a written set of answers. All of this is reproduced below. The questions are indicated in bold. Written answers are reproduced verbatim in quotes. Answers that came out of our discussion follow the written answers. My comments added to many of the questions during my later analysis and assessment are shown in italics.

1. How does a truncated chlorophyll antenna size lead to increased hydrogen production? (I had heard/thought that the chlorophyll antennae were sites that promoted photosynthetic conversion of $\mathrm{CO}_{2}$ into plant matter and oxygen. And that smaller antennae reduced this tendency allowing light-induced water splitting to be the preferred reaction. But what I'm reading in your reports is that the smaller antennae lead to more efficient photosynthesis. How does this all tie together?)

"Green algae (and other photosynthetic organisms) synthesize and assemble large arrays of chlorophyll, placed within protein (large Chl antennae), in order to capture as much sunlight as they can. Absorbed sunlight is channeled to a specialized $\mathrm{Chl} \mathrm{a}$ molecule (reaction center $\mathrm{Chl}$ ), where the energy of sunlight is converted into chemical energy. The evolutionary trait of "large Chl antennae" helps the organism to compete for sunlight under weak light-intensity conditions. Thus, when the light intensity in the environment is low, large arrays of Chl-proteins confer a competitive advantage for the survival of the organism.

"When the light intensity is strong, large Chl antennae absorb sunlight in excess of what photosynthesis can utilize and wastefully dissipate up to $90 \%$ of it.

"In a commercial biomass/hydrogen production process, based on the conversion of solar energy, such wasteful loss is not acceptable. The solution: genetically truncate the size of the Chl antennae in the green algae to limit their ability to absorb sunlight. Such mutant strains would lose their competitive advantage in the wild. However, in mass culture for biomass/hydrogen production, they will be prevented from wastefully absorbing and dissipating valuable solar energy. Thus, a mass culture of "truncated Chl antenna" strains will show significantly greater solar conversion efficiencies and, therefore, biomass/hydrogen productivities."

Basically, what I'd heard before was wrong. You don't want to interfere with making plant matter; you want the light to be used efficiently. You have about 2000 photons striking a cell's antenna each second, but you only have about 200 reactions per second, so you are wasting about $90 \%$ of the photons. Therefore, you want to shrink the antenna size so that (ideally) only about 200 photons will strike the antenna. The other 1800 photons can strike other cells. This is a more efficient use of light.

Why do the cells have large antennae, then? One would think that nature would try to be efficient. But in nature, the algae need large antennae to absorb as many photons as 
possible under dim light conditions. Being able to survive under dim light conditions is much more important than using all the bright light photons. However, in a hypothetical hydrogen producing pond, the system would likely be sited in an intense bright light region. The large antennae will not be needed for survival. Furthermore, in this bright light environment, the large antennae could absorb too many photons resulting in a phenomenon known as "destructive photo-oxidation".

So having small antennae does not inhibit plant growth. Water splitting is part of photosynthesis. You want the chloroplast to use as much light as possible; it's not a plant matter vs. hydrogen situation.

Dr. San Pietro mentioned a very useful way of visualizing the way the antenna work. If we look at the antennae as funnels, and we see large funnels with wide flutes, they would capture a large amount of whatever they were collecting, and send it all to one concentrated spot. What we want instead are more, smaller fluted funnels, so the matter they are collecting gets distributed to more spots.

\section{What is chlorophyll $b$ as opposed to chlorophyll $a$, and why does this research concentrate on $\mathrm{Chl} b$ ?}

"They are slightly different tetrapyrroles. $\mathrm{Chl} b$ is biosynthetically derived from $\mathrm{Chl} a$. They have slightly different spectroscopic properties and help one-another in the capture of sunlight."

Basically, Chl $a$ contains a methyl group, which can be oxidized (via an oxygenase) in a two-step oxidation to an aldehyde. The aldehyde-containing species is $\mathrm{Chl} b$. The difference between the $a$ and $b$ configurations is enough so that they can be distinguished spectroscopically.

"Chl a antennae are placed closer to the reaction center of the photosystems and are essential for photochemistry. Chl a as a photosynthetic pigment cannot be dispensed with. $\mathrm{Chl} b$ occupies a more peripheral position in the $\mathrm{Chl}$ antennae and can be dispensed without affecting photochemistry. Thus, in the absence of $\mathrm{Chl} b$, one would expect smaller $\mathrm{Chl}$ antenna sizes. This is the reason why, in efforts to generate a truncated $\mathrm{Chl}$ antenna size, $\mathrm{Chl} b$ was designated as one of the mutagenesis targets.

Chl $b$ is a component of the peripheral area of the antenna - a "building ingredient" of the trimer that makes up this antenna portion. Chl $b$ basically only operates in dim light conditions.

When you interfere with the gene - the chlorophyll $a$ oxygenase $(\mathrm{CAO})$ gene - that oxidizes chl $a$ to chl $b$, you shrink the antennae. Dr. Melis' laboratory reported on this effect with Chlamydomonas reinhardtii and has confirmed it with the Dunaliella salina algae. They are confident that they can use the same process on other green algae as well. Dr. Melis believes that the alga Dunaliella salina will be the one that eventually will go to commercialization due to its ability to survive in a salt-water environment. Dr. Melis also believes that they can identify similar genes that will affect other components of the antenna periphery region: 
"Similarly, "xanthophylls" are peripherally localized carotenoids. They are part of the lightharvesting antennae and contribute to the stability of assembly of the Chl-protein arrays. Insertional mutagenesis to knock out xanthophyll biosynthesis is another approach by which to minimize the $\mathrm{Chl}$ antenna size in green algae."

3. Both standard photosynthesis and water splitting (both are part of 'normal photosynthesis') result in the evolution of oxygen. How does oxygen evolution measurement serve as a monitor of standard photosynthesis decrease?

"Oxygen evolution is a convenient method by which to measure the performance of "normal photosynthesis' in the algae."

\section{At what point do you foresee actual hydrogen production-based testing of reduced-antennae algae? What level of increased hydrogen production do you predict as a result of the antenna reduction?}

"Hydrogen or biomass production could be attempted with any of the "truncated Chl antenna size" strains. The positive effect would be manifested under mass culture conditions, i.e., conditions where the geometry of the reactor and/or the density of cells in the mass culture would result in a $100 \%$ absorption of the incident irradiance.

"Integrated over the course of the day and through the depth of the culture, the prediction is for a 5 -fold increase in productivity (maximally truncated Chl antennae vs. normally pigmented cells)."

Dr. Melis mentioned that this success would be manifested as a 5-fold increase in either biomass or hydrogen production. (A "normal" cell at noon, only uses $5 \%$ of the available light)

A 5-fold increase (which, I suppose reflects an increase of efficiency to 25-50\% -depending on whether you are talking about 5\% normal efficiency at noon, or the 200 of 2000 photons used per cell) is substantial. One key reminder, however: Dr. Melis speaks of increase in biomass or hydrogen. His goal is to reduce the antenna size. It is the responsibility of others to turn that into hydrogen. Cooperation between the laboratories is necessary, and it must be reciprocal cooperation.

\section{Will the reduced antennae in any way play in the tendency of hydrogen production to be inhibited by the presence of oxygen?}

"Based on current knowledge, there is no reason to believe that genetic interference with the Chl antenna size would have a direct effect on the activity of the hydrogen producing enzymes. Nevertheless, a drastically smaller $\mathrm{Chl}$ antenna size for photosystem-Il would lower the rate of oxygen evolution in the chloroplast and, therefore, may diminish the tendency of hydrogen production to be inhibited by oxygen."

Dr. Melis also mentioned that under low light you might get less oxygen, and therefore, more hydrogen. However, with less activity, you'd get fewer electrons, and therefore, less hydrogen. But the reduced antenna size will not affect the hydrogenase. (In other words, there are a lot of potentially conflicting phenomena, but it does not at this time appear to be a matter of concern.) 


\section{Much of your FY 2000 Annual Review report compares wild and mutant (Chl b -less) algae that are grown in either TAP (Tris-Acetate-Phosphate), TABP (TAP supplemented with Tris-HCl) and with sodium bicarbonate), or TBP (Tris-HCl- phosphate supplemented with sodium bicarbonate). If the mutant algae were to be used in the "real world" to split water for hydrogen, is it to be expected that one of these media would be used to grow the algae? Would this be a reasonable thing to expect in large scale?}

"Yes, exactly! Experimentation with different growth media in my lab is a way by which to prepare for a "real world" scenario. It is a prelude to defining conditions suitable for scale-up. We were also testing the different growth media to find out whether they exert any effect on the Chl antenna size in wild type and mutant."

Dr. Melis added that although TBP will grow cells, you need the acetate component to get hydrogen. You would likely add acetate for that purpose, perhaps using just enough bicarbonate to grow cells, and then when it runs out, you would replace it with acetate. In small scale, you could filter and replace.

The question is what would you do in large scale?

\section{In the same report, please explain Table 3.}

"Table 3 is the cornerstone of our analytical approach and a unique Berkeley capability. It provides measurements of the number of $\mathrm{Chl}$ molecules that are specifically associated with each of the photosystems (i.e., it measures the $\mathrm{Chl}$ antenna size of the photosystems). This type of measurement and experimental analysis is absolutely essential in this project. Such technological know-how (the measurement of the Chl antenna size of the photosystems) is an exclusive know-how of the Melis Laboratory (sole source provider). The technology has not been duplicated in any other photosynthesis research lab worldwide. (We receive 2-3 requests for help with such direct $\mathrm{Chl}$ antenna size measurements from photosynthesis colleagues each year)."

"Table 3" is reproduced in this report as Exhibit 2. The various "N"s refer to the number of available sites for photons. That is directly related to antenna size. The smaller values for $\mathrm{N}$ for PS II for the $\mathrm{Chl} b$-less mutants indicate a decrease in antenna size for PS II. (Note that for Photosystem II, there are no $\alpha$ and $\beta$ breakdowns for chl $b$-less mutants.) PS I antenna actually appear to be increasing. Dr. Melis believes that this is because chl $a$ may be taking the place of chl $b$ in the trimers, keeping the peripheral sites intact.

Dr. Melis also states that PS II photosynthesis is the rate limiting step, so that the size of the PS II antenna sizes are probably more important than the PS I sizes.

\section{What is a "regulatory mutant?"}

"Green algae have the ability to adjust the number of the $\mathrm{Chl}$ molecules that assemble in the Chl antennae of the photosystems. These adjustments are triggered by the prevailing environmental conditions. For example, persistent exposure of the algae to bright sunlight triggers the assembly of smaller size Chl antennae; a meaningful response by the cells designed to conserve resources. 
"Conversely, persistent exposure of the algae to low-intensity illumination triggers the assembly of large size $\mathrm{Chl}$ antennae; again a meaningful response designed to enhance sunlight absorption. A "regulatory mutant" is one that has lost the ability to make such adjustments and either assembles the maximum possible or minimum possible $\mathrm{Chl}$ antenna size, irrespective of the prevailing conditions."

Ideally, you would like to have variable antennas that would get larger in low light and smaller in bright light. This sort of phenomenon could not happen quickly enough to follow the amount of sunlight.

The light-harvesting mutant (thl-1) that Dr. Melis' group has isolated shows smaller antennae for PS II sites - although not as small as the chl $b$-less algae. Encouraging, however, is the fact that the PS I antennae were somewhat smaller. Exhibit 3, taken from Dr. Melis' work over the last couple of years shows antenna sizes for wild, chl $b$-less, thl1 , and lutein-less versions of the algae, together with the minimum theoretical antenna size that could exist.

If we examine Exhibit 3, and use the antenna sizes for the wild algae as baseline we see that for PS II, chl b-less transformants produce 60\% smaller antennae, thl-1 produces 49\% smaller antennae, and lutein-less transformants produce $42 \%$ smaller antennae. For PS I, thl-1 reduce antenna size by 22\%. The other two species show an increase in PS I antenna size. A better measure, however, might include looking at the theoretical limits as the ideal. We can show roughly how far the group has gone toward reaching the "goal" - the theoretical values. For the PS II system this is: 72\% of the way toward the theoretical value with chl b-less transformants, 58\% for the thl-1 mutant, and 52\% of the way for lutein-less transformants. For PS I only the thl-1 mutant produces a reduction in antenna size, and it goes $41 \%$ toward the theoretical.

\section{Has there been general consensus among the photobiological hydrogen group that Chlamydomonas reinhardtii is and will be the alga of choice for water splitting? If this turns out not to be the case, will the data gathered here be easily transferable to the "new" alga?}

"My own feeling is that Chlamydomonas reinhardtii will not be the alga of choice for either hydrogen or biomass production. There are other better candidates. However, Chlamydomonas is an excellent model organism to collect the data, which then can be transferred to other microalgae. The approach in the Melis laboratory is to clone those genes that affect the size of the Chl antennae in this microalga. These can be later over-expressed or down-regulated in other algae that are more amenable to mass culture for biomass/hydrogen production. In this respect, the Melis laboratory is developing and applying transformation technologies in a number of green algae, including Chlamydomonas reinhardtii and Dunaliella salina. Transformation technologies will permit the delivery of plasmid constructs into the genome of novel green algae that are promising for mass culture. Such plasmids will be designed:

(a) to over-express a certain gene by selection of the gene's promoter region or,

(b) via the application of antisense technology, transformation will be used to silence genes of interest, thereby affecting the size of the Chl antennae." 
In the DOE program, they are looking only at Chlamydomonas, but their USDA work, which will benefit DOE as well, involves Dunaliella. According to Dr. Melis, Chlamydomonas is not a very hardy organism. If the transformation can be performed on other algae such as Dunaliella, it will be able to be tested under a larger variety of different conditions.

The laboratories involved with photobiological hydrogen are all working with Chlamydomonas, but at least two of them have other "pet" algae that they think might be better suited toward their specific work. Care must be taken that either consciously or subconsciously the work does not individually migrate toward incompatible organisms. Equally important is the need to step back and ask (as a group): when do we move away from Chlamydomonas and toward the organism(s) that will be the mass hydrogen producer?

\section{Collaborations:}

We spoke to some degree about the functions of the various laboratories that make up the hydrogen photobiological group - meaning the people who are trying to get algae to use sunlight to split water and make hydrogen. Dr. Melis summarized the original intention of the collaborative effort to include:

- Dr. Eli Greenbaum's group at ORNL: produce hydrogen and oxygen simultaneously from a single organism and use a mechanical method of removing the oxygen.

- Drs. Mike Seibert and Maria Ghirardi at NREL: use chemical mutagenesis to find hydrogenase mutants that were not sensitive to oxygen.

- Dr. Melis: Tackle the chlorophyll antenna problem.

Dr. Melis states that he also teamed with NREL to promote his idea that sulfur deprivation of green algae might facilitate hydrogen production. However, Berkeley is no longer part of this latter project, and now does only antenna reduction work. I am not quite clear on how the roles have all played out-or will play out.

\section{Tour of Facility:}

Dr. Melis took Dr. San Pietro and me on a tour of his laboratories.

The centerpiece of the laboratories, at least as far as the DOE work is concerned, is an instrument that was designed and built by Dr. Melis to measure antenna size. He calls it a "sensitive, split-beam, differential kinetic spectrophotometer." This is certainly not a piece of equipment that comes in a box from a science supply store. It is put together piece by piece, and includes some components that look very similar to some I remember from my days in graduate school in the early '70s. This is not to say that the system is outdated (although I wonder what he could do with today's equipment!). As Dr. Melis presented it to me, it appears to be right on target. 
The main components are:

- A stable white light beam for source radiation,

- a monochrometer with a manual crank for setting the wavelength you wish to use for studying a particular site,

- a split-mirror that will divert $5 \%$ of the light to a photomultiplier (as reference beam) detector,

- a sample holder

- an actinic (reaction-causing) light source, perpendicular to the main beam path to cause photosynthesis

- a second photomultiplier detector

- Enabling electronics.

The existence of the reference photomultiplier allows differential data to be accumulated. The amount of light absorbance as well as the rate of absorbance can then be measured. Since the monochromatic light can be set to observe the change in any species (e.g., chl $b$, lutein, etc.) it can be used to determine amount of this species present, and from this, antenna size.

Dr. Melis also has a second, less sensitive, but scanning-capable (over wavelengths of light) spectrophotometer.

Other equipment/facilities in the laboratories included laminar-flow hoods for sterile transfers, freezers to store biological samples at $-80^{\circ} \mathrm{C}$, incubation chambers utilizing light and $233^{\circ} \mathrm{C}$ heat, a second totally separate growth room (with a multitude of cultures present), and preparation rooms with centrifuges, incubators and bacterial growth chambers. They use the bacteria to produce DNA, which is then transferred into the Chlamydomonas alga for transformation.

Physically, insertion of DNA into a cell is done in one of two ways. In the first, the cells and DNA are shaken together in the presence of glass beads. The beads break the cell wall, allowing admission of the DNA. In the second method, an electric field and a very short pulse of high voltage is used. The DNA is negatively charged, and tries to jump to a positive electrode, but the cells are in the way, so the DNA penetrates the cell wall.

\section{Discussions with Others:}

Dr. San Pietro and I also spent some time talking to Drs. Kanakagiri and Masuda. Dr. Kanakagiri, a geneticist, is performing genetic insertion for antenna size reduction. She has made over 6,500 transformants. These were screened by fluorescence - a transformant with small antennae will not fluoresce strongly due to its low chlorophyll concentration. Dr. Kanakagiri found 60 of the 6,500 transformants exhibiting low fluorescence. Not all low fluorescing transformants, however, have small antennae; they could just be inefficient photosynthesizers.

Dr. Kanakagiri then tested the chl $a / \mathrm{chl} b$ ratio of the 60 remaining candidates, and attempted to grow the transformants under high light (recall that under high light, chl $b$ 
presence leads to inefficient use of light.) She found that 4 transformants showed good growth under high light conditions. A DNA analysis on the four transformants indicated that one (out of 6,500!) appeared suitable.

Dr. Kanakagiri mentioned that the plan is now to clone the gene so that they can introduce it into different algae if desired.

Dr. Masuda, a molecular biologist, is working with Dunaliella salina, using high (2000 $\mathrm{W} / \mathrm{m}^{2}$ and low $50 \mathrm{~W} / \mathrm{m}^{2}$ light conditions and looking for low total chlorophyll and high $\mathrm{chl} a / \mathrm{chl} b$ ratios. He is looking for these conditions in two projects. In one, he is trying to inhibit the overall production of chlorophyll by inhibiting one of the reaction steps that leads to a chlorophyll precursor using gabaculene as the inhibitor. He found that although chlorophyll production was down, the chl $a / \operatorname{chl} b$ ratio was actually decreasing. He believes that the $a$ variety was changing to $b$.

In his second project, Dr. Masuda is looking specifically at chl $a$ to chl $b$ conversion. He is trying to inhibit this by working with the CAO gene. (See Question 2).

A third research associate, Dr. Juergen Polle, a spectroscopist/biochemist, also works on the hydrogen program, but he was out of the country. Dr. Melis briefly described his work to us. Dr. Polle is basically responsible for the measurements. He compares data on wild type, chl $b$-less type, thl-1 type and lutein-less type of algae. Comparisons are done both spectroscopically and by Western blot measurements for chlorophyll proteins. These two totally separate tests serve as a check against one another.

\section{Final Thoughts:}

I think it's of value to try to determine how far Dr. Melis has come in the antenna reduction process, and if he is still making progress. So we turn again to Exhibit 3. The first point is that there is significant reduction demonstrated for all three types of altered algae (chl b-less, th-1 and lutein-less) for PS II. In addition, we are seeing a reduction in PS I antenna size for th-1. Progress is being made; the th-1 and lutein-less results represent this year's work.

Next, I think it's only fair to bring up the point that other researchers do indeed look at antenna size reduction as a means of increasing photosynthesis efficiency. I'll mention one: a paper by Y. Nakajima and R. Ueda, J. Appl. Phycology 12, 285-290 (2000), discuss the effect of reducing "light-harvesting pigment" in Chlamydomonas perigranulata algae. Light harvesting pigment and antenna size are basically synonymous. The reduction reported by Nakajima and Ueda comes after UV mutagenesis on the algae. They report a decrease in PS I antenna size by 50\%, and an increase in PS II size. Thus, (putting aside the fact that it's a different Chlamydomonas,) it appears that these researchers are more adept at reducing PS I antennae and Dr. Melis' group is far more successful with PS II. 
What may be troublesome, however, is the report in the same paper that photosynthetic activity improvement does not keep pace with antenna size reduction. In other words, the question is the same one that we continue to ask ourselves in all hydrogen production projects: How much hydrogen does it make?? The answer may not be part of Dr. Melis' particular task, but it's the leading question of the overall photobiological hydrogen program. 
Exhibit 1. Schematic of Photosystem II light receptor antennae

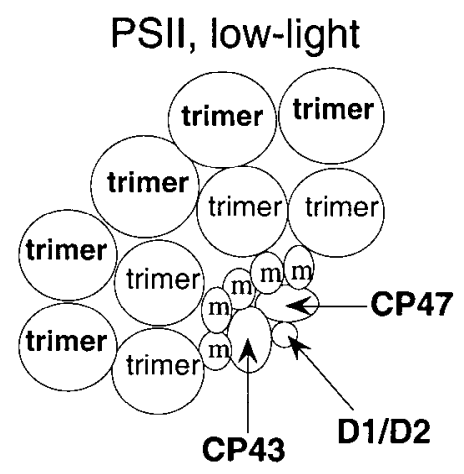

PSII, medium-light

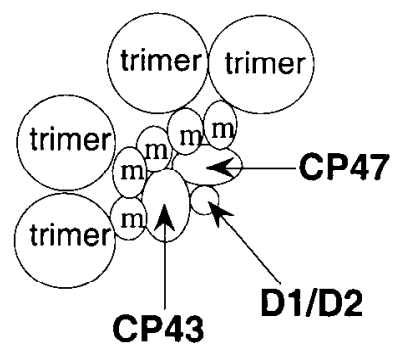

PSII, high-light

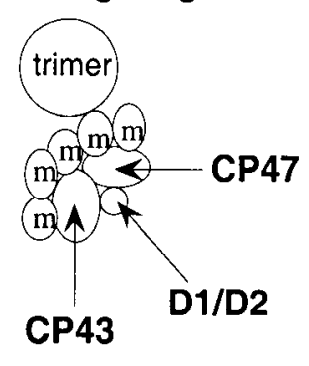

Exhibit 2. Dr. Melis' FY 2000 Annual Review Report, "Table 3" showing chlorophyll antenna sizes for various wild type and chlorophyll $b$-less mutants.

\begin{tabular}{lllllll}
\hline \multicolumn{5}{c}{ wild type } & \multicolumn{5}{c}{ Chl $b$-less } \\
\hline Parameter & TAP & TABP & TBP & TAP & TABP & TBP \\
\hline PSII $_{\alpha}$ & $42 \pm 7.4 \%$ & $53 \pm 10.5 \%$ & $29 \pm 9.5 \%$ & - & - & - \\
& & & & & & - \\
PSII $_{\beta}$ & $58 \pm 7.4 \%$ & $47 \pm 10.5 \%$ & $72 \pm 9.5 \%$ & - & - & - \\
$\mathrm{N}_{\text {(PSIL) }}$ & $322 \pm 7$ & $284 \pm 49$ & $474 \pm 49$ & - & - & - \\
& & & $(325)$ & & & \\
$\mathrm{N}_{\text {(PSII })}$ & $127 \pm 3$ & $141 \pm 3$ & $119 \pm 3$ & - & - & - \\
$\mathrm{N}_{(\text {PSII) }}$ & & & & $93 \pm 3$ & $107 \pm 9$ & $88 \pm 7$ \\
$\mathrm{~N}_{\text {(PSI) }}$ & $291 \pm 17$ & $217 \pm 8$ & $204 \pm 4$ & $245 \pm 14$ & $284 \pm 6$ & $289 \pm 12$ \\
\hline
\end{tabular}

Exhibit 3. Summary of latest results on antenna sizes for different mutants or transformants.

\begin{tabular}{|c|c|c|c|c|c|}
\hline Parameter & Wild type & Chl $b$-less & tlh-1 & lutein-less & $\begin{array}{c}\text { Theoretical } \\
\text { Limit }\end{array}$ \\
\hline $\begin{array}{c}\text { N (PS II) } \\
\begin{array}{c}\text { Average of } \alpha \\
\text { and } \beta\end{array}\end{array}$ & 222 & 88 & 114 & 125 & 37 \\
\hline N (PS I) & 204 & 289 & 159 & 294 & 95 \\
\hline
\end{tabular}


Technical Evaluation Report

Project: Reversible Solid Oxide Fuel Cells

Company: Technology Management Inc.

P.I.: Drs. Robert Ruhl and Christopher Milliken

Site-Visit Date: March 20, 2001

Evaluation by: Edward G. Skolnik, Energetics, Inc.

\section{Summary:}

Technology Management, Inc. (TMI) is developing a reversible solid oxide fuel cell (SOFC) designed primarily for off-grid residential use. It can act as an electrolyzer, utilizing excess renewable resources to make hydrogen. As a fuel cell, it can operate off the stored hydrogen to make electricity. If no hydrogen is available, it can operate off of reformed propane.

Phase 1 of the project, completed last year was a paper study. Phase 2, where TMI is getting into hardware was just beginning at the time of my visit. Originally, TMI based their paper study on a system in Boulder, CO that used PV as the renewable resource. A summary of the data they presented for this is shown in Exhibit 1. In the later stages of Phase 1, however, they modified their case study, and considered a wind-based system in Colorado Springs, CO. Exhibit 2 summarizes their findings for this system.

I see the following strengths:

- SOFCs, due to higher operational temperatures provide the opportunity for increased efficiency operations. SOFCs have several advantages over Proton Exchange Membrane (PEM) fuel cell systems for stationary applications.

- The TMI project presents a good opportunity for a near-term water-based reversible fuel cell test/demonstration.

I see the following matters of concern:

- I am not convinced that there is a "middle ground" here for a more complex, expensive system, with some environmental benefits. I think we need to find out.

- The jump from solar to wind while done for valid reasons needed to be adequately explained in the formal reporting mechanism. It is not the kind of thing we should have to ask about.

- We need to take care that the propane fuel cell mode does not become the only mode. 


\section{Introduction and Background:}

I visited TMI at their facility in Highland Heights, $\mathrm{OH}$, outside of Cleveland, to discuss their rather unique kind of reversible solid oxide fuel cell. Present at the meeting from TMI were Benson Lee, President; Michael Petrik, Vice President; Dr. Robert Ruhl, Vice President, Engineering; and Dr. Christopher Milliken, Research Materials Scientist. Dr. Ruhl was the PI for Phase 1; Dr. Milliken is the PI for Phase 2

Mr. Lee provided some background information on his company. TMI was founded in 1990. Its major product is solid oxide systems. Solid oxide fuel cells were originally developed by BP/Sohio, which is also in Cleveland, hence the interest in this field by TMI.

TMI has had many Department of Defense contracts. The focus was on small, lightweight systems running on liquid fuel. The main problem was sulfur contamination. TMI thus focused on making a sulfur-tolerant reformer and a sulfur tolerant SOFC. Dr. Lee indicated that at the time, DOE was not interested in liquid systems. He mentioned that the then Federal Energy Technology Laboratory, now the National Energy Technology Laboratory, was working with SOFCs that ran on clean, natural gas.

It was actually through conversations with people from National Renewable Energy Laboratory that TMI decided to write a proposal to the DOE Hydrogen Program. TMI is not proposing their "mainstream" TMI fuel cells for this project.

\section{Tour:}

I was given a tour of the facility, but was asked not to comment on any specific details of their setup. TMI has moved into this new facility only in the past few months. It is impressive in capability for a small company; TMI has the necessary equipment to manufacture and test SOFC components.

\section{General Discussion:}

Solid oxide fuel cells generally operate at about $900^{\circ} \mathrm{C}$ and rely on migrating oxygen ions. All SOFCs are designed in three layer "sandwiches" consisting of a solid electrolyte between two electrodes. The major difference is in configuration. For instance, the Westinghouse SOFC design is three concentric cylinders. The TMI fuel cell is three roughly two inch diameter discs (per cell) with holes in them for fuel flow. The porous design cuts down on manifolding.

TMI uses particulates to make their three layers. It is therefore not necessary to co-fire the three layers. (Other manufacturers need to co-fire to avoid cracking.) Therefore, TMI has the capability of testing and substituting new materials easily. In general, however, SOFC electrode and electrolyte materials are similar throughout the industry. 
TMI makes $2 \frac{1}{2}$ " diameter cells. They believe that this size will maximize efficiency and lower costs. This will happen through superior cooling and temperature control, ease of manufacturing, and lower pressure drops. Smaller diameter cells give a higher volumetric power density, which translates to lower costs.

Seals have not been a problem as TMI's designs to date have involved seals in the middle of the discs. However, they are now looking at rim seals as well.

In order to keep costs down, TMI uses low cost manufacturing processes and no precious metals.

Without getting into actual material descriptions at TMI, I can make a comparison with another (European) SOFC manufacturer that I had the opportunity to visit about a year ago. This other company used particulate component starting materials as well, using a yttria zirconia electrolyte sandwiched between a nickel oxide anode and a strontiumdoped lanthanum manganite cathode.

The electrolyte was cast onto plastic tapes, after which sintering was used to burn off the plastic. The electrolyte layer is then sandwiched between the green electrodes, which have been made as pastes in organic binders and passed through a sieve before the sandwich is made. The three-layer system is then co-fired. That particular manufacturer mentioned that sulfur poisoning was a problem. TMI's claim is that their system is sulfur tolerant.

TMI is also a systems house; they make their own reformers. Their systems are able to switch between natural gas, propane, and jet fuel (JP8). They have run for 1600 hours continuously on JP8. They have not yet tried diesel, but recognize that diesel would be harder to reform. As we mention later, their initial proposal included diesel rather than propane.

TMI has targeted grid independent residences. Without the selling electricity to the grid issues, these are somewhat easier to study. There are about 200,000 of these homes in the United States (about $0.2 \%$ of all residences) not including seasonal housing. People who live in these houses are "doomed" to pay higher prices, says Dr. Ruhl.

Dr. Ruhl presented comparative data from their final report of their FY 2000 paper study. This is reproduced in Exhibit 2. (We discuss these data in more detail in the Questions and Answers) For the scenarios including wind power (Cases B, D, and E), TMI used a 3 $\mathrm{kW}$ wind turbine. In the "Wind + TMI Fuel Cell" cases (D \& E), TMI assumed a battery backup for quick start-up. This was the high cost component of the system. The battery was described as a valve regulated lead acid (VRLA) battery of the glass mat design.

TMI thought that a $3 \mathrm{~kW}$ wind turbine would be appropriate for a house; anything much smaller wouldn't provide enough energy. In the case study, the $3 \mathrm{~kW}$ wind turbine provides about $71 \%$ of the total energy needed. If we look at the earlier solar case 
(Exhibit 1), TMI showed cases where $99 \%$ of the energy could come from the PV panels. An analogous wind system would have made a good comparison.

Their "propane only" SOFC system (this is the "mainstream" system that TMI has been mentioning, Case C) gets $60 \%$ efficiency on a lower heating value level. For the system that they are developing for the Hydrogen Program (Case E), they claim a round trip efficiency of $73 \%$ (wind $\rightarrow$ SOFC, electrolyzer mode $\rightarrow$ hydrogen storage $\rightarrow$ SOFC, fuel cell mode $\rightarrow$ load.) In fact, Dr. Ruhl claims they can likely get up to $80 \%$, but this would be more expensive than the $\$ 0.30 / \mathrm{kWh}$ they claim in Exhibit 2.

The TMI system is planned to contain four $1 \mathrm{~kW}$ modules, which would be running in parallel to ensure reliability (see also Question 12). Each module would weigh less than $100 \mathrm{lbs}$. Note that Exhibit 2 only assumes 3 modules.

TMI actually sees their straight-propane fuel cell (Case D in exhibit 1, and Case C in Exhibit 2) as the most viable in the short term. Note that these are also the most inexpensive systems, providing electricity at less than $\$ 0.17 / \mathrm{kWh}$. As renewable energy becomes more desirable, the reversible fuel cell option becomes more attractive. TMI does point out, however, that battery storage makes a pretty good competitor. It comes down to how long do you want to (or need to) be able to survive in the absence of the wind blowing or the sun shining and how many batteries do you want to own and maintain.

\section{Questions and Answers:}

Dr. Ruhl led the discussion on the questions that I had sent to TMI earlier. The questions are shown here in bold, the discussion is presented in normal type, and some of my later thoughts are in italics.

\section{What properties of solid oxide systems make them superior to, say, PEM systems for reversible fuel cells? Please look at both the electrolyzer and fuel cell "halves" of the system to answer the question.}

There are several advantages; some are in one direction, some in both:

a. As both an electrolyzer and a fuel cell, the TMI SOFC can operate at low voltages due to the high operating temperatures $\left(800-900^{\circ} \mathrm{C}\right)$. There is very good high temperature kinetics, and there is no activation polarization at high temperatures. Therefore, TMI in fuel cell mode, can operate at about 880 $\mathrm{mV} / \mathrm{cell}$, and in electrolyzer mode, they can operate at about $1030 \mathrm{mV} / \mathrm{cell}$. This gives an efficiency of about $85 \%$; Analogous PEM efficiencies would be around $30 \%$. True if you're operating the PEM in the electrolysis mode at an overvoltage of about $2000 \mathrm{mV}$, and operating the fuel cell at about $600 \mathrm{mV}$. I believe we should be able to at least use a higher voltage for the fuel cell maybe about $800 \mathrm{mV}$. I'm not sure the comparison here is fair. 
b. The ceramic membrane does not leak; PEM membranes do leak. Again this is an advantage in both directions.

c. In the electrolysis mode, there is more favorable thermodynamics using high temperature steam than liquid water. The free energy is much lower.

d. Also in the electrolysis mode, they can make use of thermal storage. In the fuel cell mode, excess heat is produced, so they let the temperature "float" upwards during fuel cell operation, and then use the heat in the electrolysis mode. In addition, the heat of condensing water during fuel cell operation can be used to vaporize water during electrolysis. Not on a one-to-one basis, of course.

Dr. Ruhl also indicated that they have a solid oxide electrolyzer that will operate with about $95 \%$ efficiency (if they have only a very small power conditioning factor) and makes 5000-psi hydrogen.

2. Your FY 2001 Annual Operating Plan contribution speaks of demonstrating the system in "storage battery mode." Does this simply mean storage of hydrogen as opposed to lead acid batteries? How will the hydrogen be stored? Is this part of the project, or will it just be off the shelf.

It does simply mean storage of hydrogen. TMI's design calls for the hydrogen to be stored as a compressed gas; there are more inefficiency issues with hydrides, especially the need for temperature to remove the hydrogen. Might not this actually be a good candidate for hydrides seeing the high temperature operation anyway?

TMI's design also calls for storing the electrolysis-produced oxygen, and use it in the hydrogen/fuel cell mode. They use air in the propane/fuel cell mode. The need for highpressure oxygen storage helps to justify the use of high-pressure hydrogen storage.

Phase 1 was just a paper study; there is no plan to do any storage development in later phases.

\section{Do you anticipate home units? Would they include hydrogen storage at high pressure?}

TMI's major market thrust is toward non grid-connected residences. Conceptually, hydrogen would be stored as a compressed gas. TMI believes that safety issues in this regard would be handled by others.

4. In your FY 2000 Annual Review Report you use a hypothetical home in Boulder $\mathrm{CO}$ as your test case. What conditions were you meeting by choosing this application? Do you feel that this is a typical application (domestically/ internationally) for your system? What other applications do you see for this type of system? 
TMI recognized that there were a large number of homes in Colorado that were not connected to the grid. In addition, solar data was available for the Boulder area. (Later, they switched to wind as the renewable resource and moved their hypothetical site to Colorado Springs (See Question 6)).

The use of Boulder was more "favorable" than typical. The home in the case study does not use air conditioning, but this is not unusual for non grid-connected homes.

5. Your cost of electricity from what appears to be your most advanced system (labeled “G” in your FY 2000 Annual Review Report is \$0.66/kWh. This seems rather high, especially if it is being used as the only source of energy. What (other than the low emissions) will make such a system attractive?

The data are shown in Exhibit 1. The number has come down. Now using wind resources, TMI is quoting $\$ 0.30 / \mathrm{kWh}$ (Exhibit 2 Case E) for the analogous system. Dr. Ruhl says that they can even beat $\$ 0.66$ for solar. The other side of the coin is that some people are willing to pay more for renewable power. Granted, it's a small fraction of the people. Dr. Ruhl believes that the price will come down further with improved renewables technology.

Actually, I think Case $\underline{F}$ in Exhibit 1 (the older, solar-based system) is more analogous to Case E in Exhibit 2. The case that I was actually asking about (Case G in Exhibit 1) is not really represented in Exhibit 2, the newer, wind-based data. Case $G$ is more of an "ideal" set up, where you have adequate renewable energy to take care of most of your needs (99\%). It would seem that TMI has abandoned the scenario where the use of the fuel cell in propane mode is only a minor player.

The "small fraction of the people" who are willing to pay more for green energy might have a tendency to occupy these non grid-connected houses. At the same time, however, would they also want to use propane, or would they be more interested in a two-way reversible fuel cell only? It would be more expensive to rely totally on hydrogen storage, but would this market care?

\section{Your Final Report (September 2000) changes the site to Colorado Springs, and changes from solar to wind power. What was the reason(s) for this? (Wind numbers seem more attractive than solar; $I$ assume this is part of the reason.)}

The lower price for wind power is indeed the main reason. The suggestion to move from solar to wind came from Dr. George Thomas (Sandia National Laboratories) (I later have come to believe that Dr. Ruhl actually meant Dr. Sandy Thomas of Directed Technologies Inc.) according to Dr. Ruhl. The move from Boulder to Colorado Springs was due to the fact that wind data was available for Colorado Springs.

7. Do you see this system as more or less attractive in a scenario where grid connection is also a possibility? 
The grid-connected scenario may become attractive when fuel cells "really take off," but probably not until then. Perhaps it can be attractive in specific scenarios; it's hard to tell.

It would be too expensive to sell propane-based electricity back to the grid. Natural gas would be another story.

8. Please discuss heat flows to and from your reversible fuel cell. What is your operating temperature? What is the source of heat? Where does the waste heat go?

The TMI system runs at $900^{\circ} \mathrm{C}$ most of the time. When you are in fuel cell mode, you invariably produce more heat than you need. You need to have a cooling system, because you are not always operating in a mode where you can use the heat. So you don't really have a lot of waste heat.

TMI, however, has looked at using whatever waste heat there is for a domestic hot water system. They thought that this seemed reasonable.

9. Since efficiencies are generally greater for electrolysis than fuel cell operation, is it necessary for you to oversize your system to maximize your renewable resource input.

TMI's system-level study showed that the optimal case may be one in which they may have to "throw away" a little renewable energy. This was economically favorable to oversizing the system.

10. I assume that to run your system in propane mode, it needs some kind of a reformer. Is this a separate operation? What happens to the byproducts?

Yes, the propane mode uses a reformer, but it is heated by hot exhaust. It also burns highly depleted fuel and produces no $\mathrm{NO}_{\mathrm{x}}$.

In the propane mode, the waste products are vented. This is primarily $\mathrm{CO}_{2}$ and a small amount of $\mathrm{SO}_{2}$, as there is sulfur in propane. This strikes me as possibly alienating the very people you are trying to market.

There is also a small VRLA battery in the system. This is used to get fast response during the time the system is switching between modes. A fuel cell will take about four seconds to respond, while the battery is instantaneous.

11. The reviewer's comments in answer to your FY 2000 Peer-Reviewed Presentation indicate that you were concentrating on diesel engine backup rather than a propane fuel cell. (They make no mention of propane.) Were you presenting the propane system at the time? 
TMI had spoken of propane during the review. Dr. Ruhl theorizes that the reviewers might have seen a copy of TMI's original proposal, which was keyed to diesel reforming because of the Alaska tie-in.

Recall that TMI mentioned that their reformer was robust enough to handle NG, propane or JP8, but they were unsure about diesel. Yet, they originally proposed diesel.

Dr. Ruhl admits that the system is complicated (the FY 2000 reviewers found fault in the complexity of the system), but it is the most cost effective system.

TMI has looked at two separate systems (electrolyzer and fuel cell), but found that you lose too much heat in this manner. The need to conserve heat might be a major reason why a company making PEM systems might opt for a two-stack system (ala Proton Energy Systems) while a solid oxide system manufacturer would desire a single stack.

12. In your September $\mathbf{2 0 0 0}$ report, you show four reversible fuel cell modules for the wind/reversible fuel cell case (system $\mathrm{E}$ ). Is the plan that all modules will be running on the same fuel at the same time, or might, say a couple be running on hydrogen and a couple on propane? Would it be fair to assume that if you're running in electrolyzer mode, all four modules are in that mode? In system $\mathrm{E}$, will any of the wind-produced DC electricity go directly to AC conversion and the load, or will it all go through the fuel cell?

When in the wind mode, wind power first goes directly to power conditioning and the load. Excess wind goes to the electrolyzer for conversion to hydrogen and oxygen. When in the fuel cell modes, all of the hydrogen and oxygen is depleted first (hydrogen fuel cell mode). You only switch to propane when you have to. Also, recall that the battery is there for the quick start.

\section{The New (Phase 2) Effort:}

Dr. Milliken, who is the PI on the newly started hardware-based phase, briefly discussed TMI's plans and technical hurdles. TMI will resolve performance over a full range of conditions. They will concentrate on multi-stack systems (their later Phase 1 work was based on three modules, and they have said that they envision four modules as a likely scenario), and will address life and gas cycling. They are especially concerned with degradation of the system under electrolysis conditions.

TMI is not planning to do much in the way of stack seal development. Recall that the seals are in the center of their discs, but that they will need some rim seals as well. Their contract, however, does not have sufficient funding for seal development.

TMI also plans cost studies in which they will be evaluating stacks over a wide range of conditions. 


\section{Final Thoughts:}

In FY 2000 at the Hydrogen Peer Review, the reviewers showed concern that the proposed process was too complex. At the time, it was in the PV mode. The reviewers felt that more detailed cost breakouts were needed (although presumably, the data we show here in Exhibit 1 and the data backing it up should have been available.) Since that time, TMI basically revamped their study, turning it from a PV-based single module system, heavily reliant on renewable energy in Boulder, to a wind-based three-module system, only partially reliant on renewable energy in Colorado Springs. This was done in what looks like a complete severance from the earlier PV work. The PV portion, which was quite detailed, is not even mentioned in the September 2000 final report. While wind, as it was pointed out is indeed a less expensive system, the solar case studied had some merit, and should not be lost to the ages.

The major question, however, is where does this work fit in? It is heading toward a demonstration of a reversible fuel cell - certainly a worthy goal. The hydrogen community is in need of assessing reversible fuel cells adequately once and for all. On the other hand, is this type of system the right one for such an assessment? The non-grid connected domestic market may be one that is willing to pay more for electricity. But what is its motivation? If it's environmentally based, why does it want a propane reformer and sulfur emissions as opposed to a fully renewable system with perhaps a larger stack and more hydrogen storage (or battery storage, I suppose). If it is not environmentally based, but just needs remote power, why not just the "old" TMI fuel cell (the one-direction, propane fuel cell)? Add to this that the proposed system is a complex system that will require much optimization, and this optimization is not likely to be generic, but might be case by case. Is there a market for a somewhat expensive, somewhat environmentally friendly system?

The comparison I would have liked to see would be the TMI three-way fuel cell system to a TMI two-way reversible SOFC and a diesel generator backup-preferably in the mode where the backup system is rarely used. 
Exhibit 1. System Comparison From FY 2000 Annual Review Report, Solar-based Scenario, Boulder, CO

\begin{tabular}{|c|c|c|c|c|c|c|c|}
\hline Case & $\mathrm{A}$ & $\mathrm{B}$ & $\mathrm{C}$ & $\mathrm{D}$ & $\mathrm{E}$ & $\mathrm{F}$ & $\mathrm{G}$ \\
\hline $\begin{array}{c}\text { Solar Power } \\
(\%)\end{array}$ & 0 & 33 & 99 & 0 & 33 & 33 & 99 \\
\hline $\begin{array}{c}\text { Primary } \\
\begin{array}{c}\text { Fossil Fuel } \\
\text { Generation }\end{array}\end{array}$ & $\begin{array}{c}\text { Propane } \\
\text { Engine }\end{array}$ & $\begin{array}{c}\text { Propane } \\
\text { Engine }\end{array}$ & None & $\begin{array}{c}\text { Propane } \\
\text { Fuel } \\
\text { Cell }\end{array}$ & $\begin{array}{c}\text { Propane } \\
\text { Fuel } \\
\text { Cell }\end{array}$ & $\begin{array}{c}\text { Propane } \\
\text { Fuel Cell }\end{array}$ & None \\
\hline $\begin{array}{c}\text { Backup } \\
\text { Fossil Fuel } \\
\text { Generation }\end{array}$ & $\begin{array}{c}\text { Diesel } \\
\text { Engine }\end{array}$ & $\begin{array}{c}\text { Diesel } \\
\text { Engine }\end{array}$ & $\begin{array}{c}\text { Diesel } \\
\text { Engine }\end{array}$ & $\begin{array}{c}\text { Propane } \\
\text { Fuel } \\
\text { Cell }\end{array}$ & $\begin{array}{c}\text { Propane } \\
\text { Fuel } \\
\text { Cell }\end{array}$ & $\begin{array}{c}\text { Propane } \\
\text { Fuel Cell }\end{array}$ & $\begin{array}{c}\text { Propane } \\
\text { Fuel Cell }\end{array}$ \\
\hline $\begin{array}{c}\text { Primary } \\
\text { Storage }\end{array}$ & VRLA & VRLA & VRLA & VRLA & VRLA & Hydrogen & Hydrogen \\
\hline Pollution & Highest & High & Low & $\sim 0$ & $\sim 0$ & $\sim 0$ & $\sim 0$ \\
\hline $\begin{array}{c}\text { Noise } \\
\text { Installed } \\
\text { Cost } \$ / \mathrm{kW})\end{array}$ & 8,000 & 13,900 & 27,300 & 1,800 & 10,300 & 8,600 & 16,800 \\
\hline $\begin{array}{c}\text { Fuel Cost } \\
(\$ / \mathrm{kWh})\end{array}$ & 0.269 & 0.193 & 0.002 & 0.071 & 0.051 & 0.049 & 0.001 \\
\hline $\begin{array}{c}\text { Maintenance } \\
(\$ / \mathrm{kWh})\end{array}$ & 0.329 & 0.330 & 0.555 & 0.046 & 0.196 & 0.129 & 0.215 \\
\hline $\begin{array}{c}\text { Cost of } \\
\text { Electricity } \\
(\$ / \mathrm{kWh})\end{array}$ & 0.811 & 0.895 & 1.286 & 0.166 & 0.521 & 0.407 & 0.666 \\
\hline $\begin{array}{c}\text { CO } \\
\text { Emissions } \\
\text { tons/year) }\end{array}$ & 9.5 & 6.9 & 0.07 & 2.5 & 1.8 & 1.7 & 0.021 \\
\hline
\end{tabular}
A. Engine-Generator
B. Solar + Engine-Generator
C. Solar + Engine backup
D. TMI Fuel Cell
E. Solar + TMI Fuel Cell
F. Solar + TMI Reversible Fuel Cell
G. Solar + TMI Reversible Fuel Cell (TMI Propane Fuel Cell backup only) 
Exhibit 2. Comparison Data from TMI Final Report, September 2000. Wind-based scenario, Colorado Springs, CO

\begin{tabular}{|c|c|c|c|}
\hline System Type & $\mathrm{A}$ & $\mathrm{B}$ & $\mathrm{C}$ \\
\hline$\%$ Wind Power & 0 & 71 & 0 \\
\hline Primary Fossil Fuel Generation & Propane Engine & Propane Engine & $\begin{array}{c}\text { Propane } \\
\text { Fuel Cell }\end{array}$ \\
\hline Backup Fossil Fuel Generation & $\begin{array}{c}\text { Diesel } \\
\text { Engine }\end{array}$ & $\begin{array}{l}\text { Diesel } \\
\text { Engine }\end{array}$ & $\begin{array}{l}\text { Propane } \\
\text { Fuel Cell }\end{array}$ \\
\hline Energy Storage & VRLA & VRLA & None \\
\hline Pollution & Highest & Medium & $\sim 0$ \\
\hline Noise & Highest & High & Very low \\
\hline Total Installed Cost $(\$ / \mathrm{kW})$ & 22,900 & 33,900 & 5,500 \\
\hline Unit Cost $(\$ / \mathrm{kW})$ & 7,600 & 11,300 & 1,800 \\
\hline Fuel Cost (\$/kWh) & 0.279 & 0.069 & 0.070 \\
\hline Maintenance (\$/kWh) & 0.365 & 0.416 & 0.048 \\
\hline Cost of Electricity $(\$ / \mathrm{kWh})$ & 0.826 & 0.758 & 0.167 \\
\hline $\mathrm{CO}_{2}$ Emissions (tons/year) & 9.8 & 2.4 & 2.5 \\
\hline
\end{tabular}
A Engine-Generator
B Wind + Engine-Generator
C TMI Fuel Cell
D Wind + TMI Fuel Cell
E Wind + TMI Reversible Fuel Cell 
Technical Evaluation Report

Project: Vehicular Hydrogen Storage Using Cryogenic Hydrogen

Company: Lawrence Livermore National Laboratory

P.I.: Dr. Salvador Aceves

Site-Visit Date: May 2, 2001

Evaluation by: Edward G. Skolnik, Energetics, Inc.

\section{Summary:}

The Lawrence Livermore National Laboratory (LLNL) cryogenic hydrogen project is centered on the concept that on-board hydrogen storage can be addressed by realizing that although a driving range of a few hundred miles is sometimes required, it is not always required. The cryogenic pressurized tank is designed to hold compressed hydrogen gas $\left(\mathrm{C}-\mathrm{H}_{2}\right)$ for short commutes to work, and to hold liquid hydrogen $\left(\mathrm{L}-\mathrm{H}_{2}\right)$ for longer-range trips. Since it can hold either form of hydrogen, it can be built smaller than "standard" compressed hydrogen tanks, requiring lesser amounts of $\mathrm{C}-\mathrm{H}_{2}$ when used to commute to work, and relatively infrequent fill-ups of the more costly, denser $\mathrm{L}_{-} \mathrm{H}_{2}$ for longer trips.

In the approximately twenty months since I last visited this project, LLNL has moved from the small sized $\left(1 \mathrm{~kg} \mathrm{H}_{2}\right)$ prototype to the full size tank $\left(6-7 \mathrm{~kg} \mathrm{H}_{2}\right)$, which they are now building and testing. The tank consists of an aluminum liner, a composite (carbon/ or aramid/epoxy) overwrap, and layers of aluminized Mylar insulation over this. The entire tank is encased in a stainless steel shell.

I see the following strengths:

- There is definite progress. LLNL has moved from prototypes to full-scale tanks, and most aspects of the project are proceeding as expected.

- LLNL has a demonstration partner in SunLine who has and will have the proper vehicles, facilities and infrastructure to enable a meaningful demonstration. This will provide meaningful data that will represent a good first step in validating this type of tank.

I see the following matters of concern:

- The lack of LLNL to readily be able to test actual hydrogen systems remains a serious concern in my mind. How do you tell a potential customer that even though the laboratory researchers had to shield themselves in a bunker to perform tests with hydrogen, its all right to have a full tank of hydrogen under your car? The SunLine demonstrations will help, but aging tests of tank materials in the presence of hydrogen, including some overall tank structural tests are needed. 
- The possibility of unbonding between the liner and composite remains an issue. It happened with the smaller tanks. Will it happen with the full-size tanks? Does it matter? Is an actual liner/composite physical bond necessary?

- The failure of one bimetallic seal in one of the prototype tanks has not been resolved yet. In addition, seal testing needs to be done in the presence of hydrogen.

- A lot of thought/analysis is needed to map out usage and infrastructure scenarios. If this project is to be a success, we need to know if the dual hydrogen scenario will be workable. This needs to emphasize "people" aspects - how easily will people adapt to a dual fuel infrastructure.

- Consideration needs to be made for hydrogen transfer into the tank. (How does one put $\mathrm{L}-\mathrm{H}_{2}$ into a tank half full of C- $\mathrm{H}_{2}$ ?)

\section{Introduction and Background:}

I visited Dr. Salvador Aceves at his facility at LLNL to review progress on his cryogenic, pressurized hydrogen storage tank since my last visit in September 1999. We discussed the project in detail and toured the assembly and pressure testing laboratories. Dr. Aceves has been working on the cryogenic pressurized tank concept for the past several years, first choosing this approach from a series of alternate storage scenarios (including glass microsphere storage); designing, building, and testing prototype vessels; and now building and preparing to test full size tanks.

\section{Tour:}

The tour consisted of stops in two different buildings at LLNL, one housing highpressure testing facilities, and the other, a new location for assembly of tanks. In the highpressure laboratory, Dr. Aceves and I were joined by Tim Ross, Chuck Borzileri, and Vern Switzer, whose functions include oversight of the high-pressure facility and safety coordination. When I arrived, there were two full size tanks in the facility, and structural pressure and leak tests were scheduled to be run at a later time.

In a "manned" area, LLNL insists on a 5X safety margin for high-pressure vessels.

The test bed is basically the same as it was 20 months ago, but some of the instrumentation has been upgraded. Also, more consideration has been given to handling the tanks. A full size, insulated tank filled with water (for pressure testing) or liquid nitrogen (for cryogenic testing) weighs about 900 pounds.

(Dr. Aceves mentioned that the primary pressure cell was the same one where LLNL previously performed their glass microsphere hydrogen storage system tests. They were looking to see how quickly they could pressurize the microspheres, using helium at the time. They had just gotten certified to test with hydrogen (so apparently it can be one at $L L N L)$ and the contract got terminated and the Principal Investigator left the laboratory.) 
In the second building, we were met by Mark Fowler who led us through the new facility where tanks are being assembled. It is here that following leak testing (at the pressure facility) the composite tanks are wrapped with the multi-layer insulation. (The tanks themselves currently are manufactured at SCI.) Following this, a vapor shield (a series of heat transfer tubes welded to a jacket, with spaces filled with thermal epoxy) is installed. This reduces heat transfer loses. More insulation is wrapped over the vapor shield. Finally, a stainless steel outer shell is placed around everything. The plan is to "fit out" or assemble the entire tank in this facility. Any welding will be done here as well.

The shields and shells are made by an outside contractor. In actuality, LLNL does not have a shell yet; Dr. Aceves cites contractor problems.

\section{Questions and Answers:}

I sent Dr. Aceves a set of discussion questions prior to my arrival. He responded in writing and we also discussed the questions and answers in detail. This is all reproduced here, with the questions indicated in bold, written answers reproduced verbatim in quotes, our discussion shown in normal type, and my comments added to many of the questions during my later analysis and assessment shown in italics.

\section{We have discussed previously the problems that arise logistically when wanting to test hydrogen-filled tanks. Has anything happened recently to alleviate the situation? If not, how will this important (in my opinion) part of materials and components testing be addressed?}

"Nothing has changed. Being a DOE laboratory there are a lot of regulations for us to follow. The energy in the hydrogen exceeds the maximum energy limit for our high-pressure cells. We can move to our high explosives facility, but this is expensive. Instead, we'll try to do the tests at either $\mathrm{SCl}$ or SunLine, where we are away from DOE regulations."

The bottom line is - it's too expensive. When Dr. Aceves used LLNL's remote test facility for three days in 1999, it cost about 1/3 of that year's budget. The use of the remote high explosives site is part of LLNL's policy; there is "too much energy" to allow testing in LLNL's standard high-pressure laboratories. To test in the normal laboratories, the tank would have to be approved by the Department of Transportation (DOT). But, Dr. Aceves claims, they are moving beyond that need. Testing will be performed at one of their partners' facilities - either Structural Composites Industries (SCI) or SunLine Transit Agency. Hydrogen testing should be easier to accomplish there, where the laboratory limitations won't stand in the way. Dr. Aceves recognizes the fact that the tank needs to be certified.

While the current program does include some off-laboratory testing, it does not include hydrogen testing. I think I would test with hydrogen at the first opportunity.

2. You had a milestone in which you tested 5 insulated pressure tanks. You indicated six tests - four cycling tests (cryogenic, ambient temperature, 
environmental, and thermal), a hydraulic burst test and a gunfire test. While the last two are destructive tests, the cycling tests (I hope) are not. How were the tests apportioned among the five tanks? Did any tank see a series of, say, all cycling tests? Are some of these tanks the same ones that will be used for the upcoming bonfire and drop tests?

"We originally built 5 tanks with insulation.

- One tank was used for the ambient temperature cycling test and then for the gunfire test.

- One tank was used for the environmental cycling test and then it was burst tested.

- One tank was used for the thermal cycling test and then it was burst tested.

- One tank was used for cryogenic cycling. This will be now used for the bonfire test.

- The remaining tank will be used for the drop test."

The tanks referred to here are all the small, 1-kg tanks. All of them were aramid fiber tanks, not carbon fiber. The tanks that were burst after cycling all passed a $3 \mathrm{X}$ burst pressure threshold, and failed in the hoop direction. They essentially acted like new tanks, according to Dr. Aceves. The $3 \mathrm{X}$ criterion was imposed for aramid tanks to compensate for the fact that aramid ages faster than does carbon. No aging studies have been done, however. Dr. Aceves indicated that they are proceeding according to DOT regulations.

All except the fifth tank were cycled thousands of times. The fifth tank was only subjected to thermal shock via liquid nitrogen cooling. It will be next subjected to a drop test.

\section{Have any cycling tests been performed (or are being planned) to simulate "real life" conditions? For instance: something like three cycles with compressed hydrogen (or even nitrogen) followed by a cycle with liquid hydrogen, with the process repeated several times.}

"We did cryogenic cycling, where we did a cryogenic cycle with $L N$ followed by 10 cycles with gaseous helium. We believe this may be close to "real-life" conditions, with the only exception of using helium and nitrogen to replace hydrogen."

That's a very important exception!

Dr. Aceves recognizes that some hydrogen testing will eventually be necessary. When the National Hydrogen Association's (NHA) standards become International Organization for Standards (ISO) standards (sometime in the next few months, hopefully), there will be more direction. Dr. Aceves believes that the NHA standards will be similar to DOT or ISO standards for compressed natural gas (CNG).

He believes, however, (as do I) that testing with hydrogen is needed for materials compatibility. Dr. Aceves stated that he believes that NHA is not adequately addressing materials compatibility issues with hydrogen. Embrittlement is the main concern.

Dr. Aceves noted that it might be a little easier to test with hydrogen at LLNL after the NHA standards come out - at least for gaseous hydrogen. Cryogenic conditions still represents a problem that needs to be addressed. Perhaps, suggests Dr. Aceves, SAE tests 
for liquid natural gas (LNG) can be used as a model. The SAE tests consist of a drop test and a bonfire test.

Anything that will make people more comfortable with hydrogen is worthwhile.

\section{Are you using both aramid and carbon composites at this time, or have you down-selected?}

"We are using only aramid vessels, mainly due to availability. The size that we required was only made in aramid. In the long term a decision will be made probably based on cost. In the foreseeable future I believe aramid will be cheaper than carbon fiber, so we'll probably keep using aramid."

Even though the aramid version is twice as heavy, it's one-sixth the cost of the carbon fiber version when purchased from SCI. (This is based on aerospace grade carbon fiber; perhaps a cheaper grade could be used.) Since the system drivers appear to be cost and volume rather than weight, aramid tanks are more likely to be the choice commercially. Dr. Aceves cited a Ford study that showed that the main item for the additional cost (about \$3000) for a hydrogen car over a conventional car would be the tank. The analysis was for a C- $\mathrm{H}_{2}$ tank.

Cost estimates I've seen for a hydrogen tank are more of the order of \$1000. In my 1999 analysis of the PowerBall process, I made a comparison to a $\mathrm{C}-\mathrm{H}_{2}$ tank, and I used $\$ 750$, based on some Sandy Thomas analyses.

To estimate the cost of his tank compared to a C-H $\mathrm{H}_{2}$ tank, Dr. Aceves considers the costs to be proportional to the amount of fiber used. Since his tank is roughly $1 / 3$ the size of a $\mathrm{C}-\mathrm{H}_{2}$ tank, he estimates that it will cost about $1 / 3$ to $1 / 2$ that of the $\mathrm{C}-\mathrm{H}_{2}$ tank.

\section{When I visited in 1999, we discussed the composite to aluminum bond, and you told me that the bond "fails somewhat." Is this still the case? Is this failure mode present both with aramid and carbon composites?}

"We only did ultrasonic testing in the aramid vessels, so we don't know for sure if the carbon fiber vessels present the same form of detachment. In the cryogenic tests it is possible to hear the tanks making slight popping sounds during the first few cycles. We interpreted these sounds as an indication that some detachment is occurring at the liner-fiber contact. We heard these sounds both in the carbon and in the aramid vessels, so we believe that yes, there is debonding in the carbon pressure vessels. We have not done cryogenic testing of the full-size pressure vessels, so we don't know whether the same effect will exist."

It is important to know if unbonding is really occurring and what its consequences are. Some of the compressed hydrogen tank designs do not bond the liner to the composite. They use the theory that it is safer to design without a physical bond rather than to bond the two components and have a bond failure.

\section{Last time, we spoke about seal issues, and you mentioned that you were having some leak problems with a bimetallic seal. What is the seal situation now?}


"The bimetallic seal failed in one of the tanks we made. This only happened one time. We talked to the company that makes the bimetallic seals and they told us that it was a very rare event. We also shipped the failed part to them to see what went wrong with it."

The seals were manufactured by High Energy Metals in Seattle. Of the 14 seals that LLNL purchased, there was only the one failure. These seals are necessary to bond together the aluminum liner and stainless steel filler tubes. The filler tubes need to be high strength to accommodate filling the tank with $\mathrm{C}-\mathrm{H}_{2}$, and low thermal conductivity to fill the tank with $\mathrm{L}-\mathrm{H}_{2}$ efficiently. Aluminum will not do this. Meanwhile, the liner itself needs to be aluminum to minimize embrittlement (although low temperature testing is needed) and cannot be plastic to survive cryogenic temperatures. Therefore the tank needs stainless steel filler tubes, an aluminum liner, and bimetallic seals.

I am concerned by the 93\% reliability record (13/14) and not assuaged by the "very rare event" statement from the manufacturer. I think this needs further investigation. In addition, the seal testing must include exposure to high pressure and cryogenic hydrogen.

Dr. Aceves wondered about the capacity expansion capabilities of the explosion-bonded bimetallic seal "industry" and whether a new business will evolve if the pressurized cryogenic tank becomes a commercial product. It certainly will be a serious consideration necessary for mass production of pressurized cryogenic tanks. The failure is of more pressing importance however.

7. Please describe the nature of the upcoming demonstration with SunLine. As a bus company, I would think that SunLine's requirements would tend to a frequent refueling capability and a relatively short driving range. How does this sort of duty cycle translate to bona fide tests for the pressurized cryogenic tank? Is it actually the SunLine pickup truck that will be used for long-range liquid hydrogen fills?

"The superbus is used for long distance trips, carrying commuters from Palm Springs all the way to Los Angeles area. The pickup truck is used for general services over a wide range of conditions. So both vehicles do require a long-range capability. The pickup truck may have a more variable schedule, which may be more similar to the schedule of a personal vehicle."

This justifies the use of the two vehicles as stated.

\section{Will the two vehicles at SunLine be equipped with ICEs or fuel cells? You note that the "superbus" is fueled (currently, I assume) with LNG. Is the plan to switch to LH2 exclusively, or to run on blends?}

"The vehicles at SunLine run with ICEs. The pickup truck uses hydrogen fuel, and the superbus is fueled with LNG. So our pressure vessels will be used with LNG in the superbus. No attempt will be made of running on mixed fuels. This will be a good first attempt at demonstrating insulated pressure vessels. Also, SunLine already has a fueling station for LNG. SCAQMD likes LNG so it is good to demonstrate LNG use to enhance our opportunities to obtain complementary funding."

There is no plan to use hydrogen on the "superbus" at all. The bus actually has several tanks on-board, the cryotank will just be one of them. While the DOE Hydrogen Program 
is funding production and installation of the tanks for both vehicles, the South Coast Air Quality Management District is funding the LNG part of the project.

I agree that the superbus is a good first demonstration of the tank in use - as long as we remember that it's not a hydrogen tank in this instance - different fuel, different temperature.

Currently, the pickup truck is using electrolytically produced hydrogen that is stored in a low-range (50-60 miles) pressure vessel.

SunLine will have a $\mathrm{L}-\mathrm{H}_{2}$ facility within a year. While they get the facility ready, LLNL will be installing the tanks in the truck and superbus.

9. Do the finite element analysis tests include results for both liquid hydrogen temperatures and liquid nitrogen temperatures (I believe from our previous discussions that you do much of your cryogenic testing with liquid nitrogen)? Does the plastic deformation that you report after five cycles manifest itself at liquid nitrogen as well as at liquid hydrogen temperatures? If so, how does the deformation differ at the two temperatures?

"The finite element analysis was done for liquid nitrogen temperatures because most experiments were done with liquid nitrogen. We are planning to run an analysis with liquid hydrogen temperatures. It will be interesting to see how the results compare."

The liquid nitrogen finite element analysis matched up well with experimental data according to Dr. Aceves.

10. In 2000, the Annual Peer Review team had concerns about the potential difficulties of developing two infrastructures - a gaseous hydrogen infrastructure and a liquid hydrogen infrastructure. How do you envision refueling stations? Gaseous hydrogen stations in the cities and liquid on interstates, all stations having both fuels, etc. Has any thought been given to the infrastructure question?

"Ideally, people would have an electrolyzer in the garage that would produce enough hydrogen for the daily fill-up. This would make refueling much easier for people. This could be complemented by compressed hydrogen stations in the city. Then, liquid hydrogen would be sold on the highways for people to use in long trips."

Dual stations that sell both forms of hydrogen are possible. However, if you made $\mathrm{C}-\mathrm{H}_{2}$ from $\mathrm{L}-\mathrm{H}_{2}$, there would be no savings. The project's forte is in minimizing the amount of $\mathrm{L}-\mathrm{H}_{2}$ you have to make. If the dual station evaporated $\mathrm{L}-\mathrm{H}_{2}$ to make $\mathrm{C}-\mathrm{H}_{2}$, there would be no savings. The electrolyzer scenario appears to be more economical.

These thoughts seem to make sense. However, I think a more in-depth infrastructure scenario analysis needs to be performed to make sure that we are not going to produce a product that will require an unwieldy infrastructure. The analysis would have to include 
a means to determine whether consumers would be able to (and willing to) adapt to the dual fuel approach.

Dr. Aceves likened the home electrolyzer scenario to the electric vehicle (EV) system. Women especially liked the EV concept because they never had to go to a refueling station.

11. (This question is a little different) The overall premise of using compressed hydrogen for commuting and liquid hydrogen for long trips is a clever one. My concern is that people who drive cars are not necessarily clever. People will have to refuel with what will be to their way of thinking, two different fuels. It will likely take some getting used to, especially in cases where people are driving intermediate distances, or change their plans, or several other scenarios. Is there any plan to develop sets of instructions (or training) for the driver as to what fueling options to use? ( $I$ assume the last thing that a driver would want to do is vent half a tank of compressed hydrogen to take on a tank of liquid hydrogen.)

"I totally agree with this comment. We can't count on people to optimize their use of hydrogen. However, I think that in the long term, when we switch to renewable hydrogen, energy will be more expensive than today and people will have a greater motivation to optimize hydrogen use. Then our vessels may achieve their full potential. Some instructions on how to minimize energy consumption (or money spent) would be necessary at that time. In the meantime, while we can buy gasoline at $\$ 1.50$ per gallon, hydrogen will never be used in big scale."

This can be a real issue. Education will certainly be needed.

The infrastructure analysis indicated above should include provisions for training/educating the various types of drivers that would be using the cryogenic tanks. The alternative would be to modify the tank design (if possible) to allow, say, filling the tank with $\mathrm{L}-\mathrm{H}_{2}$ without losing stored $\mathrm{C}-\mathrm{H}_{2}$

\section{Other Items:}

- The outer shell also serves "unofficially" as a secondary containment vessel.

- To date, none of the full size, fully assembled tanks have been tested. Five of the smaller tanks were hydro burst within their outer shell.

\section{Final Thoughts:}

This project continues to make good progress. It appears that LLNL is going down the right path with the exception of the inability to test in the presence of hydrogen. This is worrisome. Dr. Aceves is concerned about materials issues (as am I) in the presence of hydrogen. He recognizes the problem, but has no solution until a test site (perhaps as he suggested, SCI or more likely SunLine) can be identified outside LLNL. When the test site is determined, a rigorous test program in recommended - one that will provide data in 
areas that non-hydrogen testing cannot. This includes cryogenic testing at $\mathrm{L}_{-} \mathrm{H}_{2}$ temperatures $\left(20^{\circ} \mathrm{K}\right)$, and materials aging tests.

The other key item is the entire issue of how the tank and associated infrastructure will be utilized. I think some analyses need to be performed to see where and when the user gets the $\mathrm{C}-\mathrm{H}_{2}$, where and when he gets the $\mathrm{L}-\mathrm{H}_{2}$, and whether that scenario is both economical and palatable to the consumer. 
Technical Evaluation Report

Project: Hydrogen Internal Combustion Engine Research

Company: Sandia National Laboratories (Livermore, CA)

P.I.: Dr. Peter VanBlarigan

Site-Visit Date: May 3, 2001

Evaluation by: Edward G. Skolnik, Energetics, Inc.

\section{Summary:}

Sandia (Livermore) National Laboratories (SNL) is conducting an internal combustion engine (ICE) project that is developing a free piston, two stroke cycle-based engine that can burn hydrogen and/or several other fuels using the energy to run an alternator to generate electricity.

One of the key premises to this work is that if you use a lean, premixed fuel/air mixture in the ICE, you can limit the amount of emissions you get without using a catalyst.

While the initial objectives for this project involved the development of the ICE for vehicular hydrogen combustion, the recent focus has been on the production of electricity in stationary, distributed energy scenarios. They are currently working on a $30 \mathrm{~kW}$ prototype system.

I see the following strengths in the project:

- As a stationary electricity resource for distributed power, the ICE system has estimated efficiencies reported by SNL to be in the 50\% range (likely still in the mid40 s even when you include some alternator losses). This makes it competitive with fuel cells and well ahead of microturbines.

- This is one of very few utilization projects that provides an alternative to fuel cells. It's a good thing to keep an ICE option open.

I see the following weaknesses:

- Hydrogen is just one of many materials being used as fuel. (They're also looking at several alkanes as well as methanol and ammonia.) As a hydrogen project (and granted, they are receiving funding from the Office of Distributed Energy Resources (DER) as well,) they need to focus more on hydrogen. Even the ammonia argument (see Question 5) is a bit of a stretch.

- The very attractive efficiency numbers appear to be tied (at least in part) to some older data (see Exhibit 1 and Question 7). Some validation of these data is needed to increase confidence. 


\section{Introduction and Background:}

I visited the SNL site and met with the PI for the ICE project, Dr. Peter VanBlarigan. Dr. VanBlarigan has been involved with the ICE work at Sandia for about five years coming on-board when it was fairly new. Originally the project was a multi laboratory project with Lawrence Livermore National Laboratory (LLNL) and Los Alamos National Laboratory (LANL). Dr. VanBlarigan originally was developing the power plant for a vehicle. The goal now is to generate electricity, with stationary systems the main thrust.

Currently, the project is one year into a three year $\$ 500 \mathrm{~K}$ project that is half funded by the Hydrogen Program and half funded by the Office of Distributed Energy Resources as part of their Reciprocating Engine Program. The project is receiving additional internal funds from SNL. The money is to develop the components and build a $30 \mathrm{~kW}$ prototype engine.

Dr. VanBlarigan is currently concentrating on the development of a linear alternator and scavenging (pulling in fresh input and blowing out exhaust) efficiency for the 2-stroke cycle engine - not combustion.

Dr. VanBlarigan took me on a tour of the appropriate facilities, and we also spent a significant amount of time in discussion. This included discussing a series of questions that I sent him prior to our meeting.

\section{Tour:}

\section{Piston Systems:}

The first stop was the $30 \mathrm{~kW}$ free piston experimental setup. The chamber is three inches in diameter and contains a long-stroke piston which displaces $1000 \mathrm{cc}$. The piston is placed at one end, and a premixed fuel/air mix is admitted to the other end of the tube. High pressure helium is used to push the piston to the other end. The compression ratio is determined by the driver pressure, usually $8,000-11,000$ psi. They measure the pressure and the displacement. Since they know the fuel/air ratio, they can determine the efficiency. They measure emissions via flame analysis. Kinetics had been performed on the combustion reaction previously by Dr. Charlie Westbrook at LLNL.

A combustion test is "one shot" of the piston down the tube. A test is done in about 20 minutes. A real-life situation would likely encounter a little more turbulence, but Dr. VanBlarigan feels that this is probably not important. They get good reducibility.

SNL also has a smaller piston system. It has a $12 \mathrm{~mm}$ bore, and is equivalent to a $1 \mathrm{~kW}$ sized system. This is a step in a scale-down process that Dr. VanBlarigan is looking for to provide soldier (portable) power - at the $\sim 30 \mathrm{~W}$ level. 


\section{Alternators:}

SNL is evaluating two alternators. One is being developed by SNL; the second was built by Magnequench at no charge to SNL. Power is generated in the alternator by having a series of magnetic rings which are magnetized radially with alternating polarity. This results in a series of flux loops with adjacent loops going in the opposite direction. This results in electricity being generated. Dr. VanBlarigan referred to the SNL alternator as a brushless DC motor in a linear configuration.

In the SNL design, the pieces are laminated; the Magnequench model uses powdered iron in epoxy to make the iron part.

Dr. VanBlarigan has calculated alternator efficiency at about $95 \%$ for the SNL design. Losses are due to eddy currents and heating of the coils.

SNL will be testing the alternators with a different engine - not the prototype. They wanted to use a piston with a little shorter stroke so they could test the alternator under full power conditions.

\section{Flow Bench:}

Finally, I saw the system for testing swirl reduction. This was the engine head built by LLNL with shrouded valves. It is discussed below in Question 1.

\section{Questions and Answers:}

I sent Dr. VanBlarigan a list of questions prior to the site visit. The results of our discussion on these questions follows. The questions appear in boldface and the discussion in normal type. My comments, added later, are shown in italics.

\section{The Hydrogen ICE project, I know, has been ongoing for several years including a period where it was a multi-lab project. Since this is the first time I've reviewed the project, we should spend a little time going over it's history - who was doing what; to what degree and how the goals have changed; what have been the key accomplishments over the years.}

The original concept was to build an ICE that would run on hydrogen in a lean mode to minimize $\mathrm{NO}_{\mathrm{x}}$. They used a quiescent combustion chamber. Five years ago, they had built a new cylinder head designed to minimize swirl.

A German paper written during World War II spoke of an ICE hydrogen engine that could obtain an efficiency of $52-53 \%$. In the mid 1990 s, SNL was getting efficiencies of $42-43 \%$. They therefore switched from an Onan Engine to a Perkins Engine with a modified cylinder head. They introduced a shrouded valve to try to reduce swirl and 
tumble. The result was that they were still in the low 40s in efficiency, but had reduced $\mathrm{NO}_{\mathrm{x}}$ emissions to 2-4 ppm at an equivalence ratio of 0.4 .

The project was a 3-lab project at the time, with LANL and LLNL basically providing modeling services and SNL developing the engine. In 1997, the project got downsized due to a report from the President's Council of Advisors for Science and Technology (PCAST) that, in evaluating renewable energy options, advised against demonstrations of hydrogen-based ICEs. It has since been an SNL project only.

One of the major changes that has occurred is that the ICE project is no longer specific to vehicles. It has become a project in which the main goal is to produce high efficiency electricity using equipment that is less complex (and more familiar) than a fuel cell.

Dr. VanBlarigan identified the demonstration of a high efficiency, low emissions combustion system as the key accomplishment to date. The next key objective is to design an alternator that will work at a good power density and a high efficiency. Following this, focus will move to the scavenging system in the combustor. SNL want $s$ to have a uniflow scavenging system that will have an $80 \%$ scavenging efficiency (that is, $80 \%$ of the old, spent, gases will go out the exhaust with each stroke, but none of the new flow goes with it.

This project has had its share of ups and downs due to the politics of ICEs being "in" or "out" as a vehicular hydrogen technology. The fact that Dr. VanBlarigan and his group were able to move to a non-vehicular application and keep the work going is commendable in itself.

\section{During your FY 2001 presentation you spoke of both vehicular and stationary applications for your ICE, converting the hydrogen to electricity. What stationary applications do you have in mind?}

The unit currently being developed is a $30 \mathrm{~kW}$ unit. This is the right size for distributed applications; its high efficiency make it very attractive competing with other distributed energy generators. Reported microturbine efficiencies are around 28\%; the piston provides about twice that efficiency.

As we stated above, the DER focus seems like a smart fit. The efficiency (if we are indeed comparing apples with apples here) of the ICE system makes it potentially attractive here, as does the possibility of using locally available fuels. (The latter fact may not be best for the furthering of the Hydrogen Economy, however) Continuing an effort to develop a system that does not rely on a fuel cell also makes sense.

My apples with apples comment stems from making a comparison with a $28 \%$ efficient microturbine. The DOE microturbine efficiency goal of $40 \%$ might be a better number to compare the ICE system with, if the ICE system is using projected $50 \%$ efficiency numbers. 


\section{What benefits do you obtain from this engine design that makes it more attractive to other designs? Is fuel versatility a large part of it? What parameters do you vary to optimize the engine to the various fuels?}

The design leads to a high efficiency, low emissions system that has multi-fuel capability without hardware changes. SNL arrives at optimization for different fuels by varying the compression ratio. The present design works very well at $30 \mathrm{~kW}$. Dr. VanBlarigan believes that you could use the same design up to, say, $200 \mathrm{~kW}$, but he is not really addressing large applications.

\section{What is the status of the linear alternator (both designs)? What criteria will be/has been used to quantify the performance of the designs?}

They are nearly ready to test the Magnequench alternator. The SNL design still requires some minor design changes, primarily to allow easier assembly.

The main criterion for the alternators is efficiency. SNL will test both alternators, obtaining load vs. time and power vs. time data, and calculate efficiency. Then they'll do a down-select, or if necessary, design a new alternator.

\section{Please discuss the combustion of ammonia. How does this process fit into the} overall scheme of hydrogen research? (I assume you are not making hydrogen from ammonia.) What are the overall advantages of burning ammonia in this scheme?

Dr. VanBlarigan reiterated that the SNL ICE is not limited to burning hydrogen - or hydrogen blends, for that matter. It is a multi-fuel device. In the case of ammonia however, he stated that there is a strong hydrogen connection. You can make ammonia from hydrogen (Haber Process: $3 \mathrm{H}_{2}+\mathrm{N}_{2} \rightarrow 2 \mathrm{NH}_{3}$ ), and if the hydrogen comes from a renewable resource, so does the ammonia. This is why they are using ammonia. (They have also looked at biogas as part of the renewable effort.)

In addition, an infrastrucure for ammonia exists today, especially in the farming industry. The distribution network is already there, and ammonia also stores easily. One good early application would therefore be the running of farm equipment.

It's a bit of a stretch to use that kind of argument to consider ammonia renewable hydrogen unless there is an effort to tie ammonia to hydrogen storage. But maybe doing just that is not that bad an idea.

\section{How efficiently does passing $\mathrm{NO}_{\mathrm{x}}$ over ammonia reduce $\mathrm{NO}_{\mathrm{x}}$ emissions? How much of an energy penalty does one pay for this?}

It turns out that both $\mathrm{NO}_{\mathrm{x}}$ and $\mathrm{NH}_{3}$ are already in the exhaust gas stream at about the same level - about $600 \mathrm{ppm}$. Therefore, all you need is the catalyst. If the numbers weren't the same, you might have to add a little ammonia. The amount of ammonia you would lose in this manner is not enough to indicate any significant energy penalty. 


\section{You presented some efficiency data for several fuels in your FY 1999 Annual Review report (Exhibit 1). Is there any update on these data?}

Exhibit 1 (which is attached) included extremes and "maybe shouldn't have been used. Some data was questionable." SNL has not been working on the combustion efficiency since then. They would like to do some tests in which they vary the piston speed to study its effect on efficiency, but they haven't the time or the money.

If the data are questionable, and SNL has not been working on efficiency matters since then, it would be good to have something to back up the high efficiency claims.

\section{In the same table, you show non-zero $\mathrm{CO}$ and hydrocarbon emissions for hydrogen fuel. What is the emission source?}

The emission source is likely an external contaminant, possibly from a lubricant. It could also be a decomposition product of the piston rings.

\section{How do emissions in general compare for the current engine design compared to more standard ICEs?}

Emissions are about equivalent to what could be done with a spark-ignition engine and a three-way catalyst, but the efficiency is much higher. Compared to a diesel engine, however, the current design is far superior in emissions, and also has some efficiency advantage. Compared to a turbine, emissions are about the same (perhaps a little lower $\mathrm{NO}_{\mathrm{x}}$ ), but with much better efficiency.

If the projected efficiency and emissions results are borne out at the end of the final year, I would think that the project would be successful. It appears that the ICE could compete favorably in the distributed energy market.

\section{Are there any plans to address systems issues?}

Next year's plan will be focused on selecting the alternator, and working on the control system and doing the design layout of the overall system. The following year (the final year of the current program) they will be building the overall prototype. They also have to determine "how to start the thing." Dr. VanBlarigan is considering using the alternator, although for the prototype, perhaps he'll just use compressed gas to start it.

SNL's goal is to operate the prototype system under one set of conditions as part of that final year effort.

Dr. VanBlarigan is considering, as a way to control the system, a $\mathrm{NO}_{\mathrm{x}}$ feedback loop. That is, if the $\mathrm{NO}_{\mathrm{x}}$ level starts going up, it will send a signal to drop the equivalence ratio or the compression ratio. 


\section{Additional Discussion:}

- SNL decided to work with the free piston concept. With the Otto cycle you have constant volume combustion, but as you get to a higher compression ratio you deviate from this condition as the burn slows down. You want a fast burn.

One way to increase the burning rate is to premix the fuel and air. This has the additional advantage of reducing both $\mathrm{NO}_{\mathrm{x}}$ and hydrocarbon emissions. SNL uses homogeneous charge compression ignition (HCCI) as a means to ignite the premixed charge: You compress the mixture to higher temperature and the mixture ignites but, since there is no flame propagation, it remains at constant volume. This is a very fast process, taking about 20 microseconds. (The Otto cycle itself is about two orders of magnitude slower.) The microsecond range is sufficiently rapid so that the piston is effectively not moving during ignition. Furthermore, the process is not held to flammability limits; there is no flame.

The process is controlled by the compression ratio. The alternator, by drawing off electricity, slows down the piston so that the compression ratio is the same at both ends. The free piston system is shown in Exhibit 2. (You can run HCCI in a standard diesel engine, but is difficult to control the compression ratio.)

Dr. VanBlarigan has found efficiencies of about $56 \%$ with fuels that have higher compression ratios. These include hydrogen, natural gas and propane all of which have compression ratios in the 30-40 range. Materials with lower compression ratios (higher alkanes, for instance, with compression ratios under 20) have lower efficiencies. With some of these higher alkenes (e.g., hexane, heptane), they don't get complete combustion; with others they find the combustion mechanism to have two steps.

- Aside from the tie-in with Magnequench, SNL has received interest from Caterpillar, Unique Mobility (a power conditioner manufacturer), and Delphi (a valve manufacturer).

- This project is having the same kind of problems as is common for other projects: feast or famine. At times, the budget is constrained too tightly to work effectively, and at other times, they have the money, but they can't get the staff (who have moved over to other projects during the lean times) to support the level of effort they need.

- The current DOE project has two more years left to run. After that, Dr. VanBlarigan is not sure. He mentioned that perhaps at that point, they won't need DOE support. 


\begin{tabular}{l|ccccccc}
\hline \multicolumn{1}{c|}{ Fuel } & $\phi$ & $\mathrm{T}_{\text {hi }}$ & $\mathrm{CR}$ & $\eta_{T H}$ & $\mathrm{NO}_{x}$ & $\mathrm{HC}$ & $\mathrm{CO}$ \\
\hline Propane & 0.337 & $22,54^{\circ} \mathrm{C}$ & $34-70: 1$ & $50-60 \%$ & $<15 \mathrm{PPM}$ & $100-800$ PPM C $\mathrm{H}_{\mathbf{y}}$ & $300-800$ PPM \\
Natural Gas & 0.365 & 23,67 & $30-54$ & $50-55$ & $10-130$ & $600-2000$ & $250-800$ \\
Hydrogen & 0.319 & $22,49,67$ & $17-50$ & $40-55$ & $1-550$ & $<25$ & $<120$ \\
Methanol & 0.330 & 25 & $38-70$ & $54-58$ & $15-45$ & $<600$ & $300-800$ \\
n-Pentane & 0.335 & 25 & $23-36$ & $47-50$ & $<10$ & $900-1050$ & $800-1050$ \\
Hexane & 0.336 & 26 & $19-34$ & 40 & $<5$ & $1000-2000$ & $1000-2500$ \\
n-Heptane & 0.334 & 24 & $16-47$ & $10-40$ & $<5$ & $2000-4500$ & $900-3000$ \\
Isooctane & 0.321 & 25,70 & $16-74$ & $30-55$ & $1-70$ & $800-1050$ & $300-3000$ \\
\hline
\end{tabular}

Exhibit 1. Table from 1999 Hydrogen Annual Review Paper "Homogeneous Charge Compression Ignition with a Free Piston: A New Approach to Ideal Otto Cycle Performance" P. VanBlarigan

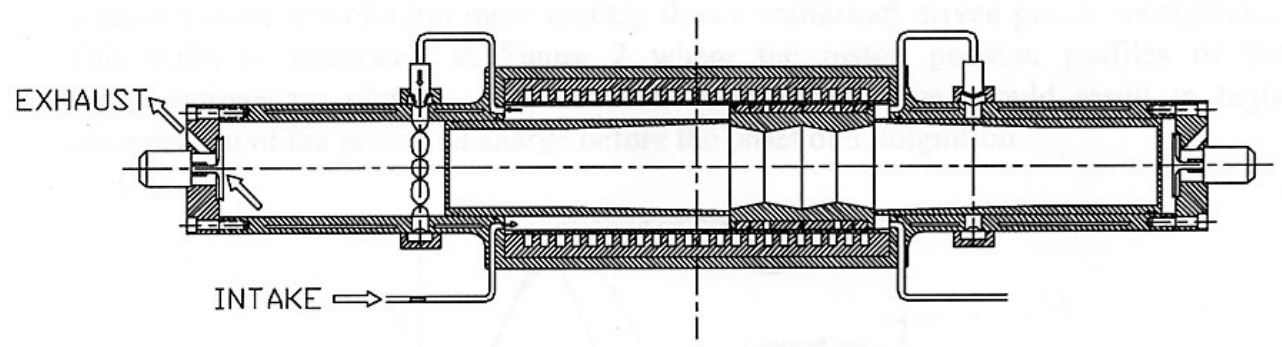

Exhibit 2. The 2-stroke Free Piston/Linear Alternator System. Combustion occurs alternately at each end. (From same reference) 
Technical Evaluation Report

Project: Thermal Dissociation of Methane Using Solar Coupled Reactor

Company: University of Colorado \& NREL

P.I.: Dr. Al Weimer (CU) (with Dr. Al Lewandowski (NREL))

Site-Visit Date: June 13, 2001

Evaluation by: Edward G. Skolnik, Energetics, Inc.

\section{Summary:}

The hydrogen production R\&D project being carried out by the University of Colorado (CU) with a subcontract to the National Renewable Energy Laboratory (NREL) involves the use of a solar reactor to provide the heat necessary to dissociate natural gas into hydrogen and carbon black. The solar reactor project is an intriguing one. It allows for non-catalytic thermal dissociation of methane by providing very high temperatures $\left(\sim 2000^{\circ} \mathrm{C}\right)$ where the dissociation reaction kinetics are orders of magnitude faster than at more commonly used temperatures for hydrogen production from hydrocarbons (700$1000^{\circ} \mathrm{C}$ ). It provides a means of producing no greenhouse gases, and offers a saleable byproduct (carbon black) that could offset the cost of producing hydrogen. Alternately, the carbon black could be burned, perhaps supplying energy to a steam turbine. This would negate the $\mathrm{CO}_{2}$ benefit, but it would increase the energy output from the natural gas and still leave a renewable approach to producing hydrogen.

In general, projects of this type suffer from two major criticisms: 1) Solar thermal energy is generally viewed as being economically viable in too few locations to have a strong impact on the overall energy mix, and 2) converting methane to hydrogen and carbon fails to release all of the energy from the methane; if you discard the carbon, you are discarding energy.

I see the following strengths in the project:

- The process produces hydrogen from fossil fuel without releasing $\mathrm{CO}_{2}$. Whether they sell the byproduct carbon black (assuming it doesn't eventually become a combustion resource) or bury it, it seems a better solution than sequestering $\mathrm{CO}_{2}$. Thus (energy efficiency and economics aside) it is an environmentally attractive process.

- The dry reforming option (this is not part of the DOE Hydrogen Program) seems like an attractive method for reactivating $\mathrm{CO}_{2}$-contaminated natural gas wells.

- Much of the experimental work has been built on solid scientific and engineering models.

I see the following weaknesses:

- The range of applicability for such a system appears limited. Death Valley is a rather unique location. How many other locations will provide sufficient insolation for 
acceptable efficiencies? These other locations would also have to be fairly sizeable. Heliostats take up a lot of room.

- Because of this apparent location limitation, it is even more important to have a good plan for where and how the hydrogen will be used. Scenarios such as the ones discussed in Question 1, below, need to be developed and justified.

- The direction that this project appears to be headed is to develop a non-stand-alone system. With a quoted solar capacity factor of 0.28 , either the heliostats will have to be upsized and storage added, or large capacity backup (or more accurately a different primary system with the solar thermal system as backup) will be needed. If the backup is fossil, the contribution to $\mathrm{CO}_{2}$ reduction will be small.

- Sensitivity analysis shows the cost of hydrogen is heavily based on the cost of natural gas and the cost of heliostats, two items out of the projects control.

\section{Introduction and Background:}

I visited both CU and NREL to meet with the researchers and view the system that is meant to produce hydrogen by thermally dissociating natural gas using concentrated solar-thermal as the heat source. Dr. Al Weimer, Professor of Chemical Engineering at $\mathrm{CU}$, heads the project, which is in its second year of funding. A subcontract to NREL to run the solar furnace is led by Dr. Al Lewandowski, Senior Engineer. I met with both of these people as well as with Dr. Weimer's postdoctoral associate, Dr. Karen Buechler, and his graduate student, Ms. Jaimee Dahl. I saw the UC laboratory where the first generation reactor (Exhibit 1) was present but disassembled, and the second-generation reactor (Exhibit 2) was being built. We also went to the Solar Furnace Facility at NREL where a $10 \mathrm{~kW}$ heliostat provides the heat to decompose methane. Drs. Weimer (Overview), Lewandowski (Economics), and Buechler (new reactor design) and Ms. Dahl (results and modeling) all made presentations. I had provided Dr. Weimer with a list of questions in advance of my visit, and he responded in writing. These were discussed in detail during our meeting as well.

\section{Overview:}

\section{Chemistry:}

The dissociation reaction in question is simply:

$$
\mathrm{CH}_{4}(+ \text { heat }) \rightarrow 2 \mathrm{H}_{2}+\mathrm{C} ; \quad(\Delta \mathrm{H}=75 \mathrm{~kJ} / \text { mole })
$$

The group is also looking at the potential for "dry reforming" of methane as a means of recovering natural gas from wells that have been capped because they have become contaminated with $\mathrm{CO}_{2}$. The product is a syngas:

$$
\mathrm{CH}_{4}+\mathrm{CO}_{2}(+ \text { heat }) \rightarrow 2 \mathrm{H}_{2}+2 \mathrm{CO} ; \quad(\Delta \mathrm{H}=250 \mathrm{~kJ} / \mathrm{mole})
$$


The concept of solar-based thermal dissociation is of interest because the system can easily reach temperatures of the order of $2000^{\circ} \mathrm{C}$, where the dissociation kinetics are orders of magnitude faster than at more "conventional" temperatures, where one would need a catalyst to drive the reaction.

\section{Carbon Black:}

As stated earlier, byproduct carbon black can either be combusted, buried, or sold. From an energy standpoint burning is favored, but it negates the $\mathrm{CO}_{2}$ elimination "hook". Burying is attractive in that it is easier to sequester carbon than $\mathrm{CO}_{2}$, but it puts the entire economic onus on the cost of hydrogen (unless carbon credits exist). Selling provides the best of both worlds - providing the market does not get flooded with carbon black from this process, and provided a reasonable price target can be reached.

Dr. Weimer states that bulk carbon black costs about 20 cents per pound. This is the impure material that is used in the tire industry for rubber reinforcement and strengthening. Better grades of carbon black, made from natural gas range in cost from 35 to 60 cents per pound. High purity "acetylene black" costs about $\$ 1.40$ per pound. Carbon black is also used in paints, plastics, inks, brake liners, and many specialty products. It is used for its thermal conductivity and electrical conductivity as well as a filler, pigment, and viscosity control. Dr. Weimer's group is currently using 35 cents per pound as a reasonable estimate of for how much they believe they could sell their byproduct. The group is also trying to get Cabot Corp., a large carbon black manufacturer, on their team. Cabot could assess "the real value" of carbon black.

\section{Commercial Location:}

The research group is targeting Death Valley, CA as a potential site for a commercial system. The area possesses the highest solar intensity in the country, and is the home of the Barstow 10MW Solar Thermal Facility. CU is looking at a $30 \mathrm{MW}$ facility. A $30 \mathrm{MW}$ solar facility translates to about 5 million standard cubic feet per day (scfd) hydrogen (based on 0.28 solar capacity and a 50\% thermal efficiency). (Dr. Weimer mentioned that in conversations with the DOE Hydrogen Program's Dr. Sig Gronich, Dr. Gronich indicated that perhaps $10 \mathrm{MW}$ would be a more attractive size.)

Dr. Weimer also uses the approximation of a $30 \mathrm{MW}$ unit making about 5 million $\mathrm{kg}$ of hydrogen per year, using the following calculation and justification:

$30 \mathrm{MW}$ x $1000 \mathrm{~kW} / \mathrm{MW}$ x 0.28 x 0.5 x $1000 \mathrm{~W} / \mathrm{kW}$ x $(1 \mathrm{~J} / \mathrm{s}) / \mathrm{W}$ x $3600 \mathrm{~s} / \mathrm{hr} \times 8760 \mathrm{hr} / \mathrm{yr}$

x $1 \mathrm{~kJ} / 1000 \mathrm{~J}$ x $1 \mathrm{~mol} \mathrm{CH} 4$ reacted $/ 74.9 \mathrm{~kJ}$ x $2 \mathrm{~mol} \mathrm{H} 2$ produced/1 mol CH4 reacted x 2 grams H2/1 mol x $1 \mathrm{lb} / 454 \mathrm{~g}$ x $0.454 \mathrm{~kg} / 1 \mathrm{lb}=7.1$ million $\mathrm{kg} \mathrm{H} 2$ per year. 
Some sensible energy (enthalpy) goes to heat up the $\mathrm{CH} 4$ to reaction temperature and some leaves with the produced $\mathrm{H} 2$. This is accounted for in other calculations to conservatively give 5 million $\mathrm{kg} / \mathrm{yr} \mathrm{H} 2$.

Since there are 365 days/year, and for hydrogen 424 scf/kg, then:

7.1 million $\mathrm{kg} / \mathrm{y} \quad x 424(\mathrm{scf} / \mathrm{kg}) / 365(\mathrm{~d} / \mathrm{y})=8.25$ million scfd, which I guess can also be conservatively approximated as 5 million scfd.

Dr. Weimer recognizes the potential problems that could arise at the desert site. They would either have to run a fuel cell on site or would need a compressor to prepare the hydrogen to be pipelined away. Hydrogen comes out of the reactor at one atmosphere; compressor costs could be high.

\section{$\underline{\text { Status and Plans: }}$}

$\mathrm{CU}$ is currently building the second-generation reactor. The major improvement is that the graphite reactor will go the full length of the outer quartz tube, and the annular space between the quartz and graphite will be completely separate from the reaction zone inside the graphite tube. (The old design had the graphite reactor only about $1 / 2$ the length of the quartz tube. Deposition on the quartz was a big problem.) CU plans to use the new reactor "extensively" during the next year.

They plan to/are starting to use a secondary concentrator. They need to concentrate more of the heat on the tube, but spread it out over the entire tube. The secondary concentrator is mounted right on the reactor; it further concentrates the solar radiation that had been gathered by the primary concentrator and reflected toward the tube. Work on the reactor has slowed due to a funding hiatus for the first six months of FY 2001.

The group is currently doing a mass and energy balance closure for the system.

CU/NREL is at various states of agreements or negotiations with five companies that they hope to get to partner with them on this project. These are the aforementioned Cabot Corp., BP Amoco (natural gas supply), Harper International (solar furnace design), Foster-Wheeler (carbon black boiler), and Plug Power (fuel cell integration).

The group is also thinking of building a $100 \mathrm{~kW}$ solar furnace facility at NREL (the current facility is $10 \mathrm{~kW}$ ) that would be dedicated to thermal dissociation.

There is no plan to try to make the system continuous, nor has CU addressed hydrogen storage. We discussed the various scenarios for how a real system would work in Question 1 below. Since the sun isn't out all the time, and there is no plan for storage (any plan would likely need a compressor as well) this is certainly not a stand-alone system.

Dr. Weimer stated that the project "looks promising" but more research is needed to determine if it will really work. 


\section{Modeling and results from first generation reactor:}

Ms. Dahl presented the results of the modeling effort she has undertaken. The model for the reactor was taken from an electrically heated reactor developed and patented by Thagard Technology Company (Irvine, CA) in 1977. The reactor also used hydrogen added through the porous reactor walls. A key finding of the Thagard work was that residence time in the reactor is a non-factor if the temperature is above $1900^{\circ} \mathrm{K}\left(2173^{\circ} \mathrm{C}\right)$ (Exhibit 3).

Using the Thagard results, Ms. Dahl also performed mathematical modeling to back out the reaction kinetics at $2000^{\circ} \mathrm{C}$. These kinetics are used to design the solar reactor. There is no doubt that there is a lot of up side to the high-temperature kinetics (short residence time, high conversion, no catalyst). The question is how does it balance against capital cost, intermittent periods of production, and limited high insolation regions.

With the first reactor, CU/NREL was using only about $10 \%$ of the solar thermal energy, that is, $10 \%$ of the $10 \mathrm{~kW}$ being delivered by the heliostat. With the single concentrator (see description of the NREL Solar Furnace below) much of the energy was not focused on the reactor. The new reactor will incorporate a second concentrator wrapped around the reaction zone. The concentrator has an octagonal opening with a diameter of $23 \mathrm{~cm}$. It concentrates down to $9.4 \mathrm{~cm}$ in the area wrapped around the reactor. This will further focus the solar radiation, the group believes, and result in about $74 \%$ of the energy going to the reactor. (The rest of the energy is lost either by being absorbed before it gets to the reactor, reflected back through the entrance, or leaked out of the ends. CU believes that with the second concentrator they will get $100 \%$ conversion to hydrogen at $2000^{\circ} \mathrm{C}$. Should the secondary concentrator not be sufficient, it is conceivable that there could be several smaller secondary concentrators used instead, each wrapped around and focusing the energy on a different section of the reactor.

Results from the first generation reactor showed $90 \%$ conversion of methane to hydrogen from a feed of $0.45 \%$ methane in Argon. (The gas chromatograph showed about $0.81 \%$ hydrogen after the reaction, corresponding to nearly $90 \%$ conversion). Residual methane was measured at less than $0.02 \%$; an equal amount of acetylene was also measured. The same set of results showed a $\mathrm{CO}$ concentration of $0.06 \%$ and $\mathrm{CO}_{2}$ concentration of $0.05 \%$. Ms. Dahl and the rest of the team attributed these two readings to a sampling anomaly. We really need to see numbers for pure methane dissociation, not highly diluted methane; Dr. Weimer recognizes this. Hopefully, the second-generation reactor, which will use a pure methane stream, will lead to accurate numbers.

Results with the first reactor indicated that better conversion efficiency was obtained when carbon black particles were added to the feed. The carbon black aids in heat transfer. (See questions 3 and 4 below.) Dr. Weimer, however, believes that eventually, with the right design, they may not require the added carbon black, and that the generated black may be sufficient. 
Dry reforming in the first reactor at $1500^{\circ} \mathrm{C}$ produced about $70 \%$ conversion to hydrogen, but again this was obtained from a diluted feed stream of $\mathrm{CO}_{2}$ and methane in argon.

\section{The Second Generation Reactor:}

Dr. Buechler presented the new reactor design. They recognized that the needed to improve the feeder system and to keep the particles off the quartz tube. In the new design (see Exhibit 2) the graphite tube actually extends beyond the quartz tube, but it should be relatively cool at the edges, probably under $500^{\circ} \mathrm{C}$.

Models are showing that the quartz tube will not get above about $1000^{\circ} \mathrm{C}$ (Exhibit 4) even if there is not a cooling system with concurrently flowing water. $\mathrm{CU}$ is a little concerned about the quartz nevertheless. Quartz melts at $1200^{\circ} \mathrm{C}$. If the second concentrator heats the reactor to well over $2000^{\circ} \mathrm{C}$, it would likely overheat and melt the quartz.

\section{Economics:}

Dr. Lewandowski presented an economic analysis. The analysis started from a standard carbon black process, added solar components, and developed a cost/performance spreadsheet.

In their base case, Dr. Lewandowski used a heliostat cost of $\$ 200 / \mathrm{m}^{2}$. This assumes a scenario where heliostats are being mass-produced; today's cost is closer to $\$ 500 / \mathrm{m}^{2}$. They assume hydrogen production at 5 million scfd, and carbon black production at 15 million kg per year. They allow for $20 \%$ hydrogen recycling (for the commercial reactor, they plan for hydrogen to be the annular gas), a residence time of 0.1 seconds, and a reaction temperature of $2000^{\circ} \mathrm{C}$. The cost of natural gas was set at $\$ 3 / \mathrm{MMBtu}$ (see Question 13) and a 0.28 solar capacity was used. They assume that there is very little methane loss.

A sensitivity analysis was developed, and the results are shown in Exhibit 5. It shows that if carbon black could be sold for $\$ 0.48 / \mathrm{lb}$, hydrogen would be free. Conversely, if you had to throw away the carbon black, hydrogen would cost $\$ 23 / \mathrm{MMBtu}$, under base-case conditions. The analysis is very sensitive to the cost of the heliostat, but Dr. Lewandowski believes that the lower costs are achievable. The biggest sensitivity issue, however, is the reactor efficiency.

The capital requirement for a $30 \mathrm{MW}$ plant is about $\$ 25$ million, about $2 / 3$ of that being the cost of the heliostats.

\section{Tour:}

\section{CU Reactor:}


There was really not much to see here. Phase I was completed in FY 2000, and the old reactor was disassembled. The FY 2001 money didn't arrive until March. They are still building the Phase II reactor.

What I did see was a vertical screw feeder with a gas port on the side to disperse particles (i.e., added carbon black). The old system used a spinning brush to disperse the particles. The system tended to clog, however, and they couldn't get a good carbon mass balance.

The dissembled graphite reactor is one inch in diameter, and four inches long.

\section{NREL Solar Furnace:}

The solar furnace facility at NREL is located on a hill overlooking the major portion of the overall laboratory. The furnace facility includes a $10 \mathrm{~kW}$ flat-plate heliostat, 33 square meters in area, which has the ability to track the sun across the sky. Solar energy is reflected down to a 12.5 square meter primary solar concentrator from which it is reflected again into the laboratory building through a set of slits that can be controlled much like Venetian blinds.

The hydrogen reactor was not in place at the time of my visit, but its former and future position was pointed out to be at the focal point of the reflected sunlight. A 3-axis moveable track and gas-handling system was in place to be used with the reactor.

\section{Questions and Answers:}

I sent Dr. Weimer a set of discussion questions prior to my arrival. He responded in writing and we also discussed the questions and answers in detail. This is all reproduced here, with the questions indicated in bold, written answers reproduced verbatim in quotes, our discussion shown in normal type, and my comments added to many of the questions during my later analysis and assessment shown in italics.

\section{Please discuss how a "real" system would work - one where the sun isn't always shining. How would start-up and shutdown conditions affect the overall output and efficiency?}

\footnotetext{
"Specifically, as far as the solar-thermal aerosol reactor is concerned, there is no insulation in the reactor and the required residence time at $2000^{\circ} \mathrm{C}$ for complete reaction is on the order of 0.01 second. Hence, the start-up and shut-down times would be associated with heating the graphite tube, which will be extremely fast using concentrated sunlight (probably at most, minutes). At the NREL High Flux Solar Furnace (HFSF), the presence of clouds is continuously tracked and, hence, it is known if a cloud is going to pass by. In this case, it would be possible for the methane to be replaced by recycled hydrogen if need be (just to prevent unreacted methane from passing through the process and to keep air out; one would not use inert gas as it would need to be separated at the outlet).

"Different processes would be affected differently. We envision the following various process configurations: (1) a solar-thermal natural gas dissociation process feeding a hydrogen gas pipeline and collecting carbon black for sale; (2) a solar-thermal natural gas dissociation process feeding tube trailers and collecting carbon black; (3) a solar-thermal natural gas dissociation
} 
process feeding a fuel cell on demand (operating only when the sun is out) and stockpiling carbon black for sale; (4) same as 3 , but with carbon black not only being sold into the carbon black market, but also being used to feed a carbon black boiler to supply steam to drive or to have offgas directly drive a turbine to generate electricity.

"Configuration 1 (hydrogen pipeline/carbon storage): For this case, the intermittent operation would be an issue for the pipeline. Most likely, some hydrogen surge tank with a compressor would be needed where the surge tank pressure would vary (increasing when the sun is out as hydrogen is fed to it; decreasing at night when hydrogen is not being made). Hence, a pipeline would always be fed at constant pressure, but the upstream surge tank pressure would vary. We would expect both the compressor and surge tank to be expensive. Carbon storage would be unaffected

"Configuration 2 (tube trailers/carbon storage): For this case, the compressor would be needed, but there would be no need for a surge tank (use the tube trailers). Carbon would be unaffected.

"Configuration 3 (fuel cell/carbon storage): For this case, the hydrogen would supply a fuel cell and generated electricity would supply a grid. There would be no major storage or transportation issues.

"Configuration 4 (fuel cell/carbon burning boiler/carbon storage): For this case, the hydrogen would be the same as in (3) without storage issues. Also, instead of trying to sell all of the carbon black into the carbon black market, it is possible to operate a carbon black boiler burning clean and fine carbon black (probably $<20 \mathrm{ppm}$ sulfur and no ash; fine micron sized particles). The boiler could be sized so that it operates continuously on the basis of the solar-thermal operating time (stockpiled carbon black). This scenario takes advantage of the fact that the heating value of the produced carbon black and hydrogen is approximately $10 \%$ higher than that of natural gas and that the carbon black is high purity and fine. Coal could be left in the ground and minimal environmental pollution control equipment would be needed. In addition, some of the carbon black could be sold into the carbon black market. This scenario may make the most overall sense."

Dr. Weimer stated that an economic analysis would be needed to evaluate the four configurations.

I am concerned with some of these configurations. The system only runs when the sun is out, so additional energy must come from somewhere. For Configurations 1 and 2, surge tanks, compressors, and tube trailers provide hydrogen storage, so in theory, at least, sufficient hydrogen can be made during daylight hours to supply hydrogen (to a fuel cell, I presume) at night. Configuration 3, which provides no hydrogen storage, requires either some alternative source of hydrogen for the fuel cell when the sun is not shining (perhaps a steam reformer) or an entirely separate electricity generating system. (I am assuming a local grid rather than simply providing electricity to the national supply.) It also assumes that the alternative supply is running constantly (i.e., that the solar reactor is undersized for the amount of required electricity). Otherwise you would have to either make exactly the amount of hydrogen you need, or you would have to flare some hydrogen. Configuration 4 is a double-edged sword. It allows you to get all of the energy out of the methane rather than storing, burying or selling carbon black, but it removes one of the real "hooks" that I believe this project has: not making $\mathrm{CO}_{2}$.

It's true that you have a nearly 10\% higher heating value in carbon black and hydrogen than you do in methane: 


$$
\begin{gathered}
\mathrm{CH}_{4}+\mathrm{O}_{2} \rightarrow 2 \mathrm{H}_{2}+\mathrm{CO}_{2}(\Delta \mathrm{H}=-802.5 \mathrm{~kJ}) \\
V S . \\
2 \mathrm{H}_{2}+\mathrm{O}_{2} \rightarrow 2 \mathrm{H}_{2} \mathrm{O}(\Delta \mathrm{H}=-483.7 \mathrm{~kJ}) \\
\mathrm{C}+\mathrm{O}_{2} \rightarrow \mathrm{CO}_{2} \quad(\Delta \mathrm{H}=-393.7 \mathrm{~kJ})
\end{gathered}
$$

$$
\text { Total: } \Delta H=-877.4 \mathrm{~kJ}
$$

Perhaps you can argue that you can keep the coal "in the ground" as a first approximation, but a lot more detail is needed.

\section{What is an HEPA filter? Does the presence of a downstream filter alter the gas flow rate?}

"HEPA (High Efficiency Particulate Filter) is used only to collect all of the carbon black for research material balance purposes. HEPA is required for asbestos, but is overkill for our process. I expect that typical baghouse filters used in the fine chemical industry would be suitable in this process. At most, maybe Gortex ${ }^{\mathrm{TM}}$ bags are used. The filters would be backpulsed to control pressure drop and maintain operations continuously. Any alteration of the gas flow rate should not be an issue."

3. When you use carbon black particles for heat transfer, what is their concentration compared to the amount of carbon black you are generating by methane decomposition?

"The voidage in the aerosol reactor is around 0.9999, hence, the amount of carbon black is minimal. The amount generated by natural gas decomposition will be much more and most likely the carbon black feeding can be stopped once the reaction is initiated (the Thagard Patent using an electrically heated graphite aerosol tube describes this). This is not a big issue since carbon black is generated in-situ."

Dr. Weimer did mention, however, that as they scale up in reactor size, the surface to volume ratio would decrease. Thus, more carbon black feed may be necessary to optimize heat transfer. Carbon deposition may be the more important problem, however.

4. You state in your FY 2001 Review report that in one set of experiments feeding carbon black to the system resulted in a $30 \%$ conversion of methane to hydrogen and carbon; when carbon black was not fed, the conversion was down to $18 \%$. Yet shortly thereafter you make a statement that the formation of carbon black itself "provides an in-situ method of generating carbon black radiation absorbers in the reactor without having to feed it." It would seem that if you do not add carbon black your efficiency decreases considerably. Please comment on this. Also, have you looked at all at the effect of using different carbon blacks with different surface areas? 
"Again, we don't think carbon black will be a big issue. The data given in the report are taken out of the examples used in the U.S. Patent filing. We also claim in the patent filing that the carbon black can be generated in-situ. The intention was to show that carbon black feeding was desirable and so a most extreme case was reported. We believe that the carbon black requirement is reactor size dependent. We will see much less need in the lab reactor where the wall surface area to reactor volume is large. As we scale-up, the reactor wall surface area to reactor volume decreases and the need for carbon black particles to be co-fed to initiate the reaction will be greater. This is an area of significant investigation. Our math modeling sensitivity studies are taking to take a hard look at this. This is not a big issue. Carbon black particle are fed commercially through graphite aerosol reactors (heated electrically) today for processes to make ultra-fine tungsten carbide."

In addition, particle size is not an issue. The blackness of the particles is more important for absorbing sunlight.

I would think that if heat transfer is surface-dependent, the particle size of the carbon black would be quite important as well.

I also question why, if the decreased surface to volume ratio in the scaled up reactor is "not a big issue," is it "an area of significant investigation."

\section{You mentioned that your apparatus was also used to study "dry reforming" of methane. Are there plans to look at this further? What are the advantages/disadvantages of dry reforming as opposed to thermal decomposition?}

"We submitted a proposal ("Dry Reforming of Methane Using a Solar-thermal Aerosol flow Reactor") last August, 2000 to the DOE Sequestration RFP that was issued (Applied Research and Development of Technologies for the Management of Greenhouse Gases," FE-PS2699FT40613. The proposal was not funded (too bad - great project).

"For hydrogen production solely, we believe that thermal dissociation is advantageous since carbon black can be easily stored and sequestered. Any gas separation - if required for dissociation - will be minimal compared to separating $\mathrm{CO}$ from $\mathrm{H}_{2}$. However, if syngas is desired to produce methanol or other hydrocarbon chain building processes (via Fischer-Tropsch syntheses, etc.), dry reforming is an excellent alternative since it uses $\mathrm{CO}_{2}$. Also, there are a number of $\mathrm{CO}_{2}$ contaminated gas wells (BP says their largest producers in the Four Corners area are capped due to high $\mathrm{CO}_{2}$ content) containing approximately $15 \% \mathrm{CO}_{2}$. Currently, this gas is not being utilized because of the cost of separating $\mathrm{CO}_{2}$ from $\mathrm{CH}_{4}$ and then having to deal with it. A solar-thermal process carried out on this gas stream would allow combined dry reforming and thermal dissociation to occur. Such a process would make use of such gases to produce a product consisting of a high $\mathrm{H}_{2}$ content syngas and some carbon black.

"A key consideration in dry reforming is to look at the relative reaction rate for dry reforming at $2000^{\circ} \mathrm{C}$ vs. $700^{\circ} \mathrm{C}$ (where many catalyst researchers are trying to make incremental changes in process improvement). The bulk of dry reforming research today is directed at reducing the temperature in order to reduce the amount of energy needed to carry out the endothermic reaction and to prevent (or at least try to minimize) carbon deposition that kills the catalyst. Hence, conventional dry reforming is being directed at $700^{\circ} \mathrm{C}$ temperatures (carbon is still depositing out) operating continuously vs. solar-thermal at $2000^{\circ} \mathrm{C}$ with carbon deposition not being an issue. If one looks at the relative reaction rate ratio of solar-thermal $\left(2000^{\circ} \mathrm{C}\right)$ vs. conventional $\left(700^{\circ} \mathrm{C}\right)$ dry reforming, assuming similar order of magnitude pre-exponential factors 
and activation energies, Rate $(2273 \mathrm{~K}) /$ Rate $(973 \mathrm{~K})=\exp \left(0.00059{ }^{*} \mathrm{E} / \mathrm{R}\right)$. For typical $\mathrm{E} / \mathrm{R}$, the relative reaction rate is two to four orders of magnitude faster at $2000^{\circ} \mathrm{C}$ relative to reaction at $700^{\circ} \mathrm{C}$. Hence, it should be possible to design a solar-thermal process for massive throughput when the sun is out $\left(2000^{\circ} \mathrm{C}\right)$ - say $28 \%$ of the time - and that this throughput will be significantly higher than that for a process operating at conventional temperatures $\left(700^{\circ} \mathrm{C}\right)$. To make equivalent amounts of product, the solar-thermal would need to be about 4 times faster. The 100 to 10,000 times faster is truly significant. A brute force high temperature process such as dissociation or dry reforming takes advantage of this significant relative reaction rate. The challenge comes with designing a process for massive throughput (when the sun is out) to operate semi-continuously."

The dry reforming portion of the project is not funded by the hydrogen program. However, says Dr. Weimer, perhaps you can shift the syngas. (The syngas was said to be composed of 6 hydrogen molecules to one CO.) The reaction shown earlier in the paper says it's a one-to-one mix. To switch from thermal decomposition to dry reforming is a simple process - you just change your feed bottle.

If you shift the syngas, you of course get $\mathrm{CO}_{2}$ back, but what you've accomplished is that you've recovered the previously unusable natural gas. It's not a hydrogen technology, but I think it has some real merit.

\section{In the new reactor you are building (built?) will your graphite reactor tube extend throughout the quartz tube? (In other words, is this how you will prevent deposition on the quartz tube?)}

"Yes, the new graphite reactor tube extends throughout the quartz tube. For the lab, inert gas will flow in the annular region between the two concentric tubes. For the commercial process, we envision that this annular gas could be hydrogen (of course, inert gas would be safer). The gas will prevent air from attacking the graphite tube on the outside. Also, the process gas stream and resulting carbon black will never contact the inside quartz wall or mix with the annular gas."

Deposition is an issue, but may be less of one in a commercial system where the reactor and the annular region will be larger.

In the redesigned system, the annular gas can be kept entirely separate from the reactants. If hydrogen is used, it can simply be recycled from product hydrogen. It appears that the new reactor was designed with lessons learned from the first system incorporated well. I will be very interested in hydrogen production efficiency in the new system.

\section{Figure 16 in your report seems to show that you are switching from argon to nitrogen as a carrier/purge gas. Is this due to cost, thermal considerations, or some other reason?}

"In the lab reactor, we will have $99 \%$ methane flowing through the reactor tube (actual flow will be down and not up as shown) with a $1 \%$ of argon as an internal standard. We will either flow $\mathrm{N}_{2}$ or $\mathrm{Ar}$ in the annular region between the two concentric tubes. Argon is preferred because of higher heat transfer, however, nitrogen may be used. With no experience yet in the processing, argon is 
a more conservative gas to use. In practice, hydrogen will most likely be used. In practice, pure NG will feed the reactor tube. The $1 \%$ standard is only to close atomic material balances in the lab unit for research purposes."

\section{I am confused by the annular cooling gas. Aren't you operating at cross- purposes, heating and cooling the same material?}

"The annular "cooling gas" is to both prevent oxidation of the graphite reactor tube and to cool the outside quartz tube. The graphite tube will be heated by concentrated solar radiation. Although the sunlight will pass through the quartz tube, the quartz tube will be heated by the hot graphite tube (heated by radiation). We have done and will be doing additional modeling calculations to determine the temperature of the quartz tube. So, the "cooling gas" is to cool the quartz tube and not the graphite."

\section{Could this system be used as a heat source for steam reforming?}

"Yes, except that we would be concerned with reaction of the graphite tube with water. Fine cofed carbon black would be much more reactive than the graphite wall, however, wall attack would be inevitable. If, however, lower temperatures were desired, we could use an oxide or metallic alloy tube that is not reactive with water. However, the real advantage of the solar-thermal process is to operate at extreme temperatures $\left(>2000^{\circ} \mathrm{C}\right)$ that cannot be easily or cheaply achieved using conventional heating. The ultra-high temperature to carry out "brute force" dissociation or dry reforming reactions is a unique niche of the solar-thermal aerosol process."

Their patent includes the thermal dissociation and dry reforming processes, and also includes a process to react the carbon black with water to make syngas.

\section{How will the hydrogen be separated from the carrier gas, unreacted methane, etc.? Will the methane be recycled?}

"There is no carrier gas. If gas is used to sweep carbon black into the process, it will be methane or hydrogen. The annular gas will be kept separate from the process gas. At the temperatures we hope to operate at $\left(2000+{ }^{\circ} \mathrm{C}\right)$, dissociation should be nearly complete. Experimental results from Thagard Research, contained in their US Patent, indicate complete conversion at these temperatures. Our results of nearly $90 \%$ conversion at $1600^{\circ} \mathrm{C}$ are consistent with what Thagard reported. We expect there to be some acetylene, etc., but at $<100 \mathrm{ppm}$ levels. Any separation system should not be big and may not be required. We do not expect any significant amount of unreacted methane, if any. Please note that those processes carrying out dissociation at 1300 to $1800^{\circ} \mathrm{C}$ (like the Florida Solar Energy Fluid Bed NG Decomposition Process) will have significant separation issues and recycling of methane. This is a big advantage for the $2000^{\circ} \mathrm{C}$ solar-thermal process. The degree of conversion achievable will be a key consideration in our experiments. This is why we are building the new reactor system - to achieve the $2000^{\circ} \mathrm{C}$ needed. We don't believe separation and recycle will be an issue. It is possible that there might be some selective adsorption process, etc. to eliminate trace impurities, but we have not yet considered any details."

Dr. Weimer believes that they can get essentially $100 \%$ conversion to hydrogen at $2000^{\circ} \mathrm{C}$. They'll know later this year. 
11. On a commercial scale, this process would be run using natural gas rather than methane. This will presumably increase the types of and amounts of impurities present in the mix, both reactant and product. How do you intend to deal with this?

"Any hydrocarbon should "crack" to carbon black and hydrogen. Other impurities, like $\mathrm{H}_{2} \mathrm{~S}$, will crack to $\mathrm{H}_{2}$ and elemental $\mathrm{S}$. Typical natural gas carbon blacks (like Cancarb Thermax) have sulfur contents less than $20 \mathrm{ppm}$. Any residual $\mathrm{CO}_{2}$ will reform to $\mathrm{CO}$ and may be an issue for a fuel cell. We need to eventually look at this. We intend to run natural gas in this reactor as part of the program."

They'll also likely get some higher hydrocarbon reaction products, acetylene, for example.

12. In your new process design you indicate that some of the hydrogen is recycled to prevent deposition of carbon black on the reactor window. I assume this isn't a chemical process. Why are you using hydrogen recycle? Why not just use purge gas?

"Carbon deposition on the quartz tube will not be an issue for the graphite tube going all the way through. What you are referring to is the early reactor. We don't want any inert gas in the methane feed stream (or mixed with it) because it would require separation downstream. We are concerned with carbon deposition on the inside of the graphite tube. If we swept any gas along the inside wall to prevent deposition, it would be hydrogen. One advantage of no insulation and a reactor system shut down at night is that operators can clean out the tube if any buildup occurs."

Dr. Weimer stated that it would be easy to remove carbon black buildup from the graphite reactor wall. Deposition on the quartz outer tube will not be an issue with the modified reactor as long as nothing comes off of the outer wall of the reactor. CU is using a high quality graphite for the reactor, and don't expect it to volatilize.

\section{Please comment on your use of $\$ 3 / 1000$ scf of natural gas as a base price in light of current costs being double that.}

"We worked with Maggie Mann of NREL on this one. We used the $\$ 3 / 1000$ scf as the base case as most people are familiar with this value and most economics involving NG have used it in the past. We did use it as a low value base and then investigated higher cost NG. Each additional $\$ 3 / 1000$ scf in NG cost adds about $\$ 4.40 /$ MBtu to the cost of hydrogen. This is independent of the selling price of carbon black, therefore, the relative impact on hydrogen selling price is higher when carbon black sells for reasonable amounts."

It's really probably not a bad number to use. The number of analyses is rising that says that the high natural gas price will not last very long.

14. During the annual review, I heard a comment from one of the reviewers about the concern that by dissociating methane rather than combusting it, you fail to recover all of the energy. Obviously you can rebut that by indicating that 1) you have a saleable product in carbon black, and 2) that you do not contribute to 


\section{global warming. Although $I$ am in agreement with what $I$ would think is your position, I think it makes a good discussion topic.}

"You can't have your cake and eat it to! We know of no other process (other than nuclear) that can produce $\mathrm{H} 2$ without generating greenhouse gases if that is the purpose. In addition, solid carbon black is much easier to sequester and store than $\mathrm{CO} 2$. However, if one wants to take advantage of the heating value, the solar-thermal process actually increases the heating value of the feed by almost $10 \%$ (the heating value of the $2 \mathrm{H} 2+\mathrm{C}$ is $10 \%$ greater than the $\mathrm{CH} 4$ ). One could leave coal in the ground, and have a fine high purity carbon black to burn and end up with almost a $10 \%$ increase in energy. The pollution considerations would be minimized due to low $S$ and ash (none) in the NG produced carbon black. In addition, no $\mathrm{CO} 2$ would be generated mining coal or grinding or transporting it, etc.

"One other very important aspect is that we can make use of CO2 contaminated NG that is currently capped and not used! We can carry out ultra-high temperature dry reforming using the $15 \% \mathrm{CO} 2$, and methane dissociation using the excess $\mathrm{CH} 4$ (see our experiments that used a 2/1 ratio of $\mathrm{CH} 4$ / $\mathrm{CO} 2$ ). The product is a $\mathrm{H} 2 / \mathrm{CO} \sim 6 / 1$ syngas and some carbon black."

The carbon black sell or burn issue can be debated back and forth. Hopefully the talks with Cabot will help answer the question. Personally, at this point I'm not sure whether burning the carbon black is preferable to just combusting the methane. Sequestering $\mathrm{CO}_{2}$ as carbon black, however, seems to be of some interest.

\section{Additional Items:}

Dr. Weimer believes that the carbon black they are producing might be unique, or at least of high quality. It is a small diameter (20-40 micrometers), high surface area material. In fact, Dr. Weimer wonders if the process could produce carbon nanotubes as a byproduct; it hasn't happened yet. You make hydrogen and the material in which to store it at the same time! Interesting. Nevertheless, I would concentrate on the basic process for now and not worry about nanotubes.

Dr. Lewandowski pointed to a strong educational component to this project. Groups of undergraduates are performing design and life cycle studies.

\section{Final Thoughts:}

This project presents an interesting dichotomy, which, perhaps, is true for many renewable energy concepts. It is based on sound science and on what appears to be evolving into a good engineering design for the reactor: The kinetics at $2000^{\circ} \mathrm{C}$ are a lot faster than at $700^{\circ} \mathrm{C}$; thermal dissociation produces no $\mathrm{CO}_{2}$; there is a reasonably good chance that the final reactor design will efficiently recover close to all the hydrogen in methane. Furthermore, the ability to sell carbon black could favorably impact the cost of hydrogen. However, the overall usefulness of the project as a means to result in a largescale commercial project needs to be considered. The locations where the process could be run efficiently appear significantly limited to very high insolation areas. Uses of hydrogen would either be limited to installations on site or close to the high insolation area, or transport costs (which would likely include compression) would have to be added. Also, the system, as it's currently envisioned, does not go beyond hours when the 
sun is shining. Either the system will need to be used in conjunction with another energy source or it will need to be built large enough to make enough hydrogen for nighttime use as well. This again would necessitate compression and storage components.

The economic analysis shows the system to be quite sensitive to at least two items out of its control: the cost of natural gas, and the cost of heliostats. These are areas of concern as well.

I believe that the researchers, need to address location (how efficiently does the system perform outside of Death Valley?), application (where will you use the hydrogen, and how will you get it there?), and systems considerations (what percentage of the load will be supported by hydrogen; if it is to be stand alone, how will storage be addressed; if a backup (or more likely a second primary system) is to be used what is it, and how will it be integrated?) 
Exhibit 1. Schematic of First Generation CU Reactor (Figure supplied by CU)

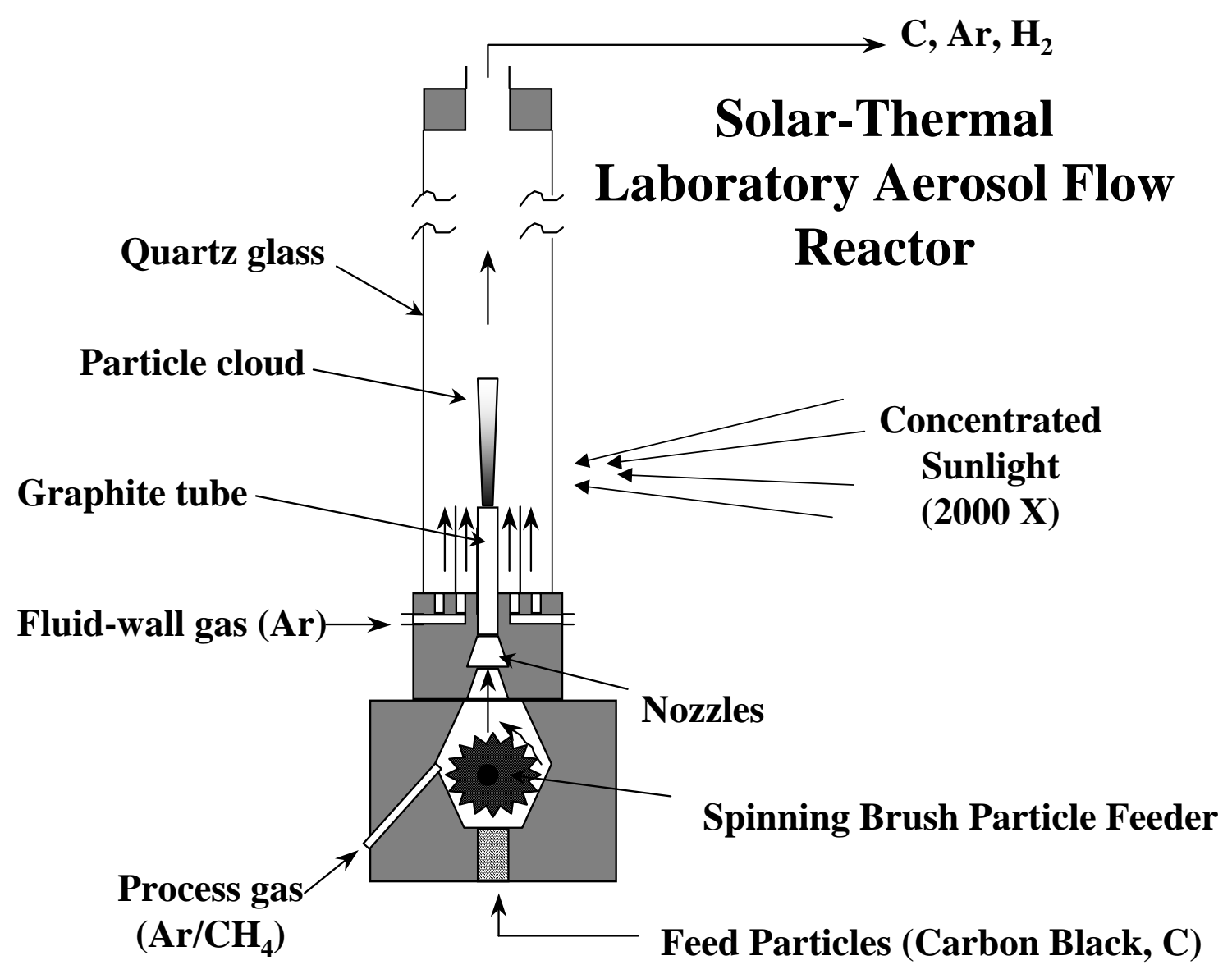


Exhibit 2. Schematic of Second Generation CU Reactor. (Figure supplied by CU)

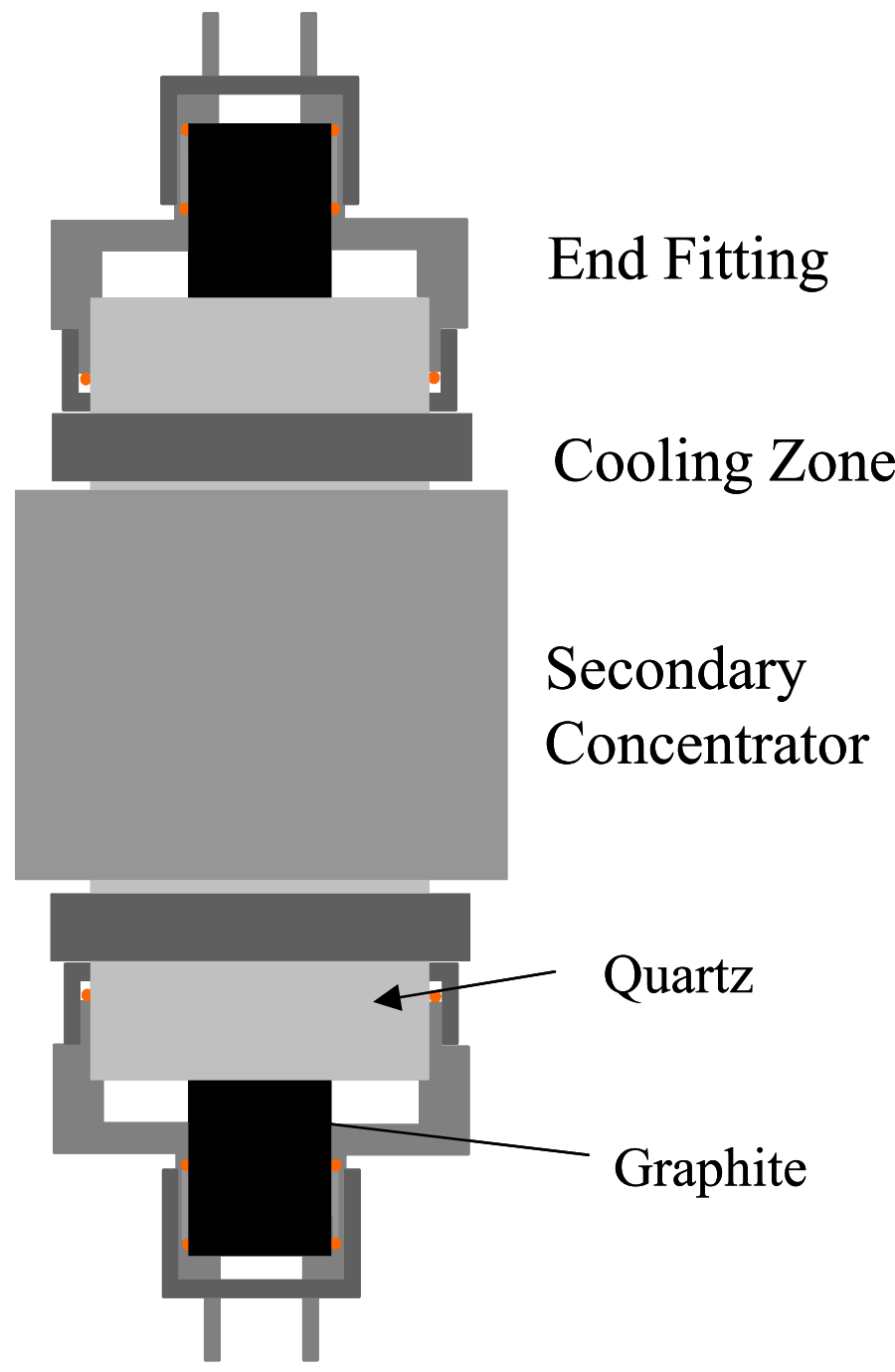


Exhibit 3. Data Derived from Thagard Patent (U.S. Patent \# 4,056,602 (1977)) that Demonstrates Increased Methane Dissociation with Temperature.

(Figure supplied by CU)

\section{Thagard Reported Data: Effect of Residence Time \& Temperature on Conversion}

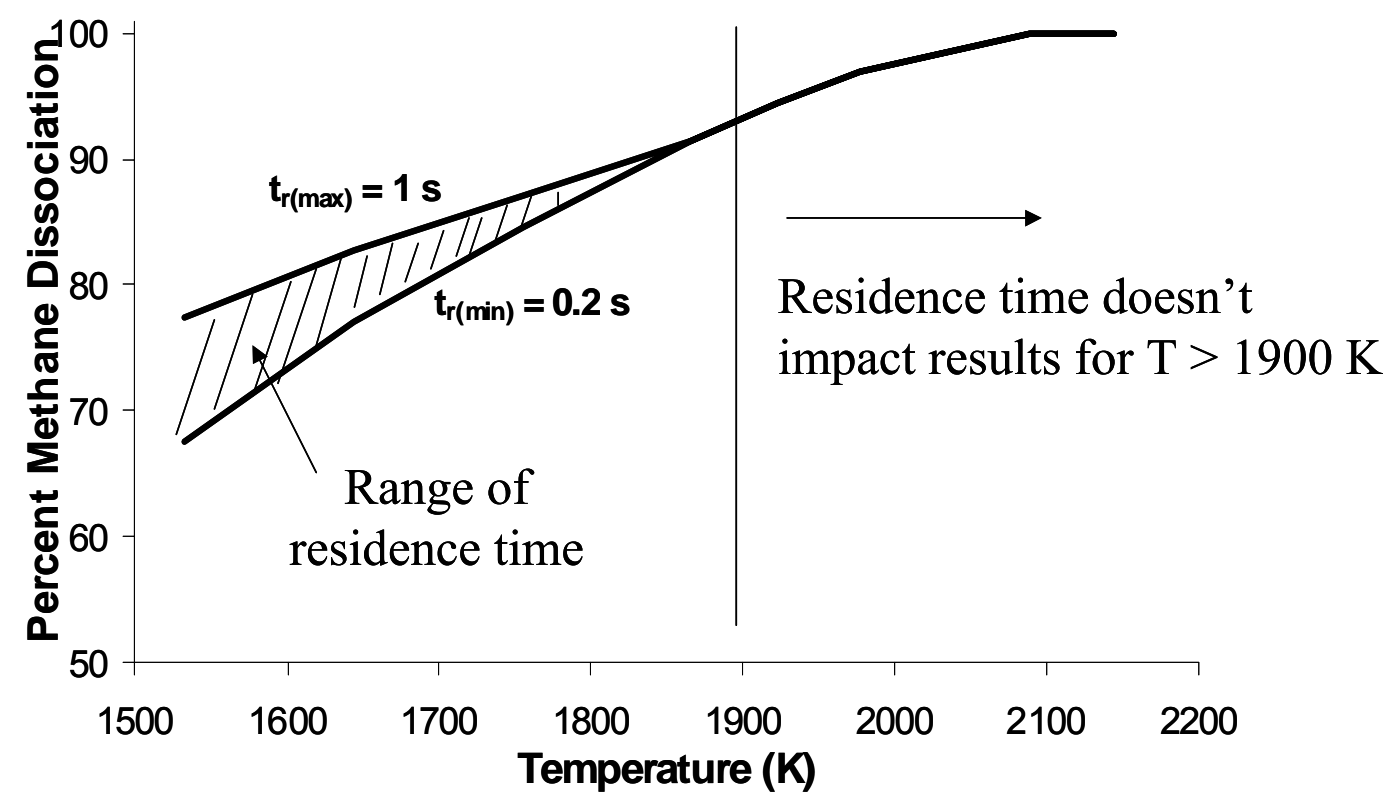


Exhibit 4. Heat Transfer Model for Second Generation Reactor. (Figure supplied by CU)

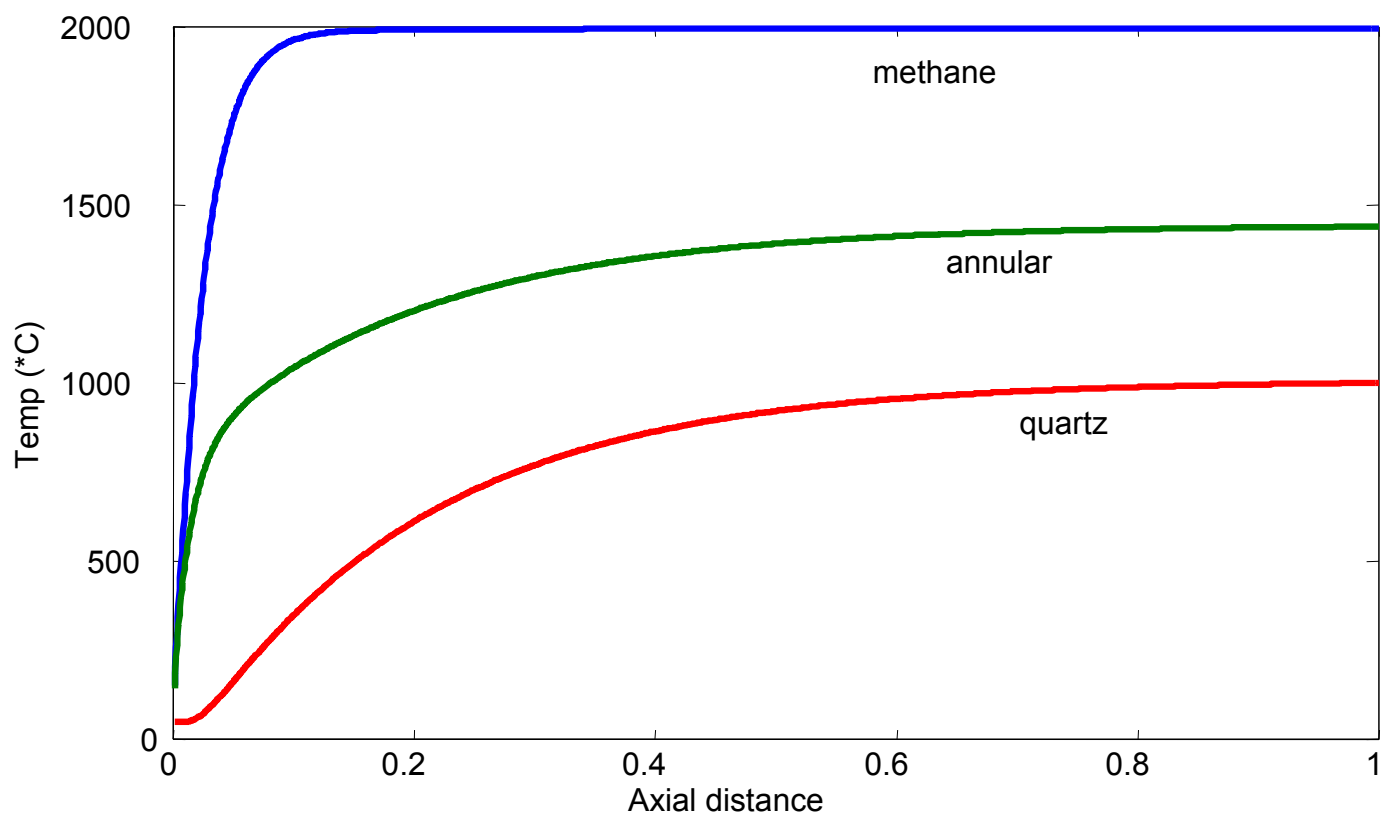


Exhibit 5. Sensitivity Analysis for the Price of Solar Thermal Dissociation-Produced Hydrogen. (Figure supplied by NREL.)

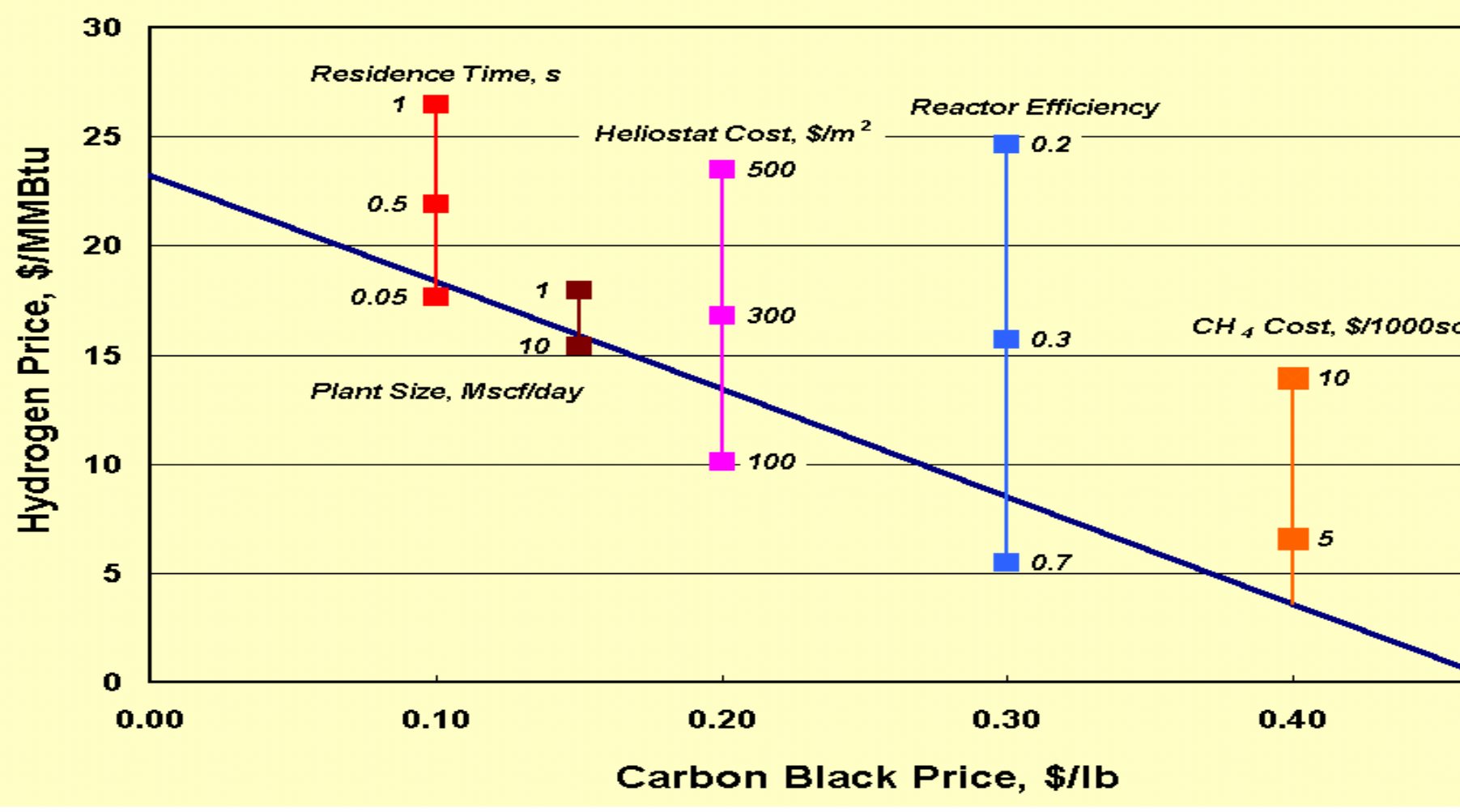


Technical Evaluation Report

Project: Biological $\mathrm{H}_{2}$ From Fuel Gases and Water

Company: National Renewable Energy Laboratory

P.I.: Dr. Pin Ching Maness

Site-Visit Date: July 2-3, 2001

Evaluation by: Edward G. Skolnik, Energetics, Inc.

\section{Summary:}

Among the photobiological projects that are part of the hydrogen production effort, the subject project is somewhat unique. First of all, its primary component is not directed at water splitting (although this goal was previously part of the project), but at the water shift reaction. Secondly, the primary process is not photobiological at all. The bacteria perform the activity in the dark.

The researchers at the National Renewable Energy Laboratory (NREL) are looking to optimize an organism that can perform the shift reaction biologically at room temperature. (The reaction,

$$
\mathrm{CO}+\mathrm{H}_{2} \mathrm{O} \rightarrow \mathrm{H}_{2}+\mathrm{CO}_{2}
$$

is conventionally run chemically in the presence of catalysts in two operations at $800^{\circ} \mathrm{C}$ and then at $400^{\circ} \mathrm{C}$.) In a separate project that is not being reviewed in this report (although we will discuss it somewhat), NREL is designing and building a reactor that will allow the biological water shift reaction to be performed at a larger scale, and ultimately, commercially.

I see the following strengths in the project:

- If the bacterial water shift proves to be economically sound, it presents an opportunity for an important component to the overall hydrogen/PEM fuel cell system - a single step shift and purification (CO removal) process.

- Even if hydrogen production via bacterial water shift does not prove to be a costeffective process, if the bacteria can reduce CO to PEM fuel cell levels it's a very valuable contribution.

- The process appears to be quite robust, and would apparently work with any syngas regardless of source.

- The fact that the bacteria work in the dark will allow for a more compact system and one that can be located more widely.

I have following concerns: 
- Focus. NREL recognizes that the Peer Reviewers had recommended that the project focus on water-gas shifting - not water splitting. There is still a lot of water splitting data being reported, especially oxygen tolerance issues. Also, if the work is supposed to center on the CBS bacteria, care must be taken not to go overboard with the mutant species.

- The robustness of the species needs to be demonstrated.

- Favorable economics need to be proven.

\section{Introduction and Background:}

The development of bacteria for both shifting $\mathrm{CO}$ and water to hydrogen and $\mathrm{CO}_{2}$, and for splitting water to hydrogen and oxygen has been an ongoing project at NREL for the past several years. Until recently, the project was led by Dr. Paul Weaver.

Unfortunately, ill health has forced Dr. Weaver to reduce his workload. The Principal Investigator (PI) role for the biotechnology development work has been therefore taken over by Dr. Pin-Ching Maness, who has been working on the DOE Hydrogen Program project with Dr. Weaver since its inception. The accompanying work, building the bioreactor, is now led by Dr. Ed Wolfrum. Since my goal was the evaluation of the bacteria development project, I spent most of my time (the afternoon of one day, and the morning of the next) with Dr. Maness, although I did get the opportunity to talk with Dr. Weaver for a few minutes, and did visit Dr. Wolfrum in his laboratory. The laboratories are located in NREL's Field Test Laboratory Building.

Dr. Maness and I spent many hours in discussion of the project including in-depth analysis of several questions that I had sent to her prior to the meeting and for which she had prepared answers in writing. Dr. Maness also took me on a tour of her laboratories, and I also was shown Dr. Wolfrum's bioreactor systems.

Aside from the personnel changes, the key development over the past year is the allocation in focus entirely to the water shift process. This was done at the recommendation of the Peer Reviewers who felt that the transfer of the bacterial vector into a cyanobacteria or an alga was complex and unlikely to succeed. Thus, the water splitting component of the research has (at least temporarily) been halted.

\section{General Discussion:}

Dr. Maness compares the NREL project to the conventional water shift process and feels that they hold a two-fold advantage: $\mathrm{CO}$ removal capability and a bacteria that is easy to grow as opposed to having to use an expensive catalyst.

The bacteria that has been used by NREL to perform the water shift reaction is of the type Rodocyclus gelatinosus, and is known by the acronym "CBS". Dr. Maness, in looking to harvest the proper bacteria felt that for a bacterium to be able to use $\mathrm{CO}$, it should come from a CO environment. Dr. Maness thus harvested material from areas 
containing vegetation around parking lots - vegetation that would come in contact with high concentrations of $\mathrm{CO}$ from automobile exhausts. The CBS bacteria were harvested from the shrubbery at the edge of a parking lot at a Denver area Mexican restaurant. The bacterium was thus named for where it was found: Casa Bonita Shrubbery (CBS). NREL has now been working with CBS for 7-8 years.

Dr. Maness' group have found many other organisms that are akin to CBS in that they have water-gas shift properties that are similar. Nevertheless, if CBS were to turn out to have widespread application, Dr. Maness suggests that the CBS itself be transported and grown in other areas rather than try to find/use a similar material. Another material may have the same tendency toward $\mathrm{CO}$, but, for instance, reaction rates would likely be different. Does this imply that there could be bacteria out there that would be even better than $C B S$, if we go hunting in parking lots?

$\mathrm{CO}$ is a primordial gas as is $\mathrm{CO}_{2}, \mathrm{H}_{2}$ and $\mathrm{N}_{2}$. Bacteria, such as $\mathrm{CBS}$ live on $\mathrm{CO}$, or at least use it, getting energy out of it. So (unlike other biological undertakings) what the bacterium is doing is not against its nature. It does not have to be mutated.

The reaction to make hydrogen, which is actually a two-step process:

$$
\begin{gathered}
\mathrm{CO}+\mathrm{H}_{2} \mathrm{O} \rightarrow \mathrm{CO}_{2}+2 \mathrm{H}^{+}+2 \mathrm{e}^{-}[1] \\
2 \mathrm{H}^{+}+2 \mathrm{e}^{-} \rightarrow \mathrm{H}_{2}[2]
\end{gathered}
$$

and requires an electron mediator, takes place in the dark. The bacteria would produce cell mass in the light. Dr. Maness suggested alternatives of making hydrogen at night and growing cell mass during the day, or using two systems that would alternate between making cell mass and hydrogen, or perhaps making cell mass for a few days and then pumping the material into a dark reactor. Later, (see Question 11) she spoke of perhaps only needing cell growth every year or so, but also considered the possibility of admitting limited light to allow cell growth in situ. It is obvious that this portion of the project has not yet been worked out. It's more of an engineering problem, but it could involve some manipulation of the bacteria if using multiple reactors or different reactors for mass growth and hydrogen production are not cost effective. Dr. Maness refers to the bacteria as "a self-replicating catalyst for shift reactions."

A bright spot (pardon the pun) is that the hydrogen production process is not hindered (unlike other biological undertakings) by the efficiency of the photolytic reaction except, of course, during cell mass growth. The bacterial cells are grown with $\mathrm{CO}$ as the only carbon source.

CO uptake is very rapid, only taking a few seconds, says Dr. Maness. The best method of exposing the bacteria to $\mathrm{CO}$, however, is unclear. Dr. Maness suggested a sprinkler head. I'm not quite clear on this. As will be seen later, reactor systems using high surface area reaction beds are being developed. I don't know how a sprinkler head would fit in, or why you'd want one. These bacteria are quite hardy, and have no problem being pumped; they handle pressure well. 
Dr. Maness emphasized that the bacterial water shift process both produces hydrogen and removes $\mathrm{CO}$ at the same time; an additional purification step would not be needed. If the plan is to use the hydrogen in a PEM fuel cell, $C O$ would have to be virtually eliminated $(<10 \mathrm{ppm})$. NREL has one piece of data that shows that the bacteria removed CO down to the $0.2 \mathrm{ppm}$ level. Dr. Maness, however, was quick to caution that this was one "special experiment" that Dr. Weaver ran. It proves that the bacteria are capable of removing virtually all of the $\mathrm{CO}$, not that they can do it efficiently, continuously, and commercially. If they can, this is a major breakthrough!

Where the project stands now is the need to prove durability and recycling capabilities.

\section{Tour:}

Dr. Maness took me on a tour of the laboratories where the bacterial strain is being developed, characterized and tested. Later, we visited Dr. Wolfrum's laboratory where I saw the bioreactors.

The first stop was the Water-Gas-Shift Laboratory. Among the testing and analysis equipment in the lab were: an "old but reliable" gas chromatograph (GC) that samples the headspace of the sample bottles for hydrogen; a hydrogen/oxygen cell (electrode system) to measure hydrogen production in solution (this is a homemade device), and a high performance liquid chromatograph (HPLC) to determine intermediates.

Adjacent to the laboratory were a standard sterile transfer room and an anaerobic chamber where the oxygen is removed from the air to condition it for the enzymes, as the enzymes are anaerobic.

Dr. Maness' laboratory shares centrifuges and spectrophotometers with Dr. Mike Seibert's laboratory.

In another room many bacterial cultures were growing. These brownish-orange CBS species absorb in the orange, red and infrared light regions, using the part of the solar spectrum that is "wasted" by blue-green algae.

An old "carpet reactor" developed by Dr. Weaver was also present in this room. Dr. Weaver's premise was that since CO take up is controlled (at least at the laboratory scale) by mass transfer, the piece of shag carpet provided the surface area on which bacteria could be immobilized and CO efficiently taken up.

An inclined bubble reactor is used by the group to condition fuel gases (that is, to try to remove all of the $\mathrm{CO}$ so that the hydrogen can be used in a PEM fuel cell.) This is Dr. Weaver's old reactor according to Dr. Maness. While the carpet reactor immobilizes bacteria, the bubble reactor allows free movement. Mass transfer is bubble related smaller bubbles equal more surface area. The tubes are long (a few feet in this instance) to allow a long contact time between the $\mathrm{CO}$ and the bacteria. The reactor looks like a 
smaller version of the one at the University of Hawaii that I saw two years ago. The tube can be sampled at various locations so that one can see how long it takes for the $\mathrm{CO}$ levels to be down to acceptable levels. A very sensitive near-infrared $\mathrm{CO}$ detector is used. It can measure down to "a few ppm." This, of course is necessary for PEM fuel cells. I'd like to see some data.

The reactors in Dr. Wolfrum's area were not running when I visited there, but I was able to see one- and five-liter tubular "trickle-bed" reactor systems (they are looking at scaling, and will go to 25 liters next) and components including transfer media. I was shown the reactors by Dr. Wolfrum and his associate Andrew Watt. They are looking at wood fiber and cellulose primarily, but glass as well. Porous materials such as these are about five times more effective at mass transfer than non-porous material, and to quote Dr. Wolfrum, in the real world it is "way mass-transfer limited."

They plan to look at pressurized reactors also; this will aid the transfer process. In addition, they will be checking to see at what pressure hydrogen can be produced. They have already shown that the bacteria can operate at ten atmospheres of pressure.

Reactor flow rate is not very fast because you really need that contact time. Dr. Wolfram estimated residence times to be in the "tens of minutes". There is a sensitive balance between contact time and reactor size. However, as they move into pressurized systems they believe they will be able to reduce contact time significantly. At 200 psi, Dr. Wolfrum estimates an order of magnitude drop in residence time. Then, as they identify the most efficient bed material, they should be able to reduce the residence time by another factor of 2 to 4 . Eventually residence time will be under a minute, they predict.

One "rule" in Dr. Wolfrum's laboratory: they don't deal with sterile conditions here; they'd rather consider real world situations. This is an excellent approach, and should definitely answer questions about the robustness of the CBS bacteria.

The plan involves looking at the effects of toxicity. Generally, with biomass products you do a water scrub first. This leaves approximately $1 / 3$ hydrogen, $1 / 3 \mathrm{CO}$ and $1 / 3 \mathrm{CO}_{2}$. There are, however, small amounts of benzene and toluene present. NREL plans to determine how CBS reacts to these impurities. It's more than just keeping the bacteria alive; they have to keep water-shifting. It would take less benzene or toluene to inhibit the shift reaction than it would take to kill the bacteria. Some initial indications show that the CBS bacteria remain viable, but they are not sure about shift yet.

Dr. Wolfrum mentioned that they had hooked a reactor up to the back end of a biomass pyrolysis system as a proof of concept study.

\section{Questions and Answers:}

I sent Dr. Maness a set of discussion questions prior to my arrival. He responded in writing and we also discussed the questions and answers in detail. This is all reproduced here, with the questions indicated in bold, written answers reproduced verbatim in 
quotes, our discussion shown in normal type, and my comments added to many of the questions during my later analysis and assessment shown in italics.

1. Your project is titled "Biological $\mathrm{H}_{2}$ from Fuel Gases and from $\mathrm{H}_{2} \mathrm{O}$ " which seems to imply that you are working with two microbes - one that produces hydrogen from fuel gases and another that produces hydrogen from water. I seem to remember in past years, there being two tasks, one devoted to fuel gases and another to water. Your recent reports indicate that you are concentrating on shifting $\mathrm{CO}$ and water to hydrogen and $\mathrm{CO}_{2}$. How does the current work relate to the original work?

"We use the same microbe to accomplish both subtasks. " $\mathrm{H}_{2}$ from fuel gases" uses the microbe as is, and " $\mathrm{H}_{2}$ from water" requires a mutant of bacterial-cyanobacterial hybrid. However, DOE review panel had suggested last year to discontinue the work of $\mathrm{H}_{2}$ from water due to its level of difficulty. They recommended that we focus on the " $\mathrm{H}_{2}$ from fuel gases" portion, as it has more potential and immediate success. " $\mathrm{H}_{2}$ from water" requires cloning the hydrogenase gene, constructing a vector, and getting the hydrogenase and its cofactor incorporated and expressed in a cyanobacterium."

Bacteria do not use water as an electron source; algae and cyanobacteria do use water this way. So in order to split water they would need to construct an algae or cyanobacteria. This is now beyond the scope of the project. Dr. Maness is concentrating on the water shift reaction.

"Even though the focus is shifted, we are still working on cloning the hydrogenase gene, and if successful, it has applications beyond " $\mathrm{H}_{2}$ from water". Elucidating the genetic system allows us to understand the components involved and the rate-limiting step of the overall system. With this knowledge, we can then enhance the rates and durability of $\mathrm{H}_{2}$ production from $\mathrm{CO}$ shift via biochemical and genetic approaches."

They are not planning to go back to water splitting in the future; they are looking at the molecular biology of the shift reaction. However, the information they are obtaining could be used for the water splitting project as well - should funding ever come back in this area. (See also, Question 9)

2. You say that the rate constant for the hydrogenase enzyme Rhodocyclus gelatinosus CBS-2 is greater than 60,000 . Is this a first-order reaction (i.e., $k=$ $60,000 \mathrm{~s}^{-1}$ ), or are you indicating an equilibrium?

"It is an equilibrium constant at $30^{\circ} \mathrm{C}$ temperature."

That's what I thought, but the report had called it a rate constant.

Dr. Maness provided a temperature/equilibrium constant curve, shown in Exhibit 2. Since the equilibrium favors hydrogen production at cooler temperatures, they would want to pull any heat out. Dr. Maness says that they could use the heat to power the reactor.

3. Please discuss the three different hydrogenases in the system, describing what each one is (or is supposed to be) doing. 
"Formate-linked hydrogenase, or the fermentative hydrogenase: induced under fermentative condition with a proposed function to dissipate excess reducing equivalents during growth. This enzyme normally equilibrates at low $\mathrm{H}_{2}$ partial pressure and is extremely sensitive to $\mathrm{O}_{2}$.

"Uptake Hydrogenase - induced under low redox condition. Its main function is to oxidize $\mathrm{H}_{2}$ as a source of energy to support $\mathrm{CO}_{2}$ fixation, therefore, it is not suitable for $\mathrm{H}_{2}$ production. Uptake hydrogenase is quite stable to $\mathrm{O}_{2}$.

"CO-linked hydrogenase - induced under low redox condition with CO present as part of a water-gas shift pathway. Only a few organisms have this pathway. In our organism, its function is to capture the energy in $\mathrm{CO}$, via the enzyme $\mathrm{CO}$ dehydrogenase, and convert the reducing equivalent into the form of $\mathrm{H}_{2}$, which can then be oxidized by the uptake hydrogenase for $\mathrm{CO}_{2}$ fixation. CO-linked hydrogenase is most robust and favors the $\mathrm{H}_{2}$ production direction.

"An organism may contain one, two, or all three of the hydrogenase enzymes."

For the NREL system, the key hydrogenase is the CO-linked hydrogenase. It is much faster than the formate-linked. In fact, the CBS bacteria do not even contain the formatelinked hydrogenase.

The formate-linked hydrogenase is not even a good candidate for hydrogen production because the enzyme is not long-lived. The uptake hydrogenase works only in the light, while the CO-linked hydrogenase can work either in the light or darkness. In darkness it uses $\mathrm{CO}$ to make hydrogen, and in the light it uses $\mathrm{CO}$ to make cell mass.

The hydrogen producing aspect of the CO-linked hydrogenase is helped by the high equilibrium constant of the shift reaction at ambient temperature (see Exhibit 1) and by the high ratio of the hydrogen evolution to uptake ratio (about 43-50).

The basic goal is to obtain mutants that will chose the hydrogen-forming CO-linked hydrogenase over the mass-growing uptake hydrogenase. Most bacteria would rather use hydrogen as an electron donor - that is, the uptake hydrogenase function.

\section{In your FY 2000 Annual Review report you state that it is difficult to measure oxygen resistance for the CO-linked hydrogenase because of the presence of the uptake hydrogenase. Yet you state that the uptake hydrogenase is very tolerant of oxygen. How does the fact that one material is tolerant of oxygen affect the oxygen tolerance of another material?}

"The existing hydrogenase assays do not discriminate one hydrogenase activity from the others. One might mistakenly attribute the $\mathrm{O}_{2}$ tolerance of uptake hydrogenase to the hydrogenase of interest. That is why the hydrogenase of interest has to be purified from the other to avoid confusion."

This answer needed some clarification. I had assumed that if you were producing hydrogen in the presence of oxygen, and if the CO-linked hydrogenase was the key factor for hydrogen production, then by inference, the CO-linked hydrogenase was oxygen tolerant. Dr. Maness assured me that this was indeed the case, but for accuracy you needed to prove it separately. 


\section{In your FY 2001 report you indicate that the CO-linked hydrogenase is tolerant to $3 \%$ oxygen, and that this is sufficient for scale up. How did you determine that this was sufficient for scale-up? What final tolerance level do you feel will be necessary for a successful system?}

"To be real conservative, the hydrogenase would have to be functional in the presence of full air, that is, $21 \% \mathrm{O}_{2}$. However, it all depends on the activity of cellular respiration, which will scavenge $\mathrm{O}_{2}$, and also how $\mathrm{O}_{2}$ partial pressure is partitioned within cells. A hydrogenase functioned at $3 \%$ $\mathrm{O}_{2}$ gives us a starting point to examine a hybrid system. Most evolving hydrogenase has a halflife of $1 \mathrm{~min}$ in full air. Our hydrogenase has a half-life of 21 hours in full air and is partially functional in $3 \% \mathrm{O}_{2}$. Comparing to other hydrogenase reported in literature, our hydrogenase is probably the best candidate to be transferred into a cyanobacterium.

"To scale up $\mathrm{H}_{2}$ production from $\mathrm{CO}$ shift reaction, $\mathrm{O}_{2}$ tolerance is not an issue since syngas is $\mathrm{O}_{2}$-free."

In fact, says Dr. Maness, in a real system, tolerance would have to exist at least at $21 \%$ oxygen. Oxygen levels could go above $21 \%$ in a closed system with the bacteria making more oxygen.

The methodology for testing oxygen tolerance that the laboratory was using involved stirring CBS in full air, taking a sample of about $0.5 \mathrm{ml}$, and injecting it into a new assay vial with methyl viologen and sodium dithionate (a mediator reductant). Hydrogen concentration is then measured at different time intervals. This gives the rate. The problem is that sodium dithionate scavenges oxygen itself.

NREL has therefore switched to the "HD" assay. You add deuterated water to the bacterial suspension allowing a deuterium atom to exchange with an atom from water shift-produced hydrogen, to form HD. This procedure requires neither an electron mediator nor a reducing agent. Oxygen cannot be scavenged, and you have a better system for measuring oxygen tolerance.

It is all somewhat moot, however. Oxygen tolerance is only an issue in the now defunct water splitting mode.

6. In Figure 1 of your FY 2001 report (shown as Exhibit 2 in this Report), is the ion current representative of HD concentration? I'd like to spend a little time on this Figure during our meeting. I'm especially interested in understanding what you mean by the hydrogenase being not only tolerant of $\mathrm{O}_{2}$ but also partially functional.

"Yes, the ion current corresponds to mass 3, presumed to be HD. We have not yet calibrated ion current of HD in relation to its absolute quantity such as moles.

"Referring to "tolerant and also functional": "tolerant" means that hydrogenase activity can be restored once $\mathrm{O}_{2}$ is removed. This was determined by exposing cells to $\mathrm{O}_{2}$, followed by the removal of $\mathrm{O}_{2}$ and then assayed hydrogenase activity anaerobically. "Functional" means that we 
observed partial $\mathrm{H}-\mathrm{D}$ exchange activity in the simultaneous presence of $\mathrm{O}_{2}-$ activity was determined in $\mathrm{O}_{2}$. Tolerance and functionality in $\mathrm{O}_{2}$ were determined with two different assays."

\section{Still on the same Figure: You show decreased - but nevertheless measurable HD at $3 \%$ oxygen. At what oxygen concentration does HD cease to exist?}

"We have not titrated $\mathrm{O}_{2}$ concentration versus $\mathrm{H}-\mathrm{D}$ exchange activity yet. It's in the plan."

The key is that the hydrogenase will work at least up to $3 \%$ oxygen. The rate decreases, but the reaction still produces HD in a linear manner - only slower. I asked if the HD production rate here was directly proportional to the hydrogen concentration. Dr. Maness believes it is, but is not yet sure. The " $\mathrm{H}$ " in HD likely comes from hydrogen production, and both the HD exchange and hydrogen production work at the same active site on the enzyme. For now, however, the HD exchange only demonstrates that the hydrogenase is working in the presence of oxygen; it doesn't necessarily relate directly and proportionally to the amount of hydrogen being produced. They need to find out if it does relate directly, Dr. Maness stated.

Again, this is a water-splitting concern. Nevertheless, Dr. Maness stated that they would like to publish these data, and will therefore try to reproduce it using purified CO-linked hydrogenase.

I think the reader can see a bit of a trend here. Having read several reports written by the PI, including the yet-to-be released (as of this writing) FY 2001 Annual Review Report, I see a lot of attention paid to oxygen tolerance. That is why I asked several questions about it. But oxygen tolerance is not an issue for water shifting of $C O$, which is what the project should be concentrating on-and what they indeed appear to be now concentrating on. Care needs to be taken that the focus continues to be on the water shift reaction.

Dr. Maness discussed the methodology they will use to actually measure hydrogen production.

\section{You reported surprising results in which seven mutants were isolated that increased rather than decreased hydrogen production compared to the parent species. Were these particular mutants unique? That is, did other mutants show the expected decrease, or were these seven the only mutants isolated? Were the results reproducible?}

"The results are the average of four independent measurements. They are reproducible and most importantly, the mutants are stable. We are not sure on the uniqueness. These seven were the only mutants isolated. Had we obtained some mutants with reduced activity, I would then say yes, they are unique. We plan to repeat their rate measurements again this summer. If still reproducible, we will propose to DOE in the AOP to characterize these mutants further."

The key factor is stability. Variants are not always stable; they have a tendency to revert to the properties of the wild type. (Mutants are generally less competitive than the wild type of bacteria, and it is difficult to keep them under the right conditions.) They need to 
find a way of determining if the mutants are stable, and don't degrade over time. If the mutants are indeed stable, they will try to get funded for the characterization work, and then eventually do some bioreactor work with them. This is well in the future, however.

The key thing that Dr. Maness pointed out, however, is that they do not use mutants generally. Their bacteria of choice is the parent (wild type) CBS. The mutants do help them to understand the water gas shift pathway, however.

Care must be taken to stay focused on the CBS bacteria if this is the organism of choice.

\section{What is the status/plan for putting the hydrogenase into cyanobacteria or algae?}

"DOE review panel has recommended that we discontinue that portion of work and instead focus on $\mathrm{H}_{2}$ production from the water-gas shift reaction using $\mathrm{CO}$ as the feedstock. Our current effort in cloning the hydrogenase gene will facilitate that portion of work in the future."

They are looking to hire a molecular biologist to clone the gene, not to pursue watersplitting activities. They believe this will help in determining the mechanism for bacterial water shift.

10. Where would CO come from in an overall system? If it is part of a syngas, there is the likelihood that there is some unreacted fossil fuel (natural gas, coal gas, etc.) present together with various impurities (sulfur-containing materials, for example). Have you looked at all at the effect of these substances on your bacterial system? Would you expect any poisoning?

"The source of $\mathrm{CO}$ is syngas, generated from the gasification of waste biomass. Methane is present in minute amounts, and it will simply pass through the system unchanged diluting other gases. Most photosynthetic bacteria prefer sulfur in the form of $\mathrm{H}_{2} \mathrm{~S}$ to up to $3.5 \mathrm{mM}$ level, although some can tolerate more. Sulfide is routinely used in medium preparation to scavenge $\mathrm{O}_{2}$ and could even serve as an electron donor for certain microbes. Even with the waterscrubbed pyrolysis gas, there are usually still traces of toluene, benzene and phenols. Preliminary testing reveals that our organisms are fairly tolerant of both toluene and benzene in terms of cell viability and growth. No data yet on effect of phenols on growth/viability and effects all three solvents on shift activity although work is in the plan."

Dr. Maness referred to a four-day run that they did with the bioreactor using biomass pyrolysis products. The bacteria appeared to be unaffected by the impurities in the pyrolysis products.

Coal gas would contain more sulfur. The CBS bacteria are a non-sulfur bacteria. Dr. Maness thinks that it may not be able to tolerate sulfur, but she is not sure. She said, however, that they have isolated bacteria from a coal pile that appeared capable of performing a water shift. These bacteria would be sulfur tolerant.

11. If you were to set up a "real world" shift reactor at, say, a size by which a hydrogen refueling station could be maintained (assume 200 cars per day about $1000 \mathrm{~kg} \mathrm{H}_{2}$ per day), how large would you envision your reactor to be? 


\section{How would it work within the overall system? What are the problems you foresee having to overcome?}

"We don't have a number on how large the reactor should be. We underestimate the shift activity at this point due to the mass transfer limitation of $\mathrm{CO}$ into liquid phase. Ed Wolfrum, an engineer and PI of the "Bioreactor Development" task, is examining various microbial immobilization techniques and bioreactor design to overcome the mass transfer limitation. With proper design, both cell mass and shift rates can be increased significantly. Ed has provided reactor volume and reaction rate data to NREL analyst to conduct an economic analysis of the overall process.

"For the overall system, induced microbes with good CO shift rates are immobilized onto a bioreactor. The bioreactor will receive water-scrubbed syngas from a gasifier after the syngas is cooled down to $35 \mathrm{C}$. The bioreactor can serve two purposes; one is to produce additional $\mathrm{H}_{2}$ from CO shift, the other is to condition the fuel gas to very low CO levels so that the resulted $\mathrm{H}_{2}$ can be injected directly into a PEM fuel cell.

"Through biochemical and genetic analysis, we hope to understand mechanism of the underlying pathway in order to further improve the activity and durability of the shift reaction. Another research area is to examine various packing materials to immobilize microbes so that both activity and durability of the shift activity can be maintained. Through immobilization and reactor design, we hope to overcome the mass transfer limitation. To summarize, this project is to enhance $\mathrm{H}_{2}$ production through biochemical, genetic, and engineering approaches."

The laboratory-scale system is in a liquid suspension. This will not be the case for a dynamic bioreactor. As they scale up they will know more. Dr. Maness feels that Dr. Wolfrum and analyst Wade Amos will be able to answer the questions "fairly soon".

The eventual size of the reactor will be a function of the bed packing material. The packing material must have a high surface area and a surface that will accept the bacteria. Close packing is not a problem as it may be for other bioreactor systems because the shift reaction does not require light. The only time that light is needed is when you are trying to grow (regenerate) the bacteria. Dr. Maness thinks that this may be on the order of once a year, and plans to look at bacteria durability during the next year. Nevertheless, Dr. Maness believes that the regeneration will likely be done in situ. Therefore it will be necessary to have a reactor that will admit some light.

The regeneration process will be important. It appears that it could determine the size of the reactor, if in situ regeneration is warranted.

\section{Additional Topics:}

If the source of Dr. Maness' feedstock is to be waste biomass, it must go through some kind of reforming or gasification process prior to the biological water shift process. Currently Dr. Maness is working with a refinery (that wishes its identity to be proprietary information) that does some reforming, but is interested in biological shifting. The refinery is also interested in high-pressure hydrogen.

Dr. Maness is also working with the University of Victoria (British Columbia) who does a lot of PEM fuel cell research, and is interested in a $\mathrm{CO}$ reduction method. 


\section{Final Thoughts:}

This is a good project, with potentially a very significant contribution. There's a long way to go, but if NREL can show that the CBS bacteria can not only shift water, but more importantly, remove CO down to acceptable levels for PEM fuel cells efficiently and economically, it will further the case for on-board hydrogen fuel cells. I think that this is the most significant component of the research.

I realize that we are specifically evaluating the project using biomass as a feedstock, and a lot of my favorable comments do not focus specifically on biomass; the removal of CO from natural gas reformate or any fossil fuel gas is also attractive for the same reasons. Of course, biomass feedstocks provide the potential for a $\mathrm{CO}_{2}$-neutral process.

I am not trying to belittle the role of this project as a potential hydrogen producer. It's just that the CO purification aspect can be decoupled from the hydrogen production if necessary, and still play an important role. As a shift reactor plus purifier it's even stronger.

On the other hand, it can't be a stand-alone hydrogen producer. You need a reformer, gasifier, pyrolyzer, or other syngas production system upstream.

I know that I always say that the primary role of a hydrogen production project is to make hydrogen - lots of hydrogen. In this case, however, I say the role of the project is to start with hydrogen (in syngas), and make it very pure. 
Exhibit 1. Water Shift Equilibrium As a Function of Temperature.

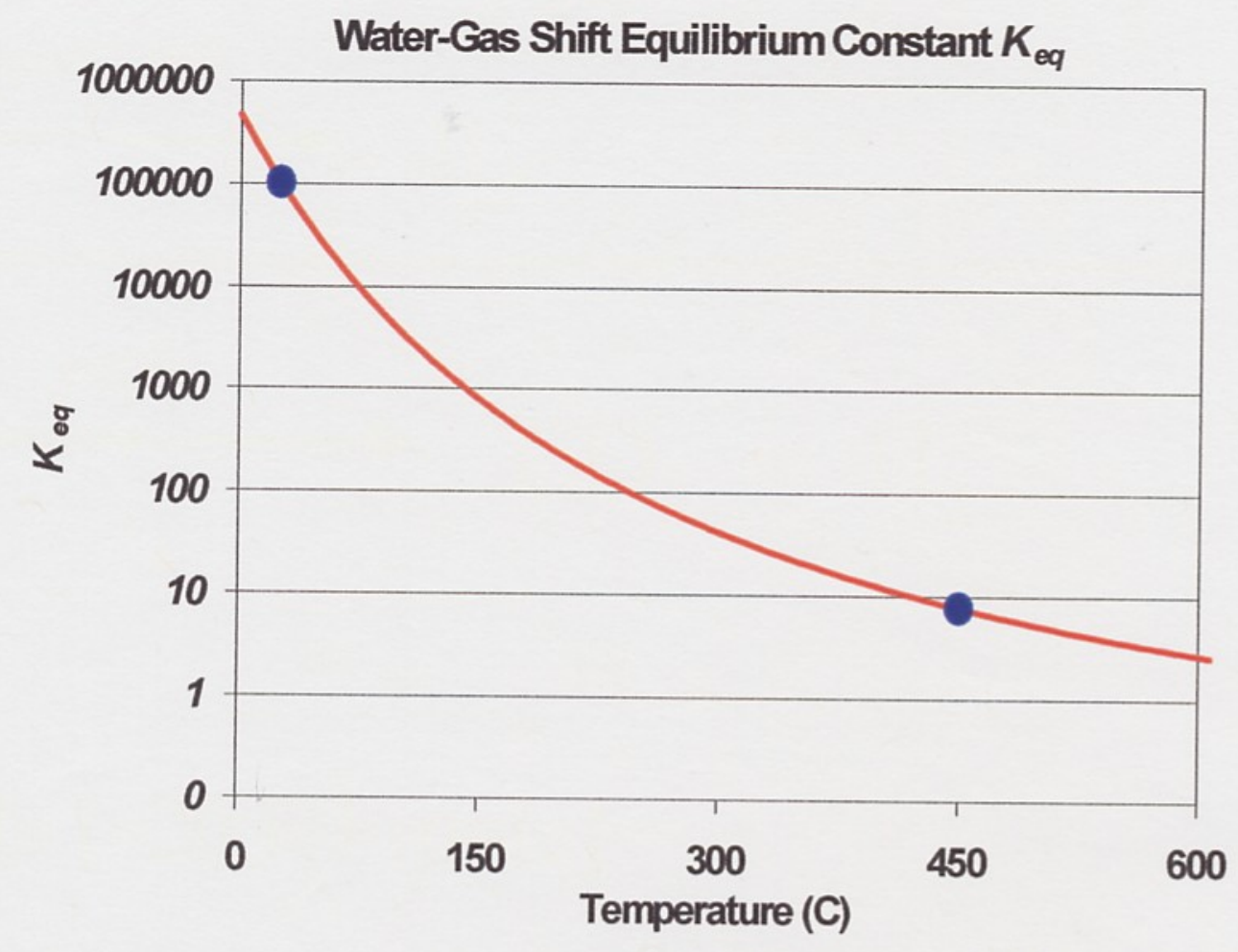

Note: An equilibrium constant is calculated from the concentrations of the reaction products divided by the concentration of the reactants. For the reaction:

$$
\mathrm{CO}+\mathrm{H}_{2} \mathrm{O} \rightarrow \mathrm{CO}_{2}+\mathrm{H}_{2}
$$

a high number for $\mathrm{K}_{\text {eq }}$ would indicate that the concentration of the products $\left(\mathrm{CO}_{2}\right.$ and hydrogen) would be favored. In other words, hydrogen would be more easily produced. 
Exhibit 2. Measure of Hydrogen Production in the Presence of Oxygen

(From Maness FY 2001 Annual Review Report)

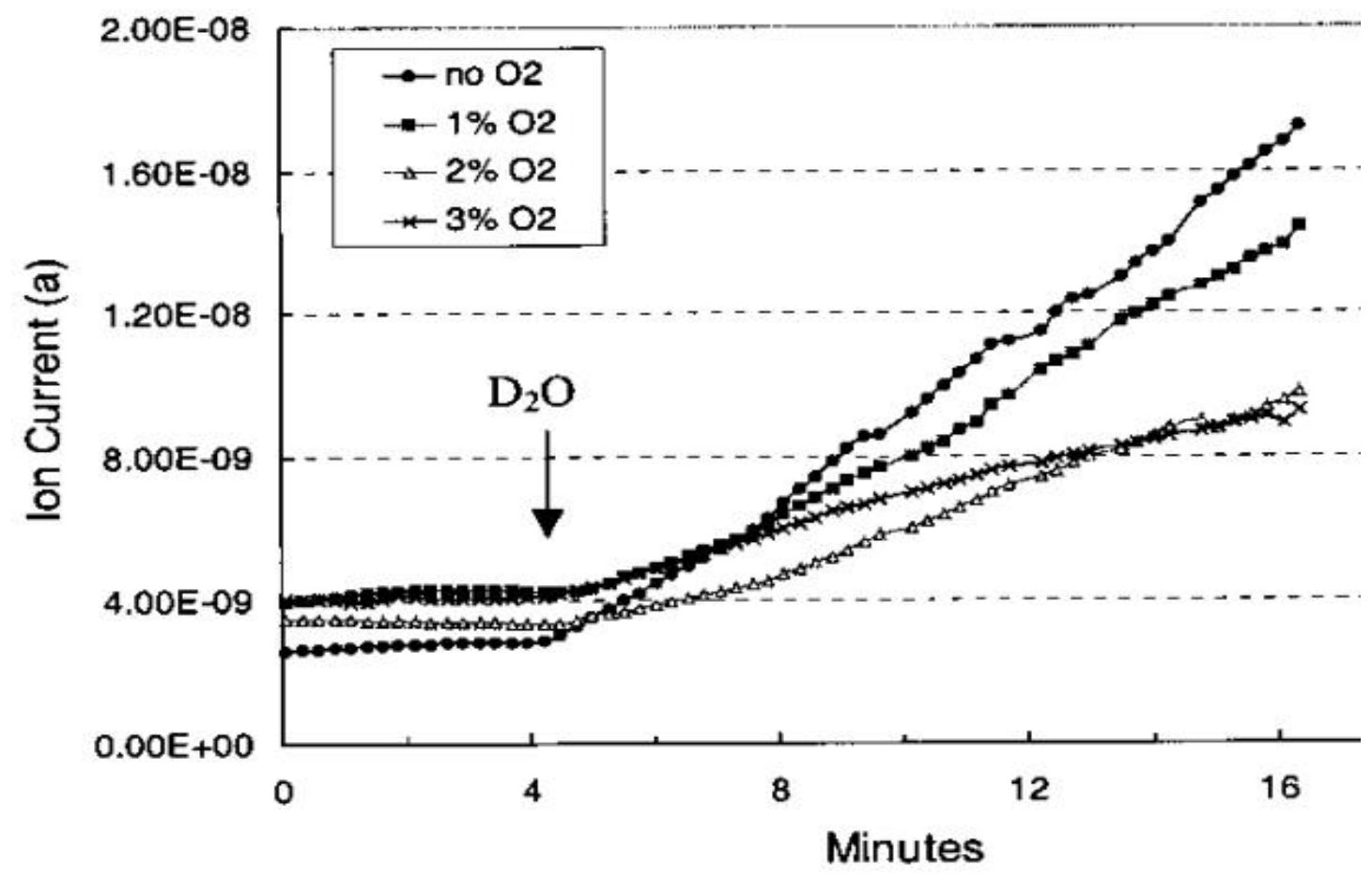


Technical Evaluation Report

Project: Gallium Nitride Integrated Gas/Temperature Sensors for Fuel Cell System Monitoring for Hydrogen and Carbon Monoxide

Company: Peterson Ridge LLC/ Fluence

P.I.: Dr. Stephen Pyke

Site-Visit Date: September 5, 2001

Evaluation by: Edward G. Skolnik, Energetics, Inc.

\section{Summary:}

A key need for the use of Proton Exchange Membrane (PEM) fuel cells is that the feedstock hydrogen be virtually free of $\mathrm{CO}$. Although research on making the system and its platinum-based catalyst more robust to $\mathrm{CO}$, the current rule of thumb is that $\mathrm{CO}$ concentration should be no greater than about $10 \mathrm{ppm}$. Therefore, in order to protect the PEM fuel cell should the feedstock composition change, there is a need for the ability of rapid detection of low levels of CO. Peterson Ridge LLC/ Fluence of Sisters, OR is addressing this important issue by developing sensors that can detect low levels of $\mathrm{CO}$ in the presence of large concentrations of hydrogen.

The product sensor is envisioned to be an array of various "gates" consisting of metals bonded to doped semiconductors. These field-effect transistors (FETs) operate by exhibiting a change in gate voltage due to exposure of the metal component to $\mathrm{CO}$. The gate metals being used are platinum $(\mathrm{Pt})$, Rhodium $(\mathrm{Rh})$, and a palladium/silver complex $(\mathrm{Pd} / \mathrm{Ag})$. These metals are all employed as catalysts in preferential oxidation (PROX) reactors that are employed to reduce the concentration of $\mathrm{CO}$ in fossil- (or biomass-) based hydrogen prior to use in a PEM fuel cell. These particular gate metals were chosen because, as catalytic components of the PROX process, they are known to be sensitive to $\mathrm{CO}$ in a hydrogen atmosphere. Each gate metal has its own level of sensitivity based on the concentrations of $\mathrm{CO}$, hydrogen, and oxygen and on temperature. The Peterson Ridge product is a sensor array that is made up of these metal/semiconductor gates consisting of at least one gate each having a Pt, $\mathrm{Rh}$, or Pd/Ag metal component. By finding the responses (in gate voltage change) by all of the gates to combinations of variations in temperature and concentrations of hydrogen and oxygen for various $\mathrm{CO}$ concentrations, one can calibrate the sensor. (It's like solving a series of simultaneous equations.)

Peterson Ridge is working with IdaTech, a Bend, OR fuel cell company that is interested in using hydrogen purified from reformed methanol as a feedstock for the fuel cell.

I see the following strengths in the project:

- An inexpensive, quick response sensing of $\mathrm{CO}$ prior to a reformate/PROX feed being sent to a PEM fuel cell is very important to the health of the fuel cell. Any feedstock other than hydrogen evolved from water is going to contain CO. Thus, the project addresses a key need. 
- The PI is very knowledgeable in the theories and developmental procedures of the gate-based sensors.

- The 3-dimensional data (see Question 13) showing gate voltage as a function of concentrations of $\mathrm{CO}$ and oxygen appears to be reproducible.

- The home laboratory leads to a low-overhead and therefore by comparison, to a lowcost facility. (We did not discuss this; it's an assumption on my part.)

I see the following weaknesses:

- The system relies on a complex combination of sensors with various gate metals to provide an overall map of CO concentration. Changes in metal chemistry caused by exposure to feedstock changes and impurities, or simply due to prolonged exposure to $\mathrm{CO}$, hydrogen and oxygen themselves may make data interpretation difficult. One could detect a problem with, say, one gate. But with results depending on an array of gates and an array of numbers, a discrepancy could go undetected. In other words, I am concerned that the system may be too complex.

- As far as the Hydrogen Program is concerned, the utility of the CO sensor may be limited. In the transportation area, the Program is concerned with reforming fossil fuels at the refueling station size (or perhaps bigger) - that is, off-board the vehicle. These reformers are likely large enough (and the PI agrees with this) so that it becomes cost-effective to invest in a standard gas chromatograph to measure $\mathrm{CO}$. The use of Peterson Ridge sensors to detect on-board CO likely has merit, but is not an objective of the Hydrogen Program. (The Office of Transportation Technologies, on the other hand may be interested.) In the electricity generation area, one might make the same argument about gas chromatographs. Spending about $\$ 10 \mathrm{~K}$ for a chromatograph seems reasonable for distributed generation systems except residential-sized ones. Thus, the Peterson Ridge sensor may be limited to small (a few $\mathrm{kW}$ ) residential-sized reformers where chromatographs are not a cost-effective option.

- The PI, while extremely knowledgeable in the technology of his sensors, needs to increase his understanding for what the potential markets of this product are, and what conditions the sensor is likely to face other than those for IdaTech (see discussion below).

- It is extremely difficult to follow the project reports. For instance, it was not until we had the site meeting did I understand that the plan was to use all of the different gate metals and gate configurations in an array. I had interpreted the reports to mean that the various options were part of a down-selection process. The vagaries concerning the test gas mixtures (see Question 6) is another example. 


\section{Introduction and Background:}

Of the thirty-odd site visits I have made to date, the subject of this report is possibly the most unique. Peterson Ridge LLC/Fluence is a one-man operation. Dr. Steve Pyke works in a laboratory in his house, which is located on a dirt road in the woods just south of the small town of Sisters, Oregon. (Dr. Pyke's lab/home is located on Peterson Ridge Road; fluence is defined as a flux (flow) of particles passing across a unit area.) Dr. Pyke designed the sensors at this location and also runs his sensitivity experiments there. The sensors themselves are built under subcontract to the University of Utah by Dr. Larry Sedwick's laboratory in the department of Electrical Engineering. The project is about two years old at this point.

The plan is for the sensors to initially be a device that will be a "red flag" for increases in $\mathrm{CO}$ concentration. Eventually, they will be process controllers or analytical instruments for the PROX process.

\section{Sensor Description:}

As we have stated, a sensor consists of a semiconductor strip with a metal strip bonded to it:

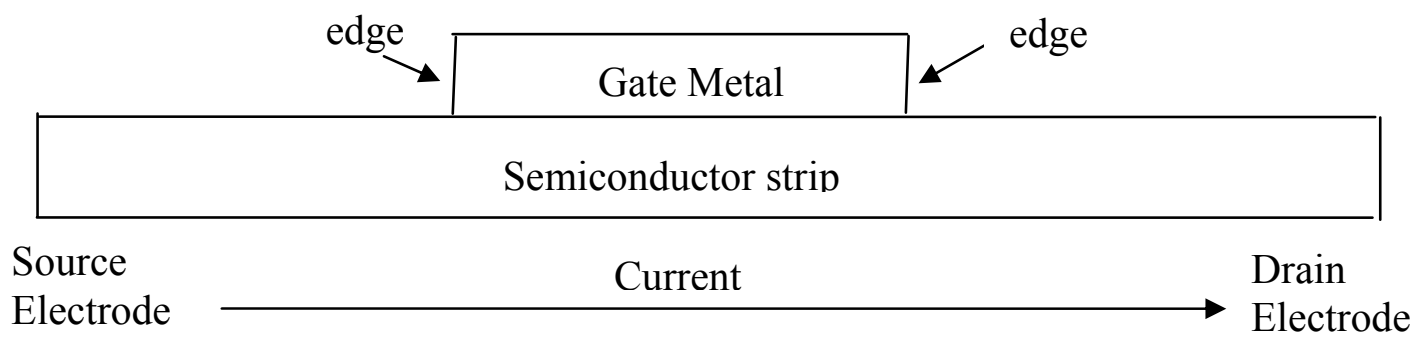

If the proper voltage is placed on the gate metal, current will flow from the source to the drain electrode. A dipole field is formed. The field is affected by the number of edges; edge effects are key to dipoles. Dual gate sensors have two metal strips, and therefore, four edges. Dr. Pyke says that he does not believe edge effects have a significant bearing on his results, but he will soon try to show this, ruling out the edge effect by making a sensor with no edges. This is done by making the gate metal strip the same length as the semiconductor strip.

As stated, the metal is either $\mathrm{Pt}, \mathrm{Rh}$, or $\mathrm{Pd} / \mathrm{Ag}$. The semiconductor is gallium nitride $(\mathrm{GaN})$. Dr. Pyke stated that silicon would be less expensive, but it becomes a conductor above $200^{\circ} \mathrm{C}$, and would therefore lose sensitivity. In principle, $\mathrm{GaN}$ should be able to operate up to $600^{\circ} \mathrm{C}$, and would therefore be a good combustion gas sensor. Dr. Pyke has data at this point up to $400^{\circ} \mathrm{C}$. 
The longer term problem with GaN might be availability. Larry Sadwick, the subcontractor at the University of Utah, owns a small company, Innosys, which will start to make GaN in the next year or two. This will become a chief source for Dr. Pyke, although more material than Innosys can produce may be necessary in the longer term.

The mechanism that drives the sensor is unclear. It may be dissociation of the gas molecules into atoms, which then penetrate the metal and put a dipole on the metal/semiconductor interface. It may also have more to do with edge effects, although this is unlikely. Dr. Pyke thinks the real mechanism may be a third path, unknown as yet. This will be one of the items that he will be investigating in the next year.

\section{Tour:}

Dr. Pyke took me on a tour of his laboratory, which, as I have mentioned, is located in his house. He showed me several sensor arrays, each with four sensor gates that were built at the University of Utah. Each gate is wire-bonded to a 1/8 inch square pad. The gate region is about 200 microns $\times 10$ microns, with the metal itself about 0.1 microns thick. The gates are of one of two designs - single or dual gates - indicating the number of metal strips involved. The sensor array is placed in a quartz housing and sealed.

In this initial phase of the project, Dr. Pyke is set up to monitor four sensors simultaneously.

Data is taken via a sensor drive system where the source-drain voltage is set at 15 volts, and the drain current is set as predetermined by the University of Utah, who sends the current parameters along with the sensors. The sensor drive also reads the gate voltage. When there is "chemistry" on the gate (when it is exposed to a gas blend) the drain current drifts, and is reset by the system. This causes the gate voltage to change, but the electronics readjusts the gate voltage to what it was before. What is measured, then, is the degree of the system's adjustment needed to keep current and voltage constant.

The sensor testing system also resides in the laboratory. It includes a valve/manifold type of gas-handling system set up to handle up to five input gases and one output blend, run off of a computer program. For now, there are three bottles of blended gases that are mixed to provide the various blends. (We discuss this at length in Questions 7 and 8)

The gas blend temperature is controlled using a quartz/halogen lamp, accurate to 0.1 degree C. For each data point, the temperature is stabilized and the gas mixture is set. Data can be taken as rapidly as one second per point.

Dr. Pyke is also in the process of building an outdoor facility under an overhang of his house. He plans to move the system to this location soon. Then, in another year or two, he may need to rent commercial space. 


\section{Questions and Answers:}

I sent Dr. Pyke a set of discussion questions prior to my arrival. During our meeting, we discussed the questions and answers in detail. This is all reproduced here, with the questions indicated in bold, our discussion shown in normal type, and my comments added to many of the questions during my later analysis and assessment shown in italics.

\section{Is the sensor being designed exclusively for use in off-board PROX systems? Is} the system meant to be a pre-PEM fuel cell sensor as well?

Dr. Pyke is looking at small systems in general. With a large system, a $\$ 10 \mathrm{~K}$ gas chromatograph would probably work, and would be more cost effective. (Response time might be an issue.) He would look at systems where a standard sensor (i.e., chromatograph) would represent more than $5 \%$ of the overall system cost. Thus, even a refueling station sized reformer would not fall into his category; you could use a chromatograph. Therefore, Dr. Pyke is likely looking at residential sized systems. Within time, the Peterson Ridge sensor systems could become reliable enough to replace chromatographs even in large systems. This would likely be a long-term issue. One would hope that reliability wouldn't be the issue at all.

I am concerned that the sensor's use appears to be limited.

\section{To what degree, if at all, does the initial reformer feedstock affect the sensor results?}

Dr. Pyke is not sure yet. Right now, he's using the IdaTech feedstock (methanol). Their final product hydrogen reportedly contains about $1-4 \%$ water, less than $1 \mathrm{ppm}$ $\mathrm{CO}$, and less than $5 \mathrm{ppm} \mathrm{CO}_{2}$. This product results from steam reforming followed by a methanation step at $300-350^{\circ} \mathrm{C}$. (For those interested, the IdaTech process is discussed on their website www.idatech.com, and is also the subject of a paper by IdaTech's Dr. David Edlund - who is Dr. Pyke's contact - that is published in the Fuel Cells Bulletin \#14.) The sensor is meant to quickly reveal a process breakdown leading to increased $\mathrm{CO}$.

The use of methanol for residential applications would seem to further limit the market - but other feedstocks could be used as well.

\section{Please discuss the differences between MESFET and MODFET-based sensors, structurally, operationally, and effectiveness.}

MESFET stands for metal/semiconductor field effect transistors. There is direct contact of the metal to the semiconductor. MODFET is a variation that involves modulation doping of the semiconductor. By doping the GaN semiconductor with aluminum, you can increase the bandgap, resulting in a larger barrier to electron flow. 
You don't want electron flow between the metal and semiconductor; you want it from the source electrode to the drain electrode along the semiconductor. The MODFET sensor is less prone to leakage current, which can be a problem at high temperatures.

\section{What properties are you looking for in a Schottky barrier?}

The interface between the metal and semiconductor is the Schottky barrier. You want to minimize current leakage across the interface. Dr. Pyke is considering using a thin layer (about 250 Angstroms) of silicon nitride as a potential barrier layer, to reduce leakage. Dr. Pyke also believes that this layer might help to provide better adhesion between the metal and semiconductor layers.

In the next phase, Dr. Pyke is thinking of using an adhesion metal (perhaps tantalum or tungsten) as an "island layer" - a dusting of the surface, to help improve adhesion. Since silicon is smaller than gallium, if the contact for the island layer is silicon nitride rather than gallium nitride, adhesion may be improved.

We are building a more and more complex system, it seems.

\section{Please define "gate metal" or "gate material".}

The terms were used interchangeably in the reports. Simply stated, the gate material has to be a conductor.

6. In your FY 2001 report, you state in your experimental procedure, that oxygen, $\mathrm{CO}$, and balance gases were all $35 \%$ by volume hydrogen. Please explain. What is the balance gas composed of?

- and-

7. In Table 2 of the FY 2001 report, please explain how the gas flow rates correlate with their concentrations. They don't appear consistent.

We are handling these two questions together, because the explanation answers both of them. "Table 2" of Dr. Pyke's report is reproduced as Exhibit 1 in this document.

There are three tanks. Each of them contains nominally $35 \%$ by volume hydrogen. The tank that Dr. Pyke refers to as "oxygen" should really be called the "oxygencontaining" tank. It is $35 \% \mathrm{H}_{2}, 1 \% \mathrm{O}_{2}$, and the balance nitrogen. Correspondingly, the "CO" tank contains $34.9 \% \mathrm{H}_{2}, 2010 \mathrm{ppm} \mathrm{CO}$, and the balance nitrogen. The third tank (also called the "balance tank") contains 35\% $\mathrm{H}_{2}$ and the balance nitrogen. Thus, the balance gas is nitrogen.

Using these numbers, Exhibit 1 (Table 2) makes more sense (although some $C O$ concentrations seem slightly off). The problem here was that the report was not very clear on what the gases were. It also seems a round-about way to buy these specially mixed gases and then blend them. If you are going to be blending via a computer program anyway, why not just buy the neat gases? 
8. You state that gas exposure experiments were run at temperatures $\$ 125^{\circ} \mathrm{C}$, but then discuss results at temperatures up to $125^{\circ} \mathrm{C}$. Are these two different sets of tests? If so, what were the experiments run for the two sets?

Dr. Pyke stated that there is no appreciable sensitivity below $125^{\circ} \mathrm{C}$. The platinum sensor in particular gave a weak signal. This is somewhat confusing in that he shows data at lower temperatures, and it appears reasonable. The results for the Pt gates at 50, 100, and $150^{\circ} \mathrm{C}$ are shown in the Figures in Exhibit 2 and are discussed in Question 13. As will be seen later, there is some sensitivity. It does seem to increase with temperature, and, as Dr. Pyke states, higher temperature tests are needed. I think there is a little confusion in the report here, again.

The Rh sensor was tested up to $200^{\circ} \mathrm{C}$, at which point the system couldn't take more heat in the way it was designed at the time. The heating system is currently being redesigned. It's still a quartz-halogen lamp, but it will be a 300-600 watt bulb with a smaller filament, and will have an elliptical or parabolic reflector.

\section{At what temperature(s) do you want to operate the sensor?}

The target set by Dave Edlund at IdaTech is $300^{\circ} \mathrm{C}$. The "right answer" is wherever he gets the best sensor response time and resolution. The goal would be to heat or cool the gas to get to the optimal sensor temperature, regardless of the temperature of the reaction.

Since the IdaTech PROX processor runs at $300^{\circ} \mathrm{C}$, Dr. Pyke is designing primarily for that temperature. Peterson Ridge will be working with IdaTech extensively in the next phase. Since sensitivity is a function of temperature, however, Dr. Pyke is also considering running his system at higher temperatures (looking to find steady state conditions). He would then calibrate back to the "real" conditions.

On the positive side, if the optimal temperature is predetermined, the information that the sensor system has to process would be less complex. On the negative side, one has to take care that post-reaction temperature manipulation, especially increases in temperature, could alter the gas composition. If he achieves steady state, this may not be a problem.

10. Do you have any data comparing $\mathrm{CO}$ detection in the presence of hydrogen vs. in the absence of hydrogen - or in varying amounts of hydrogen? It appears that all your experiments were run at $35 \%$ hydrogen.

They were all run at $35 \%$ hydrogen. Variation in the hydrogen concentration is a Phase II task. 
11. You indicate in your report that the target levels for CO sensitivity is $<500 \mathrm{ppm}$. Why 500 ppm?

Dr. Pyke said that the number is "way lower" than $500 \mathrm{ppm}$. It would be about $5 \mathrm{ppm}$, and is a detection limit not a sensitivity.

Again, the report called it a sensitivity and said it was 500 ppm. It's not an upper limit; Exhibit 1 shows higher CO levels being tested. Perhaps it is a target for a sensor inserted prior to the final purification step.

\section{What gate voltage is considered sufficient sensitivity?}

Sensitivity is shown in the change of gate voltage. Dr. Pyke believes that the change should be sensitive to about $10 \mathrm{mV}$. He believes that this level will be resolvable from background noise. He thinks that he'll get there in the next phase.

\section{I would like to spend some time going over the 3-D plots in detail to identify trends.}

These figures show single- and dual-gate Pt sensors at three different temperatures: 50,100 , and $150^{\circ} \mathrm{C}$. They show gate voltage as a function of $\mathrm{CO}$ concentration and oxygen concentration. Dual-gate sensors appear to perform a little better (but not significantly better) than the single-gate sensors. More significant, says Dr. Pyke is the fact that the shapes of the single and dual sensors are very similar, showing reproducibility. What is needed is additional data at higher temperatures.

Reproducibility is certainly encouraging, although if this is the purpose of the test, it would be just as significant to show that you got the same shape if you ran the same conditions with one sensor in three or four separate tests. It would seem that the information you receive with one sensor (say the dual-gate since it seems a little better) would be adequate, and you don't need both single and dual in an array.

We will show the interpretation of these figures through an example. Looking at the dual gate sensor for $50^{\circ} \mathrm{C}$ : At $1014 \mathrm{ppm} \mathrm{CO}$ (the maximum value on the $\mathrm{CO}$ axis), if we increase oxygen concentration from 0 to $833 \mathrm{ppm}$, the gate voltage increases from about 1.97 to about 2.02 volts. Between 833 and 5000 ppm oxygen, there is no change in voltage (i.e., the sensor is insensitive).

While the 3-D plots are very good for showing reproducibility between the single and dual gate sensors, a series of 2-D plots (say, gate voltage vs. oxygen concentration at constant $\mathrm{CO}$ concentration, and a series of lines for different $\mathrm{CO}$ concentrations) would be easier to follow.

Dr. Pyke also mentioned that the other sensor types ( $\mathrm{Rh}$ and $\mathrm{Pd} / \mathrm{Ag}$ ) would each have a different sensitivity pattern. So you would use the sensors in conjunction with one another. 


\section{Are there any plans at this time to "field test" the sensor, that is, test it in a PROX environment?}

The first test will be at IdaTech. Peterson Ridge also has verbal agreements with Plug Power and with Epyx.

\section{Since this system detects hydrogen as well, has there been any thought to trying to adapt it as a hydrogen leak detector?}

Dr. Pyke thought that his array could be used for hydrogen sensing quite easily. He envisioned using silicon instead of $\mathrm{GaN}$ as the semiconductor layer. Since you would be trying to detect hydrogen at room temperature, silicon would work (recall that silicon becomes a conductor only above $200^{\circ} \mathrm{C}$ ) and would be a lot cheaper to make.

\section{Additional Items:}

Dr. Pyke states that some of the problems with sensors to date may have been due to the fact that they are all being made by students (U Utah), and the lower skill level may be the source of reproducibility problems. Since the overall sensors are such complex items, and the need for accurate calibration is so critical, I would suggest that at least some of the sensors be made by more skilled hands to see if there is indeed a student-induced reproducibility problem. On the other hand, the data in Exhibit 2 seems to indicate quite good reproducibility.

Proper adhesion is one of the major difficulties in producing the sensors. Typically, the metal is sputtered onto the semiconductor. You need to get enough mixing for adhesion, but not so much as to change the properties of the sensor itself. The aforementioned "island layer" of tungsten or tantalum, planned for the next phase is expected to improve adhesion.

Currently, testing for adhesion is done by a "scotch tape" test. Tape is placed over the metal and pulled off. If the metal stays bonded to the semiconductor, the adhesion is acceptable. They'll get more sophisticated later.

\section{Final Thoughts:}

If we are going to make hydrogen from any carbonaceous resources and then run it through a PEM fuel cell, we either have to make the PEM sufficiently robust to handle $C O$, or we need to reduce the CO sufficiently that it does not harm the PEM. The current thinking is 10 ppm or less. That number will likely rise with technology improvements, but whatever it is, a sensor to protect the PEM from unexpected CO surges (e.g., a PROX reactor failing or something similar) is a necessary system component.

The sensor system that Dr. Pyke is developing to address this problem appears to be very complex, relying on proper responses for several different sensors. This is not to say that 
the system won't work. Proving its ability to produce rapid, accurate readings on $\mathrm{CO}$ concentration, however, will be very difficult. The few completed tests show a degree of reproducibility for one kind of sensor at a limited number of conditions. To be successful, however, all of the different types of sensors $(P t, R u, P d / A g)$ will have to be proven out for $C O$ sensitivity at a much wider range of temperatures, including some critical ones in the $200-350^{\circ} \mathrm{C}$ range, and at a wide range of hydrogen and oxygen concentrations. (This doesn't even begin to address the several other gases, especially sulfur-containing gases, that could be present in the sensor feed.) Deterioration of the sensors over time will be another issue.

A defined, clear plan to address these needs must be prepared Reporting on this project to date has been unclear as to what the actual tests have been, why they were run, and what the results were. This needs to change.

Finally, we need to look closer at the potential applications for this sensor, and determine under what conditions it would be useful. A gas chromatograph would likely be of at least equal worth (if not superior), if affordable. Any application from the size of a refueling station and up would likely choose a chromatograph. On board reforming might be an option for this sensor, but this is not of interest to the DOE Hydrogen Program. This leaves primarily residential scale systems or small industry. Niche markets, like the one occupied by Peterson Ridge's partner, IdaTech, may be developed as well.

Thus, this product presents technical complexities and market limitations that may harm its chances of success. 
Exhibit 1. Table of Gas Experiments from Peterson Ridge/Fluence Hydrogen Annual Peer Review FY 2001 Report

Table 2: Order of experiments.

\begin{tabular}{rrrrrr}
\hline Total Flow (SCCM) & $\mathrm{O}_{2}$ (SCCM) $\mathrm{CO}$ (SCCM) & Balance (SCCM) & {$\left[\mathrm{O}_{2}\right]$ ppm } & [CO]ppm p \\
\hline 600 & 300 & 15 & 285 & 5000 & 51 \\
600 & 300 & 300 & 0 & 5000 & 1015 \\
600 & 300 & 150 & 150 & 5000 & 507 \\
600 & 50 & 150 & 400 & 833 & 507 \\
600 & 50 & 300 & 250 & 833 & 1015 \\
600 & 50 & 15 & 535 & 833 & 51 \\
600 & 0 & 300 & 300 & 0 & 1015 \\
600 & 0 & 150 & 450 & 0 & 507 \\
600 & 0 & 15 & 585 & 0 & 51 \\
\hline
\end{tabular}

The flow rates of gases in Table 2 are in standard cubic centimeters per second. 
Exhibit 2. 3-D Sensitivity Plots Showing Gate Voltage as A Function of CO and Oxygen Concentrations for Platinum Based Sensors (Figures 12-14 of the Peterson Ridge/Fluence Hydrogen Annual Peer Review FY 2001 Report)

$V_{g} 4 \approx 50 C$

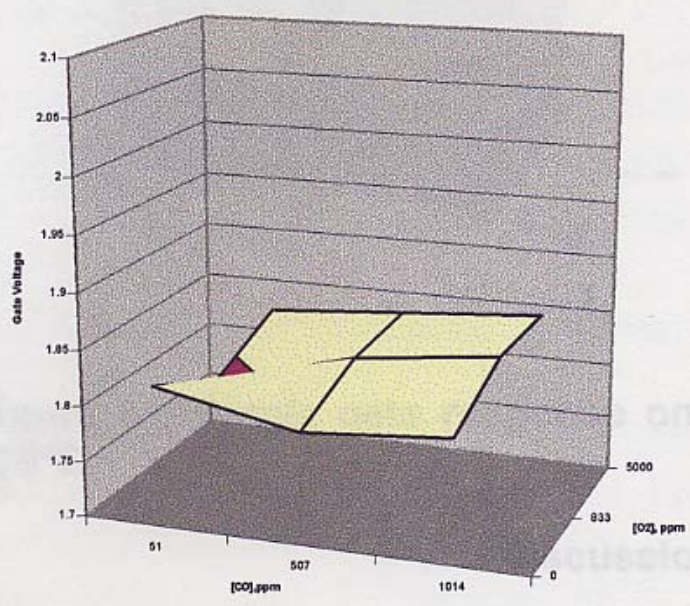

Figure 12: Single gate response on left. Dual gate response right. Both at $50 \cdot C$.
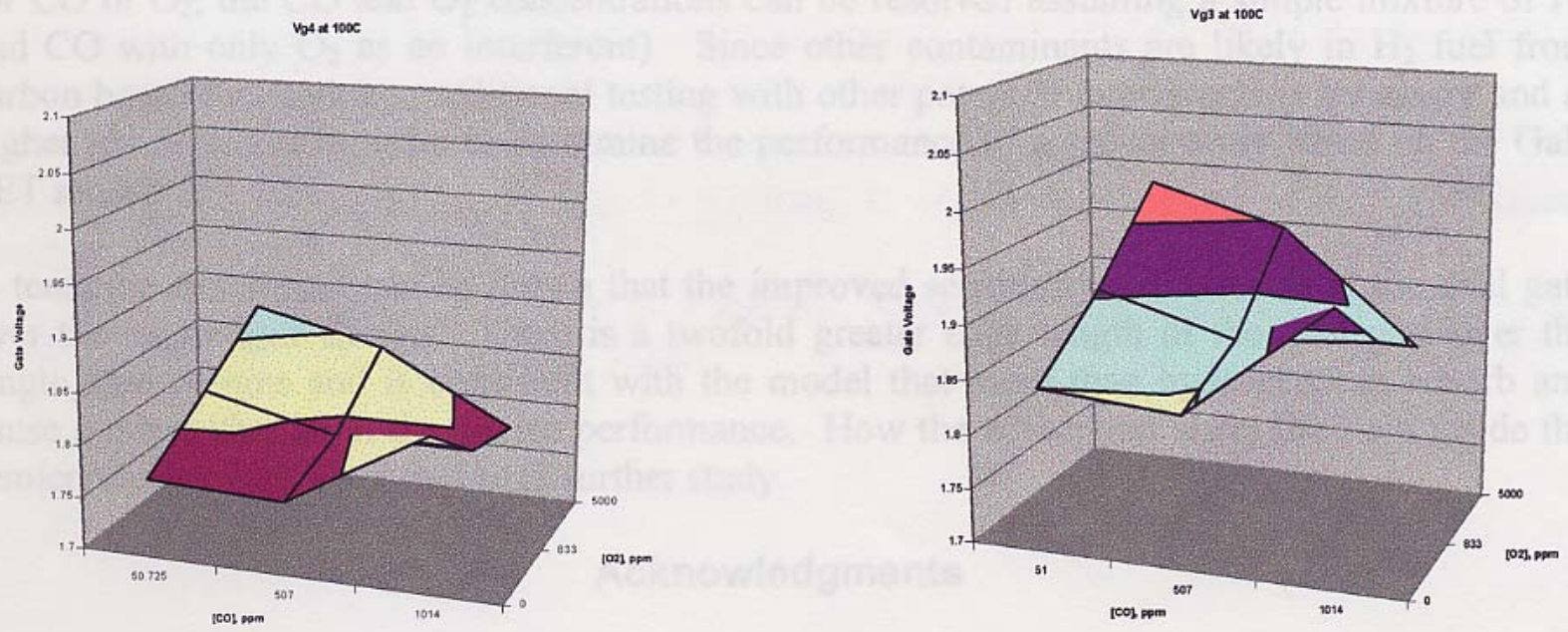

Figure 13: Single gate response on left. Dual gate response right. Both at $100^{\circ} \mathrm{C}$. 


\section{Exhibit 2 Continued}
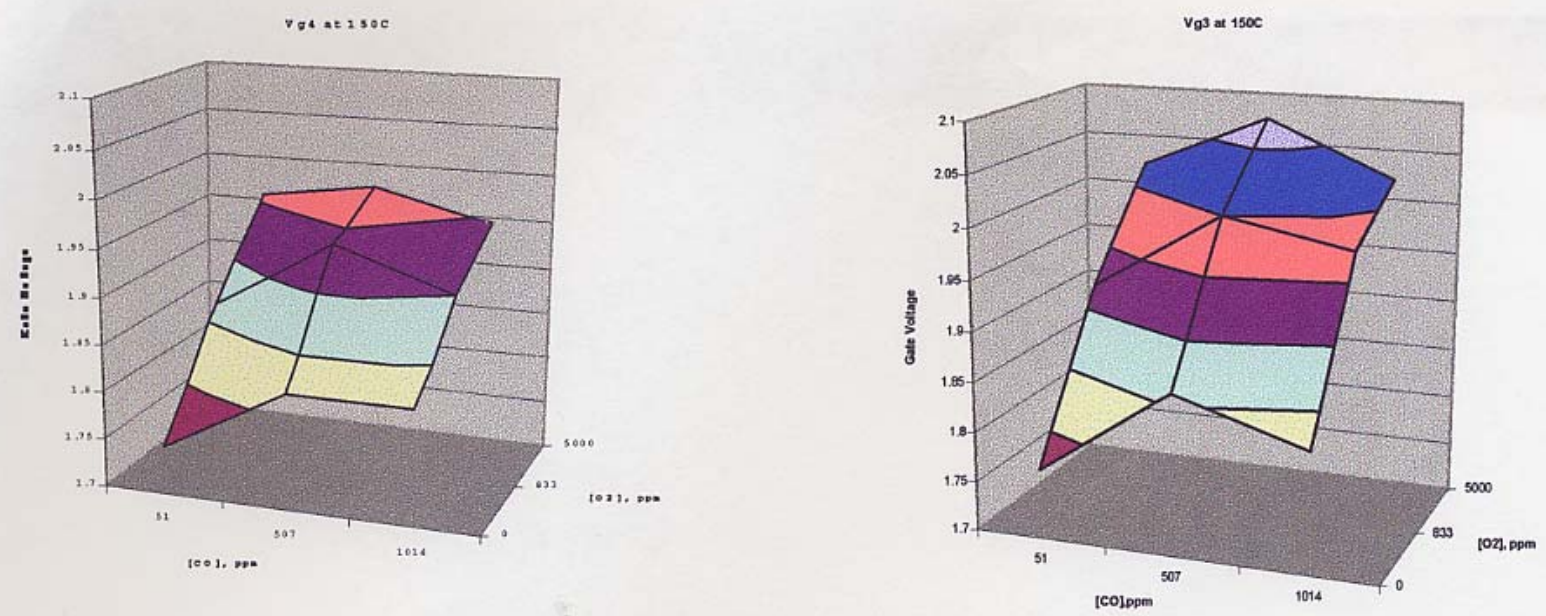

Figure 14: Single gate response on left. Dual gate response on right. Both at $150^{\circ} \mathrm{C}$ 
Technical Evaluation Report

Project: Supercritical Water Partial Oxidation

Company: General Atomics

P.I.: Niles Johanson

Site-Visit Date: November 7, 2001

Evaluation by: Edward G. Skolnik, Energetics, Inc.

\section{Summary:}

General Atomics (GA) of San Diego, CA is investigating the use of supercritical water partial oxidation (SWPO) as a means of producing hydrogen from waste biomass, and/or coal feedstocks. The project is somewhat similar to a project that was previously funded by the DOE Hydrogen Program at the University of Hawaii (UH) under Dr. Michael Antal. The major technical difference between the two projects is that the UH project used supercritically heated water to drive a biomass steam reforming reaction, while the GA process includes an oxygen injection step to increase the reaction temperature and thereby increase their hydrogen yield. In addition, GA includes municipal solid waste (MSW) and sewage sludge among their potential feedstocks, while UH claimed that their own process was not efficient with non-cellulose-based materials.

The GA process is only about one year old, but GA was able to bypass much of the bench-scale development process, and went directly to a small pilot plant scale. This was made possible by GA's expertise with SWPO as a demilitarization process.

Demilitarization is a process by which substances, toxic and otherwise, formerly being used in military applications, can be rendered harmless. Early on, however, GA found that low feed flow rates would be necessary to provide sufficient residence time in the reactor to maximize hydrogen production. These low flow rates coupled with the small reactor size led to clogging within the narrow portions of the reactor. GA therefore initiated a scale-up to a larger, wider aperture system. This action has caused delays in the DOE project, with data acquisition being held-up as portions of the larger pilot plant gets built and tested.

At this time, much of the larger pilot plant has been built. The only smaller component remaining is the down-flow reactor, one of two options for the site of the main reaction following the injection of oxygen.

I see the following strengths in the project:

- The expertise that GA gained by using SWPO as a demilitarization tool has allowed them to skip a lot of the bench-scale work that would otherwise have been necessary.

- The potential for using MSW and sewage sludge as feedstocks presents an opportunity for producing hydrogen from materials that have a negative cost associated with them, while at the same time, reducing the need for landfill. 
- GA appears to have successfully developed a methodology for producing slurries of these waste products so that they can be easily fed into the SWPO system.

I see the following weaknesses:

- The hydrogen content of sewage sludge and of compost is only about two percent by weight. Despite the fact that additional hydrogen will be obtained from the steam (via the reforming and shift reactions), the total available hydrogen is lower than what would be obtained from cellulose-based biomass (which is about $5 \%$ hydrogen by weight) subjected to the same process.

- The cost of hydrogen from this process may be increased due to low hydrogen output combined with potentially high feedstock transportation costs (on a unit hydrogen basis.)

- Better planning might have foreseen the residence time problem with the small reactor, and allowed GA to design around it.

\section{Introduction and Background:}

I visited General Atomics to see their SWPO project and to discuss it with the project manager, Niles Johanson. Also present at the meeting was Bill Rickman, who wrote the original proposal, had previously been the project manager, and who still devotes a portion of his time to the project. I also met briefly with Bill Davison, who is the group director for Advanced Process Systems. I was able to see the reactor system, as well as several feedstocks in both their raw and processed forms. We held an in-depth discussion of the process, and spent several hours on a series of questions that I sent to Mr. Johanson prior to our meeting.

At the outset of the meeting, Mr. Johanson pointed out that the up-grading of the reaction system, making it larger so that adequate reaction time can be realized without the system clogging due to slow flow, delays the project, but is not being paid for by DOE funds. GA is funding the pilot plant scale-up themselves. When I met later with Mr. Davison, he made a point of reiterating that GA was using their own funds for the change.

\section{Status:}

GA showed me a schedule for their work from April 2001 through essentially, the day before the site visit. It showed what problems had arisen and what the remedies were. Most of the problems appeared to be due to attempts to get an adequate reaction temperature (about $650^{\circ} \mathrm{C}$ ). The aforementioned flow rate reduction was based on an attempt to increase temperature and improve the reaction kinetics by allowing more time in the preheater. Much of the subsequent problems were due to clogs. So they reconfigured the plant so that they could use the preheater and tube reactor. They are gradually getting up and running again. 
At the time of the site visit, GA was running the reactor in a pre-heat mode. A $20 \%$ solids compost slurry is preheated, and run into a tube reactor. No oxygen is injected in this configuration. (See the tour discussion below.) The flow rate is about $1 \mathrm{~kg}$ per hour. Eventually, GA will use a scaled up down-flow reactor in place of the tube reactor, and they will inject oxygen.

\section{Tour:}

Mssrs. Johanson and Rickman gave me a detailed tour of the SWPO reactor facility. For part of the time, we were joined by Mr. Howard Cunningham, a Senior Staff Technician, who provided some of the tour information.

For clarity, I am attaching, as Exhibit 1, a copy of a rough schematic of the SWPO process that was included in GA's FY 2001 Annual Review Report.

The slurried feed (often with a paste-like quality) is mixed with water and fed toward the preheater by a positive cavity pump, which in turn, pushes a syringe pump. A tube-andshell heat-exchanger heats the feedstock.

A $500 \mathrm{~kW}$ ohmic heater preheats the steam to $600^{\circ} \mathrm{C}$.

A skid holds three $4000 \mathrm{lb}$ pumps for pumping water: one for the steam generator (ohmic heater), one for the reactor water and one for reactor quench (cooling water). In the same area, is a diaphragm pump for liquid fuel feed (ethanol, kerosene), and a high pressure system for injecting oxygen. They use bottled oxygen and boost it to $5000 \mathrm{psi}$.

Following the preheat mode, the feedstock is mixed with the $600^{\circ} \mathrm{C}$ steam (or steam/injected oxygen mixture at $650^{\circ} \mathrm{C}$ ) and fed into one of two reactors. One is a tube reactor, in which heat is transferred to the reactor via heating tubes. The other is a downflow reactor, with a mixing zone at the top. While the majority of the present system has been scaled up to about $1 \mathrm{~kg} /$ minute feedstock, the present down-flow reactor is only about $1 / 3$ that size.

Upon exiting the reactor, the products are cooled (reaction quenched) via another heat exchanger.

Gas analysis is performed on $\mathrm{CO}_{2}$ (infrared detection), $\mathrm{CO}$ (infrared detection), methane (flame ionization), hydrogen (thermal conductivity) and oxygen (paramagnetic detection).

In the same area, GA also has a full scale oxidation reactor that is used for military applications. It runs on several different fuels, and can be used to oxidize nerve gases. Basically everything that is fed into this reactor turns into water, $\mathrm{CO}_{2}$, metal oxides and halogen salts. GA considers this a mature system, and they think that the hydrogen system will grow like this one. 
Finally, I saw some feedstock material. Raw and slurried compost proved to be the most interesting and encouraging. The slurried material, at about $20 \%$ solids, appeared very fluid.

\section{Questions and Answers:}

I sent Mr. Johanson a set of discussion questions prior to my arrival. Mr. Johanson provided written responses to the questions; during our meeting, we discussed the questions and answers in detail. This is all reproduced here, with the questions indicated in bold, written answers reproduced verbatim in quotes, our discussion shown in normal type, and my comments added to many of the questions during my later analysis and assessment shown in italics.

1. How does your supercritical water/hydrogen production process differ from the one that Dr. Antal was pursuing at the University of Hawaii? One item of particular interest: Dr. Antal had reported that the supercritical water process did not work well with non-cellulose feedstocks such as sewage sludge. You report success with sewage sludge. Is the difference due to the mechanism of steam reforming vs. partial oxidation or is there another reason?

"At this stage of development there is no fundamental difference between Antal's process and the GA process. GA's results with sewage sludge were within the range of results reported by Antal, and we consider them partially successful in that a significant hydrogen conversion (28\%) was achieved. A fairly wide range of results was found by Antal $(6$ to $52 \%$ hydrogen conversion to $\mathrm{H}_{2}$ ), leading to the conclusion that sewage sludge was a problematic feedstock for hydrogen production. Given the very limited data obtained thus far, it is premature to say that SCWG does not work well for sewage sludge.

"The report "Technical Review of the General Atomics Sewage Sludge Gasification Pilot Plant Tests" by Combustion Systems, Inc. (1999) provides a good discussion of the comparison between the GA and University of Hawaii tests with sewage sludge."

Note that the numbers in this response are in volumetric (or mole percentage) units, not mass.

The main difference between the two projects is the oxygen addition in the GA process. Mr. Johanson indicated that the key contribution of the oxygen is to raise the reaction temperature.

As to what is successful, it is a matter of opinion. The GA team considers the sewage sludge numbers, including Antal's numbers, acceptable. They do admittedly achieve a much higher hydrogen yield with cellulose-based biomass (50 mole percent vs. 25).

Combustion Systems, Inc. (Bob Divilio) did a comparison of the GA and UH results on cornstarch. A summary of this is shown in Exhibit 2. 


\section{Your FY 2001 report, which would have been written, I assume, in the April}

2001 timeframe coinciding with the Peer review, deals primarily with a test plan. What results have been achieved since that time? Any information on the amount of hydrogen produced as a function of theoretical hydrogen would be of value.

"During the pre-Test Series systemization runs, before we had completed the installation and checkout of the high-pressure oxygen system, we operated the system with ethanol feed. Using external heating without partial $\mathrm{O} 2$ we produced approximately $40 \mathrm{vol} \% \mathrm{H} 2$ in the effluent gas stream. This substantially exceeded $100 \%$ yield compared to the input hydrogen stream.

I"n June we ran cornstarch in Test Series 1 with partial oxygen. The results of this Test Series [summarized in a separate handout] showed a product gas with a high concentration of hydrogen gas, averaging 49.6 vol\%. Calculated hydrogen yields ranged from 92.4 to $125.6 \%$.

"An attempted run with compost feedstock in August was unable to achieve required reactor temperature. This run was punctuated with repeated short term feed plugs in the feed line from the syringe pump. However during periods of stable flow it was apparent that the partial oxygen addition was not providing the necessary temperature boost to nominal $650 \mathrm{C}$ reactor temperature.

"Subsequently discussions with a consultant, Mike Modell, provided a new perspective into what constitutes "rapid heating." We understand that rapidity of heating to minimize char formation can be accomplished in a timeframe of minutes as opposed to a time frame of a few seconds or less. This time frame allows the use of external preheat in conjunction with partial oxygen addition to achieve the desired $650 \mathrm{C}$ reactor temperature.

"We have reconfigured the pilot plant to preheat a compost feedstock with $20 \%$ solids and have run had two short runs without oxygen (1.5 hrs and $\sim 1 \mathrm{hr}$ ) in October during which we saw product gas compositions with $\sim 26 \% \mathrm{H} 2$ and $44 \% \mathrm{CH} 4$. After we establish reliable operation we will add partial oxygen and look for an optimum balance of preheat and O2."

The high hydrogen yields are, of course, due to a substantial amount of water shift also taking place in the reactor.

Exhibit 3 shows the individual cornstarch runs, and is, in fact, the source of the SWPO results shown in the comparison with Dr. Antal's work in Exhibit 2.

\section{With supercritical water present, doesn't the standard steam reforming reaction} play a part in the reaction mechanism? Using the configuration you show in Figure 3 of your report, do you have any data for the effect of adding oxygen to (or removing oxygen from) the steam feed?

"Equilibrium calculations using a thermodynamic program (STANJAN) indicate that hydrogen yields of about $80 \%$ should be readily achievable at proposed SWPO conditions. Experimental data with a wide variety of biomass feeds (Antal and Xu, 1998) indicates even higher hydrogen yields (139-199\% of feed hydrogen content), thus supporting the premise that significant steam reforming and/or water shift reactions are taking place in the SWPO system, according to the equilibrium reaction of carbon monoxide and methane with water as follows: 


$$
\begin{aligned}
& \mathrm{CO}+\mathrm{H}_{2} \mathrm{O}=\mathrm{CO}_{2}+\mathrm{H}_{2} \\
& \mathrm{CH} 4+2 \mathrm{H}_{2} \mathrm{O}=\mathrm{CO}_{2}+4 \mathrm{H}_{2}
\end{aligned}
$$

"With a sufficiently high hydrogen yield in the SWPO system, requirements for additional reforming and shifting downstream of the SWPO system may be reduced or eliminated, further improving process economics.

"GA has preliminary data for the effect of adding oxygen to (or removing oxygen from) the steam feed for cornstarch feedstock, Test Series 1."

The injected oxygen is primarily used to raise the temperature of the reactants.

No catalyst is used in the system, although char, compost, coal and/or metal surfaces may serve as catalysts for the reaction.

GA needs to examine closely what their best combination of reforming, shifting, and partial oxidation is. There is not a lot of hydrogen in some of their feedstocks, and the ability to get hydrogen out of the steam will be important.

GA, like many others who work with biomass, report hydrogen yield on a percent of feedstock hydrogen content. Since a relatively large portion of the hydrogen comes from the steam, the yield percentage is often in excess of 100\%. But for comparison purposes, since different feedstocks have different hydrogen content, the number can be very misleading. If a kilogram of sewage sludge that has 2\% hydrogen produces 30 grams of hydrogen, it would be reported as a $150 \%$ yield. If a kilogram of a cellulose-based material that has 5\% hydrogen produces 60 grams of hydrogen, it would be reported as a $120 \%$ yield, even though the actual amount of hydrogen produced is more than with the sludge. Perhaps the number should be based on total hydrogen in all reactants including reaction water. Then one could compare apples to apples. This would also remove the false perception of high yields that the present way of reporting allows. (E.g., a methane steam reformer whose hydrogen yield is 100\% based on the feedstock, is a pretty poor reformer.) This is not a knock specifically on GA; this is the way the industry reports these numbers. While it's fine for partial oxidation or gasification, it breaks down on reactions with water present.

\section{Your FY 2001 report speaks of trying to use "heavy slurries" as feedstocks, yet Table 2 in your report indicates you will use (used?) a bituminous coal slurry of only 8-13.1\% solids. Is this to keep the solids concentration in line with other feedstocks? What is the hydrogen content of the coal being used?}

"GA has proposed a SWPO system that will achieve high hydrogen yields from negative value feeds such as sewage sludge and MSW. GA is exploring the use coal as a high energy density additive to boost the heating value of the resultant mixture without seriously compromising its pumpability. The hydrogen content of the Pittsburgh bituminous coal is $5.3 \%$ (dry basis).

"Solids are mixed with water up to a feed concentration of $40 \%$ by weight. This mixture is then pumped up to reactor pressure and mixed with hot water, which is at reactor pressure and 1,112 ${ }^{\circ} \mathrm{F}$, in a mixing tee. Mixing the hot water with feed in a 2:1 water to feed ratio, will result in a 
reactor feed that has a solids concentration of approximately $13 \%$ at a temperature over $780{ }^{\circ} \mathrm{F}$, which is well above the temperature where char forms.

"During the pilot plant coal test (Series 4), coal will be fed in a $40 \mathrm{wt} \%$ slurry (paste) along with hot water to yield a net coal concentration of 8-13.1 $\mathrm{wt} \%$ in the SWPO reaction zone, the same solids concentration as with other feedstocks. Coal is being fed by itself in this test to provide independent data on its gasification parameters and gas composition. Test Series 6 will include coal at ratios of $25-50 \%$ of the total (compost + coal) solids."

They are indeed trying to keep solids content at about the same level. Also, they are trying to make sure that the have enough water present to accommodate the water-shift reaction.

They have made $40 \%$ coal slurries, and found that it was difficult to keep it flowing. Note that GA refers to it as a" paste" in their written answer. They certainly don't use particle size tailoring or add surfactants to their slurries. Add to this that water will be lost during the reaction, and they need to keep flowing.

Having higher loadings is probably not critical to them at this point. But should their process change and they need to concentrate their feedstock, they would likely have to consider coal particle-size distribution and/or surfactants.

\section{What method ensures that the slurry feeds are relatively uniform?}

"Both the cornstarch and the powdered bituminous coal are uniform, homogeneous powdered solids. Both of these materials are mixed with water and thoroughly blended into a paste-like slurry with about $40 \mathrm{wt} \%$ solids content. A small amount of suspending agent ( 0.5\% Xantham gum) is added to prevent settlement or stratification of the solids. Should be Xanthan gum

"The raw compost feedstock would be expected to exhibit considerable variation and more care must be taken insure a uniform feed. However, we have found that the analysis of grab samples taken from various locations in as-received bulk material in the shipping drums [separate handout with analysis] actually exhibits surprising uniformity of elemental analysis and heating value stated on a dry basis. This material is ground down to a very fine size with a Gorator pump and blended into a slurry with a pudding-like consistency. The resulting feed paste is resistant to stratification or settling; no Xantham gum is added."

\section{I am somewhat confused as to what you are referring to as a "pilot-scale" reactor. You mention delaying testing until General Atomics finishes the construction of the pilot plant, but then you speak of designing and building a pilot plant in Phase II. I think you're talking about two different pilot plants, but I'm not sure. Please explain.}

"In Phase I we are using GA's pilot "test" facility in lieu of the bench-scale equipment proposed originally. The start of the project was delayed to take advantage of the availability of this new pilot test facility located in Bldg. 37.

"This pilot test facility incorporates a small down-flow reactor that is undersized relative to the flow capacity of the remainder of the facility. 
"In the discussion of Phase II, we are referring to the design and construction of a new, largerscale reactor, optimized for the SWPO role, that would be incorporated into the existing pilot test facility. Thus it would be more accurate to refer to one pilot plant with either the existing Phase I reactor or a new larger scale Phase II reactor."

The current down-flow reactor has a throughput of about $0.3 \mathrm{~kg} / \mathrm{minute}$; the Phase II down-flow reactor will have a throughput of about $1 \mathrm{~kg} /$ minute. Even the present reactor is about 20 times larger than what GA refers to as their "original reactor.

This all is a result of the clogging problems they had when they tried to slow down the flow rate in their smaller reactor.

\section{Do you have any elemental analyses on your feedstocks?}

"Yes we do. We have obtained elemental analyses for two feedstocks: raw compost and coal. These analyses are provided in Attachment 1."

There is concern with the low hydrogen content of compost. GA is hoping that they'll be able to get a lot of hydrogen out of water along the way - otherwise they may have to look at other feedstocks.

On the other hand, says Mr. Johanson, compost is an abundant material, and people are trying to get rid of it. He thinks an overall comparison with other biomass is in order.

Exhibits 4 and 5, provided by GA, and referred to as attachment 1 in this question, show typical analyses for the compost and the coal that $G A$ is currently using.

Mr. Johanson shares our concern over the low hydrogen content of compost as well as sewage sludge. An analysis is needed to determine if and in what markets the fact that there is a negative cost associated with these materials overcomes the low potential hydrogen yield. We also cannot forget that the material itself may have a negative cost associated with it, but shipping it may be costly - especially if you are shipping water. (Note that the compost is over $42 \%$ water.)

The coal appears to have the typical 5\% hydrogen, and (although the volatile matter test was apparently not done) appears to be a reasonably high rank.

\section{The FY 2001 report indicates that the SWPO process will include an investigation of the follow-on processes such as separation/purification. What is being considered? Will $\mathrm{CO}_{2}$ sequestration be part of the package?}

"With reference to GA's SWPO proposal dated December 15, 1999, Phases I and II focus on the core process of the SWPO reactor and optimizing hydrogen yields.

"Separation/ purification of product gases will be studied in detail during Phase III, for implementation in Phase IV. As mentioned in the proposal, technologies under consideration for reactor effluent cleanup include cyclones, ceramic filters, conventional separators (gravity) and 
reverse osmosis. Technologies under consideration for hydrogen separation include gas scrubbing systems, polymeric membranes, and pressure swing adsorption.

" $\mathrm{CO}_{2}$ sequestration is a potential longer-term improvement but is not part of the Phase III or IV objectives."

GA has not yet looked at purification, but they believe that they will use "standard" methods. In a system, they would likely team with someone for the purification aspect. They believe that purification technology will be there when it is needed.

Mr. Johanson also pointed out that the GA product is self-scrubbed. That is, there are no tars, no particulates, and the gas is bone dry when depressurized. They have a clean, noncondensable gas stream.

Mr. Rickman indicated that GA is "sequestration ready;" their output is already highpressure.

\section{How generic is the SWPO process? That is, are there many modifications based on feedstock, and if so, what are these modifications?}

"GA expects that the SWPO process will be strongly generic exhibiting a tolerance for a wide range of feedstocks. Of course, that's one of the parameters that GA wants to explore but it is yet to be defined."

GA will be looking at several different types of biomass. Getting the feedstock into a condition where it can be easily fed will be a "big concern."

\section{Please discuss a methodology for the commercial use of your system. How do you see it being used?}

"GA is targeting negative value, renewable, and/or low cost feedstocks such as sewage sludge, municipal solid waste, biomass, and coal. Our focus initially is on simple systems for hydrogen production that can be used for transportation fuel cells for example. The next step would be small fixed power plants using fuel cells and/or gas turbines operating on the SWPO product gas. Ultimately we intend to develop integrated power cycles that take advantage of both SCWG and SCWO. Such plants would incorporate fuel cells, gas turbines, and steam turbines."

They are targeting both hydrogen and syngas systems, and are considering both vehicular and distributed energy markets. Right now, they are using whatever waste feedstock that they can get. For example, they are currently looking at some pre-sorted MSW.

From the aspect of moving toward a hydrogen economy, we need to be aware of the possibility that the syngas system "wins out". Remember, that many of the feedstocks are not particularly rich in hydrogen. This could make a syngas path more appealing than a hydrogen path. It's not necessarily in the best interests of hydrogen, although it could result in a more lucrative product for $G A$. 


\section{Additional Items:}

GA has not yet determined which system (tube reactor or down-flow reactor) will be used in the final configuration. The down-flow reactor is more compact and also more corrosion resistant. It's easier to increase the residence time in the tube reactor, however. It is not entirely clear to me whether GA considers the tube reactor as a viable alternative to the down-flow reactor, or if it is just an interim process. I heard a little of both during my visit. I think they prefer the down-flow reactor, but want to keep their options open if the larger (1 kg/min) down-flow reactor does not perform adequately once it is on line.

The GA goal with using coal is not to make it a primary feedstock, but is only to boost the hydrogen output when needed.

Of course, coal itself is generically only about 5\% by weight hydrogen on a dry basis. (As an aside: in talking to a colleague, I briefly summarized the GA project. He said:

"They're adding coal to increase the hydrogen yield?") Having coal in the mix is not a bad thing. We need to include coal in the portfolio of hydrogen technologies. In this instance, however, it just reemphasizes the small hydrogen content of the waste material. In addition, bituminous coal won't be a particularly cheap feedstock, especially if it has to be transported over a long distance.

\section{Final Thoughts}

The value of this project comes from the negative value of its feedstock. If a clean, lowcost supply of hydrogen can be obtained from waste material, it's a valuable contribution to distributed energy resources in several markets.

One must step back, however, and look at the potential. If you start with a feedstock that's only 1-2\% hydrogen, even if you get (through reforming and shifting) a 150\% hydrogen yield, that's only $1.5-3 \%$ hydrogen based on the weight of the feedstock. Second, the waste may be free or maybe someone will even pay you to take it, but you'll still have to pay to transport it. If it's wet (the sample compost analysis shown in Exhibit 4 indicates it's $42 \%$ water), you'll be paying to transport water.

If it costs, say, $\$ 10$ per ton to transport the waste, and dry waste results in $3 \%$ hydrogen, then it will cost over $\$ 5.50$ per million Btu of hydrogen just to transport the material.

$\{[\$ 10 /$ Ton raw waste] $x$ [100 Ton raw/58 Ton dry waste] $x$ [1 ton dry waste/60 lb H2] $x$

[1 lb H2/.0516 MMBtu (LGV for H2)]\} = \$5.57/ MMBtu. This is just for transportation alone, and could negate the benefit of a negative cost feedstock.

This would indicate that you would likely want to limit yourself to distributed, localized feedstock resources and, on-site or "over the fence" usage. 
Next, let's compare the process to Dr. Antal's: It's basically the same if you consider (as $G A$ does) the oxygen as being there for temperature boost. Dr. Antal actually ran hotter (700-800 $\mathrm{C}$ ) and used a catalyst (carbon). Results are basically the same for the two processes, if you look at Exhibit 2, for cornstarch, as being typical.

Dr. Antal rejected non-cellulose based waste, while GA embraces it, but simply argues that relatively speaking, the low hydrogen yield is sufficiently good considering the cost of the feedstock.

Dr. Antal's project migrated from a hydrogen-based focus to a syngas-based focus, eliminating much of the purification problems. With the low hydrogen yield, I would think it possible that the GA project could also move in that direction. (This is just my opinion, not a fact.) While extracting energy from waste matter is an attractive prospect, it of itself does not necessarily fit into a hydrogen economy.

Finally, I will make a comment about the mid-stream scale-up to allow for a longer residence time. The need for the scale-up, the results obtained to date for the partially renovated system, and the fact that GA is making the improvements on their own funding, all seem reasonable to me, although perhaps the residence time issue might have been anticipated. 


\section{Exhibit 1. Simplified Process Flow Diagram of GA's SWPO Pilot Plant}

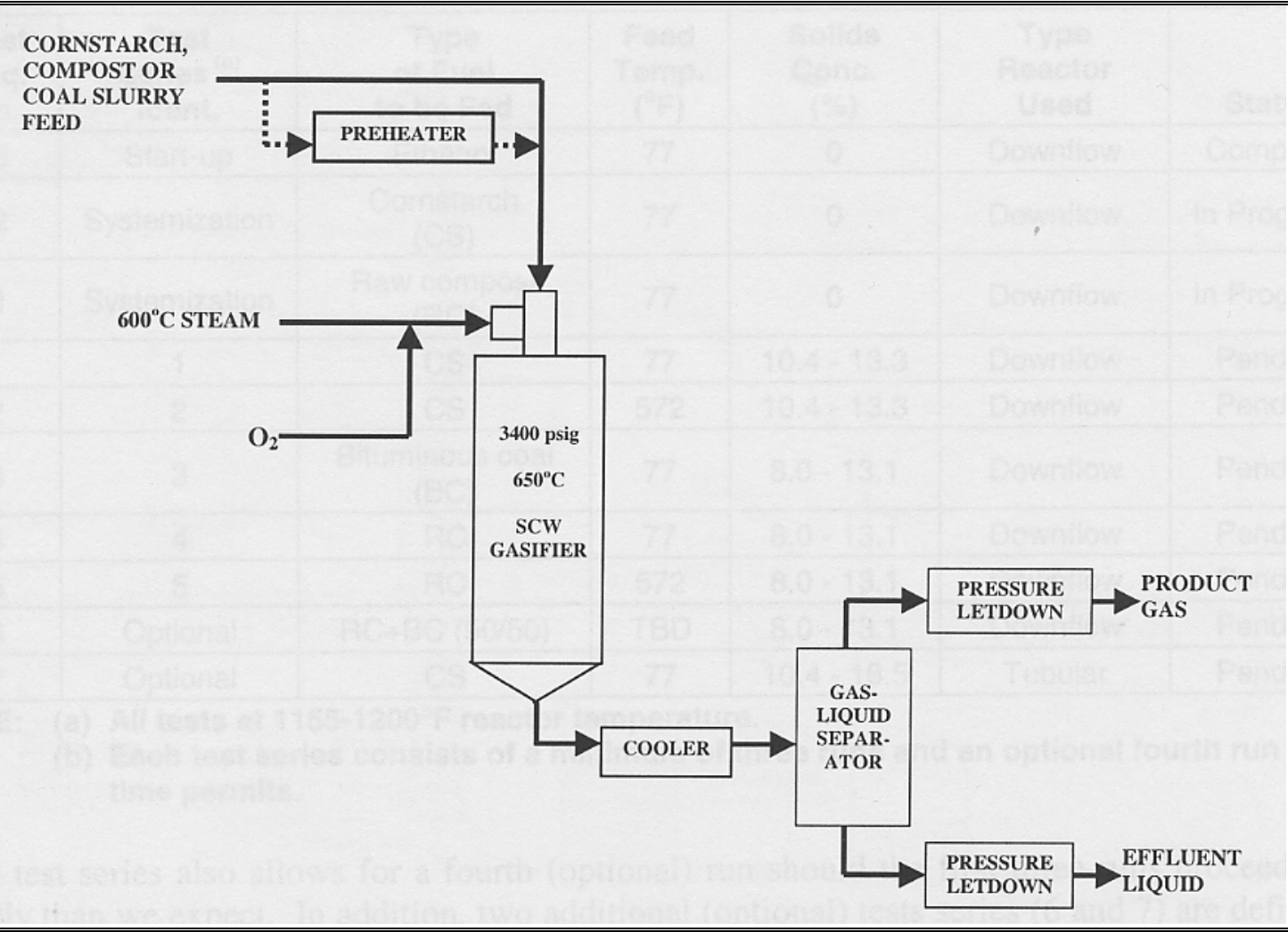


Exhibit 2. Comparison of UH and GA Processes on Cornstarch Feedstock. (Provided by GA from Analysis by Divilio)

\begin{tabular}{|c|c|c|c|c|}
\hline Product, Mole Fraction & \multicolumn{3}{|c|}{$\begin{array}{c}\text { Antal }{ }^{1} \text { SCW Pyrolysis Data with } \\
10.4 \% \text { Corn Starch }\end{array}$} & \multirow{2}{*}{$\begin{array}{c}\begin{array}{c}\text { SWPO } \\
\text { Test } \\
\text { Results }\end{array} \\
0.50\end{array}$} \\
\hline $\mathrm{H} 2$ & 0.48 & 0.48 & 0.47 & \\
\hline $\mathrm{CO}$ & 0.02 & 0.02 & 0.02 & 0.12 \\
\hline $\mathrm{CO} 2$ & 0.36 & 0.36 & 0.37 & 0.17 \\
\hline $\mathrm{CH} 4$ & 0.14 & 0.14 & 0.14 & 0.22 \\
\hline g Gas/g Organics & 1.29 & 1.33 & 1.34 & 1.13 \\
\hline \multicolumn{5}{|c|}{$\begin{array}{l}\text { 1. Antal and Xu, "Hydrogen Production From High Moisture Content } \\
\text { Biomass in Supercritical Water", Proceedings of the } 1998 \\
\text { US DOE Hydrogen Program Review, p } 639 .\end{array}$} \\
\hline
\end{tabular}

Exhibit 3. Individual SWPO Test Results on Cornstarch.

(Provided by GA)

\begin{tabular}{|l|ccccc|}
\hline \multirow{2}{*}{ Run No } & \multicolumn{5}{|c|}{ SWPO Test Results } \\
\cline { 2 - 6 } & $1 \mathrm{~A}$ & $1 \mathrm{~B}$ & $1 \mathrm{C}$ & $1 \mathrm{D}$ & Average \\
\hline Temperature at 3", C & 650 & 611 & 647 & 643 & 638 \\
\hline Product, Mole Fraction & & & & & \\
$\mathrm{H} 2$ & 0.458 & 0.534 & 0.504 & 0.488 & 0.496 \\
$\mathrm{CO}$ & 0.165 & 0.075 & 0.091 & 0.156 & 0.122 \\
$\mathrm{CO} 2$ & 0.172 & 0.173 & 0.155 & 0.161 & 0.165 \\
$\mathrm{CH} 4$ & 0.204 & 0.218 & 0.250 & 0.192 & 0.216 \\
& & & & & \\
Water Flow Rate, g/min & 300 & 300 & 300 & 300 & 300 \\
Paste Feed Rate, g/min & 98.1 & 98.1 & 98.1 & 98.1 & 98.1 \\
O2 Flow Rate, g/min & 27.75 & 23.58 & 28.01 & 27.11 & 26.61 \\
Calculated H2 Yield & 92.42 & 125.58 & 110.93 & 104.72 & 108.41 \\
g Gas/g Organics & 1.13 & 1.15 & 1.08 & 1.14 & 1.13 \\
\hline
\end{tabular}


Exhibit 4. Typical Analysis of Compost Used By GA

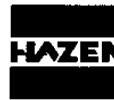

Hazen Research, inc. 4601 Indiana St. - Golden, CO 80403 Tel: (303) 279-450 Fax: (303) 278-1528

General Atomics

Niles Johanson

3483 Dunhili Street

San Diego, CA 92121-1194

Reporting

Basis >

As Rec 'd

Proximate (\%)

Moisture

Ash

Volatile

Fixed C
Total

Sulfur

Btu/1b (HHV)

MMF Btu/lb

MAF Btu/1b

Air Dry Loss (\%)

Ultimate (\%)

$\begin{array}{lr}\text { Moisture } & 42.29 \\ \text { Carbon } & 19.76 \\ \text { Hydrogen } & 1.71 \\ \text { Nitrogen } & 1.26 \\ \text { Sulfur } & 0.35 \\ \text { Ash } & 22.72 \\ \text { Oxygen* } & 11.91 \\ \text { Total } & 100.00\end{array}$

Chlorine**

Forms of Sulfur (as $S, z$ )

\section{Sul fate \\ Pyritic}

Organic

Total

0.35

Water Soluble Alkalies (\%)

$\mathrm{Na} 2 \mathrm{O}$

$\mathrm{K} 20$
Date October 2, 2001

HRI Project 002-3HK

HRI Series No. I154/01-2

Date Rec'd. 09/12/01

Cust. P.O.\#

Sample Identification Coxmport
A Midpoint

Dry

Air Dry

42.29

0.00

39.37

2.23
$38 \cdot 49$

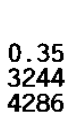

4286

40.97

$\begin{array}{ll}0.61 & 0.60 \\ 5620 & 5495\end{array}$

9620

9269

5495

* Oxygen by Difference

** Not usually reported as part of the ultimate analysis. 


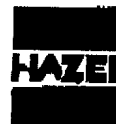

Hazen Rezerareh, Ino. 4601 Indiane 5t. - Golden, CO 804003 Tel: (303) 279.4501 Fax: (303) 278-1528

General Atomics

David Ordway

PO BOX 85608

San Diego. CA 92186.9784

\section{Reparting \\ Basis >}

Proximate (x)

Molsture
Ash
Volatile
Fixed C
Total

Sulfur

Btu/ ID (HHV)

MisF Btu/lb

MAF Btu/lb

Air Dry Loss $(x)$

Uitimate ( $x$ )

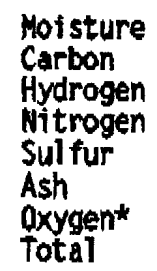

1.89

73.53

5.18

1.66

2.32

8.03

$\frac{7.39}{100.00}$

\subsection{6 \\ 14769}

1.89
B. 03

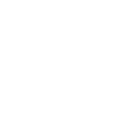

Date

HRI Project

HRI Sertes No.

Date Rec'd

Cust. P. O.:

Sample Identiftcation

0626-1 Neat Fuel 0500 x:Z

$x: 2\left\{\begin{array}{l}1<A T \\ 0, A L \\ P L D E \pi\end{array}\right.$

Dry

Afr Dry

Chlortne**

Forms of sulfur (as $S, x$ )

Sulfate
Pyritic
Organic

Total

2,32

Water Soluble Alkalies ( $x$ )

$\mathrm{Na2O}$

$\mathrm{K} 20$ $\begin{array}{r}0.00 \\ 74.95 \\ 5.28 \\ 1.69 \\ 2.37 \\ 8.18 \\ 7.53 \\ \hline 100.00\end{array}$

1.25

74.01

5.21

1.67

2.34

B. 08

7.44

100.00
0.00

8.18

1.25

2.34

13674

15086

0.65

* Oxygen by Difference.

* Not usualiy reported as part of the ultimate analysis. 
Technical Evaluation Report

Project: Hydrogen Commercialization for the $21^{\text {st }}$ Century

Company: SunLine Services Group

P.I.: Bill Clapper

Site-Visit Date: November 27, 2001

Evaluation by: Edward G. Skolnik, Energetics, Inc.

\section{Summary:}

The SunLine Services Group (SSG) of the SunLine Transit Agency of Thousand Palms, $\mathrm{CA}$ is operating one of the most (if not the most) complete hydrogen demonstration projects in the United States today. It incorporates hydrogen production from both renewable (PV/electrolysis) and fossil (natural gas reforming) resources, pressurized hydrogen storage and hydrogen utilization in an assortment of vehicles powered either by fuel cells or internal combustion engines (ICE). The ICE utilization also includes the use of Hythane TM, a 20/80 hydrogen natural gas blend. SSG also provides an outreach component of their project, giving guided tours (soon adding self-guided tours) of their "Clean Fuels Mall". This area contains all of the aforementioned hydrogen technologies plus options for compressed and liquid natural gas (CNG and LNG). SSG also refers to themselves as a beta test site for all of these technologies.

Public funding for the array of SunLine projects is or has been provided by the U.S. Departments of Energy, Transportation and Defense (DOE, DOT, DOD), the South Coast Air Quality Management District (AQMD), the California Energy Commission (CEC), and the Imperial Irrigation District (IID). There are some private donations as well, primarily for the education component. The Hydrogen Program is the only source of DOE funding for SSG.

I see the following strengths in the project:

- SSG has developed a reputation as a forward-thinking leader in clean and alternate fuels utilization. They are making a very significant contribution to a hydrogen infrastructure, and The Hydrogen Economy.

- $\quad$ The Clean Fuels Mall, while using the concept as having the ability to shop for what you want, is strongly slanted toward hydrogen as the fuel of choice.

- SunLine considers itself a beta test site. This can be of use throughout the hydrogen community to validate many technologies. It is a valuable resource.

I see the following weaknesses:

- The ability to eventually run the fleet of SunLine buses on hydrogen fuel cells may be in jeopardy if a means is not found to purchase fuel cell buses. Conversion of some or all of the present NG bus fleet to Hythane is a potential alternative. While this would 
demonstrate some aspects of the benefits of hydrogen, it is disappointing in that it could reduce or delay the U.S. role in the road to a hydrogen economy.

- The tracking PV system is not working well at all, and the reason is unclear. Furthermore, the manufacturer of the system is out of business. This does not appear to be an easily recoverable situation, and may make this portion of the project a failure.

\section{Introduction and Background:}

I spent a day with Bill Clapper, Executive Director of the SunLine Services Group discussing SunLine's Hydrogen Program work and their general commitment to clean fuels. As part of the day's activities, Mr. Clapper gave me an extensive tour of the SunLine facility, especially their "Clean Fuels Mall", fueling station, and vehicle bays. Mr. Clapper and John Williams, Engineering Manager of the Clean Fuels Program, who joined us later, also answered several questions that I had earlier submitted to SunLine. In addition, Polo Del Toro, an Associate Engineer at SunLine, joined us to discuss maintenance.

SunLine's interest in alternative fuels began in the summer of 1992 when, during a heat wave, roughly $2 / 3$ of their 37 diesel bus fleet, which serves the Coachella Valley were off line. SunLine needed to do something quickly. Their Board of Directors (made up of the mayors, councilmen, and county supervisors of the various jurisdictions in the Valley) opted to replace diesel fuel with natural gas. By 1994, SunLine had converted the entire fleet to natural gas.

One member of SunLine's Board of Directors (the mayor of Palm Desert) actually wanted to convert to hydrogen fuel cells even back then. Fuel cells, however, were not close to maturity then, at all; putting a fuel cell in a bus would mean the removal of 36 of the 40 seats.

The city of Palm Desert has been particularly forward-thinking. Recall that they were active in fuel cells in the mid '90s via the Schatz/Humboldt State University project headed by Dr. Peter Lehman. In 1998 the project got taken over by SunLine, and resources formerly used by Clean Air Now! (CAN) were added.

Next, SunLine used its own money to build the Zweig Education Building in 1999. This 1800 square foot facility was also the site of the 2000 fall meeting of HTAP. SunLine also began to showcase their alternative energy technologies in their "Clean Fuels Mall". Tours are conducted of this showcase every Friday morning. The "Mall" premise is, that like at a shopping mall, you can see a great variety of goods, and pick and choose as you desire. Only here you are choosing alternative/renewable energy equipment.

Contributions to components of the Mall come from DOE, CAN, the City of Palm Desert, SunLine itself, and other private industries. 
SunLine, especially their SSG, considers themselves to be a beta test site for various alternative fuels technologies.

\section{Tour:}

Mr. Clapper took me on my own private guided tour.

SSG has two of the original three fuel cell golf carts, or personal utility vehicles (PUV), and the larger Neighborhood Electric Vehicle (NEV) that were originally built by Humboldt State. The third PUV is being used by the Palm Desert Parks and Recreation Department. The PUVs use $4 \mathrm{~kW}$ PEM fuel cells, and the NEV uses a $10 \mathrm{~kW}$ PEM fuel cell. The NEV is "street legal" but is not allowed to exceed speeds of $40 \mathrm{mph}$. The vehicles are owned by SunLine, and their use is currently being funded by DOE and by the South Coast Air Quality Management District (AQMD).

Hydrogen for these vehicles is made by a Teledyne Electrolyzer with a production rate of 40 standard cubic feet per hour ( $\mathrm{scfh}$ ). The electrolyzer is not only used as a fuel source for the vehicles but also is used as an educational tool. Visitors can see the hydrogen being made. This small electrolyzer was also originally part of the Humboldt State project. The building that houses it has a combustible gas sensor as well as a smoke detector. A total air exchange in the building can be accomplished in 30 seconds.

Hydrogen for the PUVs and NEV is compressed to 2000 psi and kept in " $\mathrm{K}$ " size gas bottles near the electrolyzer building. The vehicles are brought to this site for refueling. The Palm Desert PUV has its own K bottle.

The solar component of the Clean Fuels Mall consists of both fixed and tracking photovoltaic panels. The flat-plate, fixed solar panels were made by Siemans, and are "pre-1995". They originally came from CAN. There are a total of 218 panels, 48 on the education building roof, and the remaining 170 on dedicated structures. Total capacity is about $13 \mathrm{~kW}$. The panels provide electricity for the $40 \mathrm{scfh}$ Teledyne electrolyzer, contributes electricity to the Stewart Energy electrolyzer described below, and is integrated to the grid as well.

The other part of the solar component to the Mall is an array of 144 tracking panels. These panels, installed in 2000, were manufactured by PVI (which has been taken over by Echo Energies), and are of a now obsolete design. These panels are not performing well at all, delivering only a small fraction of their $22 \mathrm{~kW}$ rating.

The workhorse electrolyzer of the Mall is a $1400 \mathrm{scfh}$ Stewart Energy model. The electrolyzer has a built-in compressor, and fills two CAN tanks to 4000 psi. SunLine also has 3130 psi tube tanks on a trailer, which they use to refill buses. The electrolyzer produces sufficient hydrogen to supply hydrogen to 1-3 buses, depending on their route. A fuel cell bus operating for 19 hours requires about 17,000 scf per day of hydrogen. 
SSG is currently talking with Teledyne about an even larger, $4800 \mathrm{scfh}$, electrolyzer.

The Mall also includes a natural gas reformer from H-Burner and Griz de France. This system, which includes high and low temperature shift reactors as well, is not supported by the DOE program. It is capable of producing 4,200 scfh of hydrogen, but does not run very often. When it is run, the hydrogen is sometimes flared. The pressure swing adsorption (PSA) component is currently being resized. The reformer would be capable of supporting about five fuel cell buses.

The refueling station stores and dispenses compressed and liquid natural gas (CNG, LNG), hydrogen, and Hythane (an 80/20 natural gas/hydrogen blend). There are two islands. One has two hoses, and handles commercial sales of CNG. Taxicabs, school buses, postal vehicles, some transit buses, and rubbish trucks regularly fill up at this island. There are about $800 \mathrm{CNG}$ vehicles in the Coachella Valley, and this island is used regularly. During our tour, a taxi pulled up and refueled. Later, Mr. Clapper demonstrated the refueling process on his own truck (currently running on CNG, soon will be using hydrogen - see Question 3 below.) While we refueled, two rubbish trucks got in line behind us.

The second island also has two hoses, one that can supply hydrogen from the Stewart Energy electrolyzer, and the second that can supply Hythane, mixing the electrolyzer hydrogen with CNG. This island at the present time appears to be mostly for show. The small vehicles (PUV, NEV) are filled from compressed hydrogen bottles, and the fuel cell bus is filled from tube trailers.

An LNG tank/station was installed in April 2001. The tank holds 15,000 gallons of LNG and boasts of twelve levels of safety devices from bollards ringing the tank to prevent a vehicle from running into it, to flame and gas detectors.

Two Knox Western $600 \mathrm{scfm}$ compressors are used for hydrogen or, alternatively, for CNG.

Housing and refueling of the SunLine buses and other large vehicles is at a site behind the Mall. The bus refueling island for $\mathrm{CNG}$ has dispensers with two different sized nozzles. There are also seven other CNG refueling stations in the Coachella Valley. Prior to these stations being built, an eight-tank truck operated as a moving refueling station for the $\mathrm{CNG}$ buses.

At the time of my visit there was only one bus on-site that ran on hydrogen. That was the Ballard/XCELLSIS fuel cell bus. It was, however, in the process of being sent back to Vancouver. The bus project was partially funded by DOT's Federal Transit Administration (FTA).

There are several enclosed bays for servicing CNG vehicles. Mr. Clapper indicated that in the event of a leak, a total air exchange could be accomplished in a bay in 90 seconds. 
In front of one of the bays, there is a canopy structure for servicing hydrogen buses. This enclosure is funded by DOE. There are no ignition sources above the buses. For instance, the lights are explosion-proof.

On site also was a 4000 gallon water tank truck that runs on CNG. It is the first of its kind in the country.

\section{Questions and Answers:}

I sent Mr. Clapper a series of questions that we discussed in detail during our meeting. The questions are shown below in bold, the answers appear in normal type, and my comments added later are seen in italics.

\section{The DOE Hydrogen Program has been funding SunLine for about two years. Please discuss how the Hydrogen Program funding fits into the mix with other related funding you have received.}

Funding for the various components of SunLine's alternative fuels projects have come from federal (DOE, DOT, and DOD), state (AQMD, CEC, and IID), and some private funding. Private donations have been especially significant in the education portion of SunLine's project.

AQMD projects are mostly concerned with infrastructure, and CEC is involved with Hythane and with a reformer verification study. IID contributed $\$ 60 \mathrm{~K}$ toward the solar trackers, and recently contributed $\$ 184 \mathrm{~K}$ toward a stationary fuel cell to power the Zweig Engineering Building. Schatz/Humboldt State will also contribute toward this effort.

SSG looks at the federal portion (DOE, DOT, and DOD) as their "Hydrogen Program". They see their DOE projects to be mainly infrastructure related, DOT to be primarily involved with the fuel cell bus (via FTA), and DOD to provide funding for education via the development of a technician's manual for fuel cells for the Army. Other DOD work involves on-board reforming for a fuel cell.

The aforementioned manual (actually a joint DOD/DOT effort) includes on-board reforming, but is much more strongly focused on hydrogen, according to Mr. Clapper. It includes sections on hydrogen, internal combustion engines, all types of fuel cells, codes and standards, systems, and facilities. It is a "living document" and will be of use to DOD, DOT, and DOE, says Mr. Clapper.

Funding sources are highly distributed. What is significant is that it all appears to go together so well.

\section{Has any decision been made on fixed vs. tracking solar arrays?}

If a decision had to be made right now, they'd go with the fixed array. The tracking array is not performing effectively at all right now. It's still early in the game, however. 
I did not get the impression that SunLine had a lot of confidence in being able to fix the problem with the tracking panels. As stated above, this type of panel is no longer being manufactured. The attempts at fixing motorized components have not helped. SunLine does not appear to know what is causing the problem or how to fix it. They are obviously getting very little support from the manufacturer.

\section{Please discuss the two vehicles (bus and truck) that are/were using the Livermore cryotanks for hydrogen storage.}

They'll be using two trucks instead, one being Mr. Clapper's company truck. After the cryotanks are installed, one truck will run on compressed and liquid natural gas and the other (probably Mr. Clapper's) will run on compressed and liquid hydrogen.

Mr. Clapper mentioned that if you have a half-full tank of LNG, you can top it off with CNG. You cannot top-off a half full CNG tank with LNG, however. SunLine believes that the same result would occur with liquid hydrogen.

This would make spur-of-the-moment long distance trips difficult for the vehicle that has a fuel tank half full of compressed gas.

\section{How often does SunLine produce and deliver hydrogen for the Palm Desert golf carts?}

SunLine supplies about 600 standard cubic feet each month. 3600 psi hydrogen is pressure-transferred down to about 2000 psi for the vehicles.

\section{What percentage of the hydrogen produced by the electrolyzers is renewable- based?}

Only about $10 \%$ of the electrolyzer-produced hydrogen is made from renewable electricity; the rest is from grid electricity. All of the hydrogen produced by the small Teledyne electrolyzer, however, comes from the renewable solar panels in the Clean Fuels Mall.

The need for the larger electrolyzer needing to use $90 \%$ grid electricity is one of the results of the tracking solar panels not operating properly.

\section{How are the two electrolyzers being used? Is it a competition?}

There is no competition, even with the anticipated arrival of the larger Teledyne electrolyzer. SunLine just wants to show what the two electrolyzers can do. Of course, when the two larger electrolyzers are both running, data will be produced (such as cost of hydrogen, for instance) and people will ask questions. The cost data will, however, be mainly SunLine specific, and may not be relevant in the larger sense. Information on such items as maintenance, however, will be of more general value. 
And the "winner" will publicize the data.

7. What hydrogen storage options (both on- and off-board) are being considered? Is there any plan to look at metal hydride storage?

SunLine has no plans to consider on-board reforming; their choice is on-board hydrogen. They would produce hydrogen, store it in (compressed hydrogen) tanks, and pump it on board. Mr. Clapper said, "We have 53 buses, and don't want to have 53 [onboard] reformers, which equals 53 problems." Furthermore, Mr. Clapper feels that on-board reforming does not make sense for a vehicle that "comes home every night". SunLine is doing some on-board reformer work for the Army, however.

I kind of like "53 onboard reformers equals 53 problems" as a mantra for on-board hydrogen.

SunLine is looking at metal hydrides, but can't talk about it at this point. A company has approached SunLine with an idea involving several sub-projects, but it's all proprietary at this point. This adds yet another desirable technology.

8. What is the status of the natural gas-based hydrogen portion of the project? How was the hydrogen thus produced used? Was any purification performed on the reformate?

SunLine is in the process of improving the reformer system. They are now mainly resizing the PSA purification system. Once they do this, they will start putting the hydrogen in tanks. For now, lacking any purification, the hydrogen from the reformer is simply flared.

\section{Your FY 2002 Annual Operating Plan (AOP) submittal (aside from outreach} efforts) includes several tasks involving maintenance on various components of your hydrogen system. What do you see as the key concerns in the maintenance area? What types of problems have arisen to date?

This question was answered by Mr. Del Toro, who gave quite detailed accounts of the maintenance issues for the various components of SSG's alternative fuels systems.

The Teledyne electrolyzer is checked for leaks regularly, according to its maintenance manual. Small leaks have been found occasionally. The major problem with the electrolyzer has been with the program logic controller for the dryer component. It apparently had to be replaced and this turned into a lengthy process.

The PV tracking arrays were not tuned (aimed) properly and this had to be fixed. In addition, some of the units had grounding problems. 
As we can see from some of the other comments made by Mr. Clapper, the problem or problems with the PV tracking units have not been solved, and may not be solved. The tuning and the grounding fixes did not appear to really increase output significantly.

The Stuart Energy electrolyzer had hot weather problems in the summer. The unit could not be run at full capacity in the summer, but had to be run at about $90 \%$. In addition, the recirculation loop has been a problem for a while. Routinely, new regulators and relief valves are installed every six months.

SunLine experienced some hard water problems with the reformer. They have installed a reverse osmosis membrane as well as a cascading deionization system to reduce scaling with the process water.

The PSA unit was not adequate to achieve the $99.999 \%$ hydrogen purity desired without slowing it down unacceptably. They are therefore currently up-sizing the PSA.

Compressor problems have arisen from moisture carryover. In addition they have had a materials problem with the rings due to lubrication. They had to redo the lubrication system. Finally, the tips on the blow down circuit valves were being eroded by the hydrogen, and they needed to change the material.

With on-board hydrogen storage, they found large pressure drops at first, not atypical of new systems. They also found that the capacity of their compression tank on the bus was dropping off. This was traced to residue from a cleaning process on a filter.

When they first tried to store some Hythane, they used a new CNG line. When they blew out the line, they got a "volcano" of rust.

The refueling area was experiencing false alarms from the infrared flame detector during the summer due to thermals from the concrete. A new infrared/ultraviolet detector has been installed with a 3-5 second delay lock-in. This is believed to have solved the problem.

Mr. Del Toro and the rest of the team felt that the major obstacles will be not the systems themselves, but training the workers in the electrical, chemical and high pressure aspects of the systems. In addition, public relations will continue to be important to alleviate the public's fear of the unknown.

\section{The AOP also includes a data collection and analysis task. What type(s) of data have been collected so far, and what are they indicating? Is there anything so far that would indicate a single favorable technology in any area (e.g., NG reformer vs. electrolyzer, liquid hydrogen vs. compressed hydrogen, ICE vs. fuel cell, etc)?}

The data gathered from the electrolyzers include: amount of hydrogen produced (scf), the number of kilowatts needed to produce it, and general maintenance data. 
For the reformer, data include the electricity requirement, amount of natural gas used, and the amount of hydrogen produced, and the purity of the components. They generate a cost of hydrogen, and report it on a price per gallon of gasoline equivalent.

SunLine does not believe it has enough information to see whether the reformer or electrolyzers will prove to be the best. Mr. Clapper pointed out that these pieces of equipment are beta test units, not commercial equipment.

For the solar panels, they record the amount of energy being produced by the panels. (See Question 2 for the discussion on comparison between fixed and tracking arrays.)

As stated earlier, SunLine will soon be fitting a truck (likely Mr. Clapper's) with a LLNL pressurized cryotank. They'll use this to develop liquid vs. pressurized hydrogen data. One concern they have in this area is the cost of making liquid hydrogen.

If SunLine is to bill themselves as a beta test site, comparisons, trade-offs, and competitions are bound to occur eventually. There is nothing wrong with this; it is a desirable outcome.

\section{You have indicated that you will be looking at wind-based hydrogen in the future. What size wind turbines will you be evaluating? What will the stationary fuel cell to be operated with the wind-hydrogen be powering?}

Mr. Williams answered this question. SunLine will not be actually evaluating turbines. They were offered three $65 \mathrm{~kW}$ wind turbines by Wintec, a California company that makes wind power plants. Wintec approached SunLine about a demonstration project that would simply evaluate a wind/electrolysis hydrogen production pathway with the hydrogen then being stored in a tube trailer for either stationary power generation or transportation. SunLine may investigate some hydride storage here as well.

One of the parameters that will likely be evaluated is the use of the fuel cell to actually keep the wind turbine turning when the wind isn't blowing, to remove the effects of inertia on the turbine at startup.

\section{How do you envision the operation of buses in the Coachella Valley in 2010 ?}

Unless the price of hydrogen buses comes way down, it will be difficult for SunLine to purchase new buses without federal help. SunLine thinks they will probably have less than ten hydrogen buses by 2010 .

Alternative possibilities are:

If hydrogen buses are successful in Europe, maybe the price will come down, and make them more affordable for SunLine. 
If automobile companies produce a quantity of fuel cell buses, SunLine might be able to get some.

If Hythane works as a bus fuel (see the discussion in the next section), SunLine might be running its entire fleet on Hythane by 2010. This could arguably be either a positive or negative thing. It's certainly getting away from fuel cell/hydrogen, but it could be a valuable step in leading to using hydrogen ICEs.

\section{Additional Items:}

- SunLine's Board of Directors likes them to undertake projects that have valley-wide implications. In this light, SunLine has undertaken street-sweeping and graffiti removal duties. They use CNG-powered trucks for these purposes.

- Mr. Clapper ventured an idea: When someone buys a house, they buy a CNGpowered car as part of the package. Thus the car payments are part of the mortgage and therefore deductible. From here, it's not a long step to fuel cells and hydrogen with home (heat and) electricity and the vehicle both being fueled by hydrogen. SunLine actually looked at this concept (with CNG) in a local gated community, Sun City, about 5 years ago. It didn't happen, but SunLine is still considering the idea elsewhere. The automobile as part of the mortgage package is an interesting concept, that I would think has been thought of before. I'm not sure if it is legal tax-wise (although I don't know why not), but it appears to be a possibly attractive way to help defray the costs of a hydrogen vehicle.

- SunLine will be commencing a Hythane project in the first quarter of 2002. The plan is to first get Hythane certified in California. They are planning to work with Cummins, Inc. to achieve this objective. If this is successful, they'll convert one bus and run it for 90 days and inspect it. If they find the test successful, they'll convert a second bus, etc. They'd like to have perhaps 4-6 buses converted by the end of 2002. SunLine has spoken with Frank Lynch (Hydrogen Consultants, Inc.) who believes that since the region in question is virtually at sea level, there would be no retrofitting necessary in the switch from $\mathrm{CNG}$.

- Once the Ballard bus goes back to Vancouver, there will be no fuel cell buses left in the U.S. The focus of fuel cell buses will be in Europe, where there is an order of magnitude more bus sales than in the U.S. anyway. Although SunLine warns about the temporary end of fuel cell buses here without external support, I sense that they might actually see the European route with subsequent lowering of fuel cell bus costs as the best way to eventually get hydrogen buses here. In the meantime, they appear to be fairly comfortable with a conversion to Hythane.

- SunLine is working with a company called Sun Law to put up a $120 \mathrm{MW}$ gas-fired turbine power plant. 
- According to Mr. Williams, SunLine could become a net supplier of hydrogen and/or electricity if their solar and wind resources can make the Coachella Valley self sufficient with zero emissions and still have left over energy. This could happen by 2010, if SunLine "had the money."

\section{The Future:}

We discussed where SunLine was heading, and where they were looking to DOE for additional help. SunLine has recently bought some land, on which to extend their resources. As a beta test site, they feel they could help with other DOE projects - perhaps in the storage or sequestration areas. Mr. Clapper listed several areas where SunLine could use funding from DOE:

- One area is in hydrides. Recall that SunLine is currently working in this area with another company in a proprietary manner, but they may be looking for government support in the future.

- Another area for potential support is that they would like to put some fuel cells in some of their buildings and use their existing hydrogen infrastructure to power them. In conjunction with this, SunLine believes that they may make some use of the low value heat/hot water coming off the fuel cell. Perhaps vehicle cleaning would be an option.

- SunLine would like to look at NG/hydrogen blends other than $80 / 20$. They recognize that others are doing this as well.

- SunLine needs some help in getting some buses and trucks. This may really be the most critical need. If the path is to go to hydrogen buses, I believe that the on-board hydrogen/fuel cell path would likely be more effective than the NG/hydrogen ICE path. At least a parallel path is needed.

- SunLine is also looking for help to install an infrastructure for their wind farm. (See Question 11.) They'd like to transport the hydrogen back to their headquarters. They'd also like to have a fuel cell to provide backup power to the wind turbine to keep it moving (uninterruptible power.)

\section{Final Thoughts:}

SunLine is a very valuable commodity for the DOE Hydrogen Program. As arguably the premiere hydrogen technology and systems demonstration site in the U.S., SunLine is often in the spotlight. Based on the premise that fuel cell buses, or funding for such buses, is not available, SunLine appears to be headed toward a conversion to Hythane. It is unclear as to whether such a conversion would be positive or negative for the Hydrogen Economy. NG/hydrogen blends could lead to pure hydrogen ICEs, and that's good. But we also recognize that abandoning fuel cells at a time where fuel cells are getting a lot of positive attention elsewhere is the wrong message. On-board hydrogen/fuel cell systems 
on a vehicle where weight isn't critical (i.e., a bus) is, I believe a necessary step toward legitimizing the Hydrogen Economy. SunLine needs to find a way to keep this activity going.

My visit to SunLine was the $35^{\text {th }}$ site visit that I have undertaken since starting this activity. As far as providing a positive thrust for hydrogen and the Hydrogen Economy, SunLine in my opinion, ranks at or near the top of that list of 35. 
Technical Evaluation Report

Project: Thermocatalytic $\mathrm{CO}_{2}$-Free Production of Hydrogen from Hydrocarbon Fuels Company: Florida Solar Energy Center

P.I.: Dr. Nazim Muradov

Site-Visit Date: February 11, 2002

Evaluation by: Edward G. Skolnik, Energetics, Inc.

\section{Summary:}

One of the many advantages of using pure hydrogen as an energy carrier is the fact that its use results in no direct emissions of $\mathrm{CO}_{2}$. If the hydrogen is produced from renewable resources there are also no $\mathrm{CO}_{2}$ emissions (or at least no net $\mathrm{CO}_{2}$ emissions) due to its production. When hydrogen is produced from fossil fuels by conventional steam reforming or partial oxidation processes, $\mathrm{CO}_{2}$ is an unavoidable byproduct. If the fossil fuel is pyrolyzed (decomposed by heat rather than oxidized), however, the ultimate products are only hydrogen and carbon. This is environmentally more attractive, but is a more energy intensive process, requiring a higher reaction temperature than the oxidation reaction. In addition, energy release is not "complete", with a portion remaining in the carbon.

The Florida Solar Energy Center (FSEC) has for the past several years, been developing a process in which the pyrolysis reaction can be run at a lower temperature by employing a catalyst, and in which the energy in the byproduct carbon does not have to be "wasted."

The key developments over the past couple of years for the FSEC project has been the change from metallic catalysts to carbon catalysts for the thermocatalytic "cracking" process, and the discovery that when produced under the right conditions, the byproduct carbon can also serve as a catalyst.

I see the following strengths in the project:

- The process provides a pure hydrogen product without concurrent production of $\mathrm{CO}_{2}$.

- The process appears to work for most (and maybe all) gaseous and liquid saturated, non-oxygen-containing hydrocarbons.

- The P.I. has a reasonable approach to moisture and sulfur removal from the feedstock and/or product.

- The coking of the catalyst by carbon byproduct is being addressed by operating in a fluid bed. In addition, the fact that the carbon being produced acts as a catalyst itself, at least slows the potential coking problem.

- Potential markets for the carbon byproduct have been identified.

I see the following items that need to be addressed: 
- A substantial amount of the energy (about half) remains trapped in the carbon. Some people consider this a major weakness. I am not as convinced. Certainly we don't want to waste energy, but the energy in the carbon is not wasted or lost. Some of it will be used as a catalyst. The remaining carbon (which makes up the majority) can be stored and burned at a later time. It can, perhaps even be transported to a centralized location where it can be combusted to produce meaningful heat or electricity under conditions where the resulting $\mathrm{CO}_{2}$ can be more easily sequestered. Alternatively, the carbon could be used for other purposes more valuable than energy storage, such as carbon electrodes, for instance. So there are many options. The task is to determine which option or combinations of options make the most sense, and then see if they make enough sense. For instance, if you are making electrode material, are you also producing hydrogen efficiently at the same time?

- The process by which the formed carbon is ground and continuously added to the catalyst bed must be demonstrated. It also must be shown to be economically feasible. Data will apparently soon be available form NREL.

\section{Introduction and Background:}

I visited FSEC to review the thermocatalytic cracking project for the second time. The first time was almost six years ago, in April 1996. Now as then, the PI is Dr. Nazim Muradov. In 1996, FSEC was using iron and nickel based catalysts in a fixed bed. At the time, Dr. Muradov was able to demonstrate that he could convert methane to hydrogen at up to $95 \%$ theoretical yield. However, the process was subject to fairly rapid coking of the catalyst by the carbon byproduct. Dr. Muradov would then burn the carbon off to create fresh catalyst surface. This oxidation process, however, compromised the very thing that FSEC was striving for $-\mathrm{CO}_{2}$-free hydrogen production.

After several iterations and at least one stop and re-start, Dr. Muradov is now working with carbon catalysts, having screened several, and the coking problem seems to be solved.

\section{Tour:}

Dr. Muradov had his $1 \mathrm{~kW}$ thermocatalytic reactor operating, and gave me a demonstration. He used propane (in this case, a high purity version) rather than methane as his feedstock, and seems to be leaning to continue in that direction. The decomposition of propane is a thermodynamically more favorable process, and gaseous byproducts such as methane can be recycled. The reaction was run at $870^{\circ} \mathrm{C}$, with an electric heater providing the reaction energy. As previously, Dr. Muradov uses gas chromatographic detection. A rotometer measures flow rates of hydrocarbon in and hydrogen out.

The $1 \mathrm{~kW}$ reactor is a fixed-bed type. The catalyst used was a reagent grade carbon black. Dr. Muradov does have fluidized bed reactors, but they much smaller (10 W each). Since the project's critical milestone is a demonstration of a $100 \mathrm{~W}$ system, Dr. Muradov 
wanted to demonstrate components of that system rather than the smaller one. The fixed bed reactor is 15 inches in height, and $1 \frac{1}{4}$ inches in diameter. It is capable of producing about 5 liters per minute of product gas, which typically is $70-80 \%$ hydrogen.

The fluid bed reactors are each $15 \mathrm{~mm}$ in diameter, with a $10 \mathrm{~cm}$ bed height. They each use 2-3 grams of catalyst. With the fluid bed reactor, it is easier to draw the carbon out and recycle it. I would have preferred to see the fluid bed system in operation, but I understand the reasoning

Dr. Muradov first ran a gas standard (79\% hydrogen, $21 \%$ methane by volume) through the chromatograph, and used this to calculate his reaction product yields. In his first run, at $870^{\circ} \mathrm{C}$, the gas products were $67.9 \%$ hydrogen, $32 \%$ methane. A trace of ethane was also detected. A second run at a lower temperature $\left(810^{\circ} \mathrm{C}\right)$ produced an expectedly lower hydrogen yield $(64.6 \%)$. No decrease of hydrogen yield due to catalyst degradation was seen in either run. No $\mathrm{CO}, \mathrm{CO}_{2}$, propylene, or ethylene were seen in the chromatograph traces.

The carbon reaction product is very similar in nature to the carbon black catalyst but has somewhat more of a graphitic structure. If a longer residence time and/or lower reaction temperature is used, the product is graphitic pellets, which are grayish in color, and are not good as a catalyst. Dr. Muradov, however, believes that these pellets are a potentially saleable byproduct as electrodes for lithium ion batteries. He plans to send some pellets to battery manufacturers. He is also sending some samples to Materials and Electrochemicals Research Corp. (MER) in Tucson.

Using a long residence time regime, Dr. Muradov could "very likely" produce $95 \%$ of the theoretical amount of hydrogen. The remainder of the hydrogen would be contained in product methane, which could either pass through a PEM fuel cell unaffected, and could then be recycled, or could be used to provide process heat.

Using a proprietary temperature residence time regime and a different catalyst, Dr. Muradov can also produce nanotubes, he stated.

If Dr. Muradov begins with a tank containing $20 \mathrm{lbs}$. of propane, he says, he will produce about 15-16 pounds of carbon black. In the right residence time/temperature regime the material is catalytically active. $100 \%$ theoretical conversion to carbon would only produce $16.36 \mathrm{lbs}$. of carbon, so Dr. Muradov is either referring to a very long residence time process (which would not be the correct residence time to produce catalytically active carbon), or is including the effect of recycling of methane. In either case, in this estimation, he is also not using propane or methane to provide heat to the thermocatalytic reaction. Dr. Muradov has run a $20 \mathrm{lb}$. tank of propane and has shown very little degradation in hydrogen production rate through the run. After the tank is empty, Dr. Muradov uses nitrogen gas to blow out about $90 \%$ of the carbon, and keeps the remainder for seed catalyst for the next run. Note that I did not witness a $20 \mathrm{lb}$. tank being run, nor the carbon being blown out. 
Dr. Muradov also has a $100 \mathrm{~W}$, single cell, $3 \times 3$ inch membrane, PEM fuel cell that he obtained from Energy Partners (now Teledyne Energy Systems). This is the unit that Dr. Muradov is using to demonstrate the use of the hydrogen from the output of his $1 \mathrm{~kW}$ reactor. Among other things, he is verifying the $\mathrm{CO}$-free nature of his product. Of course, only a portion of the hydrogen produced by the $1 \mathrm{~kW}$ reactor goes to the much smaller fuel cell. The rest is vented. Fuel cell data is currently generated by coupling the fuel cell to a load, in this case a battery tester. FSEC is building as new load system to replace the current rough system.

Dr. Muradov mentioned that in the last review, one of the Peer Reviewers opined that the fuel cell may be superfluous in this project. I don't believe that the fuel cell electricity/load data obtained here is necessary. Everyone knows that if you feed hydrogen and oxygen to a fuel cell you'll make electricity. The amount you produce, especially in this case where the fuel cell is undersized, is a measure of fuel cell properties, not hydrogen. Ironically, where fuel cell data would be of value would be in determining how efficient the reactor and its purification system(s) are in prevention of CO production, and in sulfur removal (see Question 1). However, if the fuel cell were used in this way, its catalyst would be poisoned. Thus this application is not recommended either. The only benefit of having the fuel cell in the system may be when the reactor is being used as an education/outreach tool - but that is not a bad application.

\section{Questions and Answers:}

I sent Dr. Muradov a set of discussion questions prior to my arrival. A significant portion of the meeting was spent discussing these questions in great detail. This is reproduced here, with the questions indicated in bold, our discussion shown in normal type, and my comments added to many of the questions during my later analysis and assessment shown in italics.

\section{Are there any plans to look at results vs. the purity of feedstock gas?}

The next phase (Phase 3) of the project will look at purification - primarily removal of moisture and sulfur. This is scheduled to start in April 2002, and some preliminary results will be available by the time of the Annual Review in May.

Dr. Muradov will investigate two methods to get rid of moisture, which can lead to formation of carbon oxides. These would be essentially only $\mathrm{CO}$ and $\mathrm{CO}_{2}$. He will either dry the natural gas prior to the reactor, or install a methanator on the downstream side. This is basically a reformer, run in reverse:

$$
\mathrm{CO}+3 \mathrm{H}_{2} \rightarrow \mathrm{CH}_{4}+\mathrm{H}_{2} \mathrm{O} \text {. }
$$

Dr. Muradov believes he can get to less than 10 ppm $\mathrm{CO}$ using the methanator. $\mathrm{CO}_{2}$ will be in very low concentration anyway, and won't be a problem. 
I would think that the methanator would be a better choice than drying since carbon oxides can be formed from impurities other than moisture.

Dr. Muradov will also consider two options with sulfur impurities. These are hydrodesulfurization, or a post-reaction cleanup, trapping the sulfur compounds. Hydrodesulfurization is simply reaction of the sulfur compounds (for example, the sulfur odorant) with hydrogen over a catalyst such as molybdenum sulfide. The reaction product is $\mathrm{H}_{2} \mathrm{~S}$.

Sulfur is not a problem in the reactor; carbon catalysts are not poisoned by sulfur the way metal catalysts are. In fact, sulfur slightly activates a carbon catalyst. Therefore the postreaction cleanup is also viable. The sulfur, Dr. Muradov believes, will go to $\mathrm{H}_{2} \mathrm{~S}$ in the reactor, anyway. One of the upcoming tests will be to see what other forms of sulfur the post-reaction products include.

In either case, hydrogen sulfide can then be removed by passing it over a bed of zinc oxide at $300-400{ }^{\circ} \mathrm{C}$ :

$$
\mathrm{ZnO}+\mathrm{H}_{2} \mathrm{~S} \rightarrow \mathrm{ZnS}+\mathrm{H}_{2} \mathrm{O}
$$

The process can take $\mathrm{H}_{2} \mathrm{~S}$ levels down to $1 \mathrm{ppm}$, according to Dr. Muradov.

It seems that the key is the presence or absence of non- $\mathrm{H}_{2} \mathrm{~S}$ sulfur in the post-reaction gases. If there is only $\mathrm{H}_{2} \mathrm{~S}$ you should probably do everything post-reaction. If other sulfur species show up, hydrodesulfurization prior to the thermocatalytic cracking is probably called for.

2. How are you able to differentiate between your catalyst and the carbon black produced by the thermocatalytic process so that you can measure carbon black yield?

There is really no need to differentiate, as long as the product carbon is active, catalytically. This question is also taken up in Question 5.

\section{In your FY 2001 Annual Review Report, Figure 3 plots the rate of methane decomposition as a function of catalyst surface areas. What is the significance of the linearity of the plot? Does the relationship hold for activated carbon as well? Are there any data for carbon blacks with surface areas midway between the data points shown (say $600-1200 \mathrm{~m}^{2} / \mathrm{g}$ ) to validate the linearity of the plot?}

Dr. Muradov redid the Figure to include a larger number of carbon blacks and activated carbons. The old and new figures are attached as Exhibit $1 \mathrm{a}$ and $1 \mathrm{~b}$. The linearity is related to surface area and indicates a catalytic, heterogeneous process. That is, it is not a homogeneous thermal decomposition. Dr. Muradov also pointed out that the linearity only holds for initial methane decomposition rates. 
The new curve (Exhibit 1b) lends more credence to the relationship, although there is considerable scatter, perhaps due to difficulty with identifying initial decomposition rates. The fact that this was presented as a log-log plot as opposed to a linear plot, does not affect the linearity of the line, but does tend to mask scatter somewhat.

\section{In measuring surface areas of catalysts, are pores included in the measurements, and if so, to what degree? Do the carbon crystallites have pores?}

Pores are important only for the activated carbons. Carbon blacks (the crystallites) are simply an agglomeration of tiny particles, and have no pores. So activated carbons work well until the pores get blocked; then the reaction slows. The interstices in the agglomerated carbon black particles can get blocked as well, but this is a much slower process.

With a dynamic system, one involving both a fluid bed and a grinding and recycling mechanism, it appears that one can keep the reaction rate optimized.

\section{Have you found that hydrogen production rate is always consistent with methane decomposition rate? Do you have a direct comparison of methane decomposition (as a measure of hydrogen production) as a function of time for various catalysts - with all else constant?}

Dr. Muradov provided Exhibit 2 to show a typical methane decomposition run indicating that there is no "hidden" gaseous hydrocarbon product. It shows that the sum of methane and hydrogen concentrations always equals $100 \%$. In addition, he offered the following calculation based on that particular experiment:

Input: $\quad 1430 \mathrm{ml} \mathrm{CH}_{4} ; 0.20$ g. carbon black

Output: $\quad 1730 \mathrm{ml} \mathrm{H} / \mathrm{CHG}_{4}$ mixture; 0.332 g. carbon Average hydrogen concentration $=34.8$ volume $\%$ $1730 \times 0.348=602 \mathrm{ml}$ hydrogen $=0.0246$ moles hydrogen at ambient Stoichiometrically, since $\mathrm{CH}_{4} \rightarrow \mathrm{C}+2 \mathrm{H}_{2}$, $1 / 2 \times 0.0246=0.0123$ moles of carbon would be produced $=0.148 \mathrm{~g}$ carbon So, theoretically:

there should be $0.148 \mathrm{~g}$ carbon from reaction $+0.20 \mathrm{~g}$ carbon catalyst $=0.348 \mathrm{~g}$.

This represents only about a $4 \%$ error from the actual result of $0.332 \mathrm{~g}$ carbon measured: $(0.348-0.332) / 0.348 \approx 4 \%$

I could argue that the $0.20 \mathrm{~g}$ of catalyst should not be included in the calculation and that the carbon yield was $0.332-0.20=0.132 \mathrm{~g}$, where theoretically it should be $0.148 \mathrm{~g}$ : $(0.148-0.132) / 0.148=10.8 \%$ error. 
More important might be the question as to why Dr. Muradov used for an example a run that yielded such a small percentage (34.8 vol. \%) hydrogen? The demonstration run that he performed for me, had hydrogen yields in the 60-70\% range.

\section{Why are you looking at other hydrocarbons than methane? Is the plan to recycle the non carbon-black byproducts?}

If you run under the right conditions, you don't get any non carbon black byproducts. If you do get any, the plan is to recycle.

\section{Do the carbon blacks produced from different hydrocarbons have different characteristics and/or catalytic properties?}

Different hydrocarbons produce different structured carbons. They have different crystallite sizes. The hexagonal structures are in planes, but in carbon black, the planes are irregular in orientation to one another; in graphite the planes are orderly. The crystallite itself is regular in structure.

Smaller crystallites are more reactive than larger ones. Methane produces larger crystallites than higher hydrocarbons. Unsaturated hydrocarbons are typically more reactive than saturated ones.

\section{In Figure 9 of the FY 2001 report, you show linearity (albeit this time in a semi- log plot) between carbon crystallite size and relative activity for different hydrocarbons. Again, why is the linearity significant?}

There are actually two plots: one that was Figure 9 in the report (Exhibit 2A) and one that Dr. Muradov gave me for this meeting (Exhibit 2B). Dr. Muradov didn't specifically discuss the linearity issue, but said that the plot indicated the importance of producing small crystallites. Smaller size crystals can be produced by running at higher temperatures (increasing the reaction kinetics), but one wouldn't want to go above about $900^{\circ} \mathrm{C}$, or more exotic (and costly) reactor materials will be needed. If there are small amounts of unsaturated hydrocarbons present, ethylene for example, smaller crystallites will be produced, and this will help to keep the catalyst active. This is another argument for using propane as a feedstock also.

One other thing to point out is that the relationship between crystallite size and relative reactivity does not appear to be as pronounced as originally thought. In Exhibit $2 \mathrm{~A}$, benzene crystallites were shown to be three times as active as methane crystallites; in the more recent Exhibit $2 B$, it is only twice as much.

\section{Do you foresee a scenario where all of the needed catalyst is produced via the reaction, and you need no external catalyst source?}

Yes, especially if the catalyst is kept active by recycling some of the product. Dr. Muradov indicated that if you periodically add some unsaturated hydrocarbon (or if you 
recycle some product that contains unsaturated hydrocarbon) such as ethylene, you will activate the catalyst. This is the argument seen in Question 8. This phenomenon is shown in Exhibit 4, where each hydrogen spike is an indication of ethylene injection. Dr. Muradov refers to this as "internal activation". Alternatively, "external activation" can be accomplished by removing, grinding, and heating the product carbon. Finally, the catalyst can be reactivated by adding some steam, which will gasify the surface of the catalyst.

The injection of ethylene seems to be a reasonable, less costly approach for catalyst activation. Exhibit 4 indicates that the process appears to work. The grinding approach also likely will work (although I have no data), but will mean a new subsystem. The prospect of applying steam to the catalyst surface does not seem as good an approach. It either implies a shut-down of the system for the regeneration, or if it is done during a run, it would probably result in steam reforming and formation of $C O$.

10. Your technological scheme indicates that your reactor pressure will be 100-500 kPa (about 1-5 atm.) What is the basis for choosing this pressure range? Have previous tests shown this range to be optimal?

Running at about one atmosphere precludes needing special equipment. Also, lower pressure increases the production rate as seen in Exhibit 5. Low pressure, however, means needing too large a system. Dr. Muradov also found that 5-10 atmospheres is an ideal pressure for putting their reaction product through a separation membrane. Therefore, they will likely go with about 5 atmospheres.

\section{How do you plan to deal with tar formation -- or don't you expect to have any?}

With some of the higher hydrocarbons, (diesel, gasoline, for instance) you may get some tars. Dr. Muradov believes that you can avoid these by optimizing your temperature and flow conditions.

\section{If you were to use some of the carbon byproduct to heat the reactor, how much} carbon dioxide would you produce?

Dr. Muradov calculated the $\mathrm{CO}_{2}$ produced thusly:

$$
\begin{aligned}
\mathrm{CH}_{4} \rightarrow \mathrm{C}+2 \mathrm{H}_{2} & =75 / \mathrm{kJ} / \text { mole } \\
\mathrm{C}+\mathrm{O}_{2} \rightarrow \mathrm{CO}_{2}= & -395 \mathrm{~kJ} / \mathrm{mole} \\
75 / 395 & \approx 0.2
\end{aligned}
$$

So you would use (theoretically) about 0.2 moles of carbon to provide sufficient heat to produce 2 moles of hydrogen. This would produce 0.2 moles of $\mathrm{CO}_{2} \cdot\left(0.1\right.$ moles $\mathrm{CO}_{2}$ produced for every mole of hydrogen.) 
Steam methane reforming produces about $1 / 2$ mole of $\mathrm{CO}_{2}$ for each mole of hydrogen, Dr. Muradov indicated. There are two sources of $\mathrm{CO}_{2}$ for the reforming process: The reaction itself that produces 1 mole $\mathrm{CO}_{2}$, for every 4 moles of hydrogen, and the reaction heat process which uses about $20 \%$ additional methane, thereby producing another 0.2 moles of $\mathrm{CO}_{2}$ for 4 moles of hydrogen. The total is about 0.3 moles of $\mathrm{CO}_{2}$ for each mole of hydrogen, rather than 0.5, but that's still three times the amount from the thermocatalytic cracking process.

\section{Please describe the jet attrition system.}

The carbon particles, about $1 \mathrm{~mm}$ in diameter are flowed into a pipe. Methane is added tangentially through jets, creating a vortex. The carbon particles collide with and abrade one another. Larger, heavier particles are more subject to the centrifugal force created by the vortex, and they move to the walls of the pipe where they are continuously abraded. The smaller, lighter particles (at 5-10 microns in size) are not affected as much and can get carried down the center of the pipe by the jet stream.

\section{In the 2001 Report, you discuss a $1 \mathrm{~kW}$ "hydrogen reactor" that appears to run on liquid fuels. You have indicated in the FY 2002 AOP that you are scaling this unit up to 3-5 kW. How and where would you intend a commercial version of this unit to operate?}

Dr. Muradov says that they will likely run the $1 \mathrm{~kW}$ reactor (the one he demonstrated for me) on a liquid fuel such as gasoline. He would first dry the gasoline, and also would place a methanator in front of the fuel cell in case any carbon oxides were formed.

I'm not sure if a gasoline system is appropriate now; most current thinking is going in the opposite direction. Also, I am not sure that the Hydrogen Program is the correct venue for thermocatalytically cracking gasoline.

The $5 \mathrm{~kW}$ unit would be very applicable to a distributed or portable system, perhaps in a remote area, or perhaps in a small residential setting (2-3 houses). It could be totally grid independent. Dr. Muradov thinks that this system would be superior to (and smaller than) a small steam methane reformer, as no water-gas shift or purification system would be necessary. You could "just attach it to the propane tank." Dr. Muradov also indicated that the carbon black formed could be used as a source of heat for the site.

For the sizes that Dr. Muradov indicates, one probably wouldn't find a steam reformer economical anyway. If a grid connection were available, or renewable energy resources were available, the comparison would best be done with an electrolyzer.

Finally, Dr. Muradov mentioned that he has been in contact with a local company that is interested in matching his system with an alkaline fuel cell.

\section{You have stated that the output of your generator contains "no" or "no appreciable" amounts of carbon oxides. Has any CO been detected at all? Is the}




\section{level below the $10 \mathrm{ppm}$ that is generally considered the maximum allowed in a PEM fuel cell?}

Dr. Muradov states that he sees no CO at all. This is to be expected if the feedstock is pure. If he were to find $\mathrm{CO}$ present he would use a methanator to get rid of it.

It might be of value to run a standard containing low concentrations of $C O$ to ensure that FSEC's system can pick it up.

\section{What happens to the sulfur that might be present in the feedstock?}

We already discussed this somewhat in Question 1. Dr. Muradov will probably install a zinc oxide bed between the reactor and fuel cell when he is ready to switch to industrial gas feedstock.

\section{Where did the selling price of $\$ 300 /$ ton of carbon black come from? You quote that number in your 2001 report.}

In discussing this, Dr. Muradov first mentioned that one of his industrial partners is Universal Oil Products (UOP), who are very interested in carbon products, and performed an analysis of the carbon produced by this process. It was found to be very similar to graphitic carbon. I assume they were talking about the reaction product of lower temperature/ longer residence time reactions, where the kinetics are slow enough to grow graphite. UOP feels that this product could be very valuable to the aluminum industry as well as iron alloy manufacturers. The application is in electrode materials.

In the aluminum industry, for instance, about one-half ton of carbon electrode material is consumed per ton of aluminum manufactured. (When referring to "tons", Dr. Muradov means metric tons.) In the U.S. there are about 4 million tons of aluminum produced annually. There are about 0.14 tons carbon used per ton of some iron alloys, but it is only 0.01 ton per ton of steel.

Currently, these industries manufacture their carbon electrodes from petroleum coke, made by coking residual oil. This material is contaminated with sulfur and metals such as vanadium and nickel, and must therefore be purified. This purified electrode material costs these industries about $\$ 300$ per metric ton (30 cents per $\mathrm{kg}$ ).

P. Spath and W. Amos of NREL have published an analysis of the solar thermal process for methane splitting at the University of Colorado and at NREL and quoted costs for specialty carbon blacks in the \$1.75-3.30 per $\mathrm{kg}$ range, and for graphitic carbon that range from 22 cents to $\$ 1.90$ per $\mathrm{kg}$. Drs. Weimer and Lewandowski who are doing the solar thermal work also estimated a cost of about 44 cents per $\mathrm{kg}$ for low grade carbon black. As expected carbon black is more valuable than graphitic carbon, and Dr. Muradov's numbers for his graphitic carbon fit into the lower range of the NREL data. If companies are indeed interested in Dr. Muradov's graphitic material in quantity, it seems to solve one major problem. However, the question remains as to how efficient at 
producing hydrogen the system would be under the conditions needed to produce this electrode carbon material.

Dr. Muradov estimated that a 60 million standard cubic feet per day hydrogen plant would produce 120,900 tons of carbon per year. If you assume that there would be a need for 5 million tons of carbon per year, this could be produced in 41 plants. So, Dr. Muradov states, there is a sizeable market for this type of graphitic carbon, and this doesn't even begin to look at the carbon black market and products like carbon filaments and nanotubes, which could also be produced under certain reactor conditions. As long as we remember that we need to make hydrogen.

\section{What quantities of carbon byproduct do you envision producing? What is a reasonable amount of carbon black that could be produced without upsetting the carbon black market? If you had to sequester large quantities of carbon, what would it cost?}

Much of this is really already answered in Question 17. On the carbon sequestering question, Dr. Muradov stated that it is easy to put carbon in a landfill, and the cost would roughly be equivalent to $2 \%$ of the price of hydrogen.

\section{You refer to new markets evolving for carbon black. Have any studies been performed estimating what size this market(s) might be?}

The aluminum production electrodes already mentioned is a potential large market for carbon black.

In addition, Dr. Muradov cited a possible construction use - building blocks as a potential market, replacing a quantity of cement. If carbon black could be used in this application, it would also cause a reduction of $\mathrm{CO}_{2}$ emissions. Cement is a large $\mathrm{CO}_{2}$ producer.

The Intergovernmental Panel on Climate Change (IPCC), Working Group II, the "official UN technical document used for global climate change negotiations" states that every ton of cement produced emits $3 / 4$ ton of $\mathrm{CO}_{2}$ from energy use, and an additional $1 / 2$ ton of $\mathrm{CO}_{2}$ from calcining the limestone.

\section{In the economics, has any provision been made for needing to constantly grind the carbon byproduct? About how much would you estimate this process would add to the cost of hydrogen?}

The NREL economic study included the cost of grinding. NREL will be publishing the results of the study.

\section{The Question of Burying Energy in Carbon:}

Dr. Muradov and I discussed a concern that the Peer Reviewers had at the FY 2001 Annual Hydrogen Review meeting: If you pyrolyze or crack methane (or any $\mathrm{C}_{\mathrm{x}} \mathrm{H}_{\mathrm{y}}$ 
hydrocarbon) producing hydrogen and carbon, a large fraction of the potential energy remains in the carbon, compared to combusting the hydrocarbon. If you then bury the remaining carbon, you've "wasted" that energy - somewhere around half of the total energy, depending on the hydrocarbon.

Dr. Muradov took issue with this criticism, saying that the comparison was unfair, and thermocatalytic cracking should be compared to steam reforming, not to combustion. We are trying to make hydrogen, and combustion does not make hydrogen.

Thermodynamically, cracking is favored over steam reforming:

SMR: $\mathrm{CH}_{4}+\mathrm{H}_{2} \mathrm{O} \rightarrow 4 \mathrm{H}_{2}+\mathrm{CO}_{2} 253 \mathrm{~kJ} ; 63.3 \mathrm{~kJ} /$ mole $\mathrm{H}_{2}$ produced

Cracking: $\mathrm{CH}_{4} \rightarrow 2 \mathrm{H}_{2}+\mathrm{C} \quad 75 \mathrm{~kJ} ; 37.5 \mathrm{~kJ} /$ mole $\mathrm{H}_{2}$ produced

In addition, Dr. Muradov also offers potential saleable uses of carbon (see Question 17) or could use the carbon to provide process heat.

While I see the reviewers' concern, I think Dr. Muradov has a good argument on the correct comparison issue. In addition, in my opinion, the environmental benefit of not producing greenhouse gases is a big plus. Also, the carbon energy is not lost; the carbon could always be burned later, with (as the reviewers suggest) coal-perhaps in a central, $\mathrm{CO}_{2}$ sequestration-capable facility. Finally, Dr. Muradov in Question 17 addresses alternative uses for the carbon.

\section{Final Thoughts:}

This is still a difficult project to assess thoroughly. There are some very good aspects to the project and to the progress that has been made over the past couple of years. The old metal catalyst has been replaced with carbon, there is no longer a need to burn coke off the catalyst, and some real progress has been made in identifying several ways of dealing with byproduct carbon. In general, I find most of this very encouraging.

The concerns come in on two fronts: first there is the fairly large number of items that FSEC believes can be done, but have not yet been demonstrated. This is not to say that they are incorrect in their assumptions. I just believe that some demonstrations of these concepts, subsystems, and processes need to happen soon. This includes: successful demonstrations of a methanator, a desulfurization scheme, a grinding process for byproduct carbon with subsequent use of the material as a catalyst, a reaction scheme that will give both a high hydrogen yield and a saleable/usable byproduct, and the details of how the byproduct will be sold, used or sequestered.

My second concern has to do with reproducibility and inconsistencies within the data. For instance, Dr. Muradov spoke of 70-80\% hydrogen yields, demonstrated to me two runs with yields in the 60-70\% range, and used as examples to answer several of my questions, runs where the hydrogen yield was in the 30-40\% range. In another example, the reactivity differences between crystallites formed by different hydrocarbons appear to 
be unclear from the data. Are benzene crystallites two times or three times as active as methane crystallites? These may be reproducibility problems or they may be due to data being taken under vastly different, but undocumented conditions.

I believe that FSEC needs to address these two areas of concern in order to keep this project going forward. And at this point, I do feel that there is enough that is encouraging about this project to keep it going forward. 
Exhibit 1. Effect of Surface Area of Carbon Catalysts on Methane Decomposition Rate Showing Limited (Exhibit 1A) and Augmented (Exhibit 1B) Data

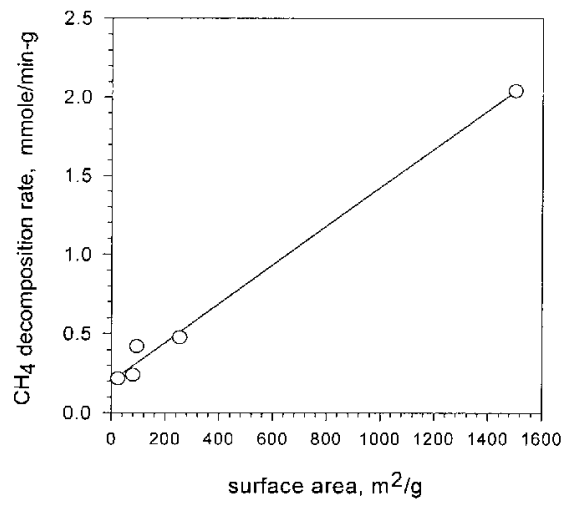

Exhibit $1 \mathrm{~A}$

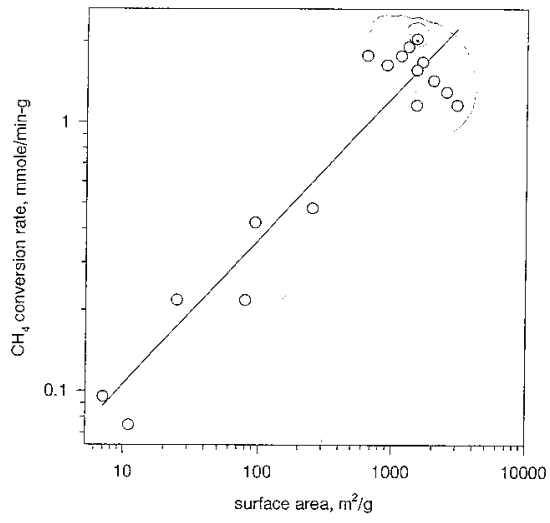

Exhibit 1B

Exhibit 2 Gaseous Products from Methane Pyrolysis over Carbon Black at $850^{\circ} \mathrm{C}$

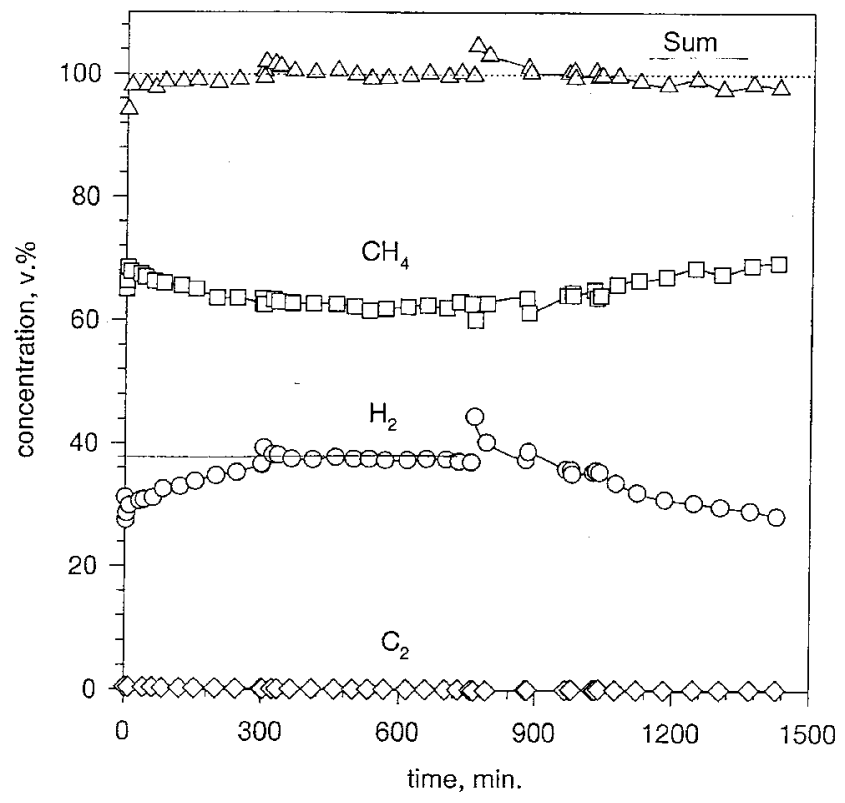


Exhibit3. Relative Activity of Carbons Produced From Hydrocarbons as a Function of Crystallite Size

from FY 2001 Review (Exhibit 3A) and from 2/11/02 Site Visit (Exhibit 3B)
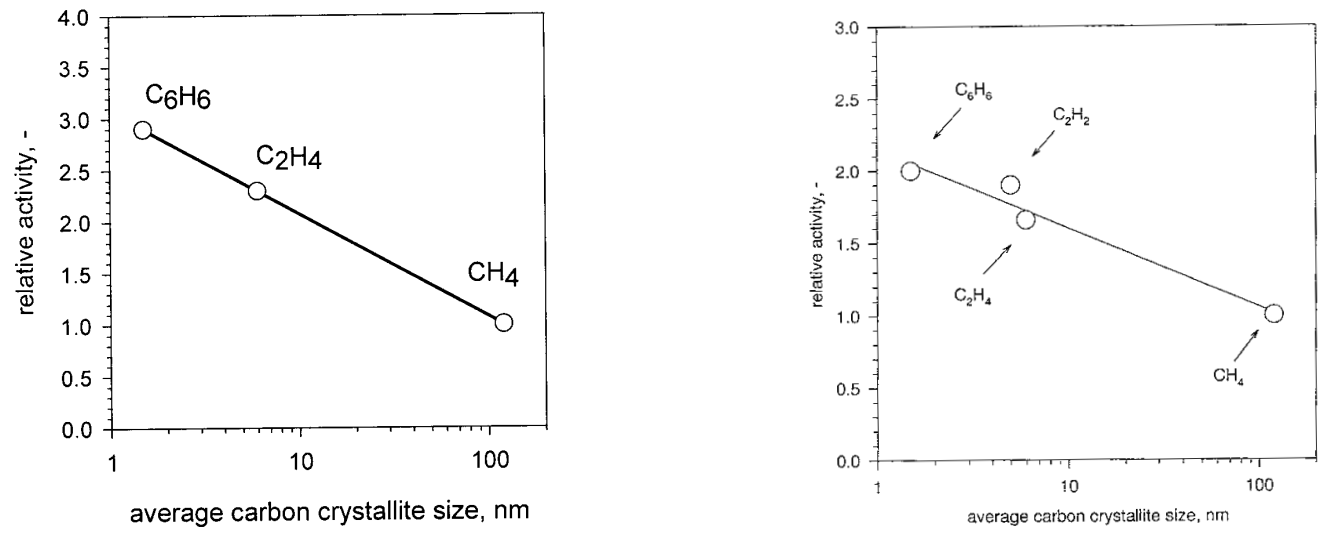

Exhibit 3A

Exhibit 3B

Exhibit 4. Effect of Activation of Catalyst by Ethylene

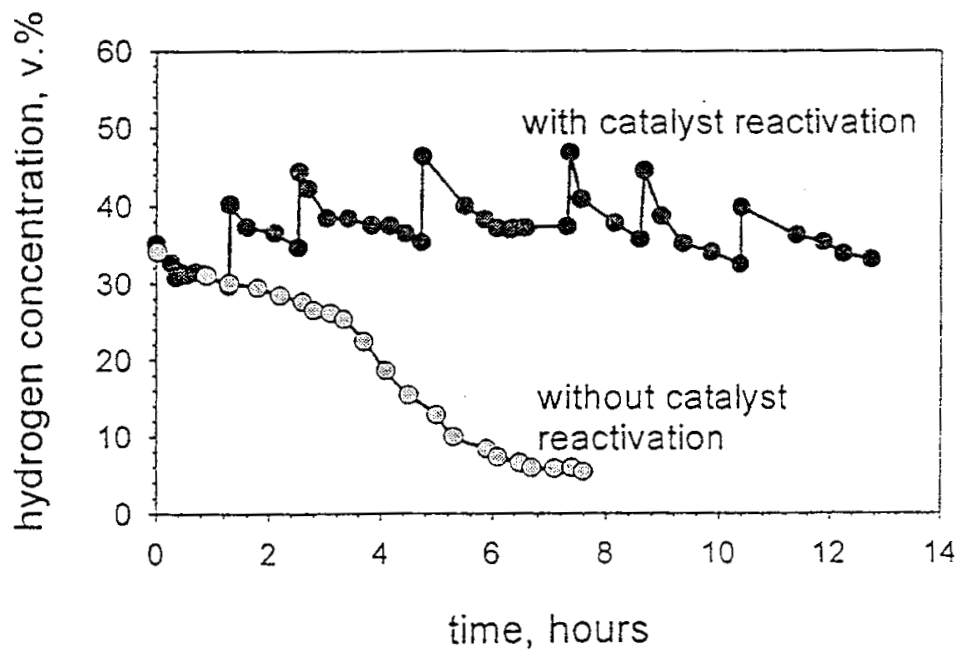


Exhibit 5. Effect of Pressure on Methane Decomposition and Hydrogen Formation

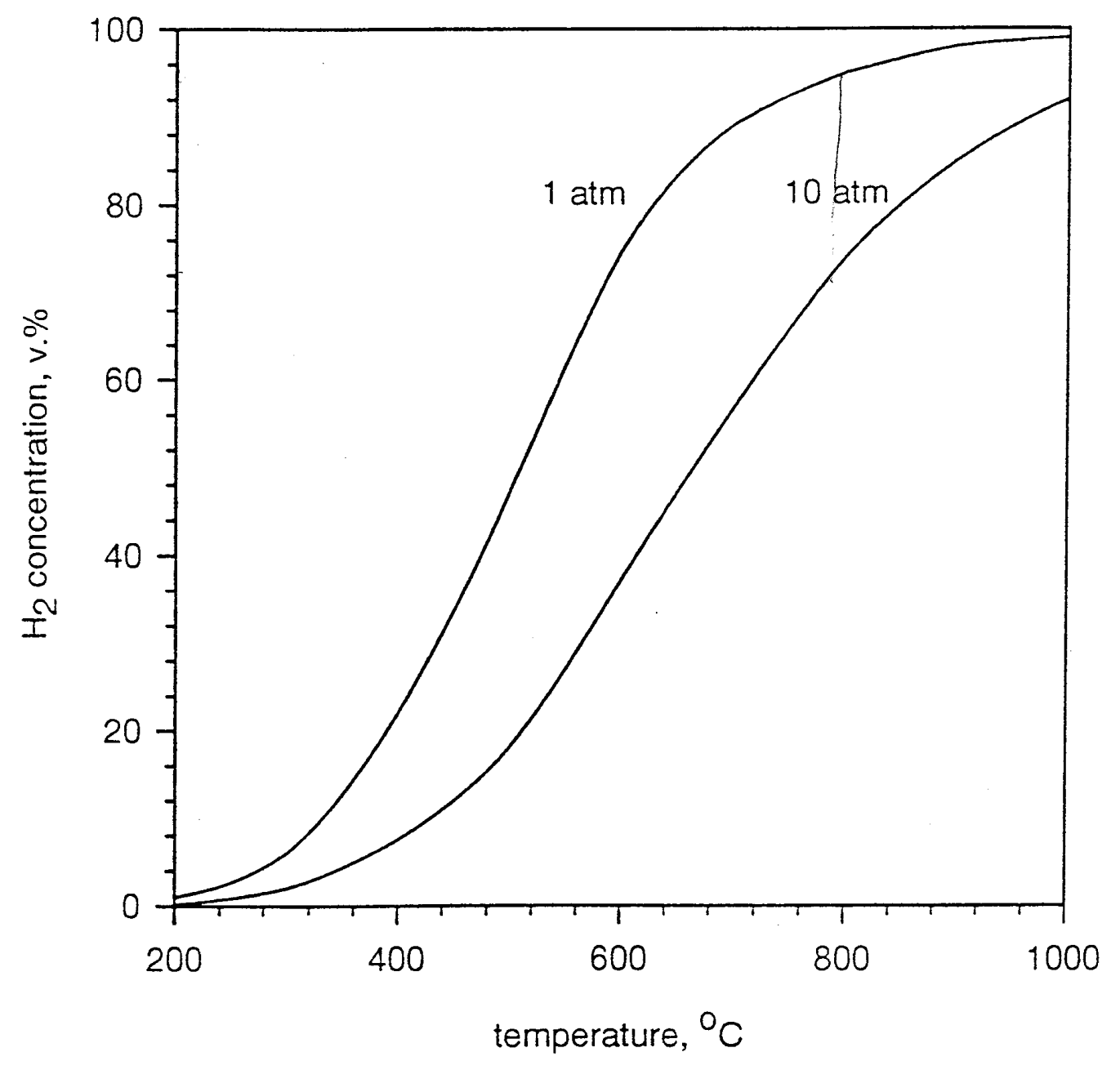


Technical Evaluation Report

Project: High-Efficiency Steam Electrolyzer

Company: Lawrence Livermore National Laboratory

P.I.: Dr. Quoc Pham

Site-Visit Date: February 20, 2002

Evaluation by: Edward G. Skolnik, Energetics, Inc.

\section{Summary:}

The high temperature electrolyzer project being carried out at Lawrence Livermore National Laboratory (LLNL) first takes advantage of high temperature operation to reduce the operating voltage compared to a conventional electrolyzer. A standard Proton Exchange Membrane (PEM) electrolyzer that operates at under $100^{\circ} \mathrm{C}$ has a potential of about 1.2 volts at zero current density and a potential of about 1.8 volts at a reasonable current density (say, $0.4 \mathrm{amps} / \mathrm{cm}^{2}$ ). At $1000^{\circ} \mathrm{C}$, the steam electrolyzer has a zero point voltage of about 0.8 volts, and is about 1.3 volts at $0.4 \mathrm{amps} / \mathrm{cm}^{2}$.

The second difference from conventional electrolysis (and this is the "hook"), is that it employs natural gas instead of air to act as a reducing agent at the anode of the electrolyzer to further reduce the potential. It is actually negative, -0.2 volts at zero current density, and is only about 0.2 volts at $0.4 \mathrm{amps} / \mathrm{cm}^{2}$.

Using this process, LLNL is able to produce hydrogen using far less energy than with conventional electrolysis, substituting natural gas based thermal energy for a portion of the more expensive electrical energy.

I see the following strengths in the project:

- The cost associated with electrolysis remains a serious obstacle to producing hydrogen from water. The fact that the LLNL project opts to reduce the amount of electricity needed by operating at high temperature is a benefit, albeit a non-unique benefit. The fact that LLNL is reducing the voltage needed even farther by oxidizing methane at the anode provides a much greater benefit, and one that is unique to the Program.

- LLNL has overcome adversity to develop what appear to be successful solid oxide electrodes.

- The high pressure output will mesh well with some hydrogen storage concepts, and will make additional compression easier.

I see the following items that need to be addressed:

- While the gel casting method (see below) of making anode tubes seems to be working, I think it is still too early to gauge the level of success here. I think LLNL 
still needs to answer questions such as: 1) how long should the tube be (it almost seems from some of the arguments that LLNL has made, they wanted a shorter tube until they found out they could make a longer one,) and 2) how pure must the starting materials be - is it different for gel casting than it was for the other processing methods?

- LLNL has made a decision to combust methane at the anode rather than use a partial oxidation process that would increase the hydrogen yield, but would lend separation and purification complexities to the system. This may or may not be the right decision. I question not the decision, but ask on what it is based. According to LLNL, the partial oxidation method produces four times as much hydrogen as does the total oxidation process. The separation/purification process, I would think, wouldn't be any more or less difficult than for any other partial oxidation system. On the other hand, the total oxidation process leaves the hydrogen totally CO-free. I think we need to see numbers (engineering and economic) that confirm the decision to go with total oxidation.

- How much of a problem is the unwillingness of manufacturers to work with nickel oxide going to be?

\section{Introduction and Background:}

I visited LLNL to discuss the high temperature electrolyzer project with PI Dr. Quoc Pham and his associates, Dr. Brian Anderson and Dr. Peter Martin. The researchers made a more or less formal presentation (using last year's annual review report) on the project. I also got a tour of the project area including a demonstration of the spray coating process, and we also spent a considerable length of time discussing the questions I had earlier sent to Dr. Pham, as well as other aspects of the project. Program Manager Dr. Bob Glass also joined the discussion for about an hour.

Dr. Pham began by making a statement that he attributed to a spokesman from Ford Motor Company who, while addressing PEM fuel cells said that if the fuel cell uses "lowgrade" hydrogen, the stack will fail irreversibly in about 120 hours. With pure hydrogen it will last over 1000 hours. (I would hope it would last longer than that.) In addition, Dr. Pham added, if you are producing hydrogen at a fueling station you are somewhat limited. The amount of hydrogen used by a fueling station is not a constant. Thus, hydrogen production and storage must be flexible. Steam methane reforming is not very efficient at the fueling station size because of heat exchanger costs. On the other hand, if you use centralized reforming, a new hydrogen pipeline costs about one million dollars per mile.

Dr. Pham believes that a metal hydride system is best for flexible amounts of storage at a fueling station. Since metal hydride storage generally needs about $200 \mathrm{psi}$ pressure to take up hydrogen, this type of storage is most compatible with electrolysis. Regardless, of the type of storage, it would even be easier to compress hydrogen (fewer stages) if one started at 200 psi. 
Conventional steam electrolysis operates at $1000^{\circ} \mathrm{C}$, still needs about 0.8 volts to overcome the thermodynamic potential (as opposed to 1.23 volts for conventional electrolysis), requires about 1.1 volts at a current density of 0.3 , and in addition, the process "wastes" co-product oxygen.

The LLNL system uses the oxygen to combust methane. The methane, acting as a depolarizer, requires even less voltage, as shown in Exhibit 1. In fact, at under 0.2 amps $/ \mathrm{cm}^{2}$, you are actually generating electricity (of course, you wouldn't operate at such a low current density unless you were prepared to pay a high capital cost.) Dr. Pham mentioned that with some of the higher porosity coatings, they have actually seen zero voltage at $1 \mathrm{amps} / \mathrm{cm}^{2}$.

While $\mathrm{CO}_{2}$ is indeed generated, it is done so at a much lower rate than conventional electrolysis, where one can assume that the grid electricity used to power the electrolyzer comes from coal. This does make it attractive, but to be fair one has to consider that electrolysis could be powered by renewable resources. In addition, even if it is coalderived, $\mathrm{CO}_{2}$ sequestration would be more suited to the centralized coal-fired power plant than to the distributed natural gas assisted electrolyzer.

The system is modular, making it ideal for distributed generation.

\section{Status:}

LLNL had been evaluating two different modes of operation. In one, the oxygen coming through the electrolyte is used to totally combust the methane. In the other, a partial oxidation process is used, resulting in hydrogen formation at the anode, and requiring separation and purification of this hydrogen, as well as a water shift step to convert CO to $\mathrm{CO}_{2}$.

LLNL no longer is considering the partial oxidation mode of operation. They have decided on the total oxidation approach, with no hydrogen being produced (or at least recovered) on the anode side. While it is true that the partial oxidation mode results in more hydrogen, about four times as much, Dr. Pham believes that the associated shift and cleanup necessary outweighs the benefits of getting the extra hydrogen. I think we need to see an analysis comparing the two options. While total oxidation results in all the hydrogen coming from electrolyzing water making it CO-free, the four-fold increase in hydrogen production from partial oxidation bears reconsideration, I think. We could even ask why anyone would do partial oxidation at all if cheaper hydrogen can be obtained from high temperature methane assisted electrolysis.

\section{Tour:}

Dr. Pham and his associates took me through the laboratories where the components of the high temperature electrolyzer are being developed. 


\section{Tubes:}

We first went to the characterization laboratory, and looked first at models of the processing of the nickel oxide and zirconium oxide ceramic tubes that serve as the anode for the electrolytic process, and some actual successful and failed tubes as well. Dr. Pham indicated that there had been big problems with the manufacturing of these tubes. (We saw the actual processing equipment later in the ceramic processing lab, discussed below)

Originally, LLNL planned to outsource the development and manufacture of the tubes. However, they found that companies were reluctant to work with nickel oxide, which is carcinogenic. Therefore, LLNL decided to develop their own tubes. They tried isostatic pressing (cold molding) but had a porosity problem. They then tried to make the material more homogeneous by adding some starch for the mixing step and then burning out the starch later. This, however, caused the tubes to crack. In addition, there were raw materials variation problems.

The nickel oxide problem is quite disturbing. Nickel catalysts and nickel oxide are used in many applications including reforming technologies and solid oxide fuel cell components. The fact that LLNL could not get an industrial organization to work with them either says they didn't ask the right people, couldn't get anyone to work with them within budget, or perhaps LLNL shouldn't be using nickel oxide. (Actually, I'd be surprised if the latter were the case.)

After about a year of these types of problems, and also an attempt to develop a difficult extrusion process for the tubes, LLNL began using a different technique called "gelcasting." This technique was originally developed at Oak Ridge National Laboratory, and was then refined by Dr. Pham. This was described as a polymerization process that uses a proprietary polymer and also uses some starch to provide porosity. Dr. Pham indicated that this was a low cost process, and that now LLNL is making good tubes.

Following the gel casting process, the organic (starch) is burned out. Next, a ten micron thick zirconia electrolyte layer is spray-coated onto the anode tube. This is sintered at over $1400^{\circ} \mathrm{C}$ to densify the electrolyte. This is followed with a proprietary nickel-based cathode coating, which is also spray- coated on top of the electrolyte. The cathode coating is several tens of microns thick. There is then another sintering step. Porosity is less of a problem with the coatings when they are sprayed-on. Finally, the electrode assembly is reduced in a hydrogen atmosphere, producing nickel.

Currently, LLNL makes short (3-6") tubes which are brazed together. With the gel casting process, they are evolving toward longer tubes, and will soon be making electrolyzers with full length tubes. They will then have to explore a different method of obtaining low current/ high voltage. (See Questions 13 and 14.) 


\section{Seals:}

LLNL used to use a ceramic paste seal, but it leaked at $80 \mathrm{psi}$, and broke with thermal cycling. They now use a metal to ceramic seal whose composition is proprietary. They can now cycle the seal, and pressurize it to $150 \mathrm{psi}$.

\section{Spray-Coating:}

Dr. Pham demonstrated the spray-coating procedure for me, using a flat plate rather than a tube. Without getting into some of the details that are proprietary, the spray coating process is computer-controlled, and sprays micron-thickness layers of material (electrolyte or cathode) onto the substrate (anode tube). The spray coating system relies on multiple passes of thin layers rather than fewer passes of thicker layers to ensure uniformity of the coating. With this process, LLNL is able to control porosity easily.

LLNL is currently working on a new process that will reduce the inclusion of foreign materials into the tube structure. These foreign materials can prove to be a serious problem (see Question 5). This process works at room temperature and takes about $1 / 20^{\text {th }}$ of the time of the original spray coating process.

\section{$\underline{\text { Reactor: }}$}

Dr. Pham also showed me the high temperature reactor that produces the hydrogen. It is interesting that it is called a "reactor" and not an "electrolyzer". There is a boiler to produce steam, and the reactor is heated to $700-800^{\circ} \mathrm{C}$. Electric voltage is used to produce the hydrogen. Steam is condensed and recycled. The only material to come out of the cathode side (the outside of the tube) is hydrogen.

Methane goes through the center of the tube (anode) and is oxidized. The product gas is a combination of unrelated methane, $\mathrm{CO}, \mathrm{CO}_{2}$, water, and some hydrogen. This material is recycled and burned to produce process heat. Note that no anode hydrogen is considered to be part of the hydrogen production process. If this is indeed the anode side process, it would appear that partial oxidation is still taking part in the overall reaction scheme. If it were a pure total combustion process, no CO or hydrogen would be formed. Perhaps they are still moving toward a total combustion process, but are not there yet. If they do go to total combustion, they will, of course, not have any gases to recycle and burn for process heat.

Dr. Pham pointed out that since the shell side of the tube (cathode) is at high pressure, and the inner side (anode) is at low pressure, any leak developing would cause hydrogen to bleed into the methane and the combustion gases rather than vice versa. Thus the hydrogen will not be contaminated.

Because of hood problems, LLNL was unable to actually show me hydrogen being produced. 
Dr. Pham also mentioned that LLNL has a proprietary process for producing high pressure, room temperature hydrogen.

\section{Ceramic Processing:}

In a separate laboratory, Dr. Pham showed me the ceramic processing equipment. Powder processing includes ball mills to break down agglomerates, and vats to boil off solvents. There are cylindrical molds for isostatic pressing, and a table-top extruder. Isostatic molding did not work, as we have already discussed, and the extruder was essentially never used due to safety reasons. It was meant to extrude nickel oxide, and did not have an adequate fume hood. (Why buy equipment and then find out you can't run it? I've seen this type of phenomenon several times in my career. I don't understand it.)

This led LLNL to turn to gel casting. This is done using an aluminum mold, with an aluminum rod for the bore hole. The mold is 12 inches long. Since ceramic shrinks, however, the tube is only about $10 \frac{1 / 2}{2}$ inches long. A mixture of monomer, starch (for porosity), nickel oxide powder, zirconia, polymerization catalyst, and a solvent is blended into a paste. It is put into a syringe and injected into the mold. It is then heated to crosslink the polymer. It is the polymerization process that locks everything in place. The tube is then removed from the mold, and the organics are burned out.

\section{Questions and Answers:}

I sent Dr. Pham a set of discussion questions prior to my arrival. Dr. Pham responded in writing to the questions, and we also spent a significant portion of the meeting in discussion of these questions in great detail. This is all reproduced here, with the questions indicated in bold, the written answers shown in "quotations", our discussion shown in normal type, and my comments added to many of the questions during my later analysis and assessment shown in italics.

\section{How does high temperature electrolysis with methane depolarizer compare to steam reforming in its ability (efficiency, emissions, economic) to produce hydrogen.}

"The efficiency of the Natural-Gas-Assisted-Steam Electrolyzer is $74 \%$ at peak value. The efficiency is dependent on the current density passing through the system. At high current densities, the efficiency is lower but the production rate is higher. The selection of the operating conditions will depend on the compromise between capital cost and efficiency requirements. For comparison, the efficiency of the steam reforming (SR) plant is $65-75 \%$. However, steam reforming is typically done at large central plants and the hydrogen must then be delivered to the users either via pipeline or by trucks. Furthermore, the hydrogen from steam reforming plant is made at low pressure due to the negative effect of pressure on the equilibrium reactions. The SR hydrogen must then be either compressed to high pressure or liquefied before the transportation step. Therefore, although the efficiency of the NGASE could be somewhat lower than that of the steam reforming, if one includes the need for hydrogen pressurization and delivery, the NGASE is much better suited for a distributed hydrogen production system. The same argument applies to the emissions. We estimate an emission rate of 0.4 mole of $\mathrm{CO} 2$ per mole of $\mathrm{H} 2$ produced." 
An "ideal" $100 \%$ efficient steam reforming system would produce 0.25 moles of $\mathrm{CO}_{2}$ for each mole of hydrogen. An $80 \%$ efficient system would produce about 0.3 moles of $\mathrm{CO}_{2}$.

LLNL tries to keep the efficiency at least at $60 \%$.

Dr. Pham estimates that hydrogen can be produced for the gasoline equivalent of $\$ 1.70$ /gallon (not including gasoline tax). This is a very preliminary number. Dr. Pham stated that if you put $4 \mathrm{~kg}$ hydrogen in your car - enough to go 320 miles, it would cost about $\$ 7$ to refuel the car.

The "hook" is the distributed nature of the hydrogen production.

\section{Do you have schematics of the two options for methane use in the electrolyzer?}

"Originally, we developed two options for the electrolyzer. However, the option, called "total oxidation" is the preferred one due to it much greater simplicity. Indeed, hydrogen is produced only on the cathode side and is not mixed with the fuel gas at any time. There is no need for any extra gas purification device. The reaction in the anode side is somewhat between a total oxidation and a partial oxidation. The exact nature is not a matter, it is the fuel utilization that is an important factor. We want to have as high a fuel utilization as possible, typically it will be 80 to $85 \%$."

Dr. Pham considers the reactions occurring at the anode as simply combustion of a mixture of combustible material. So even though a little reforming takes place at the anode, the syngas that is formed gets burned as well. The hydrogen produced isn't product hydrogen at all. All of the product hydrogen is produced at the cathode. At this time, LLNL has already down-selected to the "total oxidation" mode. This is a simpler cleaner option. Nevertheless, both options are shown in Exhibit 2.

\section{In your partial oxidation mode, are you dealing with standard partial oxidation catalysts or is this something different?}

"We have been using conventional catalysts. We are also developing new formulations."

They are looking at new catalysts that will reduce the amount of carbon deposition. This would be the case for either mode of operation, total or partial oxidation.

\section{Does the electrolyzer employ a solid oxide electrolyte?}

"Yes."

It has to be solid oxide at these temperatures.

True. It's just that this was never mentioned in the report at the time.

Dr. Pham considers the system very similar to a solid oxide fuel cell, only less expensive. Since most solid oxide electrolytes are made using chemical vapor deposition which is an 
expensive process, LLNL is looking at a cheaper alternative. They are developing a process called colloidal spray deposition.

\section{In your FY 2001 Annual Review Report paper you spoke about tube fabrication, and stated that at first you had a coating yield of less than $10 \%$ for the 3 -inch tubes. Does this mean that only $10 \%$ of the coatings were defect free?}

"Yes. The original coating technique was very sensitive to defects on the substrates. We had very low yield. Last year, we improved that yield by modifying the coating technique. Recently, we further improve the coating technique to make it much more reliable. We have been able to coat tubes as long as 10 " without defects."

The problem was that earlier, LLNL was using a lower purity nickel oxide. Dr. Pham described a typical impurity as a "rock." This would sometimes be pulled out during the process, resulting in a large, unpluggable hole. Also, sometimes dust would blow out of a hole, resulting in a bad coating. They now have far fewer defects.

\section{Please discuss current tube fabrication processes to whatever extent that is possible}

"Originally, the tubes were fabricated using cold isostatic pressing. The process is very labor intensive and is not very suitable for our purpose of making porous tubes due to the use of high pressures. We have looked for companies to sub contract the tube fabrication since this is not our expertise. However, due to the presence of $\mathrm{NiO}$ which is carcinogenic, no one is willing to take the job. This has forced us to develop our own process. We considered tube extrusion, which is the well-known method to make tubes. However, this is a difficult process that could take year to develop. Recently, we have been successful in making tube using a novel technique called gel casting. We have been able to make tubes as long as 12 "."

This has also already been discussed in detail in the "Tour" section.

\section{If you cover a defect in a tube with a defect-free coating, does that render the defect harmless?}

"Almost. The biggest issue with defect is the short-circuiting problem between the two electrodes. When the defect is covered, no more short-circuiting can occur. But the coating at that point can be mechanically weak."

This mechanical weakness is exacerbated by the pressure differential between the inside and outside of the tube, and can lead to cracking. So ideally, you don't even want a covered defect.

\section{When you tested your tubes by temperature cycling, was this done under pressure?}

"No." 
During the temperature cycling phase, the pressure seals were not adequate. Now, however, they have good seals, and they have now successfully pressure cycled both tube and seal.

But apparently they have not yet temperature cycled the tubes under pressure.

\section{What does the statement that "tube performance is still only $30 \%$ of disk data" mean? Is it the amount of hydrogen produced at a given current density or a given methane feed rate?}

"That means that the normalized resistance of the disk is about $30 \%$ of the tube, meaning that the tube has higher resistance, i.e. that for a same electrical voltage, each area of the tube puts out $30 \%$ hydrogen as compared to the disk case. But this is somewhat unfair comparison because we used the outer area of the tube for normalization. "

This is referring to a flat plate electrolyzer which LLNL uses as a reference system.

The tubular design was chosen by LLNL because it makes it a lot easier to pressurize one side (the steam/hydrogen, or cathode side) to, say 100-350 psi, while leaving the other side (the methane or anode side) at atmospheric pressure. If a flat plate design were being used, it would need a complex system to support the pressure differential.

\section{What steps have been taken to improve the tube performance?}

"The tube microstructure is the main reason of lower performance as compared to the disk case. In particular, the tubes did not have enough porosity, that is related to the isostatic pressing process that was used. We have been working on improving the tube porosity."

The microstructure of the anode is critical. Improving its porosity is the key process improvement. This has been accomplished by gel casting, as discussed during the tour.

\section{What is the target pressure/temperature for the tubes and for the sealant?}

"For the first phase, we just plan to demonstrate a pressure of $150 \mathrm{psi}$ and the operating temperature of $700-750^{\circ} \mathrm{C}$. Ultimately, the target is $350 \mathrm{psi}$ to make the hydrogen produced directly compatible with metal hydride storage. The temperature will be $800^{\circ} \mathrm{C}$."

The short-term target of 150 psi was chosen simply because it's ten atmospheres. The long-term temperature target of $800^{\circ} \mathrm{C}$ is optimal for the total oxidation process.

\section{Are you currently focusing on upgrading the sealant, working on the design that eliminates the sealant, or both? Can you say anything about the new design?}

"In the past, as reported last year, we had a seal that failed at 80 psi and could not withstand temperature cycling. Recently, we have successfully developed a better sealant approach. The seal survive 150 psi pressure differential and multiple temperature cyclings. We have readily developed a design that do not have sealant problem! However, this design requires improved tube manufacturing before it can be implemented." 
The new approach is proprietary. However, Dr. Pham pointed out that if a tube broke, hydrogen (high pressure side) would leak into the methane (low pressure side), so you would not be contaminating the hydrogen, and you would shut down when you saw the pressure drop.

So with the recent improvements in tube design via the gel casting process, they should be able soon to cycle at both temperature and pressure.

Dr. Anderson also pointed out that they are considering all sorts of failure scenarios such as tube cracking, because they would ultimately like to run the process unattended.

\section{Why are you trying to increase the voltage via tube-to-tube connections?}

"The issue with one single long tube is that we have very high current and low voltage. This is difficult to do while being also inefficient, and requires expensive electronics. The ideal is to have high voltage and low current to minimize resistive heating. That is the purpose of the tube-to-tube series connections. However, this design while solving the high current problem, introduces other problems such as complex brazing, difficulties in keeping good alignment. We have developed a much better design (proprietary)."

So they have abandoned the multi-tube-in-series option because there are too many brazing steps. This can lead to leakage problems. With the long tube process, they no longer have this problem.

\section{Why are three tubes connected end-to-end preferable to one longer tube?}

"See above."

The bottom line appears to be that despite the high current/low voltage properties of long tubes, the real problem was that they were unable to make long tubes. The three short tubes brazed end-to-end, however, were not the answer; they appear to cause more leakage problems than anything. Since the new process seems to be successful in making long tubes, they are giving up short tube approach. This apparently means that they will have an added task of current/voltage adjustment when they use the long tube.

Dr. Pham did point out, however, that if they did use the short tubes, replacement would be easier.

\section{Please discuss the term "fuel utilization" as you use it in your System Analysis discussion in the FY 2001 Review Paper.}

"Fuel utilization is defined as the ratio of moles of methane consumed during the electrochemical oxidation in the electrolyzer over the initial moles of methane introduced to the system. Similar to a fuel cell, this fuel utilization should be as high as possible or the system would waste un-used fuel. In an integrated system, the remaining fuel is typically burnt to generate heat that is needed to boil water." 
Ideally, fuel utilization is $100 \%$. But since it is necessary to heat the steam anyway, the unreacted methane can be burned to make steam.

\section{You refer to efficiency comparisons with conventional electrolyzers. Please show how you calculated these efficiencies.}

This question was not answered in writing, but was discussed during the meeting.

The key is that the conventional electrolyzer uses coal-derived electricity. LLNL calculates efficiency from the original fuel to the final hydrogen product - efficiency is always calculated with respect to primary energy.

While a large portion of our electricity is indeed coal derived, I think it is a little presumptuous to use it as the only basis of determining comparative efficiencies especially without stating that this assumption is being used. If the initial electricity source is not coal, the overall efficiency will be different.

\section{Additional Items:}

LLNL is working with an industrial partner, a small company, Solid Oxide Systems (SOX). SOX will do the scale-up, manufacturing and demonstration.

\section{Final Thoughts:}

This project represents a quite clever way of reducing the cost of electrolyzing water to make hydrogen. There has been much work done in developing a method to produce anode tubes, and process the deposition of the electrolyte and cathode. In addition, the determination has been made that the total oxidation mode will prevail over partial oxidation. On the whole, this is a very good project. It may provide a way for inexpensive small scale electrolysis. It may also help to be a stepping stone to pure electrolysis without methane involvement - which would have to be the very long term goal for hydrogen production.

I am, however, still concerned with the tube manufacture. It's not the process that bothers me as much as the fact that LLNL may have a problem getting a manufacturer regardless of the process due to the nature of the nickel oxide powder.

Finally, I think an analysis is necessary that will include both modes of oxidation. We're talking about four times the hydrogen. I think we need to say a little more than shifting and purifying will be difficult. (Note that I am not advocating partial oxidation; I think a little more data is necessary.) 
Exhibit 1. Comparison of Voltage Requirements for Low Temperature Electrolysis, Steam Electrolysis, and Natural Gas Assisted Steam Electrolysis.

\section{Total oxidation mode}

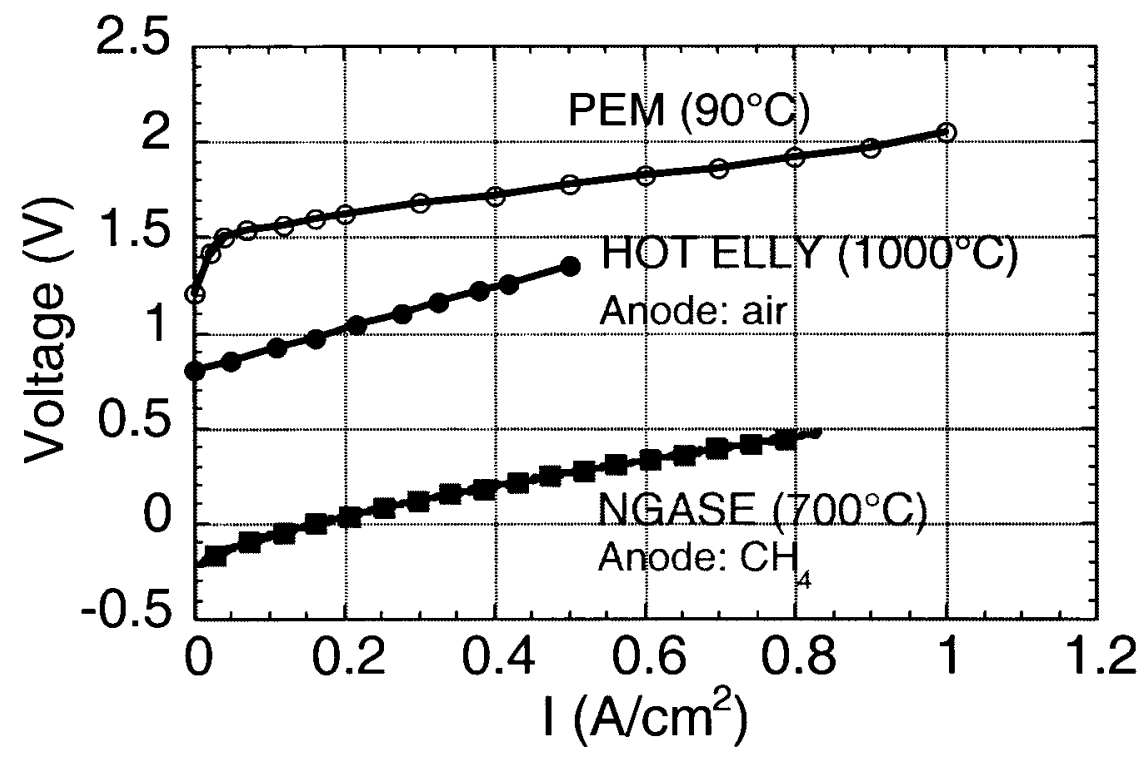

Exhibit 2. Schematic of Total and Partial Oxidation Modes for the High-Efficiency Steam Electrolyzer

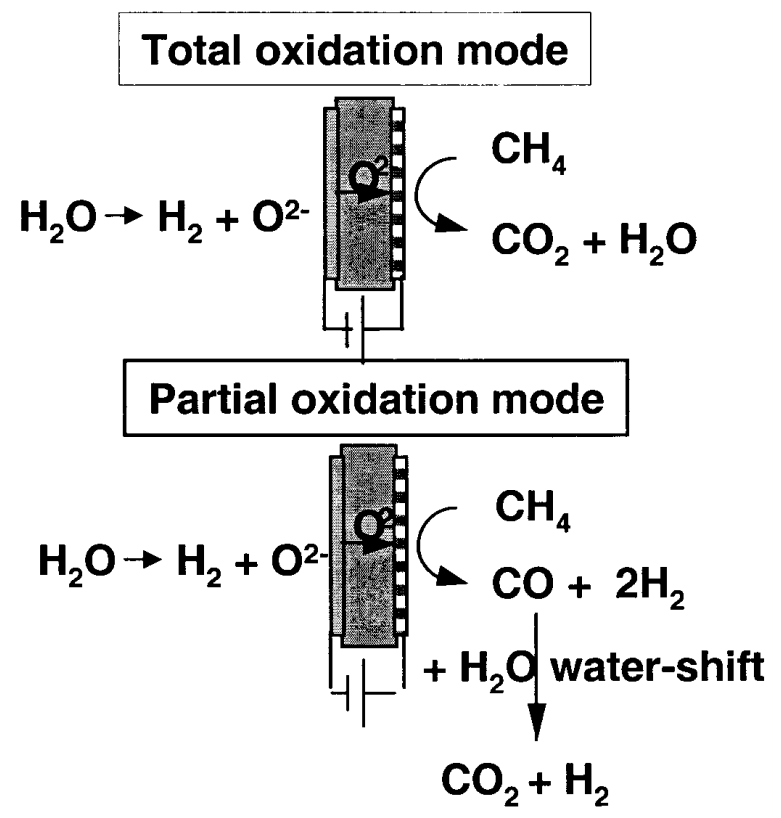


Technical Evaluation Report

Project: Advanced Thermal Hydrogen Compression

Company: Ergenics, Inc.

P.I.: Dave DaCosta/ Mark Golben

Site-Visit Date: March 19, 2002

Evaluation by: Edward G. Skolnik, Energetics, Inc.

\section{Summary:}

Ergenics, Inc., of Ringwood, NJ (not to be confused with Energetics, Inc. who is providing this evaluation) is taking advantage of the fact that metal hydrides can, at a particular temperature, take up quantities of hydrogen without an increase in system pressure over a wide "plateau region" of hydrogen capacity (Exhibit 1). If the temperature is then raised, the pressure rises exponentially. This provides the means to use a thermal process to compress hydrogen. A rise in temperature of $50^{\circ} \mathrm{C}$ would result in a 5-fold increase in pressure, theoretically.

Ergenics has identified and developed metal hydrides that will provide this type of phenomenon, and has developed heat exchange constructions that will rapidly heat or cool the hydride. In addition, Ergenics has constructed a purification scheme that will remove materials that will either actively poison the hydride or will passively blanket the hydride, limiting hydrogen take up.

I see the following strengths in the project:

- This is a very important project. Hydrogen compression is a key component of most potential hydrogen applications. Yet, prior to this project, it had not been addressed adequately. Not only is the Ergenics project addressing compression, it is developing a system that stands to be more efficient and less expensive than standard mechanical compression.

- The project represents an astute combination of knowledge of hydride chemistry and physics, thermal engineering, and gas handling.

- While much development and testing must be done, Ergenics seems to be on the right track for likely success. They are methodically identifying and determining how to overcome potential obstacles.

I see the following items that need to be addressed:

- The purification process is at this point, I feel, the major area for concern in the entire project. I'm not in any way saying that the process won't work. Ergenics is addressing purification (except for sulfur, see below) very methodically. It is a very complex process, however, and must be studied meticulously. There are many things that can go wrong. 
- Since most near-term applications are more likely to involve fossil-based hydrogen, it is important that Ergenics add sulfur-containing species to their list of impurities that will need to be dealt with. In addition, CO concentration might be higher than in most of the hydrogen production processes that Ergenics was initially targeting. This could cause some problems.

- Initial plans for scaling up to a "real system" needs to be addressed.

\section{Introduction and Background:}

Ergenics is a ten-man company that spun-off from Inter Nickel Co. in 1984. Their main product has been hydride batteries. Using their hydride expertise, they have been developing a thermal compressor. They increase the temperature of the hydride to cause a pressure increase without changing the composition (Exhibit 1). They can get large pressure increases this way, and if they perform this procedure several times at everincreasing input pressure, they can achieve over 5,000 psi hydrogen. They believe they can compress hydrogen by this thermal process more efficiently and less expensively than standard mechanical compression processes.

The system relies on complex transition metal and rare-earth metal alloys as hydriding materials; compact, high surface area heat exchange tubes in a configuration called a ring-manifold; and a fairly complex series of purification options that remove materials that would either poison the hydride bed, or would at least blanket the bed and thereby prevent hydrogen take-up.

I met with Ergenics' president Dave DaCosta and their vice president of R\&D, Mark Golben. We discussed the thermal compression project including the answering of a series of questions that I had sent to Ergenics, and I was also given a tour of the facilities and witnessed some demonstrations of some of the process steps.

\section{Status:}

At this point, much of what Ergenics is doing is concentrating on the purification system. A test stand is currently being built that will extensively test the ability of the system to purify the hydrogen prior to compression. The test stand is described in the "Tour" section of this report.

Purification involves the removal of materials that can either poison the hydride or can make it inaccessible to hydrogen. Water vapor, for instance, can dissociate to oxygen which then oxidizes the hydride surface, rendering it inactive (or less active) to hydrogen. $\mathrm{CO}$ and $\mathrm{CO}_{2}$ can form nickel carbonyl groups on the hydride surface, also rendering it inactive. "Inert materials" such as nitrogen and methane can physically blanket the hydride, lowering the absorption rate of hydrogen. 
Most of the purification on the hydrogen is done in the first compression stage, although some passive purification continues into later stages. Mr. DaCosta indicated that the first stage is more of a cleaning step than a compression stage. In fact, Ergenics has been designing to double-size hydride beds for the first compression stage because they don't know how well the hydride will handle impurities.

I wonder if an outcome of this may be that the hydrogen will have to be pre-purified before any compression stage at all, and that perhaps only inert impurities will even see the hydride.

Ergenics has recently identified a new alloy system that will not dissociate at higher temperatures. They can thus increase their temperature differential by about $30^{\circ} \mathrm{C}$. This will allow for a much simpler, more efficient system needing fewer compression stages. What they are now looking to do is to include a propane heater in their system to bring the upper temperature to about $120^{\circ} \mathrm{C}$.

\section{Tour:}

The overall system to do the Phase 2 work is not yet in place. I was, however, shown several pieces of test equipment, compressor components, blueprints, and a single stage compressor.

Mr. DaCosta showed me a small one-stage compressor with a hydride cartridge. It operates as follows: The input is hydrogen from a Proton Energy Systems PEM electrolyzer at $250 \mathrm{psi}$. It is allowed to be absorbed by the metal alloy for about 20 minutes. The heater comes on, the temperature is raised to about $200^{\circ} \mathrm{C}$, and this raises the pressure to about $2400 \mathrm{psi}$. It should be pointed out that this is a slow system. There are no high surface area heat exchangers as with the system being made for the Hydrogen Program. This particular compressor was made for Sterling Thermal Motors in Michigan.

I also saw a little demonstration showing hydride properties. There were two coils of tubing each containing a metal alloy; one contained hydrogen, and the other did not. The valve between the two coils was opened, and hydrogen could flow from one to the other. The coil into which the hydrogen flowed got very hot almost instantly. It was too hot to touch. This is due to the heat of formation of the hydride. The other coil, where the hydrogen came from got very cold, to the point that ice crystals formed on the outside of the coil. This is a very nice little demonstration of hydride properties.

Heat exchange will happen even more quickly and efficiently with systems with higher surface area, such as Ergenics ring manifold system, which they also showed me. It is an intricate maze of narrow diameter tubing made specially to place as much surface area as possible within a given volume to optimize heat transfer. The ring manifold is further discussed in Question 11 below.

Ergenics is just now ordering parts for the hydrogen compressor test stand. This will mainly be testing the purification system. It will use discrete sensors, tanks of pre-mixed 
gases, and its own heating and cooling system, consisting of a propane burner and a fan and coil cooler. The test stand will be built over the next two months. Ergenics will have five gas bottles:

- Hydrogen,

- water/hydrogen,

- $\mathrm{CO} /$ hydrogen,

- $\mathrm{CO}_{2} /$ hydrogen, and

- Methane/hydrogen.

They will use methane as an "inert gas" to look at passive blanketing because they could not find a nitrogen sensor that would respond to changes in a sufficiently rapid manner. Infrared detectors will be used for methane, $\mathrm{CO}$ and $\mathrm{CO}_{2}$, and a moisture analyzer based on aluminum oxide technology will be used for water. They will be looking to see what goes into the hydride, and what comes out. There will be an automatic venting section that will use a quantity (to be determined) of gas (hydrogen) in a quick burst to flush out inerts and $\mathrm{CO}$.

I was also given a brief tour of the remainder of the development and testing facilities and saw the following:

- Computer-controlled welders.

- Test systems for high vacuum. Ergenics have been looking at making nickel hydride batteries for hybrid electric vehicles, and need $1 \times 10^{-9}$ atmospheres to test the battery seals.

- A moisture tester for a hydride bed that is continuously cycled and uses wet hydrogen.

- A Sievert (pressure/temperature/concentration) apparatus, that was hand-made.

- A small (40 gram) alloy melter. Ergenics only makes small alloy samples on site. They have larger quantities made by others.

- Alloy particle-size reduction and sorting equipment includes sledgehammers (!), a jaw-cutter mill, ball mills, and sieves. They also have a hydrogen adsorption grinder that uses embrittlement to crack the metal.

\section{Questions and Answers:}

Prior to my visit, I sent Dr. DaCosta a list of questions that I thought would be important to cover during my visit. These are shown below in bold type, together with the answers brought forth by Mr. DaCosta and Mr. Golben during our discussion period, shown in normal type. Comments and reflections added by me during the analysis of the project and the writing of this report are included in italics.

1. Would the Ergenics compressor be more effective or less effective for more “conventional” hydrogen production technologies such as steam methane reforming? Would it still be economical compared to standard compressors if the feed were, say, 200 psi rather than atmospheric pressure? 
This question was prompted by the fact that Ergenics, during the first phase of their project was trying design their system for use with hydrogen from a number of potential sources supported by the DOE Hydrogen Program, but involving primarily non-fossilbased hydrogen resources.

A lot of what Ergenics had written was based on DOE's long-term hydrogen production projects as listed 2-3 years ago. Steam methane reforming, however, is a "great way" to provide hydrogen for the compressor because it typically comes out clean from the pressure swing adsorption (PSA) system at 100-200 psi. This makes it ideal for the compressor: it will require relatively little purification and can be pressurized using fewer stages, still being more economical than mechanical compressors.

An advantage of thermal compression over mechanical compression is that the latter system is usually manufactured within a given frame size, even though each system's need is a little different. Thus, mechanical compressors often have to operate at less than full capacity. The thermal compressor can better be tailored for each individual need. In addition, at large flow rates, a mechanical compressor will be huge, while Ergenics' thermal compressor can be much smaller, with the alloy tubes from the various stages neatly stacked on top of one another.

Another advantage is that thermal compression uses methane (or possibly propane) to achieve their higher temperatures, while standard mechanical compressors use more expensive electrical heat.

\section{Please describe the type of refueling station for which you are designing the 2000 scfh compressor.}

The 2000 scfh compressor was designed for the Las Vegas fueling station. This has a fleet of 10-15 vehicles. Ergenics got the specifications from Air Products.

I asked this question because it was not clear at first as to why Ergenics would design to a size that would serve only 1-2 vehicles per hour. It is clear now. I would suggest that Ergenics make items such as this clear when reporting in the future.

\section{Since hydrogen will almost certainly need to be compressed to at least $\mathbf{5 0 0 0}$ psi, why was the original design done at 3600 psi, and why the 100 psi inlet pressure?}

Three-and-a-half years ago, when Ergenics originally proposed this project, 3600 psi was thought to be sufficient, so the design was based on that figure. I remember talking about 5,000 and 10,000 psi seven or eight years ago. The $100 \mathrm{psi}$ inlet pressure came from the design for the Las Vegas fueling station.

A 10,000 psi compression system is within the capability of Ergenics, but beyond the scope of the current contract. They may, however, "throw in" a 10,000 psi run as well if 
market forces warrant it. I would think that this would likely require a different hydride, especially judging from what Ergenics said about 5,000 psi (see Question 13).

4. When you perform, or plan to perform a "run" with a compressor, does it always include all three types of purification systems?

The systems are always there, but they'll be essentially looking at one contaminant at a time. The exception is that inert blanketing and high temperature desorption $\left(\mathrm{CO} / \mathrm{CO}_{2}\right)$ are handled together (although they are separate mechanisms) because the venting is being run at a high temperature.

5. Does the metal hydride ever become embrittled with use, and will it eventually break down, changing the surface area and surface conditions, thereby hurting (or, perhaps, helping) the compression process?

After a number of cycles, the particle size of the hydride is reduced to about 20-40 microns, and it doesn't fracture anymore. Perhaps this is due to the fact that at this size, the crystal structure is such that it can stretch more easily to accept the hydrogen. A mischmetal/aluminum/nickel alloy was found to have only $1.4 \%$ of is particles under one micron after 1500 cycles.

Size reduction helps with the surface area, but can hurt particle containment. Check valves need to stay clean, so particle filters are necessary in front of the check valves.

\section{How does the system handle sulfur?}

They don't handle sulfur at this time. It's something that Mr. DaCosta says they will have to deal with at some time, and that it might be a problem. Certain sulfur species, such as hydrogen sulfide do poison the hydride at lower temperatures, but perhaps not at higher temperatures; they'll have to see. For right now, Ergenics has neither the time nor the money to look at sulfur.

I don't think this should be put off very long. Ergenics has done a very commendable job of identifying potential active and passive purification problems. Sulfur needs to be added to the list.

7. When you speak of "catalytic recombination of oxygen impurities" does this mean it converts to water?

Yes, that is what it means. The water can then be carried out with the hydrogen.

8. Please discuss where and how the purification treatments are administered. Is the plan to demonstrate these with "real" hydrogen feedstocks in the current phase? Does the effectiveness of the various purification processes vary with cycling? How do/will you handle the "tolerate vs. remove" decision on impurities? 
Currently, Ergenics is using manufactured gas blends. They are going to start with hydrogen containing low impurity levels, and gradually increase the amount of impurities in order to determine at what level they will begin to inhibit the hydride, and also how effective the purification processes are at getting rid of the impurities. It is an experimental testing procedure. Ergenics already has some cycling data on water vapor, as well as some old CO desorption data (Exhibit 2), but for the most part, the experiments still need to be done. The main concern will be the first stage hydride, and how well it tolerates the impurities.

If the impurity levels are small enough and don't effect the hydride, they can probably just pass through the entire system (toleration). In a practical sense, however, it is more likely that everything except water vapor will have to be removed. In fact, water vapor may be removed as well if the automatic venting system is capable of removing it.

\section{In your Phase 1 Final Report, Figure 4 shows the effect of the $\mathrm{CO}$ removal process on hydrogen loss. In this particular figure, it shows it takes exactly ten parts hydrogen to remove one part CO. Does this vary with inlet or outlet pressure? How much additional hydrogen is lost if other impurities must be swept out as well? Is there any value in recycling the hydrogen?}

The Figure is reproduced here as Exhibit 3. They originally had no plans for the hydrogen that is swept out with the impurities. During our discussion, however, Mr. Golben raised the possibility of cycling the hydrogen to the propane burner. (Recall that Ergenics is contemplating using a propane burner to achieve the higher temperatures that will allow fewer compression stages.) Ergenics does not yet know how the amount of hydrogen needed to remove the impurities will be affected by inlet or outlet pressure. This will be resolved in the testing phase, where they will be trying microventing bursts. The Figure itself, says Mr. Golben, probably actually represents the total amount of impurities, not just CO. Then why does it say CO?

Ergenics is not sure how water vapor will be affected by the automated venting process. It may turn out to be a problem; water vapor could condense at the higher pressures. They will likely look at condensing the water vapor out first. If they were to go with the partial oxidation mode, they would have less water. Water vapor is an issue for all electrolyzers. In reformers it is generally taken out by PSA.

I guess the statement that partial oxidation would reduce the water vapor problem refers to a per-mole-of hydrogen basis. The cathode (hydrogen/steam) side would not be affected by the presence or absence of water vapor on the anode side. In the POX mode, however, $3 / 4$ of the hydrogen comes from the anode side, and the anode side will have less water vapor in POX than in total oxidation.

One of the most important features of the system will be its ability to tolerate and recover from inadvertent exposure of the system to impurities. 


\section{Your schedule indicates that the purification work might have been completed already. If so, how did the tests turn out?}

Ergenics only started this phase in the fall, so they are not as far along as they would like. Their funding arrived late, and when it did arrive, personnel were busy with other projects putting this project even further behind. (The additional hidden consequence of late funding) Ergenics recognizes that they are late, but hope to finish the project by the end of December 2002.

\section{Please explain how the different heat exchangers operate, especially the ring manifold system.}

The "ultimate compressor will use ring manifolds, but in near-term systems Ergenics will use conventional shell and tube systems, consisting of a stainless steel tube with a metal hydride inside and water on the shell side inside a copper jacket. It is just easier to do initial tests this way.

Ergenics, however, is getting better in their fabrication of ring manifolds, and perhaps could have proposed to use these for the first tests. They didn't want to jeopardize the tests, however. Probably a good decision, as long as they switch to the ring manifolds when ready, and run some confirmation tests.

The ring manifold is a system in which one can get a large amount of surface area in a manufacturable form. The key is a narrow tube diameter, and tight windings, or rings. The narrow diameter would be a problem for many fluids, but not for hydrogen. Making a multitude of tube joints, however, is expensive.

The ring manifold is a high volume, manufacturable, mass-producible system. You can make "thousands" of stackable heat exchanger modules, or you can make a few compressors. Check valves keep high pressure hydrogen from flowing in the wrong direction, say, into a cold tube. Using check valves provides a method of "passive compression". There are no rotating seals; the system is silent.

Ergenics is still looking at improving the ring manifold design perhaps by dipping the tube in copper filings to increase surface area.

\section{You wrote of the compressor system being divided into six "nodes". What are these nodes?}

This is a safety feature. A gas company whose name Ergenics wants to keep confidential, uses a hazardous operations matrix to evaluate a system for safety. Using this methodology, six nodes were defined for the compressor system:

- Hydrogen suction

- Compressor stages/hydride bed

- Discharge (high pressure) section (e.g., pressure relief) 
- Inlet and outlet water system (mainly valves and piping)

- Water jackets (heat exchange shells)

- Control system

One looks at operations or parameters such as startup, shutdown, flow, temperature, pressure, compression, and containment, and considers them in relation to each of the nodes. One addresses deviations from the norm, what caused the deviation, and how you safeguard.

13. You discuss a new alloy for the final (5000 psi) compression stage. Do all the other stages use a single alloy? If, say, it is not necessary to use a new alloy at $5,000 \mathrm{psi}$, will you develop a new alloy for a higher pressure? In other words, will you try to get to 10,000 psi? Is the alloy development already underway?

Previously, (at the time of their Phase 1 report) Ergenics had only demonstrated up to $3,500 \mathrm{psi}$, so had included a new alloy for high pressure work in their Phase 2 proposal. Subsequently, they have already demonstrated compression in their standard alloy (or a variation of that alloy) up to 6,000 psi in a single stage compressor.

If they do want to develop a new alloy, they can select what they want using a van't Hoff plot that shows hydrogen dissociation pressure as a function of temperature $(1 / \mathrm{T}$, actually) to determine what alloy to use for what compression stage.

14. You plan to build a pilot system that will be sized to refuel a vehicle overnight. My back-of-the-envelope calculation tells me that this is about one order of magnitude smaller than the system you previously designed. Is this correct?

Yes. Ergenics is building a smaller size system to stay within budget. It is about a 15 liter per minute unit. We also need to remember that there was no previous unit. It was just a design, not a real system.

15. In general, what are the hydrogen uptake capabilities of your metal alloys; is it somewhere in the $1 \%$ by weight region?

Yes. Actually it is up to about $1.2-1.3 \%$. When the hydride is treated with the passive purification material, however, some non-hydrogen-adsorbing material is added, effectively bringing the hydrogen loading down to $1 \%$ by weight.

\section{Additional Items:}

Ergenics would be interested in compression for hydrogen liquefaction as well, but they don't know if this would be practical.

Ergenics had never initially intended to raise the temperature by thirty degrees, but now doing so seems to offer a tremendous advantage. 


\section{Final Thoughts:}

The thermal compression process offers the hydrogen community what appears to be a very plausible way of handling hydrogen compression. I am quite impressed with the work that has been done here.

The newly started Phase 2 will undoubtedly unveil some new obstacles, but for the most part, Ergenics seems to have anticipated many of the potential problems.

My main concern was and still is the purification process. The fact that Ergenics is anticipating the potential problems is good; the fact that there are a multitude of potential impurities is not good - it leads to what is a complex situation, with many materials having to be swept out with hydrogen, thereby losing product (although perhaps supplying an additional heat source). Other materials, such as oxygen, must be chemically reacted first. We will have to see if the purification can be performed in a practical way, and how much the process will have to vary for different feedstocks. $C O$ removal can be a very crucial step. Unfortunately, the best that I can offer for the potential problem is to offer up yet another concern: Sulfur removal needs to be added to the mix.

Finally, at some point in the not too distant future, (probably once we understand what the impurity removal system is really going to look like) an economic feasibility study needs to be run. 
Exhibit 1. Pressure/ Concentration Curves for Hydride Isotherms

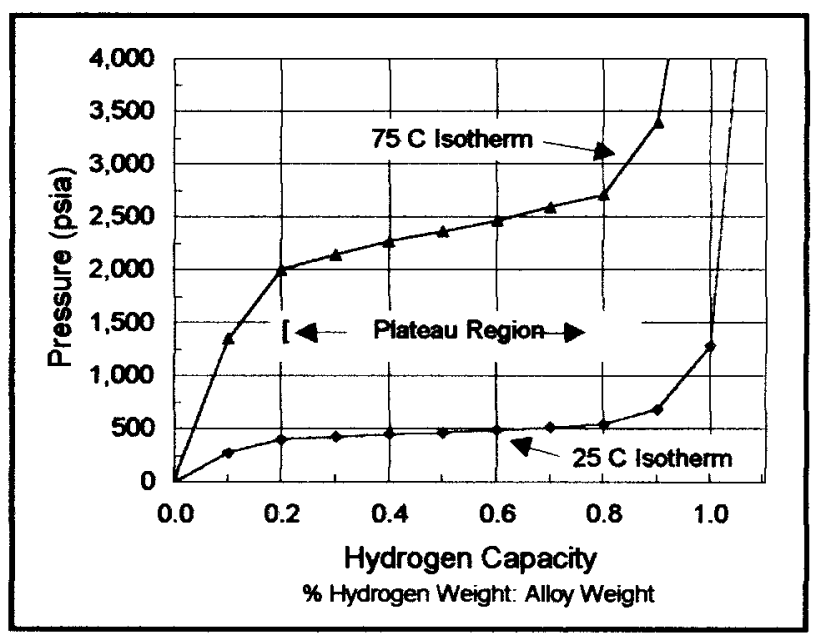

Exhibit 2. CO Desorption Data from Eisenberg F.G. and P.D. Goodell, "Cyclic Response of Reversible Hydriding Alloys in Hydrogen Containing Carbon Monoxide,"

J. Less-Common Metals, 89, 55 (1983).

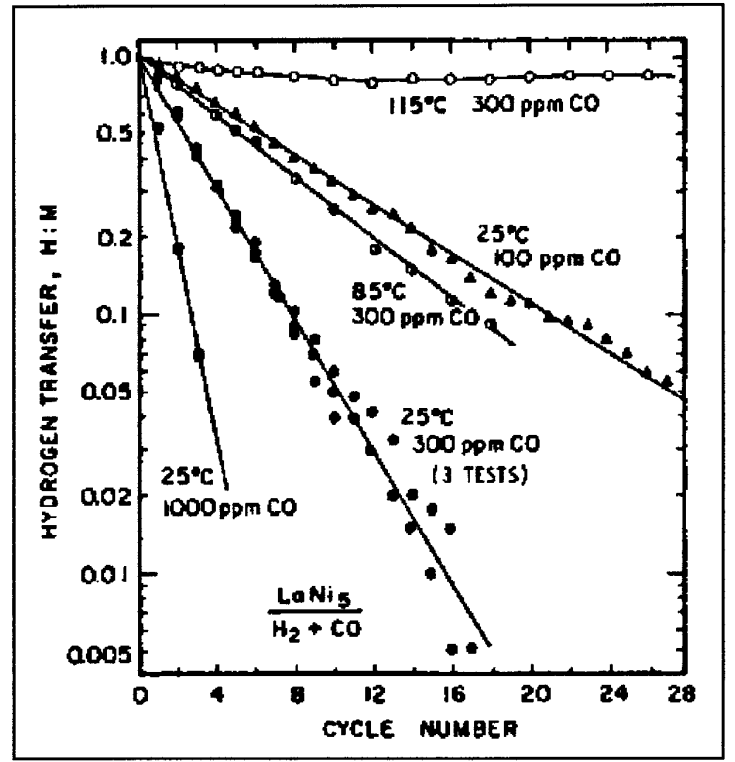


Exhibit 3. The Effect of the CO Removal Process on Hydrogen Loss

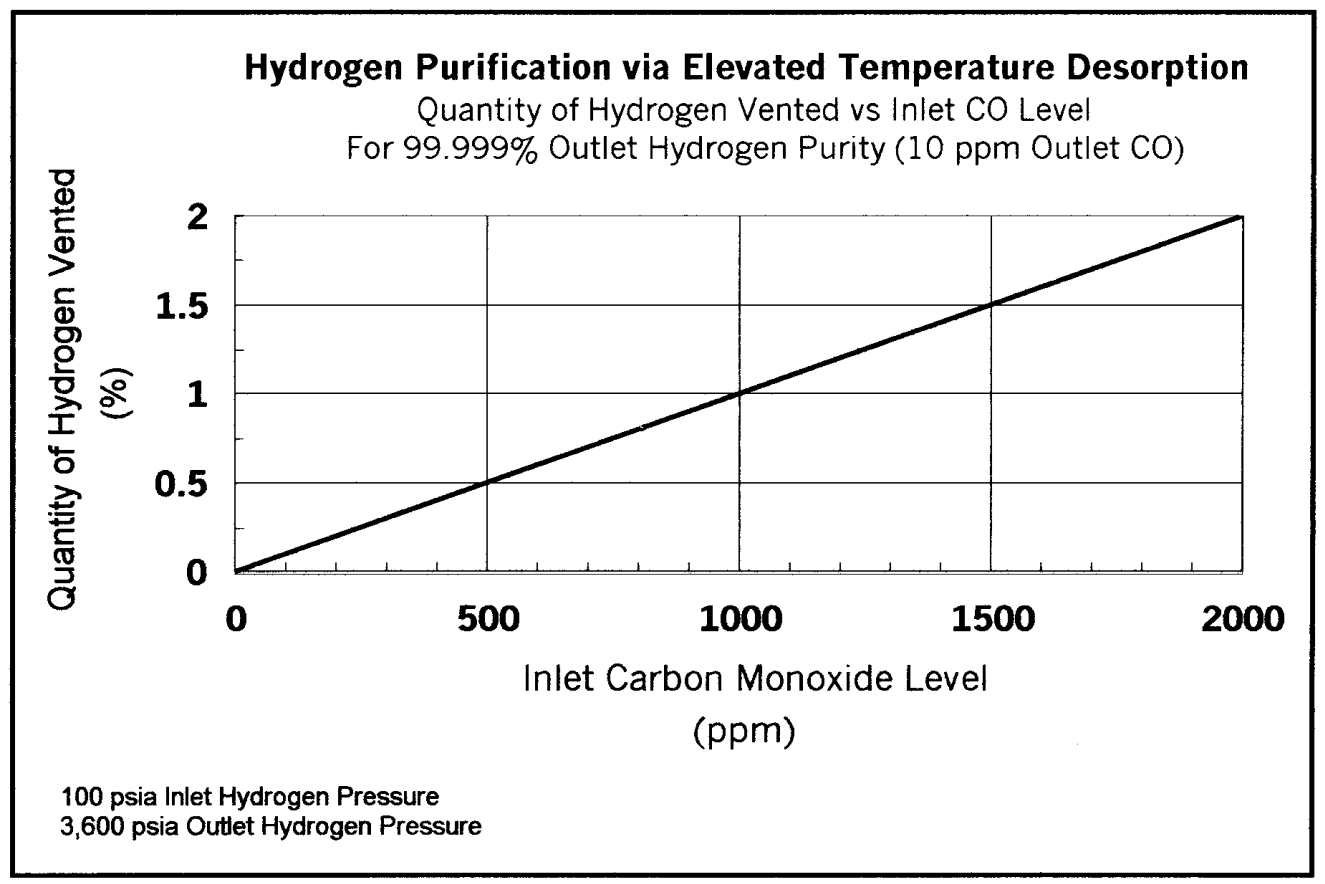


Technical Evaluation Report

Project: Novel Catalytic Fuel Reforming with Advanced Membrane Technology

Company: InnovaTek, Inc.

P.I.: Dr. Lloyd Allen

Site-Visit Date: April 17, 2002

Evaluation by: Edward G. Skolnik, Energetics, Inc.

\section{Summary:}

The InnovaTek project for the Hydrogen Program involves making hydrogen from natural gas via steam reforming, but on a small scale. This becomes feasible because InnovaTek employs fast microchannel heat exchangers and appropriate catalysts. It is a carefully balanced approach in which the reformate is purified by passing the hydrogen through a membrane, and the waste stream, or raffinate, is recycled to provide heat for the steam. Heat exchangers also take heat from the hot reformate to superheat the steam.

InnovaTek does not try to maximize its hydrogen production; it tries to optimize it. It is better to get $70 \%$ of the theoretical hydrogen as product, and recycle the raffinate, made up of $\mathrm{CO}, \mathrm{CO}_{2}$, and the remaining $30 \%$ of hydrogen. If they alternatively tried to maximize their hydrogen production, they would have to at least add a water shift step with its associated capital costs, and would need an external heat source to make the steam.

InnovaTek is also performing similar processing on liquid hydrocarbons such as gasoline and diesel for non-DOE clients. This helps them gain experience with a wide number of fuels under a wide number of conditions.

I see the following strengths in the project:

- A major barrier to reforming in small scale is heat exchanger inefficiencies. The InnovaTek microchannel heat exchangers appear to overcome this barrier.

- InnovaTek has shown that their proprietary bimetallic catalyst is unaffected by sulfur in natural gas.

- Complementary projects help build experience.

I see the following concerns that need to be addressed:

- InnovaTek's current detection system, a gas chromatograph (GC), has a detection limit of about $50 \mathrm{ppm}$. It is essential that they are able to detect $\mathrm{CO}$ down to $10 \mathrm{ppm}$, at least for today's fuel cells.

- We need a techno-economic analysis to compare this technology with other potential small scale technologies such as electrolysis, high temperature electrolysis, and small 
scale "standard" steam reforming for applications such as small fueling stations and residential use.

- InnovaTek still needs to learn why their membranes work as they do. This includes counterintuitive aspects such as increased pure hydrogen permeation rate following exposure to impure reformate.

\section{Introduction and Background:}

I visited InnovaTek in Richland, WA, where my host was Dr. Lloyd Allen, InnovaTek's Chief Technical Officer and the PI of the Hydrogen Program project. I also met with InnovaTek's President and owner, Dr. Patricia Irving, as well as with Staff scientist Dr. Quentin Ming. InnovaTek is a small business consisting of eleven full-time employees. They also employ a part-time consultant, and collaborate extensively with a professor at Washington State University.

InnovaTek started on their reformer work a few years ago, with a project funded by the Hydrogen Program involving the reforming of methanol. Currently, their reformer work is funded on four different contracts. The largest is a diesel reforming project that is being funded by the Army. It is about three-times the size of the DOE project, which has moved to using natural gas rather than methanol as the primary feedstock. Dr. Allen also indicated that there is still some interest at DOE in diesel reforming. The Hydrogen Program Project is a Cooperative Agreement, with cost-sharing being supplied by the (State of) Washington Technology Center. This contract is supplying funding for the burner system, the fuel injector, and mixing components. Finally, the Army, through a Small Business Innovation Research (SBIR) contract, is supporting the sulfur-tolerant catalyst research. It is obvious that the four projects all dovetail with common interest. Thus, says Dr. Allen, they get a "big bang for the bucks."

I spent most of a day at InnovaTek, during which time I was given a tour of the facilities, shown a demonstration of natural gas reforming, and spent several hours in discussion, primarily with Dr. Allen. He provided me with background on the company and project, and we discussed the project in detail including the answering and discussion about a series of questions that I sent prior to the meeting.

\section{Initial Discussion on the Process:}

The details of the InnovaTek process are proprietary, but Exhibit 1 provides a generic schematic of the process. The catalyst is also proprietary, but Dr. Allen indicated that we could say that they are using bimetallic catalysts, and they are non-nickel. The catalysts for all feedstocks are similar.

InnovaTek is trying to develop a heat transfer methodology that will allow very rapid transfer so that the reaction can be kinetics-dependent rather than thermodynamicsdependent. 
A key concept of the InnovaTek system involves combusting the exhaust gases (raffinate) from the membrane as the first stage steam generator. The combination of hydrogen and $\mathrm{CO}$ that is present in this stream (along with $\mathrm{CO}_{2}$ ) is sufficient to make saturated steam. The steam is superheated via the heat exchangers, using the heat in the crude reformate $\left(800-850^{\circ} \mathrm{C}\right)$.

\section{Tour:}

InnovaTek currently rents space in a laboratory building that is owned (or managed?) by Batelle. Dr. Allen showed me a large warehouse-sized high bay area in the building that InnovaTek could possibly rent for scale up.

Currently, InnovaTek is renting more conventional laboratory space. Their reformer is more or less at a roughly $1 \mathrm{~kW}$ modular stage. They are using a tube furnace to provide the heating for the reaction. The system consists of the reactor, a gas chromatograph for detection, and thermocouple monitoring. The membrane separator is not part of the existing system, but InnovaTek is just about to begin the installation of the integrated system that will include the membrane separation step. It will also provide heat for the steam from combustion of recycled raffinate, and by heat exchange from the hot hydrogen. The integrated natural gas reforming system for DOE will likely be done by next January. Dr. Allen indicated that they can get about 15 standard liters of hydrogen per minute with this system. A $1 \mathrm{~kW}$ fuel cell would use about 12 liters/minute. The reformer could respond to a load, in "a few minutes."

Dr. Ming did demonstrate the reformer running; crude reformate was being simply bubbled into water, with no separation. He also showed me a sample of catalyst that had been used for reforming natural gas for 500 hours. Very little coke could be seen in the sample, and Dr. Ming informed me that most of that had formed during the first few hours of reforming.

The diesel reforming system, awaiting integration, is adjacent to the natural gas reformer system, and includes an atomization/vaporization component. Uniform mixing and coking are considered to be the two biggest problems that InnovaTek will have to overcome for the diesel project. The diesel system will be integrated for the Army prior to the integration of the DOE system. This should be done by September 2002.

The Army SBIR project is currently using a smaller $(50 \mathrm{~W})$ reformer for catalyst screening purposes. It reforms gasoline and follows the catalyst kinetics. This project uses a sulfur-free gasoline as baseline, and then slowly adds catalyst, and follows sulfur tolerance. Several detectors are employed. These include: flame photometric detection for sulfur, thermal conductivity for hydrogen, and flame ionization in combination with a methanator (for quantification) for $\mathrm{CO}$ and $\mathrm{CO}_{2}$.

I also was shown a totally unrelated project, where InnovaTek is looking at aerosol capture of potential biohazard material. It includes a multi cyclone system capable of 
concentrating the material by a factor of one million, and also employs plasma discharge decontamination component.

\section{Questions and Answers:}

Prior to my visit, I sent Dr. Allen a list of questions that I thought would be important to cover during my visit. These are shown below in bold type. Dr. Allen answered the questions in writing, reproduced here in quotes, verbatim. In addition, answers to supplement what was already given were brought forth by Dr. Allen and Dr. Ming during our discussion period. These are shown in normal type. Comments and reflections added by me during the analysis of the project and the writing of this report are included in italics.

\section{In your FY 2001 Annual Review Report, please explain what we are seeing in Figure 1, the H2GEN Fuel Processor.}

"This unit was our first prototype of an integrated reactor utilizing a layered architecture. We attempted to include all elements of the process. This system has evolved into a radial design that is more compact and easily integrated. Work since then has focused on developing the required subsystems: fuel injection, catalytic reactor, internal burner, heat exchange, water separation and hydrogen separation."

The Figure, which we are reproducing here as Exhibit 2, shows an old flat-plate design. It was really a "publicity model", suffered from heat losses at the edges, and became readily coked. The new design, which should avoid the heat loss and coking problems, is concentric, with the burner in the center, and the reactor radially around it. The microchannel heat exchange system for the radial reactor is still being worked on.

Dr. Allen indicated that InnovaTek is much beyond where they were a year ago using the old multi-plate reactor system.

\section{You say that your separation membrane yields " $100 \%$ hydrogen (no $\mathrm{CO}, \mathrm{H}_{2} \mathrm{~S}$, or $\mathrm{CO}_{2} \ldots$..) what are the actual concentrations of these impurities in ppm, if any? In another part of your report you call it "nearly pure hydrogen". Please explain.}

"We recently added analytical capability for low level sulfur determination and are pushing our levels of detectibility for $\mathrm{CO}$ and $\mathrm{CO}_{2}$. The mechanism of hydrogen permeation through the metallic membrane provides no means for passage of any other species. Imperfections such as pinholes or improper sealing provide routes for passage of impurities. At the present, $\mathrm{CO}$ and $\mathrm{CO}_{2}$ are below calibrated levels of precise determination, about $50 \mathrm{ppm}$. We are working to refine our GC procedures to quantify them at down to about 10 ppm. "

InnovaTek is "assured" that they can calibrate their chromatograph to allow them to detect $\mathrm{CO}$ down to $10 \mathrm{ppm}$. 
Detection levels down to $10 \mathrm{ppm}$, and the assurance that the system is removing $\mathrm{CO}$ at least down to this level is a crucial step that InnovaTek must take. We also should be aware of any possibility of sulfur products getting through to the fuel cell.

\section{What is in the reject stream? How are sulfur products, $\mathrm{CO}$, and $\mathrm{CO}_{2}$ handled in that stream?}

"The reject stream (raffinate) contains approximately $32-42 \%$ hydrogen, 33-38\% CO and $25-27 \%$ $\mathrm{CO}_{2}$ by volume. Any traces of sulfur appear as $\mathrm{H}_{2} \mathrm{~S}$ that is also retained in this stream. This material is burned in the combustor with air to produce the heat required for the catalytic steam reforming process."

Dr. Allen believes that recovery of $75-80 \%$ of the hydrogen is very achievable. They could recover more as well, but would be in what they consider to be a diminishing returns scenario. The hydrogen remaining in the raffinate is part of the recycled fuel and should be left as such. This is part of the optimized system concept.

Dr. Allen also cited a rule of thumb for sulfur in the InnovaTek system. For every 1000 ppm of sulfur by volume present in the fuel, about $150 \mathrm{ppm}$ by volume will remain in the reformate. I'm not quite sure where this comes from. It just may be what InnovaTek discovered in their system, or it may be a rule that refineries use. I would assume, however, that this would be pre-membrane reformate, if it were to be acceptable.

\section{You indicate that your reformate goes through heat exchangers to be dried and is then heated for the membrane step. Does this mean that the reformate is cooled after its formation, then reheated after drying for purification, and then cooled again for storage?}

"This step is the most difficult of our heat management plans. The permeation rate of hydrogen through the membrane is a function of its partial pressure. In the process, steam is used at about $40-50 \%$ excess to help drive the reforming reaction. Leaving the excess steam in the reformate going into the membrane separator will dilute the hydrogen causing less efficient separation. Although there may be some advantage to leaving steam in the raffinate to moderate the burner temperature and assist in heating incoming water, the required increase in the size of the membrane may be a costly compromise. Out present plan is to use two small heat exchangers and a water "knock-out" pot for this step. Two process streams exit the membrane, $450^{\circ} \mathrm{C}$ raffinate that is sent to the burner without cooling, and pure hydrogen product. The hydrogen will need to be cooled to $50-60^{\circ} \mathrm{C}$ for PEM consumption. The heat loss in this step is about 100 watts/kW hydrogen produced. In all other process steps the change in heat content ranges from 0.6 to $1.5 \mathrm{~kW}$ per equivalent $\mathrm{kW}$ of hydrogen produced."

Yes, InnovaTek does have to cool and reheat. They have recently added the "knock-out" pot (condenser) as part of the process. The need to cool the hydrogen stems from the fact that InnovaTek's design tries to make the reformer more-or-less load-following. They may consider a buffer storage system to accommodate changes in load, but mainly, they would feed the fuel cell directly.

This is another process optimization effort in which InnovaTek must make compromises to maximize performance. 


\section{At what pressure is product hydrogen recovered?}

"Hydrogen is produced by the membrane purifier at ambient atmospheric pressure."

They will pressurize upstream of the membrane to get the material to flow through the membrane. The raffinate is at pressure, but the hydrogen pressure drops across the membrane to about one atmosphere.

\section{What is your target for the amount of time a catalyst needs to remain active in the presence of sulfur-containing fuels?}

"Our initial target is for a year (5000 hours of operating time at $60 \%$ of full time capacity.) We have recently completed 500 hours with no degradation of activity. In-place regeneration of catalytic activity is an issue that we are investigating to provide renewed catalytic activity so that replacement is not required until some time of irreversible failure."

So, they are about 10 percent of the way to the target now. They will be doing much testing on sulfur tolerance, a major goal of their SBIR work, over the next year.

To date, they have seen a "little softening" of catalyst activity at 500 hours of use, but no serious drop-off. One option they will consider is only running for about 500 hours, making a short stop, and regenerating the catalyst.

If this kind of process change is being considered, InnovaTek may be considering catalyst life to be a potential show-stopper. The long term catalyst life test should be watched with interest. The regeneration every 500 hours could potentially impact efficiency. We shall have to see if this is indeed a problem. Of course, as Dr. Allen pointed out, it takes 5000 hours (nearly a year in real time if running full time) to see if the catalyst will survive.

\section{You indicated that some initial coking occurred during the reforming of iso- octane with sulfur. What stopped the coking?}

"We have attacked the problem of coking using three strategies. Early in our testing, we observed that coking, or soot formation was associated with exposure of liquid fuel or fuel/ steam to moderately hot or hot metallic surfaces in the reactor piping system for times in excess of that required for catalytic conversion or it was due to catalyst systems that were sufficiently slow to permit dehydrogenation to occur before reforming. To solve this we designed our catalyst to be highly specific to fuel/steam reforming and kinetically "fast" in that reaction. We continue to observe coke-free reforming with our catalysts. Secondly, we design very short passages where exposure of fuel to hot walls is minimized. Our final strategy is to utilize fuel injection. In this design, cold fuel is atomized into steam at $400-550^{\circ} \mathrm{C}$ the temperature of the resulting drops $150^{\circ}$ $\mathrm{C}$ for liquid fuel and about $70^{\circ} \mathrm{C}$ for natural gas. The fuel vaporizes and or is mixed in 80 milliseconds. In the mixing tube, gas flow is focused so that hot walls are exposed to steam and not fuel until the uniform mixture reaches the entrance to the catalytic chamber. Higher steam/carbon ratios will help to mitigate coking, but will reduce operating efficiency."

As stated, coking is a bigger problem when liquid feedstock (diesel) is employed. Some catalysts are more prone to coking than are others. With the present design, there is not a lot of coking at any rate, regardless of fuel. Dr. Allen feels that if they keep cold liquid 
off the hot surfaces by employing an injector/vaporization system, they will not have a problem at all.

Coking does not appear to be an issue with the natural gas system that DOE is more concerned with at this time.

\section{How many and what different forms of sulfur were tested in the reactor?}

"We reviewed the issue of what sulfur surrogates should be used. Since we have begun using some fuels with naturally occurring sulfur, the issue is not one of design or operational significance in our present program. For sulfur carrying surrogates we selected chemicals that were easily available and that matched the volatility of the base fuel to be used. For the hexadecane base we selected thiophene, for isooctane, thioxane was used, and for methane, dimethyl sulfide. Thermodynamic equilibrium calculations were done for each material in the presence of typical reformate at reforming temperature. All calculations predict that, the sulfur carrying material will be completely converted to $\mathrm{H}_{2} \mathrm{~S}$ under our reforming conditions. "

InnovaTek does see significant differences in the condition of their catalysts after exposure to natural gas versus methane due to the presence of sulfur in natural gas.

\section{Are no unsaturated hydrocarbons formed during the reforming of iso-octane?}

"So far, we have not detected any. For our testing, we normally conduct some range finding tests to determine the optimum operating ranges for temperature, steam/carbon ratio and space velocity. Our selection of operating conditions precludes operating in conditions where formation of degraded hydrocarbons is favored."

Iso-octane is a little harder to reform than other hydrocarbons, likely because of its branched structure. Hexadecane (which is linear), even though it has twice the number of carbons as iso-octane, is easier to reform. Dr. Ming also provided the following degrees of conversion for iso-octane and hexadecane:

\begin{tabular}{|c|c|c|}
\hline Temperature $\left({ }^{\circ} \mathrm{C}\right)$ & Iso-Octane (branched) & Hexadecane (linear) \\
\hline 650 & $30 \%$ conversion & $40 \%$ \\
\hline 750 & $70 \%$ & $>90 \%$ \\
\hline 800 & $100 \%$ & $100 \%$ \\
\hline
\end{tabular}

Dr. Ming defined conversion as the amount of hydrocarbon that has become a $\mathrm{C}_{1}$ species $\left(\mathrm{CH}_{4}, \mathrm{CO}, \mathrm{CO}_{2}\right)$. He added that the amount of methane was "very low."

Reforming methane is not that easy in itself; its symmetrical structure makes it more difficult for the water molecule to attack it.

Liquid fuels are not difficult to reform, says Dr. Allen; the difficulty is in the vaporization step.

\section{Is the catalyst chemically inert to sulfur, or is it a matter of minimizing the} residence/contact time? 
"We have speculated some as to the mechanism, but at the present have no firm thoughts about this."

We talked about this in a little more detail with Dr. Ming, who has some theories. The catalyst is not chemically inert to sulfur. With the bimetallic catalyst, Dr. Ming believes that one component creates an "assembly" of itself on the surface of the catalyst, and this assembly ties up the sulfur. The other component is then able to act as a reforming catalyst. Dr. Ming also believes that possibly hydrogen then scrubs the catalyst surface. He stated that this is mainly speculation at this point, but he will be investigating this further this year.

InnovaTek is also presently working with another company who will make the sulfurtolerant membrane.

\section{How much fuel does it take to provide the heat to reform and purify one mole of hydrogen?}

"Since we are using membrane raffinate as the burner fuel this is not a direct calculation. Also, since we are now in the process of beginning to integrate the process there is no experimental data using fuel in vs. hydrogen out to get actual operating efficiency. Using our thermodynamic process calculations and the industry method for calculating reformer efficiency,

LHVproduct/LHVfuel, we can theoretically be $70 \%$ efficient on an energy basis, knowing that in the final device there will be additional heat losses that will reduce this number. From a theoretical mass balance, we would use $7.1 \mathrm{~g}$ of methane to generate a mole of hydrogen."

The one mole of hydrogen does not include any hydrogen that is in the raffinate and recycled, and does assume that some of the hydrogen comes from the water.

If we are dealing with reforming without any shifting, the reaction is:

$$
\mathrm{CH}_{4}+\mathrm{H}_{2} \mathrm{O} \rightarrow \mathrm{CO}+3 \mathrm{H}_{2}
$$

Stoichiometrically, one mole of methane (16 grams) would produce 3 moles of hydrogen; 1/3 mole of methane (5.33 grams) would produce one mole of hydrogen. Thus, an additional 1.77 grams of methane (33\%) is needed for providing heat, directly or indirectly in the raffinate.

\section{Please explain how the layers and separators of catalyst and fuel mixer in their particular arrangement leads to optimal performance.}

"The most critical issue in reactor design is that of heat loss management. Our solution is to keep interconnections short by tight integration of processor functions. We found that the plate structure had problems with excessive heat loss through the sides. The new radial design provides a better overall solution to heat management."

The new design does not use layers and separators. 


\section{In Figure 7 of your FY 2001 report, what eliminated the coking problem compared to Figure 4?}

These two tests, shown as Exhibit 3 here, really represented two different fuels, simulated gasoline in Figure 7 and iso-octane in Figure 4, and two different reactors according to Dr. Ming. There may have been some leaks as well. The two Figures should not be compared.

\section{What is the target thickness for the membrane? What is the thickness driver - cost, permeation rate, etc.?}

"Factors that affect permeation rate of hydrogen include, temperature, hydrogen partial pressure and membrane thickness. The trade-off is cost vs. integrity. The best solution is nominal thickness supported by a suitable substrate. In this way, it is possible to increase permeation rate and reduce cost while assuring membrane integrity."

InnovaTek had targeted one micron for membrane thickness, having been working at the 10 micron range. They found, however that with the design they were using, a metal on non-metal substrate, they were getting a lot of pinholes. They are now using a metal on metal system, and this seems to help the problem. The membrane system is proprietary, but Dr. Allen did say that the membrane operates by "palladium-like permeation."

\section{How does the percentage of hydrogen recovery vary with feed pressure and temperature?}

"It is positively correlated. We will show recent results to illustrate this."

Permeation rate is proportional to the difference between the square roots of the upstream and downstream absolute pressures (note: not gauge pressures). It is also positively correlated with temperature up to about $500^{\circ} \mathrm{C}$; then it reaches a maximum.

Dr. Allen showed me, but kept proprietary, some curves illustrating this effect.

\section{Is one of the goals the increase of hydrogen recovery percentage, or is the $\sim 18$ - $20 \%$ loss acceptable?}

"Our process thermodynamic calculations have revealed much to direct us in this area. In the laboratory, we can achieve greater that $80 \%$ hydrogen separation from crude reformate. In addition, we have considered using a WGS step between the reactor and membrane where the temperature is lowered enough to realize a significant conversion of $\mathrm{CO}$ to hydrogen using the excess steam in the reformate. However, pushing hydrogen recovery above $75 \%$, reduces the heat value of the raffinate to a point where there is insufficient heat from the burner to fully reform the fuel input. This deficiency can be remedied by adding raw fuel to the burner. Interestingly, the gain in fuel efficiency is only marginal. This gain is more than off set by increased operational complexity. In addition, added WGS and membrane capacity increase size, weight and cost of the integrated device. Therefore we are targeting about $70-75 \%$ conversion as most efficient for our overall system design (none of the hydrogen is actually "lost")." 
InnovaTek had considered incorporating a water gas shift component and using additional fuel (as opposed to the raffinate) to heat the steam. There is a slight gain in fuel efficiency, but the capital cost of the shift equipment plus the added cost to operate it makes it an unattractive alternative.

The way Dr. Allen put it, was that InnovaTek would not do what everyone else was doing (i.e., autothermal reforming, shifting, PROX, etc.) and still come out with an impure product. They decided that they would design the best system that they could that would deliver $100 \%$ pure hydrogen. They therefore move the separation stage into the reformer system. This means that they feed pure hydrogen to the fuel cell, increasing its flexibility and likely increasing its efficiency.

So they optimize the system, not the hydrogen recovery. This seems like a sensible way to run the system. The question may be as to how much the size of the system effects the parameters for optimization. For instance, if they were making a system for a refueling station (say 150 cars/day) would this optimization scheme still hold.

\section{Is the plasmatron basically an igniter, or is it being used to make hydrogen itself? How would the plasmatron regenerate catalyst?}

"We were asked to evaluate the plasmatron by our US Army client. MIT and others have reported the use of plasma in conjunction with the Auto Thermal Reforming (ATR) process. We delayed the plasmatron evaluation until we have a working fuel injector to properly evaluate the system. It will be important to position the plasmatron in the heated mixture of steam and evaporated fuel and to operate the system sub-optimally, either at lower reactor temperature or at higher space velocity so that the effect can be measured against a system operating at $80-90 \%$ conversion. We have entertained thoughts that a plasma system may be useful in the warm-up and ignition phase of our process. Plasmas formed in inert gas streams have been used to regenerate catalyst beds because of the presence of highly active free radical species that can clean the active surface and pores of the catalyst."

If InnovaTek shows that they can run at less than optimal conditions and more than make up the difference with a plasmatron (significantly increase the output, perhaps) they would try it.

It appears that unless there is a serious catalyst regeneration benefit, the plasmatron would only be used for liquid feedstocks, which are, at least currently, not part of the DOE project.

\section{The Future:}

We spoke about where InnovaTek sees their reformer system going in the future.

The natural gas system (the DOE work) would likely go into a hydrogen service station for buses. This system would have to include hydrogen storage, and would likely need a different set of optimization conditions. I would think this would be a larger system. A question may be: how big can you make the InnovaTek system and still be competitive? 
Dr. Allen also sees the natural gas system in residential use. This would be used with about a $5 \mathrm{~kW}$ fuel cell. InnovaTek is not yet including a fuel cell in their next demonstration (next January for natural gas), but is planning to integrate a fuel cell with the reformer after that.

The Army project is leading toward possibly replacing portable internal combustion generators (that use JP8) with $5 \mathrm{~kW}$ reformer/fuel cell units. InnovaTek also sees commercial application in recreational generator units, auxiliary power units for trucks, and refrigeration power packs.

InnovaTek is currently working with three different fuel cell manufacturing companies.

They are not looking at scaling up to centralized size plants at the present time, although they may in the future. If these are economical at all, they would likely need a totally different approach to optimization.

InnovaTek has developed a business plan for first introduction of these reformers for the Army and the marketplace.

No economics have been developed for the process yet.

\section{Additional Items:}

The microchannel concept being used in this project is, at least for the time being, being limited to heat exchanger technology. Their ultra-fast, high surface-to-volume ratio system provides $90 \%$ efficient heat exchange, Dr. Allen says. The reformer itself is not a microchannel design, although InnovaTek may be looking at that concept in the future.

Dr. Allen showed me some recent data that presented:

- Increased monometallic catalyst deterioration when natural gas rather than methane is used as a feedstock, due to the presence of sulfur in natural gas, but no such deterioration with a bimetallic catalyst.

- A somewhat strange result of the effect of reformate on a membrane. First pure hydrogen was run through the membrane and the permeation rate is measured. Then crude reformate was run through the membrane. Finally, pure hydrogen was run through the membrane again and the permeation rate was found to be about $60 \%$ higher. Neither InnovaTek nor I have a good explanation for this at this time.

\section{Final Thoughts:}

This is a very good project. As a system, it provides for what could be (although we need an economic analysis) a viable way to reform natural gas on a small scale. InnovaTek has developed catalysts that now appear to be sulfur-resistant, membranes that will 
produce pure hydrogen, and a micro-heat exchange system that will allow the reformation to occur efficiently on a small scale. My major technical concern is that I think we need a better read for the purity of the hydrogen. The GC does not have sufficient sensitivity to the point where we can ensure that a fuel cell will not be poisoned by the presence of too much CO or too much sulfur.

InnovaTek's system optimization approach, using hydrogen to heat the system, and avoiding expensive capital equipment also appears well thought out. We do, however, need to see an analysis that will put more credibility toward what intuitively seems correct - that InnovaTek is indeed optimizing the system We always used to say that the bottom line for a hydrogen production project should be 'how much hydrogen can you make/are you making?' In this case, the better question is: 'in your optimized system, how much will your hydrogen cost?' The above analysis also needs to tell us if the optimized system is good enough. 
Exhibit 1: Rough Schematic of the InnovaTek Process

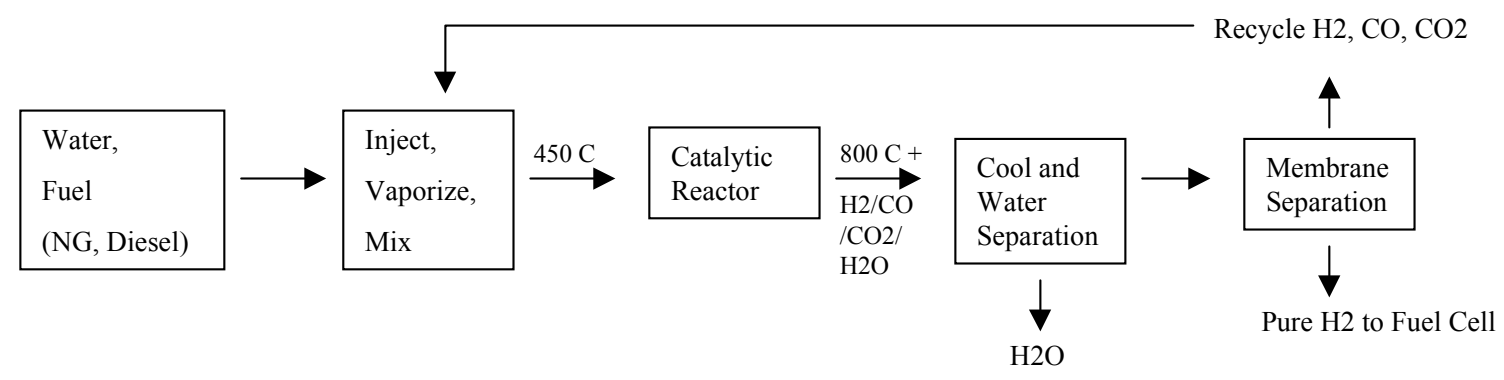

Exhibit 2 InnovaTek’s “Old” Processor Design

Exhibit 3. Product Gas Composition for Reforming of Simulated Gasoline and Iso-octane Showing Coke Formation as Reduction in Hydrogen Concentration

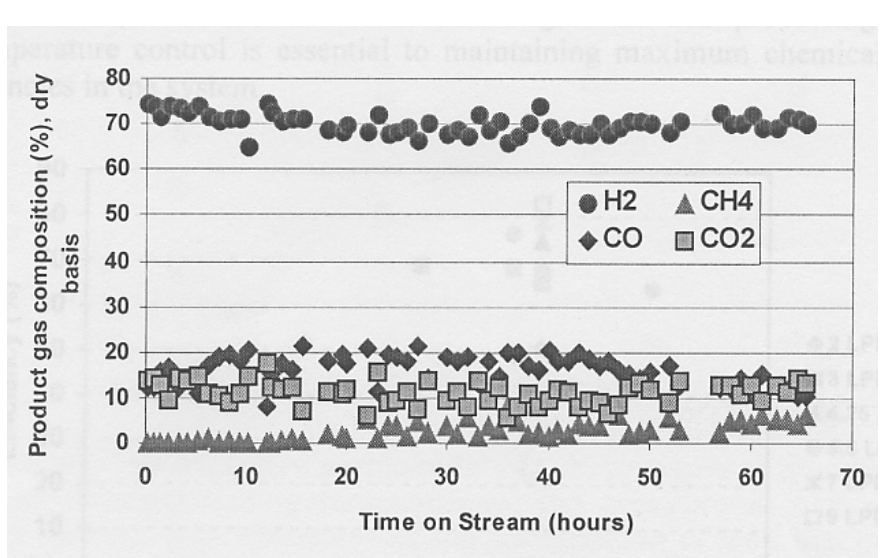

Simulated gasoline ("Figure 7")

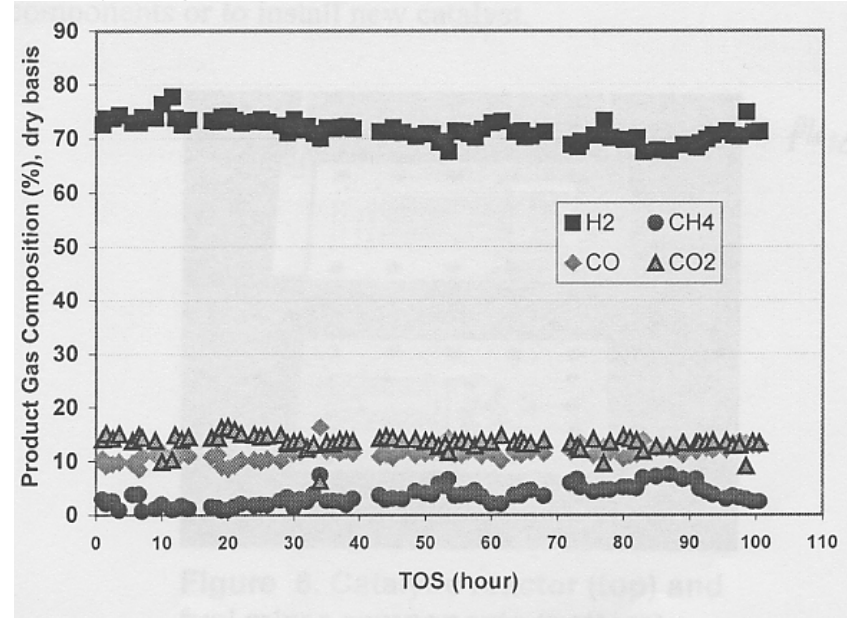

Iso-octane ("Figure 4") 
Technical Evaluation Report

Project: Production of Hydrogen by Superadiabatic Decomposition of Hydrogen Sulfide Company: Gas Technology Institute

P.I.: Dr. Rachid Slimane

Site-Visit Date: April 23, 2002

Evaluation by: Edward G. Skolnik, Energetics, Inc.

\section{Summary:}

The Gas Technology Institute (GTI) is developing a process for producing hydrogen from waste hydrogen sulfide. It basically involves taking the hydrogen sulfide and partially oxidizing it within a packed-bed reactor. The exothermic reaction (which produces sulfur and water) provides the energy, and the reactor bed provides the medium for increased temperature to allow the decomposition reaction for hydrogen sulfide (forming hydrogen and sulfur) to favorably compete.

The process was first modeled for feasibility, and was found to be feasible. Following a funding hiatus of about a year, GTI recently began work on Phase 2 , an experimental study that will last seven months (ending in November 2002). Currently, GTI and their partners have assembled the system with which they will develop the process - a 2-inch diameter lab-scale reactor.

I see the following strengths in the project:

- This is a unique project for the program. No one else is trying to make hydrogen from waste-gas streams. The concept is worthy of investigation.

- An extensive modeling effort and some preliminary experiments show that the concept is at least feasible.

- A strong team representing both industry and academia has been assembled.

I see the following concerns that need to be addressed:

- The conversion of $\mathrm{H}_{2} \mathrm{~S}$ to hydrogen is only about $28 \%$ of theoretical. Low conversion will likely limit where this system will be viable. Recycling should be investigated.

- Hydrocarbon type and amount in the feedstock is a concern at least in how it may tie up the sulfur; it may cause other problems as well.

- Product purification is a concern. The sulfur condenser may or may not be sufficient. GTI will have to either confirm that it is sufficient, or develop alternative/additional removal methods. Separation of hydrogen from $\mathrm{H}_{2} \mathrm{~S}$ must be addressed as well. 
- The economic viability of this process will be a critical consideration. With the potential need of both pre-combustion and post-combustion separation steps, we may be in a very limited process viability regime.

\section{Introduction and Background:}

Hydrogen sulfide is generally regarded as a toxic byproduct of refining of sulfurcontaining fossil fuels. Its uncontrolled combustion results in oxides of sulfur $\left(\mathrm{SO}_{2}, \mathrm{SO}_{3}\right.$, etc.) which are also undesirable. Hydrogen sulfide is generally removed from combustion streams and converted to elemental sulfur by processes such as the Claus Process where uncombusted $\mathrm{H}_{2} \mathrm{~S}$ is reacted with already oxidized $\mathrm{SO}_{2}$ :

$$
2 \mathrm{H}_{2} \mathrm{~S}+\mathrm{SO}_{2} \rightarrow 3 \mathrm{~S}+2 \mathrm{H}_{2} \mathrm{O}
$$

GTI is developing a process in which $\mathrm{H}_{2} \mathrm{~S}$ is also converted to sulfur, but the "byproduct" is hydrogen rather than water. In the GTI process, partial oxidation of a portion of the hydrogen sulfide (reaction [2]) provides the heat to raise the temperature in a packed-bed reactor sufficiently to allow the remainder of the hydrogen sulfide to undergo decomposition to elemental sulfur and hydrogen (reaction [3]):

$$
\begin{gathered}
\mathrm{H}_{2} \mathrm{~S}+1 / 2 \mathrm{O}_{2} \rightarrow \mathrm{S}+\mathrm{H}_{2} \mathrm{O} \text { [2] } \\
\mathrm{H}_{2} \mathrm{~S} \rightarrow \mathrm{H}_{2}+\mathrm{S} \quad \text { [3] }
\end{gathered}
$$

In the first phase of the project, the process was modeled thermodynamically and kinetically to establish operating conditions. Presently, GTI and its partners, the University of Illinois, Chicago (UIC), and UOP, are ready to shake down a lab-scale system that will develop the process. The schematic of this system is shown in Exhibit 1.

I visited GTI and was hosted by Dr. Rachid Slimane, the Principal Chemical Engineer who is the project PI. Also present at the meeting were Dr. Francis Lau, Director of Process Development and Engineering, who is the Program Manager, and GTI team members Dr. Mark Khinkis and Mr. Remon Dihu. Also attending was Dr. Alexei Saveliev of UIC, who was responsible for most of the modeling. Unfortunately, the UOP team member was unable to attend.

At GTI we held extensive discussions on the project, Dr. Slimane gave a more or less informal presentation, that was really centered around the questions that I sent prior to my arrival. Dr. Saveliev made a more formal presentation on the modeling effort. The team also gave me a tour of the facilities, concentrating on a "dry runthrough" of the superadiabatic reactor.

\section{Questions and Answers:}

Prior to my visit, I sent Dr. Slimane a list of questions that I thought would be important to cover during my visit. These are shown below in bold type. Dr. Slimane answered the questions in writing, reproduced here in quotes, verbatim. In addition, answers to 
supplement what was already given were brought forth by Dr. Slimane and his team during our discussion period. These are shown in normal type. Comments and reflections added by me during the analysis of the project and the writing of this report are included in italics.

\section{Why is the process referred to as filtration combustion?}

"Burning of fuel is carried out within porous media. We prefer to refer to this process as partial oxidation or superadiabatic thermal decomposition (or dissociation) of $\mathrm{H}_{2} \mathrm{~S}$."

Filtration combustion is a common mechanical engineering term according to Dr. Saveliev. It is not a filter per se. The reaction takes place within the porous media, and gas is filtering through the media. The media is a heat sink (this is how the temperature rises). You could say that the media is "filtering heat".

\section{How pure does the $\mathrm{H}_{2} \mathrm{~S}$ have to be for the reaction to occur?}

"Theoretically, streams containing as low as $10 \% \mathrm{H}_{2} \mathrm{~S}$ can be treated. We do have some data on feed gas consisting of $20 \% \mathrm{H}_{2} \mathrm{~S}$ in $\mathrm{N}_{2}$. However, in practice economics will dictate the appropriate concentration of $\mathrm{H}_{2} \mathrm{~S}$ in the feed gas."

Dr. Slimane also said that even if they had 1-2\% hydrogen sulfide, they could extract enough heat (presumably from half of the $\mathrm{H}_{2} \mathrm{~S}$ ) to run the reaction (on the other half).

I was actually more or less asking the question from the point of view as to what impurities could inhibit the reaction. But, the answer is very enlightening in itself. However, the answer to Question 10 (as well as some economic concerns on the presence of impurities in Question 7) provides more information on the effect of impurities.

\section{You use the reaction $\mathrm{H}_{2} \mathrm{~S}+1 / 2 \mathrm{O}_{2} \rightarrow \mathrm{S}+\mathrm{H}_{2} \mathrm{O}$ to provide heat for the superadiabatic reaction. How do you prevent the production of $\mathrm{SO}_{2}$, or alternatively, how much $\mathrm{SO}_{2}$ do you produce? How will it be dealt with? In your modeling, does the optimum hydrogen recovery process also result in optimally low $\mathrm{SO}_{2}$ production?}

"In the superadiabatic decomposition reactor, oxidation of a portion of the $\mathrm{H}_{2} \mathrm{~S}$ in the feed provides the thermal energy required to drive the decomposition reaction. $\mathrm{SO}_{2}$ formation can be minimized, but not entirely prevented. Some $\mathrm{SO}_{2}$ will inevitably form. Preliminary modeling work indicated it would be feasible to recover $99 \%$ of the sulfur in the feed as elemental sulfur (S), and only about $1 \%$ will show up as $\mathrm{SO}_{2}$ in the product gas. At this point, it is not known for certain whether operating conditions that are optimum for hydrogen production would also be optimum for minimizing $\mathrm{SO}_{2}$. In the experimental program currently underway, the $\mathrm{SO}_{2}$ concentration in the product gas will be measured and conditions to minimize its level will be determined.

"It should be noted that up to $3 \% \mathrm{SO}_{2}$ are emitted in the tail gas from the Claus unit."

You are oxidizing the feedstock; you can't help but make some $\mathrm{SO}_{2}$. 
In trying to optimize the system, GTI will look at filtration velocity (interstitial gas velocity, or, the velocity of the gas in the void space between the packed-bed pellets), $\mathrm{H}_{2} \mathrm{~S}$ content, equivalence ratio, pellet size (which I would think would effect the interstitial gas velocity), and the need to quench the gas or not. They will be optimized by considering $\mathrm{SO}_{2}$ vs. $\mathrm{H}_{2}$. It is important to make hydrogen even if you have to make a little $\mathrm{SO}_{2}$. The major goal is to minimize overall sulfur emissions, including $\mathrm{H}_{2} \mathrm{~S}$ emissions.

One option may be to do this work in conjunction with a Claus plant. It may make the superadiabatic process viable where a stand-alone plant may not be.

The experimental optimization data is what we need to see, modeling aside. If the only way you can make hydrogen is by making an unacceptable amount of $\mathrm{SO}_{2}$, or if you are limited to operate in line with another sulfur removal system such as a Claus plant, you have narrowed your options considerably.

\section{What is the sulfur concentration in the "pure" hydrogen stream, following the condensation of sulfur?}

"In practice, $\mathrm{H}_{2} \mathrm{~S}$ decomposition product gases may require quenching to block any recombination of $\mathrm{H}_{2}$ and $\mathrm{S}_{2}$. Following the rapid quench, the product gas is further cooler (by heat exchange with the feed gas, for example) until sulfur condenses. After the sulfur condenser, sulfur concentration in the gas is probably at the ppm level. However, if there is significant carryover of sulfur, the overhead stream may require additional processing to prevent liquid sulfur from entering the compressor and membrane. Therefore, after the membrane separation system, the permeate stream should be pure hydrogen."

GTI also raised the possibility of pressure swing adsorption as well as membrane separation as potential purification methods. Team member UOP will be providing the expertise on evolving purification technologies.

It does appear that purification will be a necessary step. Judging from the written answer, it does not appear that GTI is extremely confident that the sulfur condenser will be all that is needed.

\section{How many different systems have been designed and/or built? Are the terms "bench-scale" and "lab-scale" referring to two different systems?}

"The Phase I final report included a design of a bench-scale system capable of handling up to $1,400 \mathrm{scfh}$ of feed gas. This system was based on the use of a 6 -inch I.D. reactor for the superadiabatic decomposition of $\mathrm{H}_{2} \mathrm{~S}$. The Phase I report also contained a proposal for Phase II requesting about $\$ 1.1$ million to construct and operate the bench-scale reactor system, in addition to updating process economics and market analyses.

"While DOE was interested in funding Phase II, only about $1 / 3$ of the money required was available. Therefore, the scope of work was changed to the redesign and construction of a labscale system with a 2 -inch I.D. reactor. This reactor is capable of handling up to about 100 scfh."

With only $1 / 3$ of the funding available, GTI had to undergo a big "redo" on the design to scale down to a system that is about an order of magnitude smaller. Working with the 
smaller system, GTI may gain more knowledge in areas such as flame stability, but in another aspect, the smaller system is more subject to heat loss.

In my opinion, the 6-inch diameter unit may have been too large for the first operating unit following only a modeling exercise. A proof of concept at the smaller scale, I think, is called for.

(As an aside, a "2-inch diameter unit" vs. a "6-inch diameter unit" tells me a lot more than does "lab scale" vs. "bench scale”)

\section{In your model, under an optimum scenario, you claim $50 \%$ conversion of $\mathrm{H}_{2} \mathrm{~S}$. Do you recycle? You reported that you produce $\mathrm{H}_{2} / \mathrm{H}_{2} \mathrm{O}$ at the ratio of 57/43. Is this mole fraction? Overall, for each mole of $\mathrm{H}_{2} \mathrm{~S}$ including that which is used to heat the system, how many moles of pure hydrogen are formed?}

"In one of our papers, we report that 'The most optimum scenario in the results of the computer modeling to-date indicate that, with feed gases entering the reactor at ambient temperature, a maximum temperature of $1631 \mathrm{~K}\left(1394^{\circ} \mathrm{C}\right.$ or $\left.2541^{\circ} \mathrm{F}\right)$ can be achieved in the SAC reactor, resulting in an overall $\mathrm{H}_{2} \mathrm{~S}$ conversion of $50 \%$, with a hydrogen $\left(\mathrm{H}_{2}\right) /$ water $\left(\mathrm{H}_{2} \mathrm{O}\right)$ selectivity of $57 / 43$ and an elemental sulfur $\left(\mathrm{S}_{2}\right)$ /sulfur dioxide $\left(\mathrm{SO}_{2}\right)$ selectivity of $99 / 1$.'

"The $50 \%$ overall conversion is reported for a single pass (i.e., no recycle). $57 \%$ of the $50 \%$ of the hydrogen in the converted $\mathrm{H}_{2} \mathrm{~S}$ will show up as $\mathrm{H}_{2}$ and $43 \%$ as $\mathrm{H}_{2} \mathrm{O}$. Therefore, 0.285 mole of $\mathrm{H}_{2}$ is produced from each mole of $\mathrm{H}_{2} \mathrm{~S}$ in the feed gas."

Dr. Slimane believes that this is not necessarily the optimum scenario. He thinks they can do better. If they ran at a higher equivalence ratio ( 3 instead of 2 , for instance) they would probably decompose more hydrogen sulfide.

I am a little concerned here. If the model is telling them that they have a $28.5 \%$ conversion rate (and that's what it is - not 50\%) but they think they can do better at a higher equivalence ratio, why didn't they model a higher equivalence ratio? Or why don't they recycle? They are going to separate the remaining $50 \% \mathrm{H}_{2} \mathrm{~S}$ anyway.

Dr. Khinkis used the philosophy that right now, no hydrogen is produced from the $\mathrm{H}_{2} \mathrm{~S}$ waste stream from natural gas. Even if only 30 or $40 \%$ of the hydrogen sulfide becomes hydrogen, it is a large number.

True, but it's a matter of economics, and the final cost is going to be determined on a per unit hydrogen basis.

\section{Economically, how does your overall process $\left(\mathrm{H}_{2} \mathrm{~S}\right.$ decomposition and hydrogen purification) compare with “conventional” $\mathrm{H}_{2} \mathrm{~S}$ cleanup and steam methane reforming to make hydrogen?}

"Rather than speculate on a system that is at a very early stage of development, I selected two systems that have undergone significant development and are considered to have acceptable capital costs and good prospects for large scale hydrogen production (provided an economic way to separate the hydrogen product can be devised). 
"The cost of producing $\mathrm{H}_{2}$ was cited at $\$ 1160 /$ ton $(\$ 3.08 / \mathrm{Mscf}$ ) (for the natural gas-fired system, [(...Exhibit 2)], compared to $\$ 670 /$ ton (\$1.78/Mscf) for a comparatively sized Claus plant plus steam methane reformer. However, the portion of the $\mathrm{H}_{2}$ cost attributable to natural gas fuel for the decomposition reactor was $\$ 727 /$ ton, or $63 \%$ of the total. The superadiabatic decomposition reactor, on the other hand, does not use natural gas under normal operating conditions, and is a self-sustaining process obtaining all of the necessary heat from oxidation of a small portion of $\mathrm{H}_{2} \mathrm{~S}$ in the feed. In addition, in the GTI process, higher temperatures are achieved leading to improved $\mathrm{H}_{2}$ yields.

"[Exhibit 3 ...] shows a scheme that was proposed by Alberta Sulphur Research Ltd. (ASRL) as a retrofit to existing Claus plants. A portion of the acid gas feed is passed through "cracking" coils placed in the reaction furnace, where considerable heat is generated. The product stream is rapid-quenched on exiting the reactor, and then cooled further to condense the sulfur. The gas is then compressed and the $\mathrm{H}_{2}$ separated using a membrane facility. Unreacted $\mathrm{H}_{2} \mathrm{~S}$ is recycled and fed to the Claus reaction furnace.

"Laboratory experiments with a $90 / 10 \%$ by volume mixture of $\mathrm{H}_{2} \mathrm{~S}$ and $\mathrm{CO}_{2}$ without catalyst showed that conversions of 26 and $28 \%$ were obtained at the typical Claus furnace temperatures of 1100 and $1200^{\circ} \mathrm{C}$. Contacts times of only fractions of a second were needed.

"When pure $\mathrm{H}_{2} \mathrm{~S}$ was passed through the "cracking" coils at a coil operating temperature of about $1200^{\circ} \mathrm{C}, \mathrm{H}_{2}$ yields of 34 to $36 \%$ were observed. For $\mathrm{H}_{2} \mathrm{~S}-\mathrm{CO}_{2}$ mixtures, $\mathrm{H}_{2}$ yields were about 19 , 24 , and $28 \%$ for 70,80 , and $90 \% \mathrm{H}_{2} \mathrm{~S}$.

"To avoid flame stability problems, up to $25 \%$ of the feed could be safely directed through the 'cracking' tubes for an acid gas consisting of $83 \% \mathrm{H}_{2} \mathrm{~S}, 10 \% \mathrm{CO}_{2}, 1 \% \mathrm{CH}_{4}$, and balance $\mathrm{H}_{2} \mathrm{O}$.

"Another scheme investigated at the University of Calgary is shown in [... Exhibit 2...] and is essentially a stand-alone facility with natural gas supplying all the energy required for dissociation. All the fresh feed, plus the recycle $\mathrm{H}_{2} \mathrm{~S}$, goes to the decomposition reactor. This reactor comprises a set of ceramic tubes containing catalyst, operating at about $1100^{\circ} \mathrm{C}$, installed in a gas-fired furnace."

Dr. Slimane thinks that the superadiabatic process can do better than either the Alberta or the Calgary scheme. It takes only a small amount of energy to decompose $\mathrm{H}_{2} \mathrm{~S}$. The difficulty is heat. (It's a thermodynamic problem, not a kinetic one.) The superadiabatic process overcomes that difficulty.

The issues that might make an impact on the economics, Dr. Slimane believes, are the separation system and the handling of impurities in the feed. As indicated in Question 9, GTI has not directly addressed the membrane issues yet. As far as impurities go, based on our discussion here, as well as in Question 10 where we discuss the manner in which hydrogen sulfide might react with hydrocarbons, I get the feeling that impurities could be a big problem.

I asked this question because currently there is a process to clean up $\mathrm{H}_{2} \mathrm{~S}$ (Claus process) and there is a process to make hydrogen (let's say steam methane reforming). Does it make sense economically to invest in this new process? 
Dr. Saveliev pointed out that some companies might have $\mathrm{H}_{2} \mathrm{~S}$ and not have a steam methane reformer, but might need hydrogen. Thus, the superadiabatic process may be of value to them.

\section{Does catalytic "conventional" decomposition of $\mathrm{H}_{2} \mathrm{~S}$ lower the temperature for acceptable hydrogen production to any reasonable extent?}

"A catalyst would speed up the decomposition reaction rates at lower temperatures; however, because conversion is very low at such temperatures, this would not provide a means for improving yield.

"It is reported in the literature that 'above approximately $800^{\circ} \mathrm{C}$ there is a decreasing advantage to use a catalyst since the thermal decomposition reaction proceeds to equilibrium rapidly."'

The problem is not kinetic; it is thermodynamic. The reaction is already fast, but it is equilibrium limited.

9. You mention that ceramic and polyamide membranes "are being developed for similar applications." Is this at GTI or elsewhere? Are these membranes being evaluated against one another, or would they be used for two separate applications?

"A polyimide membrane system can separate $\mathrm{H}_{2}$ from $\mathrm{H}_{2} \mathrm{~S}$, but these polymeric membranes cannot handle more than $10 \% \mathrm{H}_{2} \mathrm{~S}$. Ceramic membranes can effect the separation, but they have poor separation factors, typically 2 or lower. Air Products and Chemicals, Inc. have been developing a Selective Surface Flow ${ }^{T M}$ membrane with a separation factor $>4.1$. More importantly, the $\mathrm{H}_{2}$ from this membrane will be available at high pressure, since the $\mathrm{H}_{2} \mathrm{~S}$ will preferentially permeate the membrane.

"Alcoa and Bend Research have developed other membranes, specifically for the separation of $\mathrm{H}_{2}$ from the product gas at high temperatures, as a means of shifting the equilibrium.

"More importantly, systems that are directly applicable to separating product gas from our process have been investigated. ASRL indicated in a 1995 publication they had plans to test such a system. Because our focus so far has been on the superadiabatic decomposition reactor itself, we have not yet thoroughly investigated the available product/byproduct separation schemes."

These membranes are potential candidates for GTI's system.

The Air Products membrane that works apparently in reverse is an interesting device, and could be of great value for pre-compression hydrogen.

The ability to separate hydrogen from $\mathrm{H}_{2} \mathrm{~S}$ is a critical part of the process, and perhaps should have been worked in parallel with the reactor. The fact that others are looking at membrane separation, and that GTI has sited several potential candidates is good, but I think that GTI needs to get this portion of the process tested as well.

10. For fuel gas, what do you consider $\mathrm{H}_{2} \mathrm{~S}$-rich and $\mathrm{H}_{2} \mathrm{~S}$-lean? What are the other components of the feed? What happens to the other components? Is the success of the reaction at all dependent on the makeup of the non- $\mathrm{H}_{2} \mathrm{~S}$ components? 
"Examples of lean-fuel combustion applications include destruction of methane containing exhaust gases from coal mines and destruction of VOC emissions from industrial processes. An example of a rich-fuel combustion application includes recovery of sulfur and hydrogen from a refinery gas stream using very little oxygen, such as what the superadiabatic decomposition process aims to do.

"Commercial $\mathrm{H}_{2} \mathrm{~S}$ feeds usually contain $\mathrm{CO}_{2}$, light hydrocarbons, and other impurities. For example, a refinery acid gas typically has a composition of $80 \% \mathrm{H}_{2} \mathrm{~S}, 8 \% \mathrm{CO}_{2}, 7 \% \mathrm{H}_{2} \mathrm{O}$, and the remainder paraffinic hydrocarbons.

"Impurities lead to formation of side products. For example, in one Canadian study on feeds containing up to $10 \%$ of $\mathrm{CO}_{2}$ or methane $\left(\mathrm{CH}_{4}\right)$, it was determined that $25-45 \%$ of the $\mathrm{CO}_{2}$ was converted to $\mathrm{CO}, 5-20 \%$ to $\mathrm{COS}$, and $0.5-2 \%$ to $\mathrm{CS}_{2}$. For the case of feeds containing up to $10 \%$ $\mathrm{CH}_{4}$, it was determined that $40-75 \%$ of the $\mathrm{CH}_{4}$ was converted to $\mathrm{CS}_{2}$. In addition, some soot (coke) was formed when $\mathrm{CH}_{4}$ was present.

"Gas separation systems are capable of handling these side products resulting from the impurities in the $\mathrm{H}_{2} \mathrm{~S}$ feeds. They would most likely be rejected in the retentate stream."

It may be important to minimize the amount of hydrocarbons in the bed (Dr. Lau suggested that maybe you reform them first), but the hydrocarbons do not chemically effect $\mathrm{H}_{2} \mathrm{~S}$ decomposition (meaning the ability of $\mathrm{H}_{2} \mathrm{~S}$ to decompose). What could be an issue, however, is the potential presence of $\mathrm{CS}_{2}$ and $\mathrm{COS}$, which could form at high temperatures and would need to be handled. GTI is not sure yet how to do this. This differs somewhat from the written answer. They may not be sure if the gas separation will work. They need to find out; hydrocarbon impurities seem to be a potential problem.

\section{We should discuss initial experimental results of your reactor.}

"We are currently getting ready to start shakedown testing of the 2-inch lab-scale reactor system. We do have some data from tests that were carried out by UIC as cost-sharing in Phase I. These tests used an insulated alumina reactor tube with a 1.5-inch ID and a 18-inch long diagnostic part (reaction zone). Data from these tests will be discussed during the review meeting."

Results from the UIC tests are shown in Exhibit 4. The feedstock for this test was a mixture of $20 \%$ hydrogen sulfide in nitrogen. The Exhibit shows the result of a series of runs each of which was conducted at a particular constant equivalence ratio ranging from 2 to 15 , and a constant filtration velocity of $12 \mathrm{~cm} / \mathrm{s}$ (although in other runs, the filtration velocity was varied from 10 to $60 \mathrm{~cm} / \mathrm{s}$ ). Note that nitrogen which comprises $80 \%$ of the feedstock is not shown. It appears that one of the major things this preliminary test showed was that hydrogen production would be maximized in the 2-3 equivalence ratio range.

For the lab scale system that they are now shaking down, they use an electric furnace to supply heat. With a larger system, they believe that once the reaction is going, it will be self-sustaining, and they would not need the furnace. In fact, if they can minimize heat losses, they won't even need it for the lab scale reactor. They would need an igniter, however, for even a commercial scale system. 
As stated above, GTI has no data yet on the lab scale system; they are still shaking down. In addition, they were not able to perform a demonstration during the site visit due to a crack in one of the flanges of the quartz reactor tube.

It is unfortunate that the data is limited to the small UIC reactor at this point. I look forward to seeing some data from the GTI unit.

12. Please discuss how you envision this process fitting into the "real world" of $\mathrm{H}_{2} \mathrm{~S}$ decomposition and hydrogen production. What size would a plant be? Would you be looking at centralized or distributed plants? Would hydrogen be compressed, transported, etc.?

"The $\mathrm{H}_{2} \mathrm{~S}$ superadiabatic decomposition process offers an innovative pollution abatement technology that also produces a valuable product, hydrogen. Because the petroleum refining industry generates large amounts of $\mathrm{H}_{2} \mathrm{~S}$ and has on-site demand for $\mathrm{H}_{2}$, we see this industry as the most lucrative market for this process. Typically, the market size for the petroleum refining industry ranges from 50 to 100 tpd of sulfur.

"Natural gas producers currently operate large Claus units and may benefit sufficiently from the sale of byproduct $\mathrm{H}_{2}$ to justify the capital costs for installing new technology, especially if end users of $\mathrm{H}_{2}$ are close to the treatment facility. The market size in this case is significantly larger than that of the petroleum refining application (about $\mathbf{8 0 0}$ tpd of sulfur).

"Finally, there is also the possibility that the $\mathrm{H}_{2} \mathrm{~S}$ superadiabatic decomposition process can be retrofitted to a Claus plant to recover part of the hydrogen, similar to the scheme being developed in Canada by Alberta Sulfur Research Ltd ([..Exhibit 3..])."

\section{At what pressure will the product hydrogen be produced?}

"Hydrogen pressure will depend on product gas separation system; likely to be at atmospheric pressure."

If the Air Products membrane is "real" however, the pressure could be higher. GTI is not working with Air Products at this time, and does not know how much use this membrane will be.

\section{Dr. Saveliev's Presentation}

UIC looks at both filtration combustion (fuel-lean stoichiometry) and partial oxidation (fuel-rich stoichiometry). They were the cost-share partner for Phase 1 of this work and are providing the thermodynamic and kinetic modeling for Phase 2.

Dr. Saveliev explained that one can change the properties of combustion if the reaction takes place in an inert, porous medium. For one thing, very efficient heat exchange can take place. Also, combustion stability is possible over a wide range of power loads, filtration velocities and equivalence ratios. For instance, under "normal" combustion 
conditions, natural gas flammability limits range from equivalence ratios of about 0.5 to 1.6; with filtration combustion the range is about 0.05 to 10 .

The process being used for the GTI/UIC project is "transient" filtration combustion. That is, traveling (rather than stationary) waves of combustion zone are developed. In the present design, the combustion zone moves slowly up the reactor tube, reaching the end in about two hours (Exhibit 5).

In an interesting aside, Dr. Saveliev indicated that a burning cigarette is an example of filtration combustion with a transient wave. Once it is ignited, the cigarette will continue burning, even without anyone smoking it, with the combustion zone traveling down the cigarette. The tobacco is the porous medium in this case.

\section{Tour:}

I was shown the lab scale reactor and basically taken on a dry run by Mr. Alek El-

Khoury, who is working on the reactor for GTI, but who is also a graduate student at UIC. As stated, a crack in a flange leading into the reactor tube prevented an actual demonstration. Recall, however, that the system has not been tested yet, so the demonstration may have been abbreviated at any rate.

The system (Exhibit 1) is located in an area that is basically a full floor-to-ceiling hood. Gas bottles of $\mathrm{H}_{2} \mathrm{~S}$, nitrogen and oxygen, flow into a mixing chamber via a set of flow meters and controllers, and the mixture then flows into the reactor.

The reactor is heated by a three-zone electric heater with three temperature controllers. The 2-inch diameter quartz tube itself was currently empty, but would be filled with 2-3 mm diameter alumina beads. Below where the beads will go, is a porous frit that serves as a gas distribution device. (Actually, GTI will place a section of larger beads in the reactor below the reaction zone, under the frit to help support the column.) In the postreaction scheme, from the top of the reactor the gases go to a sulfur condenser unit. This consists of seven tubes (for gas flow) in an oil bath at $300^{\circ} \mathrm{F}$. This temperature allows specifically the sulfur to condense and drip into a drum at the bottom. The $300^{\circ} \mathrm{F}$ gases then flow through a water-cooled tube that serves as a water condenser. The noncondensed products stream is split at this point with about 1 liter/minute going into a gas chromatograph for analysis. The remaining gas (about 24 liter/minute) goes through a sulfur scrubber for both $\mathrm{H}_{2} \mathrm{~S}$ and $\mathrm{SO}_{2}$, and is then vented.

The system is well thermocoupled. There is a thermocouple in the gas mixer (in case the gases will have to be pre-heated), and seven " $S$ " type thermocouples in the porous media ("S" types are made of junctions of $10 \%$ rhodium-platinum with platinum), which can measure temperatures between 980 and $1450^{\circ} \mathrm{C}$, covering the necessary reactor temperatures. Additional thermocouples include two in the post-reaction region of the tube, and four in the sulfur condenser bath. This needs to be well controlled.

There are also three pressure transducers to measure pressure drop across the bed. 
Temperature, flow rates, and pressure are all controlled and monitored by a computer. $\mathrm{SO}_{2}$ and $\mathrm{H}_{2} \mathrm{~S}$ monitors are hung near the reactor for safety.

An HP 5890 Series II gas chromatograph is used to analyze the reaction gases $\left(\mathrm{H}_{2}, \mathrm{SO}_{2}\right.$, $\mathrm{H}_{2} \mathrm{~S}$ ). A Rosemount $\mathrm{SO}_{2}$ analyzer is also employed for real-time readings.

At the present time, since they are using bottled gas feeds, they do not look for $\mathrm{CO}$ or $\mathrm{CO}_{2}$. Once they switch to actual waste streams, these detectors will be added.

The eventual plan is to use natural gas to ignite the reaction, and then let it run itself. It is unclear whether this will be doable with the lab-scale system, but it appears that when GTI scales up to the 6" diameter bench-scale system, this will be doable, and presumably, no tube furnace will be needed.

Mr. El-Khoury indicated that the reaction "wave" (as shown in Exhibit 5) is the hydrogen combustion zone. It moves slowly up to the top of the tube, reaching there in about two hours, and then the reaction stops. GTI is looking for ways to make a more continuous system. They believe that with proper temperature and gas control, they can make the wave travel back down the tube. Alternatively, they could look at a multiple tube system.

\section{Next Steps:}

At the end of my visit, Dr. Slimane indicated that when this particular phase is completed in November, GTI will be funded to build the originally-planned 6" diameter system. With this system, they will be able to minimize heat losses and work in a regime that will be closer to a commercial system. At that time, they would plan to look at contaminants in the gas mix, as opposed to the "ideal" system they are/will study with the lab-scale reactor.

\section{Final Thoughts:}

Whenever someone tries to make a useable product (hydrogen) from a waste material $\left(\mathrm{H}_{2} \mathrm{~S}\right)$, it is worth some attention, especially when the organization is known to be quite knowledgeable. This is the situation here.

There is no doubt that GTI can make hydrogen out of $\mathrm{H}_{2} \mathrm{~S}$; the question is: can they economically remove hydrocarbons from their feedstock, and make and purify hydrogen in sufficient quantity. The separation process is a very intricate one, but one that GTI appears to have a good handle on. The problem is that the overall system is also very complex. Effort must be made to better address these pre and post reaction issues. They will make or break this project. 
Exhibit 1. Schematic of GTI's Lab-Scale Superadiabatic Combustion System
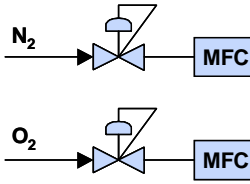

$\mathrm{H}_{2} \mathrm{~S}$

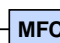

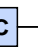
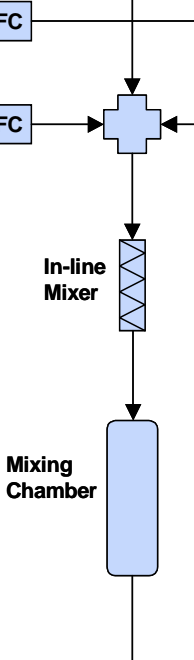

Flexible SS Hose

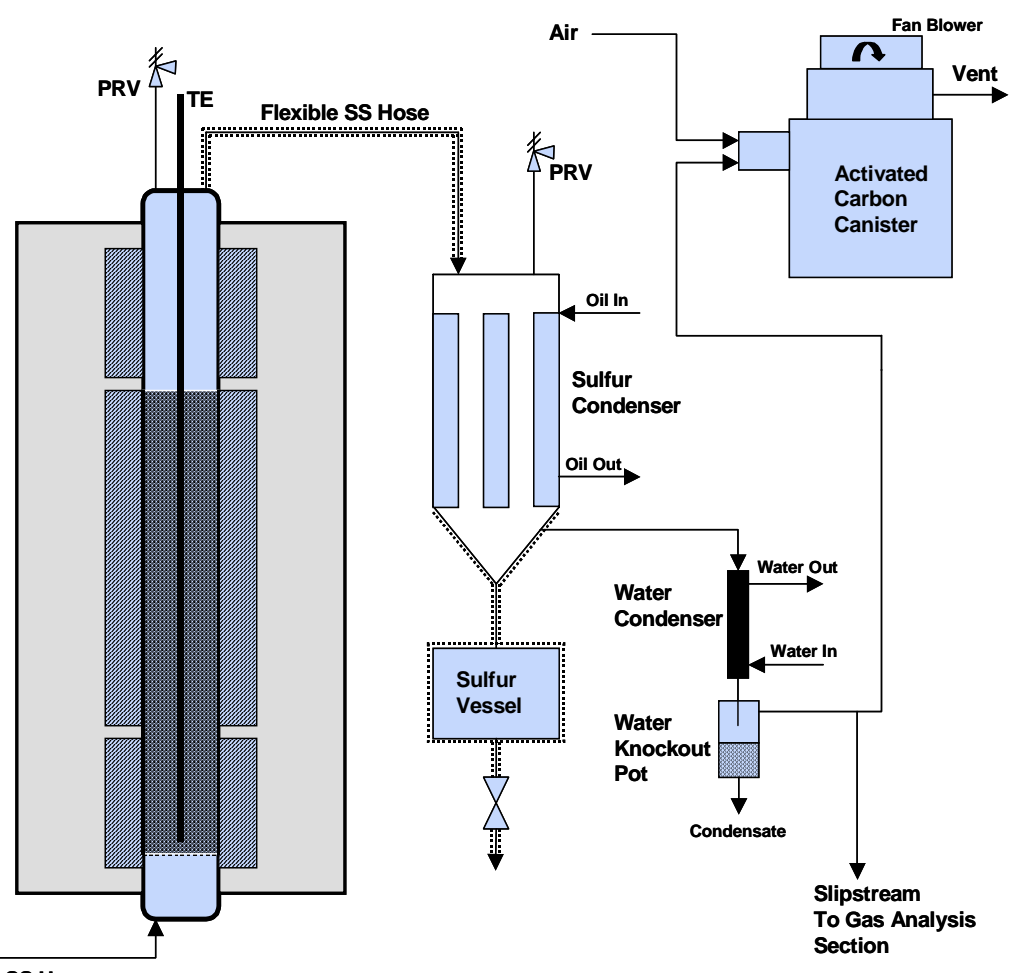

Exhibit 2. Thermal Decomposition using Heat from Natural Gas

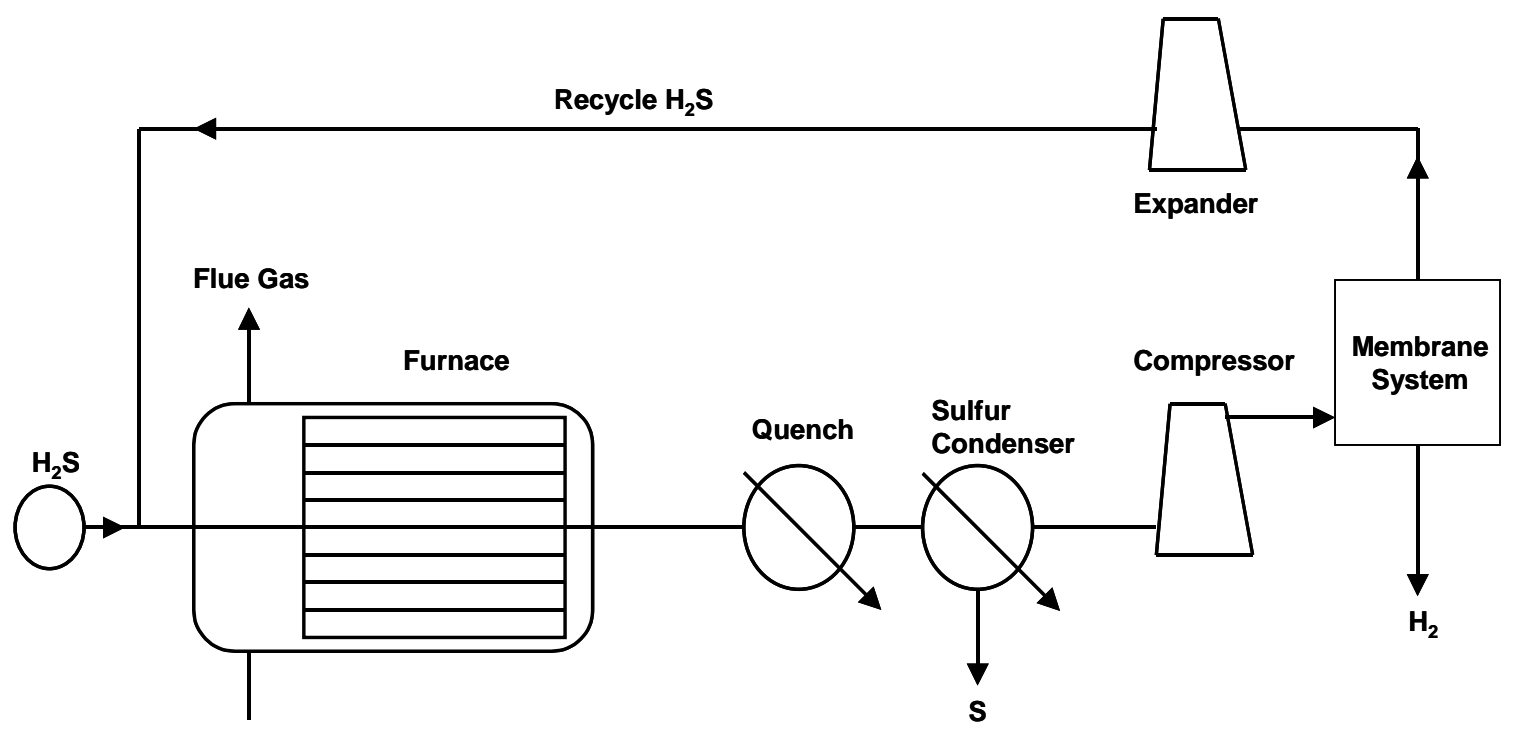

Nat. Gas 
Exhibit 3. Thermal Decomposition using Heat from Claus Reaction Furnace - ASRL Scheme

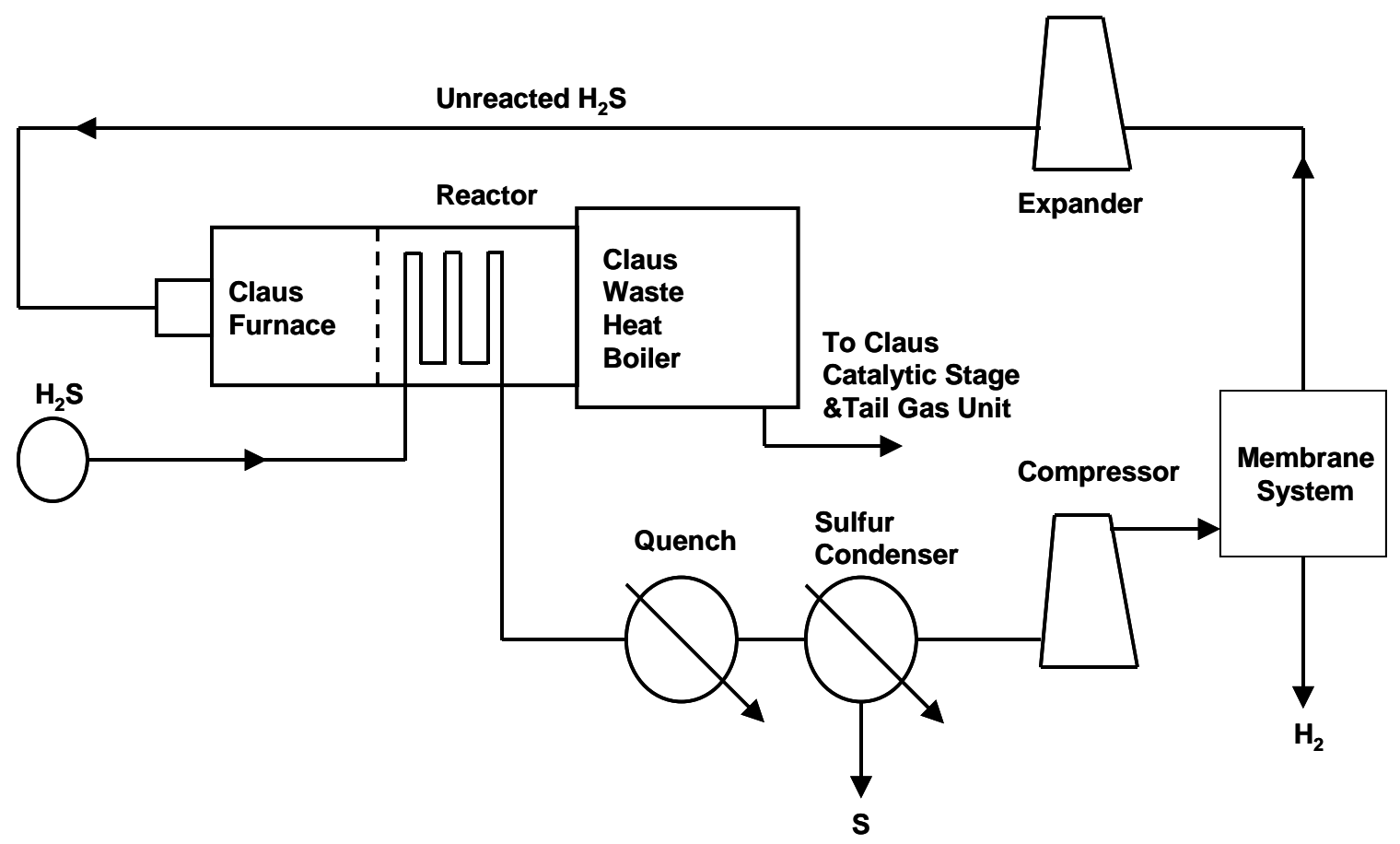

Exhibit 4. Experimental Results from UIC in Phase 1.

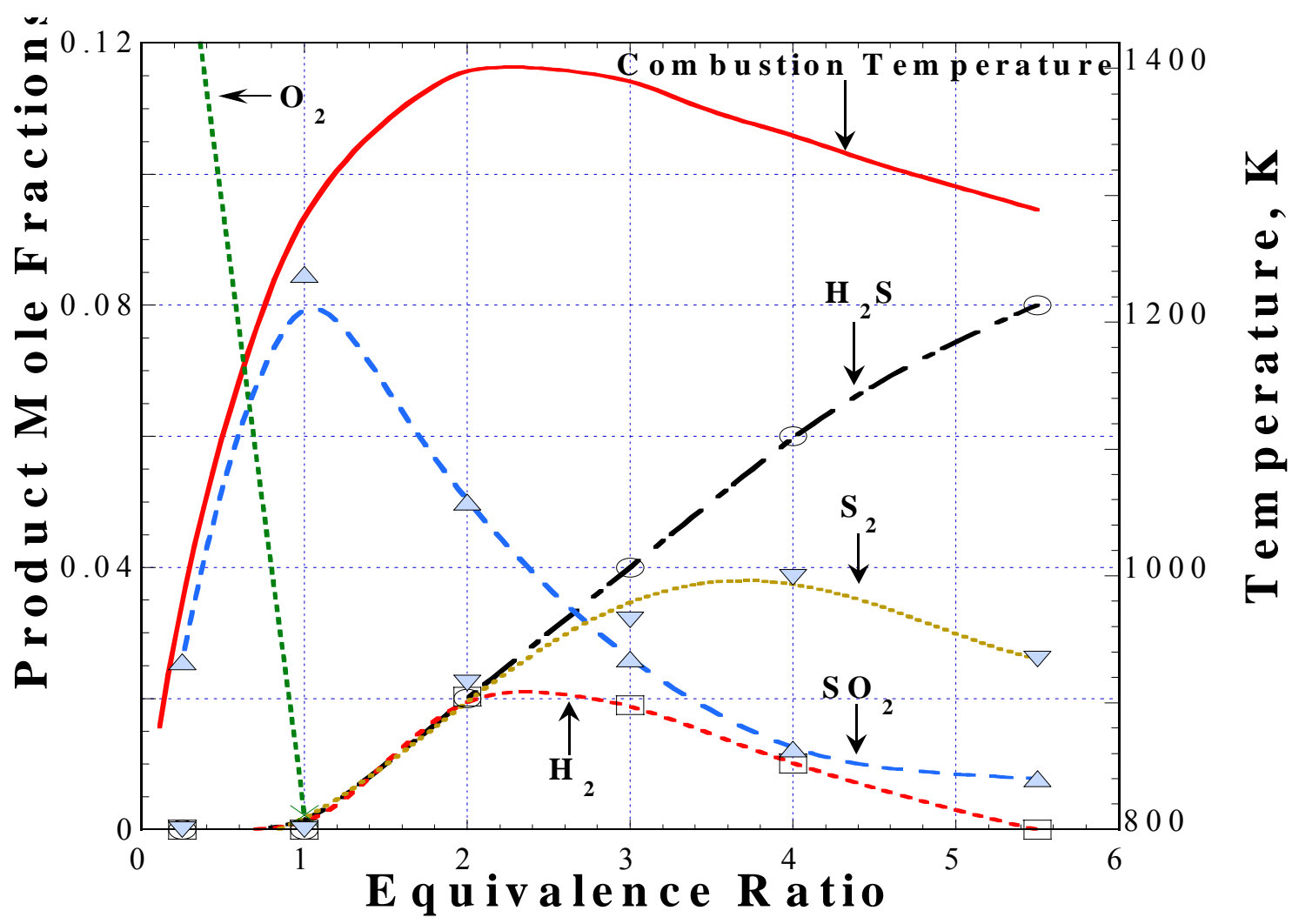


Exhibit 5. Transient Filtration Combustion Wave

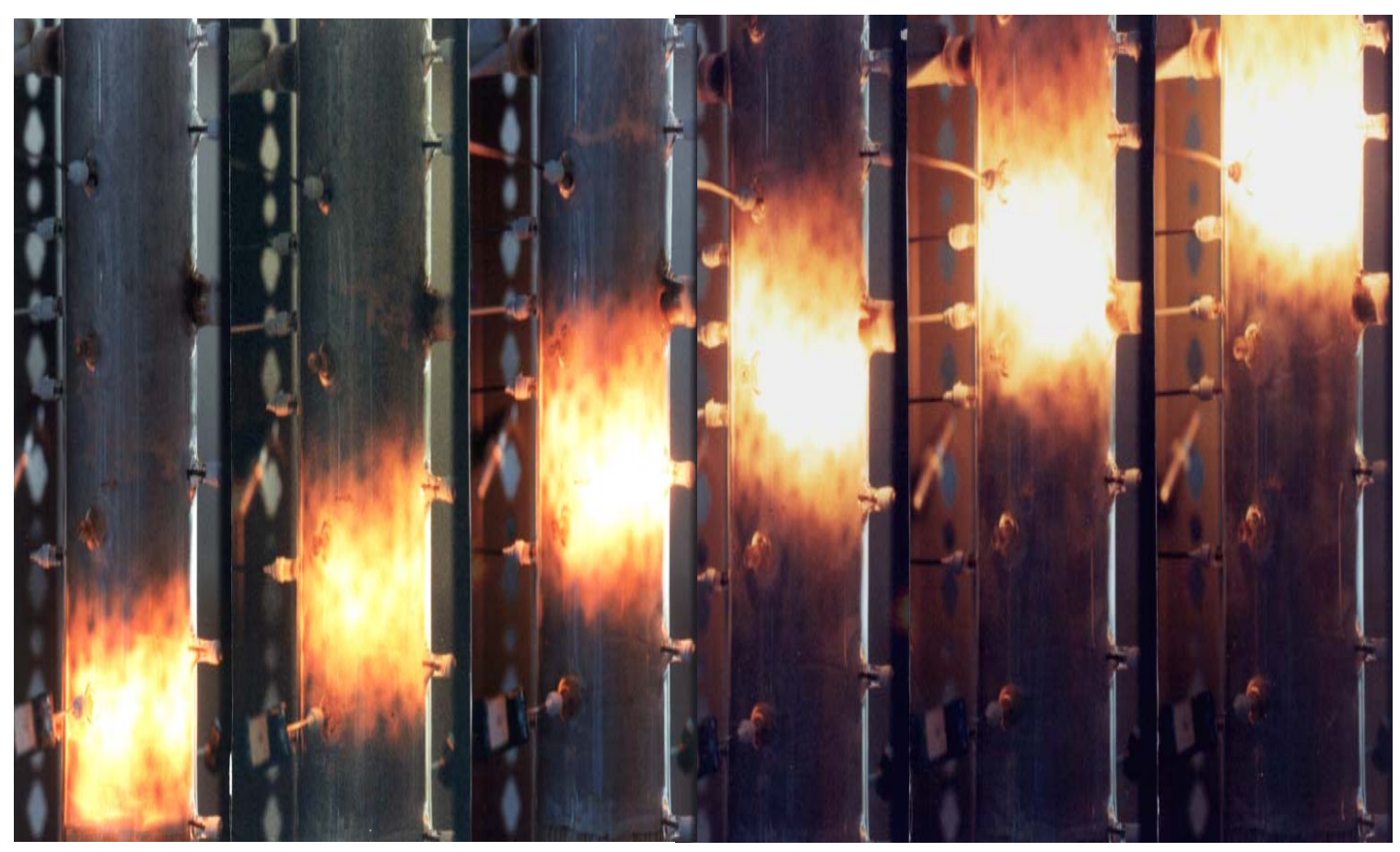


Technical Evaluation Report

Project: Biohydrogen Production in a Mixed Culture Fermenter

Company: Iowa State University

P.I.: Dr. Shih-wu Sung

Site-Visit Date: August 7, 2002

Evaluation by: Edward G. Skolnik, Energetics, Inc.

\section{Summary:}

A group of researchers from the Department of Civil and Construction Engineering at Iowa State University (ISU) in Ames, Iowa, is attempting to produce hydrogen from waste material containing mixed cultures of bacteria. The waste material is wastewater containing low concentrations of suspended solids.

ISU has used a series of batch tests to try and optimize conditions for hydrogen production rather than methane production. This involves heat-treating the material in order to destroy methane-producing bacteria and promote Clostridium, the hydrogenproducing bacteria.

Having identified conditions, ISU has moved to a laboratory semi-continuous process, where material is periodically being taken out of the reactor for heat treatment. Once the process is optimized, they plan next to incorporate it into a pilot-plant process with their cost-share partner.

I see the following strengths in the project:

- Any time you can make a useable product out of waste material, it's worth looking at - if it can be done economically.

- The heat treatment procedure seems to have an effect on hydrogen production and methane depletion.

- Using a mixed culture will likely lower the cost of the process.

I see the following items that need to be addressed:

- I'm not sure that the methodology for the process has been sufficiently worked out yet. How much heat treatment is necessary and when, is I believe, still an issue that needs to be studied. The results on the batch and semi-continuous runs are not conclusive, and even seem contradictory.

- The reporting on the various batch tests does not adequately express what tests are being performed and why. The difference in reporting methods (compare Exhibits 1, 2 , and 4 , for instance) make it difficult to compare results. 
- I am not at all sure how robust the process is. How well will it work on different waste streams; how will it handle/remove potential impurities that could poison the bacteria? (The presence of hydrogen sulfide is already recognized as a problem by ISU)

- The amount of hydrogen being produced seems low on a theoretical basis.

\section{Introduction and Background:}

The Biohydrogen Production Research Team at ISU is led by Dr. Shihwu Sung. It includes Dr. Samir Kumar Khanal, a Postdoctoral researcher, Mr. Wen-Hsing (Albert) Chen a PhD student, Mr. Jae-he Ho also a PhD student, and Mr. Thanapong (Jack) Duangmanee an MS student. They are all part of the Biotech Research Group.

The Biotech Research Group in the Department of Civil and Construction Engineering at ISU works on byproducts from waste treatment and anaerobic bioconversion technologies. They had been looking at anaerobic production of methane, when they found that one set of reactor conditions was producing hydrogen.

According to Dr. Wu, ISU and now Penn State (headed by a former student of Dr. Wu's) are the only institutions looking at mixed cultures rather than pure cultures. They use engineering techniques to try to enhance the activity of the proper bacteria within the culture.

In addition to the hydrogen work, the group is working on using mixed wastes to make standard, class " $\mathrm{A}$ " (safe) fertilizers that can be sold commercially. Also they are using the wastes in the production of alcohols and organic acids, but separation costs are the problem here.

The Biotech Research Group has a patent on a process known as Temperature Phase Anaerobic Digestion (TPAD). Dr. Sung described the process as one in which methane and class " $\mathrm{A}$ " biosolids are made from sewage sludge. The work is being funded by a cattle farmers group. The process works on highly concentrated sludges and on animal wastes. ISU is currently also looking at food waste, and at produce wastes. The latter includes boxes in which produce has been stored. This poses a problem as the boxes often have a wax coating which is not very biodegradable.

\section{General Discussion:}

Mr. Duangmanee used a presentation that he made at the World Hydrogen Energy Conference in June 2002 as a basis for much of the general discussion.

ISU employs the EMP Pathway (named for its three developers, Embden, Meyerhof, and Parnas), also called glycolysis, to produce pyruvate. $\left(\mathrm{CH}_{3}-\mathrm{C}(=\mathrm{O})-\mathrm{COO}^{-}\right)$which then produces hydrogen. 
The process uses real waste; it is a mixed culture. Although pure cultures have shown significantly higher hydrogen yields, they are not realistic for real waste. Clostridium is the hydrogen-producing bacteria.

Dr. Sung and his group see three major challenges to the use of mixed cultures:

1. There is a tendency to produce alcohols instead of acids. The formation of hydrogen coincides with the production of acids (see Question 1 below).

2. The coexistence of hydrogen producers and hydrogen consumers (methanogens) within the mix poses a problem. Methanogens are bacteria which promote hydrogen depleting reactions such as:

$$
4 \mathrm{H}_{2}+\mathrm{CO}_{2} \rightarrow \mathrm{CH}_{4}+2 \mathrm{H}_{2} \mathrm{O}[1]
$$

3. Spore formation (see Question 4) reduces hydrogen production. But the ability to form spores indicates that the species is capable of producing hydrogen.

Aside from $\mathrm{pH}$ control, you can use kinetics to reduce methane formation. Hydrogen is produced before methane.

ISU has found that heat treatment of the waste will activate spore-forming bacteria (those that can produce hydrogen) and will eliminate bacteria that cannot produce spores. Spore formation is a mechanism bacteria use to preserve their lineage when threatened by a harsh environment, such as heat. You only need to heat-treat the inoculum one time in order to make spores. Then you can preserve them in the reactor. From then on, you can continuously use non-sterile waste.

ISU first performed a series of batch tests, varying $\mathrm{pH}$ and heat treatments. These tests, which defined optimum conditions, were precursors to using a continuous reactor. These test are discussed below in Questions 7 and 8, and Exhibits 1-4.

Using the data from the series of batch tests, Dr. Sung's team then moved to a system which can be called continuous, or better, semi-batch. The system features a five-gallon Completely Stirred Tank Reactor (CSTR). The semi-batch part comes from the fact that material was periodically (three times a day) pulled out of the reactor for heat treatment. The system is discussed in the "Tour" section. Results are seen in Exhibit 5. Hydrogen starts off at a high level and then drops off, eventually reaching an equilibrium. This reactor is producing about 7 liters of hydrogen per day. It does not appear that repeated heat treatment either helps or inhibits hydrogen formation.

Mr. Duangmanee in his presentation indicated that each mole of sucrose in a heat treated system results in 2.15 moles of hydrogen vs. 1.81 moles in the non heat treated system. Both these numbers are far below theoretical hydrogen from the fermentation process (see Question 1 below.) 
The plan for the next phase is that the project will move to a reactor at the Biomass Energy Conversion Facility (BECON) run by The Iowa Energy Center, a cost share partner. The hydrogen formation would be an add-on to a system that would also produce methane. The system would not be fully stabilized. You would reduce $30 \%$ theoretically, $20 \%$ actually of the Chemical Oxygen Demand (COD), to make hydrogen. COD refers to the amount of oxidizing agent necessary to oxidize all the carbon in the sample. Since hydrogen production kinetics is faster, the hydrogen production would be done first. Then the remaining material would be moved to a different reaction system (being studied now in a different project) where methane would be produced, and the waste would be stabilized. The "Tour" section discusses the reactors at BECON.

So in the final scheme of things, the hydrogen system will be a module. You get the hydrogen out and partially stabilize the waste. The final waste stabilization occurs in the second more "standard" module. Dr. Sung himself asks if it is worth it. It's all in the economics.

If you can argue that the majority of the preparation would be done anyway for the stabilization/methane production process, maybe the cost will not be all that bad. If the project is to continue, however, an economic analysis to determine the cost of hydrogen production would be recommended.

Mr. Duangmanee indicated that recent experiments in which the temperature to which the material is heated was tested, the results were as good at $70^{\circ} \mathrm{C}$ as at $90^{\circ} \mathrm{C}$ (which was the temperature that they had previously been using) as far as amount of hydrogen produced was concerned. There is a thought that some beneficial organisms may be destroyed at $90^{\circ} \mathrm{C}$. One possibility that $\mathrm{Mr}$. Duangmanee is recommending is to heat all solids to only $70^{\circ} \mathrm{C}$ once every 2-3 days. The group is debating this possibility.

I believe that ISU is still pretty far away from being able to make a decision on which way to go. Many of the tests do not appear very conclusive.

\section{Questions and Answers:}

I sent Dr. Sung a set of discussion questions prior to my arrival. These are reproduced here, in bold type. Dr. Sung and his team provided answers during our discussion, and these are displayed here in normal type. My comments added to many of the questions during my later analysis and assessment are shown in italics.

\section{Please discuss the theoretical yield of hydrogen from glucose or sucrose depending on the conversion of the substrate.}

This question came from statements made by Dr. Sung and his group in the FY 2002 Annual Review Report.

Hydrogen is produced from glucose or sucrose by fermentation reactions such as: 


$$
\begin{gathered}
\mathrm{C}_{6} \mathrm{H}_{12} \mathrm{O}_{6}+2 \mathrm{H}_{2} \mathrm{O} \rightarrow 2 \mathrm{CH}_{3} \mathrm{COOH}+2 \mathrm{CO}_{2}+4 \mathrm{H}_{2} \text { [2] } \\
\mathrm{C}_{12} \mathrm{H}_{22} \mathrm{O}_{11}+5 \mathrm{H}_{2} \mathrm{O} \rightarrow 4 \mathrm{CH}_{3} \mathrm{COOH}+4 \mathrm{CO}_{2}+8 \mathrm{H}_{2} \text { [3] }
\end{gathered}
$$

These represent the maximum theoretical yield from glucose or sucrose, respectively, but many other reactions also take place via the fermentation pathway. For glucose, for instance, butyric acid can be formed:

$$
\mathrm{C}_{6} \mathrm{H}_{12} \mathrm{O}_{6} \rightarrow \mathrm{CH}_{3}\left(\mathrm{CH}_{2}\right)_{2} \mathrm{COOH}+2 \mathrm{CO}_{2}+2 \mathrm{H}_{2}[4]
$$

The amount of hydrogen that would be produced would depend on the ratio of acetic to butyric acids formed. In addition, many other reactions also take place, some of which don't form hydrogen at all. The pathway is not controlled.

\section{What are typical approximate atomic makeups (by weight) of your municipal wastes?}

Currently, ISU is not looking at "real" municipal solid waste. Typically, MSW would be about $40-60 \%$ organic. In the organics, carbohydrates (empirically, $\mathrm{CH}_{2} \mathrm{O}$ ) make up about $30-40 \%$, lipids $\left(\mathrm{C}_{8} \mathrm{H}_{16} \mathrm{O}\right)$ are about $5 \%$, and proteins $\left(\mathrm{C}_{16} \mathrm{H}_{24} \mathrm{O}_{5} \mathrm{~N}_{4}\right)$ are about $50-60 \%$, but it varies from waste stream to waste stream.

\section{How has the waste been pretreated prior to you receiving it (e.g., inorganics removed)?}

As stated in the previous question, ISU is using synthetic waste - molasses or dog food are typical materials. They have yet to use real waste.

Dr. Sung does not consider MSW to be a good candidate anyway. He wants eventually to look at waste water, and waste water with about $1-2 \%$ suspended solids. ISU generally uses COD to measure solids.

\section{Please explain the correlation between spore formation and hydrogen production.}

When a spore is being formed, there is no hydrogen being produced. Nevertheless, you need materials that are capable of forming spores.

Spore formation is a survival mechanism, a method that the bacteria use as a means to protect itself from excursions in temperature, $\mathrm{pH}$, etc.

Spores are about one micron (half the length of the bacteria itself) in length.

\section{What is the purpose of the nucleic acid?}


It is used to identify the population shift of bacteria. Each bacteria has an identifiable genome sequence. The nucleic acid sequence is used to define the bacteria.

6. In your discussion of the batch experiments in your FY 2002 report, you seem to make a conflicting statement. For the non-heat treated case, you first state that the methane levels were increasing, and then (apparently for the same experiment) state that no methane was detected, and that low hydrogen production was attributed to competing bacteria (rather than hydrogen consumption by methanogens). Please explain.

Methane is not produced at low $\mathrm{pH}$ values $(<5.5)$. In this experiment, the $2^{\text {nd }}$ and $3^{\text {rd }}$ runs were done only at low $\mathrm{pH}$, so no methane was being produced. The competing bacteria may have been making acid only.

This is an example of where the results are reported in a somewhat confusing manner. It was not indicated that there was no attempt to return to the higher $\mathrm{pH}$ levels.

7. Your initial set of batch experiments showed that without heat treatment your maximum hydrogen production appeared to be at pH levels of 6-6.5 (your Figure 2) Exhibit 1 in this Report, while it was optimized at 5.5 with a heat pretreatment (your Figure 3) Exhibit 2. What do you believe is the reason that the lower $\mathrm{pH}$ is preferred with heat treatment? Also, comparing the values of hydrogen production for the two Figures, it appears that the heat pretreatment causes a slight reduction in hydrogen production at $\mathrm{pH} 5.5$, and large reductions in hydrogen production at pH 6 and 6.5. Am I reading that correctly? If so, is heat treatment the proper procedure?

Even though more hydrogen was detected at higher $\mathrm{pH}$ levels, the presence of methane meant that methanogens were present. Methanogens are not present below $\mathrm{pH}=6$.

Clostridium, on the other hand, will produce hydrogen at $\mathrm{pH}=5.5$, so this is the optimum condition.

Hydrogen evolution as shown in Exhibit 2 is cumulative. If we look at production rates for hydrogen and methane (Exhibit 3), we'll see that the rate of hydrogen production starts rapidly, but then falls off as methane increases.

Heat treatment lowers initial hydrogen production, simply because it kills some of the cells; later, hydrogen production increases.

ISU's attempt to go to a lower temperature for heat treatment could alleviate the problem. Interestingly, however, data appears to show high initial hydrogen concentrations, with drop off later.

Methanogens will produce methane at $\mathrm{pH}$ levels between 6 and 8 , and are optimized at $\mathrm{pH}=6.8-7.2$. In the first batch test (Exhibit 1), where there was no heat treatment, the 
fact that methane was observed during the first run (note that there are 3 runs in the first batch test) was an indicator of reduced hydrogen levels in later runs. Indeed, runs 2 and 3 showed greatly reduced hydrogen production, due to competing reactions. If you don't heat treat, eventually the methanogens will take over, with their hydrogen to methane process.

The second batch test (Exhibit 2) looked at optimum $\mathrm{pH}$ for the heat treated system. This system will not be the same bacterially as the non-heat treated system.

These measurements are made based on volatile suspended solids (VSS). It is a standard way to measure bacteria concentration in a wastewater stream on a weight basis.

\section{Heat treatment between runs (Figure 4) (Exhibit 4) seems to result in further reduction of hydrogen production. Same question. Is this correct, and is heat treatment the proper procedure?}

This relates to the $3^{\text {rd }}$ batch test. This test used repeated heat treatments in an effort to simulate a continuous run. Some of the runs were not completed. The figure shows cumulative hydrogen production.

The only thing that the Exhibit seems to show clearly is that the system produces hydrogen and blank runs do not. The fact that some early runs were cut off before reaching equilibrium makes the results somewhat confusing. It looks like repeated heat treatment works better, but not conclusively so.

\section{How do you think that the lag phases of several hours will effect a commercial operation?}

Lag time only affects the process at the start. It is due to germination and adjustment of bacteria. It shouldn't be needed again. A commercial unit would effectively not have a lag time.

10. In your semi-continuous process (Figure 5) (Exhibit 5) you show that Reactor A (with heat treatment) goes through a period of a few days where hydrogen production is essentially zero, while Reactor B (no heat treatment) shows relatively high hydrogen production over that time period. Please explain. (You conclude that heat treatment may be "not necessary" during these early days. It appears that it may actually be detrimental.)

ISU does not really know why heat treatment resulted in zero hydrogen (and total biogas) production for days 5-10. Dr. Sung argues, however, that in the long run, hydrogen production is stable. 
The first ten days were just an adjustment phase. Counter to the batch tests, there was no effect of heat treatment observed. Dr. Sung thinks they may have heated the system too much. However, he points out that the first couple of days produced high hydrogen yields. He thinks that this could be expanded by continually pulling out hydrogen or byproduct acids.

I think this testing scheme and interpretation has a long way to go. The results are not conclusive I think, other than to say that the system does appear to equilibrate at low hydrogen production levels.

\section{Let us discuss in general what data leads you to believe that heat treatment optimizes hydrogen production.}

This question has been answered in several places throughout the discussion already.

The one main point in the favor of heat treatment is that it kills methanogens which deplete hydrogen and produce methane. However, controlling the $\mathrm{pH}$ seems to prevent methane formation as well.

As to when to heat treat, and how often, it appears that the results are contradictory to this point, and more work may be needed to determine what the process really ought to be.

\section{Is there any indication of what would happen if the experiments continued past day 25 ?}

It would appear that the 7 or so liters of hydrogen that ISU can produce each day is more or less a steady state, and would continue well past day 25 . The problem may be that this amount of hydrogen is not sufficient.

\section{In a commercial process, would the goal be to reach an equilibrium eventually, or would the need be there to always have a semi-batch process?}

In a continuous process, the ratio of food to microorganisms remains constant. With a semi-batch process, where you are taking material out periodically, you will have a period of time when you have a high ratio. This represents a high growth period, which is valuable to have. So, Dr. Sung believes the optimum process is a semi-batch process.

\section{Additional Items:}

Municipal wastes and agricultural wastes are good candidates for this technology as they are consistent enough to be characterized. Industrial wastes are not.

If you are going to use wastewater, you need a readily available source of inoculant seed material. You cannot afford to buy it. 
Dr. Sung realizes that removing hydrogen sulfide from the wastewater will be a challenge

\section{$\underline{\text { Tour: }}$}

\section{$\underline{B E C O N}$}

Dr. Sung took me on a tour not only of his laboratories, but also of the Biomass Energy Conversion facility (BECON) of the Iowa Energy Center. BECON is located in Nevada, IA, about 5 miles from ISU. The project is being cost-shared by BECON, where pilot scale systems will be built and tested. The Iowa Energy Center is supported by Iowa rate payers, and funds not-for-profit groups.

Dr. Sung and I were met by Mr. Norm Olson, Project Manager at BECON, who took us on a tour. BECON is running pilot plant scale testing on six different processes that operate on agricultural residue and wastes. These include:

- Thermal gasification - This is a fluidized bed process using biomass materials such as switch grass and corn stover (basically cornstalks with the ears removed). The product is currently about $30 \%$ hydrogen. They are trying to increase the hydrogen yield.

- Pyrolysis - This is mainly involved with making various synthetic oils.

- Biodiesel - Synthetic diesel fuel is made from soybeans and/or soybean wastes. Glycerin is produced as a byproduct.

- Alcohol production unit - A 1500 gallon stainless steel fermenter and a 50 gallon/hour distillation system produces ethanol from corn or switchgrass.

- Anaerobic digestion - Corn stover or other waste materials are used to make methane or organic acids.

- Supercritical fluids - Pressurizes plant material to 10000 psi to make synthetic fossil fuels.

BECON is also looking at systems that are made up of combinations of the above processes.

Dr. Sung's hydrogen project will fit with the anaerobic digestion project. ISU will provide waste for this system. The plan would be for waste to be first sent to a small tank for about 20 hours of retention to produce hydrogen, and then to send the waste on to the "main" digesters to make methane. 


\section{$\underline{\text { ISU Labs }}$}

Following our trip to BECON, Dr. Sung and I returned to ISU and toured his own labs. I was shown many waste conversion systems which were being used by Dr. Sung and other members of the Biotech Research Group:

- A five-liter three-compartment plug-flow digester with a 24 hour retention time. It has a divided head space, but is connected in the liquid space. The premise for this reactor is that one space can contain mainly active bacteria, where the most hydrogen can be made, and another can contain a high spore concentration where the hydrogenproducing bacteria can be generated in opposition to the methanogens. Unfortunately, this system was not in use during my visit.

- The TPAD reactor/digester. It is a two-stage semi-batch reactor, kept at 55 and $35^{\circ} \mathrm{C}$, respectively. The two stages and two temperatures result in a reduced reaction time. It's current feedstock is waxed cardboard boxes in an $8 \%$ slurry. Thermophilic bacteria are injected one time.

- A hydrogen sulfide trickling tower. It converts $\mathrm{H}_{2} \mathrm{~S}$ to sulfur and water biologically. The system is run at low oxygen concentration to prevent the formation of sulfate.

- Two columns that treat low strength waste at ambient temperature. This produces only small amounts of methane. The two columns are being used to compare an upflow process (an anaerobic "sludge blanket") with a downflow process (a watersprinkled static granite bed reactor.)

- The five-liter CSTR for hydrogen. The schematic for the system is shown in Exhibit 6. The reactor (item 3 in the exhibit) contained a blackish sludge which is kept, via controllers, to a $\mathrm{pH}$ of 5.5 and a temperature of $37^{\circ} \mathrm{C}$. As the reaction goes on, the color of the sludge will change from black to white due to iron sulfide reduction. Dr. Sung said that the sludge would be white in about two weeks.

The feed is sucrose at about 20 grams COD per liter, mixed with $\mathrm{Fe}^{2+}$ and $\mathrm{Fe}^{3+}$ nutrients for the hydrogenase. The cycle starts by removing about $1 / 3$ of content from the reactor and sending it to the settler (item 9) for about 30 minutes. The solids are then pumped to the activation chamber (item 13) where it is heat-treated, and then sent back to the reactor. Makeup feedstock (from item 1) is also added to the reactor. The liquid from the clarifier is simply discarded at this time. When they move to the pilot system at BECON, the liquid would be sent to the methane converter.

The system currently produces about 25 liters of biogas per day, about $55 \%$ of which is hydrogen. Gases are sampled through a port and fed to two gas chromatographs, one for hydrogen, and the second for methane. (A third chromatograph looks for organic acids and alcohols.)

DNA and spore counting are performed three times per week. 
ISU is also controlling the redox potential, but has found no correlation here.

\section{Final Thoughts}

There are some reasonable results from this project to date. The ISU group has shown that they can make hydrogen by this process. However, it doesn't seem that their batch tests and semi-continuous tests have produced conclusive results. It's clear that heat treatment reduces the level of methanogens in the system, but it's unclear whether it actually increases hydrogen production. It is also unclear as to whether this is the best way to limit methane formation. I would, for instance, also more thoroughly investigate pH control as a primary methanogen reducer.

I don't really think that ISU learned enough from their batch tests to warrant moving to the semi-continuous mode. The third set of batch tests (Exhibit 4) especially, I thought was inconclusive. In some cases, heat treatment helped, in others it didn't. I probably would have tried to repeat that third set. I also would have tried different feedstocks to see how generic the process is.

Be that as it may, I think that the semi-continuous process itself (Exhibit 6) is well thought out, and will yield valuable data once it is controlled properly. At this point, however, with only one set of comparative data (Exhibit 5), I think that it is too early to draw any real conclusion. The very peculiar results over the first ten days need to be explained. The low hydrogen production level of about 7 liters/day after equilibrium is reached (from about day 12 onward) needs to be improved in light of over double that amount being produced initially.

On a percent of theoretical basis, ISU has indicated that about two moles of hydrogen are being produced per mole of sucrose, while theoretically eight moles of hydrogen are possible via reaction [3]. This is a 25\% yield. However, in addition, some of the sucrose hydrogen goes into forming the byproduct acid as well. Of the 22 atoms of hydrogen present in sucrose, only 4 (2 moles) are going into making hydrogen in the process at this time. This represents an $18 \%$ yield. The fact that heat treatment produces 2.15 moles of hydrogen, and non-heat treatment produces 1.81 moles of hydrogen per mole of sucrose is nearly lost in the noise. Finally, we have to consider the fact that ISU is planning to work with a wastewater stream with suspended solids. Perhaps the question should be asked as to what amount of hydrogen is coming out of this system per unit of throughput.

On the other hand, if the feedstock is free, and the process is inexpensive, maybe it doesn't matter. An economic analysis is needed. The bottom line (as always): how much hydrogen can you produces, and how much is it going to cost? 


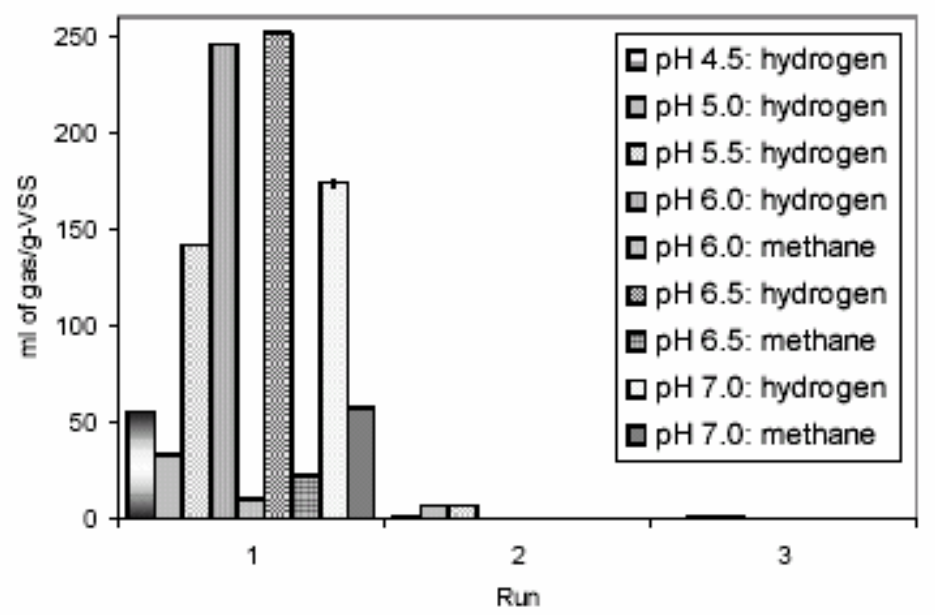

Exhibit 1. Hydrogen and methane production. First set of ISU batch tests, no heat pretreatment. (From Sung FY 2002 Annual Review Paper)

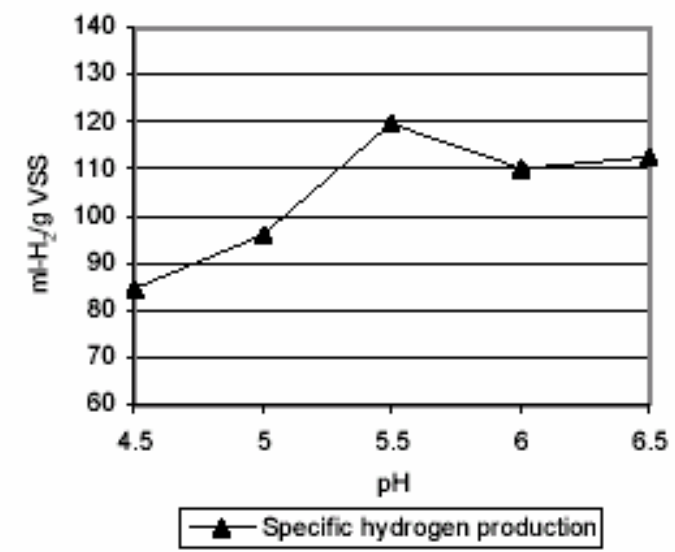

Exhibit 2. Hydrogen production. Second set of ISU batch tests, heat pretreatment... (From Sung FY 2002 Annual Review Paper) 


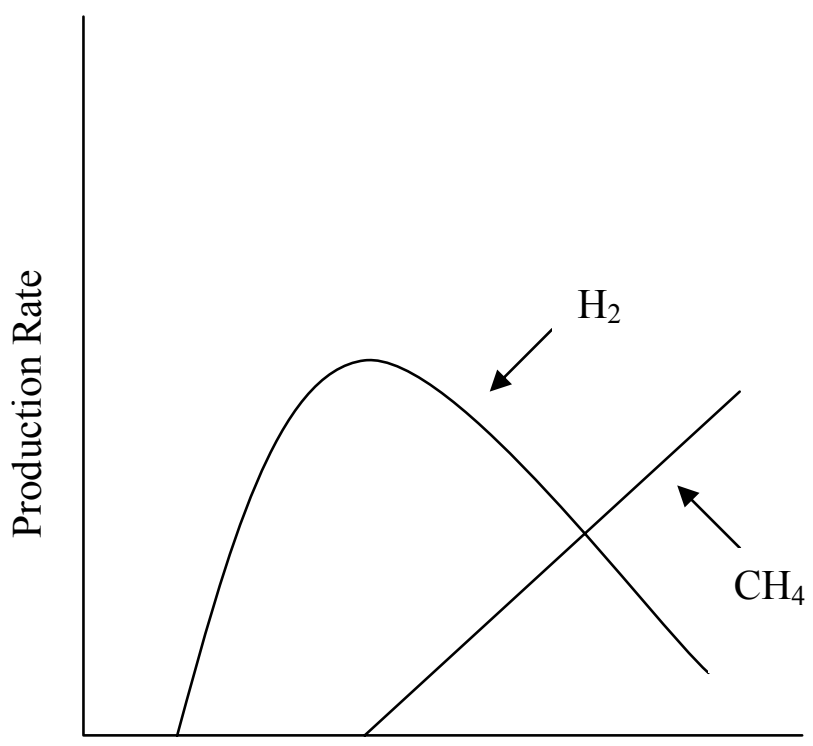

Time

Exhibit 3. Typical hydrogen and methane production in the presence of methanogens.

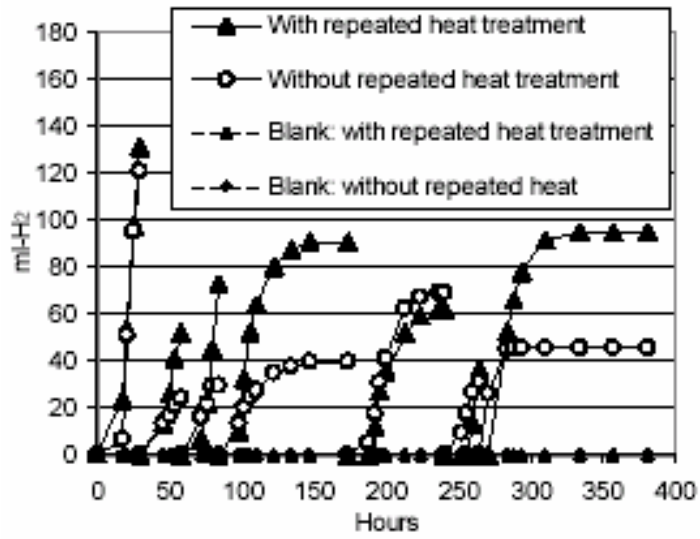

Exhibit 4. Cumulative hydrogen production with and without heat treatment.

(From Sung FY 2002 Annual Review Paper) 


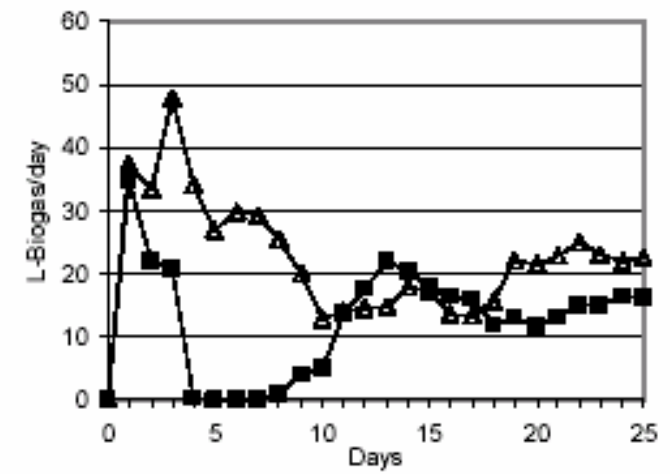

- Biogas: Reactor A with repeated heat treatment

- Biogas: Reactor B without repeated heat treatment

(a)

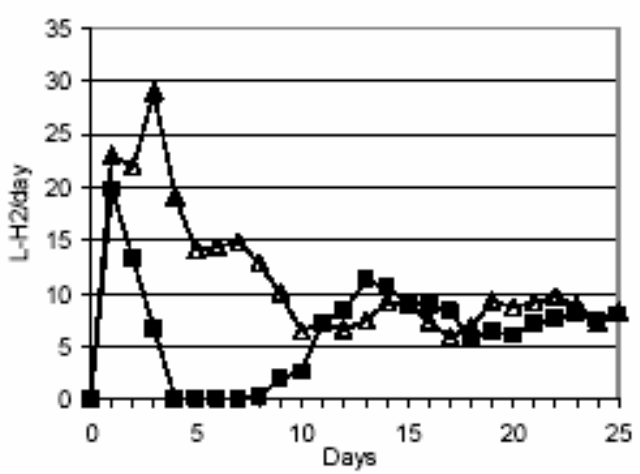

-Hydrogen Reactor A

A-Hydrogen Reactor B

(b)

Exhibit 5. Total biogas and hydrogen production per day. (From Sung FY 2002 Annual Review Paper)

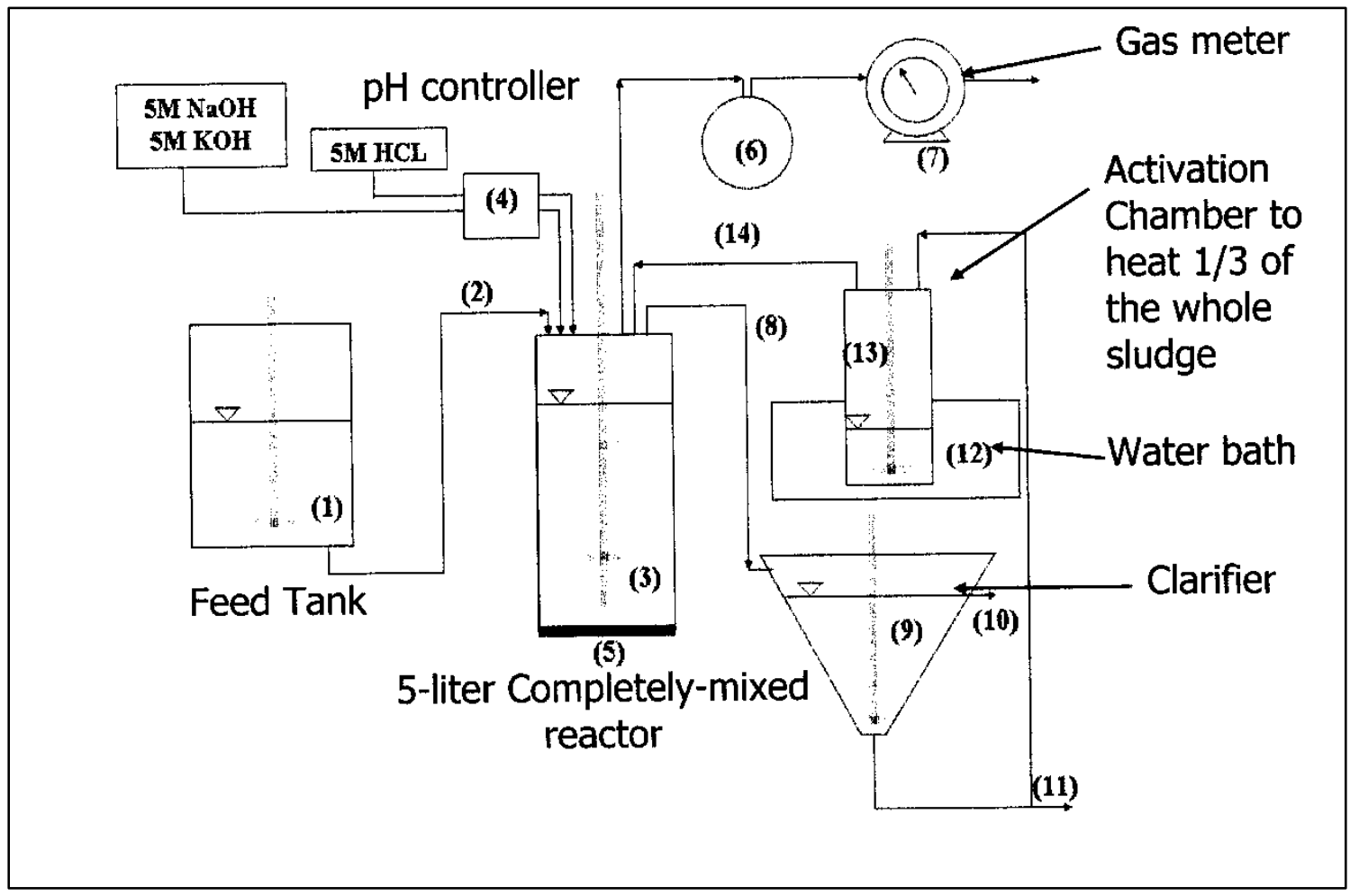

Exhibit 6. Schematic of the continuous flow reactor with activation chamber.(1) substrate reservoir, (2) influent, (3) 5-L completely-mixed anaerobic reactor, (4) $\mathrm{pH}$ controller, (5) heating mat, (6) balloon for pressure equalization, (7) gas meter, (8) reactor effluent, (9) clarifier, (10) system effluent, (11) sludge wastage, (12) water bath, (13) activation chamber, (14) return sludge line. (From T. Duangmanee WHEC Presentation, June 2002) 
Technical Evaluation Report

Project: New Glass-Ceramic Proton Conducting Membrane

Company: Iowa State University

P.I.: Dr. Steve W. Martin

Site-Visit Date: August 8, 2002

Evaluation by: Edward G. Skolnik, Energetics, Inc.

\section{Summary:}

A team of researchers at Iowa State University (ISU) are developing materials that can be used to construct a proton transfer membrane from novel substances. The project, still in its initial stages, involves the identification and development of membranes based on sulfides or mixed sulfides and oxides. These membranes can be used to transfer protons (i.e., $\mathrm{H}^{+}$) and thus can be used in a new mode of fuel cell that could be operated at temperatures between 200 and $500^{\circ} \mathrm{C}\left(392-932^{\circ} \mathrm{F}\right)$. These temperatures are well above the range for PEM fuel cells, above the upper limit for phosphoric acid fuel cells, and are below the operating temperatures for solid oxide and molten carbonate fuel cells. Thus they fill a gap in the operating temperature scheme for fuel cells.

While the project, through collaboration with industrial partners, will soon incorporate the development of the new fuel cell itself, to date, concentration has been on the identification and characterization of the membrane materials. The membrane chemistry is based on chalcogens (group VI elements including oxygen, sulfur, selenium and tellurium). The present work involves primarily sulfur, and more specifically germanium sulfide $\left(\mathrm{GeS}_{2}\right)$, in conjunction with $\mathrm{H}_{2} \mathrm{~S}$ to provide proton transfer sites. Key properties desired for the membrane materials are high conductivity, and stability to heat, oxygen, and water.

I see the following strengths in the project:

- This is one of the few totally new concepts for the Program. Instead of trying to extend or improve on the properties of existing fuel cell types, this project is looking to develop a totally new kind of fuel cell.

- The laboratory (even in its crowded state) seems well set up to pursue the development of the membrane materials.

- The research team appears very knowledgeable and well qualified.

- The presence of other similar projects (not for this program) ensures that complementary research will help move this project onward.

I see the following items that need to be addressed: 
- While the record keeping appears to be thorough, the methodology for how downselection will occur appears sketchy. Perhaps some weighting system or maybe incorporation of a Design of Experiments approach is needed to deal with the large numbers of materials, combinations of materials, and parametric studies that have been and will continue to be studied.

- ISU should begin to address the fuel cell, or at least, the membrane in the context of the fuel cell.

- Proton conductivity (as opposed to movement of other species) must be addressed separately. ISU recognizes this as an issue.

- There appears to be long reaction times in conjunction with making these membranes - on the order of weeks or even months.

\section{Introduction and Background:}

Dr. Steve W. Martin heads the group at ISU that is developing the new fuel cell membranes. Dr. Martin, who has been at ISU for 16 years, has a background in ionic conductivity. He had initially been investigating oxide glasses. When the French discovered sulfide glasses, they found that sulfides were several orders of magnitude more conductive than oxides $\left(\sigma=10^{-6}-10^{-7} \mathrm{ohm}^{-1} \mathrm{~cm}^{-1}\right.$ for oxides; $10^{-2}-10^{-3}$ for sulfides). Dr. Martin then began a fundamental study of sulfide glasses. Conductivity is the reciprocal of resistivity. " $\sigma$ " stands for "siemens", is the unit for conductivity, and is the reciprocal of ohm. (It used to be called "mho" which is ohm spelled backwards.)

Dr. Martin recognized some basic limitations with current fuel cell materials such as the temperature limits of PEM membranes or the tendency for fuel crossover, as befalls direct methanol fuel cells. The high conductivities of the sulfides made them good potential candidates for transporting protons. Dr. Martin already knew that sulfides work well for transporting lithium ions. He had previously been working with lithium batteries, and had thus developed expertise in transport mechanisms with $\mathrm{Li}^{+}$. In addition, the sulfide glasses are anhydrous, and are not subject to the limitations of fluorinated sulfonic acid membranes such as Nafion ${ }^{\mathrm{TM}}$, which becomes non-conducting when dehydrated. So the plan became to use sulfides to transport protons.

Dr. Martin was awarded the current contract by DOE to use his sulfide glass-handling expertise to develop $\mathrm{H}_{2} \mathrm{~S}$-containing sulfide glass-ceramics for fuel cell membranes. The ceramic component would provide the higher temperatures that he was trying to achieve. Dr. Martin also is working on a somewhat parallel effort for the Office of Naval Research (ONR). The ONR effort is focused on lower temperature sulfide glasses, and is more of a basic science study.

The DOE work funds Dr. Steve Poling, a postdoctoral researcher, Mr. Jake Sutherland, a Master's Degree candidate, and Ms. Carly Nelson, an undergraduate at ISU. Several other postdocs and students work on other ceramic material-based projects. I was with 
Dr. Martin's DOE team for most of the meeting, and met the rest of his group briefly as well. Dr. Martin provided an overview of the work that his group does, including the DOE project, and Dr. Poling and Mr. Sutherland made presentations of the specifics of the DOE work and its status.

\section{Overview:}

The group, as Dr. Martin pointed out in his overview, performs "glass science" and glass engineering". The science end includes studies on chalcogenide glasses (thioborates, thiosilicates, and thiogerminates), phosphate glasses, and silicate glasses. The chalcogenide glasses are engineered to produce fast ion conductors, proton conductors, and non-linear optical materials. The phosphate glasses are developed for metal/glass seals, and the silicate glasses are being engineered for use in medical lasers.

For the DOE project, the target low temperature is about $200^{\circ} \mathrm{C}$, this would be amenable to ICE-like system conditions.

The group working on the DOE project has mainly been working with $\mathrm{GeS}_{2}$ because it tends to be more stable in air and water than, say, $\mathrm{B}_{2} \mathrm{~S}_{3}$, which is a better glass former, but is not as stable. (ISU has a National Science Foundation contract to study $\mathrm{B}_{2} \mathrm{~S}_{3}$.) $\mathrm{H}_{2} \mathrm{~S}$ is the mobile proton provider. It is reacted in one of a number of ways with $\mathrm{GeS}_{2}$. The method currently being assessed by ISU is proprietary at this time.

PROPRI ETARY I NFORMATI ON EXCLUDED FROM PUBLI C VERSI ON

Since the proprietary methodology allows oxide sites to be protonated, ISU decided to use $\mathrm{GeO}_{2}$ rather than $\mathrm{GeS}_{2}$ as a starting material. The oxide is cheaper. Protonating the oxide directly:

$$
(2+\mathrm{x}) \mathrm{H}_{2} \mathrm{~S}+\mathrm{GeO}_{2} \rightarrow 2 \mathrm{H}_{2} \mathrm{O}+\mathrm{H}_{2 \mathrm{x}} \mathrm{GeS}_{(2+\mathrm{x})}(0<\mathrm{x} \leq 2)
$$

is easier and faster than protonating the sulfide.

Other sulfides are included in the mix for various reasons. For instance $\mathrm{Ga}_{2} \mathrm{~S}_{3}$ is included to increase stability.

\section{Status:}

Mr. Sutherland gave a short presentation on how the project evolved to where it is now. They had started out with the gas-phase reaction of $\mathrm{H}_{2} \mathrm{~S}$ with $\mathrm{GeS}_{2}$, and considered chemical vapor deposition, high-temperature reactions and low temperature reactions. But the sulfide did not protonate well, and the $\mathrm{GeS}_{2}$ also tended to sublimate.

They switched to a high-pressure reactor, but found that diffusion occurred through the oring seals. They also found, however, that if one worked at lower temperatures, it led to 
better protonation. High-pressure work in general, is safer at lower temperatures. This all led to the current proprietary work.

Dr. Poling presented the current work.

\section{PROPRIETARY INFORMATIONEXCLUDED FROM PUBLIC VERSION}

Right now, ISU are developing materials with conductivities in the $10^{-3}$ range, and are improving.

ISU is currently working with several companies who are interested in the ISU materials.

\section{Tour:}

Dr. Martin's projects - the DOE ceramic membrane work and other similar efforts - are housed in two quite small, but efficiently filled, laboratories. (When a new building will be completed next door, Dr. Martin's space will be 2-3 times as large. In the present setup the two labs are referred to as the "Preparation Lab" and the Characterization Lab.

The main impression that one gets when one enters the Preparation Lab, is that it is full of glove boxes. There are four of them, each with several glove ports. Some are used merely to store materials; others are employed as reactor locations where the "melt" reactions are processed. The glove boxes are kept free of water (limited to $<0.5 \mathrm{ppm}$ ) and oxygen (3-5 ppm). While many sulfides are stable, Dr. Martin wants to ensure that his group is working with very pure materials, thus preventing errant characterizations. Monitors are also present to detect $\mathrm{H}_{2} \mathrm{~S}$ leaks.

The preparation glove boxes contain crucibles into which the starting materials are placed. The crucibles, at the end of rods, are then pushed into tube furnaces connected to the glove boxes. The rods are calibrated so that the insertion distance into the furnace is fixed, ensuring good temperature control.

The record-keeping itself is excellent.

Starting materials include $\mathrm{GeS}_{2}, \mathrm{~B}_{2} \mathrm{~S}_{3}$ (for other projects), other sulfides and oxides to vary membrane properties, and $\mathrm{H}_{2} \mathrm{~S}$. The process currently being used by Dr. Martin's group to protonate the material, that is, to incorporate $\mathrm{H}_{2} \mathrm{~S}$, is proprietary.

\section{PROPRIETARY INFORMATIONEXCLUDED FROM PUBLIC VERSION}

The Preparation Laboratory contains other furnaces not attached to glove boxes, and a pneumatic press. Some materials are palletized prior to being reacted.

The Characterization Laboratory contains both spectroscopic and thermal analytical equipment. Currently, infrared (IR) spectroscopy, used for chemical characterization 
including stability is performed on two Biorad spectrometers. One is used for midrange IR, and the other for far (high wavelength) IR. These two instruments, both about 16 years old, will be replaced by a single, new system later this year. The two older IRs will be moved into the Teaching Laboratory. Dr. Martin is very concerned with his role as a teacher, and is careful to make sure that students are well taken care of. To complete the spectroscopic characterization, the laboratory has a Perkin Elmer Spectrometer that operates in the ultraviolet (UV), visible, and near IR ranges.

Additionally, chemical characterization is obtained on a Bruker Fourier Transform Raman Spectrometer. Its source illumination is from a neodymium YAG laser. This will support the 20-30 percent of materials that fluoresce at $1064 \mathrm{~nm}$. Dr. Martin is planning to obtain a second Raman Spectrometer soon, that will operate at various lower wavelength settings (400-900 nm) to cover the rest of the materials.

A proton conductivity system measures impedance, providing capacitance and resistance values. It can operate between about $-100^{\circ} \mathrm{C}$ and $500^{\circ} \mathrm{C}$, measuring phase angle and frequency. It has four channels that can be used for simultaneous measurements. (When I observed, two channels were in use.) In addition to conductivity, the system measures a number of other electrochemical properties including oxidation and reduction potentials, and output voltage.

A second unit is available to measure highly conductive samples. This unit operates at a range between liquid nitrogen temperatures $\left(-196^{\circ} \mathrm{C}\right)$ and $500^{\circ} \mathrm{C}$. Dr. Martin hopes that his laboratory will be developing materials for the DOE project that will be needing this instrument. (That is, that they will have higher conductivity than is presently being obtained, and will thus be more efficient proton transport media.)

The Characterization Laboratory also contains a thermal analysis area. Here, are two differential scanning calorimeters (DSC), one for low temperature, one for high temperature, and a thermogravimetric analyzer (TGA). These provide thermal stability data. In addition, there is a thermomechanical analyzer that can measure mechanical properties up to $900^{\circ} \mathrm{C}$. Finally, a dynamic mechanical analyzer provides the same information as a function of frequency when dynamic loads are applied to the sample.

\section{Questions and Answers:}

I sent Dr. Martin a set of discussion questions prior to my arrival. These are reproduced here, in bold type. Dr. Martin and his team provided answers during our discussion, and these are displayed here in normal type. My comments added to many of the questions during my later analysis and assessment are shown in italics.

\section{At the time of your FY 2002 AOP submittal, you were investigating materials between 100 and $300^{\circ} \mathrm{C}$. Now, you have moved to higher temperatures (200- $500^{\circ} \mathrm{C}$ ). Why the higher temperatures?}


ISU has the capability to characterize the higher temperatures so are working with a wider range. They are actually pursuing the entire temperature range from $-100^{\circ} \mathrm{C}$ to $500^{\circ} \mathrm{C}$; in fact they have measured proton conduction at $-60^{\circ} \mathrm{C}$ Some of these membranes may serve as low temperature fuel cell applications.

It's not as much discarding the $100-200^{\circ} \mathrm{C}$ range as it is including the entire temperature range.

2. What are the benefits/needs for fuel cells operating between $200-700^{\circ} \mathrm{C}$ ? Where do you see them being used?

Dr. Martin feels that they can compete with solid oxide fuel cells on the higher end, and perhaps eliminate the need for platinum electrodes at the lower end.

These ceramic membranes may also be able to be used with reformers as a separation membrane. One does not have to worry about $\mathrm{H}_{2} \mathrm{~S}$ contamination. Dr. Martin, in fact, is investigating the possibility of a reformer-based membrane project with Honda.

\section{What is the role of $\mathrm{H}_{2} \mathrm{~S}$ ?}

$\mathrm{H}_{2} \mathrm{~S}$ is a proton source, not an energy source.

4. With long reaction times for membrane production, how will the membranes be produced economically on a commercial scale?

ISU believes that they can accelerate the reaction by running in water or by using catalysts. They also would run on large scale.

I don't know how (or how much) running in water (steam?) would speed up the reaction, or might it actually result in a competing reaction? The reaction times of "several weeks to months" for making the ceramics will have to be reduced for making the membranes economically.

5. How did the chemical makeups of the membranes evolve $\left(100 \% \mathrm{GeS}_{2}, 14 \%\right.$ $\mathrm{Ga}_{2} \mathrm{~S}_{3}+86 \% \mathrm{GeS}_{2}$, etc.)? What characteristics are the sulfides of gallium, aluminum, and molybdenum adding to what appears to be the baseline $\mathrm{GeS}_{2}$ ?

The germanium compounds make good glasses at these ratios.

The gallium sulfide thermally and chemically stabilizes the ceramic, making it more resistant to oxidation.

Molybdenum goes through a metallic phase, and may work well as a catalyst. It should also increase mobility. At higher concentrations, molybdenum becomes an electron conductor (undesirable). 
They are not working with aluminum at this point, but they feel that they could make some good glasses with it. The other part of Dr. Martin's research group that deals with more basic science are looking at more compositions that could be incorporated into the applied work as well.

Finally, some of the combinations reported are merely characterization tests.

The reported ratios therefore appear to be the result of much preliminary testing. All of the details simply weren't reported in the paper. The logistics of how the group got to this point would have been informative.

\section{We need to discuss your conductivity, and chemical and thermal stability tests. What results would you be looking for with an "ideal" system? How are the current results leading toward a down-selection?}

They don't really have a good down selection methodology, says Dr. Martin, but they do know what is stable in water and oxygen and what is thermally stable. Their selection process follows well known stability data (e.g., $\mathrm{Al}_{2} \mathrm{~S}_{3}$ is unstable in water, so it is eliminated) so they don't feel that they need a formal down-selection process.

Once ISU has settled on a set of compounds to consider, the first questions are: which compounds can they protonate, which are stable even when protonated, and what is the protonic conductivity?

They then will look at four secondary parameters: processability, cost, toxicity, and compatibility. They are not paying a tremendous amount of attention to these yet. They realize that processability, cost, and toxicity will become important, and in fact, critical, as they move down the road. They will also consider what materials will be compatible with catalysts and with the membrane, while still making protons easily.

It seems that the outline for a reasonable down-selection process is there. It is important, however, to lay it out a little more carefully. Quantitative objectives and weighting factors might help, especially if the number of candidates becomes unwieldy. This project could easily become unwieldy if care isn't taken.

\section{Has any thought yet been given to the makeup and needs for the remainder of the fuel cell?}

The need for compatibility with fuel cell catalysts has already been mentioned. Similar requirements are needed for the electrodes. Dr. Martin admits that his group needs to think more about the overall fuel cell system. One item that will be watched, says Dr. Martin, is the fact that some materials will be stable in water, but are stable in hydrate form. (i.e., a material $M_{x} S_{y}$ could in the presence of water, form $M_{x} S_{y} z H_{2} O$ ) Some of ISU's mixed conducting, electronic and protonic, materials potentially may serve as wellmatched electrodes for their membrane materials. 
Dr. Martin is counting on feedback from some companies to address fuel cell issues.

Some care is needed here. The fuel cell needs to be an important part of any downselection.

\section{Is there any plan for testing for chemical stability to species other than water or oxygen, such as $\mathrm{CO}, \mathrm{CO}_{2}, \mathrm{CH}_{4}$, etc.?}

Dr. Martin does not feel that these stabilities will be crucial for the electrolyte. Also, if the selected materials are stable in water and oxygen, they should be stable in the presence of methane, $\mathrm{CO}$, and $\mathrm{CO}_{2}$. When they get to membrane electrode assemblies, there might be an issue; they will revisit this at that time. TGAs will provide the proper tests.

Again, I would think that screening should include these. I believe that it is an important issue that should not be put off.

\section{Additional Items:}

- ISU has signed a non-disclosure agreement with Giner Electrochemical Systems to pursue high temperature work, and will soon sign another agreement with MTI, who makes direct methanol micro fuel cells. ISU is talking to United Technologies as well.

- A key issue that ISU recognizes that they must address is that conductivity measurements measure just that - conductivity. What is really moving? Is it a proton, an impurity, a thiol $\left(\mathrm{SH}^{-}\right)$group, etc?

- You want the membrane to move enough protons to achieve reasonable conductivity, but you don't want to lose mechanical strength.

- Dr. Martin defined a "strong" glass-former as one that does not crystallize. If, in making a glass, you need a high cooling rate $\left(\right.$ say, $100^{\circ} \mathrm{C} /$ minute) the glass will likely crystallize. You want a low cooling rate, maybe $1{ }^{\circ} \mathrm{C} /$ minute, to make a strong glass.

- The glasses should have a high softening point - above $300^{\circ} \mathrm{C}$.

\section{Final Thoughts}

It is very good to see DOE Hydrogen projects that are exploring new areas. Fuel cells that operate in a new intermediate temperature regime is a good choice. The project is having some uncertainties, but that's acceptable for a new project, especially in a new area. 
The project is in a material selection/data gathering mode right now. I am somewhat concerned about what appears to me to be the somewhat confusing methodology in how the work has progressed to this point. Since there appears to be some positive results, I would think that the confusion is perhaps in the reporting rather than in the data gathering or even in the record KEEPING itself (which, I have noted, is excellent). The group needs to be clearer as to why a particular combination of materials are being made and studied. I suggest that test matrices be developed and used more or less formally. This will help both the project itself, and the ability of others to track it.

The down selection criteria, I believe, also needs to be expanded to include items other than just conductivity and stability in the presence of water and oxygen. I don't think that it is too soon to look at the effect of methane, $\mathrm{CO}$ and $\mathrm{CO}_{2}$ on the membrane.

Another parameter that will be important is processability. The weeks- or months-long membrane production time will have to be considerably shortened. The ability of a selected material to be processed in a timely manner needs to be added to the matrix.

The proprietary methodology, is a well-considered, logical approach, and appears to be working successfully to this point. The next year should be a key one for this project. 
Technical Evaluation Report

Project: Production of Hydrogen form Glucose with Pentose Phosphate Pathway

Enzymes

Company: Oak Ridge National Laboratory

P.I.: Dr. Barbara Evans

Site-Visit Date: August 14, 2002

Evaluation by: Edward G. Skolnik, Energetics, Inc.

\section{Summary:}

Researchers at Oak Ridge National Laboratory (ORNL) are investigating a mechanism in which glucose (or eventually cellulose) is exposed to a combination of enzymes that will convert it to hydrogen. The series of enzymes takes the glucose along a "pentose phosphate pathway to hydrogen. The result, theoretically converts all 12 hydrogen atoms in glucose to molecular hydrogen.

The key to the process involves creating artificial "cells" in which the mix of enzymes and cofactors reside. The cells are made of liposomes, membranes composed of bilayers of phospholipids (made from phosphoric acid and fatty acids) and sterols (alcohols made from steroids-4-ring, 17 carbon structures). These are similar to natural cells. The enzyme/cofactor mix is trapped within the cell. Glucose cannot penetrate the cell under normal conditions, but are carried across the membrane by so-called "transporter" molecules - boronic acid derivatives. Product hydrogen is able to diffuse back across the membrane to be collected.

I see the following strengths in the project:

- The theoretical amount of hydrogen that can be derived from glucose is maximized by this process. The researchers are able to convert all of the hydrogen in glucose to molecular hydrogen.

- The liposome process seems to be a valid process that may work well.

- The process results in at worst, net zero $\mathrm{CO}_{2}$ emissions.

I see the following items that need to be addressed:

- The actual amount of hydrogen being made is in the nanomole range. Output will have to be increased. I recognize that this is a bench scale process, but this level of production is even minimal for that. The liposome process needs to be optimized, but some degree of demonstration that somewhat higher amounts of hydrogen can be achieved. 
- The rate of hydrogen formation is also very low. Without some major process development, it will not effectively scale up.

- Some thought is going to have to be put in to how the process will be scaled up. The low quantity, low pressure of hydrogen in a high quantity carrier gas is not acceptable. A direct feed to a fuel cell with no storage system and even no buffer does not seem realistic.

\section{Introduction and Background:}

This project has been going on at ORNL off and on for at least eight years. (In fact, it was the subject of my very first site-visit evaluation in February 1996.) It was initiated by Dr. Jonathan Woodward who left ORNL to return to England only about two months before my present visit. The project lead has been assumed by Dr. Barbara Evans of ORNL's Chemical Sciences Division, who had been on the project team for several years, and was a postdoctoral associate at the time of my first visit. Also part of this team and present at our meeting was new Program Manager Tim Armstrong and team member, Hugh O'Neill who is employed both at ORNL and at the Department of Biochemistry and Molecular and Cell Biology at the University of Tennessee, Knoxville. Dr. Eli Greenbaum and Dr. James Lee also participated in parts of our discussion.

The majority of our discussion time was spent in the question and answer format below. Dr. Evans made a presentation that itself was formatted on the questions. These are discussed in the next section. Dr. Evans also showed me a small reactor in operation as well as the rest of their research facilities. Finally, Dr. Lee asked if I would take about an hour to listen to a presentation that he planned to make to the Department of Energy on a spin-off of the work that he and Dr. Greenbaum had previously been working on. This presentation was separate from, and is not included in this report.

\section{Questions and Answers:}

I sent Dr. Evans a set of discussion questions prior to my arrival. These are reproduced here, in bold type. Dr. Evans and her team provided answers during our discussion, and these are displayed here in normal type. My comments added to many of the questions during my later analysis and assessment are shown in italics.

1. The pathway shown in your FY 2002 Annual Review Report (Figure 1) (Exhibit 1) seems to contain about 15 steps. How many of these are naturally occurring processes that are just broken out for the sake of showing the mechanism, and how many represents actual process steps that must be performed in the laboratory (and eventually commercially) in order to produce hydrogen?

There are actually 14 distinct reactions that are occurring here, involving ten enzymes. Some of the enzymes catalyze more than one reaction. You could, however, put everything into one matrix along with the co-factor. You would start with glucose 6 phosphate, and you put enzymes and cofactors into cartridges in order to mimic what is 
going on in a cell and you "just go". In other words, there are 14 reactions, but only one process step to convert glucose 6 phosphate to hydrogen.

The cofactor (or activator) NADP+ (nicotinamide adenine dinucleotide phosphate) is soluble. It needs to be available at the active site of the enzyme.

If you're starting with glucose, however, you'd have other preliminary steps. In order to get glucose into the "cell" you use a liposome (see question 7). This is a lipid membrane bilayer. Glucose is converted to glucose 6 phosphate using hexokinase.

You'd also have preliminary steps if you were starting with cellulose or biomass (more steps, obviously). Biomass components are converted to glucose by hydrolysis. This is fairly complex, but much of the process has been worked out for the conversion of biomass to ethanol.

If you were starting with starch, you would need two additional enzymes ( $\alpha$-glucan phosphorylase and phosphoglucomutase). Starch is more expensive than cellulose, but needs less pretreatment.

In order to get glucose into the "cell" you use a liposome. This is a lipid membrane bilayer.

\section{How are total and specific activities determined?}

Specific activity for individual enzymes is defined as the micromoles of substrate that is converted to product per minute, per milligram of enzyme. The unit for specific activity is $\mathrm{mg}^{-1}$.

Total activity for individual enzymes is the total number of units of activity in the reaction.

The total activity based on hydrogen production by all of the enzymes in the matrix or cartridge is expressed as micromoles of hydrogen per micromole of glucose. In other words, it's the amount of hydrogen produced.

\section{In your Annual Review Report, you compare fermentation of glucose by $T$. maritima in a closed vessel with continuous growth in an in-line vessel. Please run through the comparison explaining why you indicate that the in-line reaction yield is $\mathbf{7 0 \%}$ greater than in the closed vessel.}

The in-line vessel is a continuous flow system in which products hydrogen and carbon dioxide are being continuously removed by a nitrogen stream. In the closed vessel, the presence of these products inhibits the activity of the enzymes. The superior yield with the in-line vessel is, thus, expected. 


\section{In your discussion of hydrogen production from cell extracts of T. maritima you mention that only the hydrogenase enzyme is oxygen sensitive. How did the described results allow you to make that conclusion?}

The described results are as follows: Glucose was the substrate. Using Thermotoga maritima cell extract alone resulted in a small $(0.1 \mathrm{micromole} / \mathrm{hr})$ production of hydrogen. Even this small amount indicates that the necessary enzymes and cofactors had to be present. When hydrogenase from Pyrococcus furiosus was added, the hydrogen production rate went up to $1.9 \mathrm{micromole} / \mathrm{hr}$.

The argument is that the small amount of hydrogen produced when all ingredients except the hydrogenase were present was produced in the presence of oxygen, so that these ingredients are stable in oxygen.

Dr. Evans says that perhaps she was being to optimistic, and may have overstated what was happening.

\section{Please explain the negative ( $\sim-7$ to $-12 \mathrm{nmol} / \mathrm{h})$ hydrogen production you are showing in Figure 5 (Exhibit 2) when you do not use the glucose transporter.}

The short answer is that the baseline got shifted - it's not really negative. Dr. Evans also provided a more complete answer addressing the trends seen in the Exhibit:

Glucose is in the feed solution, but cannot diffuse across the liposome membrane. The enzymes and cofactors are inside the "cell" on the other side of the membrane, and likewise cannot cross it. Glucose is transported across the membrane into the cell by a transporter - in this case, tertbutylphenyl boronic acid:

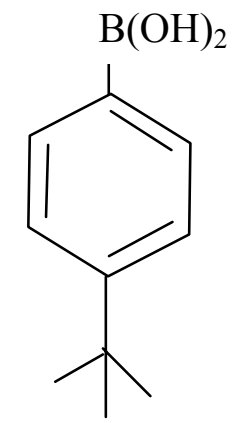

Once the glucose is inside the cell, the enzymes can work on it, and hydrogen is produced via the pentose phosphate pathway. The hydrogen is able to diffuse back across the membrane where it can be detected and captured. The enzymes and cofactors remain undiluted within the cell. Exhibit 2, showing the lack of hydrogen formation without the transporter is a good indication that there is no leakage of the enzymes or cofactors across the membrane. 
One transporter molecule can bring one glucose molecule across. The high glucose concentration outside the cell provides the driving force for the transport. The transporter molecule forms an ester linkage with the glucose molecule (Exhibit 3) and carries it through the membrane. The linkage then breaks.

The liposome structure is somewhat like having an artificial cell. The system is likely stable up to about $45^{\circ} \mathrm{C}$, (but not higher) and the liposome will remain intact, the higher the temperature, the less chance for contamination. Dr. Evans cautions, however, that the liposome system in its present form will not stay stable indefinitely. ORNL is trying to increase liposome stability by making it into a polymer or film.

Dr. Evans describes the transporter system as "a real system;" it has the capability of being a real continuous flow process.

\section{In the same Figure, you show that with the glucose transporter you are achieving up to about $15 \mathrm{nmol} / \mathrm{hr}$ of hydrogen. These numbers are orders of magnitude lower than what you show earlier in your continuous flow (in line) system. I assume that the sample size is different and that provides for what appears to be a discrepancy. How can the two results be correlated?}

The in-flow reactor work showed numbers of the order of $12000 \mathrm{nmol} / \mathrm{hr}$.

The continuous flow whole cell system used about $20 \mathrm{ml}$ of whole Thermotoga cells. The liposomes were in $2 \mathrm{ml}$ reaction volume. In addition to the order-of-magnitude volume difference, the biocatalyst loading was higher in the continuous flow system.

The real number we need is units of hydrogen/units of glucose to compare the two systems.

We can, however, use the number provided for the in-flow reactor (which at this point seems to yield more hydrogen per unit volume) to see what this means in the real world. A $20 \mathrm{ml}$ volume producing $12000 \mathrm{nmol}$ (or $12 \mathrm{micromol}$ ) hydrogen/hour, means that to produce one mole of hydrogen you would need:

$$
\begin{aligned}
& (20 \mathrm{ml} / 12 \mathrm{micromol}) \times\left(1 \times 10^{6} \mathrm{micromol} / \mathrm{mole}\right) \times(1 \text { liter } / 1000 \mathrm{ml}) \times 0.264 \mathrm{gal} / \mathrm{liter}= \\
& 440 \text { gallons of volume } / \mathrm{mole}_{2} \mathrm{per} \mathrm{hour.}
\end{aligned}
$$

Since a mole of hydrogen is 2 grams, it would take (500 $x 440$ gallons) $=$ a 220,000 gallon reactor an hour to make a $\mathrm{kg}$ of hydrogen. Thus, it would take about a million gallon reactor one hour to make enough hydrogen to fill up a car.(!)

The key thing is that by using the enzymes instead of the whole cells, you are following a set metabolic pathway. If you use whole cells, glucose will be used up in numerous reactions. 
If this is the case, than perhaps using the whole cell, 12 micromole number may be unfair. However, the 15 nanomoles of hydrogen production per hour with the $2 \mathrm{ml}$ liposome reactor system is a far lower production rate on a unit volume basis. Perhaps we need to see the liposome system optimized before we draw conclusions, however.

\section{What constitutes a liposome? How will it increase the hydrogen production capabilities of the enzymes? What is an encapsulation efficiency? How is it measured?}

A liposome is a membrane bilayer sphere formed from phospholipids and sterols. They are similar to natural cell membranes that keep enzymes and DNA in the cell, but allow water and gases to pass.

When enzymes and cofactors are kept within the cell, their concentrations are higher and catalysis is more efficient. Intermediate products are not diluted before the reaction sequence is complete.

The liposome membrane can be made permeable selectively by use of transporter molecules.

Encapsulation efficiency is the percentage of enzyme inside the liposome after formation compared to the amount of enzymes added at the start.

Natural occurring membrane lipids include phospholipids, glycolipids and cholesterol. Double bonds in the molecular structure provide the ability for crosslinking reactions that can build the polymeric membrane.

\section{What percentage of theoretical hydrogen production do you realistically hope to achieve?}

Dr. Evans has achieved close to $100 \%$ theoretical yield at bench scale. In these continuous flow tests, time and catalyst amount were not limited. In a pilot plant, key parameters that will affect yield will include the residence time of the glucose feed, the mass transfer rates of the products to the gas phase, and the amount and stability of the catalyst. In addition, the cost of catalysts and cofactors could be high (although perhaps cheaper if obtained in volume.

Looking back at our little analysis after Question 6, it appears that the high overall yield (assuming that the cases discussed were close to 100\% yield) came at the expense of reaction rate. The rates we saw were far too low.

\section{Please discuss how you envision what a potential commercial hydrogen production system based on your project would look like.}


Dr. Evans provided me with a schematic of a hypothetical process. It is reproduced in Exhibit 4. In the real world, one would start with cellulose. Also, Dr. Evans said that she would like to see byproduct $\mathrm{CO}_{2}$ "fixed", recycled, and fed to algae to make more cellulose. Even if not cycled, the process is a net zero $\mathrm{CO}_{2}$.

Separating hydrogen from the carrier gas (nitrogen) may be a problem, especially with hydrogen in "way less than 1\%" concentration. Dr. Evans is not sure how the separation would be accomplished. Dr. Evans thinks that maybe the hydrogen/nitrogen mixture could be fed directly to a fuel cell. Then again, she thought, a real system may not need a carrier gas at all. The hydrogen will be coming off at low pressure. They are running at close to equilibrium, so they will not likely have a high pressure option.

I don't think that a lot of thought has gone into a real system yet. The mechanism by which hydrogen from a process such as this is incorporated into an energy system is unclear and could be a show-stopper. I can't imagine a direct feed into a fuel cell being very practical. At the same time, compression and storage in a buffer tank may be difficult, especially in light of the fact that the hydrogen would be very diluted if a carrier gas were being used. A diffusion/compression process using a hydride bed like the one that Ergenics (see my report on my March 2002 visit) has been working on could conceivably work in such a case (although the blanketing effect of the carrier gas would have to be dealt with.)

\section{Additional Discussion:}

Enzymes from Thermatoga maritima were chosen for this project based on results from the National Energy Technology Laboratory (NETL) when a research group headed by S. Van Ooteghem found that though the thermophile is very anaerobic, small amounts of oxygen were found to be helpful. ORNL has not been able to reproduce those particular results, however.

At this time, ORNL is trying to optimize the enzyme system by modeling them Mr. O'Neill has the lead on this. There is a concern that upon scale-up, the problems may not be all engineering related, but may be biological as well. In other words, one question will be: under what conditions can the enzymes be optimized. The modeling may help to answer this.

Dr. Greenbaum made the statement: "If you want to make bubbles [of hydrogen], we can give you bubbles, but they will be expensive bubbles."

Dr. Evans believes that they can maximize the hydrogen yield in the liposome system by having a high concentration gradient for glucose. But if you have too much glucose, you shut down the system.

Mr. O'Neill is also being funded by the DOE Hydrogen Fuel Cells and Infrastructure Technology Program to make cellulose membranes as Nafion ${ }^{\mathrm{TM}}$ replacements for PEM 
fuel cells. They have bacteria that convert glucose to cellulose. The membrane is touted to be stable to $120-130^{\circ} \mathrm{C}$.

\section{Tour:}

Dr. Evans took me on a tour of the laboratory facilities.

We first saw a $2 \mathrm{ml}$ reactor/condenser that contained a mixture of glucose dihydrogenase, soluble NADP cofactor, and glucose in a buffered solution at $\mathrm{pH} 8$ and at $37^{\circ} \mathrm{C}$. Product hydrogen is carried by helium, and is exposed to a tin oxide sensor. Hydrogen reduces the oxide, changing the conductivity, and therefore changes the measured voltage. The sensor is continuously calibrated with an electrolysis standard.

A $\mathrm{CO}_{2}$ analyzer is going to be added into the system so that $\mathrm{H}_{2} / \mathrm{CO}_{2}$ ratios can be monitored.

The thermophilic bacterium Thermotoga maritime was being grown in a series of bottles.

In another area, the group is trying to isolate the genes that produce proteins. They have a system for purifying proteins using fast protein liquid chromatography. It also involves molecular sieves and ion exchange.

\section{Final Thoughts:}

The project has come a fair distance since I last reviewed it (or more accurately, reviewed its predecessor) in 1996. At that time, the process was only able to remove one molecule of hydrogen per molecule of glucose. The hydrogen yield was naturally very low, and much of the onus was based on being able to sell the byproduct, gluconic acid. When analysis showed that the amount of gluconic acid that would be made if the hydrogen production process were used widely would flood the market, the project was put on hold.

The present project utilizes all of the hydrogen in glucose, making six molecules, and the only byproduct is $\mathrm{CO}_{2}$. Furthermore, the researchers have demonstrated nearly $100 \%$ theoretical yields. The amounts of produced hydrogen that has been demonstrated, however, is measured in nanomole or at best micromole quantities. This is not what we want to see, but for a somewhat new process (although they've been researching this pathway for over two years) it is perhaps understandable; they are making progress. What concerns me is the fact that the rate of hydrogen production appears to be very low. I estimated that it might take a reactor the size of a football field, three feet deep to produce enough hydrogen in an hour to fill up an automobile.

I am also concerned about how the system will be utilized. An output that is mainly carrier gas will be hard to work with. Feeding the output directly to a fuel cell also seems unrealistic. 
While the production of hydrogen from cellulose through what is basically a "natural" process is an attractive concept, there is a long, long way to go. 


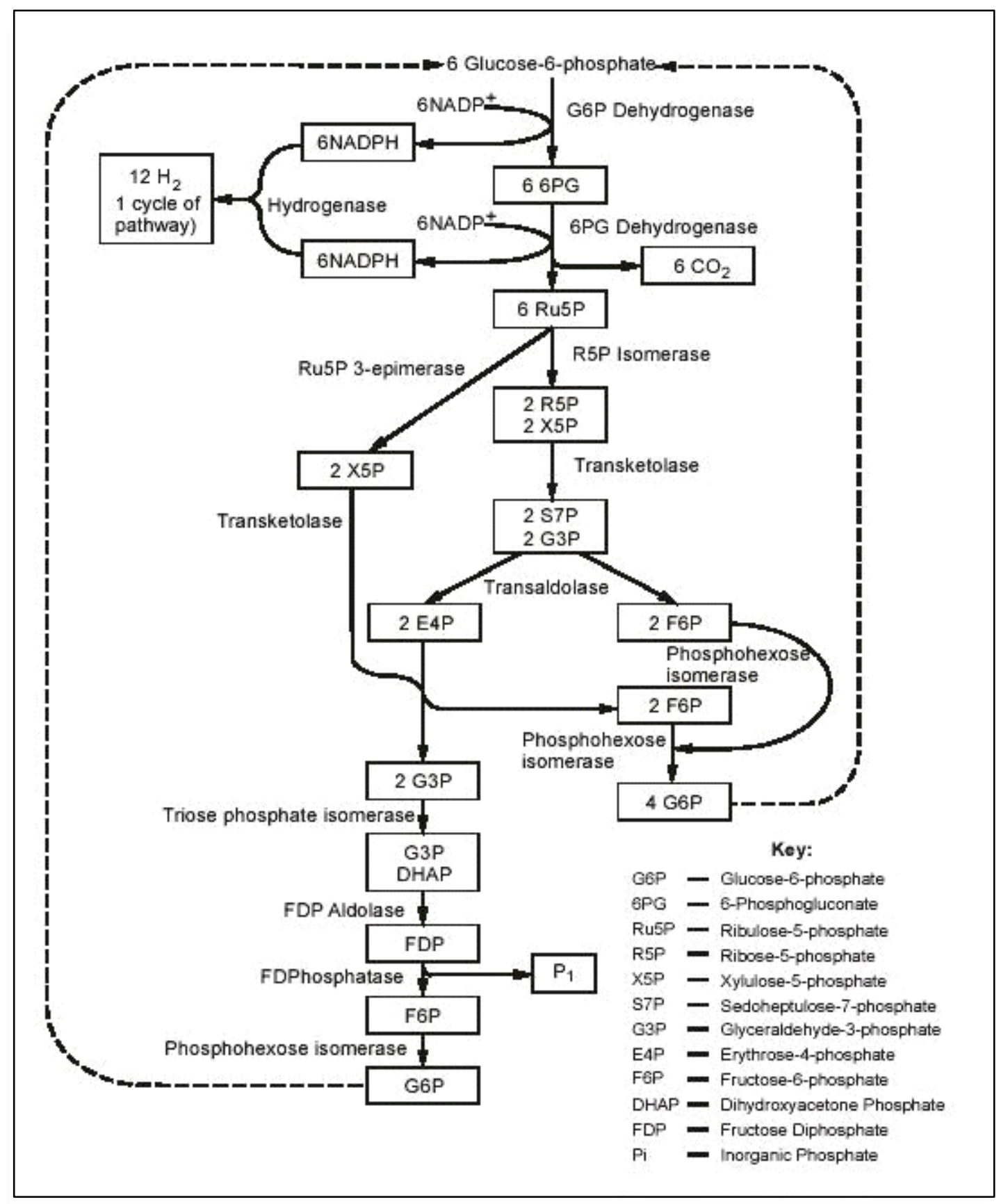

Exhibit 1. The Pentose Phosphate Pathway (From ORNL Hydrogen Annual Review Paper) 


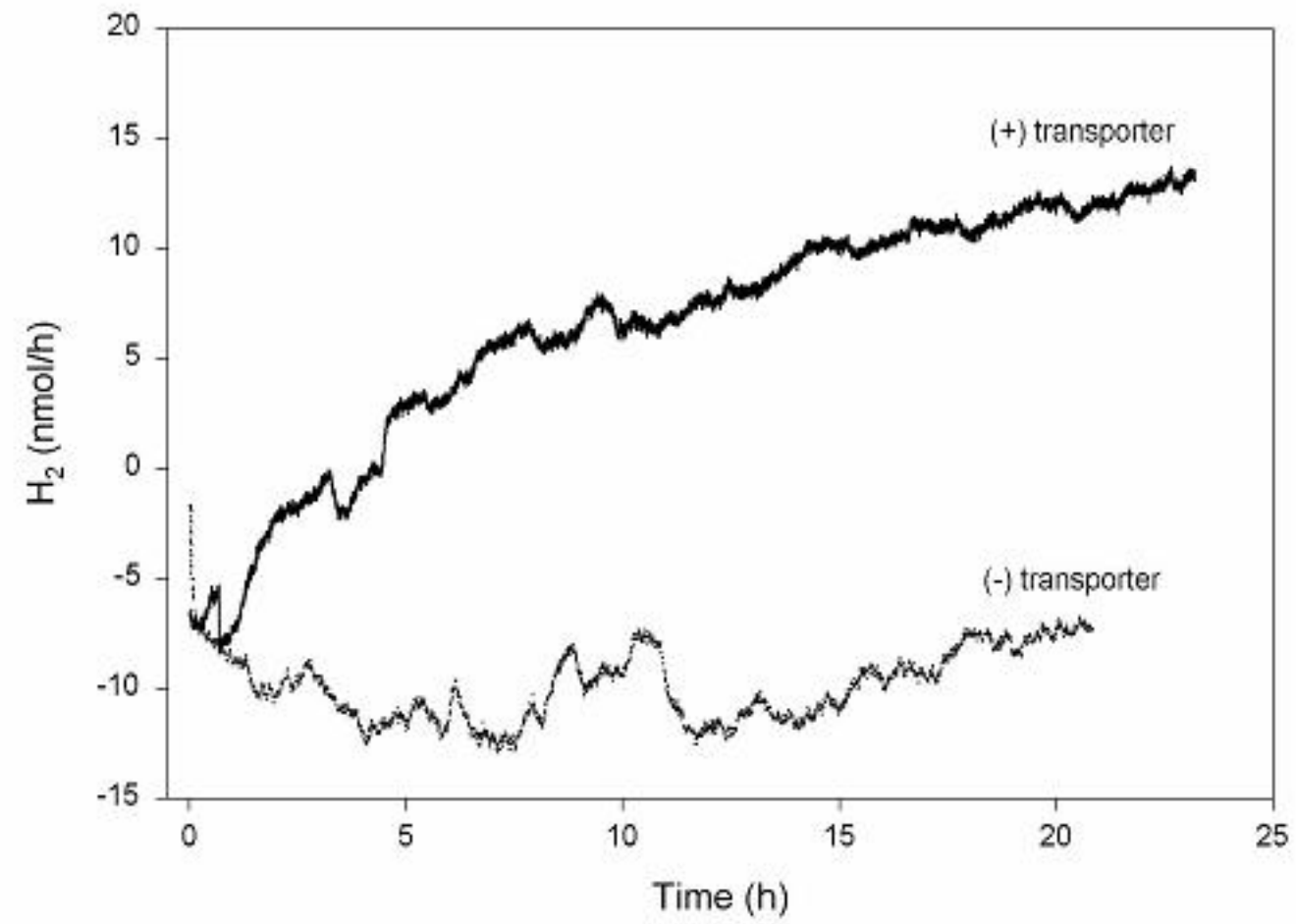

Exhibit 2. Production of hydrogen from glucose by encapsulated glucose dehydrogenase and hydrogenase with and without glucose transporter.

(From ORNL Hydrogen Annual Review Paper)

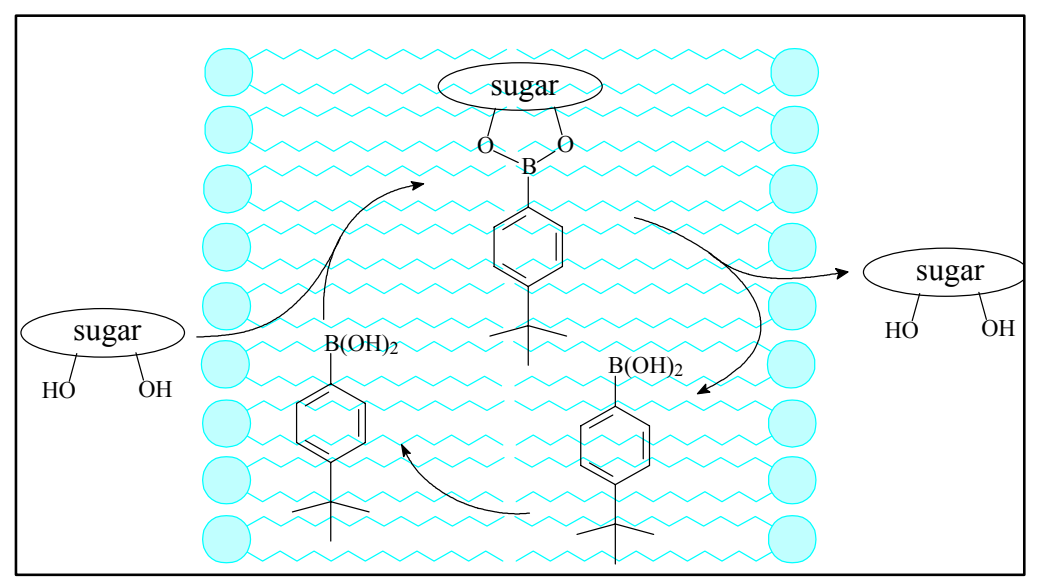

Exhibit 3. Transport of glucose through liposome membrane by boronic acid.

(From ORNL Hydrogen Annual Review Paper) 


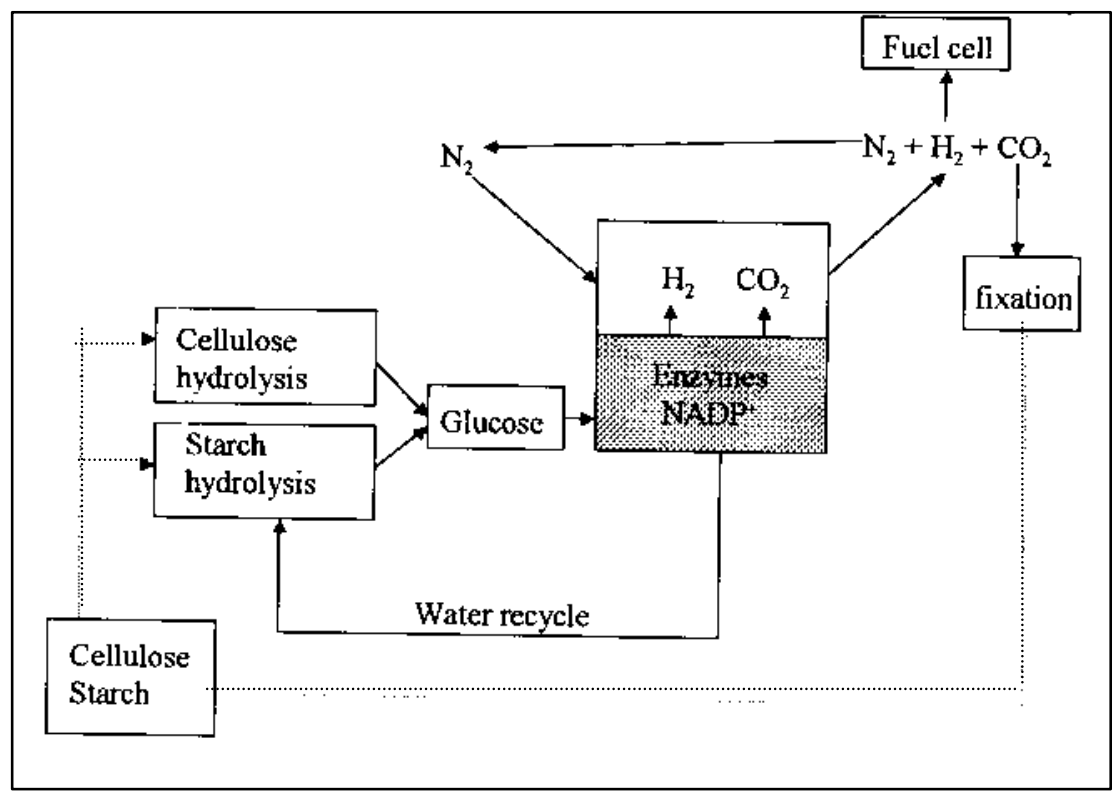

Exhibit 4. Proposed Schematic for Commercial Hydrogen Production (ORNL) 
Technical Evaluation Report

Project: Low-cost Hydrogen production Platform

Company: Praxair, Inc.

P.I.: Tim Aaron

Site-Visit Date: August 29, 2002

Evaluation by: Edward G. Skolnik, Energetics, Inc.

\section{Summary:}

Praxair, Inc. has taken a somewhat different approach toward arriving at a nearer tem solution to low-cost, fueling station sized reformers for hydrogen. The plan is to use existing technologies to develop small reformers, relying on unique processing designs to address heat-transfer-based inefficiencies. These inefficiencies make up a substantial part of the reason that small reformers are more costly on a per-unit-hydrogen basis. In addition, Praxair is looking to integrate the system into one that produces an acceptably small footprint.

The three-phase project, scheduled to be completed in 2005 , is currently about halfway through the first phase. At this point, only concepts and preliminary designs are available, as Praxair strives to down-select to a single design by the end of the calendar year.

Currently, Praxair is working with three heat-exchanger designs, the details of which are proprietary for now.

\section{PROPRIETARY INFORMATIONEXCLUDED FROM PUBLIC VERSION}

I see the following strengths in the project:

- This project is rather unique within the program, and is, I believe, a very worthwhile endeavor. The possibility of having hydrogen on-board a vehicle (as opposed to onboard reforming) in the short to mid-term depends on an available infrastructure. If hydrogen is being produced far from the dispensing point, building the transport infrastructure will be very involved. The alternative is to produce hydrogen from natural gas at the dispensing site. The program has many projects that is looking at new technologies to reform, or otherwise react natural gas or other hydrocarbons to produce hydrogen. This project is unique in that it is attempting to use existing technology, only modifying it for smaller scale. If successful, it can lead to an earlier adoption of hydrogen as a distributed energy (vehicular and stationary) resource than could other technologies that would have longer development phases.

- The investigators have identified key areas of focus (e.g., heat exchange, PSA, cost) that must be tackled if the process is to work.

- DFMA, to the degree I was able to determine, appears to be a good approach. 
I see the following items that are of concern:

- The heat exchange concepts that are being considered are quite complex, and may be difficult to implement, and more important, operate, successfully.

- The higher cost of natural gas when sold in relatively small quantities is something that is likely to be an unsolvable problem.

\section{Introduction and Background:}

I met with Mr. Tim Aaron the Program Manager/Principle Investigator of the Praxair project as well as with team members Dr. Minish Shah, Dr. Joe Schwartz, and Mr.

Rob Bollinger, all of whom are process engineers. Mr. Bollinger is the former PI for the group, now involved with global supply. Dr. Shah has recently left the group to join the cryogenic group, while Dr. Schwartz has recently joined the group. They all refer to this group and this project as "small hydrogen." Seeing that Praxair is mainly involved with production of large volumes of hydrogen, calling the development of a procedure for fueling station-sized hydrogen production, "small hydrogen" makes sense.

The goal for this project is, in the long term to produce low-cost hydrogen on-site (i.e., at a fueling station) in quantities of about 1000-5000 standard cubic feet per hour (scfh). The target cost for the hydrogen is $\$ 8 / \mathrm{MMBtu}$. The product hydrogen is to be greater than $99 \%$ pure, contain less than $10 \mathrm{ppm} \mathrm{CO}$, and is to leave the system at $100-150 \mathrm{psig}$.

Praxair's approach for the small hydrogen project is evolutionary rather than revolutionary according to Mr. Aaron. It's basically old technology with new packaging and integration. In order to perform this type of effort successfully, they want to have manufacturing personnel in addition to design people involved from the beginning. In addition, as Mr. Aaron points out (and rightly so), Praxair brings a great deal of hydrogen processing experience to the table.

Praxair has already developed a system called the Hydrogen Generating System (HGS), which is an on-site hydrogen supply system. The HGS process involves a natural gas stream going through a heat exchanger, and then being reformed. The reformate then goes through a single low-temperature shift process. Actually, several reformer/shift reactor units are run in parallel. The resultant syngas other than hydrogen, $\mathrm{CO}_{2}$, and some methane, contains about $1 \% \mathrm{CO}$. Following pressure swing adsorption (PSA), the product is $99.95 \%$ pure hydrogen. For easier installation and better quality control of the PSA, the tanks (molecular sieves and carbon) are loaded in the shop, prior to shipment.

Mr. Bollinger, who provided the HGS description, said that the unit is on skids, and takes up a total area of 42x 90 feet. ("Big!" he said). There are plans to better integrate these modular units.

There are six HGS systems in the world today, but there is no real market as yet. 
The new system, which Praxair also refers to as the Low Cost Hydrogen Production Platform (LCHPP), will be 1/5 the size of the HGS, and will produce 1/6 the hydrogen at $1 / 2$ the cost. This revelation is interesting in itself. The HGS is already a relatively small system, and produces hydrogen for \$16/MMBtu (my number, based on their stated targets) which is much higher than large systems. The LCHPP will have to be much smaller, and half as costly. That is no mean task. If it can be done, however, I assume that it would also make the HGS go away, and be replaced with a technology closer to the LCHPP.

Functionally, the LCHPP will be similar to the HGS.

\section{Overview:}

The project is scheduled to be performed in 3 phases, completed in 2005. Praxair is working with several partners, including:

- Boothroyd Dewhurst (Wakefield, RI) is performing the Design for Manufacturing and Assembly (DFMA) process. They are the originator of the DFMA process. DMFA is one way in which the Praxair team can incorporate manufacturing into the process early on.

- Diversified Manufacturing (Lockford, NY) is responsible for fabrication and design. They have extensive experience in building reformers for many customers.

- Catalyst suppliers. These companies will not necessarily be developing new catalysts, but will be looking at items such as catalyst size and placement.

Phase 1 involves the preliminary design, economic issues, and "business cases". This phase is scheduled to end in October 2002, but Praxair is "a little behind".

Phase 2 will be 18 months in duration. Mr. Aaron described this as being a major effort. It involves detailed design and tooling, and subsystem prototype and testing. A lot of this will involve modeling.

Phase 3 will also be 18 months long. Here, Praxair will fabricate a demonstration unit, verify performance, and develop the tooling.

Mr. Aaron said that they could do all of this faster if needed, but they don't think it's needed yet. They do, however, have many customers where they could potentially locate and test the system.

The biggest challenge will be hitting the cost target. About half the cost for the LCHPP system will be steam generation, and the reformer and shift processes. This is based on findings from the HGS and from larger plants. I suppose that once a heat exchanger 
system is decided upon and built, it won't be a particularly high cost item - but it's the centerpiece of the design process, however.

Another big issue is safety, codes and standards. Most standards today are written for very large plants. To meet the standards for things such as space requirements, monitoring requirements, etc., set for these large plants, Praxair would have to build in a way that would make their goals unobtainable.

\section{$\underline{\text { Status: }}$}

Currently, Praxair is about midway through Phase 1. They are modeling both high and low pressure reforming, and are considering both syngas and natural gas compression. They are concentrating on thermal integration and overall systems integration. This is the alternative to using multiple, similar units.

A large fraction of Praxair's current effort involves the design of heat exchangers. They originally defined six heart exchanger concepts, and then down-selected to three. Heat exchangers are discussed in detail in Question 1, below. Much of the detail, however, is proprietary, and will not be reproduced in the public version of this report. Praxair and Boothroyd Dewhurst currently are performing DFMA on the three down-selected processes. They will then pick one (or, perhaps, two) and carry it into Phase 2.

They are also looking at the purification system.

\section{Questions and Answers:}

I sent Mr. Aaron a set of discussion questions prior to my arrival. These are reproduced here, in bold type. Dr. Aaron and his team provided answers during our discussion, and these are displayed here in normal type. My comments added to many of the questions during my later analysis and assessment are shown in italics.

\section{One major drawback with small (refueling station sized) reformer systems are the inefficiencies associated with heat exchangers at small size. How do you plan to address this?}

Heat exchanger design is a major part of the current effort. Praxair first identified six heat exchanger designs for initial evaluation.

\section{PROPRIETARY INFORMATIONEXCLUDED FROM PUBLIC VERSION}

Praxair has down-selected to three designs at this point and are evaluating those three. PROPRIETARY INFORMATIONEXCLUDED FROM PUBLIC VERSION

The process efficiency for the small reformer system is estimated to be $61-64 \%$. (LLV). For larger systems it is $70-75 \%$ LHV (about $80 \% \mathrm{HHV}$ ). The difference is, of course, due 
to heat loss. Praxair hopes that the new heat will reduce the efficiency delta, but for right now, they are using 61-64\%.

\section{Does the design call for $\mathrm{CO}$ to be $<\mathbf{1 0} \mathrm{ppm}$ for the hydrogen output, or will another step, not part of this design be necessary?}

Praxair is designing for $<10 \mathrm{ppm}$ CO. The PSA system will get them there. The water shift itself will not be sufficient, and there is no plan to use a preferential oxidation (PROX) step.

Praxair believes that since they are not connecting directly to a fuel cell, the PSA with a high pressure output is better than a membrane.

\section{Please explain your statement that the "system pressure is limited by the high temperature material properties of the reformer portion of the system.”}

When they look into the ASME code, they get into "creep" at about 1000 hours. At higher temperatures, tensile strength decreases. This may cause Praxair to look at new materials or coatings. They may also need to use more expensive piping.

\section{Does the HGS system include shifting? How free of $\mathrm{CO}$ is the hydrogen product?}

Yes, shifting is part of the operation taking place on the reformer skid. The product is free of $\mathrm{CO}$; they're making hydrogen, not syngas.

\section{In general, how much of the unit cost differential between large and small reformers is due to capital equipment, and how much is due to operating differences.}

Operating costs will be higher for small scale reformers because efficiency is lower; you consume $10-20 \%$ more natural gas. You also pay more for the natural gas, as you are purchasing it in lower quantity. Small quantities of natural gas can cost $40-50 \%$ more per unit than large quantities. Praxair is costing this at least at 33\%. If numbers such as 40 $50 \%$ is common, Praxair should be using these numbers, not the more conservative 33\%.

For large plants, capital cost is about $80 \%$ and "utilities" (meaning natural gas in this case) is $20 \%$. For small plants, it's nearly the reverse. Thus you need to keep the cost of natural gas down.

One way that Praxair is addressing their project is by trying to get the ratio for small plants to be the same as large plants. If they could do this, they would meet the cost targets.

In here lies one of the biggest problems. The cost of natural gas is a huge contributor to overall cost, and it is not controllable. 


\section{What is the time schedule for the determination of a go/no go decision on Phase 2? What goals are being used to make the decision? What is the current status?}

Phase 1 will likely extend to January 2003. A go/no go decision will be made then by Praxair. The decision will be based on cost and feasibility of the overall design and concept - not on the market. The correct approach, I believe. At the time of my visit, Praxair was about halfway through Phase 1 work, and partner DMI is about $40 \%$ complete. The other partner, Boothroyd Dewhurst, however, has barely gotten started.

Praxair has been developing a more detailed design than they originally intended. This is because their subcontractors need this detail.

\section{Will the catalyst be an "off-the-shelf" commodity, or will catalyst development be necessary?}

Praxair is looking at catalyst configuration, catalyst particle sizes, etc., but are not planning to look for a new catalyst. One consideration is that the tubes are smaller than usual.

\section{If possible, please describe a non-proprietary/generic version of how DFMA works.}

DFMA is a process that was developed by partner Boothroyd Dewhurst. DFMA, according to Praxair, can tell you for instance, "do you make things as one big block or several blocks." Praxair provided me with a handout that is about 2 pages of what appears to be the proposal from Boothroyd Dewhurst.

Without getting into the details of a document which is likely confidential, DFMA will reduce the number of components and subsystems that need to be manufactured. Boothroyd Dewhurst is looking at combining components, and ensuring that they will be able to function effectively under normal operation as well as at start-up, partial load operations, and transients.

Boothroyd Dewhurst counts among their clients, Texas Instruments, Ford, and Digital Equipment Corp. In each case, Boothroyd Dewhurst's DFMA simplified the system.

I don't believe that Praxair understands the DFMA in detail themselves. They appear satisfied, however, with what Boothroyd Dewhurst is providing.

The concept appears very logical; I guess we have to see what happens. I don't think it will be easy.

9. In your LCHPP process flow, you show a syngas separation step. Does this imply that you expect the water shift reaction to be inefficient? 
Praxair uses the term "syngas" to refer to any gas that is not pure hydrogen. Thus, hydrogen plus $\mathrm{CO}_{2}$ (water shift reaction products) is a syngas. Praxair plans to have $\mathrm{CO}$ reduced sufficiently; The separation is hydrogen from $\mathrm{CO}_{2}$.

\section{Tour:}

Since this project is still in the conceptual stage, there was no hardware to see or experiments to witness. Instead, Praxair showed me three-dimensional computer models of their heat exchanger concepts. These are again proprietary, and the description cannot appear in the public document. Again, we must remember that Praxair is working on concepts rather than designs to this point.

\section{PROPRIETARY INFORMATIONEXCLUDED FROM PUBLIC VERSION}

Even though the designs are just conceptual, they appear quite detailed and sophisticated.

\section{$\underline{\text { Additional Items: }}$}

Praxair is using a carbon bed for sulfur removal for all types of heat exchangers. This is placed before the heat exchangers.

Praxair is currently working up the costs for the heat exchanger concepts. Two of these concepts initially appear to be about the same cost, while the third concept is apparently turning out to be somewhat more expensive. - but these are far from the final numbers. PROPRIETARY INFORMATION EXCLUDED FROM PUBLIC VERSION

Praxair has extensive PSA experience. This has involved the development of PSA pilot plants for larger systems. Praxair's work has involved materials evaluation and development, as well as process development. PSA development involves reducing cycle time, reducing the amount of adsorbent needed, and reducing capital cost. Much of the work done was performed for other projects, and is not specific to this one. The process cycle and the identity of the PSA adsorbent are proprietary, and were not discussed at this meeting. All this is aimed at reducing total cost.

Praxair sees the LCHPP as a value even to their present customers, and therefore worth pursuing.

\section{Final Thoughts:}

At the time of this visit, the project was still in a conceptual design phase. The review is therefore limited to my assessments of the concepts.

The idea of using engineering design changes to develop a small hydrogen generating platform in an evolutionary process is a good idea. The approach is also logical. My 
major concern is if everything goes as well as it possibly can, is that good enough? Will the system work efficiently and sufficiently inexpensively?

Praxair believes that the biggest challenge will be hitting their cost targets. This is obviously true. It essentially means making a small plant that will operate as efficiently and effectively as a large plant-actually more efficiently; the higher cost of natural gas when bought in small quantities constitutes an additional cost that heat exchangers can't help. It may be the showstopper.

The heat exchanger conceptual designs appear to be well thought out as to what they hope to achieve. The best of them, however, may be too complex to work effectively.

It would be interesting to see a pilot system in operation once it was built. 
Technical Evaluation Report

Project: Codes and Standards Analysis

Company: University of Miami

P.I.: Dr. Mike Swain

Site-Visit Date: September 5, 2002

Evaluation by: Edward G. Skolnik, Energetics, Inc.

\section{Summary:}

For the past several years, Dr. Mike Swain of the University of Miami has been conducting both modeling and experimental studies on numerous concepts involving hydrogen safety, leak characteristics, containment considerations, and flame properties.

Currently, the areas being studied involve a safety analysis of the California Fuel Cell Partnership (CaFCP) building, the development of methods to determine hydrogen sensor placement, and a safety analysis for writing of codes.

The CaFCP building work was based on the answering of six questions:

1. Should the garage door be opened when hydrogen is detected in bays with the garage door located on the west side of the bay? [No]

2. What happens if a pressure release device (PRD) release occurs close to the air conditioning return duct? [The duct would fill with a burnable mixture.]

3. Can restrictions be placed on a vehicle's location to allow a PRD release without hydrogen entering the air conditioning return duct? [It would make over half the bay unavailable.]

4. What can be done to the air conditioning duct location to reduce the risk during an accidental PRD release? [Lower the duct by 8 feet.]

5. What is the severity of ignition of hydrogen leaking into a 5000 square foot bay? [A $38.5 \mathrm{scfm}$ leak resulted in an overpressure of $0.17 \mathrm{psi}$.]

6. What is the severity of accidental ignition of hydrogen leaking under a large vehicle? [A $13 \mathrm{scfm}$ leak under the front end of a bus resulted in an overpressure of $0.03 \mathrm{psi}$.]

The sensor placement work has mainly involved tracing the paths of helium bubbles and bubble clusters.

The safety analysis for writing of codes investigated two areas: 1) The impingement of a hydrogen flame upon a gypsum board, and 2) a computer model of hydrogen leakage within a two car garage.

I see the following strengths in the project: 
- The P.I. is well known for his expertise in hydrogen safety modeling and testing.

- The testing is methodical and tells a definitive story.

- The combination of experiment and modeling always lends more credence to the results and this is not an exception.

I see the following items that need to be addressed:

- The weakness here is not in the work; it's in the telling. Both the written reports and the graphics therein are quite difficult to follow. (The confusion as to what is being shown in some of the hydrogen concentration drawings is a good example. - they show the area in which hydrogen is at a certain concentration in some cases, and a plane above which hydrogen is at a certain concentration in others.)

- Hydrogen safety is such an important area. A lot of what the PI is finding is that hydrogen is not more dangerous than other fuels - it's just different. The PI should be tasked with getting this message across to the public.

\section{Introduction, Background, and Overview:}

I visited Dr. Swain at his laboratory at the University of Miami to discuss his various tasks, and see his laboratory and testing areas both at the University and at a separate testing facility in a warehouse in SW Miami. We held extensive discussions on the projects in general which included a slide presentation by Dr. Swain, discussed my questions, and toured both facilities.

Dr. Swain has been working on hydrogen engines since 1971, when he was a student. $\mathrm{He}$ started doing safety work in 1988. Since then, the engine work has been at a low level, mostly for Ford. He has developed an engine which shows about $40 \%$ brake thermal efficiency with virtually no emissions.

Much of Dr. Swains work involves modeling combined with experiments that help to drive the model. For instance, he was under contract to Ford to design a garage door that would make the garage self-ventilating. Dr. Swain used a single-car garage for his study, choosing the worst case scenario of low ventilation, small volume and potentially high hydrogen concentration.

Dr. Swain constructed a wooden garage in his warehouse test facility (see "Tour"), and located a "leak", using helium to simulate hydrogen, on the floor of the garage, far from the door. He used sensors to determine concentrations of helium at various positions within the garage, and experimented with vents of various heights in the garage door. When he used a single vent, he wound up with a simulated burnable hydrogen mixture throughout the garage. By using two vents, an upper and lower, even if each was only 2.5 
inches in height (Exhibit 1), the hydrogen concentration was below the burnable limit (Exhibit 2).

Helium is a good test gas for helium because both are so much lighter than air. That outweighs the difference between hydrogen and helium. The faster that the gases try to rise, the more they mix with air, and therefore rise less rapidly.

Dr. Swain also showed me a comparison with liquid propane (LPG) showing this heavier-than air hydrocarbon to be much more likely to fill the garage - a far more dangerous material than hydrogen.

In another study for Ford, Dr. Swain showed very good correlation between a model and an experiment for a leak in a garage that had one vent in the side of the garage. The leak was located under a piece of plywood on the floor to simulate a leak under a car. Tests were done with hydrogen (lower ignition limit $=4.1 \%)$, gasoline $(1.3 \%)$ and propane $(2.0 \%)$. Experiment and model showed that of the three, only the propane leak would cause the garage to fill with a burnable mix.

\section{Questions and Answers:}

Following the presentation we discussed the questions that I had sent Dr. Swain prior to my arrival. These are reproduced here, in bold type. Dr. Swain responded in writing. His answers are "quoted using a different font." Additional discussion on these topics that took place during our meeting is displayed here in normal type. My comments added to many of the questions during my later analysis and assessment are shown in italics.

\section{$\underline{\text { CaFCP Building Project Questions }}$}

\section{Is the geometry of the California Fuel Cell Partnership (CaFCP) building considered typical of a garage? How generic is it?}

"The geometry of the CaFCP building is typical of warehouses in general. The exhaust and air conditioning system were designed specifically for hydrogen usage prior to our involvement in the project."

An architectural engineer designed the ventilation system with hydrogen in mind. Dr. Swain and the engineer discussed the types of accident scenarios that they wanted to model.

One item that they were particularly concerned about was the possibility of sparking in the air-handling system (air conditioning and exhaust), and they redesigned the system accordingly.

Dr. Swain indicated that, in fact, right up until the time the contract was signed, he planned to use a different building, but had concerns, and moved to the CaFCP building. 


\section{How were the six questions referring to the building derived?}

"The six questions referring to the building were derived from face to face meetings held in Sacramento and telephone consultations with CaFCP personnel."

\section{What is meant by "non-PRD" leakage rate?}

"A 'non-PRD' leakage rate is a leakage rate which is not the product of a failed Pressure Relief Device (PRD). The flow rate of 80 SCFM was chosen as representative of the leakage rate which would activate an excess flow valve. An excess flow valve shuts off hydrogen flow out of the tank if the hydrogen flow exceeds a predetermined value (in this case 80 SCFM)."

For a PRD, all of the hydrogen would leak out in about 100 seconds. The representative leakage rate of $80 \mathrm{scfm}$ (standard cubic feet per minute) is probably too large, Dr. Swain indicated. If the vehicle is on, even a $20 \mathrm{scfm}$ rate would be more than a fuel cell would use. Thus, for new work, they will use $20 \mathrm{scfm}$. If the vehicle is shut off, the tank is completely isolated from the rest of the system, and the valve should automatically be shut. If the computer senses hydrogen, it will shut the valve. If the valve does not shut, an alarm will go off. Once the valve shuts, it is assumed that it will stay shut.

Two comments: 1) The lower limit for hydrogen leak detection with the vehicle running should have been based on fuel cell usage to begin with, and 2) I am concerned about the assumption that the valve is assumed to stay shut. One should consider the possibility of the valve reopening.

\section{What is the significance of the east vs. west sides of the bays?}

"The floor plan for each bay is identical to, but a mirror image of the bay adjoining it. The exhaust system and air conditioning systems are identical in each bay but not the mirror images of adjoining bays. This means sometimes the exhaust system is on the same side of the bay as the garage door (east side), and sometimes it is on the opposite side (west side)."

In other words, the east bays and west bays are mirror images of one another, except that the vents are in the same position in both east and west. Therefore, you have to model both cases.

\section{What type of leak would take 16 seconds to reach $20 \%$ of LPL, but only one more second to double to 40\%? (From your 2002 US DOE Annual Review report).}

"The leak is a 80 SCFM leak from the back of the vehicle against the garage door. The hydrogen rises to the ceiling and moves across the ceiling with a concentration gradient at the forward edge. The gradient and rate of motion is such that hydrogen concentration goes from $0.82 \%$ hydrogen to $1.64 \%$ hydrogen in one second. It takes 16 seconds for the hydrogen cloud to reach the first sensor. 
"If one tracks hydrogen concentration versus time at a point on the ceiling distant from a leak one finds the hydrogen concentrations remains at zero for a while after the leak starts and then increases rapidly at first and then tapers of to the steady state concentration."

The sensor is far from the leak. It doesn't take 16 seconds for the leak to reach $20 \%$ LPL; it takes 16 seconds for the hydrogen to reach the sensor.

So, what Dr. Swain has shown, apparently, is that with a garage and sensor placement of this design, the leak could become unmanageable before it is detected. This is the type of information that one needs to know.

\section{What causes the $16-23$ second delay in opening the garage door?}

"The hydrogen takes 16 seconds to reach the first sensor location. This arrival would activate the opening of the garage door if that protocol was chosen. The garage door requires 23 seconds to go from closed to open. The 23 seconds was obtained by timing the opening of the garage door as installed."

The opening of the door itself takes 23 seconds. This is on top of the 16 second leak-tosensor delay. Unfortunately, says Dr. Swain, the door itself is an ignition source, so you could get a fire. In addition, the air conditioning system could be an ignition source as well, if its motor does not meet code.

\section{When addressing the PRD failure, you assumed that $2.5 \mathrm{lb}(1.1 \mathrm{~kg})$ of hydrogen was stored on the vehicle. Why this low number?}

"Modeling of PRD failures was done for two amounts of hydrogen 2.5 pounds and 11.0 pounds. The smaller amount came out of a meeting in Sacramento. The more severe 11.0 pound release was used to verify air conditioning return duct placement. Limiting vehicle location was determined to be an unacceptable solution to preventing hydrogen from entering the A.C. return duct even for the lower 2.5 pound PRD releases."

Dr. Swain indicated that at first, they were concerned that PRD release would prove to be too dangerous, so they started with the lower amount, and then moved up to the 11 pound $(5 \mathrm{~kg})$ level. When the building was redone, they used the higher amount of hydrogen.

With a PRD valve, you can't exhaust the room quickly enough. You have to place the air conditioning return ducts low enough on the wall (and far enough away from the PRD) that the hydrogen will not reach them. Getting sparkless motors may prove to be too expensive.

As to the low hydrogen storage, Dr. Swain also pointed out that the amount of hydrogen that one can store on a vehicle has increased in the past couple of years. In addition, most manufacturers are moving from several small tanks to one large tank. I think the several small tank scenario validates having looked at $2.5 \mathrm{lb}$ hydrogen release more than anything else. One of several small tanks might have held that amount of hydrogen- 
although a leak in a manifold might have dumped all of the tanks. At any rate, I believe that having moved to modeling and testing for an 11 pound release is much more valid now.

\section{You show (in the Annual Review Report) two still pictures (Exhibits 3 a and b) from a video showing flame propagation. How do these two pictures coincide with your written description of the results?}

"Each figure (Figure A17 and A18 [Exhibits $3 a$ and b, respectively) shows two positions of the hydrogen flame created by ignition of a 38.5 SCFM leak of hydrogen. The leak has reached its steady state size. The greatest extent of the flame (5 feet) is shown in Figure A18 [Exhibit 3b]. The steady state standing flame height is also shown in Figure A18. It is the more clearly visible short flame in the figure. Figure A17 [Figure 3a]. shows the growth of the flame from 1.3 feet to 4.0 feet. The length of time taken for this growth is $1 / 60$ second."

What we're seeing in the picture is an anomaly of the video frame. Each "shot" shows every other horizontal line. The shots are taken $1 / 60$ of a second apart, and the frame is composed of two shots.

The problem is that this phenomenon is not obvious, and it makes interpretation of the figures difficult.

Dr. Swain will add a paragraph in his report to describe how the video works.

As to the flame itself, Dr. Swain said that "if you don't have a body in the flame, it's not important."

\section{$\underline{\text { Sensor Placement Questions }}$}

\section{In the sensor placement work, why did you start with bubble clusters rather than individual bubbles?}

"Bubble clusters have the potential to result in an overall lower density than single bubbles assuming similar size bubbles."

The bubbles in a bubble cluster have shared walls, so the overall density of the cluster is less than would be the same number and volume of single bubbles. However, the bubble clusters kept bursting, so Dr. Swain had to revert to single bubbles to determine sensor placement.

\section{Won't helium bubbles be diverted by air currents less radically than would hydrogen bubbles? How is this accounted for?}

"The rate of rise of the bubble is determined by the difference between the helium or hydrogen density and their air density. These are quite similar. The experimental results of their similarities can be found in "Experimental Verification of a Hydrogen Risk Assessment Method" Chemical 
Health and Safety, May/June 1999 Volume 6, Number 3, Published by The American Chemical Society. We have a more detailed paper dealing with the similarities in print to be published later this year. In any event the bubbles rise more slowly that the gases themselves so they show the limits of travel. The actual leak impacts the ceiling between the bubbles and a vertical line from the leak."

Dr. Swain would rather that the bubbles rise more slowly than does hydrogen. They want leaks that are still small enough to be diverted by air currents. The sensors have to be located on the ceiling, or they may not sense a leak. The bubbles will tell you in which direction the leak will be diverted.

I think what Dr. Swain is saying is that the bubbles rise somewhat more slowly than does the hydrogen leak, and thus they are exposed to the air currents for a longer period of time before they impact the ceiling and are therefore diverted further from the vertical than the hydrogen leak.

Dr. Swain is now thinking to develop a portable bubbler with a button that you can push to start the bubbles. Then you can walk around with it, releasing bubbles where you wish. Dr. Swain has not yet submitted this suggestion as a task; he is currently writing it up.

\section{$\underline{\text { Safety Analysis for Codes Questions }}$}

\section{In the flame impingement tests, wouldn't it be assumed that there would be a limit on the amount of oxygen inside the enclosure? What does this test prove?}

"There would be a limited amount of oxygen in the enclosure. Since the test allowed ventilation it is a worst case scenario."

Dr. Swain thought that codes people might think that in an enclosed version, the area would get hotter, and they would not consider oxygen depletion.

When dealing with some home owners association people, one is "fighting people that are trying to fight costs. Anything that will make it more costly to build the house will be opposed."

\section{What temperature rise is considered acceptable at the back of the board?}

"The temperature rises recorded were very small compared to the temperature rises necessary to product ignition of anything on the other side of the gypsum board. We did not try to determine how large a temperature rise could be tolerated because the data was far below that value."

Originally, the temperature that was targeted (as being unacceptable) was the temperature that would cause a cotton ball to ignite, but they never even came close to this. 


\section{What is the significance of the spacing between the $2 \times 4 s$ ?}

"The spacing between 2 by 4 's was chosen to match various building code requirements."

\section{In figures $C-7$ and $C-8(C-7$ is Exhibit $4 ; C-8$ is essentially the same graphic only at later time in the leak) modeling the 2-car garage, are there actually two distinct, non connected areas of $20 \%$ LFL and burnable hydrogen? Why wouldn't there be a gradient?}

"The leaking home refueling appliance is on the floor in the lower left corner of the garage. The hydrogen comes out the top of the appliance and flows up the corner of the garage. The two contours (red and blue) can not meet without indicating two different concentrations at the same point. Gradients exist between the contours for concentrations between $4.1 \%$ hydrogen (red) and $0.82 \%$ (blue)."

The $4.1 \%$ hydrogen is clinging to the wall, because with the wall there, the hydrogen cannot get through. The $0.82 \%$ hydrogen zone is not just a plane; everything above that plane is also $0.82 \%$. and above, but below $4.1 \%$

The problem is with the manner in which the figures are presented. The description makes it appear that there is no hydrogen at all near the ceiling (which we know couldn't be the case). I suggest that the figures be more completely and accurately discussed.

\section{Additional Items:}

One area of great interest to Dr. Swain (as well as many others involved with hydrogen combustion studies, and hydrogen safety studies) is the value of the lower ignition limit for hydrogen. The textbook number is $4.1 \%$. However, that is basically a worst case scenario. For example, since hydrogen is so buoyant, the ignition limit is far different depending on the direction hydrogen is traveling. For hydrogen going up a tube, ignition upward is around $4.1 \%$ (although I have seen numbers as high as $6 \%$ even for this.) However, for hydrogen to ignite down the tube as well the number is closer to $10 \%$. Dr. Swain believes that lower ignition limits for hydrogen needs to be revisited.

Modeling hydrogen flow in a vertical vent is a difficult process. In actuality, the stream fluctuates between walls, attaching itself to one corner and then moving to another corner, responding to air currents. However, as long as you know the average value of hydrogen going up the vent, you can use the data to measure hydrogen flow in a hallway adjacent to the vent.

If there is a leak without a vent present, the key factor is the volume of the leak. If the space is not enclosed, the key item is the flow rate of the leak. The worst case is an instantaneous release, such as a PRD leak.

Dr. Swain mentioned another phenomenon associated with PRD leaks. As hydrogen is released, the work performed by the remaining hydrogen to push the released hydrogen out, cools it. This compresses the gas, and temporarily slows or stops the leak. 
The most dangerous scenario, Dr. Swain says, is if you have close to stoichiometric hydrogen (about $30 \%$ by volume) near the ceiling, and you are still early in the leak.

Dr. Swain made an excellent point about hydrogen safety testing in general. If a study is funded or otherwise undertaken that looks at hydrogen only - without comparisons - you will likely show that hydrogen is dangerous. However, you will never get the chance to show that other fuels are also dangerous - at times, more so than hydrogen. Detroit, however, is very sensitive to the fact that burnable mixtures of gasoline can build up inside automobiles, and could then ignite when the door is opened.

Dr. Swain next plans a study of buses modeled after the Savannah River Bus. It involves a method of risk assessment. A leak will be modeled using helium. The model will be validated with experimental helium data, and will then be used to predict hydrogen behavior.

Dr. Swain is opposed to the use of odorants as the key hydrogen detector method. Sensors will detect hydrogen even if there is no one there. I would probably replace the word "key" with "only". Odorants are important for personnel safety, while sensors address both personnel and system safety. The use of odorants could conceivably save lives if a sensor fails. Odorants in natural gas have worked quite effectively.

\section{$\underline{\text { Tour: }}$}

Following the discussions, Dr. Swain first took me on a short tour of his engine lab at the University of Miami. The item of interest there is a Ford Triton standard V-8 engine that was sent to Dr. Swain by Ford, and which he converted to hydrogen. Modifications included 1) a new intake manifold, which resulted in an efficiency of $34 \%$, then 2) a new crank shaft (up to $38 \%$ ), and finally 3 ) a new piston design to make it flatter (40\%).

The major portion of the tour was held at Dr. Swain's warehouse facility in SW Miami. We were met there by Dr. Swain's associate (and brother), Dr. Matthew Swain. I was shown the facility by both of them.

The warehouse is basically one large room 105 feet long by 45 feet wide by 18 feet high. This works out to about the same volume of space as a bay at the CaFCP building. They sometimes use the entire bay volume for some tests. Within the bay are a full scale single car garage, and a half-scale model of a garage. The half-scale model is basically a sealed plywood box of the proper dimensions. Hydrogen/helium comparisons are made in there. The full-scale garage is the one in which a large number of tests, including the ones for Ford discussed earlier, were held.

They can set up various fans in the garage at various locations to simulate various airflows. They can change garage doors, and also have several smaller doors that they can open and close in the garage walls. Currently there are sensor holes in the walls but no 
vents - except in the garage door. The walls, however, are made of gypsum, so they can cut vents in whenever they want.

They also have a simulated bus. This is what they used to try to determine the severity of accidental ignition of hydrogen leaking under a large vehicle for the CaFCP building project. They could not get the leak to over-pressurize.

Normally, says Dr. Swain, things are not sealed up so tightly that you can over-pressurize large volumes of stoichiometric mixtures. Usually you get small volumes of stoichiometric mixtures surrounded by larger volumes of non-stoichiometric mixtures. These burn slowly, and prevent over-pressurization and detonations.

The warehouse itself has 2 air inlets and two exhaust fans, and an air conditioner. Along the side walls. There are also windows that can crank open to provide different air flows.

I was shown several used and unused gypsum boards from the impingement tests. The backsides hardly appear affected at all.

The warehouse also houses a Ford Focus that has a 5000 psi hydrogen tank (Dynatek, Calgary, Alberta Canada) in the trunk and a PEM fuel cell stack under the floorboards. They don't use the tank for active leak tests; they use an external tank and hoses. The Focus and its components are just used as "shapes" here, to do leak analysis.

Dr. Swain has no (and needs no) special permits for the warehouse. At one time, however, he did have hydrogen insurance (they were able to find a firm that would write a policy.) They needed insurance for working at the University.

\section{Final Thoughts:}

Dr. Swain continues year after year to address various aspects of hydrogen safety in a variety of surroundings. He shows definitively that in a lot of instances, a hydrogen system is less dangerous than an alternative system. Some of his work (like his hydrogen vs. gasoline automobile fire of a couple of years ago, or this year's hydrogen hugging a wall in a garage, and a hydrogen flame not causing any significant temperature rise on the back side of wallboard) is quite eye-opening and important.

The work is very good. However, I think it would behoove Dr. Swain to publish his results in the open literature. The work is certainly good enough, and important enough. In addition, some of these results (albeit diluted for a lay audience) need to get into the hands of the general public. For this to happen, however, I feel that Dr. Swain needs to edit his reports to make them more readable and to make his graphics more understandable. 


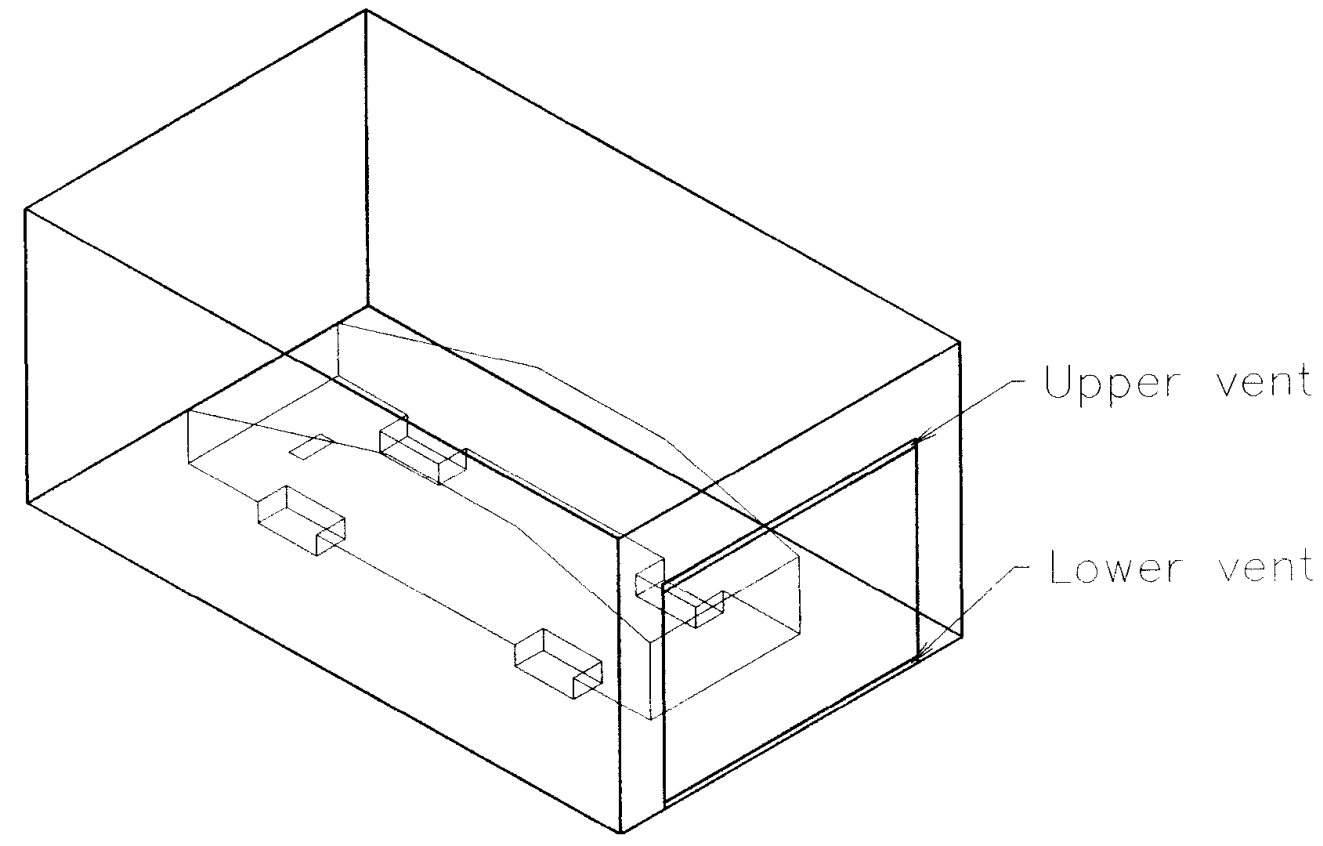

Exhibit 1. Schematic of garage with 2.5 inch upper and lower slot vents in door.

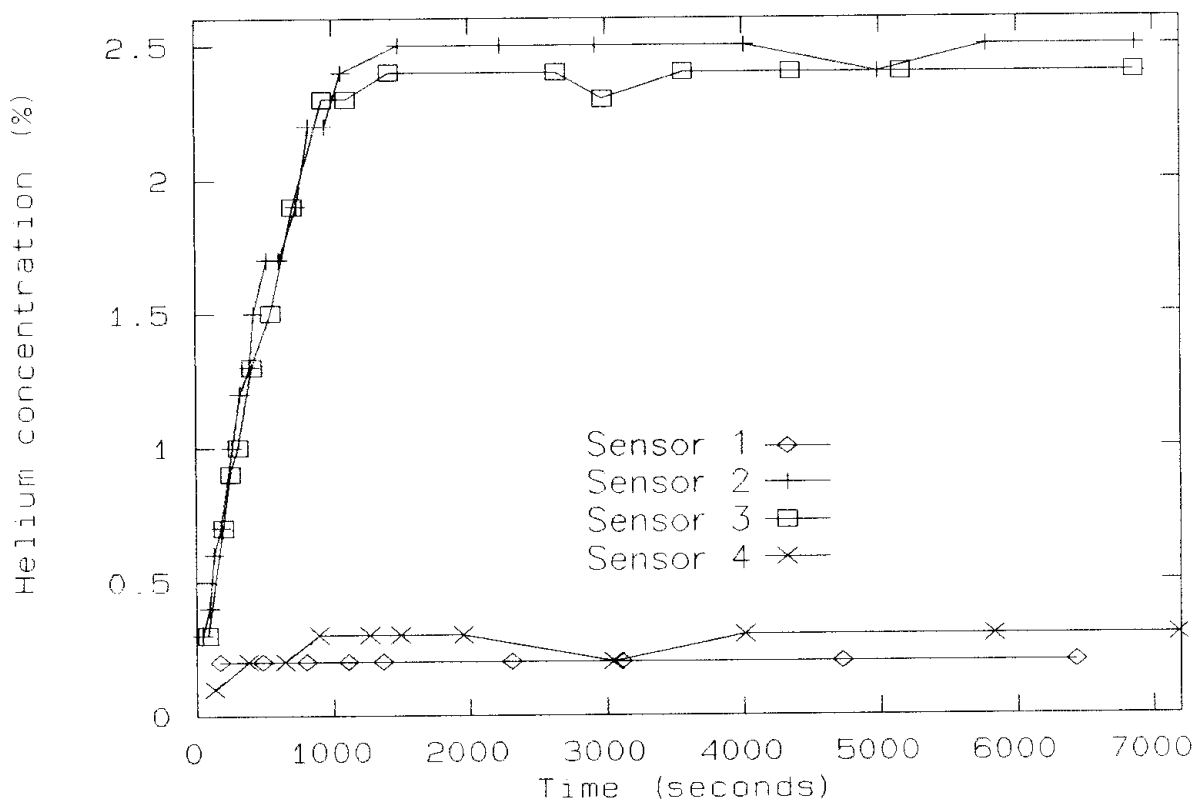

Exhibit 2. Helium concentrations for sensors at various positions within garage. 


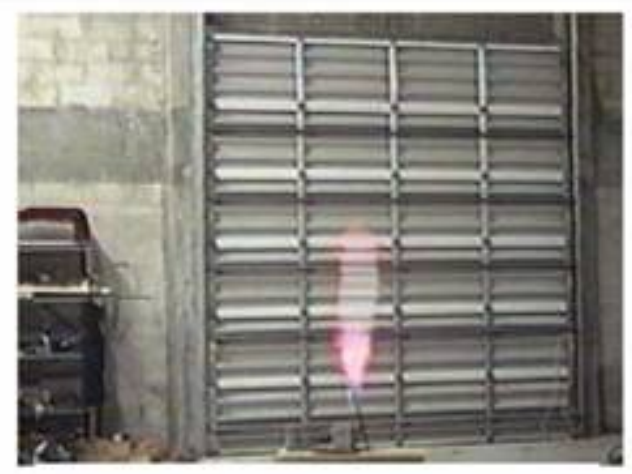

(a)

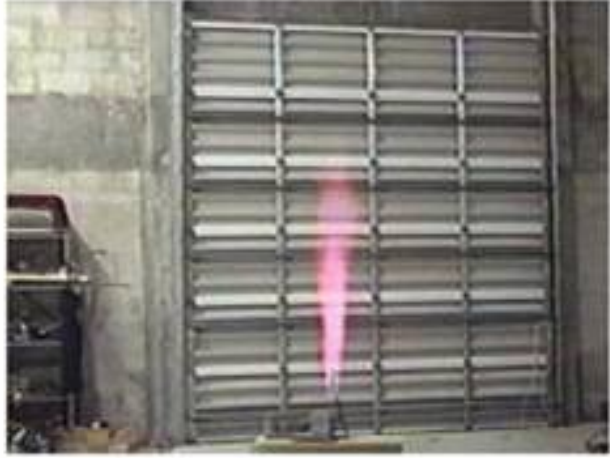

(b)

Exhibit 3 ( $a$ and $b$ ) showing two video frames, 1/60 seconds apart of $38.5 \mathrm{scfm}$ hydrogen leak

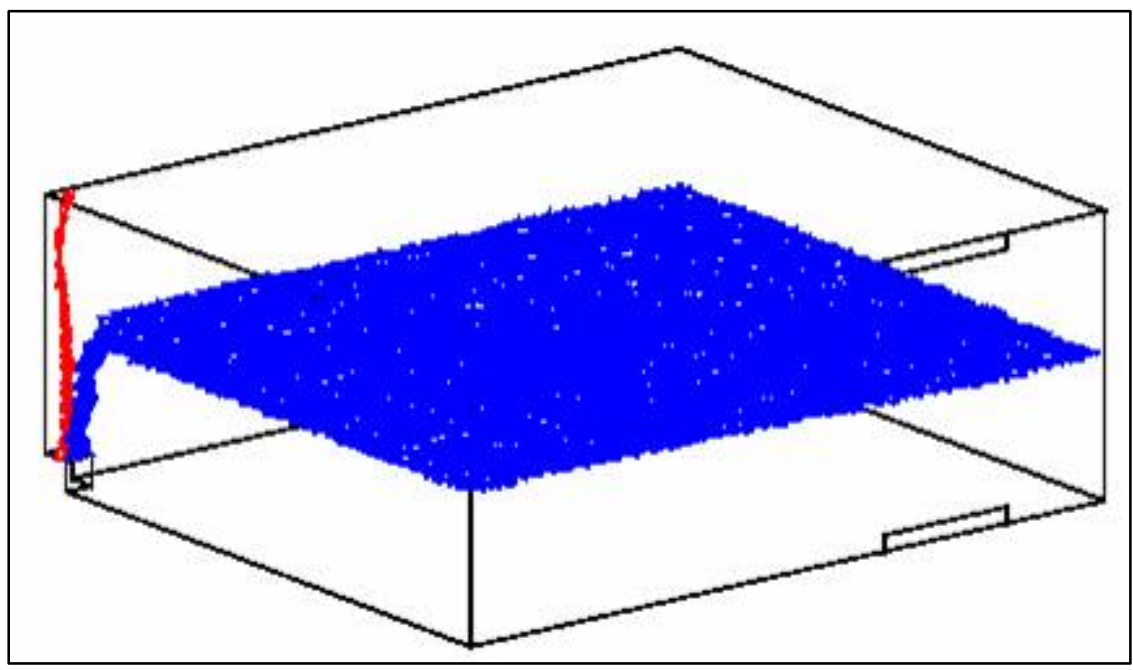

Exhibit 4.Vented 2 car garage, 4 SCFM hydrogen leak for 20 minutes. Blue: $0.82 \%$ hydrogen, Red: $4.1 \%$ hydrogen 
Technical Evaluation Report

Project: Hydrogen/Natural Gas Blends for Heavy and Light-Duty Applications

Company: NRG Technologies, Inc.

P.I.: Dr. Kirk Collier

Site-Visit Date: September 11, 2002

Evaluation by: Edward G. Skolnik, Energetics, Inc.

\section{Summary:}

NRG Technologies, Inc., located in Reno, NV is primarily involved in designing and building (sometimes by modifying existing engines) internal combustion engines (ICEs) that run on either pure hydrogen or on hydrogen/fossil fuel blends. Some of these engines are meant for vehicular use, and some for stationary use. NRG is being funded by DOE for several projects and by others for several more projects. Three of these projects, all closely related are being performed for DOE's Office of Hydrogen, Fuel Cells, and Infrastructure. One project addresses the conversion of light- and medium-duty vehicles to using engines that can run on hydrogen/natural gas blends. The second project is similar, but involves heavy-duty vehicles (buses with 200 horsepower engines). The third project involves the design and development of a larger engine that could replace the 280 $\mathrm{hp}$ engines on full-size diesel buses.

I see the following strengths in the project:

- NRG has been the mainstay of the Program's vehicular hydrogen combustion effort for the past several years.

- NRG's philosophy of using what you have and only changing what you need to makes for lower-cost projects.

- The wide variety of projects being run at NRG gives them vast amounts of resources and experience to draw from.

- The R\&D project, the full-size bus engine, after some down time looks like they have a workable plan.

I see the following items that are of concern:

- The medium duty vehicles work (the shuttle bus work) was virtually bowled over by circumstances in trying to obtain a reasonable vehicle. It leaves me wondering could NRG have done anything about it. There were two issues: first NRG didn't get a working bus and second, they weren't even sent the best of a bad lot when the initial deal fell through. Perhaps a little more investigation (or better paperwork) might have at least prevented the second happening. A backup plan would have helped. 
- In the heavy duty vehicles project, I would think that expansion problems with the aluminum plate would have been something that would have been discovered during an early part of the design phase, and the plate would not have actually been manufactured and installed.

- There are communications issues on both ends: NRG and DOE. It leads to confusion as to what the various projects are composed of, and what is being reported on, and what needs to be reported on at any given time.

\section{Introduction and Overview:}

I visited Dr. Kirk Collier at his facility, NRG Technologies, Inc., to see his site and to discuss the projects that he is working on for the Department of Energy (DOE). Dr. Collier has long been involved with projects in which engines are modified so they can run on blends of hydrogen and natural gas. Currently, Dr. Collier is working on three projects for DOE's Hydrogen, Fuel Cells, and Infrastructure Technologies Program. The first two are demonstrations; the third is an R\&D project.

\section{Light/Medium Duty Vehicle Conversions}

This project is being funded by DOE through its Nevada Test Site and Bechtel Nevada, and involves vehicles for use in Las Vegas. It is designed to convert existing vehicles to run on natural gas/hydrogen blends with hydrogen in the $30-50 \%$ (by volume) range. It uses exhaust gas recirculation (EGR) and a supercharger to get back the power lost with ERG.

\section{Heavy Duty Vehicle Conversions (Buses)}

This is also being funded by DOE through its Nevada Test Site and Bechtel Nevada. Existing buses are being converted to run on $30-50 \%$ hydrogen in natural gas. NRG developed a new engine as a replacement for existing Cummins 5.9 liter natural gas engines. The new engine will be an 8.4 liter engine. There is a 200 horsepower requirement for this engine. The bus is a "smaller" 33 passenger bus.

\section{Heavy Duty Engine Development (R\&D)}

This project, funded through DOE's Golden Field Office, involves developing an engine to replace heavy duty diesel engines. The requirement is $300 \mathrm{hp}$, larger than in "2". The target here is full-sized buses ( 40 passenger) that currently use $280 \mathrm{hp}$ diesel engines.

NRG is cost-sharing with Hess Microgen who is contributing two 12 liter Dae-Woo bus engines. NRG needs a larger engine to make up for the fact that they will be using a lean burn. They'll need either more rpms or more boost. 
Dr. Collier pointed out that this project is very different than the lighter duty engine projects. They need to have an air-break compressor as well as a gear pump for the hydraulics.

NRG is planning to take the Dae-Woo engines and "make them breathe better." The key is that the power characteristics are the same as with the diesel. You need equivalent torque and horsepower.

\section{Status:}

\section{Light/Medium Duty Vehicle Conversions}

The light duty vehicle is an F-150 Ford pickup truck that runs on 30\% hydrogen blends. It was finished last spring, and at the time of my visit, was awaiting the fueling station.

The design philosophy was to take advantage of anything that was already in the vehicle. For instance, if they stay within 2 points each way of the blend ratio (in this case, $28-32 \%$ hydrogen), they can use the Ford computer's "adaptive learn capability."

For the medium duty vehicle, NRG was originally supposed to get a paratransit bus from the Regional Transportation Commission (RTC) in Las Vegas. This is a 12-passenger bus, like a small rental car shuttle bus. In fact that would be a market for this vehicle. RTC, however, then withdrew their offer of a bus in good condition (they were all being used.) In its stead, NRG was offered one of several buses that otherwise would have been sold for scrap. NRG picked the best of what was available, and even then, was sent the wrong bus; the one they received had over 300,000 miles on it, and had numerous pieces missing. It is a "very bad bus".

NRG does not feel that they can achieve the goals of this project with this bus. They have therefore submitted a contract modification so that they can get a useable bus. If they are not successful with the modification, they are at a standstill. Dr. Collier says that they will have to figure out a way to renegotiate.

\section{Heavy Duty Vehicle Conversions (Buses)}

The engine that was developed for this bus was based on drag racing engine block technology, and used advanced technology engine bore coatings similar to what is used by Porsche, Mercedes, and BMW. However, they used an aluminum plate to mount some of the components, and did not allow for expansion differences. They thus had a failure, and started from scratch.

The new engine is being made using plated sleeves. NRG is waiting for the engine. They'll then redo the dynamometer testing and will put it on the bus.

\section{Heavy Duty Engine Development (R\&D)}


The first year of this project involved dynamometer testing. It showed that the technology developed for lean-burning natural gas engines is not compatible with hydrogen. In the design, a swirl helps the flame speed for methane in a lean burn. When hydrogen is added, however, the swirl results in a tornado effect. You get a hydrogen-rich center, resulting in higher $\mathrm{NO}_{\mathrm{x}}$ emissions. The heavier methane molecules migrate to the edge of the swirl and produce more hydrocarbon emissions.

This work was completed in May 2001. NRG had no contract on this work again until July 2002. Now that they are re-funded, NRG is addressing the swirl problem by trying to redesign the engine to get quiescent combustion. They are working on a two-pronged approach:

a. NRG will redesign their $200 \mathrm{hp}$ engine to $300 \mathrm{hp}$. Dr. Collier believes that this will only involve changing the cam. The transmission system will only operate reliably at $2800 \mathrm{rpm}$, so NRG plans to use internal gear reduction between the engine and the torque converter to reduce the $3800 \mathrm{rpm}$ they will be generating and bring it back down to 2800 .

Dr. Collier believes that they will likely have to redesign the cam. He does not believe that what they need exists now. They will estimate ramps and the effect on the power torque on a computer. Then they will look at a "library of cams", find the best profile, and grind it.

b. NRG will use the 12 liter Dae Woo engines from Hess Microgen. They will modify the cylinder head to get rid of swirl, and change the intake, exhaust, and turbocharger to get to $300 \mathrm{hp}$.

The fact that the contract was delayed, says Dr. Collier, actually gave them time to get the Dae Woo engines. Hess will cast the cylinder heads, but Dae Woo will supply them with new pistons and everything else they need. Dae Woo is a partner in this venture.

Essentially what NRG is doing is taking what they learned in other projects (see the descriptions of the work on the John Deere engines in the "Tour" section) and applying it to the 12 liter engine.

\section{Tour:}

The tour of the NRG facility was extensive and detailed. Within engineering laboratories, trailers and outdoor space, NRG has many free standing engines and reactors, refurbished cars and buses, and ancillary equipment designed to aid in developing innovative hydrogen, hydrogen/natural gas, or other fossil fuel systems. Most pieces of equipment are commercial items that have been (or are being) refurbished to varying degrees. In general, NRG will remove any computer system that comes on an engine they procure, and replace it with one of their own computers. 
- In the engineering laboratory, I first saw an 8.1 liter John Deere engine. NRG is teaming with University of California, Davis UC, Davis) on a Department of Transportation (DOT) project to convert the engine to $30 \%$ hydrogen.

- Another John Deere cylinder head is being worked on. NRG is working on the intake ports, grinding them to redirect the flow to create a quiescent chamber.

- NRG is developing a hydrogen ICE gen set for an "electrolyzer company" to be used for load following.

- In the outdoor area is NRG's blending station. They keep natural gas tanks in a pickup truck bed. [Dr. Collier pointed out that if you wanted to pull a trailer filled with tanks of compressed gas, you'd need a special permit, but putting them in the bed of a pickup is not a problem!] They buy hydrogen in "six pack" cylinders. They then put both gases into a mixing tank using sonic nozzles and needle valves. Hydrogen flow is used to adjust the mix. The blend is compressed (mechanical compressor) to $3600 \mathrm{psi}$ and tanks are filled with the mix. Flowing hydrogen from the six-pack causes condensation and sometimes ice formation on the outside of the hydrogen regulator. NRG simply uses a hair dryer to melt the ice.

- In a project for Arizona Public Service (APS), NRG is working with an 8.3 liter, six cylinder Cummins natural gas engine. Its capacity is $100 \mathrm{~kW}$. NRG is performing many modifications to allow it to run on hydrogen. One major change is that on three of the cylinders, the exhaust gas is recirculated to the intake. The trick is to remove all of the water from the exhaust gas. Heat exchangers and condensers are used for this purpose.

- The "Las Vegas Bus" awaits an engine from Bechtel.

- The Ford Crown Victoria automobile has been used for both DOE and state programs. It runs on $30 / 70 \mathrm{H}_{2} / \mathrm{NG}$ blends, using a lean burn. Right now, however, it's just running on natural gas. This vehicle was exhibited at National Hydrogen Association meetings several times.

- A second Crown Victoria that was refurbished for BC Hydro. It runs on 50/50 hydrogen natural gas blends. It features a supercharger to help boost and extra fuel injectors to make up for the loss in energy density. An NRG computer has been added to aid in getting data to the original Ford computer. There is about $25 \%$ ERG. This is just for flow, not for getting fuel from any unburnt gases. It uses ambient air and a very long exhaust pipe as a heat exchanger. This is used in an attempt to successfully burn the 50/50 mix and get low emissions inexpensively. Dr. Collier knows that the EGR would not work well without hydrogen in the fuel mixture, but does not know what the lowest amount of hydrogen is that is acceptable.

- A second hydrogen gen set project is being funded by APS. It is similar to the one being done for the electrolyzer manufacturer. NRG is teamed with The University of 
Nevada, Reno and the Desert Research Institute for this project. The projected application for this project is off-grid, with a plan to use the gen set in conjunction with renewable energy such as wind. The renewable resource would also make the hydrogen. A potential application would be ranches. They are looking to possibly run the gen set on hydrogen/propane blends, the ratio to be determined. NRG and their team are seeking to get additional funding from DOE for this project.

- Another APS-funded project involves a $50 \mathrm{hp} \mathrm{Honda} \mathrm{outboard} \mathrm{motor} \mathrm{engine} \mathrm{modified}$ with a $15 \mathrm{~kW}$ alternator. They want to use off-peak nuclear-generated electricity to make hydrogen via electrolysis, and then sell the hydrogen as a motor fuel using the Honda motor. The engine is a $15 \mathrm{~kW}$ auxiliary power unit for an electric vehicle, and is highway capable. APS is also considering a $3-5 \mathrm{~kW}$ "urban vehicle". The goal is to get to $100 \%$ hydrogen.

- In an internal project, NRG is trying to develop an on-board reformer that would reform $10 \%$ of input natural gas to make hydrogen, which would then be blended with the remaining natural gas and burned in an ICE. Heat from the EGR system would provide reformer heat.

- Next to a trailer, was a second John Deere engine for UC Davis and DOT that is running on natural gas/hydrogen blends, and on which a parametric study is being run.

- The trailer serves as a control room for many projects. Analyzers from Thermo Electron measure hydrocarbon, $\mathrm{NO}_{\mathrm{x}}$, and $\mathrm{CO}$ emissions. A GC used for the reformer test can identify the species of hydrocarbon. Cameras and controllers observe and run dynamometers.

\section{Questions and Answers:}

I sent Dr. Collier a set of discussion questions prior to my arrival. These are reproduced here, in bold type. Dr. Collier and his team provided answers during our discussion, and these are displayed here in normal type. My comments added to many of the questions during my later analysis and assessment are shown in italics.

1. Prior to our meeting, you sent me copies of statements of work (SOW) for both heavy duty and light/medium duty vehicles to run on the $\mathbf{H}_{2} / \mathrm{NG}$ blends. How do the SOWs (both written in 1999) compare with actual results and plans at this time? How have they been delayed and/or modified? What are the technical reasons for any of the changes?

We've discussed a lot of this above. We'll summarize the points here, however.

- The light duty vehicle work was completed as proposed without delay. The vehicle was a DOE-supplied Ford Triton with a 5.4 liter engine. 
- The medium duty vehicle work suffered due to the inadequate paratransit bus. RTC was not written into the contract. Right now, the project is on hold.

On the surface, it looks like poor planning. However, projects are often trying to find ways to cut costs, and this was likely one instance that backfired. A backup plan should have been investigated at the time NRG started the project. (But I'm saying this in hindsight.)

- The heavy duty engine has suffered from the decision to mount some components on an aluminum plate. Expansion differences were not accounted for, and a rod was thrown through the engine block. Repairs have been made, and NRG is just about ready to go.

I am more concerned with this problem. I think the initial design should have taken the consequences of using an aluminum plate into account.

- The swirl phenomenon, resulting in a heterogeneous gas mix, was a problem in the first year, and caused a contract delay for a continuation. With the new contract now in place, NRG is now working on their two-pronged approach discussed above.

\section{Please compare the heavy and light duty engines.}

This has been discussed in the "Overview" section.

The impetus for asking this question came from my own confusion prior to our meeting as to what projects NRG was involved in and how they were divided. This confusion is shared by many others from what I've heard. It is due, according to Dr. Collier, to DOE giving NRG only one session in which to report during the Annual Peer Review. In addition, not all projects are funded in any given year. For instance, the Golden Project had no funding between the FY 2001 and FY 2002 Peer Reviews, and was not reported on in 2002.

I think that while Dr. Collier's issues are true, a short discussion on exactly what project is being reported on at the start of the presentation is in order (a little bookkeeping, perhaps).

\section{The title of your FY 2002 Annual Review report alludes to both heavy and light duty applications, but the report itself focuses only on heavy duty systems. Is the work generic, applicable at least in part, to both systems, or has the light duty work been delayed?}

The light and medium duty engine work was performed on engines already in the vehicles. The heavy duty work used a new engine. No new light duty work was done within the present reporting period. 
Some of the confusion comes from the fact that in any one year, NRG might not report on all of the projects they are involved with. For instance, at the FY 2002 review, NRG did not report on the R\&D work because they had no contract on it during the reporting period.

4. The SOW on your Bechtel Nevada heavy-duty engine contract indicates that the engine drive train from the buses can either be modified, or used as-is. What did NRG do, and how were the engines modified?

The engine drive train will be used as is. NRG only needs to get Allison to reprogram the electronics, as they offered to do. The electronics are currently programmed for a 8.3 liter engine, and they need to be changed to 5.9 liters.

5. In your FY 2002 Annual Review paper, you list a set of goals and objectives, including emissions limits for designed engine configurations. Where do the numbers for the emissions limits come from?

The limits (4.0 g/hp-hr NOx, $15.5 \mathrm{~g} / \mathrm{hp}-\mathrm{hr} \mathrm{CO}$, and $1.2 \mathrm{~g} / \mathrm{hphr}$ NMHC) came from Bechtel/Nevada's RFP. They had referenced a specification from a California regulation

6. In the Annual Review paper, you state that the desirable compression ratio for this technology is between 12 and 15 to 1 . Is this a desired range, or an experimentally determined range?

It is actually, both. A textbook will tell you what you want for a compression ratio, and at what point you start getting diminishing returns (i.e., beyond 15 to 1). NRG verified this experimentally, but found that trying to operate beyond 12 to 1 is expensive. 14 to 1 is optimal technically, but if you factor in cost (that is, buying custom-made pistons) then 12 to 1 is best.

7. In the same paper, Table 1 (Exhibit 1), you compare four designs. What is the hydrogen to natural gas ratio(s) being used for these designs?

It is $30 \%$ hydrogen by volume. At low RPMs, it does not matter how you mix the fuel, but it was a serious concern at the higher velocity. You need to have homogeneous mixtures. There are actually only two designs; each was tested at two different velocities. So what are labeled Design 1 and Design 3 are the same, and should be labeled "Design 1", and the ones labeled Design 2 and Design 4 are also the same and should be labeled "Design 2". Design 1 indicated homogeneous mixing, while Design 2 resulted with the fuel hugging the outside of the mixing chamber, and remaining heterogeneous. Adding the hydrogen to the natural gas did not help with this design.

8. In the same table, you list only $\mathrm{NO}_{\mathrm{x}}$ emissions. What are the values for $\mathrm{CO}$ and non-methane HCs? 
The phenomenon was only seen with $\mathrm{NO}_{\mathrm{x}}$. $\mathrm{NRG}$ was not looking at $\mathrm{CO}$ or $\mathrm{HC}$ data because it wouldn't be affected as much. It seems that it would be good data to have.

\section{Please explain your result where you stated you achieved improved performance for non-optimized systems (combustion chamber and fueling system), but found only minimal effect when the systems were optimized.}

Non-optimized meant non-homogeneous mixing. If you used two spark plugs you would do better. With homogeneous combustion, one spark plug did as well as two; the second didn't help. It would have been clearer to say that modifications to the design could overcome the effects of non-homogeneous mixing.

\section{How were the weighting factors in Table 2 (Exhibit 2) in the same document determined?}

AVL has a driving test for heavy duty vehicles, but it is difficult to perform and NRG does not have the capability. So NRG has split the test into many duty components of doing the driving tests, and are performing engine dynamometer steady-state tests instead. The weighing factor is derived from asking the question as to what percentage of the time are you driving under those particular conditions. Then you do your steady state tests at these different conditions and weigh them accordingly.

\section{Also in Table 2, what is the hydrogen to natural gas ratio(s) here?}

$30 \%$ hydrogen by volume.

\section{Additional Items:}

When NRG was refurbishing a Ford Crown Victoria earlier, the biggest problem they had to face was "pick-up" from a stopped position due to the lean burn. So they would "let it make $\mathrm{NO}_{\mathrm{x}}$ " (run it richer) to get the momentary power.

\section{Final Thoughts}

Let's look at the items that NRG is working on presently. There are demonstration vehicles: the light duty vehicle, the medium duty vehicle, and the $200 \mathrm{hp}$ bus, and there is the $R \& D$ of the full size bus engine. Of the demonstrations, the light duty vehicle was delivered, the medium duty vehicle is at this point a non-starter due to a poor choice of platform, and the $200 \mathrm{hp}$ bus is behind schedule due to what I think was a questionable design decision (the aluminum plate). The $R \& D$ project had a funding delay which may have been due to the swirl problems with the engine design, but in this case I think this represents legitimate problems that occur in the course of $R \& D$ projects. NRG is addressing the heterogeneous mixing problem and responding accordingly.

So, the record isn't perfect. The light duty vehicle is the only success, and that's been over and done with. The R\&D project is just starting back up, and the medium and heavy 
duty vehicles have hit major snags (attempted rectification is proceeding on one of them now.) In addition, much of the work presented in the FY 2002 review paper is older work. For example, Exhibits 1 and 2 in this report were taken from NRG's 2002 Annual Review Report, but were originally seen verbatim in the 2001 Annual Review Report.

At the same time, NRG writes very brief reports with not a lot of information in them. In addition, it is not often clear as to which project is being referred to in the paper.

However, NRG does produce some good products for DOE and for others. The number of engines and other pieces of equipment that they are building and the level of activity in the NRG facility will attest to that. 
Exhibit 1. Effect of Fueling System Design on $\mathrm{NO}_{\mathrm{x}}$ Emissions (From NRG FY 2002 Annual Review Report)

\begin{tabular}{|lllll|}
\hline System Type & RPM & $\begin{array}{l}\text { Equivalence } \\
\text { Ratio }\end{array}$ & $\begin{array}{l}\text { BMEP } \\
\text { (psi) }\end{array}$ & $\begin{array}{l}\text { NOx } \\
\text { (g/hp-hr) }\end{array}$ \\
\hline Design 1 & 1700 & 0.51 & 101 & 0.06 \\
Design 2 & 1700 & 0.52 & 103 & 0.05 \\
Design 3 & 3000 & 0.55 & 105 & 0.08 \\
Design 4 & 3000 & 0.55 & 101 & 0.92 \\
\hline
\end{tabular}

Exhibit 2. Steady-State Emissions Summary, 200 hp Engine, Hydrogen/Natural Gas Fueled Bus Engine (From NRG FY 2002 Annual Review Report

\begin{tabular}{|c|c|c|c|c|c|c|}
\hline \multicolumn{2}{|c|}{ Individual Modes } & $\begin{array}{l}\text { NOx } \\
\text { (g/hp-hr) }\end{array}$ & $\begin{array}{l}\text { THC } \\
\text { (g/hp-hr) }\end{array}$ & $\begin{array}{l}\text { NMHC } \\
\text { (g/hp-hr) }\end{array}$ & $\begin{array}{l}\mathrm{CO} \\
(\mathrm{g} / \mathrm{hp}-\mathrm{hr})\end{array}$ & $\begin{array}{l}\text { Weighting } \\
\text { Factor }\end{array}$ \\
\hline $\begin{array}{l}1800 \mathrm{rpm} \\
2800 \mathrm{rpm}\end{array}$ & $\begin{array}{l}-100 \% \text { Load } \\
-75 \% \text { Load } \\
-50 \% \text { Load } \\
-10 \% \text { Load } \\
-100 \% \text { Load } \\
-75 \% \text { Load } \\
-50 \% \text { Load } \\
-1 \text { dle }\end{array}$ & $\begin{array}{l}0.37 \\
0.20 \\
0.10 \\
0.25 \\
0.10 \\
0.09 \\
0.11 \\
0.40\end{array}$ & $\begin{array}{l}3.70 \\
5.80 \\
5.48 \\
5.10 \\
5.63 \\
4.71 \\
6.01 \\
17.44\end{array}$ & $\begin{array}{l}0.07 \\
0.10 \\
0.10 \\
0.10 \\
0.26 \\
0.19 \\
0.26 \\
0.36\end{array}$ & $\begin{array}{l}0.00 \\
0.00 \\
0.00 \\
0.00 \\
0.00 \\
0.00 \\
0.00 \\
0.00\end{array}$ & $\begin{array}{l}0.15 \\
0.15 \\
0.15 \\
0.10 \\
0.10 \\
0.10 \\
0.10 \\
0.15\end{array}$ \\
\hline Weighted & ode (g/hp-hr) & 0.22 & 7.00 & 0.18 & 0.00 & \\
\hline Weighted & ode $(\mathrm{g} / \mathrm{kw}-\mathrm{hr})$ & 0.29 & 9.38 & 0.24 & 0.00 & \\
\hline
\end{tabular}


Technical Evaluation Report

Project: Hydrogen Storage in Metal-Modified Single-Walled Carbon Nanotubes

Company: California Institute of Technology

P.I.: Dr. Channing Ahn

Site-Visit Date: September 25, 2002

Evaluation by: Edward G. Skolnik, Energetics, Inc.

\section{Summary:}

The California Institute of Technology (Caltech) has joined the group of researchers that are trying to develop methods of preparing single walled carbon nanotubes (SWNT) that can take up hydrogen and thereby act as a storage vessel, especially on-board a vehicle. The premise that Caltech is using is that if the spacing between nanotubes can be increased, there will be more room for stored hydrogen. Caltech is looking at inserting potassium atoms (physically a fairly large atom) between SWNTs as "intercalants" to act with this purpose. Thus, Caltech is trying to both make and buy SWNTs, and to purify them. As a means to determine the ability of the SWNTs to take up potassium and increase inter-nanotube spacing, Caltech is first studying the insertion of potassium atoms between layers of graphite.

I see the following strengths in the project:

- I have often said that if we are to make nanotubes a potential hydrogen storage medium, we need several research projects, not just one. This project (and another at Savannah River) provides the Program with additional resources to the ongoing NREL project.

- Dr. Ahn is a recognized expert in the area of interpretation of diffraction data. This expertise will greatly enhance the reading and interpretation of measurements on the SWNT systems.

I see the following items that are of concern:

- Potassium as an intercalant (a more-or-less physical presence) may be similar to free potassium in pyrophoric properties. That is, it could combust spontaneously. Great care is needed in this research, and safety must be considered a priority for any commercial venture.

- The purification methodology needs to be laid out better. It is difficult to grasp the thread of where it is going. Looking in the literature and on the Internet is fine, but more interaction with nanotube manufacturers is necessary.

- The data appears to indicate that the lattice spacings for potassium-intercalated graphite in the presence of deuterium (and presumably hydrogen) will narrow with increasing temperature. (See Exhibit 4) 
- It is unclear to me as to how well the graphite tests will correlate with SWNT/potassium intercalants. I think it's time to "cut to the chase."

\section{Introduction and Overview:}

I visited Dr. Channing Ahn at his laboratory at Caltech. We discussed his nanotube project, reviewed questions I had sent him, and went on a tour of Dr. Ahn's laboratory at Caltech and also visited the Sieverts' Apparatus facility at the Jet Propulsion Institute (JPL) nearby.

Dr. Ahn got involved in carbon nanotubes a few years ago during the height of the controversy over Northeastern University's carbon nanofiber claims and other claims of high hydrogen storage capacities. Dr. Ahn wanted to be seen as "the standard-bearer of truth" Thus, he first tried to make nanofibers using a procedure that he believed was close to what Northeastern had been doing. He therefore reacted ethylene with hydrogen in a tube furnace at $600^{\circ} \mathrm{C}$, using an iron/copper catalyst. His product seemed to contain nanotubes as well as nanofibers.

Dr. Ahn used a Sieverts' apparatus to measure hydrogen in the nanotubes. This is done by a pressure differential method, which is admittedly subtracting one large number from another. (Dr. Ahn mentioned a good rule of thumb when dealing with hydrogen storage in SWNTs. At $77^{\circ} \mathrm{K}$, you get approximately $1 \%$ of hydrogen storage for each 500 square meters per $\mathrm{cm}^{3}$ of storage material at about 30-40 bar of pressure. This rule of thumb was initiated by Dr. Richard Chahine from Dr. Tapan Bose's group at Universite du Quebec a Trois-Rivieres.) Dr. Ahn found that when using a BET (which stands for Brunauer, Emmett, and Teller, the three scientists who optimized the theory for measuring surface area) surface area measuring system, he found very little hydrogen as a function of surface area.

Dr. Ahn also looked at SWNTs from Rice University (Dr. Smalley's Group) at high (60 bar) pressure, and found $8 \%$ hydrogen at $80^{\circ} \mathrm{K}$. As the SWNTs were recycled, Dr. Ahn believes the ropes seemed to be restructuring.

Dr. Ahn believes that you can store more hydrogen between nanotubes than within them, and at least at liquid nitrogen temperatures, you can push the tubes apart (Exhibit 1). He also believes that most nanotubes have about 5\% of defect associated with them. This provides ample space for material (i.e., hydrogen) to fit into, as long as there is a driving force.

\section{Status:}

As a result of Dr. Ahn's initial probing, he realized that just carbon nanotubes by themselves wouldn't be sufficient to store hydrogen. Thus, he decided to look at materials that would spread the nanotubes apart. Dr. Ahn decided to consider potassium as a likely material, and opted to first look at graphite plates rather than nanotubes. (Dr. 
Ahn is trying to get as much data as he can from graphite because SWNTs are so expensive.) At least at $88^{\circ} \mathrm{K}$, you have a slit-pore effect between graphite plates and you can capture hydrogen. A model showed that for the species $\mathrm{KC}_{24}$ you could store four hydrogen molecules $(1.2 \%)$, and that is all that fits.

Intercalation provides conduits to inner surface areas. If you look at Stage 1 material, $\mathrm{KC}_{8}$, most of the hydrogen is actually chemisorbed and thus more difficult to retrieve. For the higher stages (see Question 5) the hydrogen is physisorbed. Dr. Ahn also feels that the interaction of hydrogen with potassium itself could increase storage capacity. Exhibit 2 is a representation of Stage 1 and Stage 2 materials, including the positioning of hydrogen molecules.

Dr. Ahn is doing neutron scattering experiments at Los Alamos National Laboratory (LANL) in order to observe and characterize the intercalated graphites. He is using deuterium rather than hydrogen because you can see deuterium with neutron scattering. It was during the tests at LANL that Dr. Ahn found that Caltech was making Stage 3 and 4 material rather than Stage 2. (See Question 8). At this point, Dr. Ahn is still struggling with the LANL data. Dr. Ahn did mention, however, that if the LANL beam is not running, Caltech has a defractometer that will work. Obviously not as well as the LANL system or Dr. Ahn would just use his own.)

The spacing between graphite layers is about 3.5D; when you intercalate with potassium, it goes up to about 5.3D. When you add deuterium, it gets sucked into the slit pore, and separates the layers a bit more.

Caltech has started some purification work on SWNTs (see also Question 10). They have found that by baking out the nanotubes they can change structure by eliminating defects. Exhibit 3 shows a TGA of unbaked and baked SWNTs. Dr. Ahn wants to eliminate defects even though he recognizes that these defects (holes) provide paths to the interior of the SWNTs. He believes that the exterior sites are more important for hydrogen storage, and that when he adds the potassium intercalant, the presence of defects could cause the SWNT to "unzip".

\section{Tour:}

The tour was in two parts: first a tour of Dr. Ahn's facilities at Caltech, and second, an excursion to the Jet Propulsion Laboratory (JPL) to see the Seiverts' apparatus. For the tour at Caltech, Dr. Ahn and I were joined by his undergraduate assistant, Ms. Joanne Yim. I was first shown a 10 gram sample of SWNTs from Carbolex, and a 5 gram sample from Carbon Nanotech. I observed an on-going SWNT purification scheme. This was a reflux setup, where SWNTs were refluxed in hydrochloric acid. The reflux is performed at $105^{\circ} \mathrm{F}$ for 18 hours. The SWNTs are then filtered. The catalyst used for manufacturing the SWNTs comes off in the solvent. Dr. Ahn has also looked at using $\mathrm{H}_{2} \mathrm{O}_{2}$ mixtures with hydrochloric and nitric acids. None of these purification methods seem to be working very well. Dr. Ahn mentioned that he derived these purification techniques from the chemical literature and the Internet. I was initially surprised that Dr. Ahn is not 
working more closely with the manufacturers of the SWNTs, rather than just relying on the literature. However, as we continued to talk, it was apparent that he has been talking to Carbolex - just not with the expected results. (See Question 1)

Dr. Ahn did say, however, that they have recently also looked at using $\mathrm{NaOH}$, and that appeared to result in "a nice microstructure." So further investigation with $\mathrm{NaOH}$ is likely warranted.

Among the equipment in Dr. Ahn's laboratory are a 2-zone furnace and an x-ray diffraction system.

In a shared laboratory is a transmission electron microscopy (TEM) system. The TEM can provide micrographs with a 2.3 Angstrom resolution. I saw some micrographs showing nanotubes, some graphite surrounding a catalyst particle and a $\mathrm{NaOH}$-treated specimen (at 122,000 X magnification) showing rope bundles of SWNTs very clearly.

Dr. Ahn then took me to the facility at JPL (Caltech manages JPL, so they have a close relationship.) We were met there by Dr. Ahn's associate Mr. Bob Bowman who accompanied us for the visit to the Sieverts' Apparatus.

The Sieverts' Apparatus, which measures volume, temperature and pressure, was built at JPL about 4 years ago. They started using it to do accelerated aging studies in 1999. The system is computer controlled, and has pneumatic valves. A gas line is connected to argon for calibration and purge, while a second line is connected to hydrogen. The system was designed to minimize the possibility of contamination. They take $99.999 \%$ pure hydrogen and run it through point-of-use filters to bring the impurities down to the ppb level. They can also run deuterium if needed.

They can measure and monitor pressure changes over four orders of magnitude, with absolute values between torr level readings and $3000 \mathrm{psi}$. An absolute pressure of 25,000 torr can be read to 0.125 torr. Temperatures are accurate to within $0.1^{\circ} \mathrm{K}$, and volumes are calibrated to less than $0.1 \%$. The control system can evacuate, fill, and measure temperatures and pressures within the system. There are also take-off high pressure ports for hydrides testing. Dr. Ahn is building three new ones for nanotubes. He will be using long tubes to put his nanotubes in, but will try to minimize the volume and will put the tubes into Dewars. With a sample, Dr. Ahn will first bake the nanotube-filled tubes to $200^{\circ} \mathrm{C}$, and will then add $99.999 \%$ hydrogen. Pacifying the system before usage is important, and Dr. Ahn will be working hard at it.

There are sand baths and nitrogen-flow to set and stabilize temperature for aging studies at high temperature. They can set the value anywhere between 50 and $600^{\circ} \mathrm{C}$. There is also a fluid bath for cold temperatures.

Adjacent to the Sieverts' are several glove boxes for materials handling. Operations include the grinding and processing of powder, and welding in argon. A glove box is also connected to a bake-out oven. 
JPL is building a second system for helium.

\section{Questions and Answers:}

I sent Dr. Ahn a set of discussion questions prior to my arrival. These are reproduced here, in bold type. Dr. Ahn provided answers during our discussion, and these are displayed here in normal type. My comments added to many of the questions during my later analysis and assessment are shown in italics.

1. In your FY 2002 Annual Operating Plan, you stated that you would have SWNTs synthesized at Duke, and would also purchase SWNTs from Carbon Nanotechnologies. You have since backed off from working with SWNTs initially, in favor of working with graphites. More recently, in your Annual Review report, you indicated that you bought SWNTs from Carbolex. Why the change? Do you still plan to utilize Duke and Carbon Nanotechnologies?

Caltech is still working with Duke. Dr. Jie Liu, the SWNT producer from Duke is planning to go to Caltech to give some lectures. He will hand-deliver the SWNTs at that time.

Dr. Ahn went to Carbolex because it was a lot less expensive. In addition, he thought that Carbolex had the "recipe" for purification. However, graphite shells around catalyst particles are proving to be a problem. Dr. Ahn will also get nanotubes from Carbon Nanotechnologies in addition to Duke and Carbolex, but he thinks that purity will still be an issue. The graphite shell seems to surround catalyst particles regardless of method of manufacture. It appears that Carbolex is not gearing their production for hydrogen storage, and is not addressing the purity issues that Dr. Ahn is concerned with. I wonder if there is a problem with carbon nanotube manufacturers getting "on-board" (no pun intended) with hydrogen storage issues.

For now, Dr. Ahn appears to be on his own. Perhaps the NaOH method will work.

\section{You also stated that Carbon Nanotechnologies use both laser and CVD methods for SWNT production. What methods do Duke and Carbolex use?}

Duke will use CVD. The methodology was originally developed by Dr. Liu. Carbolex uses the laser-oven method.

Dr. Ahn actually prefers the laser material to the CVD. With the laser material you get a narrower size distribution and a higher packing density of the "ropes". CVD material is "fluffier". However, says Dr. Ahn, everyone is using the CVD process now, and this could be a problem. The CVD substance is cheaper and easier to produce. Manufacturers can make relatively huge quantities (hundreds of grams per day) quickly, and they don't really care about hydrogen-based applications. For non-hydrogen applications, CVD is 
easier to handle than laser-based SWNTs - mainly, it won't bundle up into a rope. But it's still 5-10 times as expensive as the Carbolex material.

Dr. Ahn's opinions are the opposite of Dr. Ecklund, who says that the ropes are undesirable because they make it more difficult to overcome vander Waal's forces. Ecklund feels that single, discreet tubes would be preferable.

Single discreet tubes would be much more difficult to package. It doesn't appear to me that the ropes would present a problem for storing hydrogen using the Caltech method. Caltech is already demonstrating potassium intercalation and deuterium storage with graphite layers, and the interstitial spaces between SWNTs are similar to those for graphite layers.

\section{When you speak of SWNTs having a "rope structure" are you referring to bundles of tubes? Is the "swelling" to which you refer the opening up of interstitial space, or the swelling of the single tubes themselves?}

Ropes are due to the cohesive energy of tubes forming bundles. The swelling is due to separation caused by the intercalant. Dr. Ecklund (of Penn State) had done some work with intercalated iodine this was the basis for the Caltech work.

\section{Why was the schedule changed so that the graphite studies preceded any SWNT work?}

The opportunity to get beam time at Los Alamos took precedence. But Dr. Ahn doesn't really consider the schedule as having changed. He always thought that the graphite work would either go first or at least in parallel with the SWNT purification. That isn't what the schedule showed.

\section{Please explain the meaning/significance of the various stages of your $\mathbf{K C}_{\mathbf{x}}$ compounds.}

The potassium treats the middle of the carbons as a potential well. In addition, there may be some degree of charge transfer. The potassium sits in the middle as $\mathrm{KC}_{8}$. With Stage

2 , the formula is $\mathrm{KC}_{24}$, where you get a potassium every second layer, with the sequence being:

$$
\text { .....aKabKbaKa..... }
$$

For Stage 3, the formula is $\mathrm{KC}_{36}$, with three layers of graphite between the potassiums: ...aKabaKabaKa....

And Stage 4 is $\mathrm{KC}_{48}$ : 
...aKababKbabaKa...

This makes perfect sense; it should have been better explained in the report, however.

\section{You refer to air sensitivity of the intercalated graphite compounds. In what way does this sensitivity manifest itself? Why would/wouldn't the potassium- modified SWNTs exhibit the same sensitivity?}

The air sensitivity manifests itself by the potassium being leached out and oxidized. Dr. Ahn believes that the SWNTs will behave the same way - perhaps even to a higher degree due to the higher surface area. One would need a really good closed system in a real application. Dr. Ahn, in fact, suspects that the potassium-modified SWNTs might actually be pyrophoric. This is basically why I asked this question. We know of potassium's sensitivity in moist air (it spontaneously makes hydrogen, actually); this sort of behavior or even perceived behavior could be a real show-stopper here. The closed system will be a must. Safety must be addressed up-front.

\section{In Figure 5 (Exhibit 4) of your FY 2002 Annual Review report, what does the " $y$ " axis represent? Do the rapid drop-offs with increasing temperature for the deuterated samples indicate that at room temperature the graphite samples will be too compressed to admit hydrogen/deuterium?}

Dr. Ahn was not comfortable answering the question when we met, but offered to send me an answer later. The following represents Dr. Ahn's written answer, received after the meeting.

"The $y$-axis is the change in lattice parameter that the intercalated materials undergo upon deuteriding. So the Stage 2 material has a lattice parameter of $1.74 \mathrm{~nm}$, Stage 3 has a $1.205 \mathrm{~nm}$ and the Stage 4 has a $3.08 \mathrm{~nm}$ spacing. The stage 3 has a smaller lattice spacing because of the nature of the alternating graphene sheets a-b-a stacking which mean that the potassium atoms will not arrange in alternating lattice positions within the lattice.

"The change in lattice parameter then just reflects the change in the percentage from the numbers I gave above in the lattice expansion upon deuteriding.

"The downward slope in the data indicates that there is less deuterium at R.T. and I foolishly did not take that data but thermodynamically, I expect the stoichiometry to be $\mathrm{KC} 24 \mathrm{H}(0.51)$ and $\mathrm{KC} 24 \mathrm{D}(0.31)$ from what I've seen in the literature. I'm not sure what lattice spacing this would correspond to but it should be expanded slightly over the material when it's in vacuum."

I think that Dr. Ahn meant Angstroms, not nanometers

The exhibit is quite confusing, and the "key" does not seem to quite match the lines. However, it appears that the y axis is the percentage change in the lattice spacing from the spacing expected in a vacuum at room temperature, regardless of Stage. We can see this from the fact that the "vacuum" lines all converge to zero at room temperature. Values below zero, I assume, would indicate a contraction. 
In my opinion, it seems that the figure is showing that the spacing in the presence of deuterium would not be very much at all at room temperature. If this correlates with hydrogen as well, it does not appear to be very encouraging.

\section{How/why did the Caltech synthesis err in making Stage 3 and 4 compounds? Did you try to repeat the synthesis to make Stage 2 material?}

Caltech was using a different graphite that happened to form Stage 3 and mainly Stage 4 material. Dr. Ahn had thought that he had made a Stage 2 material but he hadn't reacted it long enough. He decided to use the Stage 3 and 4 material for data, but he has since successfully made Stage 2 material.

He should then use the Stage 2 material to confirm the other data.

\section{Have any analyses of the data using the LANL analyses packages occurred yet? If so, what have they shown?}

Yes, some of the analyses have "kind of" occurred, but Dr. Ahn is not ready to report on this yet.

\section{What is the status of the SWNT work itself? Has any purification work been done yet? What methodology is being/will be used for the purification? Are the "SWNTs "capped"? If so, what is the procedure for decapping?}

Dr. Ahn thinks the tubes may or may not be capped, but feels that this is irrelevant because the hydrogen will be adsorbed between the tubes at least to a greater degree than inside the tubes (or perhaps rather than inside the tubes.) There is a limited amount of spacing within the tube, and there is no driving force for hydrogen entering the tubes via capillary action. To get the driving force you'd have to have even smaller diameter tubes, which would make the space even more limited within the tubes; if you expanded the tubes to increase the internal space, the driving force would be even less. Dr. Ahn says that "he doesn't buy" the capping and decapping arguments. He went on to say that $\mathrm{sp}^{2}$ (planar) carbon does not have any special properties that would make it adsorptive to hydrogen.

Dr. Ahn also showed me some procedure sheets for purification testing of several different Carbolex SWNTs. As mentioned previously, these come form the literature or the internet. There are five different procedures and they involve various combinations of furnace baking, refluxing with $\mathrm{HCl}$ or $\mathrm{HNO}_{3}$, and sonification with $\mathrm{HNO}_{3}$, water, or $\mathrm{NaOH}$. 
Dr. Ahn believes that the Carbolex as-received material is only about $50 \%$ pure. It is about $30 \%$ catalyst (primarily nickel and yttrium) and about $20 \%$ amorphous or graphitic carbon. As shown in the TEM micrograph in Exhibit 5, the graphite surrounds the catalyst particle. The Exhibit also clearly shows some SWNT ropes.

The fact that you cannot buy purified SWNTs is a drawback says Dr. Ahn. It's another reason (other than cost) that he has done a lot of work with graphite. He realizes that the purification issue has been holding them back somewhat.

\section{Additional Items:}

A partner in Dr. Ahn's project is HRL Laboratories (Malibu, CA), a joint-venture of General Motors and Raytheon Company.

Hydrogen, says Dr. Ahn, is difficult to measure because (among other things) it leaks everywhere.

Dr. Ahn plans to look at nickel catalyst because it will allow hydrogen to dissociate into atoms on the surface. I think that Dr. Ahn has enough to do without diluting his effort.

SWNTs are very expensive at this time. Dr. Ahn estimates that even in mass production, a tank of SWNTs would cost about $\$ 10,000$. Carbolex SWNTs, however, are coming down in price; it has dropped from $\$ 100$ per gram to $\$ 60$. I assume this is for the asreceived $50 \%$ SWNTs. So that means the price is doubled, not counting the cost of purification. I also wonder about the batch-to-batch reproducibility here.

\section{Final Thoughts}

I have some reservations here.

It starts with the fact that most of the first years' work has been based on graphite intercalants rather than SWNTs. It was supposed to be just one task. Further, the fact that Caltech made the wrong kind of intercalant (Stages 3 and 4 instead of Stage 2) did not help. More important, however, is the data from the graphite work that seems to be showing that there may be no increased spacing at room temperature in the presence of hydrogen.

The work that has been done to date on SWNTs show that purification is and will be an obstacle. This one is likely workable, however. I'm a little concerned about the logic of their present methodology, but I think that Caltech will find a way to remove the graphite shell from the catalyst particles and then remove the catalyst. The cost of doing so, however, may be high.

In the mean time, I think that with even 50\% SWNTs, Caltech should be able to try some intercalation experiments with potassium and get a feel for how good the hydrogen 
storage will be. Catalyst particles should be shielded from the potassium by the graphite shell, and probably would not interfere.

The pyrophoric nature of potassium raises safety concerns that will have to be dealt with.

I believe that the bottom line is, however, get some hydrogen into some potassiumintercalated SWNTs, see how much you get, see how easy it is to put in and take out, and go from there. 


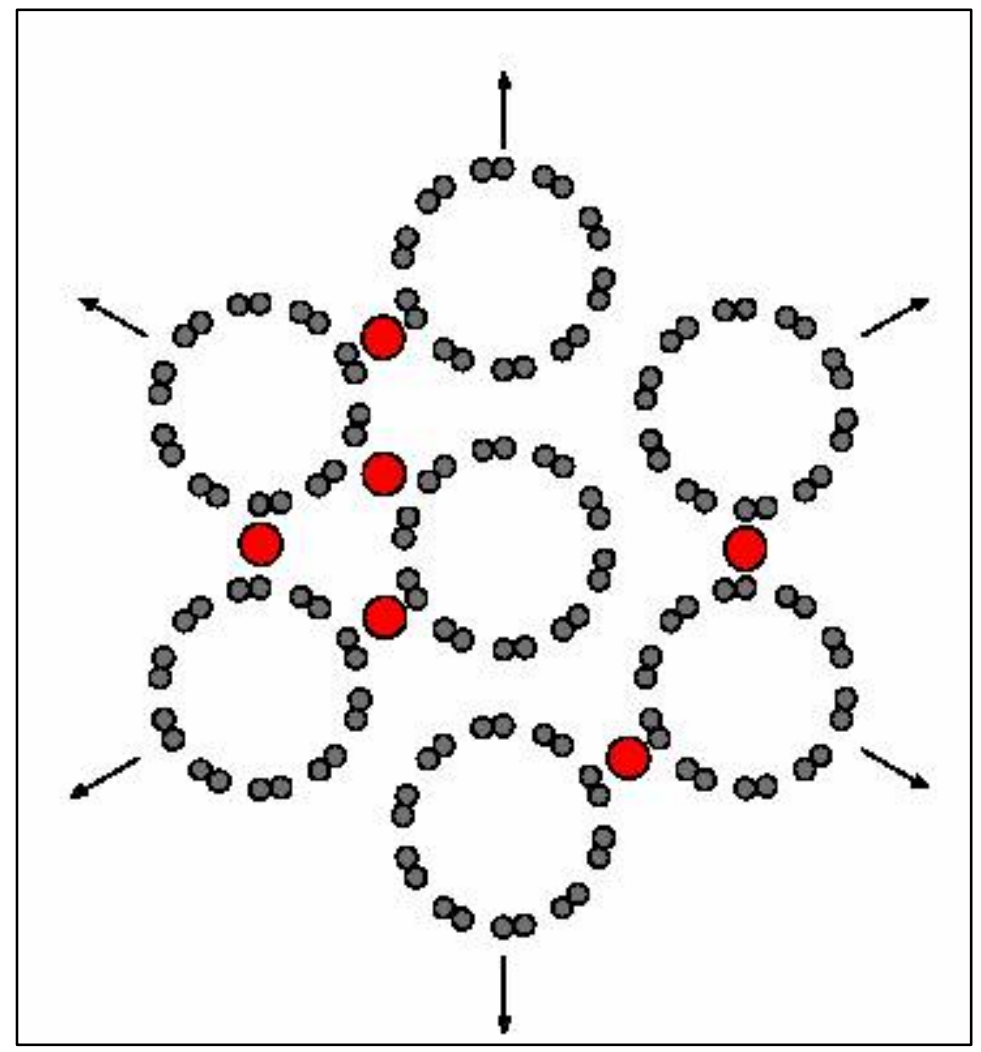

Exhibit 1. Schematic of SWNTs being separated by potassium atoms (red circles). (From presentation by Dr. Channing Ahn) 
Stage $1, \mathrm{KC}_{8}$ intercalated graphite
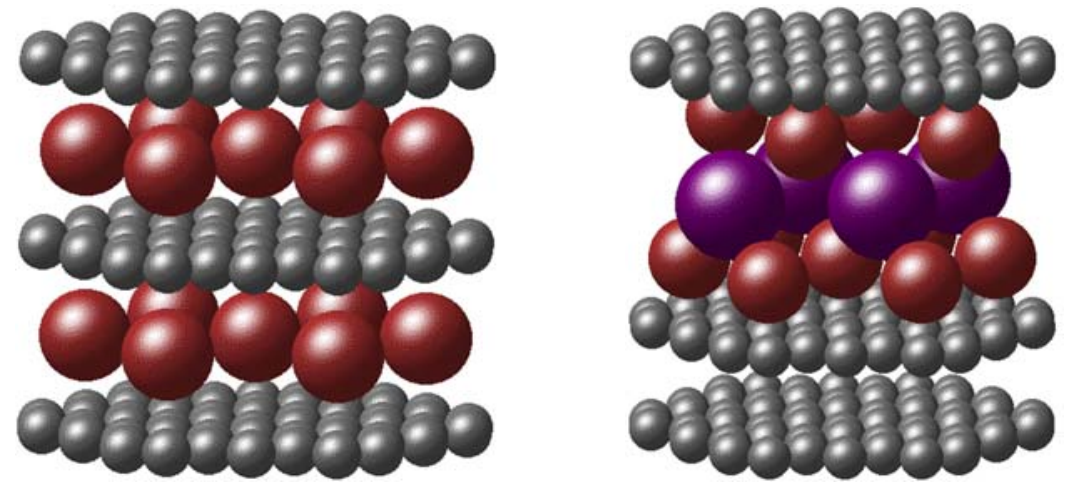

Stage 2, $\mathrm{KC}_{24}$ intercalated graphite

b

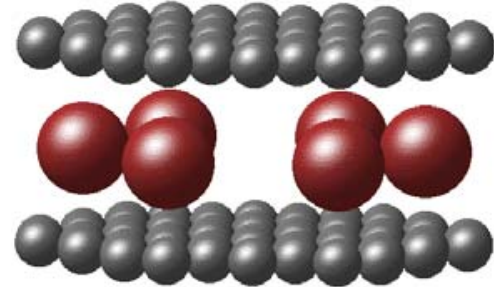

a

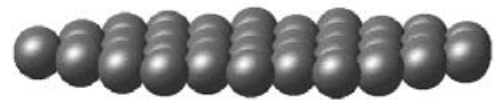

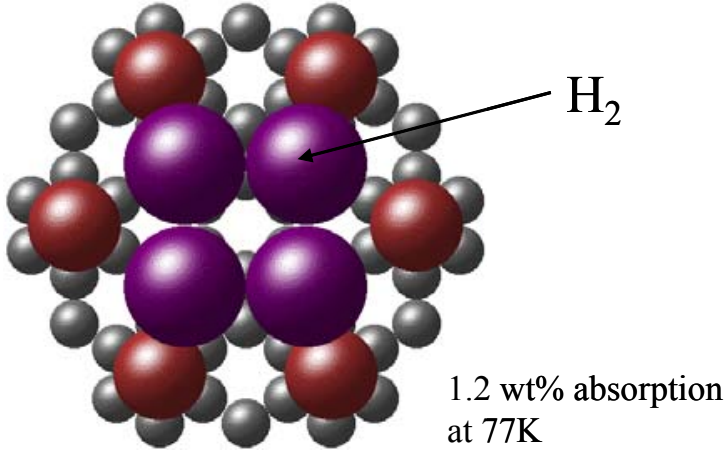

Exhibit 2. Representation of Stage 1 and Stage 2 potassium-intercalated graphite. Drawings on right show the positioning of hydrogen (or deuterium) molecules within the structure. (From presentation by Dr. Channing Ahn) 


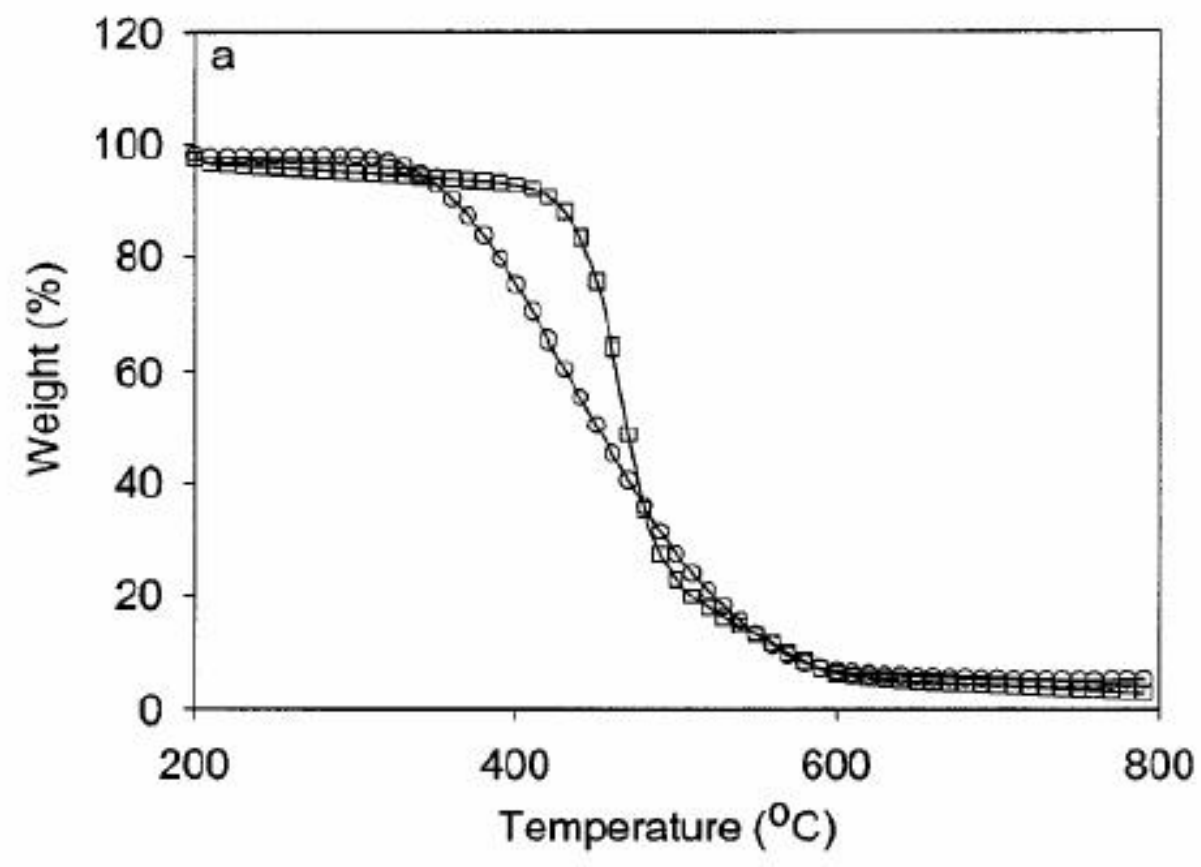

Exhibit 3. TGA data in air of raw SWNT material (circles) and the same material which was vacuum-baked at $1200{ }^{\circ} \mathrm{C}$ for 14 hours (squares). (From presentation by Dr.

Channing Ahn)

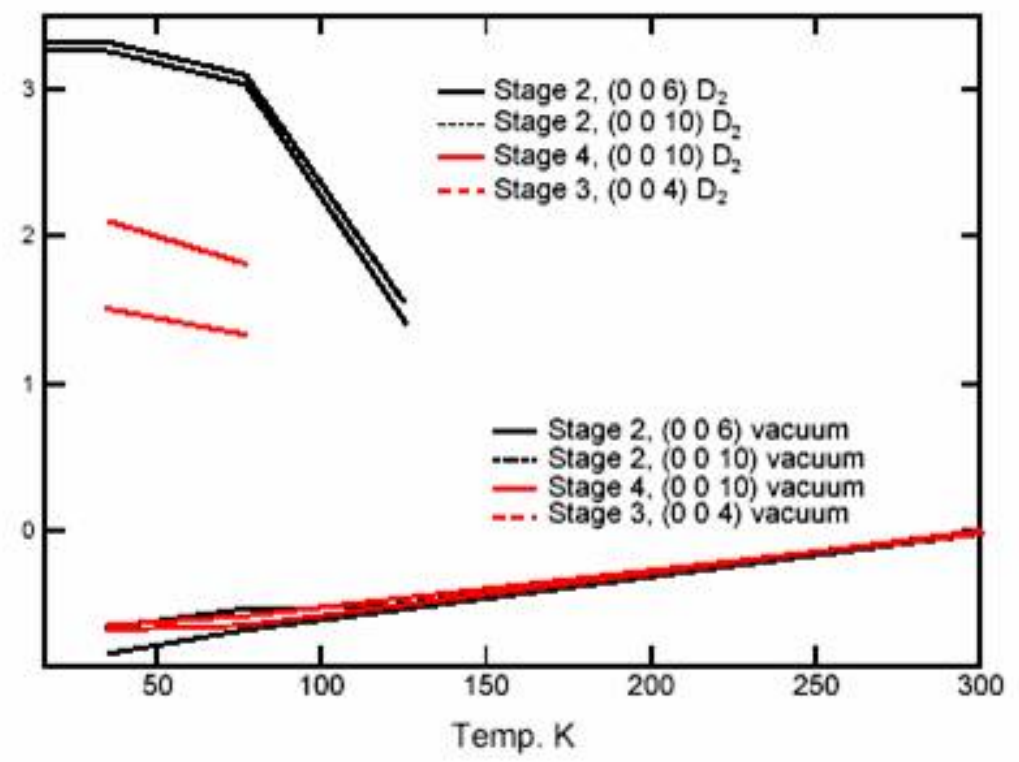

Exhibit 4. Basal plane lattice parameter changes as a function of temperature for

Stage 2, 3, and 4 compounds under vacuum (lower traces) and deuterated (upper left traces). (From C. Ahn FY 2002 Annual Review Report) 


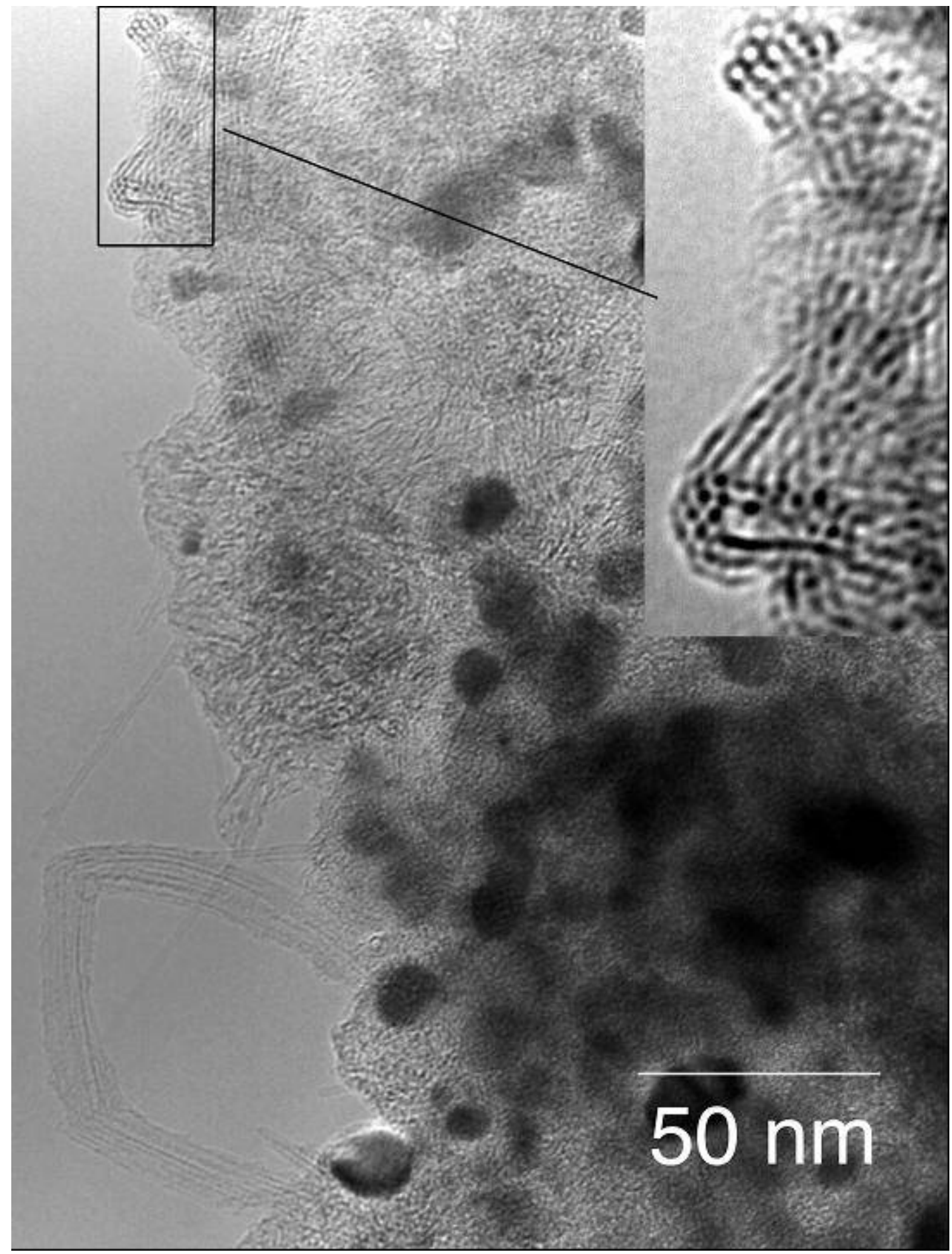

Exhibit 5. TEM of as-received material from Carbolex. The "clumps" are catalyst particles surrounded by graphite. (From presentation by Dr. Channing Ahn) 
Technical Evaluation Report

Project: Hydrogen Fuel-Cell Mining Locomotive

Company: Vehicle Projects, LLC

P.I.: David Barnes

Site-Visit Date: October 9, 2002

Evaluation by: Edward G. Skolnik, Energetics, Inc.

\section{Summary:}

Vehicle Projects, Inc. is leading a fairly large international team of participants in a project in which a PEM fuel cell and a hydride bed have been installed in a mining locomotive used to haul mine cars filled with gold ore. The low-temperature hydride (about 1\% hydrogen) holds enough hydrogen to fuel the 2-stack $17 \mathrm{~kW}$ fuel cell that powers the locomotive for at least an eight hour shift, and is controlled by a programmable logic controller.

The locomotive was evaluated at the Campbell Mine in Balmerton, Ontario, Canada during a week-long series of full-shift runs to judge its performance under real conditions. The power plant had already been built, installed, rebuilt, reinstalled, and the locomotive was tested parametrically both on the surface and underground. Here, it was put to work!

I see the following strengths in the project:

- The project represents an early commercial success story. The fuel cell locomotive operated in the Campbell Mine as would a normal mining locomotive.

- The heavy mining locomotive represents a good platform for hydrogen. Hydride storage is not a problem here; low hydrogen content, low temperature hydrides can be used without having to worry about the weight penalty. Here, heavier is better.

- This is an important step toward using fuel cell motors for many mining operations in both metal mines and coal mines. Doing away with diesel motors and their associated emissions in underground operations would be a big benefit.

I see the following items that are of concern:

- The hydride recharging process works, but its methodology (add hydrogen until a pressure gauge stops dropping or until an hour has passed, whichever comes first) does not lend itself to achieving an understanding of what is being done. It makes it look like smoke and mirrors. A good job of data collecting and interpretation would be much better.

- The biggest problem with hauling ore in this type of mine is supposedly traction. It doesn't matter if it's a hydrogen fuel cell, a battery pack or a diesel engine. If the track is wet and there is much of a grade, you are not going to be able to haul as much 
ore. Why wasn't a site chosen where the determining factor was the power supply, not a site that made all types perform below par?

- There is still a way to go to make the fuel cell system economical for this application.

\section{Introduction and Overview:}

After having performed over forty site visit-evaluations, my visit to observe a fuel cellpowered mining locomotive hauling gold ore about 4400 feet underground in a mine in a remote area of western Ontario, Canada easily qualifies as the most unusual. The project is headed by David Barnes of Vehicle Projects, Inc in Denver, CO, and is jointly funded by the DOE and the Canada Centre for Mineral and Energy Technology (CANMET) which is part of Natural Resources Canada. The power plant was developed and assembled by Sandia (Livermore) National Laboratories. The locomotive itself was manufactured by RA Warren Equipment, Ltd., the fuel cell stacks were made by Nuvera, and Hatch Associates, is responsible for safety analysis. CANMET is also responsible for the underground testing program.

The Campbell Mine is owned by Placer Dome, Inc., and is located in Balmerton, Ontario. Balmerton is about 175 miles northeast of Winnipeg, Manitoba. The mine, which opened in 1949, has about 300 employees, and processes about 1400 tons of ore per day. Each ton of ore contains about 0.45 ounces of gold.

Following parametric tests of the locomotive at Val d'Or, Québec, the mining locomotive was moved to the Balmerton location for actual ore hauling duty, to test it under normal operating conditions. The schedule consisted of a recommissioning of the locomotive and then a 5-day test (of which we observed the middle day) consisting of five 8-hour shifts. Each shift actually includes about 6 hours of actual mining and two hours of preparation.

\section{Pre-Tour Presentations and Discussions:}

The day of my visit coincided with visits by other people, and Mr. Barnes and I were joined by about ten visitors from the Ministries of Labour of both Ontario and Manitoba, Hatch, Inc., and Placer Dome Headquarters in Vancouver, BC.

Before we descended into the mine we were given the standard visitors safety briefing by Campbell Mine personnel. This was followed by a technical briefing presented by Hatch's Doug Eastiek.

The locomotive is of standard design, with the batteries replaced by a fuel cell power pack, including two Nuvera PEM stacks. The power plant weighs about 820 pounds. The hydride bed a metal alloy composed of several (primarily manganese, titanium, iron and zirconium) metals chosen for their temperatures of hydriding and dehydriding rather than for their hydrogen storage capacity (the proper consideration in an environment where weight is not a strong driver) weighs about 1100 pounds. 
The primary purpose of using a fuel cell locomotive is to reduce underground emissions caused by conventional (diesel) locomotives. Eventually the goal is to produce hydrogen in the mine, although currently, the hydride bed is transported up the shaft for recharging in a Quonset hut (see later discussion).

The hydride itself is being treated very carefully. The site requirement is 9000 cubic feet per minute (cfm) ventilation. This would protect the area if the hydride bed "broke open" and all the hydrogen was released at once (!), still maintaining the less than $20 \%$ of the lower explosion limit (LEL) for hydrogen. Note that later (Question 10) Mr. Barnes spoke of the new requirements for less than $12.5 \%$ of LEL. They treat the bed as if it were an explosive powder, just in case. If a hydrogen fire occurs, the plan is to find and identify the source, before attempting to put it out.

There are two on-board hydrogen detectors for the locomotive. One is over the bed, the other over the stack. They also use a hand-held detector when the bed is removed from the locomotive for transport to the refueling area.

The group follows a procedure for reacting to emergencies that is similar to methane procedures. That is, procedures for a lighter-than-air gas (as opposed to, say, propane, a heavier-than-air gas.) If an evacuation is necessary, this is "broadcast" by the release into the atmosphere of a "stench gas."

The fuel cell is made up of two $8.5 \mathrm{~kW}$ PEM stacks from Nuvera Europe. Each stack consists of 92 cells.

The start-up temperature of the fuel cell is about $30^{\circ} \mathrm{C}$ (remember, we're in Canada), and it takes about 5 minutes to reach this temperature. They have tried to start at colder temperatures, but Nuvera strongly recommended going to at least $30^{\circ} \mathrm{C}$. Once that temperature is reached, however, the actual start-up is instantaneous. They believe that when they have a commercial system, start-up will be quicker.

Mr. Eastiek commented that so far, the fuel cell locomotive has been able to do anything that a comparable battery pack system could do.

\section{Tour:}

In the Mine - The Locomotive

Shortly after we descended to the proper level, about a five minute ride down the shaft elevator, the locomotive came up the track hauling three cars filled with ore (Exhibit 1). It then moved each of the three cars into place over a holding bin where the cars were tipped, and the ore dumped. We were then allowed to examine the locomotive (Exhibit 2) and have questions answered by the mining engineers. Panels were removed so that we could see the power plant and hydride system. Later in the day, we followed the locomotive back down the track (slogged is probably the right word) about a quarter of a mile (I was told it was 1500 feet) to where the three cars were filled with mined ore via a 
chute from an above hopper. We then followed the locomotive and cars back to the dump-off site.

According to Mr. Barnes, the fuel cell locomotive can pull "five or maybe six" loaded cars. A battery powered mining locomotive can pull five. It is unlikely, however, that they will be able to haul five cars in this mine because of the poor traction afforded by the wet tracks. Mr. Barnes thought that maybe the Campbell Mine people could have run these tests on a different (drier, less inclined) level of the mine. The traction problem would exist regardless of what source of energy the power plant was using. The traction problem seems to be the driver for the entire test. While it is not a fuel cell problem, it prevented the demonstration from being run to its ultimate level. A heavier system would provide more traction, however.

The fuel cell power plant has its own control, and data acquisition systems. It is controlled using a programmable logic control (PLC) system.

A hydrogen sensor, located above the power plant is situated in the apex of a funnel-like arrangement (Exhibit 3). Any leak is maximized at the sensor location.

Deionized water is used to keep the fuel cell stacks cool. In addition, heat from the stacks is exchanged to the hydride bed to keep it warm during the dehydriding process. The dehydriding process itself cools the bed and would auto-extinguish the process without the external heat.

The hydride bed (Exhibit 4) consists of 16 canisters manifolded to provide a single input to the fuel cell system. It is unknown at this time how long a full hydride bed will last, but it's over eight hours.

The mean operating current for the system is about 60 amps. This represents only about half the power available.

\section{On the Surface - Recharging the Hydride Bed}

Hydrogen is fed back into the depleted hydride bed in an open-on-both-ends Quonset hut several hundred feet away from the mine shaft. Mr. Barnes and I met the refueling team (two mining engineers) at the top of the shaft, to where the bed assembly, encased in a steel box, had already been hoisted. It was then picked up by a fork lift and driven to the hut. We followed on foot.

In the hut is an area with several "six packs" of $99.995 \%$ pure hydrogen. A manifolded six pack of hydrogen is connected to the bed via a heater and heat exchanger. The system is also connected to a pressure and temperature data acquisition system. The hydrogen regulator is then turned on. 
The suggested method for recharging, say the miners, was provided by SNL. The refueling team monitors the tank and regulator gauges during the recharging process, keeping the regulator pressure in the 150-160 psi range. They also watch the time. The bed is deemed full when either the tank pressure stops dropping, or an hour has passed. (You can also hear the hissing stop.). Since they don't have a good measure directly of how much hydrogen was left in the tank from the last run, a more accurate method of recharging is difficult. On the occasion of my visit, the tank was filled in somewhat less than an hour (although subjectively, standing in the cold wind that was constantly blowing through the hut made it feel like much longer.) A full charge is about equal to 32 to 34 cubic meters of hydrogen (a little under $3 \mathrm{~kg}$ ).

The recharging process, from a purely technical standpoint makes sense, assuming that SNL had calibrated the bed, measuring how much hydrogen it would hold and how long it took to fill an empty tank. The six pack stops feeding hydrogen when the head pressure in the bed equals the regulator pressure (150 psi). From the safety aspect, I think a more rigorous approach is needed.

\section{Questions and Answers:}

I sent Mr. Barnes a set of discussion questions prior to my arrival. These are reproduced here, in bold type. Mr. Barnes and I met separately from the rest of the group between the demonstration in the mine and the later hydride regeneration demonstration to go over the questions. The answers he provided are displayed here in normal type. My comments added to many of the questions during my later analysis and assessment are shown in italics.

\section{What power plant changes were made by SNL to accommodate safety regulations? Are there additional/different safety regulations between Canada and the US?}

Sandia performed lab tests on the power plant, installed it onto the locomotive and delivered it in February 2002 for the initial functional tests. Changes after that time were made by CANMET. At the time that CANMET took over, after an initial risk assessment, one of the stacks was failing, the motor controller wasn't working (the problem was with the automation), and there was only one hydrogen sensor located on the hydride bed.

CANMET changed out both stacks installed a new motor controller. They also increased the safety aspects by adding a second hydrogen sensor. All of this and an automated shutdown were incorporated into the control system. Two accelerometers, one each for the $\mathrm{x}$ and $\mathrm{y}$ directions, to react to derailing events, were also installed and connected to the automated shutdown.

I am not going to comment on the power plant as it existed in the as-delivered state from SNL, as I did not see it in that form. I will say that the "revamped system seems to be operating very well, however. 
Most of the safety questions have been answered in Canada, but in the US, the locomotive would be run through the SAE regulations for the automobile industry.

The biggest differences in safety considerations are not US vs. Canada; they are metal mines vs. coal mines.

\section{Why are shock absorbers needed specifically for the hydride? Is there a similar situation with battery-powered mining locomotives?}

The shock absorbers are there for both the hydride and the power plant. SNL had designed the locomotive for a laboratory environment. When shaker tests were done, parts were coming loose. So shocks were installed. Battery-driven locomotives do not need shocks.

If a locomotive specifically designed for a mine were being built today, they might put shocks under the power plant, but probably would not need it under the hydride bed. There are baffles in the bed that prevent settling. Mr. Barnes then went on to say that a well designed locomotive would probably not need shocks.

It appears that Mr. Barnes is on the fence as to whether shocks are needed (it appears to be a close call). No time is wasted criticizing all SNL-designed and built components, however.

3. Please explain why the vehicle must weigh four tons, and that you need to add ballast to get there. In the future, would the locomotive be designed differently, so that it could be lighter?

It's all about traction; you need the weight. They add $2500 \mathrm{lbs}$ of ballast to equal the battery weight. They could add even more to help with the traction problem.

\section{At what temperature does the hydrogen desorb from the hydride?}

It desorbs at "all temperatures". The desorption rate is a function of temperature. Since it "dead-ends" to the fuel cell, you can use the fuel cell heat to increase the desorption rate.

\section{Does the hydrogen capacity of the bed decrease with cycling? If so, how much?}

As long as there is no moisture contamination, the capacity does not decrease. Even 6000 cycles are possible. In reality, however, there generally is moisture contamination eventually, and the capacity will decrease.

6. What is the source of hydrogen for the tests? Is purity an issue? Is it expected that the same type of hydrogen source would be used in commercial applications? 
Purity is an issue, dictated by the fuel cell stacks. They currently are using $99.995 \%$ pure hydrogen in bottles.

In a commercial venture, they plan to make hydrogen with an electrolyzer. It's a matter of cost effectiveness. In the US, a "6-pack" of hydrogen bottles costs about \$350. Mr. Barnes says that they can make it cheaper. In a commercial application, they would need about $100 \mathrm{~kg}$ of hydrogen per day.

There is no plan to make hydrogen from steam reformed natural gas.

\section{What happens to the wastewater (fuel cell output)?}

There is only a mist that comes out. There is no real wastewater.

Even if there were, it would be insignificant. The mine is quite wet. Walking in the rail bed behind the locomotive makes one definitely appreciate the fact that one is wearing high rubber boots.

\section{What were the reasons for two fuel cell stacks rather than some different design?}

Vehicle projects had calculated that they needed about $14 \mathrm{~kW}$ of power, and $8.5 \mathrm{~kW}$ stacks were available.

\section{How does the noise level in the fuel cell vehicle compare with a battery vehicle?}

Tests showed maximum noise levels of about 80 decibels (db) compared to background levels of $73.4 \mathrm{db}$. So the fuel cell locomotive was contributing about $6.6 \mathrm{db}$. Even this level was reached only during the one-second-long hydrogen purge. Real operation is at about $5.4 \mathrm{db}$.

When you listen to the locomotive as it is operating in the mine, the only thing you really hear are the wheels on the tracks.

\section{How is the hydrogen vented during the purge cycle?}

It vents through an air filter/diffuser that brings the hydrogen concentration down below the newly required $12.5 \%$ of the LEL.

\section{Please provide a brief description of a typical daily cycle for the locomotive, including the recycle of the hydride bed.}

The typical daily cycle is basically what we've seen. The locomotive goes to the chute, loads with ore or ore waste and then goes to the other chute for processing. This is repeated all shift long. At the end of the shift, the hydride bed is removed from the locomotive and taken up to the surface in a "shaft case". It takes about a half hour to 
remove the bed, bring it to the surface, and drive it to the refueling location. It takes about an hour to refuel. The next morning, it takes about a half hour to lower the bed down the shaft and reinstall it.

The loading, hauling, and unloading of ore is probably very typical, although ideally they would want to haul 5-6 cars instead of 3. The refueling right now is hopefully very atypical. Mr. Barnes stated that eventually they would want to have an electrolyzer operating in the mine. Being able to produce (or at least store) hydrogen at the working levels of the mine is, I believe, very important. There will be many logistical, and especially, safety issues that need to be addressed for this to happen.

\section{Please explain "fuel cell" vs. "fuelcell”.}

The single word version comes from the Fuelcell Propulsion Institute, another partner in this venture, and one that is closely associated with Vehicle Projects, Inc. The Institute decided that they would use the single word version; it would be an "unofficial trademark".

Perhaps they ought to make it official. Right now, it looks like a typo.

\section{What did the tests in Val d'Or show? Are there any problem areas?}

The tests showed the competency of the entire system, especially with the recent changes (new stacks and PLC). The safety measures were verified as well. The locomotive was shown to have more than adequate power as it pulled five cars underground. Mr. Barnes also stated that if the locomotive had adequate weight for the necessary traction, it would have been even more productive.

Mr. Barnes indicated that there were no problem areas. He stated that they even did an "inadvertent crash test" and one time the brushes fell out of the motor. Both times the power plant survived. It is "a very robust power plant."

\section{Additional Items:}

For commercial applications, the power plant and bed will need to be streamlined according to Mr. Barnes.

The group paid $\$ 5 \mathrm{~K}$ per $\mathrm{kW}$ for the fuel cell. To make it work as a commercial venture, the cost has to be one-fifth of that.

Late in the day (while we were observing the hydride bed recharging) the miners told us that the locomotive had hauled 50 cars that day, and it was not "a great day". Not surprising since the miners "wasted" quite a bit of time for our demonstration. During the approximately three hours that we were down the shaft, only six cars were hauled. A round trip generally only takes about ten minutes. 
Mr. Barnes and I did a quick calculation: 50 cars of ore at 4 tons per car, 0.45 ounces of gold per ton of ore amounts to 90 ounces of gold. At a gold price of about $\$ 300$ U.S. per ounce, this amounts to $\$ 27,000$ of revenue for the one subnormal shift.

After the completion of the locomotive project, Vehicle Projects will turn in earnest to their "loader" project. This is the installation of a fuel cell on a mining loading vehicle. It is here where Vehicle Projects hopes to make a real dent in the market. While the locomotive uses $14 \mathrm{~kW}$ of power (it has a $17 \mathrm{~kW}$ capacity) the loader requires about 100 $\mathrm{kW}$. The only real competition is diesel power, which, for underground mining, represents a huge ventilation problem. For the loader, Vehicle projects will be using an Elphinstone $100 \mathrm{~kW}$ power plant, on which they are currently doing the analysis. Elphinstone is an Australian subsidiary of Caterpillar.

The locomotive testing will continue, especially testing the longevity of the fuel cell. There is also a plan to do a straight-up comparison between the fuel cell and battery pack powering this locomotive.

The locomotive, following the Balmerton run was heading to Reno where it would be eventually combined with the loader and a fueling station.

During the morning briefing, one of the mine management people mentioned that despite the fact that the miners really liked working with the locomotive, some of them had started calling it "the hydrogen bomb." The mine management people were not very happy with this. I would have to agree; it's worrisome even in a joke.

\section{Final Thoughts:}

This site visit was a unique experience in itself. Unless you're a miner, you don't find yourself at the bottom of a gold mine very often - especially in a remote part of Canada. More important, however, was the very real sense of excitement I felt when I saw that locomotive emerge from that tunnel for the first time. Here is a product of a DOE-funded hydrogen project that is performing a normal work function, and performing it exactly like a conventional mining locomotive, only with less noise and no emissions. All that is missing is a more efficient way to recharge the hydride bed, and better data keeping for the recharging process. The inability to haul more than three cars was disappointing. Happily, it's not specifically a hydrogen/fuel cell problem, but it made the ability to see just how much a hydrogen fuel cell system (compared to a battery pack and to a diesel engine) COULD haul possible.

The upcoming work, developing a hydrogen fuel cell mining loader, with its much larger power requirements will be a challenge. The moving of the hydrogen regeneration system underground (in the form of an electrolyzer) will also present technical, economic, and safety challenges. But, not having the weight problem for storage makes the mine an ideal location for promotion of these technologies. 
A comment by Mr. Barnes that I felt was of extreme importance is that the miners using the locomotive seem to be quite happy with it. A system that will improve the miners' lot is always worth considering. 


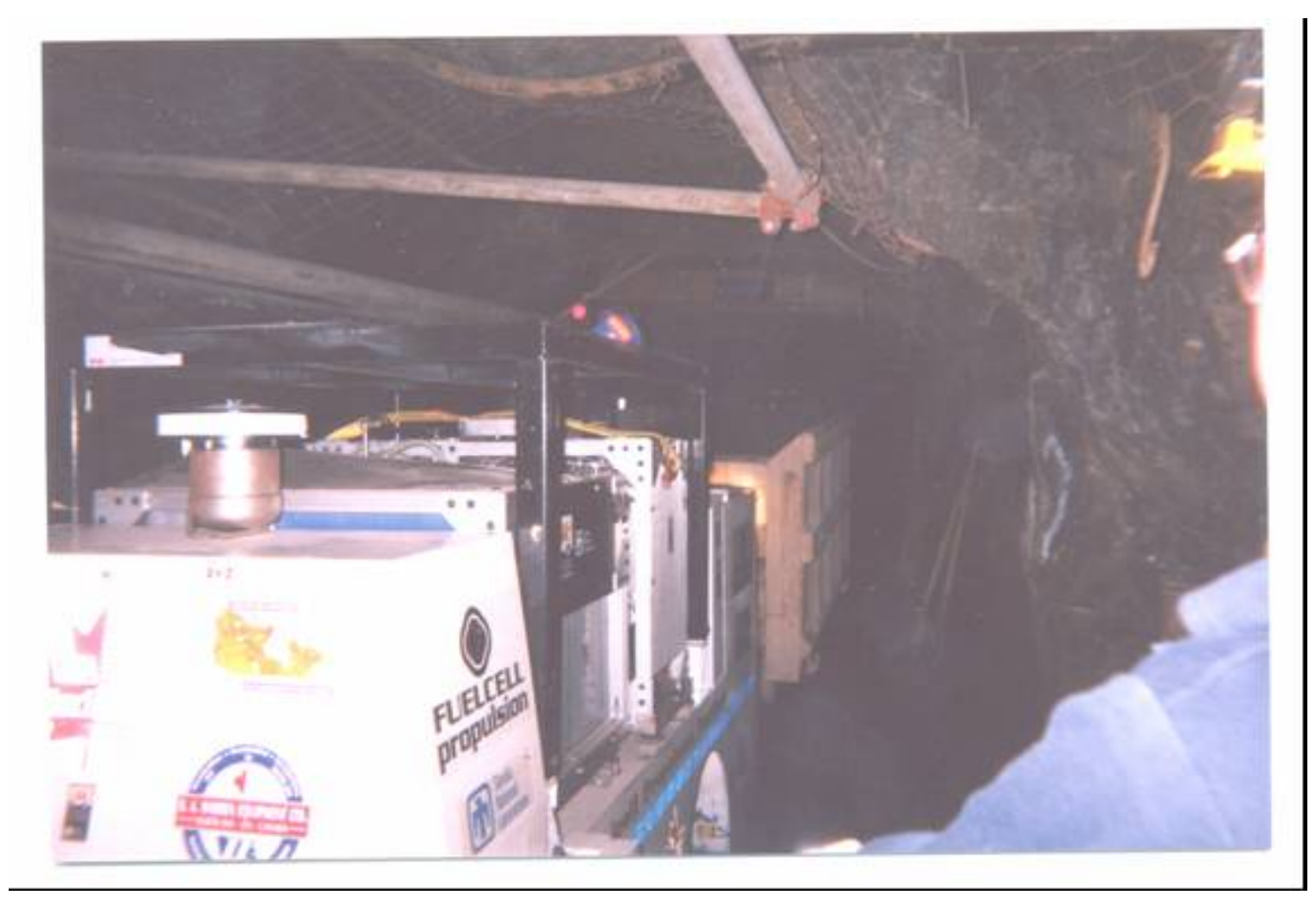

Exhibit 1. The fuel cell powered locomotive emerges from a tunnel, hauling three cars of gold ore. 


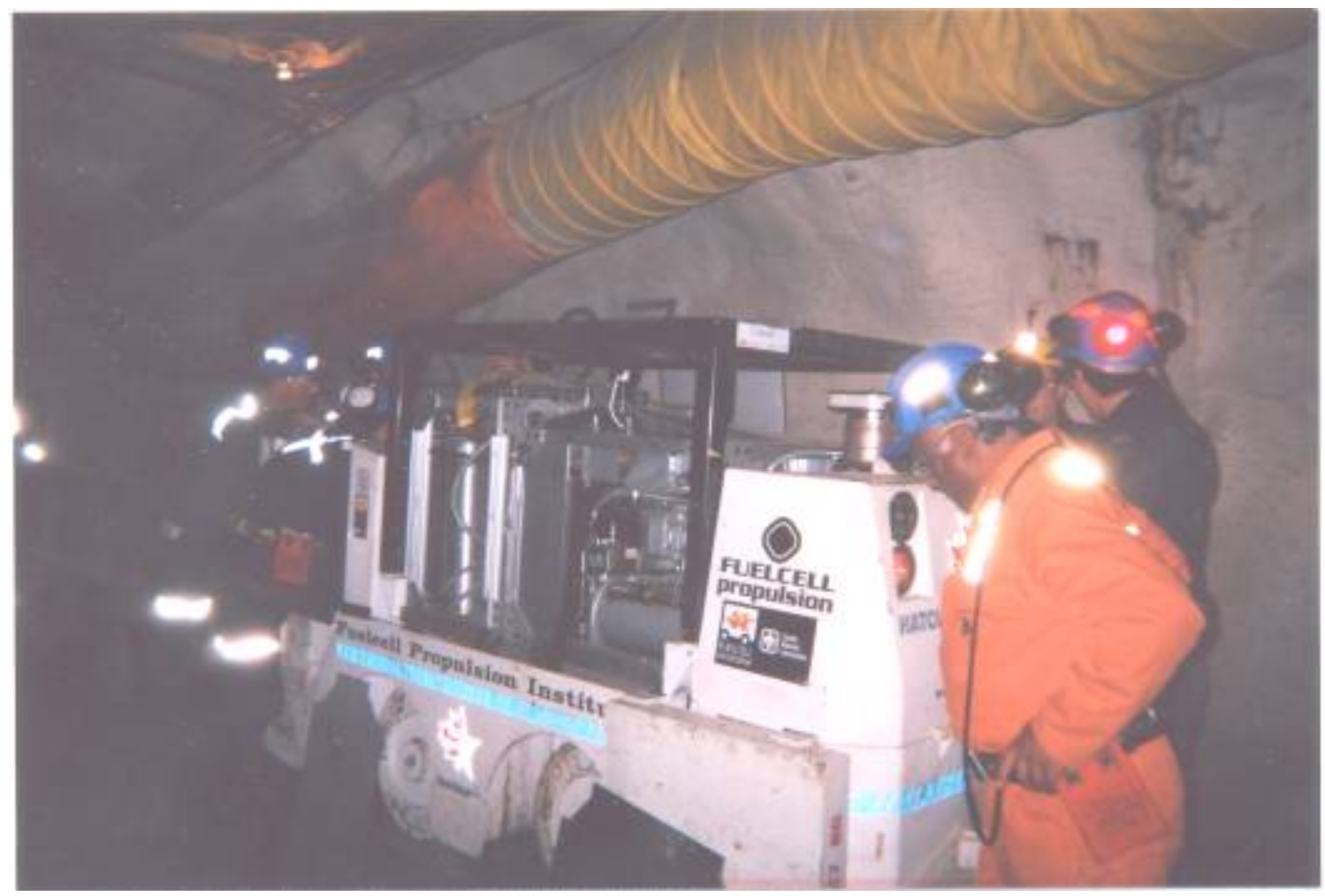

Exhibit 2. The fuel cell locomotive on display. 


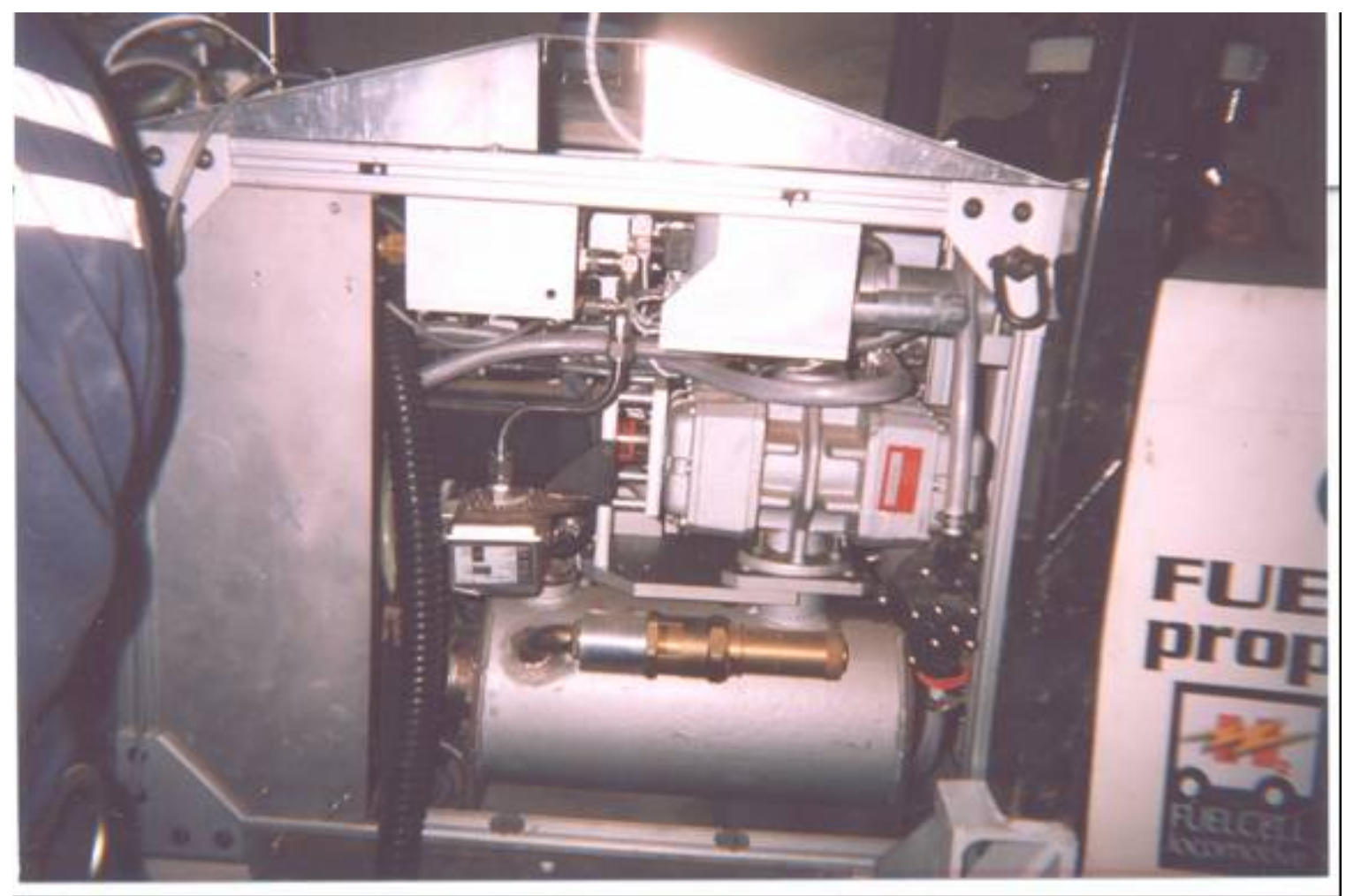

Exhibit 3. The power plant. The stacks are located in the rear, and cannot be seen. Much of what can be seen are heat exchangers. The hydrogen sensor is located at the apex of the funnel/hood-like structure at the top. 


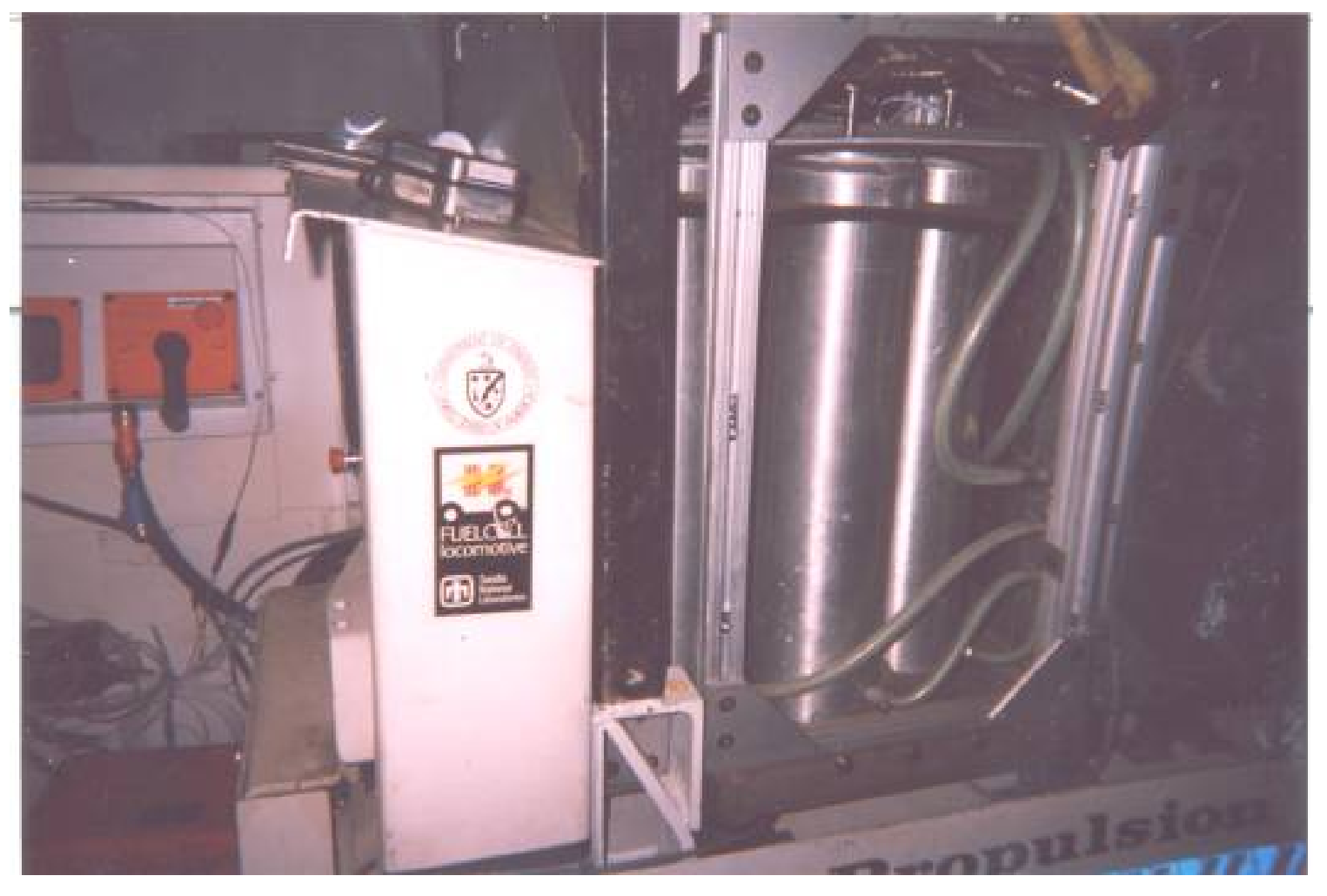

Exhibit 4 . The hydride bed. Three of the 16 cylinders comprising the bed are visible. 
Technical Evaluation Report

Project: Biomass Derived Hydrogen From a Thermally Ballasted Gasifier

Company: Iowa State University

P.I.: Dr. Robert Brown

Site-Visit Date: December 10, 2002

Evaluation by: Edward G. Skolnik, Energetics, Inc.

\section{Summary:}

A research group at Iowa State University (ISU) is investigating the production of hydrogen (or a high-hydrogen-content gas from switchgrass using stored heat from combusting a small portion of the switchgrass to pyrolyze the rest of the biomass. ISU has a target of $\$ 8-10 / \mathrm{MMBtu}$ for the cost of hydrogen from this process.

Although ISU is concentrating on switchgrass, they have designed their system with two different feed systems and can thus process a wide variety of bio-materials.

A major part of this effort involves cleanup of the resultant raw gas, and the extraction of more hydrogen from byproduct tars and other hydrocarbons through a series of reformer and shift reactors.

I see the following strengths in the project:

- There is tremendous backing for biomass-based systems in Iowa. Thus, there is a large amount of experience with handling and processing biomass. A significant part of this experience resides at ISU and the Iowa Energy Center. This project benefits and builds on this experience.

- There is a lot of thought that has gone into this work. This is a complex multi step process (as can be seen from the schematics) involving a large number of operations. It appears that the project team has worked hard to consider both individual processes and systems, and to pick and choose when to work on individual units and when to integrate them into the overall system.

- The control system seems quite complete (although it would have been preferable to see the unit in operation)

- The entire cracking/reforming system appears to be a good way of maximizing hydrogen yield. Biomass in general does not contain a very large amount of hydrogen (generally $5 \%$ by weight, tops). Trying to reform the reactor products will tend to strip hydrogen from every remaining tar or other hydrocarbon. Plus, additional hydrogen is made from the steam in the reforming process.

I see the following items that need to be addressed: 
- There is at this time, no signs of any hydrogen purification process. The final product appears to be a hydrogen/ $\mathrm{CO}_{2}$ blend. If the plan is to use this product as a fuel cell feed (we'll assume PEM fuel cell) there will be a need to purge the blend of CO, which will still be present in concentrations too high for a PEM fuel cell after coming out of low temperature shift. ISU talks of making a "hydrogen-rich" gas. This would limit its applications, and also question if the "hydrogen program" - especially under hydrogen production is the right place for this project. Even a CO-free $\mathrm{H}_{2} / \mathrm{CO}_{2}$ blend would have storage issues if it were going to be, for instance stored in an on-board tank on a vehicle.

- The cracker/reactor system is worrisome at this time. It is not doing the most fundamental of processes - reforming methane. This needs to be investigated.

- Care must be paid to safety aspects of this system. For instance, LiF is stable, but we are looking at high temperatures. The possibility of leaks and the consequences of releasing molten LiF must be addressed.

- LiF melting point consistency (impurities getting into the material could change it) should be demonstrated.

- With a target set at $\$ 8-\$ 10 / M M B t u$ for the price of hydrogen from this system, economic assessments should be performed periodically to see if the target makes sense and is continuing to make sense.

\section{Introduction, Background, and Overview:}

I met with Dr. Robert Brown of the Center for Sustainable Environmental Technologies at ISU to discuss his switchgrass to hydrogen project. The meeting actually took place at the Biomass Energy Conversion facility (BECON) of the Iowa Energy Center. In a report on an earlier site-visit to ISU (when I visited Dr. Shihwu Sung's project in August 2002) I discussed BECON in some detail. The reader is referred to that report, if interested. Briefly, BECON is located in Nevada, IA, about 5 miles from ISU. The Iowa Energy Center is supported by Iowa rate payers, and funds not-for-profit groups. Dr. Brown uses the thermal reactor at $\mathrm{BECON}$ for his project.

Originally, this project was not a hydrogen project. Its goals were more generic, and involved only obtaining a high Btu gas from a variety of feedstocks. The hydrogen/switchgrass combination is a result of the interest in these areas by U.S. Senator Tom Harkin (D-IA).

Gasification of biomass is an endothermic process. Thus, a source of heat is a high priority. The ISU project draws its roots from a century-old process called "blow and glow" where hot coal was used to store heat, and from the Battelle hot sand indirect gasification process. Dr. Brown uses tubes containing $\mathrm{LiF}$ as a phase-change material to act as a heat ballast when immersed in the hot sand. Thus, a regular indirect gasifier is turned into a ballasted system just by dropping the LiF tube system into the bed. 
ISU's target for their "raw gas" is a heating value of about $450 \mathrm{Btu} / \mathrm{std} \mathrm{ft}^{3}$. This compares to natural gas at $1000 \mathrm{Btu} / \mathrm{std}^{3} \mathrm{ft}^{3}$ and typical gasifier product, which is generally on the order of $100 \mathrm{Btu} / \mathrm{std}^{\mathrm{ft}}{ }^{3}$. The target for hydrogen is $\$ 8-10 / \mathrm{MMBtu}$ at greater than $50 \%$ by volume. There is admittedly not a lot of hydrogen in biomass, but there is a lot of energy in biomass, some of which can be used to shift $\mathrm{CO}$ and thus get more hydrogen out of the water.

Elimination of contaminants is a major concern for the project. Dr. Brown believes that if he is planning to make hydrogen downstream of his raw gas, he'll need to have a clean system to prevent catalysts from being poisoned. Hence, in addition to tar and particulate removal, he is focusing on cleanup of ammonia, hydrogen sulfide, and $\mathrm{HCl} . \mathrm{H}_{2} \mathrm{~S}$ and $\mathrm{HCl}$ in particular will poison catalysts, and $\mathrm{NH}_{3}$ will be oxidized to $\mathrm{NO}_{\mathrm{x}}$ during shift processes.

\section{Status:}

ISU is currently running the pilot scale unit at BECON. It processes 5 tons of biomass/day, and uses an atmospheric fluidized bed for the heat ballast. A pressurized bed would be too expensive.

\section{$\underline{\text { Feed System }}$}

The system is equipped with two feed systems for multi-fuel capability. One is for "well behaved" fuels like wood chips and obsolete seed corn. (Obsolete seed corn refers to corn that can not be used for food - such as contaminated corn or seed that will not give a high enough germination rate) The second feed system is for hard-to-handle fibrous material, such as switchgrass. Aside from being a difficult feed material, switchgrass also produces a large amount of tar and particulate matter.

ISU is also currently working on the switchgrass feed system, but they are also looking at ballasted gasification of obsolete seed corn with a raw gas heating value of $390 \mathrm{Btu} / \mathrm{std}$ $\mathrm{ft}^{3}$. They are working with the seed corn so that they can continue operating the gasifier without complicating matters by using the switchgrass feed system.

So it's a matter of keeping both the tough-to-use feed system and the ballasted reactor going without having one interfere with the other. That's a good way of doing it.

\section{Contamination Identification and Control:}

Much of the current work is focusing on gas conditioning and contamination removal. ISU uses hot gas cleanup to handle tar; you can't remove tar at low temperature and there is also a significant hydrogen concentration in the tar that can be captured. So, a catalytic steam reformer is used as a "cracker" to convert the tar to $\mathrm{CO}$ and hydrogen. However, prior to this step, it is necessary to remove other contaminants to keep from poisoning the catalyst. Thus, a moving bed granulate filter removes particulates, and a fixed bed of 
dolomite captures $\mathrm{H}_{2} \mathrm{~S}$ and $\mathrm{HCl} . \mathrm{NH}_{3}$ is reformed along with the tar, capturing some hydrogen as well.

Currently the particulate removal is being done at pilot scale. An isokinetic sampler has been installed (This pulls material out of the main stream at the same velocity that the main stream is moving. It is important for collecting an unbiased sample of particulates.) It will measure the performance of the moving bed granular filter. The sampling must be done at high temperature to prevent tar collection as well. ISU is currently experiencing some difficulties with this. The other contaminants are still being studied at a smaller scale, by removing a slip stream from the reactor and administering to the contaminants off line.

The characterization train is quite complex. Tars are being studied extensively. The system quantifies the amounts of tar, and distinguishes between soluble (in water) tars, light tars and heavy tars (the ones that condense at about $100^{\circ} \mathrm{C}-$ the ones that people think of as tars.) The train also includes a trace contaminant part, which is extremely labor intensive to use. It is currently being installed.

\section{Gas Conditioning:}

ISU sends their gasified biomass through gas conditioning steps - steam reforming (with the tar in the cracker) and two water shift steps. The reformer and water gas shift reactors are currently also being tested away from the main pilot system using a non-ballasted gasifier because it "simplifies things." Data from these tests are shown in Exhibit 1.

These data are a little bit hard to interpret. You produce $C O$ during steam reforming; $C O$ concentration should be increasing, not decreasing. Methane should disappear; it's only down about 20\%..I'm not quite sure what is going on here, but it doesn't look to be working quite right.

ISU is thinking of combining the particulate removal system, the guard bed, cracker, and water gas shift system into a single system. If they can pull $\mathrm{CO}_{2}$ off at the end, they can increase the system kinetics. The idea, says Dr. Brown is to have a filter with lime $(\mathrm{CaO})$ in it. The filter removes the dust, and the lime removes the $\mathrm{CO}_{2}$. If one uses engineered materials rather than gravel in the filter, it may be fine enough to remove trace materials $\left(\mathrm{H}_{2} \mathrm{~S}, \mathrm{HCl}\right)$ as well. So you'd wind up with fine particles containing the trace materials, and large limestone particles $\left(\mathrm{CaCO}_{3}\right.$, calcium carbonate from lime and $\left.\mathrm{CO}_{2}\right)$ which can be easily separated from one another.

\section{$\underline{\text { Other }}$}

Dr. Brown is currently using purge nitrogen to keep the system going and removing hot gas from the reactor. Later, they will work on a way to limit the amount of nitrogen they have to use. 
ISU is still trying to optimize the ratio of pyrolysis time to combustion time and is trying to find out why hydrogen production drops a little during the pyrolysis cycle (Exhibit 2).

\section{Tour:}

Dr. Brown and I were joined by two of his associates, Jared Smeek and Andy Suby for the close-up look at the system. They are both mechanical engineers. Dr. Brown also has an environmental engineer on staff who does the trace gas work, as well as several students who are studying the several system components. The system, unfortunately, was not operating the day I was there. Dr. Brown indicated that the students were studying. Although the tour was very informative, I am disappointed that the system was not running. A test run generally takes about 12 hours. It takes several hours just to reach steady state.

In order to aid the discussion, a schematic of the system is shown in Exhibit 3, a schematic of the sampling/gas characterization system is shown in Exhibit 4, and a blowup of the trace contaminant sampling system is shown in Exhibit 5. Note that the "product" of this process is a hydrogen $/ \mathrm{CO}_{2}$ mix. If the process is followed as shown in Exhibit 3, there will also likely be a reasonable concentration of CO present - a concentration too high for PEM fuel cell use, if that is the objective.

The feed system itself was designed by ISU. Switchgrass is first chopped and ground to enable it to be fed to the system (switchgrass stalks are over 6 feet high). A system of augers then feeds the switchgrass into a bucket elevator and then into a day hopper. An injection auger is used for feeding the switchgrass to the reactor. This is done at a high rate of speed so that the switchgrass does not preheat prior to it reaching the reactor. In addition, nitrogen is injected to cool the feed system which is subject to getting heatleak back from the reactor. They intend to water-cool, the feed system eventually, however.

Steam is generated in a special natural gas-fueled boiler. The boiler was installed by the Iowa Energy Center. The steam then goes through a super-heater. ISU is considering installing a producer gas storage unit to use instead of steam. Producer gas is an inexpensive mixture of approximately 25\% carbon monoxide, 55\% nitrogen, $13 \%$ hydrogen and 7 other gases. It is obtained by burning coal or coke in the generators with a restricted supply of air, or by passing air and steam through a bed of red hot fuel. However, here ISU is referring to the hydrogen/CO $\mathrm{C}_{2}$ blend that is the product of this process. You don't really need a lot of producer gas (or steam); the pyrolysis step only takes about 20 minutes.

The reactor/gasifier is a fluidized bed. Air comes in through the bottom, but the sand only bubbles about half way up. The $\mathrm{LiF}$ tubes are buried in the sand. The gasifier can process about 5-tons of material per day.

Following the reactor, the gases first go to a cyclone to remove the coarse particulates. If that is the only purpose of the particular test, the gas, cleaned of the coarse particulates 
simply goes though a pipe, out of the building and is flared. Alternately, the flare path can be valved off, and the gas goes through the moving bed filter. The gas is sampled on both sides of the filter, using isokinetic sampling. An ASTM standard was used to ensure isokinetic conditions (a certain number of "diameters" of straight pipe.)

For slip-stream sampling you don't have to worry about isokinetic conditions. The sample is taken right in front of the moving bed filter. The filter itself, where particulates are removed allowing tar and raw gas pass through, was only partially set up. Some sampling tubes are connected; some are not. Currently, the reactors downstream of the moving bed are not connected. They had previously been on line, when ISU was testing the non-ballasted gasifier, but were removed when the ballasted gasifier was installed. (We'll discuss the reactors briefly, later in this section.)

The analyzers for the gas contaminants are not yet installed. Real-time analyses are performed on the major gases. Hydrogen is measured on a Nova instrument, based on thermal conductivity. A single unit from California Analytical Instruments measures CO, $\mathrm{CO}_{2}$, and oxygen. $\mathrm{CO}$ and $\mathrm{CO}_{2}$ are measured by a non-dispersive infrared (NDIR) technique, while oxygen is measured by a fuel cell analyzer technique. (Perhaps surprisingly, Dr. Brown didn't know how this worked. - I would think the name itself would pique ones interest. It is simply an electrochemical system where oxygen is reduced (by water) at the cathode, and oxidizes a metal (usually lead or cadmium) at the anode. The measurement of the resulting current is a measure of oxygen concentration.)

There is also a micro gas chromatograph (GC) that measures these species over a 30 second period, following a 2.5 minute delay. Dr. Brown indicated that the real-time and $\mathrm{GC}$ systems compare well with one another.

The Iowa Energy Center "informally" supplied the hardware and software for the monitor/control system. A schematic on the computer shows all the control points and covers the entire system. Some sample control parameters include:

- Inlet temperatures

- Bed temperatures

- Steam flow rate

- Temperature at cyclones

- Temperatures at ten levels in the moving bed filter (they should all be uniform)

- Filter feed rate

- Pressure at various pressure taps

One can get trend information on all temperatures, pressures, gas analyzers, etc. All the data is then moved to an Excel spreadsheet for data handling.

As stated earlier, the reactors (tar cracker, shift reactors) are not on line, but were sitting in a different part of the room. All I could see were four grey boxes (including the guard bed, which is more of a limestone filter than a reactor, but looks the same from the outside.) This is appropriate because the reactors are identical, with the only variables 
being flow, temperature, and catalyst. For instance, the cracker uses a nickel catalyst, the high temperature shift reactor uses an iron/chromium catalyst, and the low temperature shift reactor uses a copper/zinc catalyst.

We earlier voiced our concern about the ability of the reactor system to reform methane. Dr. Brown agrees, but pointed out that it is doing a good job on getting rid of tar.

\section{Questions and Answers:}

Following the tour, we discussed the questions that I had sent Dr. Brown prior to my arrival. These are reproduced here, in bold type. Dr. Brown provided answers during our discussion, and these are displayed here in normal type. My comments added to many of the questions during my later analysis and assessment are shown in italics.

\section{Please discuss in detail an overall cycle that includes both pyrolysis and combustion portions.}

The "real" reaction is the pyrolysis; combustion just brings the reactor up to temperature. They cycle between combustion and pyrolysis (see Question 2, below) but the combustion portion makes up a very small fraction of the process; most of the biomass is consumed in the pyrolysis portion.

The cycle is also shown in Exhibits 3-5, and was discussed in the Background and Status sections.

\section{Why was LiF chosen as the heat ballast?}

Dr. Brown was looking for a material that would have a melting point in the $1500-1600^{\circ} \mathrm{F}$ range, that would melt during combustion, and then have available heat during pyrolysis. He first looked at "Muntz Metal", a copper/zinc alloy, but found that the zinc diffused into steel. So he did a literature search, and found LiF. He then did a thermodynamic calculation and showed that fluorine gas would not be formed even if there was a leak.

I believe LiF is quite stable, but there are high temperatures here. While fluorine gas may not be formed if there is a leak, some attention needs to be paid to what would happen if there were a leak. Would molten LiF escape, and where would it go, for instance.

ISU uses a fluidized bed of sand (which provides for very good heat and mass transfer), and place tubes filled with LiF into the bed. They add enough air to fluidize the bed and to burn a small amount of biomass fuel to melt the LiF. Once the LiF is melted, they switch from air to superheated steam to keep the bed fluid. As previously mentioned, they are also considering using producer gas instead of steam. At this point, they start adding a large amount of biomass, and use the heat in the $\mathrm{LiF}$ to run the pyrolysis reaction. 
I think that a demonstration indicating that the LiF stays sufficiently pure so that its melting point does not change would be in order.

\section{Your system was built with an additional hopper to accommodate multiple fuels. What fuels are anticipated?}

They have looked at "well behaved" biomass, that is, materials that flow, like obsolete seed corn (meaning shelled corn that would no longer germinate) and wood chips. They also look at "ill-behaved" biomass like switchgrass, corn stover, oat hulls, and wheat straw. They've even looked at bull manure - but not in the ballasted system.

Their proposal is specifically for switchgrass, but their reactor can work with a variety of feedstocks if it can work with switchgrass.

\section{Are any catalysts being used for the combustion and/or pyrolysis processes?}

No. Catalysts don't work in the reactor because of the contaminants in the switchgrass.

The catalysts are downstream.

I suppose that if it became necessary the switchgrass could have its contaminants removed prior to being fed to the reactor - sort of like a coal beneficiation step for switchgrass. As long as combustion and, more important, pyrolysis are not compromised by not having a catalyst, I suppose, it's moot.

\section{How generic is switchgrass? What differences in types and amounts of impurities are anticipated? Is there a significant "ash" or alkali component? If so, how is it handled?}

Dr. Brown called switchgrass a "good proxy" for many herbaceous materials It is very fibrous and has a high alkali content. There are several varieties of switchgrass, but they all belong to the same species, Panicum virgatum. The varieties differ by location, soil conditions and amount of alkali and other contaminants. The variety that ISU is using is Cave-in-Rock. This switchgrass grows well in the Midwest in higher humidity areas, growing best under average rainfall and temperature conditions. The soil should be fertile and should drain well.

Switchgrass producers are going to harvest it when it is dry enough, so the biomass fuel producer is going to have to take what he can get. If biomass-based fuel becomes big enough and important enough a usage for switchgrass the fuel manufacturers may be able to drive its availability.

There is significant alkali in switchgrass, about $2 \%$, but it is of a moderate level when compared to other biomass. It is handled by the addition of limestone to the bed. 
I wonder to what degree alkali might foul any part of the system upstream from the limestone bed over time. Could there be problems with having to clean out narrow passages?

\section{What is the purpose of a non-isometric sampler?}

A non-isometric sampler will allow one to obtain a better measurement of particulate matter. Particulate matter is measured isokinetically. The slipstream for gas sampling, however is not measured isokinetically. Gas sampling is not a function of particulate matter.

An isokinetic sampler is discussed above. ISU should just call it an isokinetic sampler, not a non-isometric sampler.

\section{You indicate in your FY 2002 Annual Review Report that you have designed new reactors to obtain better leakage control. How were the previous leak problems manifested?}

One of the reactors had cracked. In addition, gaskets were leaking. ISU found the problems when their gas chromatograph was detecting oxygen. In addition, tar was being oxidized. They have fixed the system, and no longer have a problem. They are now using a new metal jacket system. In addition, the new on-line oxygen detector looks for leaks routinely now.

\section{What are PID loop controllers?}

It stands for Proportional Integral Differential Loop Controllers. One can build a control system by integrating systems, differentiating them, or both.

\section{Are the reformer and shift "conditioning system" mainly for removing tars and similar condensates or for increasing hydrogen yield?}

The conditioning system serves both purposes.

This was something that was not obvious from my reading of ISU reports prior to our meeting, but became perfectly clear once we started talking.

\section{You are performing detailed analyses on $\mathrm{H}_{2} \mathrm{~S}, \mathrm{HCl}, \mathrm{HCN}$, and $\mathrm{NH}_{3}$. Are these typical byproducts of switchgrass gasification? How are unacceptably high amounts of these materials handled (removal as opposed to detection)?}

These byproducts are typical for any biomass. Nitrogen and chlorine are part of the plant growing mechanism. Sulfur is also usually present. These materials are harmful to catalysts, and sulfur, of course, must be minimized for fuel cell usage. Currently, the process involves a "guard bed" - primarily limestone used to scavenge these byproducts. The plan is to replace the guard bed with a moving bed combined with sorbent injection. 
Detection was emphasized in the current work, because Dr. Brown needed to show that he could measure the byproducts before looking at controlling the byproducts.

Showing the ability of the system to reduce the concentration of contaminants to an acceptable level should be the next key step for this project.

\section{How do the detection methods differ from analyses that would be performed for coal gasification, or even coal combustion?}

The detection methods parallel what would be done for coal combustion and gasification.

It is a good parallel to follow.

\section{Have the feasibility tests now been performed in the overall system? What have} they shown?

They have been performed for all the subsystems. The next step is to bring the entire system together.

\section{Have any estimates for the cost of hydrogen from switchgrass by this process been made yet? If so, what are they indicating?}

When ISU wrote the proposal, they did a back-of-the envelope calculation and came up with about \$10/MMBtu. They have not yet worked out a detailed economic analysis.

Switchgrass itself costs about \$3/MMBtu (delivered cost). A big part of this is the cost of the land to grow the switchgrass. By comparison, Powder River Coal (a sub-bituminous, low sulfur, Wyoming Coal) costs about \$1/MMBtu, delivered.

I hope these numbers aren't overly optimistic. It seems a bit low for a non-zero cost feedstock and a multi-stepped complex process - especially one that would not likely be done at extremely large scale. I would recommend that periodic economic analyses be made to ensure that they are staying on target.

\section{Final Thoughts}

Projects that fall into the "earmarked" category (as, I believe, this one does), are generally viewed with some degree of skepticism. However, when I visited this project, I was quite pleasantly surprised. I think that ISU has taken some very good steps toward a legitimate biomass process. That said, however, I am concerned as to where the product that they will be making, - a "hydrogen-rich" gas, with a high $\mathrm{CO}_{2}$ concentration - will fit in. If you are not planning to separate out the $\mathrm{CO}_{2}$, you're going to have to pay to compress and store it. That would be expensive in a stationary setting, and prohibitive on-board a vehicle. CO is also a concern. If you are going into a fuel cell, you're going to have to get rid of the $\mathrm{CO}$ - and there will be some left. The shift reactors won't take it 
down low enough. (Note that the results shown in Exhibit 1 only took it down to $0.18 \%$; you need to be in the 10 ppm range.) ISU needs to address these issues.

Most of the work that has been done so far, however, is quite good. The ballasted gasifier concept makes sense, and it seems to be applied well. I would, however, like to see some tests where they demonstrate that no impurities are getting into the LiF, and the phase change material is staying on temperature. Addressing safety/toxicity issues with LiF is also recommended.

ISU has plenty left to do to turn the components and sub-systems into a real system - but they appear to be on the right track. The reformer-train reactors aren't working well yet and need to be improved. And the progress toward the target cost of hydrogen needs to be continuously updated via economic estimates. 


\begin{tabular}{|l|l|l|l|l|}
\hline $\begin{array}{l}\text { Gas } \\
\text { constituent }\end{array}$ & Raw gas & $\begin{array}{l}\text { Steam } \\
\text { reformer* }\end{array}$ & $\begin{array}{l}\text { High } \\
\text { temperature } \\
\text { shift reactor* }\end{array}$ & $\begin{array}{l}\text { Low } \\
\text { temperature } \\
\text { shift reactor* }\end{array}$ \\
\hline $\mathrm{H}_{2}$ (wol-\%) & 8.5 & 19.4 & 23.7 & 27.1 \\
\hline $\mathrm{CO}($ vol-\%) & 14.5 & 8.9 & 1.4 & 0.18 \\
\hline $\mathrm{CO}_{2}(\mathrm{vol} \%)$ & 18.1 & 20.1 & 26.8 & 27.2 \\
\hline $\mathrm{CH}_{4}(\mathrm{wol} \% \%)$ & 4.3 & 3.5 & 3.4 & 3.1 \\
\hline
\end{tabular}

*Concentration exiting the reactor

Exhibit 1. Gas conditioning results from switchgrass gas. Data provided by ISU. 


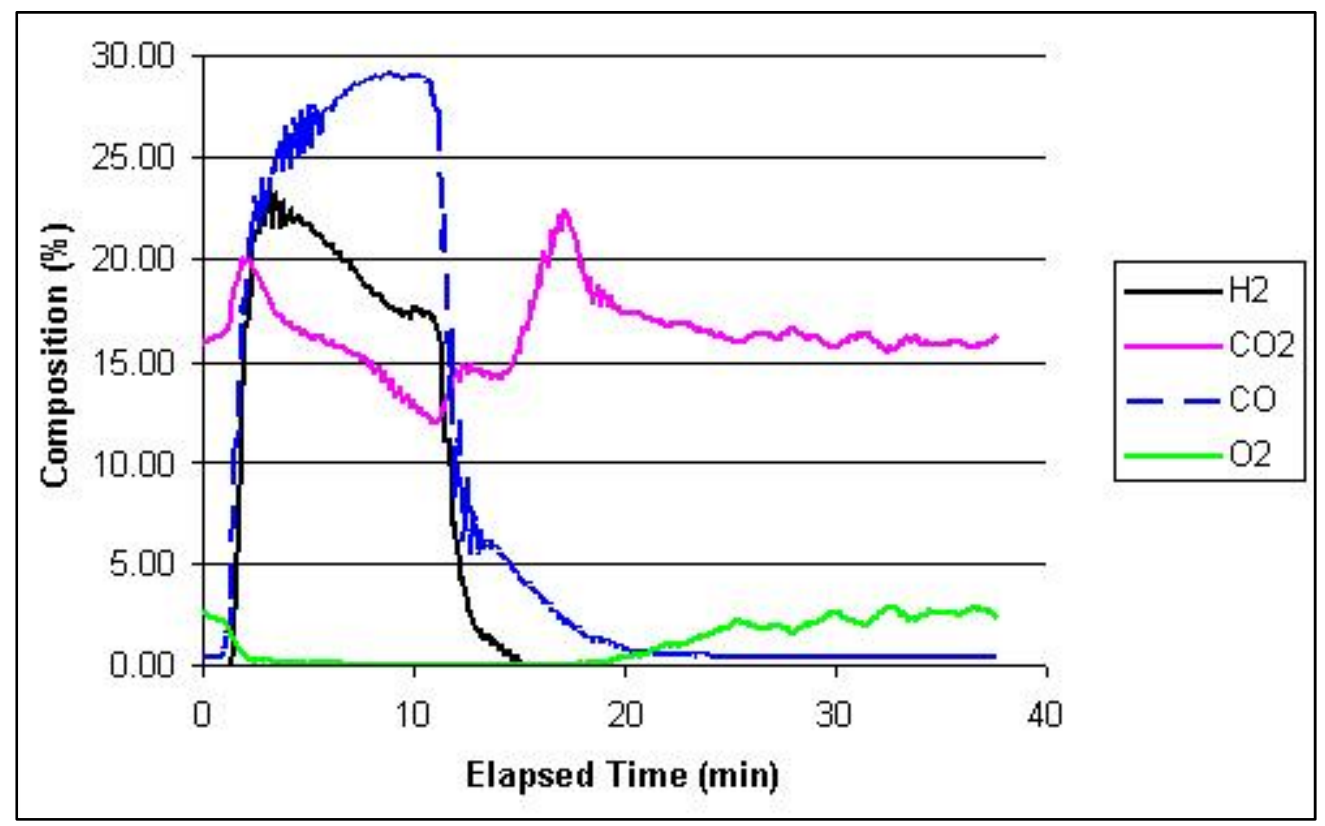

Exhibit 2. Single cycle of biomass pyrolysis process, showing dropoff of hydrogen concentration during cycle. (Real-time gas analyzer data; redrawn from ISU figure.) 


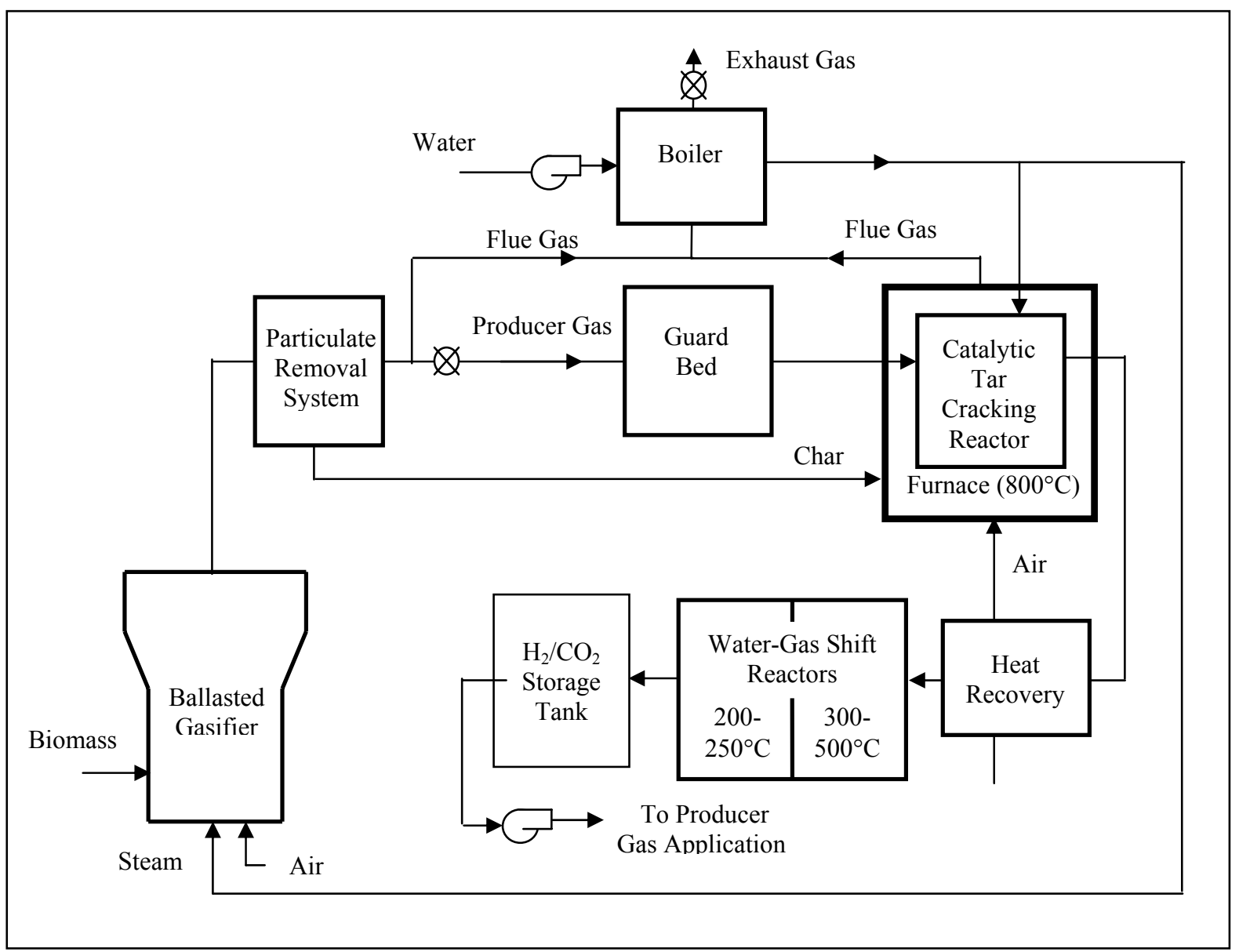

Exhibit 3. Schematic of the Ballasted Gasifier System, ISU Drawing 


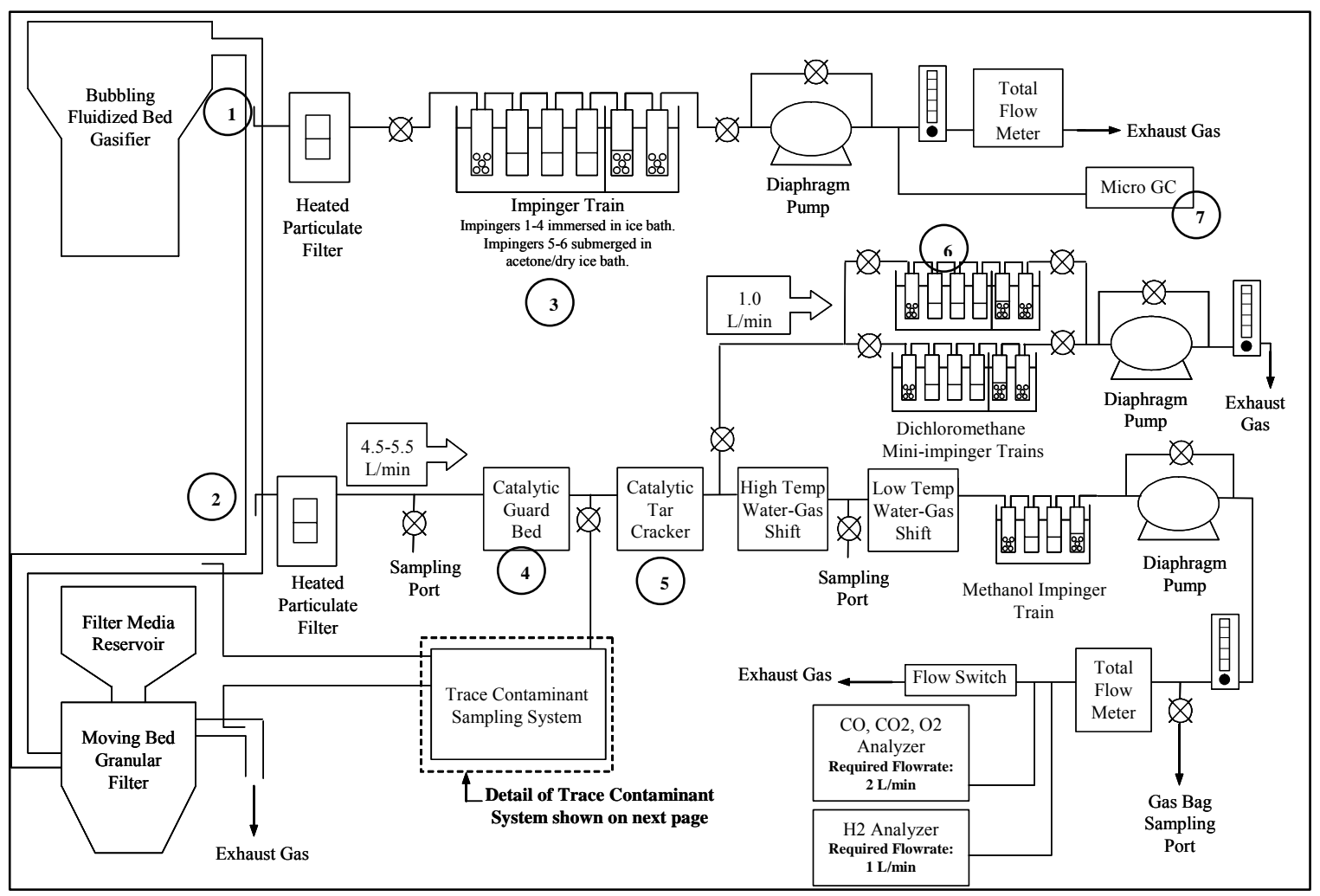

Exhibit 4. Gas Characterization and Sampling System, ISU Drawing, Notes added by EGS.

1. Sampling port quantifies raw gas (isokinetic sampling)

2. Slip-stream for gas conditioning

3. Collects water and tar for tar quantification; distinguishes between soluble tars, light tars, and heavy tars.

4. Limestone bed; gets heavy tars, $\mathrm{H}_{2} \mathrm{~S}$, and $\mathrm{HCl}$

5. A steam reformer (steam is injected)

6. Quantifies tar

7. For determination of heating value 


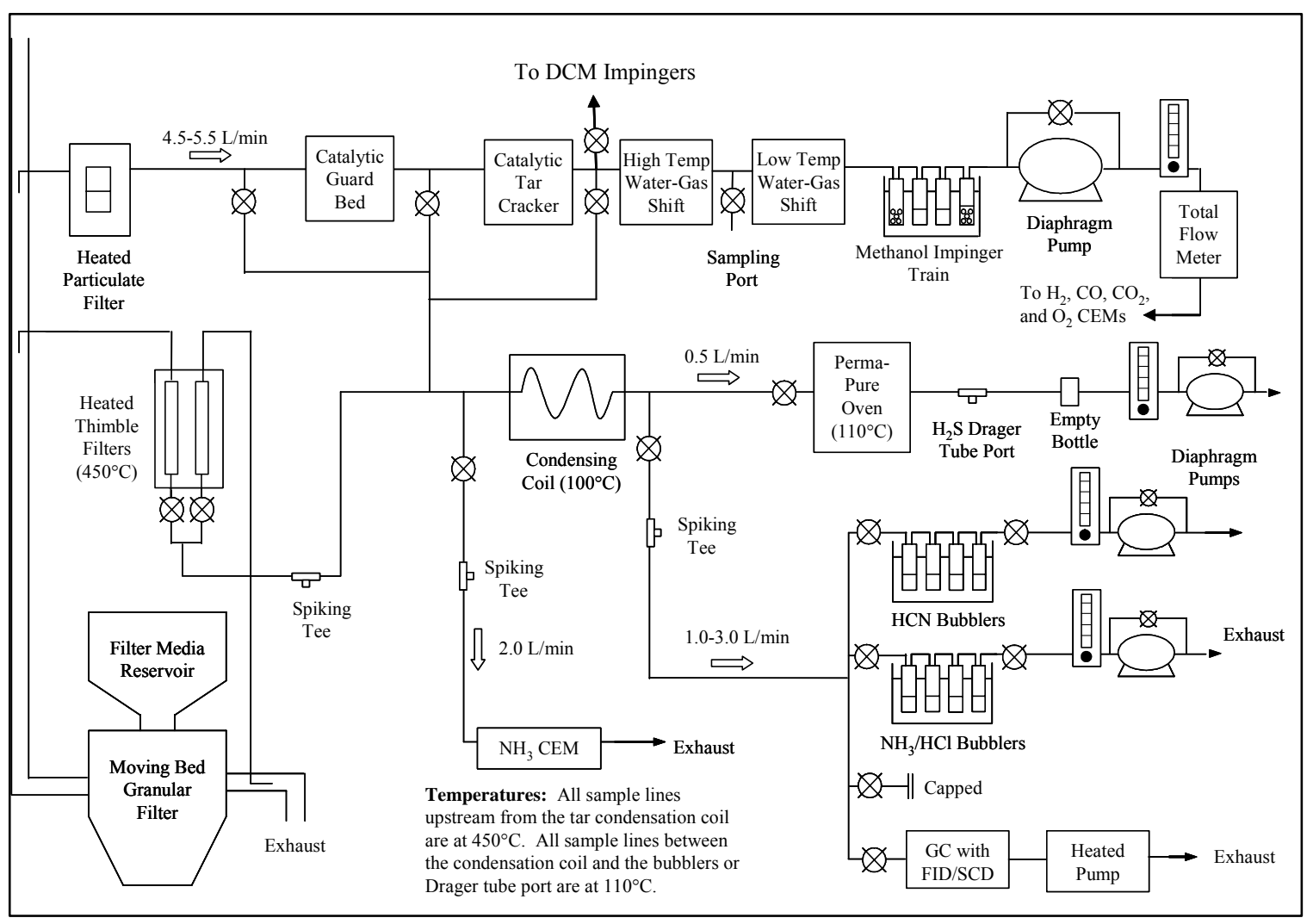

Exhibit 5. Trace Contaminant Sampling System, ISU Drawing 
Technical Evaluation Report

Project: Complex Hydrides for Hydrogen Storage

Company: Florida Solar Energy Center/University of Central Florida

P.I.: Dr. Darlene Slattery/ Dr. Michael Hampton

Site-Visit Date: March 17-18, 2003

Evaluation by: Edward G. Skolnik, Energetics, Inc.

\section{Summary:}

The Florida Solar Energy Center (FSEC) and the University of Central Florida (UCF) are conducting research on the development of high hydrogen content reversible hydrides for hydrogen storage. They had put together a list of complex hydrides of the type $\mathrm{M}_{\mathrm{x}} \mathrm{N}_{\mathrm{y}} \mathrm{H}_{\mathrm{z}}$ where $\mathrm{N}$ is either $\mathrm{Al}$ or $\mathrm{B}$, and $\mathrm{M}$ is $\mathrm{Na}, \mathrm{Li}, \mathrm{Ca}, \mathrm{Mg}, \mathrm{Ti}, \mathrm{Zr}$, or Fe. A criterion was that the weight percent hydrogen would be at least $7.5 \%$. FSEC planned to buy the hydrides that were commercially available, and prepare the others in the laboratory using literature preparations when available and developing their own preparation process for those that had never been reported. As materials become obtained or made, they are purified and characterized as to their ability to take up and shed hydrogen. Thermodynamic and kinetic properties are measured. Catalysts are also evaluated to assess their effectiveness in the hydriding/dehydring process.

I see the following strengths in the project:

- A characterization project that lays out all the highly hydrogen-loaded complex hydrides and characterizes them is a good thing. If we (the hydrogen community) are going to pursue complex hydrides as a hydrogen storage option, the more information and the more viable candidates we have, the better. I am also happy that FSEC has decided to concentrate, for the time being, on a few candidates rather than trying to synthesize a multitude of them. The multitude of candidates was one of the things I had a big concern about prior to the site visit.

- The FSEC/UCF approach of using DSCs and TVAs as primary characterization tools appears to be a sound method; it focuses on thermal effects, and that is a good focus.

- The PIs seem to be well versed in the work of others in the field.

I see the following items that need to be addressed:

- Seeing the variety of results that have been obtained so far, I believe purification of the hydrides is necessary prior to characterization.

- Care must be taken that the ball-milling process does not contaminate the samples and skew the data. 
- A lot of the data obtained to date is not yet readily explainable (differences between manufacturers, ball milling vs. doping, etc.)

- Not much has yet been done in terms of looking at multiple recycling. This needs to be done.

\section{Introduction and Background:}

Researchers from FSEC and the university of which it is an affiliate, UCF, have been buying or preparing, purifying and characterizing complex metal hydrides in an effort to identify species that will reversibly take up quantities of hydrogen greater than $7.5 \%$ by weight. They started by listing hydrides that meet the $7.5 \%$ criterion, and then determined which hydrides they could buy commercially, which they could make via a process from the literature, and for which they would have to develop a process. FSEC's plan is to characterize the hydrides via differential scanning calorimetry (DSC) and thermo volumetric analysis (TVA) in order to identify the best candidates for reversible, lowtemperature hydriding/dehydring of large percentages of hydrogen.

I met with the co-principal investigators, Dr. Darlene Slattery and Dr. Michael Hampton as well as three other members of their team. Dr. Slattery is a Senior Research Chemist at FSEC, and also holds a staff position at UCF. Dr. Hampton is an Associate Professor of Chemistry at UCF and holds a staff position at FSEC. The team also includes Dr. Nahid Mohajeri, a Research Chemist at FSEC, Mirna Franjik, a graduate student at UCF, and Edgar Perez, an undergraduate student at UCF. I spent about a day and a half with the FSEC/UCF team and toured their laboratories at FSEC in Cocoa, FL, and UCF in Orlando.

It should be noted that FSEC is a recognized Center of Excellence both nationally and for the state of Florida.

\section{Status:}

The group has made some definite progress with hydrides that are available commercially, and has presented much interesting data. Difficulties, however, have arisen in attempts to reproduce chemical syntheses of materials reported in the literature and in attempts to develop original syntheses.

\section{Questions and Answers:}

Prior to my visit, I sent Dr. Slattery a list of questions based on results I had received to date, mainly from the 2002 Annual Review Report. I subsequently received a draft final report, and added some additional questions. Both sets of questions were answered in writing and we also discussed the questions and answers in detail. This is all reproduced here, with the questions indicated in bold, written answers reproduced "verbatim in quotes", our discussion shown in normal type, and my comments added to many of the questions during my later analysis and assessment shown in italics. 


\title{
1. Why is no purification performed on the commercially available complex hydrides $\left(\mathrm{L}_{1} \mathrm{AlH}_{4}, \mathrm{LiBH}_{4}, \mathrm{NaAlH}_{4}\right.$, and $\left.\mathrm{NaBH}_{4}\right)$ ? Are the nature of the impurities and how they could effect hydriding/dehydriding understood?
}

\begin{abstract}
"Many of the literature reports published so far use the hydrides without further purification. We did not figure the excess Al likely to be a contaminant to be a serious problem and felt that obtaining data quickly was more important. We do indeed plan to purify and repeat trials to compare."
\end{abstract}

The FSEC team needs to show that the major impurity is indeed aluminum. It forms a hydride at any rate.

The argument about a lot of the impurities likely to be elemental aluminum is probably good; I have a concern, however about data from a sample that is only $85 \%$ pure, regardless of the impurity. In addition, the major impetus of this work is characterization. This is always best done on a pure sample. I will be interested in the purification process and in the subsequent results.

\section{Please explain the meaning of "flowing atmospheres."}

"The DSC is set up so the atmosphere in the cells can be either static and raised above or lowered below ambient pressure. Alternatively, the atmosphere can be at ambient pressure and flowing through the cell. This configuration allows the sample cell to be interfaced with a GC for evolved gas identification."

The configuration of the DSC has the furnace on its side. FSEC has built special cells made of Hastalloy C-22 (a high-performance alloy that is not subject to embrittlement.) The cells can either be pressurized to as high a 5000 psi (FSEC usually uses $2000 \mathrm{psi}$ ) or they can be used in a flowing system, hooked up to a gas chromatograph. The flowing atmosphere system is what they generally use. Thermocouples are set all around the sample.

\section{How does FSEC stand at this time on the ability to reproduce complex hydrides whose existence have been claimed in the literature, but are not available commercially?}

"We have had some success at reproducing reported syntheses of $\mathrm{Mg}\left(\mathrm{AlH}_{4}\right)_{2}, \mathrm{Mg}\left(\mathrm{BH}_{4}\right)_{2}$, and $\mathrm{Ca}\left(\mathrm{BH}_{4}\right)_{2}$. Other syntheses have resulted in insignificantly small product yields or overly contaminated products."

Dr. Slattery has described the success as "limited." Materials that are only reported in the literature once are problems.

I am not surprised that they have problems with old literature syntheses. The chemical literature is loaded with inaccurate data-especially in synthesis. The reliance on this literature was a concern of mine as soon as I read about it. 


\section{Have any new hydrides (those for which a synthesis needed to be developed) been produced as yet.}

"Not as yet."

FSEC is working from both the wet chemistry and solvent free preparation methodologies.

Perhaps a non-reported synthesis will be more successful than a literature-cited process. At least there are no pre-conceived notions with syntheses that have never been reported on as yet.

I expressed some concern about the potentially unmanageable task of trying to synthesize all of the compounds that are mentioned in the FSEC FY 2002 Annual Review report. At the time of my visit, Drs. Slattery and Hampton had decided that they had likely been too ambitious in the number and identity of all the complex hydrides they were going to synthesize and study. They will look at $\mathrm{NaAlH}_{4}, \mathrm{LiAlH}_{4}, \mathrm{NaBH}_{4}$ and probably $\mathrm{Mg}\left(\mathrm{AlH}_{4}\right)_{2}$. They are including the sodium borate because Dr. Hampton has a good boron background.

This will turn the project into more of a characterization project than a synthesis project. This is probably a good thing, at least for now. Let's find out all we can about hydrides that do exist.

\section{For what "earlier DOE funded hydride work" was the Parr reactor used?}

"FSEC had a hydrogen storage program from 1988 until 1994. The original project was the chemical synthesis of $\mathrm{MgH}_{2}$, patterned after the pioneering work of Boris Bogdanovic. Probably the most valuable result to come out of that work was the discovery that it was possible to do a simultaneous synthesis/doping procedure that resulted in a product that was as active as Bogdanovic's but which was much easier (and cheaper) to produce.

"In 1991, in collaboration with Mike Hampton, work was begun on the synthesis of complex hydrides for hydrogen storage. We were interested in the potential of $\mathrm{Mg}\left(\mathrm{AlH}_{4}\right)_{2}$ because of its hydrogen storage capacity of $9.34 \mathrm{wt} \%$. Unfortunately, at the end of 1992, DOE refused to continue funding on that portion of the work because 'complex hydrides are not reversible'."

This work was part of the old DOE hydrogen program (under Russ Eaton). At that time, FSEC developed a new method to add nickel catalyst.

\section{What ensures that bits of steel from the ball mill is not getting incorporated into the material being ball milled? The balls, I assume, do wear down over time.}

“There is no guarantee that bits of steel aren't being incorporated into the ball milled material. In fact, there have been reports in the literature of iron being present in a previously ball milled sample. However, our XRD analysis has not supported this claim. We do have vial and balls made of tungsten carbide that we will be using to verify results." 
FSEC will use the tungsten carbide balls to verify results, but would not expect them to be used in a commercial application. Drs. Slattery and Hampton also indicated that if bits of iron do get into the sample, they would act as a catalyst, helping the hydriding.

The ball mills that FSEC uses are very small, and use only a small number (as little as two) balls (see "Tour" section). I am concerned with ball-milled material becoming contaminated with iron or similar materials both on the research and on the commercial scale. On the research scale, impurities in the medium can skew the results either positively or negatively. Neither is acceptable. On the commercial scale, it could result in inconsistencies as to the amount of hydrogen the metal hydride can store.

\title{
7. Has any attempt been made yet to re-hydride any samples? If so, how is this done?
}

\begin{abstract}
"Attempts were made to rehydride $\mathrm{LiBH}_{4}, \mathrm{LiAlH}_{4}, \mathrm{NaBH}_{4}$, and $\mathrm{NaAlH}_{4}$. The only success to date has been with the $\mathrm{Ti}$ loaded $\mathrm{NaAlH}_{4}$. The previously dehydrided material was heated to $120{ }^{\circ} \mathrm{C}$ and pressurized to over 600 psi with hydrogen (current pressure transducer does not read higher pressures but we have another and it will be changed shortly). The system was left at this temperature and pressure for 24 hours before being cooled to ambient temperature. Pressure was released from reactor and temperature program rerun.

"The DSC system has been limited to 200 psi due to the installed transducers. At this pressure, no re-hydriding has been observed. The instrument was just equipped with 2 new transducers that allow measurements up to 1000 psi so re-hydriding studies will now be repeated and more success is anticipated."
\end{abstract}

At the time of my visit, only $\mathrm{NaAlH}_{4}$ had shown a finite amount of re-hydriding. Some of the other materials $\left(\mathrm{LiAlH}_{4} \mathrm{NaBH}_{4}\right.$, and $\left.\mathrm{LiBH}_{4}\right)$ had been less successful. A small amount (about 1\%) of re-hydriding was observed, but Dr. Slattery says that she is unwilling to say that this is really re-hydriding.

Drs. Slattery and Hampton also mentioned that in one system where they ball-milled $\mathrm{NaAlH}_{4}$ with elemental titanium they found re-hydriding of $6 \%$. Since the expected twostep dehydriding reaction should only result in $5.4 \%$ hydrogen reduction, the speculation was that perhaps they were seeing some reversal from $\mathrm{NaH}$.

I have a tough time with that one. I can't see how these conditions could lead to making $\mathrm{NaH}$ a reversible storage system. I'd look to show reproducibility and then consider other explanations - maybe something involving the titanium.

\section{What method do you use, and what degree of success have you had, to ensure that the atmosphere you are working in is moisture-free.}

\footnotetext{
"All synthetic operations are carried out on the bench using Schlenk tube techniques. A vacuum/inert gas manifold has been set up inside a fume hood. Ultra pure argon gas is fed directly to the manifold.

"Procedures such as the loading of the reactor or ball mill are carried out within a glovebox that has a AtmosPure Regenerative Drying Train. System specs are for an atmosphere of <
} 
$5 \mathrm{ppm}$ water and $<1 \mathrm{ppm}$ oxygen. Glovebox is under argon at all times and system is regenerated regularly. "

The drying train includes Drierite, $\mathrm{P}_{2} \mathrm{O}_{5}$, and an oxygen scavenger.

Drierite is a brand of water-scavenging material that is primarily calcium sulfate. Phosphorus pentoxide also takes up water, making phosphoric acid. A Schlenk line consists of a manifold that has several stopcocks, valves or openings in addition to a connection to a vacuum source (typically a mechanical and/or diffusion pump). Having several ports on the line is convenient because several different flasks or reaction vessels may be used simultaneously. For example, gases can be vacuum transferred from one flask to another or several reactions may be run at the same time.

\section{Is a "high-energy" ball mill a stirred ball mill?}

"No. The high energy ball mill used is a Spex $8000 \mathrm{M}$ Mixer/Mill. In this unit, the motion of the mixing jar is such that the media move in a figure 8 pattern. The movement is rapid resulting in high energy milling. We also have a Fritsch Pulverisette- 5 ball mill. This is also a high energy ball mill and is not stirred. In this unit, the milling jar rotates on a turntable while spinning about its long axis in the opposite direction."

10. Have you used anything other than TVA and DSC to attempt to confirm the presence or absence of the species you are either synthesizing or hydriding?

"Yes. We also use AA, IR, and XRD."

The atomic absorption spectrograph and the x-ray diffraction system are located at Dr. Hampton's facility.

\section{In your discussion of the Sandrock et al paper, you mention that they discuss} $\mathrm{NaAlH}_{4}$ as reducing $\mathrm{TiCl}_{4}$ via $\mathrm{Na}^{+}$. Would like to discuss this further, if you have a copy of the paper. Do they give chemical equations?

Note: It should be $\mathrm{TiCl}_{3}$, not $\mathrm{TiCl}_{4}$. That doesn't change the gist of the question, however. The process being discussed involves the ball-milling of $\mathrm{NaAlH}_{4}$ with $\mathrm{TiCl}_{3}$.

"The paper mentioned, is G. Sandrock, K. Gross, and G. Thomas, J.Alloys \& Compounds, 339 (2002)299-308 (copy supplied). The given equation for this process is reasonable and accurate but the analysis is not. In the Hunter process (and the Kroll process) mentioned, the reduction of the titanium is accomplished through the use of elemental (zero valent) sodium (or $\mathrm{Mg}$ for the Kroll process). While elemental sodium and magnesium are very reducing, the sodium and magnesium ions are not. The authors obviously do not understand that the $\mathrm{Na}$ in $\mathrm{NaAlH}_{4}$ exists as the $\mathrm{Na}^{+}$ion."

If we look at the equation in question, it looks like hydrogen in the hydride form is the reducing agent:

$(1-x) \mathrm{NaAlH}_{4}+x \mathrm{TiCl}_{3} \rightarrow(1-4 x) \mathrm{NaAlH}_{4}+3 x \mathrm{NaCl}+x \mathrm{Ti}+3 x \mathrm{Al}+6 x \mathrm{H}_{2}$ 
(where $x$ is the mole fraction of $\mathrm{TiCl}_{3}$ ).

For simplicity, we can take the non-reacting portion of the alanate out of the equation:

$3 x \mathrm{NaAlH}_{4}+x \mathrm{TiCl}_{3} \rightarrow 3 x \mathrm{NaCl}+x \mathrm{Ti}+3 x \mathrm{Al}+6 x \mathrm{H}_{2}$

I spoke with Dr. Sandrock, who said that he was referring to the thermodynamic similarities between the Hunter process and the ball-milling process in which, not necessarily a similarity in the redox process. The ball milling mixture most certainly does not contain elemental sodium.

\section{Why do you state that compressed hydrogen is not considered acceptable for passenger vehicles?}

"Perhaps that is an overstatement. Using steel cylinder technology, of course, limits the amount of hydrogen and does not meet DOE guidelines for weight or volumetric content. Use of new composite tanks largely eliminates that objection. However, the public is still not likely to accept gas tanks at pressures of 6,000psi or more. So what we should have said is that the public currently is not likely to accept high pressure gaseous hydrogen storage."

That is an education issue, not a technical one.

\section{What impurities are present in $86.3 \% \mathrm{NaAlH}_{4}$ ? After the THF addition process,} what is the purity of the alanate?

"With regard to the $\mathrm{NaAlH}_{4}$ obtained from Aldrich, the chemical identity of the impurities is unknown (but has been assumed to be elemental aluminum). The purity of the alanate after THF addition depends on the type of filtration process. We do decantation for our purposes and a very small amount of undesolved particles end up in the THF solution.

"The $\mathrm{NaAlH}_{4}$ from Albemarle was listed as containing 86.3\% $\mathrm{NaAlH}_{4},<0.04 \% \mathrm{NaAlEt}_{2} \mathrm{H}_{2}$, $4.7 \% \mathrm{Na}_{3} \mathrm{AlH}_{6}$, and $7.5 \%$ free Al."

Dr. Slattery mentioned that Aldrich and other manufacturers have stopped making $\mathrm{NaAlH}_{4}$ since after 9/11.

FSEC was hesitant to do any additional purification as they believe that any purification process would leave worse impurities.

Of course, in any commercial venture, the identity of any impurities would have to be crystal clear. For research purposes, I'm still concerned. Impurities, especially nearly $14 \%$ impurities are bound to skew the results - and there is no guarantee of batch-tobatch consistency.

\section{What was the driver for choosing the concentrations of the stock solutions that you use for the AA?}

"The user manual suggested these stock concentrations for reasonable dilutions to achieve a linear calibration curve." 
An autosampler does the dilutions.

I was just curious about the large number of significant figures in the discussion of the concentrations. It is user manual generated.

\section{Are the wet and solvent-free syntheses that you discuss in the report the cited literature-derived processes that you previously mentioned?}

"The wet chemical syntheses were all based on literature reports. Most of the solvent free methods were not."

16. In your discussion of the wet synthesis of magnesium alanate (or its diethyl ether complex) how does the infrared results showing a C-H stretch, an Al-H stretch, and a $\mathrm{C}-\mathrm{O}-\mathrm{C}$ bend confirm the presence of a magnesium alanate?

\footnotetext{
"The process of product identification starts from $\mathrm{NaCl}$. $\mathrm{NaCl}$ is the by-product of the reaction and quantitative analysis of this compound using Mohr method shows the extent of reaction's completion. After Soxhlet extraction, the infrared spectrum of extracted material is compared to the infrared spectra of $\mathrm{MgCl}_{2}$ and $\mathrm{NaAlH}_{4}$."
}

The $\mathrm{NaCl}$ analysis shows that since they started with $\mathrm{MgCl}_{2}$ that a reaction has taken place. Second, the most likely impurity would be a hydroxide, which is not seen. Finally, the IR peaks do correspond to literature-reported values for $\mathrm{Mg}\left(\mathrm{AlH}_{4}\right)_{2}$.

The problem, then, is in the report which simply states that the presence of the magnesium alanate is confirmed by the three IR peaks.

\section{Have you done any particle size measurements on the pre- and post-ball milled materials?}

"Unfortunately, we have not made those measurements. We would like to look at them under the SEM but with the reactivity of the materials it is difficult to do."

FSEC will try to do Scanning Electron Microscopy (SEM) and a BET (for surface area measurement) without exposure to air to help to characterize the materials.

Even some sieve separations in a glove box might help somewhat.

\section{Discussion of Results:}

I asked Drs. Slattery and Hampton to provide me with copies of their TVA and DSC results so that we could discuss them. This section reviews that discussion.

A DSC and a pressure plot for sodium alanate are shown, respectively in Exhibits 1 and 2. The DSC in Exhibit 1 shows, as expected, two endothermic peaks corresponding to the two-step dehydriding reaction: 


$$
\begin{aligned}
& \mathrm{NaAlH}_{4} \rightarrow 1 / 3 \mathrm{Na}_{3} \mathrm{AlH}_{6}+2 / 3 \mathrm{Al}+\mathrm{H}_{2} \\
& 1 / 3 \mathrm{Na}_{3} \mathrm{AlH}_{6} \rightarrow \mathrm{NaH}+1 / 3 \mathrm{Al}+1 / 2 \mathrm{H}_{2}
\end{aligned}
$$

Thus, theoretically, 75\% of the hydrogen should be released, and recoverable. Since sodium alanate is $7.4 \%$ hydrogen by weight, 5.6\% should be recoverable. Since the alanate used, according to FSEC, is only $86.3 \%$ pure, the weight percent of recoverable hydrogen should be about $4.8 \%$ of the overall sample.

Looking at Exhibit 2, a two step release of hydrogen is also evident, culminating in a final release of sufficient hydrogen to account for about $4.5 \%$ by weight of the sample. $I$ would consider this to be a reasonable result.

There is much data for $\mathrm{LiAlH}_{4}$. FSEC/UFC provided copies of DSCs and pressure data for $\mathrm{LiAlH}_{4}$ obtained from two different companies, Lancaster and Aldrich. Exhibit 3 is a DSC of Lancaster material while Exhibit 4 is the corresponding pressure plot. Exhibits 5 and 6 provide analogous data for Aldrich lithium alanate.

While de-hydriding of metal hydrides are generally endothermic processes (requiring heat), dehydriding of lithium alanate is at least, to a degree, exothermic (evolving heat). (The literature does report the exothermic behavior of lithium alanate. It has been attributed to the formation of a LiAl alloy, or alternately a rearrangement from a tetrahedral to an octahedral structure for the hexavalent material.) The pressure plots for the alanates from the different manufacturers both show a two step dehydriding process resulting in a total removal of about $6 \%$ hydrogen. The DSCs, however, are quite different for the two samples. Furthermore, Dr. Slattery states, that each of the two alanates was run several times reproducibly, and that the differences in decomposition between the Lancaster and Aldrich samples are real.

I would interpret the data as follows: $\mathrm{LiAlH}_{4}$ is $10.5 \%$ hydrogen by weight. If we assume, as FSEC indicates, a similar mechanism:

$$
\begin{aligned}
& \mathrm{LiAlH}_{4} \rightarrow 1 / 3 \mathrm{Li}_{3} \mathrm{AlH}_{6}+2 / 3 \mathrm{Al}+\mathrm{H}_{2} \\
& 1 / 3 \mathrm{Li}_{3} \mathrm{AlH}_{6} \rightarrow \mathrm{LiH}+1 / 3 \mathrm{Al}+1 / 2 \mathrm{H}_{2}
\end{aligned}
$$

we would theoretically again recover $75 \%$ of the hydrogen $\left(7.9 \%\right.$ by weight of $\left.\mathrm{LiAlH}_{4}\right)$. In this case, the purity of the lithium alanate is 95\% (Aldrich) and 97\% (Lancaster), and the hydrogen recovery should be from 7.5 to $7.7 \%$. This would indicate that FSEC is recovering less of the available hydrogen from the lithium alanate than from the sodium alanate (although the absolute amount of hydrogen storable and recoverable from the lithium alanate is higher.)

It seems that there is much yet to understand about $\mathrm{LiAlH}_{4}$. 
Exhibits 7 and 8 show the DSC and TVA results for $\mathrm{LiBH}_{4}$ from Acros. The TVA pressure plot shows a recovery of $11.2 \%$ hydrogen. The DSC shows one exotherm followed by two endotherms. Dr. Slattery believes that lithium is playing a significant role in the exothermic properties of its complex hydrides.

The total amount of hydrogen in $\mathrm{LiBH}_{4}$ is $18.2 \%$. If we apply the same $75 \%$ recoverability and take into account the fact that the material that was used is $95 \%$ pure, then $13.0 \%$ of the weight of lithium borohydride should be recoverable hydrogen. I would consider the $11.2 \%$ recovery to be encouraging especially since this material holds the potential for very high hydrogen storage amounts. Of course, in general, boron hydrides are not the easiest or safest of materials to work with.

Drs. Slattery and Hampton also showed some very old, but encouraging data for $\mathrm{NaBH}_{4}$, where the initial dehydriding step appeared to take place at less than $40^{\circ} \mathrm{C}$. More work is needed with this material.

I also was shown some data for $\mathrm{Mg}\left(\mathrm{AlH}_{4}\right)_{2}$, that showed only one peak at about $400^{\circ} \mathrm{C}$. FSEC is not entirely sure that they had indeed made $\mathrm{Mg}\left(\mathrm{AlH}_{4}\right)_{2}$, and may have only had $\mathrm{MgH}_{2}$.

Drs. Slattery and Hampton also discussed some ball milling and doping work that they had been doing. They found that ball milling had an effect on the thermal properties of the hydrides. Ball milling $\mathrm{LiAlH}_{4}$ from Lancaster turned the second and third exotherms (see Exhibit 3) into one endotherm. It indicates that dehydriding is then proceeding via a different mechanism. Doping with titanium appears to lower the temperature for hydrogen release, but it also lowers the total amount of recoverable hydrogen by about $1 \%$.

Much of the results having to do with ball milling and doping to date have not been reproducible, and need to be studied further.

At one point, Dr. Hampton mentioned that ball milling a sample (no dopant) is more likely to give you an exotherm. He believes that ball milling works in the crystal structure, and brings the material "part-way up the energy curve."

\section{Tour:}

I was shown Dr. Slattery's laboratory at FSEC one afternoon, and Dr. Hampton's laboratory the next morning.

Dr. Slattery's lab uses a SPEX 8000M Mixer Mill to ball mill powders. It is a high energy mill having a jar with a $100 \mathrm{ml}$ internal volume, and uses two 7/16 inch diameter balls. FSEC uses either tungsten carbide or hardened steel balls. The mill table moves the jar in a "figure 8" pattern. Milling is limited to about one hour at a time, or too much heat is generated. 
A Parr reactor is used for pressure work. It has an internal reaction volume of $250 \mathrm{ml}$. The reactor is fitted with a pressure transducer that can measure up to 500 psi, but FSEC is planning to get a new transducer to better measure the rehydriding process. The Parr reactor is used to react 5 gram samples, at temperatures up to $300-400^{\circ} \mathrm{C}$.

A gas-handling/vacuum-line manifold system (also called a Schlenk system) in a fume hood is used to run most of the reactions. The line is attached to a vacuum system and to an inert gas line. A small flask can be attached to the line and flushed with inert gas and/or evacuated and used as a reaction flask.

When I was there, Dr. Slattery's group was using a Soxhlet reactor (a distillation system) on the Schlenk line to try to make magnesium alanate. They are having a problem with this; the alanate will not go into solution except in the presence of ether.

The thermovolumetric analysis (TVA) system used to measure dehydriding, is a modified Sievert's apparatus. One-gram samples are used. Helium is used as the pressurizing gas. Generally, the system is heated at a steady rate of $2^{\circ} \mathrm{C}$ per minute to $300^{\circ} \mathrm{C}$. It is left at that temperature for one hour. If a re-hydriding step is planned next, the system is purged with more helium, and then brought down to the hydriding temperature. It is then pressurized with 5 atmospheres of hydrogen, and cooled.

For sample preparation, FSEC uses a Labconco glove-box with a stainless steel interior. They had considered a fiberglass interior also, but decided against it since they use tetrahydrofuran as a solvent.

Running infrared spectrometry tests on samples is difficult to do without exposing the samples to air. After multiple tests are run, you begin to see $\mathrm{OH}$ stretch peaks showing up, indicative of exposure of hydrides to air.

A new analytical lab is being set up at FSEC. It will house the infrared spectrometer, gas chromatograph and BET surface area analysis system. FSEC is interested in analysis of surface area as a function of hydriding. This is a good thing to do.

Dr. Hampton's facilities at UCF's main campus, is centered on a dedicated DSC laboratory. The unit is a Setaram DSC 111. It is about 15 years old. The unit is thermocoupled throughout the furnace, which is water-cooled. Quick disconnects are used to limit the time and the volume of space in which the sample can be exposed to air. Other features include pressure valve releases, needle valves and pressure transducers. There are two pressure transducers. One has a $200 \mathrm{psi}$ limit is used for dehydriding. The second, higher pressure unit is used for re-hydriding tests. The DSC can be run in a pressurized mode or in a floating atmospheres mode (see Question 2).

Dr. Hampton uses short lengths of 3/16 inch stainless steal tubing which has been sliced in half for sample boats. A calculation is used to determine gas temperature from sample temperature. 
The DSC sample is prepared as follows: The sample is weighed out into the sample boat in a glove box under an argon atmosphere. The boat is placed in a glass tube which is then capped with plastic. The sample is brought up to the DSC (the prep lab is on a lower floor), the glass tube is uncapped and the sample boat is introduced to the DSC via the quick-connect. Dr. Hampton was quick to point out that the time the boat is in the nonleakproof glass tube with the plastic caps is very short. But it is non-zero. I think a determination of what is happening during transfer is in order.

In the prep lab, aside from the aforementioned glove box, which is identical to the one at FSEC, are a series of ball mills. One is an old fashioned Paul O. Abbe ball mill table that actually uses a modified horse feed bucket as a ball jar. A second is a SPEX 8000M Mixer Mill like FSEC's. In addition, Dr. Hampton has a programmable planetary ball mill with an internal volume of $250 \mathrm{ml}$. A planetary ball mill is a high energy ball mill that rotates on its own axis in one direction, and revolves in the other direction about a "sun axis". The planetary ball mill has wireless temperature and pressure sensors that feed data directly to a computer. Thus, one can monitor changes in hydrogen concentration.

The UCF wet lab is similar to FSEC's. Between the two facilities, there are several redundancies (not a bad thing, if we're not talking about expensive equipment) but Dr. Hampton's lab is geared toward small samples for DSC, while Dr. Slattery's lab is geared to larger samples for TVA.

\section{Additional Items:}

Dr. Hampton also has a contract with NASA and with the State Department on a hydrogen sensor project. UCF is teamed with Setaram (the DSC manufacturer) on this project. They are investigating hydrogen sensors fort the space shuttle, looking at leaks in the vacuum spaces between layers of liquid hydrogen dewars.

Drs. Slattery and Hampton discussed a finding by the storage group at Sandia (CA) National Laboratories that $\mathrm{NaAlH}_{4}$ apparently goes through a melt phase at $180^{\circ} \mathrm{C}$ as it decomposes, and that it then resolidifies. FSEC has studied the alanate, and says that it does not appear to be different after the temperature excursion. (Some SEM micrographs, or particle size or surface area measurements might help here.)

\section{Final Thoughts}

This project brings into focus one of the bigger issues with hydrogen: how do you store it efficiently and safely in high enough concentrations to make vehicular usage feasible? Complex hydrides of the form $A_{x} B_{y} H_{z}$ (where $A$ is generally an alkali or alkali-earth metal and $B$ is either aluminum or boron) have emerged as the leading non-compressed cylinder group of candidates. The leader in this group is sodium alanate, $\mathrm{NaAlH}_{4}$. It will produce $5.6 \%$ recyclable hydrogen by weight (at reasonable temperatures with the right dopant) by the methods discussed above. This is too low by at least some standards. 
The FSEC/UCF project addresses this problem by attempting to make and characterize the hydrides that can do at least as well as sodium alanate. This is a difficult task. Most of the candidates have never been synthesized or have been reported on only once in the literature, with less than 100\% credibility. I believe that FSEC/UCF has learned that this path would be tedious at best. They have therefore, over the past few months, concentrated on the candidates that are commercially available. The one exception is they are continuing to address magnesium alanate.

The combination of DSC and TVA to perform the bulk of the characterization is a good idea, although I believe they need to add something like SEM and/or surface measurements. Working with as received materials that are of varied purity is not, in my opinion, a good idea, especially for characterizations.

So, this project has had somewhat of a change in direction. They have correctly, in my opinion, cut back on the number of materials they are trying to work with, and are concentrating on the materials they have on hand. Many questions, however, remain as data are not entirely reproducible, and the reasons for this (source of sample, purity, ball milling, doping) is still speculative. But, if alanates or similar materials are going to be the hydrogen storage medium of the future, the answers are needed. 


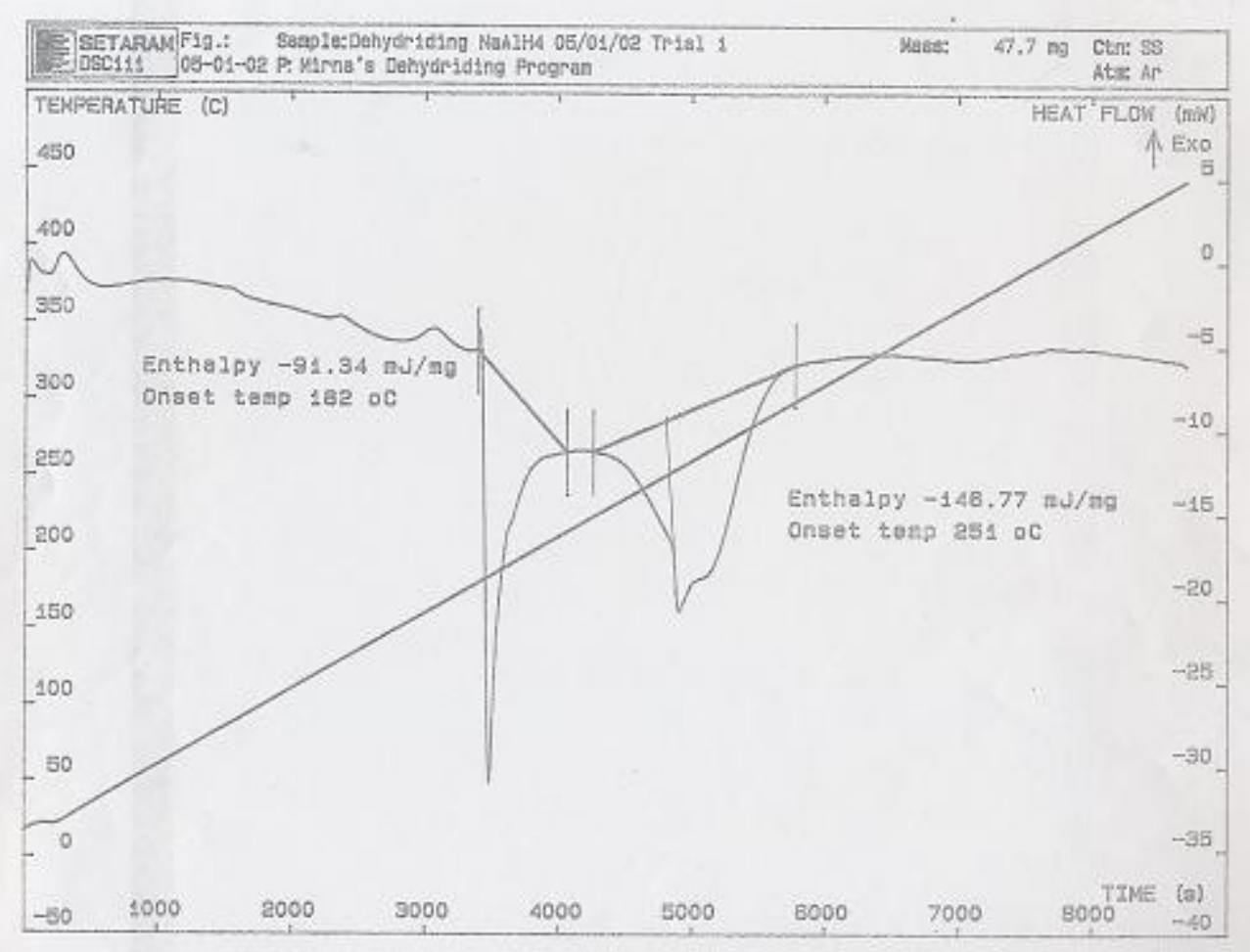

\section{Exhibit 1. DSC of $\mathrm{NaAlH}_{4}$}

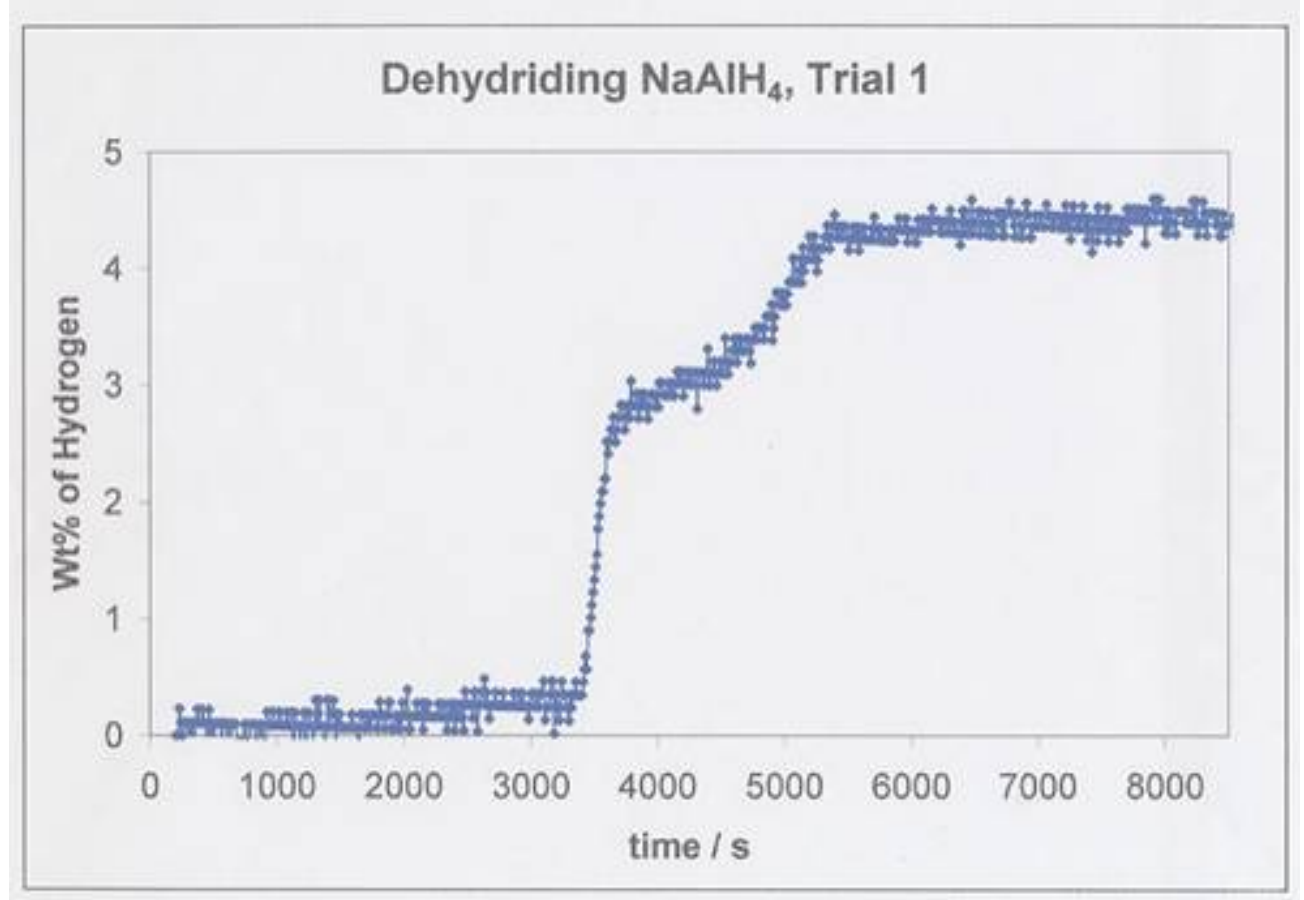

Exhibit 2. TVA Pressure Plot of $\mathrm{NaAlH}_{4}$ 


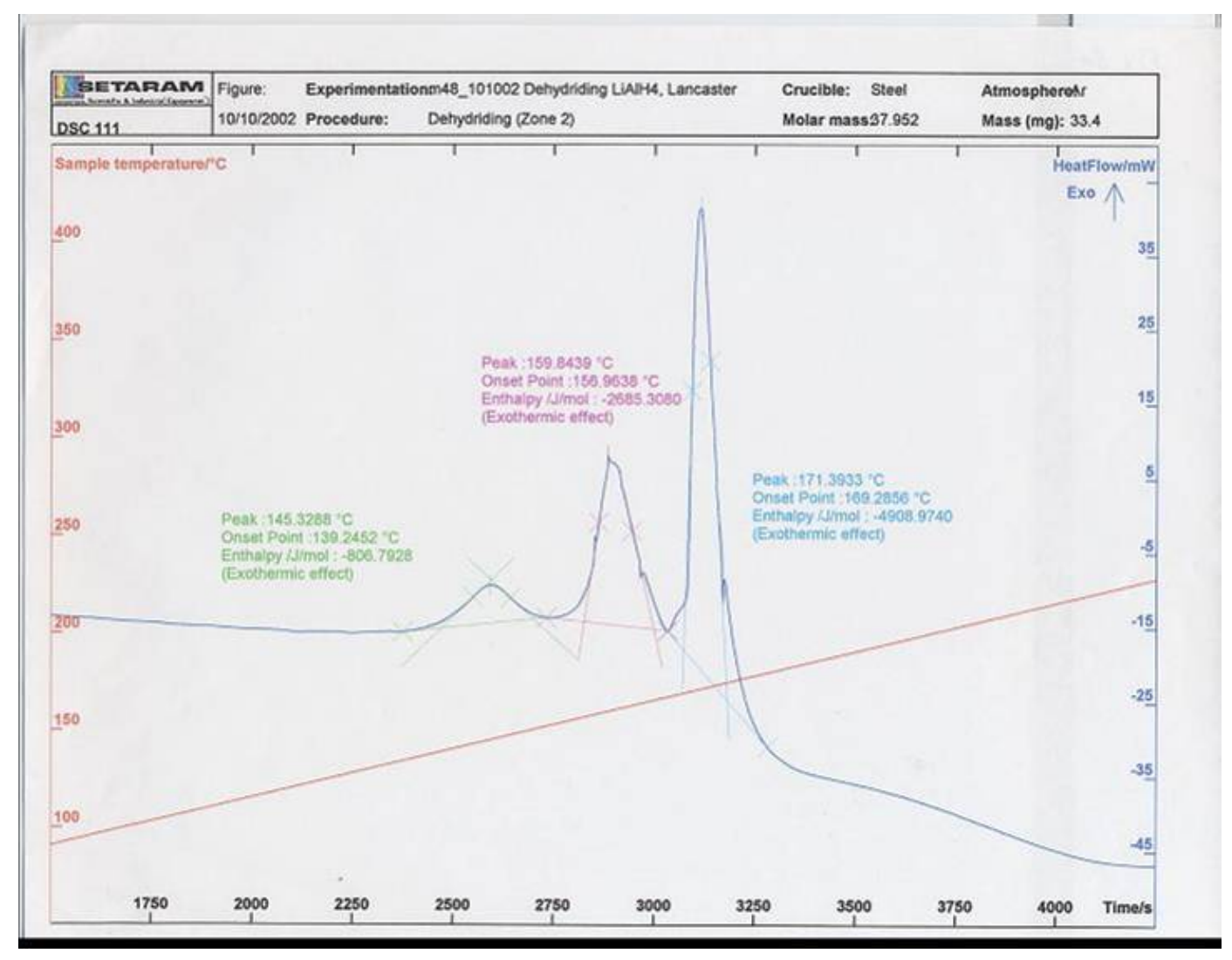

Exhibit 3. DSC of $\mathrm{LiAlH}_{4}$ from Lancaster

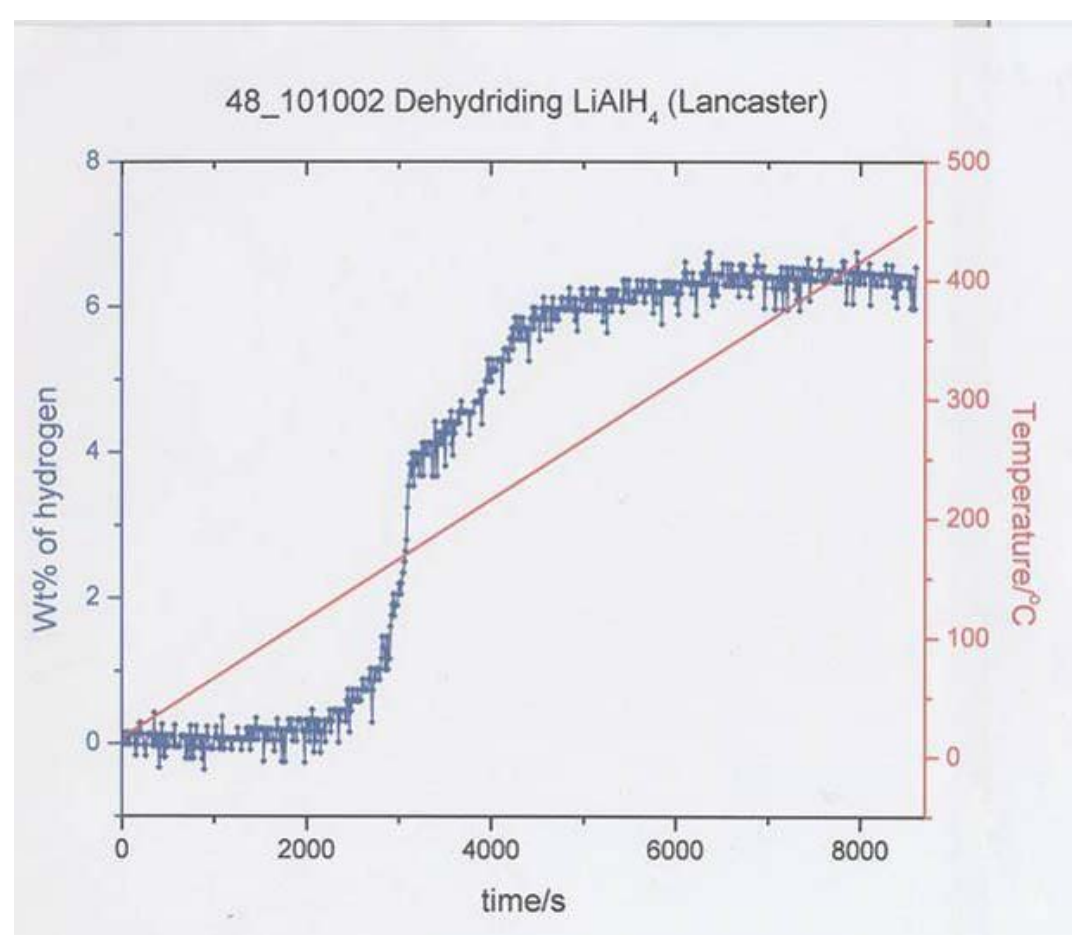

Exhibit 4 Pressure plot for $\mathrm{LiAlH}_{4}$ from Lancaster 


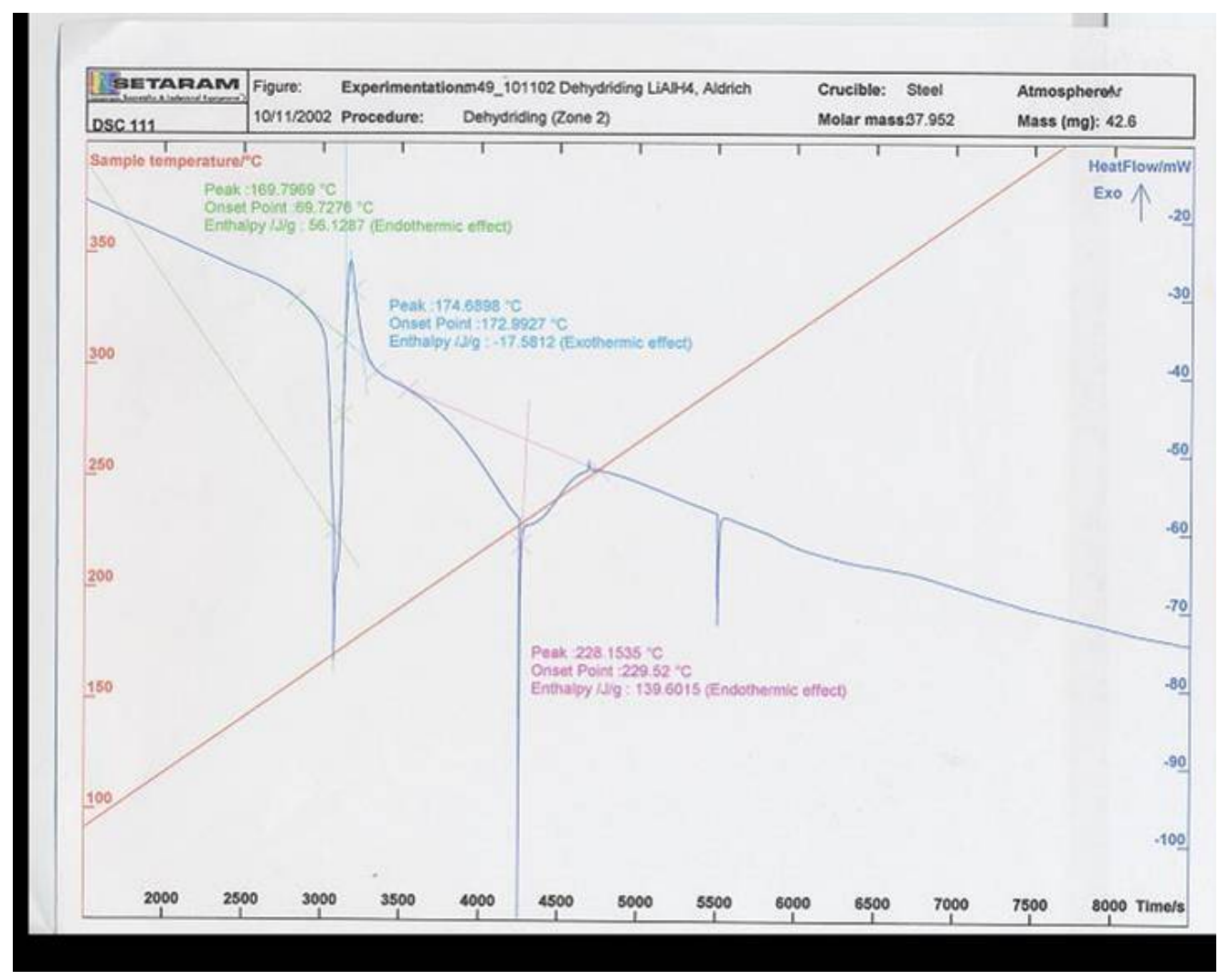

Exhibit 5. DSC of $\mathrm{LiAlH}_{4}$ from Aldrich

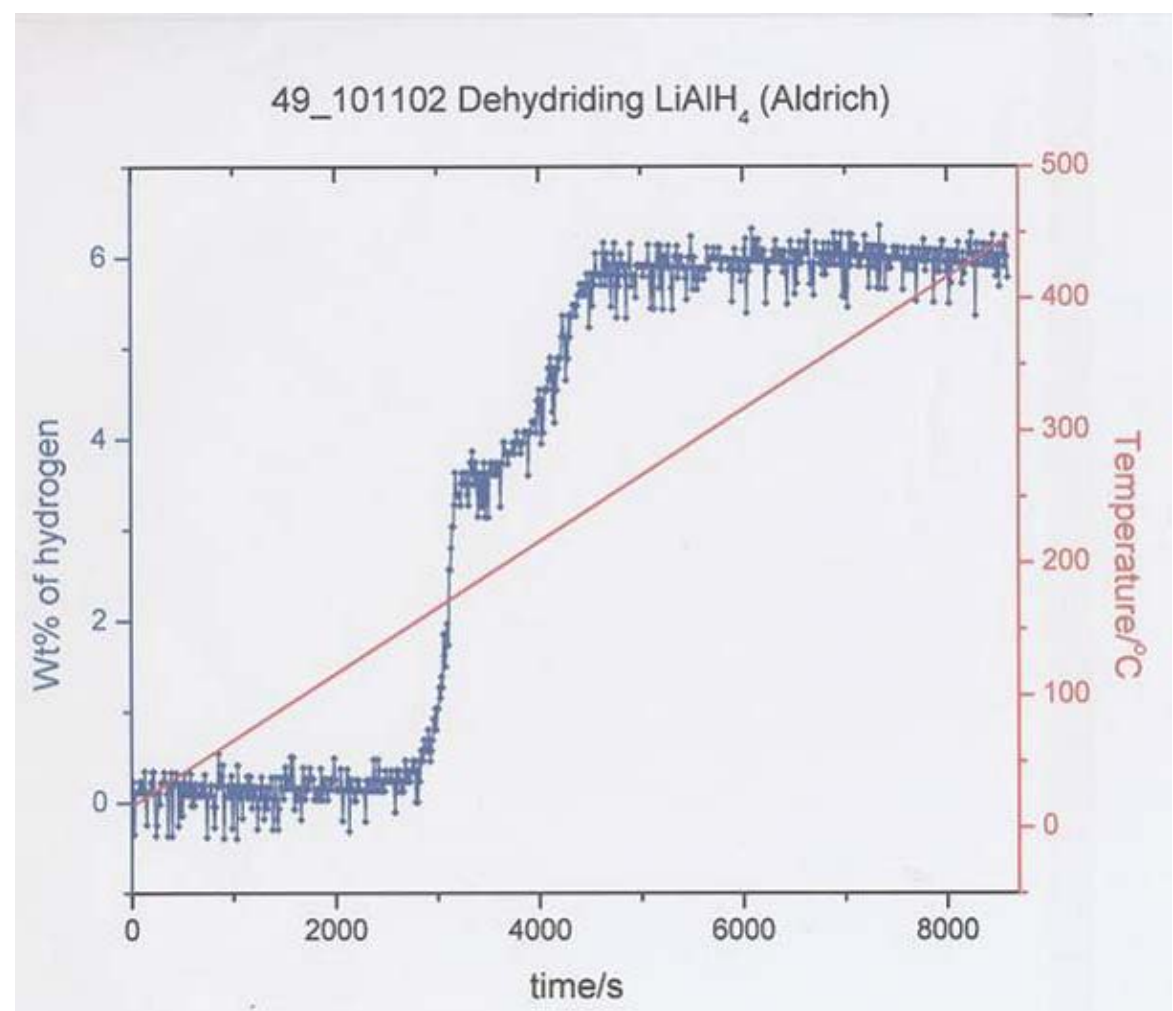

Exhibit 6 Pressure plot for $\mathrm{LiAlH}_{4}$ from Aldrich 


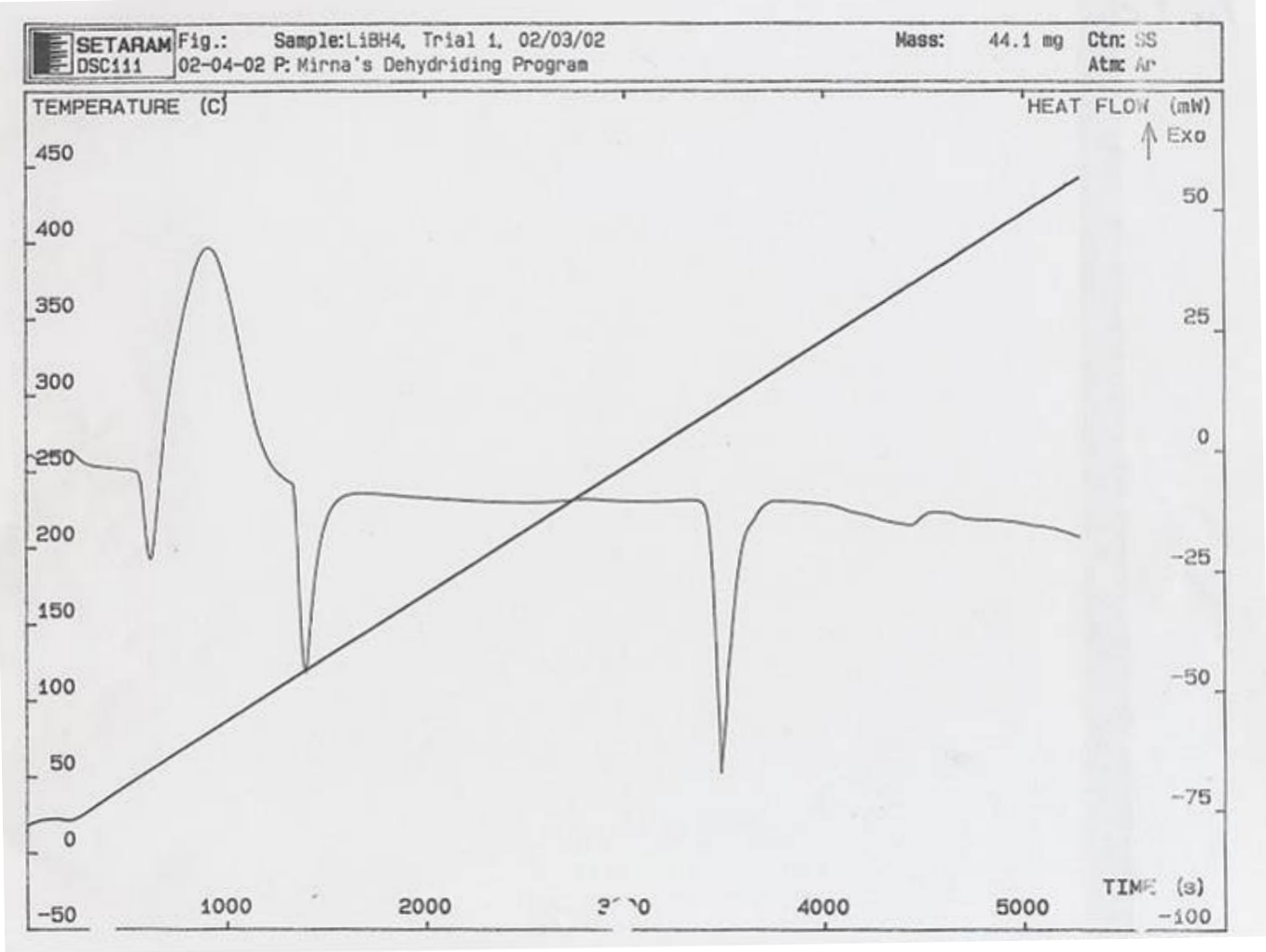

\section{Exhibit 7. DSC of $\mathrm{LiBH}_{4}$}

Dehydriding $\mathrm{LiBH}_{4}$, Trial 1

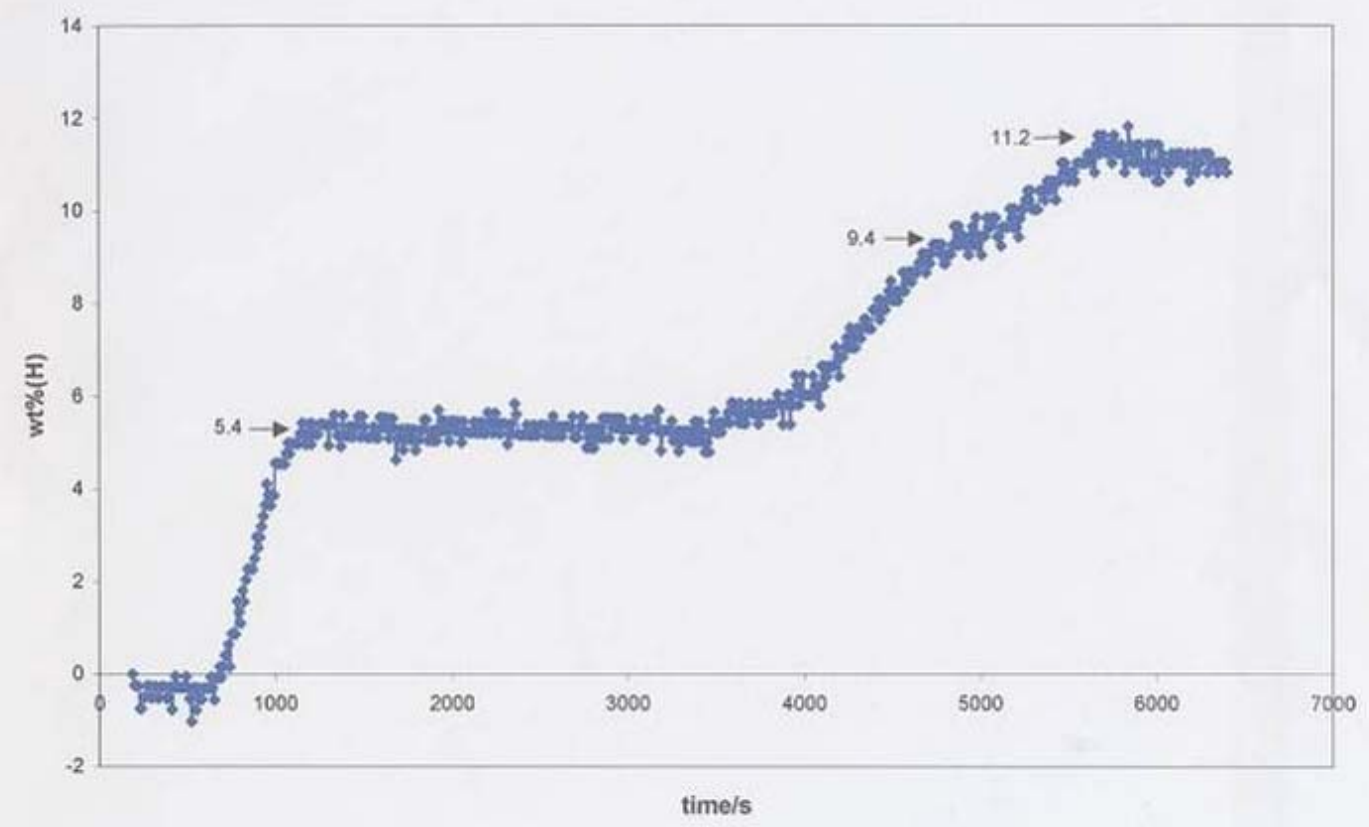

Exhibit 8. Pressure Plot of $\mathrm{LiBH}_{4}$ 
Technical Evaluation Report

Project: Maximizing Photosynthetic Efficiencies for Hydrogen Production

Company: University of California, Berkeley

P.I.: Dr. Tasios Melis

Site-Visit Date: April 9, 2003

Evaluation by: Edward G. Skolnik, Energetics, Inc.

\section{Summary:}

For the past several years, researchers at UC Berkeley have been mutating algae with the purpose of making a mutant or mutants with small receptor antennae. The smaller the antennae the more efficient will be the use of sunlight. This will result in more efficient hydrogen production.

The wild type of the "workhorse" alga Chlamydomonas reinhardtii, have antennae that support the photosystem II (PSII) mechanism that have 230 chlorophyll molecules per site, and antennae that support PSI that have 240 chlorophyll molecules per site. The theoretical lower limit for these two types of antennae is 37 chlorophylls for PSII and 95 for PSI.

When I last visited Berkeley early in 2001, the research team had measured PSII antennae containing 114 chlorophylls, and PSI antennae containing 159 chlorophylls. These numbers appear basically unchanged.

I see the following strengths in the project:

- There has been some measurable reduction in antenna size to date, both for PSI and PSII.

- Target (theoretical minimum) antenna sizes proposed by the Berkeley group have been validated by others

- Berkeley remains the only location where direct antenna size measurements can be made.

- The concept of reducing antenna size to increase hydrogen production efficiency still appears to be a viable concept, and a positive approach to the overall problem.

I see the following items that need to be addressed:

- A direct correlation is needed between antenna size and hydrogen production. The scale-up work in the greenhouse that is discussed in this report is of great importance.

- While the antenna reduction properties of several mutants, notably tla 1, but also chl$b$-less mutants, have been demonstrated, additive properties have not. In other words, 
we need to see first, if a mutant can be made that has the properties of two or more of the small antenna size species, and second to see to what degree the effect is additive. For instance, if mutant " $\mathrm{A}$ " removes 30 chlorophylls, and mutant " $\mathrm{B}$ " removes 25 , will an "A+B" mutant remove 55 - or how many will it remove?

\section{Introduction and Background:}

The University of California, Berkeley has for the past several years been investigating the development of mutant algae that have reduced size chlorophyll-based receptor antennae. In an algae pond, normal, "wild-type" algae have large photon receptor antennae so they can more readily intercept photons during periods of low light. However, during periods of high light, the chlorophyll sites accept far more photons than they can use, and the rest (maybe $90 \%$ of the total) are wasted. Meanwhile, the excess light being wasted, does not penetrate deeper into the pond to promote photosynthesis for other algae. The deeper algae must eventually reach the surface in order to grow.

The premise for the Berkeley project is that if the antennae can be made smaller, more light will filter down to algae lower in the pond, allowing photosynthesis to occur at these levels as well. Since hydrogen production depends on photons in the same manner as does photosynthesis, hydrogen production potential will also increase.

I visited Dr.Tasios Melis at Berkeley for the second time (the first being in February 2001) to determine the advances that has been made in this project since my last visit. I discussed the project with Dr. Melis and also met members of his present (and in one case, recent past) staff. These people included one past postdoc, Dr. Jorgen Polle, who is currently an assistant professor at Brooklyn College (and who I did not meet on my last visit, as he was out of the country), and two present postdocs, Dr. Yutaka Komine and Dr. Andi White.

\section{Questions and Answers:}

Prior to my visit, I sent Dr. Melis a list of questions based on several of Dr. Melis' review reports and presentations, as well as my February 2001 site visit report. Dr. Melis answered the questions in writing and we also discussed the questions and answers in detail. This is all reproduced here, with the questions indicated in bold, written answers reproduced "verbatim in quotes", our discussion shown in normal type, and my comments added to many of the questions during my later analysis and assessment shown in italics.

\section{Two years ago you mentioned that Berkeley was the only laboratory where chlorophyll type can be measured. Is this still true?}

"Yes, Berkeley continues to be the only laboratory where the chlorophyll antenna size of photosynthetic organisms can be measured. We are indeed a 'sole source' provider." 
Recently, a group in Berlin, Germany studied crystal structures in cyanobacteria. It is easier to work with bacteria than algae as they are smaller and therefore easier to examine. They looked at the photosystem II (PSII) core with x-ray crystallography, and were able to find the center and counted 37 chlorophyll molecules. This corresponds to Dr. Melis' "target" number arising from some of his earlier work (see Question 4). Thus, this indirect method verifies the Berkeley process. For the core complex to "assemble" you need at least 37 chlorophyll molecules. For photosystem I (PSI), the number is 95 chlorophylls. The reference for the German paper is: A. Zouni, H-T Witt, J. Kern, P Fromme, N Krauß, W. Saenger, and P. Orth, Nature 409, 739 (2001). This relates to PSII. The PSI work was reported in: P. Jordan, P. Fromme, H-T Witt, O. Klukas, W. Saenger, and N. Krauß, Nature 411, 909 (2001).

2. Again two years ago, you discussed a regulatory mutant that you called th1 (for truncated light harvesting) that had reduced antenna size for both photosystems. How did you get from here to tla1 - or is it the same mutant under a new name?

\footnotetext{
"It is the same regulatory mutant. We made this adjustment (from th1 to tla1) to be consistent with nomenclature in the literature. The sequences (genomic DNA, CDNA and protein) were all deposited in the GenBank under the tla1 name with Gen Bank Accession Numbers, as follows:
}

"Kanakagiri S and Melis A (2002) Chlamydomonas reinhardtii Tla1 nuclear gene for the regulation of the photosystem chlorophyll antenna size in photosynthesis, complete cds., (bases 1 to 2181). GenBank Accession Number AF534570

"Kanakagiri S and Melis A (2002) Chlamydomonas reinhardtii chlorophyll antenna size regulatory protein (Tla1) mRNA, complete cds. GenBank Accession Number AF534571

"Important Milestones from the Tla1 work:

17. First-time cloning of Tla1, a 'Chl antenna size regulatory gene' (30-year breakthrough)

18. Progress toward the goal: tla1 mutant showed enhanced productivity under mass culture conditions (Planta paper in press)

19. Recently (February 2003) the DOE's Joint Genome Institute (JGI) completed a \$ 4,000,000 Chlamydomonas reinhardtii genomic DNA sequencing effort. They released into the public domain these new genomic DNA sequences for the green alga Chlamydomonas reinhardtii. We searched this data base and found the Tla1 (Truncated Light-harvesting chlorophyll Antenna size) gene sequence there. There was a perfect match between our earlier published Tla1 sequence and that reported by the JGI. On their web site, the JGI cross-listed our published work and assigned a function to the Tla1 sequences, solely on the basis of our genetics analyses. "

Someone else had already used the $t \operatorname{lh} 1$ designation for another material in the GenBank. The tlal designation will now forever refer to Berkeley regulatory mutant.

\section{Have you ever looked for how good the correlation between fluorescence intensity and kinetic spectrophotometry is as a measure of antenna size?}

"We know for sure that there is no foolproof correlation between fluorescence intensity and kinetic spectrophotometry as a measure of $\mathrm{Chl}$ antenna size. Meaning that a small $\mathrm{Chl}$ antenna size always causes low fluorescence but low fluorescence is not always evidence of small Chl antenna." 
Thus, low fluorescence is just a good initial screening process.

4. In your FY 2002 Annual Report you show when comparing the wild type Chlamydomonas with tla1 that there is a decrease in antenna size for Chl-PSII from about 230 to 114, and for Chl-PSI, a decrease from 240 to 159. Your targets for PSII and PSI antenna sizes are 37 and 95 respectively. What are the bases for your targets, and how do you plan to get there?

\begin{abstract}
"A) The basis of these targets is pioneering experimental work from this laboratory, published in 1988 (Glick RE and Melis A, 1988, Minimum photosynthetic unit size in System I and System II in barley chloroplasts. Biochimica et Biophysica Acta 934: 151-155), where it was shown that chloroplasts cannot assemble a smaller PSII and PSI Chl antenna size than 37 and 95 molecules, respectively. The confirmation of our pioneering 1988 measurements came only last year with the X-ray crystallographic analysis of PSII and PSI core complexes. “
\end{abstract}

"B) We propose to continue with the application of DNA insertional mutagenesis and screening for the isolation of 'truncated Chl antenna' mutants. In the end, genetic properties of different mutants and genes could be genetically combined, generating strains with very small Chl antenna size.

"Should also say that among two potential approaches to arrive at a truncated Chl antenna size, the method of choice is 'genetic interference with the innate cellular mechanism that regulates the $\mathrm{Chl}$ antenna size'. Recently published research from other laboratories has shown that the alternative (deletion of genes for the LHCII proteins) would not have worked Ruban et al. Nature 421: 648-652, 2003.)"

There is a natural mechanism to reduce antenna size in high light. Dr. Melis' insertional mutagenesis works to force this mechanism to operate.

The alternate suggestion was that they try to "knock out" the genes that cause the production of trimers. Dr. Melis, however, felt that other genes would compensate for this lack, and would still build a large antenna. The Ruban paper (referenced above) appears to prove this assertion. Thus, Dr.Melis feels that he made the right decision to go with the insertional mutagenesis approach.

5. Please explain the significance of the increase in thylakoid membrane content when going from the wild type to tla1. Also, please explain the significance of the decreases in chlorophyll proteins 26 and 29.

"It should be a 'decrease' in thylakoid membrane content when going from the wild type to tla1. By that we meant that, in the tla1, two different effects of the mutation are observed. We observed loss of chlorophyll (from the wild type to tla1 it is down to $37.5 \%$ ). Two different effects of the mutation account for this substantial loss of Chl. (A) A truncated Chl antenna size in PSIl and PSI (from the wild type to tla1 it is down to 59\%). (B) Loss of photosystems and thylakoid membrane (from the wild type to tla1 it is down to 65\%). Effect (A) is desirable, effect $(B)$ is unintentional. Our spectrophotometric kinetic analysis uniquely permited delineation of the two effects. 
"The decrease in CP29, and especially in CP26, was unexpected but interesting. These subunits occur closer to the center of PSII and should not have been the subject of a truncation. This result is telling us something about the organization of the Chl antenna (please see paper by Polle et al. Plant Cell Physiology 42: 482-491, 2001). “

Exhibits 1 and 2 reproduce the tables from where these data came. In Exhibit 1, $\mathrm{Q}_{\mathrm{A}}$ and P700 represent the thylakoid membrane content, respectively, for PSII and PSI. In my question, I was referring to the total thylakoid membrane content, while Dr. Melis was referring to the per cell results. The latter is probably the more significant number. The total amount of photosystems is dropping also.

The phenomena points out that it is not enough to just count chlorophylls; you need to measure antenna size directly.

CP29 declined proportionally, but CP 26 was “obliterated". Dr. Melis is not completely sure why this happened, and his group is still investigating this. Regardless, the phenomenon is somewhat peripheral to the overall project.

\section{What is a light-harvesting complex? You show a $38 \%$ decrease in LHCII; what was the result for LHCI?}

"Light-harvesting complex is the term used to define the Chl-proteins that bind both $\mathrm{Chl} a$ and $\mathrm{Chl} b$, as opposed to the photosystem-core Chl-proteins that bind only $\mathrm{Chl} a$.

"We do not have direct measurements of the $\mathrm{LHCl}$ (lack of specific antibodies) but one can easily estimate from the spectrophotometric kinetic analysis a $56 \%$ decrease in $\mathrm{LHCl} . "$

"(It should be noted that measurement of the LHCll and LHCl by antibody does not provide unequivocal estimate of the $\mathrm{Chl}$ antenna size. This is evidenced in recent work by Ruban et al. -who showed that in the absence of one of the LHCII main components, another protein is recruited to allow it to assemble and function.')"

$\underline{\text { Ruban reference : Ruban AV, Wentworth } \mathrm{M}}$, Yakushevska AE, Andersson J, Lee PJ,

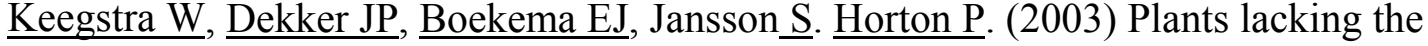
main light-harvesting complex retain photosystem II macro-organization. Nature 421: 648-652, 2003 Feb 6.

LHC refers to the peripheral parts of the photosystem antennae. A drawing of the components of PSII appears in Exhibit 3.

\section{Has there been any work done with trying to find a Dunaliella mutant that is analogous to tla1 for Chlamydomonas?}

"Work supported by the National Science Foundation has permitted us to isolate the $d c d 1$ mutant of Dunaliella salina with characteristics similar to those of the tla1 mutant. (Jin et al. Biochimica et Biophysica Acta 1506: 244-259, 2001) However, in the case of $D$. salina, unlike the tla1 mutant of Chlamydomonas, we do not know what gene was interrupted by the mutation. “ 
The "molecular tools" are not available for Dunaliella as they are for Chlamydomonas. Making antennae smaller for Dunaliella will likely be a more difficult task. It needs to be transformed using a gene that makes it more able to make hydrogen. Thus, Dr. Melis is no longer thinking about Dunaliella for hydrogen production.

However, Dr. Melis was looking at Dunaliella because he felt that Chlamydomonas was more subject to contamination. This is because some scale-up work has been done on Chlamydomonas. This was done in a 500 liter bioreactor. Chlamydomonas was grown, and hydrogen production was demonstrated. This was done in "real" sunlight. It should be noted that this work was all done with wild type Chlamydomonas.

The reactor work was not done under a DOE contract, but was done by a private company in Santa Barbara. The company is named "Melis Energy" but it is not owned by Dr. Melis. The company is owned by a group of entrepreneurs, and Dr. Melis just provides some guidance. (and his name).

Dr. Melis' group is planning to do a mini scale-up - to 4-liter bioreactors prior to going to a pilot plant. (see the next question). Dr. Melis is confident that the tlal mutant will show the same contamination resistant properties as the wild type Chlamydomonas, as it has the same structure - it just doesn't make large antennae.

This represents a reversal from Dr. Melis' position when I met with him two years ago. At that time, Dr. Melis believed that the shift to Dunaliella was necessary because of its ability to survive in a salt water medium. Thus it was considered a hearty species. Chlamydomonas was viewed as not being very robust, and therefore would pose a problem. As indicated above, Dr. Melis is no longer worried about the heartiness of Chlamydomonas and wants to continue scale-up processes with that algal group.

\section{Are there any numbers that correlate antenna size with hydrogen production?}

"Not yet. This is something we are trying to implement currently with the coming of the 2003 'sunny season' in the Bay Area. "

They have a greenhouse, and plan to run some 4-liter tests starting in May. The 4-liter bottle that they will be using is essentially the same size and shape that Melis Energy uses for their bioreactor.

UC Berkeley will compare tla 1 with wild-type chlamydomonas, looking at the relative amount of hydrogen produced. They have already looked at relative oxygen production. The relative amounts of oxygen produced by photosynthesis would be a measure of the amount of hydrogen production. Photosynthesis would also be enhanced in high-light areas by smaller antennae.

\section{Please explain your statement that hydrogen production cost is proportional to the antenna size.}


"By that I meant to convey that the smaller the $\mathrm{Chl}$ antenna size in green algae, the greater the yield of hydrogen production within a given setting of photobioreactors and, accordingly, the lower the cost of production per unit hydrogen."

When the antenna size is smaller, the cell will produce more hydrogen even though it "costs" the same amount. There is no cost (except developmental) for the mutant. The mutant is robust, and once you make it, it is there.

I was questioning the more literal statement - that the production cost is literally proportional to the antenna size rather than the more general explanation given by Dr. Melis.

\section{Please explain the nature of your collaboration with Mera on carbon sequestration.}

"We have no collaboration with Mera on carbon sequestration or anything else. Mera has a contract with the DOE to work on a carbon sequestration pilot program with green algae. Obviously, they are interested in our 'truncated Chl antenna size' mutants and, specifically, in a Dunaliella salina mutant (zea1) that accumulates the valuable carotenoid 'zeaxanthin' (Jin et al. Biotechnology and Bioengineering 81: 115-124, 2003). Mera provides an example on how industry will (gradually) becomes interested in the products of our DOE R\&D."

Mera is working on green algae that will consume $\mathrm{CO}_{2}$. The president of Mera contacted Dr. Melis, and asked for some strains of mutated Dunaliella salina. The algae make zeaxanthin, an expensive vitamin that could be a co-product with the $\mathrm{CO}_{2}$ sequestration algae. Smaller antennae would make more zeaxanthin.

Right now, Berkeley is negotiating with Mera. Dr. Melis simply was using this as an example of how industry will gradually, over time, become interested with hydrogenproducing algae as well.

So there is some interest, but no collaboration at this time.

\section{Are you at all involved now with sulfur deprivation work?}

"In the context of assessing how a 'truncated Chl antenna size' affects yields of hydrogen production under mini-scale-up conditions in the greenhouse. (See answer to question \# 8)".

Sulfur deprivation will help increase the production of hydrogen, making the scaled-up comparison of wild type chlamydomonas and tla1 as hydrogen producers easier to measure. Dr. Melis also mentioned, however, that when they do this, only a $10 \%$ yield is expected.

\section{What is the state of the "collaboration" between UC Berkeley, NREL, and ORNL?}

"It is moving in the right direction again. We are currently helping NREL with the analysis of one of the DNA insertional transformants that we made available to them over three years ago. A nice piece of work is emanating from this collaboration. 
"ORNL is now in the process of re-joining the hydrogen program with a new project and there have been UC Berkeley/ORNL consultations on project design, planning etc."

The ORNL work will be with Dr. James Lee.

\section{Discussion with Others:}

There was nothing resembling a tour on this trip because the laboratory has not changed in two years. Even the "sensitive, split-beam, differential kinetic spectrophotometer" which measures antenna size, and which was built piece by piece by Dr. Melis and his group has not changed. The reader is directed to my first report on the Melis system based on my site-visit of February 2001.

The scale-up system (4 liter bioreactors) is not set up yet. It will be located in a greenhouse likely starting in May, when the sunlight is direct enough. So there is nothing to see yet in the greenhouse.

What I was able to do, however, was to meet with members of Dr. Melis' staff (both current and former) who walked me through some of the pieces of the overall project.

\section{Dr. Jorgen Polle}

I spoke with Dr. Polle, who had been a post doc at Berkeley, but was out of the country when last I visited. Dr. Polle, who now teaches at Brooklyn College was asked to visit Berkeley by Dr. Melis, and I was able to talk with him.

As a postdoc, Dr. Polle worked on identifying and characterizing mutants and measuring their antenna size. Dr. Polle first started with a chl-b-less mutant that had been produced via DNA insertional mutagenesis. (We recall that chlorophyll-b generally appears only in the peripheral portions of antennae. If these trimers do not exist, the antenna size is smaller.) He also identified a kerotinoid-deficient mutant while at Berkeley.

Dr. Polle, when he first got to Berkeley worked with pigment mutants "because they were available". Later, he worked as a team with Dr. Sarada Kanakagiri, a molecular geneticist, who is also a postdoc in the group. Dr. Kanakagiri made the mutants and Dr. Polle characterized them. Dr. Kanakagiri, who I spoke with on my previous visit, was out of the country this time.

Dr. Polle was looking at the premise that if PSII antennae can indeed be reduced to 37 chlorophylls, is that enough? Can one ignore PSI? Or, could he cross two mutants, each one addressing one of the photosystems.

Below a particular level in a bioreactor pond, where there is little or no light, algae will naturally grow very large antennae in order to capture whatever photons they can. Later, they rise to the surface where their antennae are too big to efficiently use all the light that they absorb. If there is too much light at the surface, the large antennae actually get injured and must repair themselves. This process also uses energy. 
With a wild type chlamydomonas, 3-5 centimeters of depth is sufficient to absorb all of the light. Exhibit 4 is a rough plot that compares light levels for wild type and mutant algae as a function of pond depth.

Dr. Polle also found that for PSII, antenna size is directly proportional to photosynthetic capacity. He measured photosynthesis by measuring oxygen evolution. The correlation is not as clear with PSI.

Dr. Polle also discussed biochemical analysis that he performed on tlal as compared with the TLA gene (that Dr. Kanakagiri, was working with.)

The next steps, according to Dr. Polle, for PSII is to reduce the monomers in the antennae. (See Exhibit 3) The trimers are easy, but the monomers will be more difficult to reduce or remove. Outside of the PSI photosystem core, the structures are dimmers. These are also difficult to deal with.

Dr. Polle, prior to his departure, also looked at other mutants that Dr. Kanakagiri had produced. The mutants were screened visually, by chlorophyll fluorescence and by chl- $a$ to chl- $b$ ratio. Dr. Polle's suggestion to the continuing researchers is to look at additive mutants (e.g. tlal plus chl- $b$ mutants). Finally, Dr. Polle believes that one should try to have more sites with smaller antennae.

\section{Dr. Yutaka Komine}

Dr. Komine, another postdoc, has basically taken over Dr. Polle's work at Berkeley. He is using molecular biological techniques to clone the needed genes. One of his concerns is to make sure that the insertional mutagenesis technique is resulting in insertion at the correct gene site. He is using a polymerase chain reaction (PCR) to make a primer gene that he can clone and sequence. He is looking for the functional chlamydomonas gene, and then will clone it.

Dr. Komine is having some success with some of the mutants. He is working on two new species that could augment the effect of tlal. This is the type of work that Dr. Polle spoke about that is likely needed to push closer to the target of a 37-molecule chlorophyll PSII antenna.

\section{Dr. Andi White}

Dr. White is also a postdoc. She is a biochemist/physiologist, and is the person who will be doing the scale-up work in the greenhouse. She will be investigating photosynthetic efficiency, comparing wild chlamydomonas with tlal mutant. She has already looked at the effect of nutrient addition, but found that there was none. 
After working on other projects over the winter while the sunlight was insufficient for the scale-up work, she will be ready to try to produce hydrogen in 4 liter reactors starting in May.

Dr. White has a logistics problem; the greenhouse is at one end of campus and the GC to measure hydrogen is at the other end.

As sensitivity to contamination is a potential problem with Chlamydomonas, even though Dr. Melis, based on some recent results, is not as concerned about this as he was two years ago, I asked Dr. White her opinion about this. She believes that Chlamydomonas is fairly insensitive to contamination, but, she said, "you can't spill it on a bench."

\section{Additional Items:}

Dr. Kanakagiri, as mentioned, was out of the country at the time of my visit. Dr. Melis discussed Dr. Kanakagiri's efforts. She was responsible for the genomic DNA work, doing the gene/nucleic acid sequencing. This included the analysis of the messenger RNA. A protein analysis shows the tlal gene.

The plan for the future is to look at additive effects that would incorporate the antenna reducing capabilities of chl- $b$-less mutants, tlal mutants, and new mutants that Dr. Melis believes will come out of the work that Drs. Kanakagiri and Komine are now doing that will become tla2, and tla3, etc.

\section{Final Thoughts}

The Berkeley antenna work continues to move along. It's getting close to the time that another very important piece of the puzzle will be added: What is the direct relationship between antenna size and hydrogen production? We have indirect confirmation that smaller antenna size leads to increased hydrogen production. The increased amount of oxygen measured when small-antenna mutants are exposed to high light indicates increased photosynthesis efficiency. This implies higher hydrogen evolution as well. The upcoming greenhouse 4-liter scale up will be very important to confirm the effect on hydrogen production directly.

The tla1 mutant has proven to be very effective in lowering antenna size. However, the numbers of chlorophyll molecules (i.e., antenna size) for the best system so far has not really changed in the past two years, being about 114 for PSII and 159 for PSI. The Berkeley group is making progress toward identifying new small antenna mutants, but really need to concentrate on trying to combine the effects of several mutants to push the envelope closer to the targets. 


\begin{tabular}{lll}
\hline Parameter & wild type & tla I \\
\hline mol $\times 10^{15} \mathrm{Ch} /$ cell & $2.4 \pm 0.5$ & $0.9 \pm 0.06$ \\
$\mathrm{Chl} a / \mathrm{Chl} b$ & $3.0 \pm 0.12$ & $8.1 \pm 0.33$ \\
$\mathrm{Q}_{\mathrm{A}} /$ total Chl & $2.86 \pm 0.09$ & $5.38 \pm 0.65$ \\
$(\mathrm{mmol}: \mathrm{mol})$ & & \\
$\begin{array}{l}\mathrm{P} 700 / \text { total Chl } \\
(\mathrm{mmol}: \mathrm{mol})\end{array}$ & $1.63 \pm 0.17$ & $2.46 \pm 0.52$ \\
$\mathrm{x} 10^{-18} \mathrm{~mol} \mathrm{Q} /$ cell & 6.9 & 4.8 \\
$\mathrm{x} 10^{-18} \mathrm{~mol} \mathrm{P700/cell}$ & 3.9 & 2.2 \\
$\mathrm{PSII} / \mathrm{PSI}$ & 1.8 & 2.2 \\
\hline
\end{tabular}

Exhibit 1. Chlorophyll parameters and photosynthetic apparatus organization for wild type and tlal of Chlamydomonas reinhardtii

\begin{tabular}{ccc}
\hline Protein & wild type & tlaI \\
\hline Chl-PSII & $222 \pm 26$ & $114 \pm 36$ \\
Chl-PSI & $240 \pm 4$ & $159 \pm 12$ \\
CP26 & $100 \%$ & $18 \% \pm 6$ \\
CP29 & $100 \%$ & $64 \% \pm 2$ \\
LHCII & $100 \%$ & $62 \% \pm 6$ \\
\hline
\end{tabular}

Exhibit 2. Photosystem chlorophyll antenna size and relative amounts of various LHC proteins in wild type and tlal. 


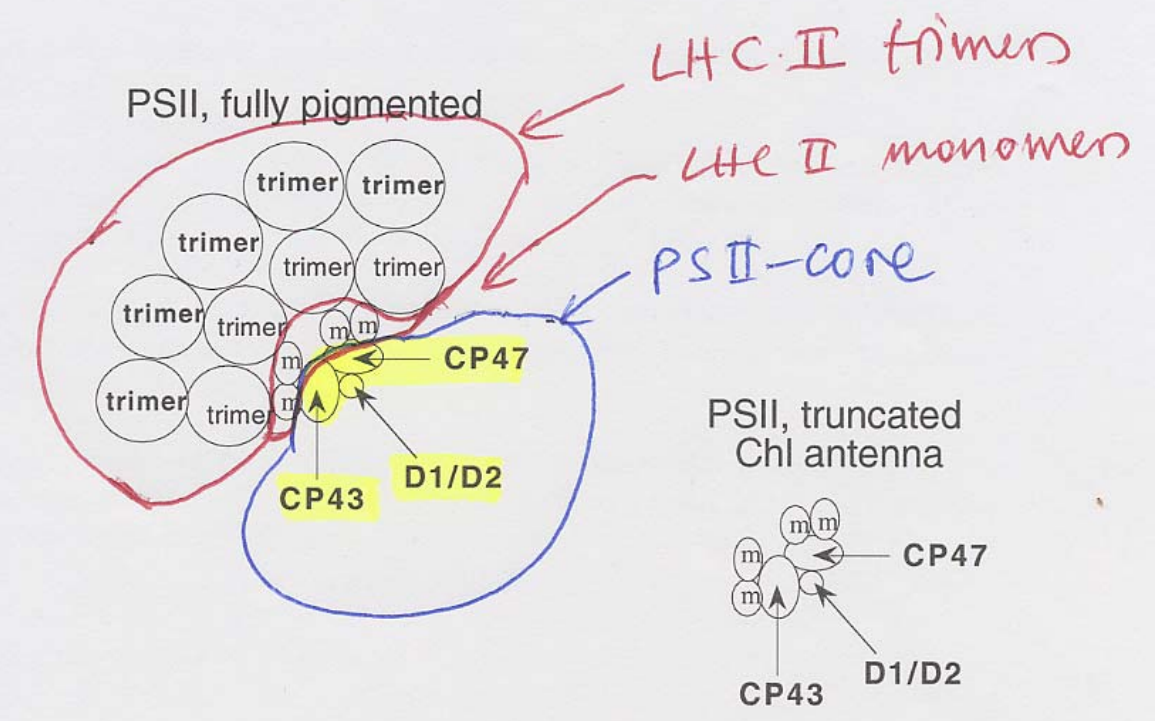

Exhibit 3. Drawing of the PSII antenna structure

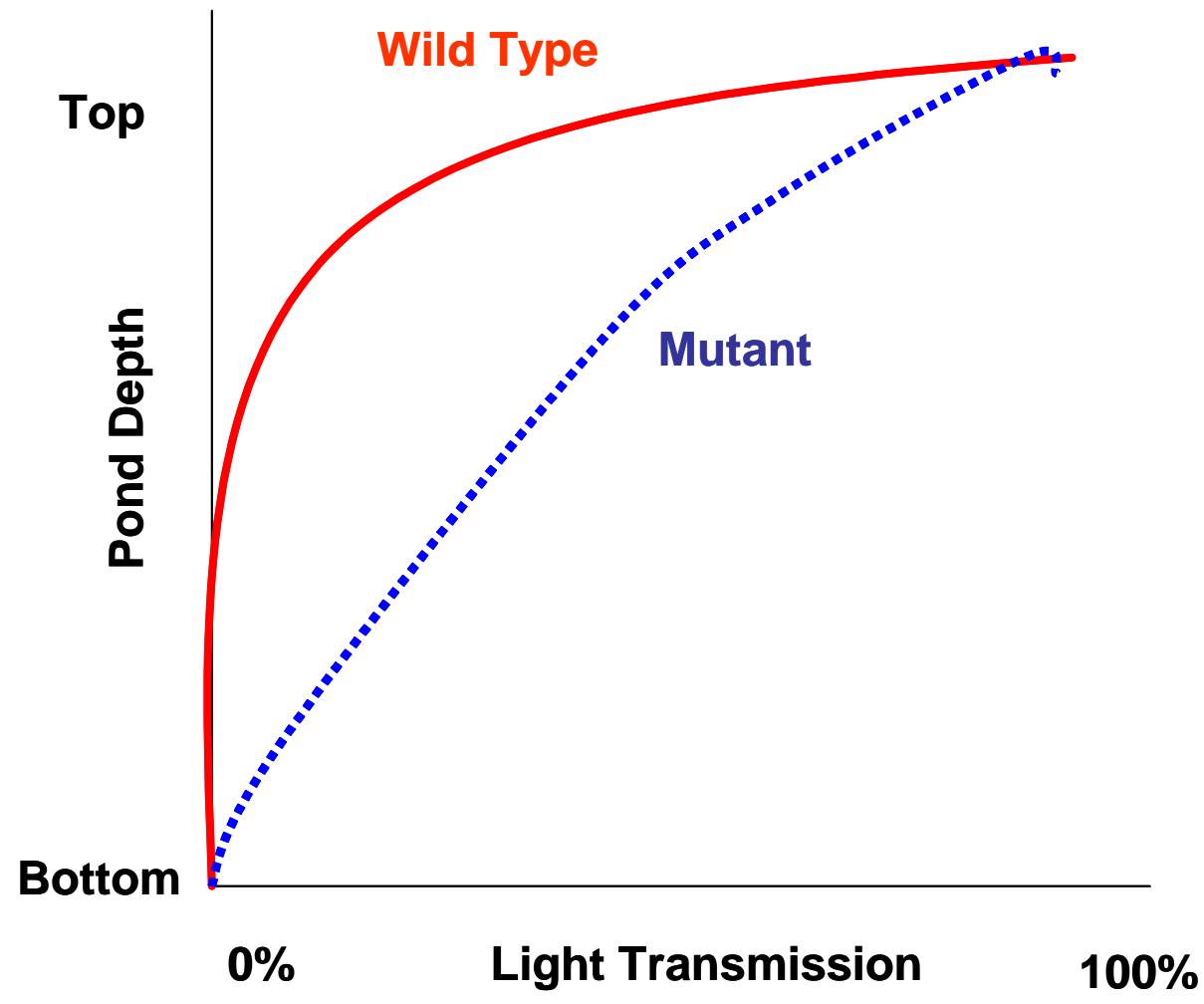

Exhibit 4. Representation of light penetration as a function of algae pond depth for large antenna wild type algae and small antenna mutants. 
Technical Evaluation Report

Project: Interfacial Stability of Thin Film Hydrogen Sensors

Company: National Renewable Energy Laboratory

P.I.: Dr. Roland Pitts

Site-Visit Date: May 6\&7, 2003

Evaluation by: Edward G. Skolnik, Energetics, Inc.

\section{Summary:}

The sensor work at the National Renewable Energy Laboratory (NREL) involves the development of materials which are placed at the end of an optical fiber and that undergo a chemical reaction when exposed to hydrogen, that results in a color change. A light source and detector will pick up this change. This "chemochromic" sensor work at NREL has progressed from work with dense tungsten oxide $\left(\mathrm{WO}_{3}\right) /$ palladium $(\mathrm{Pd})$ layers, looked at two other concepts involving surface plasmon configurations and metal hydrides, and then came back to $\mathrm{WO}_{3} / \mathrm{Pd}$ and similar systems which are more porous then the ones used earlier. Porosity allows faster diffusion of hydrogen in and out of the layers, and therefore, a quicker response time. NREL has verified sensitivity and cycling capabilities with their sensors and are currently addressing problems caused by exposure of the sensor layers to atmospheric and local impurities. Thus, recent work has involved the identification, development, and verification of protective layers for their sensors.

NREL currently has two sensor configurations that they have worked extensively with: the $\mathrm{WO}_{3} / \mathrm{Pd}$ sensor and the $\mathrm{V}_{2} \mathrm{O}_{5} / \mathrm{Pd}$ sensor. (A third candidate, a nickel oxidetungsten/palladium sensor has also shown some promise but is not nearly as far along.) With the tungsten/palladium sensor, exposure to hydrogen causes a marked reversible darkening in the tungsten oxide layer and a much lesser reversible increase in transparency in the palladium layer. The detector is effectively measuring the amount of coloration in the $\mathrm{WO}_{3}$ layer. With the vanadium/palladium sensor, hydrogen exposure causes an irreversible darkening in the vanadium level, and, as above, an increase in transparency in the palladium level. The darkening of the vanadium layer is the stronger effect, but it is both irreversible and finite. After several cycles, the vanadium layer has reached a constant degree of transmission (less than the original), and from this point on it is easy to measure hydrogen presence as an increase in transmission in the palladium layer.

NREL has also been developing a proprietary "self-cleaning" coating.

I see the following strengths in the project:

- Most of the targets appear to have been reached with the tungsten sensor

- The group is addressing what is likely the most serious remaining problem.

- A reliable, fast-response sensor is a critical need among many safety needs. 
I see the following items that need to be addressed:

- It appears that the project is being compromised to a degree, by the lack of time on shared equipment and by the presence of other projects actually poisoning the sensors.

- The targets on low temperature and relative humidity will be difficult to meet.

- Definitive performance data is needed on the proprietary coating.

- The necessity of linear response, the range over which (if any) linear response is necessary, and the implementation of those targets must be worked out.

\section{Introduction, Background, and Overview:}

I visited the sensor project at NREL, where I was hosted by PI Dr. Roland Pitts, spending the afternoon of one day and the morning of the next with him and two members of his staff, Staff Scientist Dr. Ping Liu and Postdoc Dr. Dave Smith. I also met more briefly with two other members of Dr. Pitts' staff: Senior Staff Scientist Mr. Edwin Tracy and Staff Scientist Dr. Se-Hee Lee.

I was given a tour both of the laboratories where sensors and sensor materials are made and also where diagnostic equipment is housed. We also spent several hours in discussion including several questions that I had previously sent to Dr. Pitts.

A starting point for our activities was a detailed synopsis of the history of this nine-plus year old project. Dr. Pitts discussed the original concept of the previous PI, Dr. David Benson. The crux of the work, begun in 1994, was the concept that tungsten trioxide $\left(\mathrm{WO}_{3}\right)$ would, in the presence of hydrogen, undergo chemical changes that could be measured by changes in the color of the sensor. This stemmed from some work involving an electrochromic window device. NREL found that if you take $\mathrm{WO}_{3}$ and make a plate out of it, and hook it up to a battery, the plate gets dark. This takes about 0.5 volts. (Other metals such as vanadium and molybdenum also exhibit a good electrochromic effect, but tungsten was the most deeply colored.) The thought was that hydrogen could do the same thing if there was material around that could dissociate the hydrogen molecules - such as palladium. The group showed that by depositing $\mathrm{WO}_{3}$ and then palladium onto an optical cable, the optical changes could be detected either in transmission or reflection. The signal, however, drifted, the reaction time was slow and the sensitivity was poor.

Dr. Benson worked to improve the product for about four years, and then in 1998, they branched off to consider a surface plasmon concept. Here, the thin film stack is deposited onto the end of a prism. Dr. Pitts hand-drew a sketch of the system, shown in Exhibit 1. The surface plasmon system relied on total internal reflection, and at 5-6 seconds response time, was much faster as well as more sensitive than the old system. However, it 
could easily be compromised by humidity and other environmental factors. Water caused a shift in the absorption band, and decreased the sensor life. The project was abandoned after one year.

The following year, Dr. Benson's group studied the use of rare-earth hydrides as the sensor film. The materials used were $\mathrm{GdH}_{2}, \mathrm{YH}_{2}$ and $\mathrm{GdMg}_{\mathrm{x}} \mathrm{H}_{2}$. Exposure to hydrogen creates the tri-hydride in all cases, resulting in optical changes: The di-hydride is metallic and reflective, while the tri-hydride is a weak semi-conductor and transparent. The hydrides proved to be quite sensitive (responded to $0.5 \%$ hydrogen) and the response was fairly rapid (about 10 seconds). However, the film would crack upon exposure to more than $2-4 \%$ hydrogen, was adversely affected by moist air, and had cycling problems. This approach too, was abandoned.

Drs. Pitts and Liu joined the group in 1999, and Dr. Smith, who was at that time employed by DCH Technologies was also working with the group in a joint arrangement. Dr. Benson retired that year. The work went back to looking at $\mathrm{WO}_{3}$, but focused on reducing the response time by reducing the density via increasing the porosity. This allowed for faster hydrogen transport. The high porosity $\mathrm{WO}_{3}$ is also the most sensitive sensor material that NREL has today. The work on the tungsten system has, over the past couple of years focused on developing a protective coating that will prevent sensor deterioration in the presence of impurities.

NREL has also been working on other (non tungsten) systems. The primary one is $\mathrm{V}_{2} \mathrm{O}_{5}$. This also is used in conjunction with palladium. $\mathrm{V}_{2} \mathrm{O}_{5}$ acts as a buffer layer, but also enters into the reaction with hydrogen. $\mathrm{V}_{2} \mathrm{O}_{5}$ is very robust, but Pd can still be attacked, so a protective coating layer is needed here as well.

NREL has also investigated tungsten-doped NiO. The film, 5-15\% tungsten, has the chemical makeup $\mathrm{NiO} \cdot \mathrm{W}_{\mathrm{x}}$. Here again, the Pd layer is unstable in air.

Dr. Pitt's group has limited experience with the $\mathrm{V}_{2} \mathrm{O}_{5}$ and $\mathrm{NiO} \cdot \mathrm{W}_{\mathrm{x}}$ systems because the equipment used to make these films belongs to another group. However, they have tested both of these types of sensor for "thousands of cycles" and have demonstrated good stability, except for the Pd surface.

When the $\mathrm{V}_{2} \mathrm{O}_{5} / \mathrm{Pd}$ sensor is used, the vanadium layer gets slightly (but irreversibly) darker, but the palladium gets very clear, increasing transmission. However, palladium alone would go through a decrepitation process (expansion and contraction) which eventually leads to cracking. The presence of vanadium oxide relaxes the palladium, stabilizing it against cracking. This increases the cycle life of the device, even in $100 \%$ hydrogen.

With $\mathrm{WO}_{3}$, the coloration is sufficiently deep to overcome the clearing effect of Pd.

The vanadium sensor signal is nearly linear up to about $4 \%$ hydrogen, while with the vanadium sensor, the signal becomes saturated at about $0.5 \%$. 


\section{Status:}

A common theme between the types of sensors is that there is a need for a protective coating. In fact, keeping the Pd layer clean has become the primary problem for, and the primary focus of, this research. Dr. Pitts has commented that if you leave a metal surface exposed in an ambient atmosphere at less than $100^{\circ} \mathrm{C}$, it will become contaminated.

NREL has found that they can do some cleaning using ultraviolet radiation and ozone. Thus, one of the areas that NREL is investigating is photo-oxidation.

An alternative approach was to use a sieve-like coating that would pass hydrogen, but nothing else. NREL had been considering amorphous carbon that was applied using chemical vapor deposition (CVD). It made the hydrogen diffusion rate unacceptably slow, however.

NREL has investigated both organic and inorganic types of protective coatings. Their results have led them to down-select to one material. That material and some of its properties is proprietary. We will refer to that material simply as a "protective coating". The proprietary material does not slow the hydrogen diffusion rate.

At this time, NREL is still experiencing some inconsistency in the effectiveness of the coating, and in NREL's own ability to optimize it. Dr. Pitts is not yet sure why this is happening.

Turning to questions about the sensors themselves, Dr. Pitts indicated that they have always (even before specific targets were set) tried to make the sensors quick to respond and robust. Dr. Pitts is still concerned about how they will deal with $100 \%$ relative humidity and with ice, and how they will make the sensor robust enough to last 5 years. They think that they can make the Pd catalyst last, and believe that CVD-deposited polycarbon will work to handle high humidity, even though it will slow response time somewhat. More work is needed with operating conditions near $-30^{\circ} \mathrm{C}$.

The major problem may be to "do it all at once": response time, quantitative response, $30^{\circ} \mathrm{C}, 100 \% \mathrm{RH}$. This, admits Dr. Pitts, may be very difficult.

\section{Tour:}

The laboratories where Dr. Pitts' materials are manufactured, assembled, and tested are located in the Field Test Laboratory Building (FTLB) and the Solar Energy Research Facility (SERF). All long term testing is done in the FTLB. According to Dr. Pitts, the FTLB has sufficient pollution within it to adequately test the systems. Some of the deposition work is done in the SERF.

In one of their labs in the FTLB, Dr. Pitts showed me a conceptual "box" for a sensor system. The box, equipped with 62.5 micron optical cable, would be placed in a 
hydrogen-free area, and the cables would go through the frame of the car and protrude into the areas to be tested. The end of the cable would be capped with glass with the coatings on it. These tips would be replaceable. Fibers could be bundled if necessary. Past the tip, the cable is merely standard fiber optic materials.

In the same lab is a test apparatus consisting of tanks of hydrogen, a manifold, flow meters, and a sample test specimen. The reaction chamber volume is less than $1 \mathrm{cc}$. A flatspectrum halogen light source illuminates the sample through glass A photosensor diode is interfaced to a computer . An obvious optical effect was seen after running a $2 \%$ hydrogen stream through the sensor. Much of the past year's work on this system has involved trying to solve problems with the proprietary protective coating.

Contamination testing utilizes $\mathrm{CH}_{4}, \mathrm{CO}$, and $\mathrm{H}_{2} \mathrm{~S}$ contaminants. They keep these in a hood, and either bring the sensor into the hood, or run lines from the hood to the tester. If the sensor is uncoated, says Dr. Pitts, you only need exposure for a few minutes time to lose the hydrogen signal.

The lab also contains the environmental test chamber. (See also Question 8).This is just a regular picnic-style cooler. To get to cold temperatures, they put an aluminum block in there as a heat sink, put the sample on the block, and fill the chamber with dry ice and some liquid nitrogen. Relative humidity is set by saturating the gas stream and then diluting it to get the desired percentage. They are, however, looking at improving their ability to measure temperature and relative humidity accurately.

There is one evaporator in the lab. They use this Edwards Evaporator occasionally for some deposition work, but it tends too heat the substrates a little too much.

In the SERF building the group lab contains a 20 -year old vacuum evaporator. They can load up to three "boats" in this system as there are three sets of electrodes. They have palladium boats and tungsten oxide boats. Usually they load two boats, one of each. They can put down dense $\mathrm{WO}_{3}$ or hydrated, porous $\mathrm{WO}_{3}$, letting water in to do this. They put down a layer of hydrated $\mathrm{WO}_{3}$, then pump out the water vapor, leaving the less-dense material, and then start up the other electrodes to lay down palladium.

A problem that Dr. Pitts is having is that other groups use this evaporator also, thus presenting a source for impurities. This is a serious problem if another group is using substances that poisons the sensor materials. Thus, Dr. Pitts' group is investigating other techniques: including wet chemical processes, electrodeposition, and metal/organic decomposition. While it is important to investigate other techniques, the fact that other groups use the evaporator should never be a criterion for down-selection.

In the same lab is a Microscience plasma-assisted CVD system. They use this to grow dense $\mathrm{V}_{2} \mathrm{O}_{5}$. Then they go to the evaporator and evaporate palladium on it. The CVD system is not suitable for palladium, as the precursor would be a toxic palladium carbonyl. 
When making the $\mathrm{NiO}$ sensor, they use a sputtering device that is in a separate lab that does not belong to the group.

Analysis of the sensor layers is performed using many different instruments in various laboratories that are either common to several groups or which belong to other groups. Included are:

- An XPS (X-Ray photoelectron spectroscopy) using a 5600 ESCA system that can read the first five monolayers of the film. Alternately, you can use a focused ion beam to get under the surface.

- A scanning Auger spectrometer that works as a scanning electron microscope (SEM) as well.

- Nicolet FTIR (Fourier Transform Infrared) and FT Raman instruments (but these cannot be used to study contamination.)

- There is a SIMS (secondary ion mass spectrometry) system available to measure concentration in ppm, but its availability is limited. Therefore, the group often will go to the Colorado School of Mines (also in Golden) and use their instrument.

- Surface/topographic scanning can be performed using either SEM or AFM (atomic force microscopy) instruments.

- The Raman laboratory contains the single-pass-with-filter instrument that Dr. Pitt's group uses. They use it to see where the ion inserts in a metal and oxide structure.

\section{Questions and Answers:}

Prior to my visit, I sent Dr. Pitts a list of questions based on several of his group's review reports. Dr. Smith answered the questions in writing at Dr. Pitts' request, and emailed the answers to me prior to my arrival. We all discussed the questions and answers in detail during my visit. This is all reproduced here, with the questions indicated in bold, written answers reproduced "verbatim in quotes", our discussion shown in normal type, and my comments added to many of the questions during my later analysis and assessment shown in italics.

\section{Would the protective coatings being tested work for electrically-based as well as optical sensors?}

"There is no reason that they shouldn't. Although some preliminary tests were done on ORNL thick film resistive hydrogen sensors, the majority of the work has been done on our optical thin films." 
NREL believes that the coating would work for any Pd-based sensor system, or any system that uses a hydrogen dissociation process. You would, however, always need a battery or a fuel cell to keep the sensor operating. The sensor itself, perhaps, would not have to be on all the time (running off of a pulsed diode, maybe to keep power consumption down and sensor life maximized) but the detector would have to operate continuously.

NREL hasn't really been considering the engineering design of the sensor system yet.

Dr. Pitts thought that maybe you'd need some kind of light/heat source to desorb water; maybe only the thin film needed to be heated. Water/ice on the sensor is one of the major obstacles still to be passed.

A single protective coating system that would work for all sensors would be of value.

\section{Please explain the difference in the use of tungsten in the Ito work and in the Benson work.}

"The Ito sensor was an anodized $\mathrm{WO}_{3}$ film with a thin $\mathrm{Pd}$ overcoat. The measurements were made in reflectance, otherwise quite similar to our $\mathrm{WO}_{3}$ based sensors. The Benson sensors used surface plasmon resonance (SPR), requiring an additional layer of silver or gold. The principle behind SPR is based on light adsorption in a thin metal layer causing oscillation of free electrons, or surface plasmons. Hydrogen adsorption by the underlying $\mathrm{WO}_{3}$ causes a change in its refractive index and a subsequent resonant wavelength shift, which is then measured. We steered away from SPR because of the additional complexity and the signal interference from changes in relative humidity."

In addition, the Ito sensor configuration was a tungsten foil, and was not amenable to being put on a fiber optic.

\section{What are the goals for time in operation for sensors in vehicles and stationary sensors?}

"For safety sensors, the proposed program goals are:

- Measurement range: $0.1-10 \% \mathrm{H}_{2}$ in air

- Operating temperature: $-30-80^{\circ} \mathrm{C}$

- Response time: $<1 \mathrm{~s}$

- Accuracy: $5 \%$

- Gas environment: ambient air, 10-98\% RH range

- Lifetime: $5 \mathrm{y}$

"Selectivity from interference gases, such as hydrocarbons, is needed."

These are the requirements set forth earlier by the Program based on older Office of transportation Technologies targets. NREL had earlier only been aiming for $0.5 \%$ hydrogen for the minimum on the measurement range. The older number had evolved after some discussions between NREL and Hughes Research Laboratory. 
The $5 \%$ accuracy is a difficult target. The $\mathrm{WO}_{3}$ sensor saturates early, so it's basically a "go/no-go" scenario. The $\mathrm{V}_{2} \mathrm{O}_{5}$ sensor is linearly sensitive to about $4 \%$ hydrogen, and shows change up to about $10 \%$.

NREL hasn't really looked at sensitivity to any great extent yet. They need to do a calibration, but, according to Dr. Pitts, they don't presently have the money to really investigate this.

Both Dr. Pitts and I agree that the 5\% requirement should probably be revisited.

I think that the requirement should really be more of an on/off thing. If you are within a certain range of the lower flammability limit you need a signal. This number should be tied to other requirements for lower flammability set in standards.

One key need is to ensure that we are rid of false positives. The selectivity issues (that is, making sure that if you get a reading it's hydrogen that you are sensing, not, say, a hydrocarbon. Pd sensors that work on decomposition and diffusion of hydrogen are basically selective by definition. Hydrogen is the only material that would dissociate under these conditions.

\section{How many sensors, and how many controllers would be needed for a "standard" PEM fuel cell passenger car?}

"Our estimate is that an array of 8 to 10 sensors would be needed. Theoretically they could all be monitored from a single multiplexed controller."

During our discussion, Dr. Pitts estimated: one in each wheel well (4) and one each in the engine compartment, trunk, and passenger area, for a total of 7. A bus would likely need more. Redundancy would also be a good thing to consider.

\section{Please discuss how the investigations on failed articles are carried out in the Device Characterization Lab at NREL.}

"Roland can give you more information on this. As far as our sensor films, we have a variety of surface analysis techniques to use including SEM/TEM, AFM, XPS and SIMS. "

Much of this was covered in the "Tour" section. In addition, the group used optical microscopy when they were investigating hydrides. You'd see "grains" missing where palladium came out. They don't use microscopy much now. They are looking for chemical rather than physical changes. Auger spectroscopy is best for this.

\section{Are the coatings (both organic and inorganic) physically or chemically bonded to the sensor? \\ "The amorphous carbon films were deposited by PECVD."}


Organic coatings are basically filters to screen out gases other than hydrogen. They are mainly fluoropolymers (like Nafion ${ }^{\mathrm{TM}}$ ). Most are physically adhered, but there are some polymeric films that provide some chemical bonding.

\section{Looking at Figure 3 of your 2002 Review Report:}

\section{a. What is the " $y$ " axis parameter?}

"The y-axis should read "Relative \% Transmittance".

\section{b. Was the " 100 " reading before exposure to hydrogen the same 100 as it was a year earlier when the sensor was new, or is it re-normalized?}

"The sensor is "re-zeroed" before each measurement."

Based on this, I asked what the result would be if they did not re-zero. Dr. Smith indicated that they would not be the same. The film gets darker over time. There is some hydrogen that "never comes out". After cycling a few times, however, the drift gets pretty small. It settles out in a few days. Sensors will most likely be set off based on rate of change of signal, not absolute numbers.

I guess we could surmise that if we took a sensor that had cycled 10 times, and then used it, the baseline would remain more-or-less constant from then on. This sounds like a call for exposure and cycling to be done before a sensor leaves the factory.

\section{c. Under what conditions were the sensor/coating prepared and aged?}

"Sensors are prepared by thermal evaporation. For protective coatings see question 6. Uncoated sensors are stored under nitrogen. After coating they are stored in a UV box under $365 \mathrm{~nm}$ illumination."

Ideally they'd want to find a way to activate their coating in the visible range. A visible light is cheaper than a ultraviolet source.

\section{d. What exactly are we seeing in the trace?}

"The trace is the transmittance change over time due to coloration of the $\mathrm{WO}_{3}$ forming a "hydrogen tungsten bronze". The uncolored $\mathrm{WO}_{3}$ is transparent whereas the bronze is dark blue."

The quick recovery time is due to flushing the system with air.

\section{e. How does the trace compare to one done a year ago?}

"Here is the response of a fresh sensor compared with the same sensor one year later." 
Shown in Exhibit 2. The key thing is that there is not continuous change, say continuous darkening that begins to compete with the signal initiated by hydrogen exposure.

\section{In the Environmental Test Chamber, what is the purpose of the dry ice?}

"We use dry ice and $\mathrm{LN}_{2}$ to cool the sample chamber below ambient temperature, down to 40C."

I was reading more into the environmental test chamber than was really there. The dry ice just cools the chamber.

\section{In your $P d / V_{2} O_{5}$ sensor, what is happening chemically to the $V_{2} O_{5}$ ?}

"Vanadium oxide is partially reduced by the insertion of protons. That is why we refer to it as " $\mathrm{VO}_{\mathrm{x}}$ ". During the initial exposure to hydrogen, it undergoes an irreversible optical change after which the proton insertion becomes fully reversible while the color remains unchanged. The palladium layer actually produces the optical response due to the formation of $\mathrm{PdH}_{\mathrm{x} .}$.

You probably wouldn't have to intentionally "cure" the sensor to get the vanadium color change to finish; you could still use the sensor before the color change was finalized if your electronics allowed it. However, as Dr. Smith pointed out, a sensor would be tested and standardized prior to shipment anyway. This would likely finalize the color change.

Finalization of the color change in the factory needs to become a requirement.

10. Why are the responses to hydrogen exposure a downward deflection in some cases and an upward deflection in others? (Referring to Figures 3 \& 4 vs. 6 \& 7 in the 2002 Annual Report, Shown here respectively as Exhibits $3 a, 3 b, 3 c$ and $3 d$ )

"See questions $7 d$ and 10 above. The transmittance of the $\mathrm{WO}_{3}$ decreases with exposure to hydrogen whereas it increases in the case of the $\mathrm{VO}_{\mathrm{x}}$ sensor."

The differences between the two sensors became obvious during the site-visit, though they were not as obvious in the Report.

\section{Please discuss Figure 8. (Exhibit 4)}

"Ping Liu can probably answer this question better, but I believe this is the response of a $\mathrm{VO}_{\mathrm{x}}$ sensor that was made using electrochemical deposition rather than evaporation. The lower trace is $4 \%$ hydrogen, the upper pure hydrogen. The lower trace shows the initial coloration of the $\mathrm{VO}_{\mathrm{x}}$ layer, masking the transmittance increase due to $\mathrm{Pd}$. After the $\mathrm{VO}_{\mathrm{x}}$ has colored the sensor behaves normally, although the relative signal change is much smaller than for an evaporated sensor."

Dr. Liu indicated that the $4 \%$ hydrogen curve was the first done, so the decay due to vanadium oxide coloration is seen. It more or less "overwhelms" the palladium response. The electrodeposition process results in a much more rapidly responding sensor than 
would evaporation. Electrodeposition results in long "pipes" of vanadium oxide. Electrodeposition is also a cheaper process.

The $100 \%$ hydrogen curve shows that the electrodeposition appears to protect the palladium from flaking -- which is a common occurrence in $100 \%$ hydrogen and an evaporation process. You are safe if the film is really $\mathrm{V}_{2} \mathrm{O}_{5}$, but if the material is lacking oxygen $\left(\mathrm{V}_{2} \mathrm{O}_{(5-\mathrm{x})}\right)$, the palladium layer is apt to flake. However, the process of making the film less susceptible to peeling also makes it less sensitive. Dr. Liu added, however, that they are learning how to control the evaporative process better, so they don't reduce the oxide.

The procedure for electrodeposition is as follows: NREL electrolyzes $\mathrm{VOSO}_{4}$ and water. A polymeric surfactant (polyethylene oxide [PEO] or polypropylene oxide $\mathrm{PPO}]$ ) is also present. Since the surfactant is less soluble it will assume a cylindrical form -- a micelle. The anode deposit is $\mathrm{V}_{2} \mathrm{O}_{5} \cdot \mathrm{H}_{2} \mathrm{O}$. This will coat the surfaces of the cylinder. When the surfactant is then burned off you are left with the $\mathrm{V}_{2} \mathrm{O}_{5}$ pipes.

NREL tried to use the electrodeposition process for tungsten oxide also, but found that there was no advantage to the resultant sensor -- and often it was worse.

Dr. Pitts added that the electrodeposition process might be of value if you were placing a sensor inside a fuel cell where you have $100 \%$ hydrogen and needed to eliminate peeling. As a leak detector, the evaporation process is probably better.

It appears that the electrodeposition process is of limited value. I think the statement by Dr. Liu where NREL is learning how to control the evaporative process better may be the key factor. If you do not reduce the vanadium oxide, you won't have a situation where peeling will occur in high hydrogen environments. You will also have more sensitive leak detection.

\section{How has recent work been progressing on increasing the temperature and relative humidity ranges?}

\footnotetext{
"The $\mathrm{WO}_{3}$ sensors are intrinsically susceptible to degradation at higher temperatures because the films tend to lose water. This affects sensitivity and response time. However, at higher hydrogen concentrations we have found that the effect is less pronounced for both types of sensors and we have tested them in $2 \%$ hydrogen/air up to $80 \mathrm{C}$ and $100 \% \mathrm{RH}$. Roland can show you our more recent data when you arrive at NREL."
}

They are making some progress here, but there are some problems. If the effect is less pronounced at higher hydrogen concentrations, then the overall signal is not linear. That's OK; I think we want an on/off anyway. But the implications of moisture and heat skewing the numbers will have to be determined, including its effect on sensor aging. 


\section{Additional Items:}

Repeated exposure to hydrogen at $-40^{\circ} \mathrm{C}$ will cause palladium to blister. The target is only $-30^{\circ} \mathrm{C}$, but -40 occurs in many parts of the world. Palladium is the backbone of many types of hydrogen sensors.

It is undesirable to use very much palladium; palladium is expensive and difficult to obtain. A coating no more than $20-30 \mathrm{~nm}$, and sometimes as little as $2-3 \mathrm{~nm}$, on a $500 \mathrm{~nm}$ layer of $\mathrm{WO}_{3}$ is sufficient.

Dr. Pitts has been talking to a company in Houston that is interested in NREL's fiber optic sensors.

\section{Final Thoughts:}

This project has been going on for a long time, and maybe some of it (surface plasmon work and rare earth hydrides) was unnecessary (or at least unfruitful). But that's past history. The key breakthrough for the past couple of years is the ability to make less dense tungsten oxide, and therefore to significantly reduce the response time to hydrogen exposure. This, plus the work with vanadium oxide indicates to me that the process will work.

Most of the targets are being met, although the temperature and humidity targets are proving difficult. In addition, some thought must be given to the "accuracy" target. I believe that we all need to take a step back and determine what is really needed. A blanket accuracy within 5\%, I don't believe really serves any purpose. What you mainly need is a signal that responds to a minimum amount of hydrogen. The $0.1 \%$ target seems reasonable; it really doesn't matter if the actual reading is $0.095 \%$ or $0.105 \%$ - it's just a number saying that there is a leak. What's more important is whether the number is rising. A second target should be a legitimate percentage of the lower ignition limit (perhaps Mike Swain's 20\% of L.I.L. or 0.82\%). So you'd have an "I need to look at this" number and an "I'd better get out" number. For any higher amounts of hydrogen, you'd just need to ensure that it is registering, even if the "needle is pegged".

If the NREL group is to do a thorough job on the sensors, I believe, they are going to need more control of equipment. If an evaporator is needed, they need to have/find one that won't poison their sensor layers. Using an electrodepositor simply because the evaporator is unavailable is not a good plan.

The proprietary coating work seems reasonable to date, but much data needs to be obtained, including some aging/recycling work The effect of relative humidity on the coating is also important. 


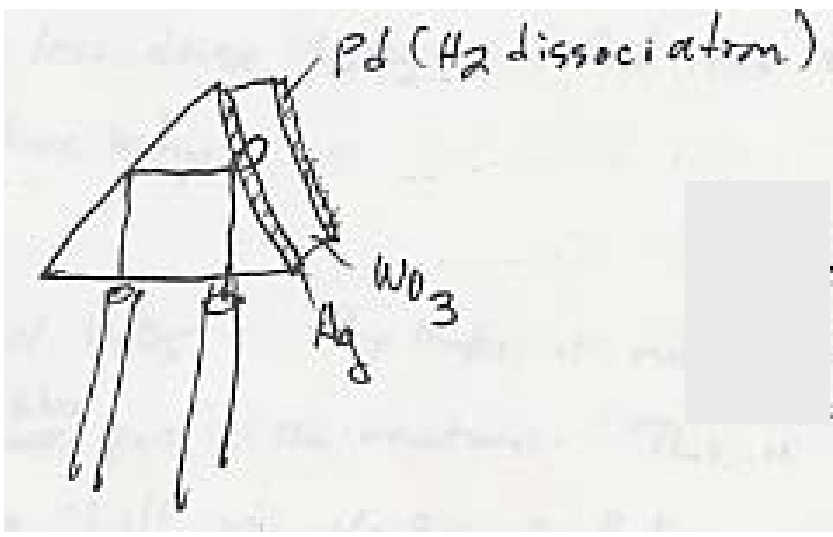

Exhibit 1. Drawing of Surface Plasmatron Sensor

w031601 (0.1\% H2)

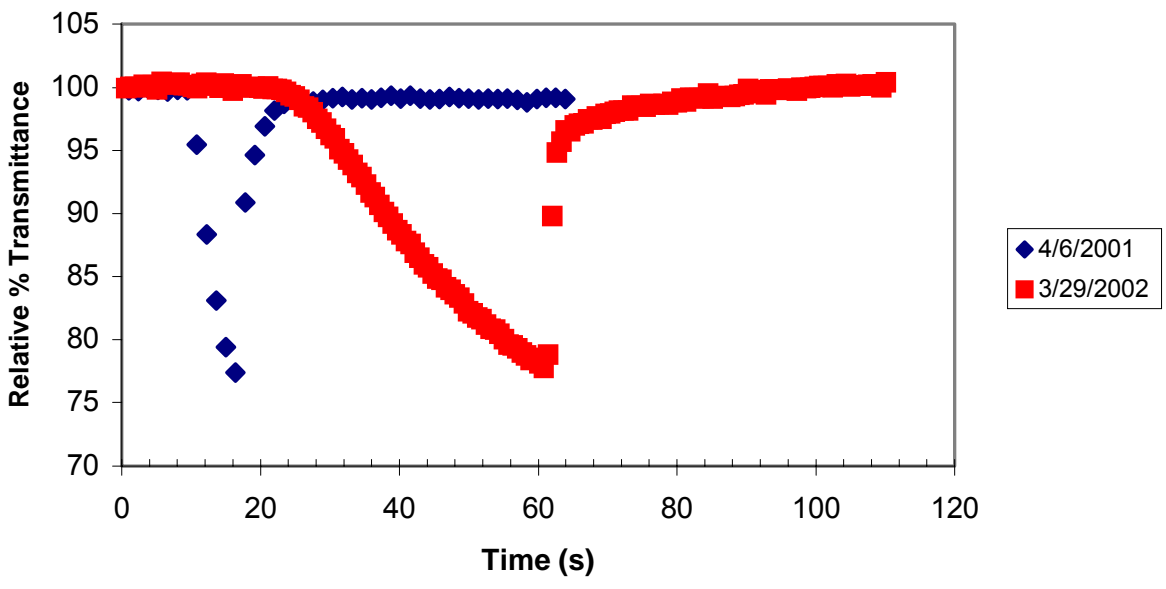

Exhibit 2. Traces of tungsten oxide/Pd film responses to $0.1 \%$ hydrogen for a new film and a year-old film. 


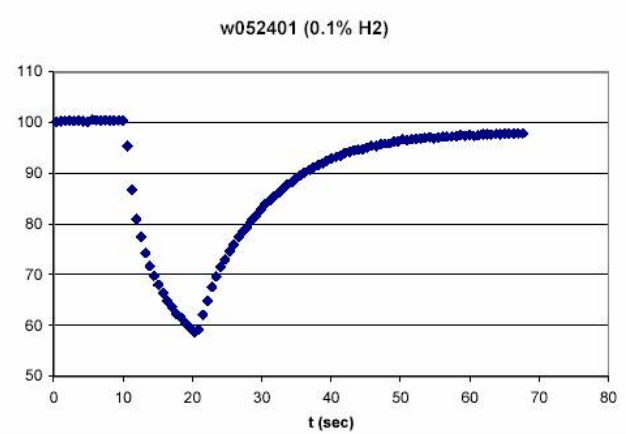

$3 \mathrm{a}$

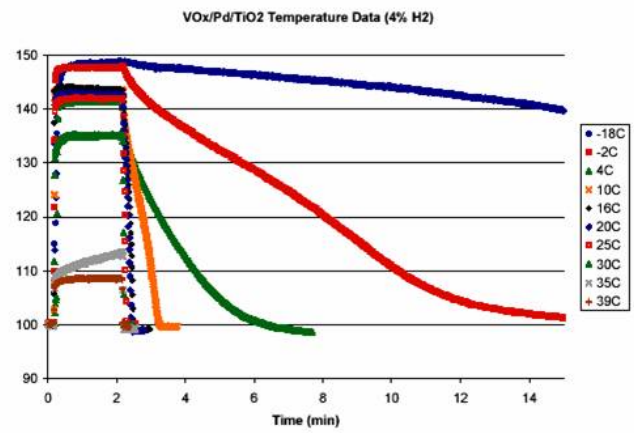

$3 \mathrm{c}$

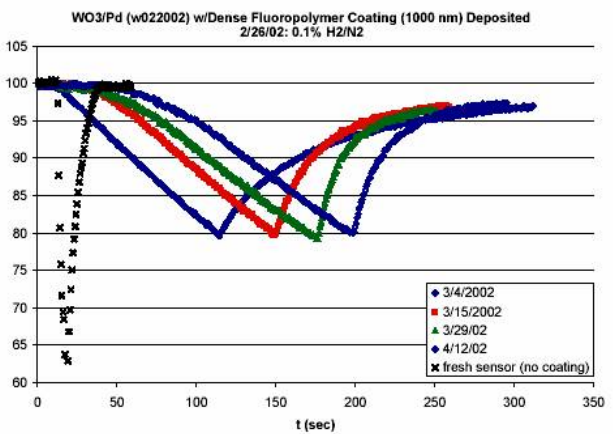

$3 b$

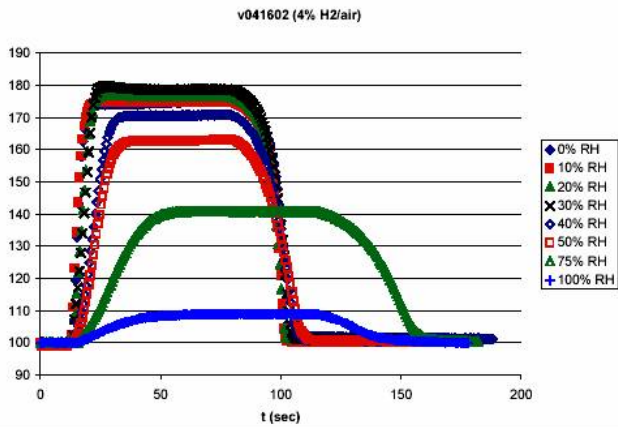

$3 d$

Exhibit 3. Typical traces for tungsten oxide/Pd films (3a and b) showing downward deflection in the presence of hydrogen, and vanadium oxide/Pd films ( $3 \mathrm{c}$ and $\mathrm{d}$ ) showing upward deflections.

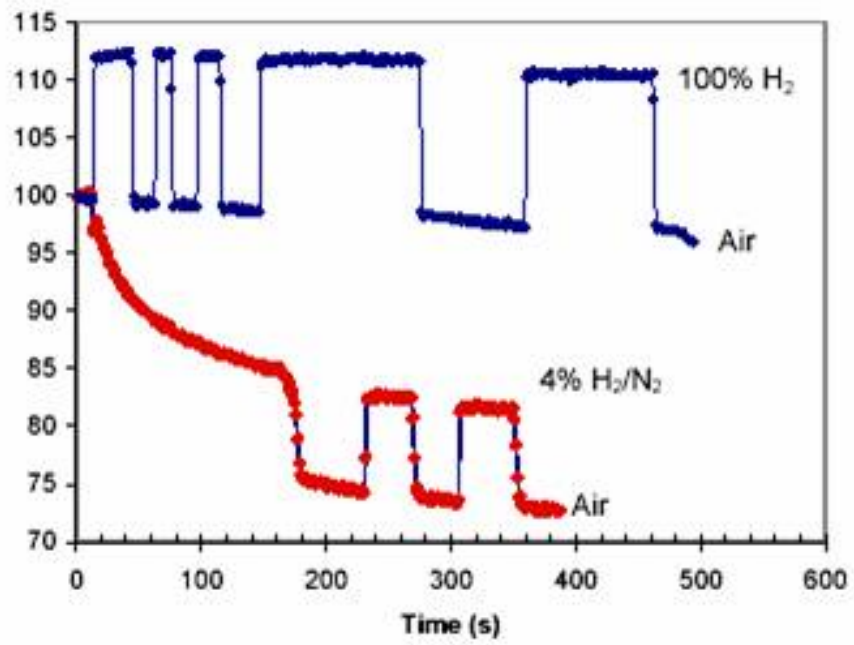

Exhibit 4. Vanadium oxide/Pd film traces in 4\% AND 100\% hydrogen 
Technical Evaluation Report/ Safety Protocol Data Report

Project: Gallium Nitride Integrated Gas/Temperature Sensors for Fuel Cell Systems

Monitoring for Carbon Monoxide and Hydrogen

Company: Fluence, Bend/Sisters, OR

P.I.: Dr. Stephen Pyke

Site-Visit Date: August 13, 2003

Evaluation by: Edward G. Skolnik, Energetics, Inc.

This report marks the beginning of a transition in our evaluation focus and methodology. With the growth of DOE's Hydrogen Fuel Cells and Infrastructure Technologies (HFCIT) Program both in size and in degree of exposure, the care that must be given by project personnel to safety has increased tremendously as well. The Codes and Standards and Hydrogen Safety arm of the HFCIT Program is in the process of developing the necessary protocol that will be used when safety evaluations are carried out on the Program projects. Currently, therefore, our site-visits include both a technical component, and also a safety component where we both address safety issues within the project itself, and solicit suggestions from the PI on what should be included in a safety review.

\section{Summary:}

Fluence, a one-man operation located in the Bend/Redmond/Sisters area in Central Oregon has been performing sensor R\&D for the past four years. Initial work was centered on the sensing of $\mathrm{CO}$ in hydrogen. $\mathrm{CO}$ is a byproduct of steam methane reforming and other types of hydrogen production from hydrocarbons. Although complete hydrogen production processes include steps to shift the $\mathrm{CO}$ (react it with more steam to produce hydrogen and $\mathrm{CO}_{2}$ ), the requirements for introduction of this hydrogen into a proton exchange membrane (PEM) fuel cell includes reduction of $\mathrm{CO}$ concentrations down to the $10 \mathrm{ppm}$ level. Higher concentrations of $\mathrm{CO}$ can poison the fuel cell. The sensor, thus is intended to identify increases in CO to the PEM fuel cell feedstock, so that the feed can be shut down. The Fluence sensors are being designed to operate in high hydrogen concentration atmospheres, such as a fuel cell would see. Much of the recent work has involved developing surface maps that plot hydrogen concentration vs. $\mathrm{CO}$ concentration expressed as sensor voltages. Common voltages are connected to form the contour lines.

Some initial work has already been done on the hydrogen sensor. The technology behind the two sensors is similar, but the applications are totally different. Some initial results indicate that the greatest voltage differences are seen where you most need them between $0.1 \%$ and $2 \%$ hydrogen concentration. There is some uncertainty about the need to measure hydrogen leaks quantitatively vs. is there a leak or not.

Issues that have been raised include: 
- Getting sufficient accuracy out of sensors of this type is done by intensive calibration. This is expensive. An understanding of the cost/benefits of level of calibration of this type of sensor is needed.

- For hydrogen leak sensing, a better understanding is needed on the value of having leak/no leak sensing or accurate leak rate or hydrogen concentration sensing.

- There are technical problems dealing with the sensor getting saturated with hydrogen.

- Response time is an important parameter that needs to be addressed.

\section{Introduction and Background:}

Dr. Stephen Pyke continues to perform sensor R\&D from his home/Laboratory in Central Oregon. I had visited Dr. Pyke about two years ago to do a technical evaluation of his $\mathrm{CO}$ sensor. The present meeting was designed to discuss progress on the $\mathrm{CO}$ sensor, investigate progress on the hydrogen sensor that Dr. Pyke is now also developing, re-investigate the laboratory area with more of an eye toward safety, and obtain opinions and insights from Dr. Pyke on hydrogen safety in general and in a small laboratory environment.

Since our last meeting, Dr. Pyke has moved his laboratory from the basement of his home to an area outside, adjacent to the house, and under a deck. Some significant progress has been made on the $\mathrm{CO}$ sensor, where now concentrations of $\mathrm{CO}$ vs hydrogen can be completely mapped in terms of sensor voltage.

Some initial work has already been accomplished on hydrogen sensors using $\mathrm{GaN}$ semiconductors. Dr. Pyke intends to eventually investigate silicon sensors which are cheaper, and which will be effective in the lower temperature regimes in which a hydrogen sensor would operate.

In discussing safety issues, Dr. Pyke mentioned that he had done quite a bit of codes and standards work albeit about 15 years ago. Thus, Dr Pyke felt confident to discuss safety issues both directly about his project and in a more general manner.

\section{Questions and Answers:}

I sent Dr. Pyke a set of discussion questions prior to my arrival. These involved CO sensor issues, hydrogen sensor issues, and safety issues. During our meeting, we discussed the questions and answers in detail. This is all reproduced here, with the questions indicated in bold, our discussion shown in normal type, and my comments added to many of the questions during my later analysis and assessment shown in italics.

\section{CO Sensor:}




\section{What are the major accomplishments/changes in the project in the past two years?}

From a physical standpoint, the major difference is the moving of the laboratory to a position outside the house. There is no longer any hydrogen inside the house. See Question 2 in the Hydrogen Safety Section for a more detailed discussion of the setup.

From a technical standpoint, Dr. Pyke has moved into a mode where he creates matrices corresponding to set hydrogen and $\mathrm{CO}$ concentrations, and plots voltages at hydrogen and CO concentration pairs. An example is shown in Exhibit 1. Recall, that two years ago, Dr. Pyke was holding hydrogen constant. Now he is varying it. (He had already done the experiments in which oxygen, $\mathrm{CO}_{2}$, methane, and ethylene were varied, so he has accounted for their effects. The responses are non-linear. The patterns (such as the one in Exhibit 1) are reproducible, but the magnitude of the "peaks and the valleys" may be different.

The non linearity and irregularities cannot be explained by current theory (that is, by the fact that the sensor is sensitive to hydrogen, and CO modulates that effect.) Dr. Pyke is still trying to explain it. This is somewhat worrisome. We are dealing with a quite complex sensor - in fact a quite complex sensor system. We need a higher level of confidence than now exists.

The more calibrations performed on a particular sensor (voltage measurement at set $\mathrm{CO}$ and hydrogen concentrations) the more accurate it will be, but also, the more expensive it will be. This, not material costs according to Dr. Pyke, is the biggest expense associated with sensors of this type. Dr. Pyke is concerned about the politics that may come into play here, and asks: "do you want a calibrated sensor or just a statistic.

\section{Why is CO detection limited to $\mathbf{3 0 - 7 0 \%}$ hydrogen concentration?}

These limits were dictated by the sensor workshop as was $\mathrm{CO}$ concentrations of up to 80 $\mathrm{ppm}$. The objective is to detect as little as $10 \mathrm{ppm} \mathrm{CO}$, while the hydrogen concentration is changing.

\section{Is the detection of $\mathrm{CO}$ still based on the relative signals from a series of sensors using different gate metals?}

Yes, but $\mathrm{Pd} / \mathrm{Ag}$ is not in the mix anymore. Over time, this mixed metal gate material seems to segregate into palladium and silver. Platinum and rhodium are still used, and iridium (another catalyst used in PROX work) has been added.

\section{Why was iridium added to the gate metal system?}

By adding Ir, the capabilities are expanded. For one thing, it has been used with $\mathrm{SiC}$ systems, which Dr. Pyke wants to get into with hydrogen sensors. It also adds an 
additional data point for $\mathrm{CO}$ sensors, and is a refractive metal that can handle high temperatures without changing.

\section{Is Innosys now providing the GaN? Is GaN availability in sufficient quantity still a concern?}

Yes and No. Hughes Research Lab (HRL) provided the GaN for this second phase of the project, but Inosys is laying down the metals and the contact materials.

GaN is available in sufficient quantity now. It's a matter of supply and demand more than technology as to the cost of the material. The most expensive part of the sensor is its calibration.

\section{Are you still working with IdaTech?}

IdaTech and Dr. Pyke had an arrangement to field-test sensors, but there hadn't been anything to field-test. They need to get back together.

The plan was to make four test articles. One would go to IdaTech, and a second would go to $\mathrm{H} 2 \mathrm{Gen}$. The destination for the other two are not so firm. Dr. Pyke has been talking to Air Products about one and to U Cal. Irvine about the other.

\section{Please explain your calibration run (slide \#15) where you use calibration pairs. What are we seeing?}

A calibration pair is simply an intersection of a $\mathrm{CO}$ concentration and a hydrogen concentration. Slide 15 is shown here as Exhibit 2. The data are then used to construct surfaces such as Exhibit 1.

\section{Hydrogen Sensor:}

\section{Please discuss the differences in concept and set-up between the $C O$ sensors and the hydrogen sensors.}

If you were looking at a hydrogen leak detector, you would likely have a lower operating temperature than with a hydrogen/CO sensor. You would most likely be at ambient temperature, and almost certainly would be below $80^{\circ} \mathrm{C}$. You could thus likely get away with using silicon instead of gallium nitride. It would be considerably less expensive. Dr. Pyke did a lot of work with silicon sensors in a "previous life," but hasn't used it as yet on this project; he's been using only GaN so far.

Since silicon sensors would be inexpensive you could use more of them, say three, to increase confidence. You could also get by with employing only one gate metal (maybe just $\mathrm{Pt}$ ) rather than three since you are only looking for a yes/no answer as to the presence of hydrogen, not necessarily a "how much." I don't really agree with that analysis. You 
need to quantify hydrogen at least at least at certain concentration levels at and below the lean flammability limit.

Dr. Pyke is concerned that the amount of effort needed to make and calibrate sensors sufficiently detailed enough to allow actual hydrogen concentration measurements (as opposed to yes/no sensors) could compromise this technology entirely. However, Dr. Pyke also addressed this issue in the next question.

\section{Please discuss slides 27 and 28.}

The two slides are reproduced here as Exhibits 3 and 4 respectively.

The voltage response as a function of hydrogen concentration is most evident in the regions of greatest hydrogen interest. There is a "huge" voltage change between zero and $0.1 \%$ hydrogen. In my opinion, this is the region where a measure of how quickly the concentration is changing would be of great value. There is a $93 \mathrm{mV}$ change per decade of change of hydrogen concentration between $0.1 \%$ and $2 \%$ hydrogen with a Pt gate. With a $\mathrm{Rh}$ gate it is about $150 \mathrm{mV}$. This is the region where a more quantitative measure of how much hydrogen is actually present is important.

If a sensor has been exposed to air for a long period, there is a 30-60 second induction period at room temperature prior to seeing a response to hydrogen. After that, it takes about 15 seconds for the sensor to reach $90 \%$ of its total response.

\section{What applications are you targeting for hydrogen sensors?}

Of course, support of the hydrogen safety program at DOE is a major target, but Dr. Pyke is also trying to get money from sales of the sensors to the utility industry. The utilities would use the sensors to monitor the "health" of transformers. An IEEE standard uses the amount of hydrogen dissolved in transformer oil as a measure of transformer health. The amount of dissolved oil is related to the amount of gaseous hydrogen through the Ostwald Diffusion Coefficient. Thus, a measure of gaseous hydrogen in the transformer is an important number. I am not very sure that the sensors needed to monitor transformers and those needed to measure hydrogen leaks in vehicles would have the same requirements. A vehicular sensor, for instance, would likely need a faster response time.

For hydrogen safety, Dr. Pyke's main target is vehicles. He would use a "point sensor" approach, having a sensor wherever there is a fitting, or wherever hydrogen may leak out. He mentioned having one sensor at each egress point. Perhaps the sensor's signal could, for instance, turn off an engine or turn on a fan. Dr. Pyke was thinking of needing, perhaps, a total of six sensors, including one in the ventilation system.

Another target is a personal point sensor that could be worn like a badge. A worker in a laboratory or a plant could wear it. The semiconductor industry may be a target here. It could also be used in a room where storage battery banks are located. Dr. Pyke spoke of perhaps trying to sell these point sensors on the Internet. The target markets make some 
sense. I know that hydrogen sensors would be valuable in an enclosed battery room where hydrogen buildup could be a serious problem. I don't think the personal sensor would be the way to handle it, however. A sensor connected to an alarm might be better. Dr. Pyke is currently working with a sensor company for his $\mathrm{CO}$ work now. (Someone like First Alert, he says). He is thinking of broaching the subject of hydrogen with them as well.

\section{Hydrogen Safety:}

\section{What do you identify as your most serious risks in conducting your research?}

Using both hydrogen and CO are concerns. Some of his "flammables" are diluted with nitrogen.

Right now, Dr. Pyke has only one cylinder of pure hydrogen. One cylinder is the limit you can have without having to report it. I'm somewhat concerned with that type of regulation.

Dr. Pyke has also recently bought a used electrolyzer. It currently has an electrical problem, and he hasn't used it yet. When it's working, it will produce $60 \mathrm{psi}$ hydrogen at a rate of $600 \mathrm{cc} / \mathrm{min}$, and will store about $250 \mathrm{cc}$. Dr Pyke will use the electrolyzer in his outside laboratory.

\section{What steps have you taken to prevent safety problems involving hydrogen?}

The major step was moving everything to an outside laboratory. This is located in an area underneath a deck attached to Dr. Pyke's house. The lab is meant to withstand an explosion without harming the house (although the deck itself could conceivably come down.) For warmth and to keep weather out, the space is enclosed with plastic strips of the type used in a walk in freezer. Draped inside of this is Nomex ${ }^{\circledR}$ fireproof fabric. This would "slow a fire down". Steel roofing material is overhead, with the wooden deck over that. The lab is equipped with First Alert smoke and CO detectors. The actual sensor work is done in a ventilated hood in the middle of the lab. The hood is equipped with an air blower, providing constant movement of air. If a tank ruptured, the gas would leak out through the plastic strips.

To keep exposed volumes of flammable gases to a minimum, all measurements are made in a GC.

Currently, Dr. Pyke does not use explosion proof electrical equipment, but relies on circuit breakers.

3. What are the special precautions necessary for a home laboratory? (These may be things that will play into the development of best practices or standards for home hydrogen use (e.g., home electrolyzer, home storage system.) 
If the laboratory were inside (which it was, previously), Dr. Pyke would use more hydrogen sensors (electrochemical and/or catalytic bead types) and would hook them up to fire alarms and/or to fans. All of they hydrogen would be run to a hood.

If he were using a cylinder of hydrogen, he would keep it outside (although, previously, he had the cylinder inside). He would also have a calibrated leak out of the room, which he would manifest by increased ventilation. He would likely, not use a hydrogen cylinder at all, however, but would make hydrogen with an electrolyzer.

\section{How do you handle the prevention of, detection of, and response to hydrogen leaks? What leak rate and amount do you consider significant? Are there mechanisms (such as vents) to prevent high localized hydrogen concentrations in the event of a leak?}

Dr. Pyke answered the prevention part by indicating that no one else gets in to the laboratory. Although it does not exist now, Dr. Pyke believes he could prevent access to his outdoor laboratory by using signage, gates and a chain-link fence. This will certainly cut down on mishaps and mischief, but I don't know how it would prevent a leak. A key method would be to use an electrolyzer to make hydrogen, thus keeping the storage volume down.

There are no commercial detectors in the laboratory - no one would hear the alarm. Dr. Pyke did speculate about setting up a fire alarm and a sprinkler system. The sensor system being developed itself, would respond to hydrogen. He has a sensor hooked up for long time periods anyway. In his outdoor lab, he's operated under temperatures between $30-100^{\circ} \mathrm{F}$.

As stated elsewhere, the laboratory is enclosed with plastic strips which provide ample ventilation.

When he is running an experiment, Dr. Pyke can contain a leak within a quartz shield, and a controlled vent to the outside. However, for the experiments he has been running with $2 \%$ hydrogen, he doesn't use the shield. He feels that he doesn't need the containment, and has difficulties flushing out the shield area, which must be done several times to get the proper concentration.

\section{Other than in high-pressure gas cylinders, where, if anywhere, is there a potential for hydrogen pressure buildup?}

There are no other means for high pressure buildup.

\section{Are any potential ignition sources present in the workspace. If so, what steps have been taken to prevent the ignition of hydrogen?}


Potential ignition sources would include switches. The mass-flow controller valves would be considered switches, but these are solid state, so are not real ignition sources. Other potential sources for ignition include the hot surface of the tungsten/halogen lamp used for temperature increases, the electrical outlets, fan motor, and the platinum sensor surface.

Another problem could be a tube of burning hydrogen. The Nomex ${ }^{\circledR}$ and metal roof sheeting would protect the area. A sprinkler system would protect against any secondary fires.

If a catastrophic failure were to occur, Dr Pyke feels, it would most likely be a rupture/explosion involving a hydrogen tank. If there were an explosion (due to the presence of an ignition source, the result could be the collapse of the deck that is over the laboratory. With the plastic strips available for releasing pressure, Dr. Pyke does not believe his house would be damaged.

\section{Safety Protocol Input:}

Dr. Pyke provided insight into several areas that will aid in building a protocol for conducting safety reviews. These are delineated here:

- When dealing with industrial demonstration projects, one must remember that safety "is a cost-center, not a profit center". Thus it tends to take a back seat when designing a system. There must be some incentive for paying more heed to safety - perhaps through something like insurance savings.

- In dealing with sensors, we must know what kind of sensors a laboratory/project has, and what their limitations are.

- Each lab/location should have two sensors (identical) to provide redundancy. We have a bit of a differing of opinion here. I suggest that 1) the sensors be of different types to eliminate error by false positive or negative signals due to a feature of one particular kind of sensor and 2) that if we want redundancy, three sensors may be better than two. (What do you do with two sensors that show different results; which do you believe?) We need to determine what kind and degree of redundancies we really need.

- Dr. Pyke suggests that contractors achieve and maintain contacts with their local fire departments.

- Dr. Pyke specifically cited the Santa Clara County (CA) fire marshals concerning a large semiconductor safety manual that they developed that includes matters of hydrogen safety. He did say, however, that the manual may be seen as somewhat "overkill". He mentioned that connectors were made by orbital butt-welded tubing, and that valves and connections were grouped space-wise so that the amount of area that needed to be monitored could be limited. 
- Safety issues have a habit of becoming political. This is a problem. (Dr. Pyke learned this in "a former life", when he'd participate in "what-if" meetings with fire officials.)

- For using an $\mathrm{H}_{2}$ sensor, the most important question is: Is hydrogen there or not? (not how much hydrogen is there). Then, if it's there, why is it there, and what do we do if it is there? It's not a matter of how much is there. This is different from an analytical instrument. True, it's not so important to distinguish between, say, 20 and $30 \%$ of hydrogen. But I'd want to know if we had $0.1 \%$ or $5 \%$. I believe the rate of change of hydrogen concentration in a leak is also an important factor. So in my opinion, the sensor has to be more than an on/off, although maybe not an analytical instrument.

\section{Additional Items:}

Dr. Pyke keeps a hydrogen sensor "on" all the time in the laboratory, basically sensing air. Every now and then he puts some hydrogen through it. He has not done any relative humidity variations with it yet. He plans to use this sensor in field tests.

Dr. Pyke indicated that once the sensor has been exposed to hydrogen, it takes "days and weeks" to recover at room temperature. If it is exposed to a heater at $110^{\circ} \mathrm{C}$, however, it will recover instantly. This sounds like it could result in a necessary maintenance step if anyone is using the sensor. The heater could present an ignition risk if there is a spark, but the temperature itself is too low to cause auto-ignition.

Dr. Pyke is looking to work with the University of Utah's Electrical Engineering Department to make Complementary Metal Oxide Semiconductor (CMOS) silicon sensors.

Some of his newer hydrogen experiments involves investigating an induction process that occurs when there is oxygen on the surface of the sensor. When exposed to hydrogen, it burns off. Thus, the sensor starts to respond quicker.

\section{Final Thoughts:}

The CO sensor work is progressing well technically, with reproducible maps of voltage contour lines defining hydrogen/CO concentration pairs. The main problem appears to be that each sensor must be individually calibrated (this would be true for all sensors of all types), and the calibration methodology here (i.e., construct a unique contour map for each sensor) appears to be a daunting and expensive task, unless one is looking at very limited applications.

The hydrogen sensor work is now underway. Hydrogen sensors should be less expensive than the CO sensors for two reasons. First, since they will operate at lower temperatures, they can be manufactured from less expensive silicon rather than from GaN. Second, calibration should be easier. The philosophy as to what a hydrogen sensor should be 
doing remains a question. Dr. Pyke believes that an on/off approach (is hydrogen there or not) would be sufficient. I believe that at the very least, if we use an on/off approach, the hydrogen concentration that will make the sensor register must be very finely calibrated, and must be very consistent between sensors. I also believe that if there is a hydrogen leak, the rate of change of concentration becomes an important parameter.

By moving his laboratory outdoors, and devoting much thought to its design, Dr. Pyke has improved the overall safety of his operation. He has become familiar with local codes and standards and has abided by them, and has reasonable answers for all questions. What has not happened, however, is a formal sign-off. I think something like this would make us all more comfortable, seeing that otherwise Fluence is responsible only to Dr. Pyke himself.

As a general comment, I am concerned about codes and standards that may not be well thought out or applied. The allowance for a full cylinder of hydrogen to be located in an area and not be subject to reporting does not make sense to me. 
Exhibit 1. A map of [CO] vs. [ $\mathrm{H}_{2}$ ], shown with contour lines for voltage values

\section{Pt Response Surface at $250^{\circ} \mathrm{C}$}

3-D mapping with contours of constant $\mathrm{V}_{\mathrm{gs}}$

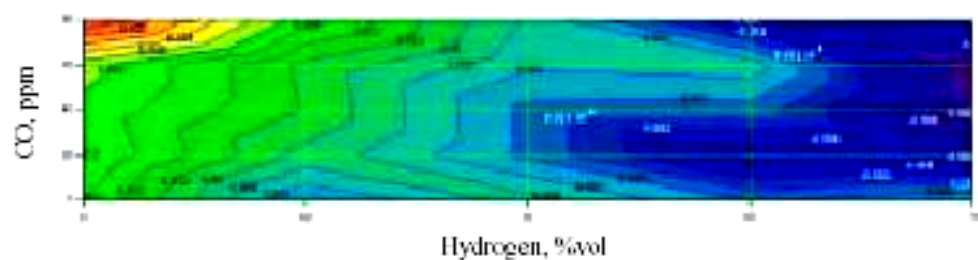

Exhibit 2. Typical calibration run. Pt sensor, 25 calibration pairs.

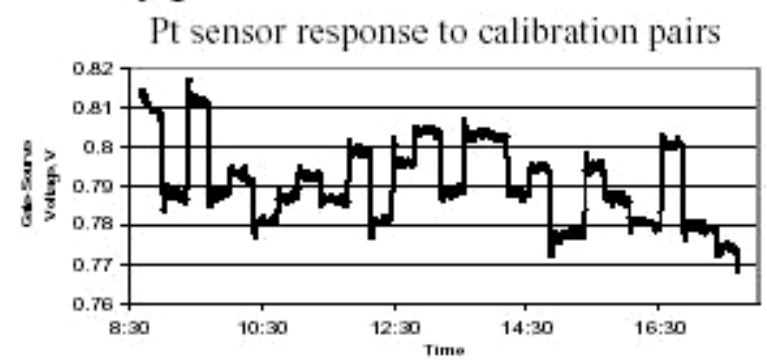

\section{Exhibit 3.}

\section{Hydrogen Response in $\mathrm{N}_{2}-250{ }^{\circ} \mathrm{C}$}
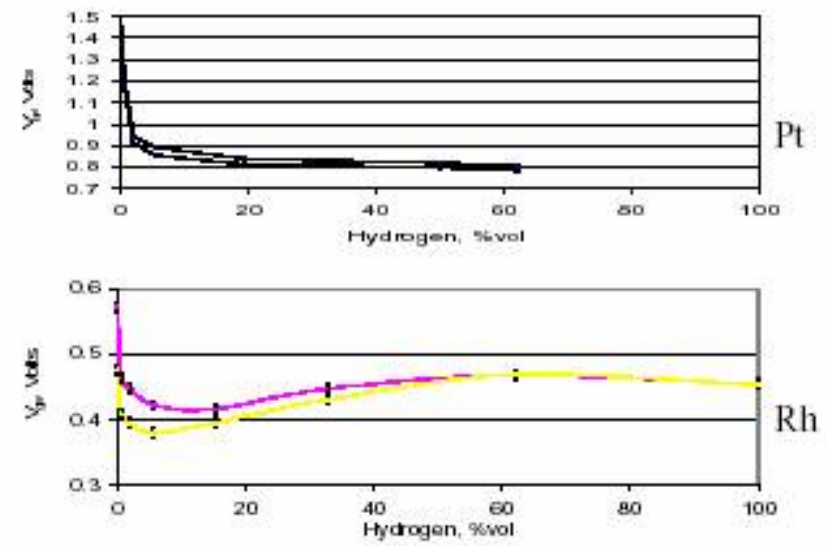


\section{Exhibit 4.}

Hydrogen Response in Air $-30^{\circ} \mathrm{C}$

$\mathrm{Pt}$

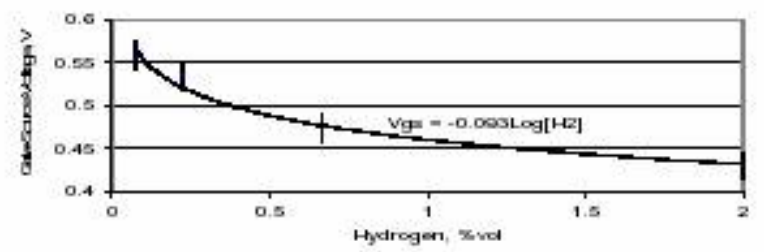

Rh

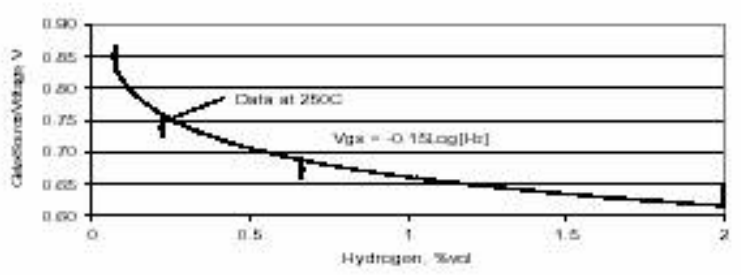


Safety Protocol Report - Hydrogen Systems

Company: SunLine Services Group

Contact: Bill Clapper

Site-Visit Date: August 27, 2003

Evaluation by: Edward G. Skolnik, Energetics, Inc.

\section{Summary:}

SunLine Services Group, affiliated with SunLine Transit Agency is one of the most forward-thinking hydrogen proponents and demonstration sites in the country today. We performed a technical evaluation at their Thousand Palms, CA site in late 2001, and have now gone back there to enlist their aid in developing a safety protocol for the Hydrogen Safety program and for the upcoming Safety Panel reviews.

With a "little bit of everything" involving hydrogen on their site, SunLine is a good place to gather safety data. They have extensive knowledge of hydrogen codes and standards and adhere to these. They also appear to think through most safety issues in a clear, logical manner, despite the fact that they don't generally deal with safety using the formal risk analyses methodologies that the Program is looking to incorporate.

SunLine believes that safety needs to be designed in the system, and that significant reliance must be placed upon the safety assurances from the equipment suppliers. The use of ventilation "gaps" for otherwise enclosed spaces, periodic leak checks using a liquidsoap based detection method, and a lower reliance on hydrogen sensors based on their demonstrated non-responsiveness are three key safety responses at SunLine.

Finally, SunLine uses "insurability" as a measure of safety/reliability in much the same way as DOE does. It's a bottom line position; if a system is insurable, it is safe.

\section{Introduction and Background:}

I returned to SunLine and met with Mr. Bill Clapper in order to find out how SunLine is handling hydrogen safety in order to better develop a hydrogen safety protocol for the Hydrogen Safety Program. SunLine makes hydrogen by reforming and by solar- and wind-based electrolysis; they store hydrogen in high-pressure containers; they possess a fueling station where they can fill several different hydrogen vehicles, they use hydrogen in fuel cell vehicles ranging in size from golf carts to buses, and in a small stationary fuel cell; and they blend hydrogen with natural gas for internal combustion engine based buses. In other words, they are working with what might be called a localized hydrogen infrastructure. This represents a perfect venue in which to obtain a wide variety of hydrogen safety data that will help us build our safety protocol.

SunLine claims an advantage over other hydrogen stakeholders because they have significant experience in handling and operating vehicles with natural gas. When they started operating buses on compressed natural gas (CNG) in 1993, they educated safety 
and building officials. When the time came for them to site hydrogen on their property, they could state that due to their experience with $\mathrm{CNG}$ the following was true:

- They were already dealing with flammable gases

- They were already dealing with compressed gases at high volumes

- They already had policies and procedures in place to deal with flammable compressed gases and associated equipment

- They already had a formal ongoing training program to deal with flammable compressed gases. All personnel were already being trained in accordance with the requirements of these gases.

\section{Questions and Answers:}

Prior to my visit, I sent Mr. Clapper a list of topics for discussion for our meeting that I thought would be important to cover during my visit. These are shown below in bold type. Mr. Clapper and I discussed these subjects, and these discussions are reproduced here in normal type. Comments and reflections added by me following the meeting are included in italics.

Hydrogen Safety Issues (How has SunLine addressed the following):

\section{- $\mathrm{H}_{2}$ Leaks:}

\section{Prevention \\ Detection}

\section{Sensor types/response times/limitations Containment/Exhaust}

Hydrogen leak prevention begins with the design. All material must be hydrogen compatible. To a degree, says Mr. Clapper, one must rely on the supplier for this. SunLine, however, is experienced in this area also.

In the hydrogen lines, the standard operating procedure is to use "soapy" leak detecting solution at the joints. If there is a leak out of the system, bubbles will form at the spot. A leak test is done every thirty days.

Mr. Clapper pointed out that their buildings are unique. Since there are gaps at the top, simple ventilation will prevent a hydrogen buildup. This solution works nicely in the California desert, but wouldn't work in northern climates.

\section{- $\mathbf{H}_{2}$ pressure issues}

SunLine has not yet been exposed to this.

Actually, they have 5000 psi storage and a nearby ignition source, which they have addressed, and which is discussed below.

\section{- Ignition sources}




\section{Identification \\ Control}

Identifying and controlling ignition sources is "all in the design and education processes."

They do use the code books, of course, but will add additional protection if they feel it is warranted. One example is the hydrogen compressor and high pressure storage tanks area. (Also discussed in the description of hydrogen systems below) A cinderblock wall has been erected even though it was not a code requirement. It was only that personnel (actually a subcontractor) were uncomfortable with a compressor and high pressure tank that close to one another.

Safety Planning (What approaches and methodologies has SunLine used):

\section{- Hazard prevention methodologies}

e.g.,

\section{Failure Modes and Effects Analyses (FMEAs)/Fault Tree Analyses \\ Risk-Probablility assessments Hazard analyses}

SunLine does not engage in prevention methodologies. Mr. Clapper says that they are "not sophisticated enough". They rely on design.

Mr. Clapper believes that all the equipment vendors do their own FMEAs or similar, and also that codes and standards would have already incorporated FMEAs into their work. If a piece of equipment failed, SunLine would send it back. The responsibility is on the manufacturers.

\section{- Risk mitigation plans}

Again, risk mitigation is handled in the design phase and involves SunLine's own safety committee.

The message here appears to be: Evaluate the design.

\section{- Communication plans}

SunLine holds safety meetings with all of its employees regularly (approximately 9 times per year.)

SunLine has a hazardous materials business plan. If a major event occurs, everyone knows what they are to do and/or where they are to go.

If the event occurred under a DOE contract, SunLine would inform DOE. This. I think needs to be stronger. If a hydrogen "event" happened involving a company 
that has a DOE contract, DOE should be notified even if the hydrogen event was not associated with the DOE funded project itself.

SunLine has their own safety committee. They also have a safety credo: The customer is first, the employee is second, and the equipment is third.

Codes and Standards (What Codes and Standards apply to SunLine's hydrogen work, and how are they applied):

\section{- Identification of C\&S}

The Codes and Standards that SunLine follows include:

o NFPA 70 (1999) National Electric Code (Chapter 5: Special Occupancies)

o NFPA 497 (1997) Recommended Practice for the Classification of Flammable Liquids, Gases, or Vapors and of Hazardous (Classified) Locations for Electrical Installations in Chemical Process Ares

o NFPA 496 (1998) Standard for Purged and Pressurized Enclosures for Electrical Equipment

o NFPA 50A (1999) Standard for Gaseous Hydrogen Systems at Consumer Sites

o NFPA 50B (1999) Standard for Liquefied Hydrogen Systems at Consumer Sites

o NFPA 853 (2000) Standard for the Installation of Stationary Fuel Cell Power Plants

o NFPA 10 (1998) Standard for Portable Fire Extinguishers

o NFPA 52 (1998) Compressed Natural Gas (CNG) Vehicular Fuel Systems Code

o NFPA 30A (2000) Code for Motor Fuel Dispensing Facilities and Repair Garages

o ISO 13984 (1999) Liquid hydrogen -- Land vehicle fuelling system interface

o ISO 14687 (1999) Hydrogen fuel -- Product specification

\section{- Application}

In general, if a code or a standard exists that concerns "hydrogen" or "gas" SunLine will examine it for relevance. They actually got much of their C\&S issues resolved four years ago.

SunLine relies on the manufacturers of the equipment they purchase to have conformed to the proper codes and standards. Mr. Clapper pointed out that SunLine is in the transit business, not the engineering business, and they have to hope that their suppliers are reliable. I would like to see a word other than "hope". Maybe, however, this is standard operating procedure for many users in many industries. For working on DOE hydrogen projects, however, I would recommend that a paper trail of some sort is available. 
SunLine picks up responsibility for the system at the interfaces of equipment. So they are using codes and standards from that point on, looking at things like separation distances.

Mr. Clapper pointed out what he considers an anomaly in the NFPA codes regarding separation distances. Citing NFPA 50A (Standard for Gaseous Hydrogen Systems at Consumer Sites) and NFPA 52 (Compressed Natural Gas (CNG) Vehicular Fuel Systems Code), he questions why a 50-foot distance is needed between CNG and hydrogen storage at consumer sites.

Altoona Testing certifies buses, but did not have to certify five demo buses used by SunLine because they are demos. I am not in agreement with using methods that could skirt safety issues. If a demo bus cannot be certified, its safety needs to be demonstrated by some other manner.

Mr. Clapper does not believe that any codes and standards cover structures like SunLine's hydrogen bay.

Safety Devices/Methods Implemented and/or Planned for Various SunLine Hydrogen Systems (We should discuss in regard to the following systems wherever possible):

\section{- Reformer lines}

The major safety implementation here is the fact that all the lines are one-piece. There are no welds, thereby greatly reducing leak probability.

(A HyRadix autothermal reformer is being installed to replace the HBT unit. It will produce $100 \mathrm{~m}^{3}$ of hydrogen per hour. The hydrogen will be compressed and stored in the high storage area discussed below.)

\section{- Renewable $\mathrm{H}_{2}$ generation (PV/electrolysis, wind, etc.)}

All of the renewable-based hydrogen production (PV on site at Thousand Palms and wind as part of the Palm Springs wind farm) is outdoors, in a zero-populated area. (A Stuart Energy electrolyzer makes hydrogen at the wind farm).

\section{- Fueling station}

Aside from compressed natural gas and liquefied natural gas, the fueling station dispenses hydrogen at 5000 psi, hydrogen at 3000 psi, and Hythane ${ }^{\circledR}$ at 3000 psi. The station contains the necessary electrical grounding cables. There is a flame detector above the pumps. This is the only outside detector at SunLine. Even this detector gives false positive readings in the summer due to thermals coming off the pavement. As Mr. Clapper said, “detectors just don't work out here." 
Interestingly, at the time of my visit, SunLine had no fuel cell buses in use. They have four Hythane ${ }^{\circledR}$ buses, but only two were in operation over the summer - the two that are air-conditioned.

\section{- Bay areas}

The hydrogen maintenance bay has explosion-proof lighting, but does not contain any sensors. (When the Ballard bus was there, Ballard wanted sensors at the top of the bay but SunLine refused, calling it an unnecessary expense). There is an eighteen-inch-wide gap at the top, and the structure is curved so that any hydrogen would be forced to the opening. SunLine knows that their biggest single risk area is the hydrogen bay. There are no ignition sources in there - except if a bus is in there.

There are two sea-tainers, used for part storage, in the bay, and there are hydrogen sensors in them. Mr. Clapper, however, doesn't see how any hydrogen could leak in there.

Explosion-proof lighting and hydrogen detectors are also present in the maintenance building adjacent to the bay, in case hydrogen should vent into the building.

\section{- Hydrogen vehicles: Buses (FC, Hythane ${ }^{\circledR}$, etc.), PUVs/NUVs, Trucks, Other vehicles}

SunLine considers hydrogen safety on the vehicles to be the responsibility of the vehicle manufacturers. However, there are no sensors on SunLine's CNG buses; there is no place for natural gas to pool. Mr. Clapper thinks it would be the same for hydrogen buses, and doesn't see this as a problem. Mr. Clapper really doesn't believe that hydrogen vehicles need sensors; there are none on gasoline vehicles.

In addition, since it is unlikely that hydrogen will pool, a sensor is not needed. If there is a sensor it should be one for ignition.

I think for DOE projects, you need to err on the side of caution. Hydrogen sensors may not be a necessity on vehicles when we're well into the hydrogen economy, but they are needed now. However, there may be times when sensors could be a detriment.

\section{- The “Mall" \& Education Areas}

SunLine has a new $3 \mathrm{~kW}$ PEM fuel cell that they got from Schatz Energy Research Center that they use in the Zweig Building for educational purposes. A Teledyne electrolyzer (see below) is used to fill the hydrogen bottles that fuel the fuel cell. The system/display is in a glass enclosure. No sensors are present because the bottles are 
vented to the roof. SunLine follows codes and standards as required. They had worked on these in conjunction with Schatz.

The building (which was designed by Schatz) housing the $40 \mathrm{scf} / \mathrm{h}$ Teledyne Electrolyzer has a hydrogen sensor, although Mr. Clapper was not sure of what kind it is. Hydrogen is apparently not readily detected in this building by this sensor. A hydrogen source has to be put right up to the sensor to detect anything according to Mr. Clapper. Leak detection is primarily done with hand wands. The building is vented (an open area) at the top. The roof is slanted to promote hydrogen flow toward the vent. There are two ways to look at the sensing situation here. Perhaps the building and vent configuration is so well designed that any hydrogen leak will swiftly exit the building through the vent, bypassing the sensor. Or perhaps the sensor is not sufficiently sensitive, or needs to be placed elsewhere. (It's on the wall, not near the vent.) The role of the sensor and its placement needs some discussion in the overall hydrogen safety regime.

\section{- Hydrogen storage}

There is an outside compressor area where the hydrogen from the Teledyne is compressed. Single piece piping (no welds) is used wherever possible. The dispensing panel is separated from the hydrogen bottles. There are no sensors here or on any of the outside equipment; they just don't work well outside. Leak tests are performed regularly using the soapy leak detecting solution.

Nearby is the storage area. There are the original tube trailers containing 96,000 scf of hydrogen at 3130 psi. Recently some 5000 psi storage has been added. This is made up of two sets of cylinders, a "six-pack" $(40,000 \mathrm{scf})$ and a "three-pack" $(20,000)$.

The biggest issue, as stated above was the discomfort felt by a subcontractor who feared the proximity of the compressor (as a potential ignition source) to the storage area. The fire department inspected the area and found it safe, but nevertheless, a protective cinderblock wall was erected between the area and the public access area.

In general, SunLine follows a strict Preventive Maintenance schedule on their equipment.

\section{Additional items for discussion:}

\section{- Safety-related lessons learned to date}

1. When SunLine did their electrical grounding, they found that it was required that they include "bonding", that is, connecting all the grounds together. This will facilitate charge dissipation.

2. SunLine found that when they ran stainless steel lines for hydrogen on or under the ground, they needed to wrap or encase the stainless steel. The outside of the line apparently reacts with something in the soil, and corrodes. 
This happens, at least, in the environment around Thousand Palms. This may be worth investigating further.

3. If hydrogen is being compressed with a reciprocating compressor, it could fail, and one might not know it. The result could be contaminated hydrogen. Thus filters and/or scrubbers are needed downstream. Not purely a safety issue, but important nonetheless.

\section{- Recommendations for safety methodologies for new/other projects/systems}

A major issue for all hydrogen projects, "a real situation", says Mr. Clapper, is insurability. The Federal Government and the states must discuss liabilities with insurance companies, and demonstrate to them that these systems are insurable. As far as equipment goes, however, it's up to the manufacturers to make it insurable.

\section{- What should a safety committee site-visit team be looking for?}

1. The overall layout of the system

2. An analysis of ignition sources

3. Separation distances between gases ( $\mathrm{CNG}$ and hydrogen, for instance).

\section{Final Thoughts:}

One of the major issues/concerns I have coming out of this meeting involves sensors. When are they needed; when are they not needed; when is their presence actually a detriment. SunLine appears to have demonstrated that hydrogen sensors (or at least currently available commercial ones) are not a panacea for detecting the presence of hydrogen. The fact that you have to move the hydrogen source right up to the sensor to get a reading in some cases is worrisome. It leads to several different possible conclusions some of which may not be correct:

- It is easy for the sensor to be incorrectly placed, and more gas-flow/diffusion strategies must be employed to identify the correct place or places to put the sensor. Perhaps more modeling is needed.

- Sensors in the "wrong" place can do more harm than good.

- Sensors are not necessary in open or well ventilated areas

- Commercial hydrogen sensors are not the answer 
The Hydrogen Safety Program's Separation Distances Project will hopefully end the speculative nature of placing a wall between two system components "just to be sure", and replace it with sound, technical responses.

The rapid corrosion of buried stainless steel hydrogen lines from the outside apparently due to something in the local soil is something that should be looked into.

The message from SunLine about designing-in safety should be followed. While the DOE plan for now is not to require preliminary safety assessments for their projects during the proposal phase, it should certainly be Phase I Task 1.

Finally, the discussion on relying on the manufacturer's safety plan for equipment makes sense as far as it goes, but there is a need to participate a little more deeply in this. A hydrogen failure based on a faulty piece of equipment will hurt the Program and the Hydrogen Vision as much as a safety violation by a project P.I. 
In-Depth Analyses 


\title{
Analysis of a Hybrid Hydrogen Production System Using a Solar Reactor and Steam Methane Reformer
}

\author{
Prepared by \\ Edward G. Skolnik \\ Christina Y. TerMaath \\ Bryan G. Towns \\ Energetics, Inc. \\ Prepared for \\ US Department of Energy \\ In partial fulfillment of Contract No. DE-FC-00G010602
}

September 6, 2002 


\section{Table of Contents}

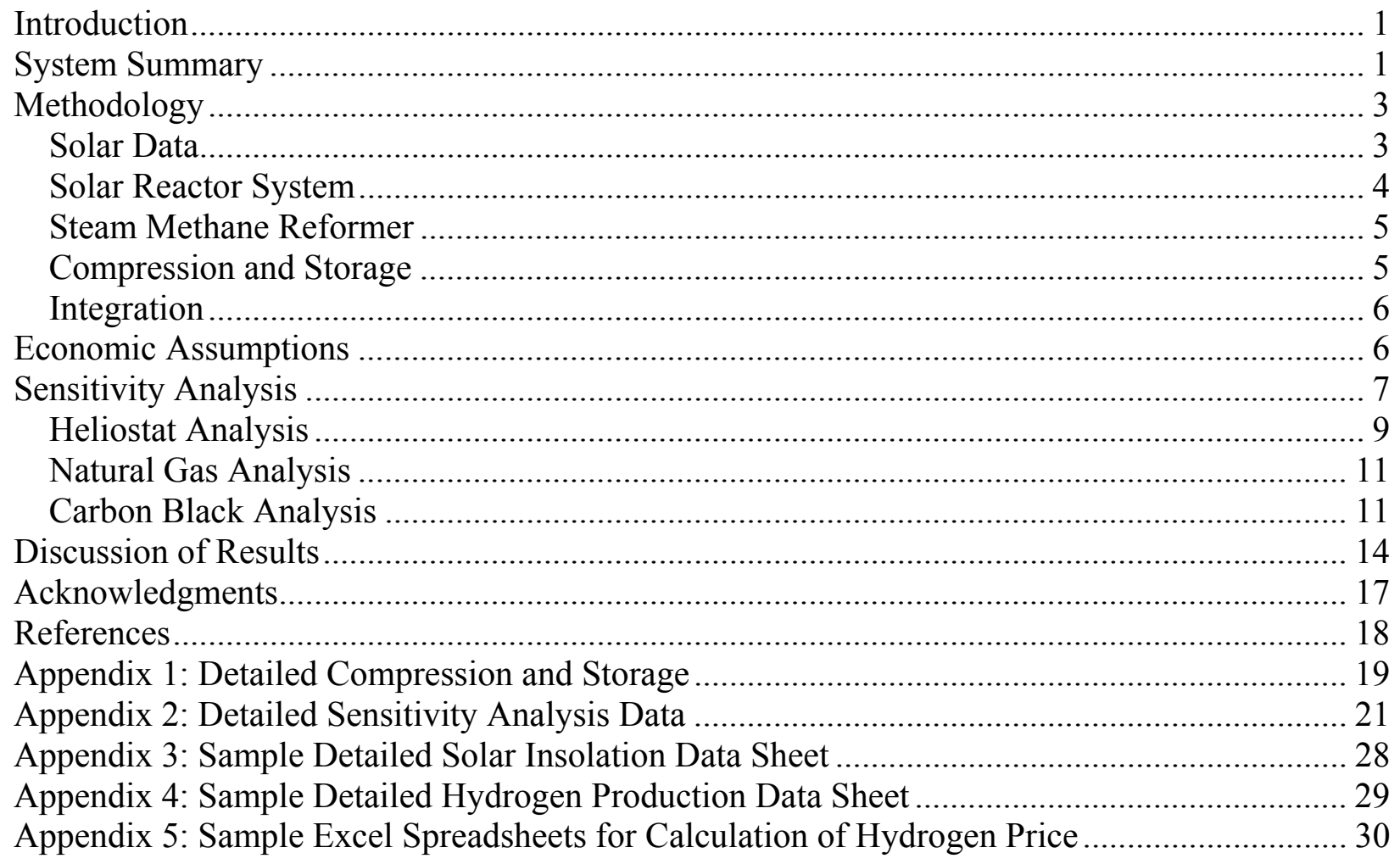

\section{Table of Figures}

Figure 1. Hydrogen Production Flowsheet ........................................................................... 2

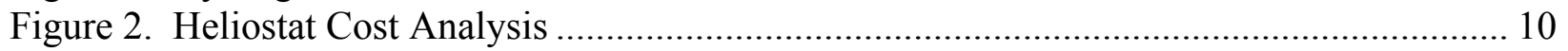

Figure 3. Natural Gas Cost Analysis............................................................................ 12

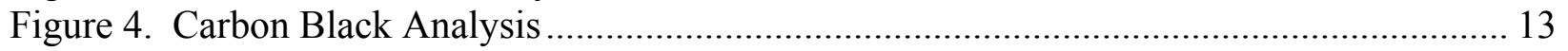

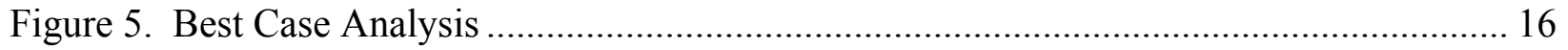

\section{Table of Tables}

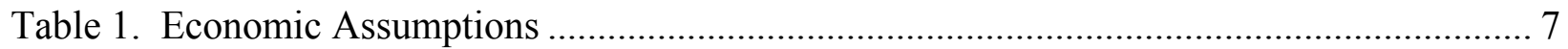

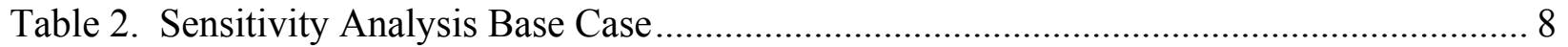

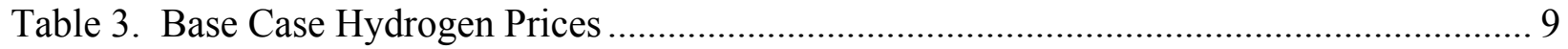

Table 4. Hydrogen Price - Varying Load Fraction.......................................................... 14

Table 5. Hydrogen Price $-\$ 50 / \mathrm{m}^{2}$ Heliostat Price ................................................................. 15

Table 6. Hydrogen Price - \$1.90/kg Carbon Black Price..................................................... 15 


\section{Table of Tables - Appendices}

Table A-1. Heliostat Cost Analysis ............................................................................... 21

Table A-2. Natural Gas Cost Analysis.................................................................................. 22

Table A-3. Carbon Black Cost Analysis............................................................................ 23

Table A-4. System Parameters.............................................................................................. 24

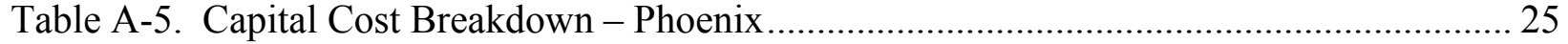

Table A-6. Capital Cost Breakdown - Miami .......................................................................... 26

Table A-7. Capital Cost Breakdown - New Orleans ............................................................ 27

Table A-8. Hourly Solar Insolation Data Sheet ............................................................ 28

Table A-9. Daily Hydrogen Production Data Sheet ............................................................... 29

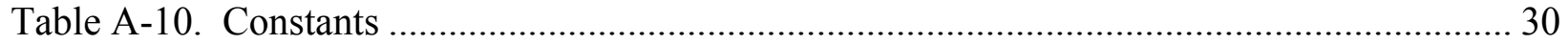

Table A-11. SMR Calculations ....................................................................................... 31

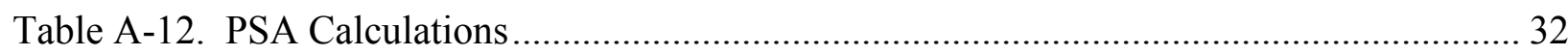

Table A-13. Solar Reactor Calculations .......................................................................... 33

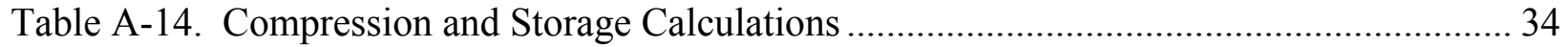

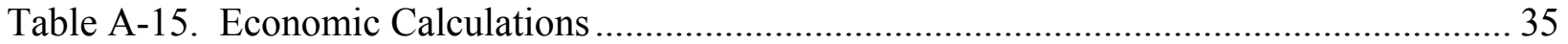




\section{Introduction}

Researchers at the University of Colorado and the National Renewable Energy Laboratory are developing a method of hydrogen production that uses solar thermal energy to dissociate methane. This process occurs at temperatures high enough to split the methane directly into hydrogen and carbon black, creating an environmental advantage over currently used methane reforming processes. No carbon dioxide emissions are created, and the carbon black can be sold for use in making tires, inks, paints, electronic components, and rubbers. The use of renewable solar energy to drive the reaction is also an environmental benefit and allows all of the methane to be a feedstock for producing hydrogen.

While these promising characteristics address the environmental needs of a hydrogen production process, there are other aspects of the process that could prevent its use and need to be considered. The process requires considerable amounts of direct solar radiation, meaning that it can only produce hydrogen under sunny skies and may not be practical in U.S. locations other than the southwest. Sophisticated solar tracking devices are used to direct the solar energy on the solar reactor. These devices require a large land area and are moderately expensive, which could create a space problem and high capital costs.

Energetics, Incorporated, is reporting on an analysis of a process in which a steam methane reformer (SMR) is used to supplement the solar process. The analysis is being performed to determine the feasibility of using this combined process at potential hydrogen fueling stations in several locations in the southern United States. The capital costs of the two systems as well as the cost of hydrogen storage are considered in this analysis. The load division between the two systems is varied to determine the best cost scenario. Solar data is used for Phoenix, AZ; Miami, FL; and New Orleans, LA to compare the performance of the system at three different sites.

\section{System Summary}

A main goal of this analysis is to analyze the impact of the addition of a steam methane reformer to a solar reactor. The key advantage of the combination of two systems is the potential benefits that the merged system can provide. The combination of these two systems utilizes the positive environmental qualities of the solar reactor system with the economic and reliability characteristics of the SMR system.

The solar reactor and steam methane reformer systems will run in parallel. Both are fed by natural gas from a utility pipeline that is passed through a zinc oxide bed to remove trace amounts of hydrogen sulfide. The purified natural gas is then delivered to either the solar reactor system or the steam methane reformer. During the periods when enough energy is provided by the sun, for instance, during clear afternoons, the solar reactor processes the majority of the natural gas. During periods of insufficient solar energy, the steam methane reformer produces hydrogen from the natural gas and steam. A schematic of the overall system is given in Figure 1.

The solar reactor system consists of a sizeable field of heliostats concentrating the energy of the sun on a single point. The reactor, elevated to a height of approximately thirty meters, is located on this point. The reactor, which consists of a graphite tube inside of a quartz tube, operates at 
temperatures as high as $2273 \mathrm{~K}$ and at ambient pressure (Spath, 2002). The high temperature decomposes the natural gas into hydrogen gas and solid carbon black particles.

After passing through the reactor, the product gas, consisting of solid carbon, gaseous hydrogen, and unreformed natural gas, travels to a baghouse filter, in which the carbon is separated from the gas stream and delivered to a containment vessel. After the filter, the gas stream, consisting of $70 \%$ hydrogen and 30\% natural gas, is compressed from $14.5 \mathrm{psi}(0.1 \mathrm{MPa})$ to $200 \mathrm{psi}(1.4$ $\mathrm{MPa}$ ) and enters a pressure swing adsorption (PSA) unit. The increased pressure is required as the driving force in the PSA unit. Two streams leave the PSA, one containing the purified hydrogen, and the other containing the unreacted natural gas and nitrogen and carbon dioxide impurities. Hydrogen leaves the PSA at $99.999 \%$ purity and $185 \mathrm{psi}(1.3 \mathrm{MPa})$ pressure (QuestAir, 2002). A small amount of purified hydrogen is routed back to the reactor as a slip stream, and the balance is compressed to $2900 \mathrm{psi}(20 \mathrm{MPa})$ for storage.

The steam methane reformer system consists of a reformer, shift reactor, PSA unit, and nitrogen oxide control system. In the reformer, methane from the natural gas reacts with water vapor to produce hydrogen and carbon monoxide. An integrated nitrogen oxide control system removes $\mathrm{NO}_{\mathrm{x}}$ from the reactor product stream. In the shift reactor, water reacts with carbon monoxide to produce carbon dioxide and hydrogen. A PSA unit purifies the product gas. After purification, the product hydrogen is routed to the compression system for storage. The product hydrogen gas is then held in the storage to satisfy the demand of the filling station. The storage system

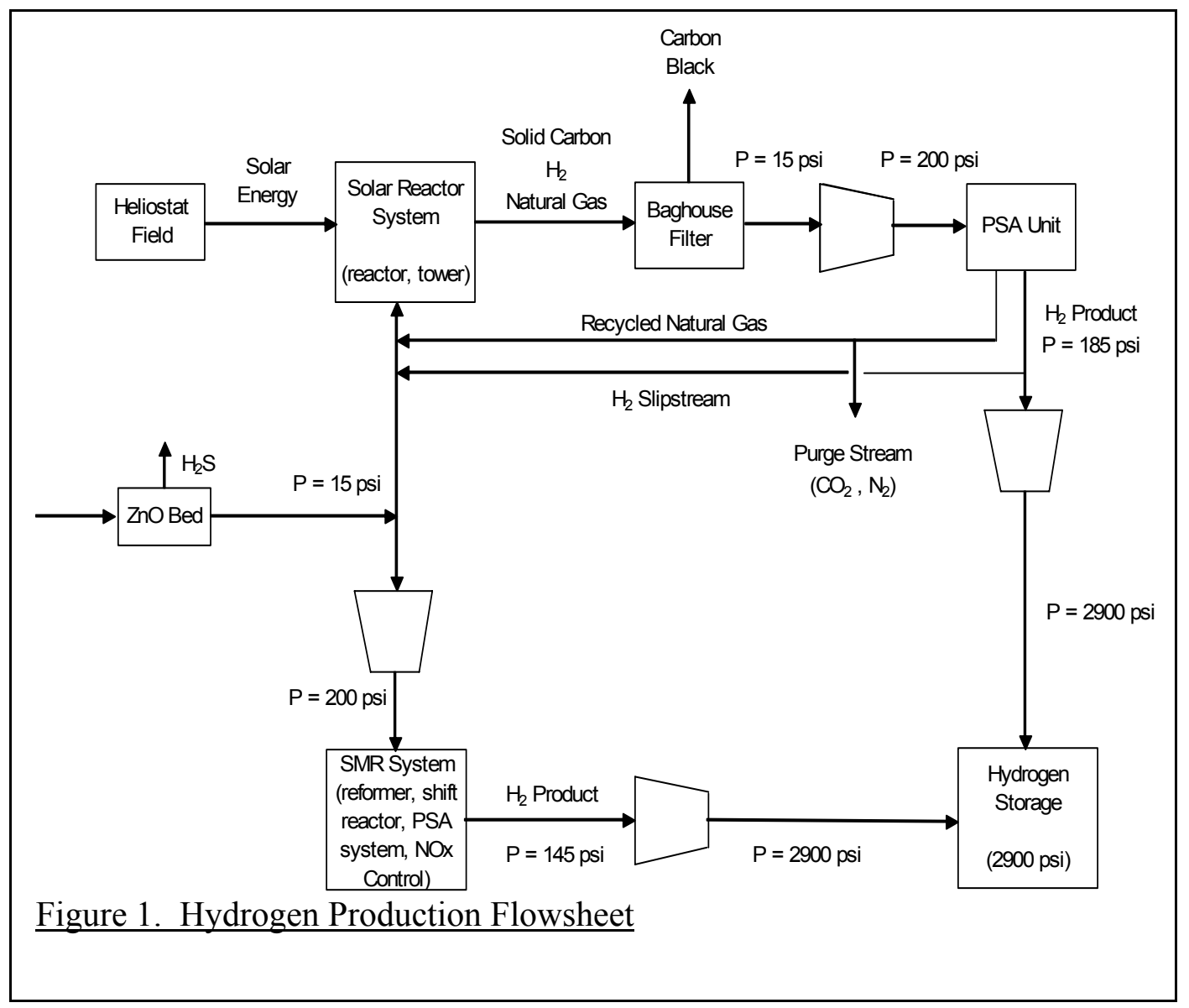


consists of high-pressure tanks that contain the hydrogen at $2900 \mathrm{psi}(20 \mathrm{MPa})$. This analysis does not include the costs or ramifications associated with the construction and operation of a hydrogen filling station.

\section{Methodology}

An Excel spreadsheet is utilized to link the contributing factors of the total system cost in order to estimate the final price of hydrogen. The total system is designed to refuel $300 \mathrm{cars} / \mathrm{d}$, each with a $4 \mathrm{~kg}$ tank of hydrogen $(1200 \mathrm{~kg} / \mathrm{d})$. The total system load is divided between the solar reactor system and the SMR in several different load fractions to determine the best configuration. These cases include SMR/solar reactor system splits of 0.50:0.75, 0.65:0.50, and 0.80:0.30. Note that in all cases the total possible hydrogen production from the two systems combined sums to more than the necessary $1200 \mathrm{~kg} / \mathrm{d}$. This allows for the ramp up of the SMR on cloudy days or for replenishing the hydrogen storage supply. For this analysis, the system splits are then normalized to $40 \%: 60 \%, 57 \%: 43 \%$, and $73 \%: 27 \%$, respectively, to represent the fraction of actual system output rather than fraction of rated production level. The extreme cases in which a stand-alone solar reactor system or SMR is used are also included in the study.

Basic research indicates that only those locations with relatively high solar radiance values would provide suitable energy for the solar thermal reactor. The southwest United States is a natural choice for such a site, as the climate is well suited for such applications. Thus, Phoenix is chosen as a potential site for this system. Other mild to tropical climatic regions are not immediately identified as potential sites for the solar thermal system. To test the potential of the solar thermal system in other regions, two other locations in the southern United States, New Orleans and Miami, are used in this analysis. These sites were chosen due to their location in the southern United States and in the variety of weather they received.

The hourly solar data for the three chosen sites is used to determine the potential hydrogen production from the solar reactor system for each day of one year, allowing the annual production from each specified solar reactor system to be estimated. The daily hydrogen produced from the SMR is also calculated to determine the storage level needed. The SMR, solar reactor system, storage, and compression capital costs are calculated for each system configuration at each of the three sites. A base case scenario of $\$ 0.95 / \mathrm{kg}$ carbon black price, $\$ 3.72 /$ GJ natural gas price, and $\$ 130 / \mathrm{m}^{2}$ heliostat cost is calculated. The base case values are either the current average prices for each commodity or, in the case of the heliostats, the representative future price. The base case is described in greater depth in the discussion of the sensitivity analysis. A sensitivity study is performed on the carbon black price, natural gas cost, and heliostat cost to determine the value at which the combined system would be competitive with a single SMR, which is commonly used for hydrogen production.

\section{Solar Data}

A key component for the solar reactor system analysis is the determination of the amount of energy provided by the sun over the course of a year. Detailed solar insolation data is provided by the Renewable Resource Data Center (RReDC), a division of the National Renewable Energy Laboratory. The measure relating time of day to usable solar insolation is termed "direct normal radiation," which is given in hourly increments by the RReDC. Data is available for every year 
between 1961 - 1990. This report utilizes the data from 1990; a statistical analysis showed little variance between the insolation values of each year.

To make the hourly data more usable, and because of the difficulty predicting the hourly refueling patterns of the cars, the total amount of hydrogen produced by a solar reactor is analyzed on a daily basis. Summing the production values from an entire day overlooks the variation in production that occurs each hour, but it provides for the most effective method of analyzing the data. In most cases, the peak insolation occurs between noon and two o'clock in the afternoon, with much lower values immediately after sunrise and immediately before sunset. A higher insolation provides for higher production levels from the solar reactor. Therefore, a measure of the solar capacity, or the hours during which the sun provides energy, is required. The system is designed such that a minimum amount of insolation is required for hydrogen production. In this analysis, the solar reactor system is not used when its production rate falls below $20 \mathrm{~kg} / \mathrm{min}$. Solar capacity is the measure that is used to assess the amount of time the sun provides suitable energy. The solar capacity is calculated by dividing the number of hours that the sun provides a minimum amount of energy by twenty-four. Typical calculated solar capacity values fall between 0.29 and 0.40 .

\section{Solar Reactor System}

The solar reactor system size and operation is based on both the reactor power and the heliostat area. Both aspects of the system are dependent on the solar data and the expected daily hydrogen production. The heliostat area is kept to a minimum when possible, but a large area is often needed to supply the reactor with enough power on days of low solar radiance. This creates too large an area for sunny days, so to avoid overheating the reactor, some of the heliostats would not be used on these days (Spath, 2002).

The methane molar flow rate is used to calculate the reactor power. Because the available solar radiance varies from day to day, an average solar capacity factor is calculated. It is used to determine the methane flow necessary during operation hours to achieve the daily hydrogen supply. The reactor power necessary to split that amount of methane is calculated using the enthalpy needed for the dissociation and to heat the methane to $1800 \mathrm{~K}$. The reactor can function at a $70 \%$ conversion at temperatures up to $2273 \mathrm{~K}$, but for the purposes of this analysis, an average temperature of $1800 \mathrm{~K}$ is assumed.

Once the reactor power is established, the heliostat area needed to provide that solar power can be calculated:

$$
\text { HeliostatArea }=\frac{\text { ReactorPower }}{\text { ReactorEfficiency } \bullet \text { HeliostatEfficiency } \bullet \text { SolarResource }}
$$

The reactor efficiency ( $\left.\mathrm{Q}_{\text {reactor }} / \mathrm{Q}_{\text {heliostat }}\right)$ is assumed to be 0.5 and the heliostat efficiency is assumed to be 0.69 (Weimer, 2000). The solar resource changes, so the amount of power that can be provided with a fixed heliostat area changes, and therefore the amount of hydrogen produced changes as well. In this analysis, the amount of hydrogen that could be produced each hour for a given set of solar data and maximum reactor power and heliostat area is calculated. The hourly solar data is used to determine the production level of the solar thermal reactor. If its 
production is not sufficient, hydrogen is drawn from the SMR and storage to meet the demand. The heliostat area and reactor power are varied to find the sizes that will produce the necessary hydrogen while minimizing the capital cost.

Once the heliostat area is established, the tower height is calculated from the following relationship:

$$
\text { TowerHeight }=10 \bullet\left[\frac{\text { HeliostatArea }}{1000}\right]^{0.5}
$$

The heliostats and tower comprise the bulk of the solar reactor system's capital cost. The capital costs of the heliostats, tower, and reactor are determined using a series of economic factors applied to the purchase cost (Weimer, 2000). The heliostat purchase cost is based on the area, and the base case cost is $\$ 130 / \mathrm{m}^{2}$ (Spath, 2002). The heliostat area is varied for each system to create the optimal design with respect to cost while ensuring the necessary supply of solar energy, the amount of which depends on the load division of the total system. The tower height is determined through a relationship with the heliostat area and a purchase cost of $\$ 7500 / \mathrm{m}$ is applied (Weimer, 2000). The solar reactor purchase cost is based on the volume of the reactor, determined through the methane molar flow rate and the ideal gas law. A cost of $\$ 38,870 / \mathrm{m}^{3}$ is used (Weimer, 2000). It has been shown that a natural gas conversion of 0.7 provides the best hydrogen production rate (Spath, 2002), so it is assumed that the methane flow rate and temperature will vary to keep a constant conversion of 0.7 . The reactor was sized using the maximum instantaneous methane flow rate and a temperature of $2273 \mathrm{~K}$, its maximum temperature.

The fuel consumption is determined stoichiometrically. The unconverted methane is recycled back through the system, so all of the methane is assumed to be dissociated into hydrogen and carbon black.

\section{Steam Methane Reformer}

The capital cost for an SMR was calculated using a relationship between the plant capacity and the installed cost of the system, including the reformer, shift reactor, PSA system, and $\mathrm{NO}_{\mathrm{X}}$ control (Ogden, 1996). The cost was translated into year 2000 dollars using the CE Plant Cost Index. Fuel consumption was calculated using an energy efficiency of 80\% (Ogden, 1996).

\section{Compression and Storage}

As the solar reactor and steam methane reformer are to be utilized in an automotive filling station, storage is a key aspect in the design of the system. Varying by location, the solar system will only produce hydrogen between seven and ten hours of the day. Furthermore, the solar reactor system is subject to extended periods of low insolation during which no hydrogen is produced and is also subject to seasonal variations in the amount of energy available from the sun. The storage system serves to accumulate hydrogen during periods of excess production and to provide hydrogen to the filling station during periods of low production. Although the steam methane reformer can produce hydrogen at any point during the day, a storage system is still required to accommodate sudden variations in the load demand of the system and for maintenance downtime in the system. Therefore, the storage provides hydrogen during periods 
when the solar reactor system produces no hydrogen and the steam methane reformer produces its maximum capacity, but does not meet demand. In this sense, the storage system acts as a buffer, concurrently accepting and dispensing hydrogen.

The compression system consists of parallel compressors, each downstream of its respective purification system. These compressors increase the pressure of the hydrogen from $145 \mathrm{psi}$ ( 1 $\mathrm{MPa})$, in the case of the steam methane reformer, and $185 \mathrm{psi}(1.3 \mathrm{MPa})$, in the case of the solar reactor, to $2900 \mathrm{psi}(20 \mathrm{MPa})$ for storage. For the base case, the compressor power required is $157 \mathrm{~kW}$ for the solar thermal reactor system and $31 \mathrm{~kW}$ for the SMR system. These values are determined from the flow rate of the hydrogen, as well as the input and output pressures, in a correlation given by Amos (1998).

The storage system consists of storage tanks capable of holding hydrogen at a maximum pressure of $2900 \mathrm{psi}(20 \mathrm{MPa})$. The size of the storage tanks is based on the cumulative length of time that passes with insufficient insolation for hydrogen production and on the amount of hydrogen required for the filling station. The tanks are depleted during periods of low solar production, and are refilled during periods of excess solar production. For the base case, the required overall storage capacity is $1,131 \mathrm{~kg}$. The parameters of the base case are discussed in a later section.

A detailed methodology of the sizing and costing of the compression and storage systems is given in the appendix.

\section{Integration}

In order to determine that the two hydrogen production systems and storage level are sufficient to supply the necessary hydrogen, a spreadsheet is used to calculate the amount of hydrogen that is used from each source. In each case, it is assumed that the solar reactor system produces the maximum possible amount of hydrogen and the SMR supplements that amount. Since the SMR is capable of minimal load following, its production is constant except during extended periods of insufficient solar insolation, when its production is increased. Typically, the storage acts as a buffer, and the net amount of hydrogen drawn from storage equals the hydrogen production. However, on days of very low solar radiance, when the SMR cannot cover the lack of hydrogen production by the solar reactor system, some is taken from the hydrogen storage. The storage is then replenished when the two systems produce more than the required daily amount. The daily storage level is calculated to ensure that ample storage can be supplied and replenished. Through this method, the storage level and the heliostat area are sized to ensure that the hydrogen supply is sufficient. The total annual production from each system is calculated and used to determine the fuel costs and production levels of carbon black.

\section{Economic Assumptions}

The key parameter when considering the economic viability of the solar/SMR combined system is the internal rate of return, IRR. The hydrogen selling price is varied to provide a $15 \%$ IRR, as this value is the point at which most commercial projects become economically feasible. For each system scenario, the solver function in Excel was used to optimize the heliostat area and storage volume in order to minimize the hydrogen price needed to reach a $15 \%$ IRR. Other assumed variables, such as the plant life, tax rate, and working capital rate, are standard values 
that are commonly assumed for these parameters. The cost of land is not included in this analysis, as its price varies across the county. Also, it is assumed that the cost of purchasing the land is recouped at the end of the project. The process capital costs and operating costs are determined from a variety of sources, each of which is listed with its respective variable in Table 1.

Table 1. Economic Assumptions

\begin{tabular}{|l|c|c|}
\cline { 3 - 3 } \multicolumn{2}{|l}{} & Source \\
\hline $\begin{array}{l}\text { Internal Rate of Return } \\
\text { (IRR) }\end{array}$ & $15 \%$ & assumed \\
\hline $\begin{array}{l}\text { Heliostat Price (Base } \\
\text { Case) }\end{array}$ & $\$ 130 / \mathrm{m}^{2}$ & Spath, 2002 \\
\hline $\begin{array}{l}\text { Carbon Black Price } \\
\text { (Base Base) }\end{array}$ & $\$ 0.95 / \mathrm{kg}$ & $\begin{array}{l}\text { Several carbon } \\
\text { black vendors }\end{array}$ \\
\hline Tower Cost & $\$ 7500 / \mathrm{m}$ & Weimer, 2000 \\
\hline $\begin{array}{l}\text { Natural Gas Cost (Base } \\
\text { Case) }\end{array}$ & $\$ 3.72 / \mathrm{GJ}$ & Spath, 2002 \\
\hline Electricity Cost & $\$ 0.05 / \mathrm{kWh}$ & Biegler, 1997 \\
\hline Cooling Water Cost & $\$ 0.01 / 1000 \mathrm{~m}{ }^{3}$ & Biegler, 1997 \\
\hline Steam Cost (350 psig) & $\$ 3.40 / 1000 \mathrm{lb}$ & Biegler, 1997 \\
\hline Depreciation Method & Straight Line & assumed \\
\hline Plant Life & $20 \mathrm{yrs}$ & assumed \\
\hline Tax Rate & $35 \%$ & assumed \\
\hline Working Capital & $18 \%$ & assumed \\
\hline
\end{tabular}

\section{Sensitivity Analysis}

The feasibility of the combined solar thermal reactor/steam methane reformer system is influenced by numerous variables, including the cost of the heliostats, the cost of natural gas, the selling price of carbon black, and the load fraction split of the system. A sensitivity analysis, performed on each of the three locations, provides the basis on which these variables are manipulated and conclusions are drawn.

For each variable, a base case is established. Table 2 summarizes the base case values for each variable as well as the range of values that are used in the sensitivity analysis. A rationale for the selection of the base case value is also given.

The load fraction split significantly affects the system economics. Although the goal of the system is to utilize the benefits of each production method, shifting the load fraction toward the steam methane reformer significantly lowers the overall system cost. Doing so, however, negates the benefits of the solar reactor system. Therefore, several system combinations are 
considered, each with a varying load fraction. The load fraction splits are detailed in Table 2, and are labeled Systems $1-5$.

System 1 is a unique case, as it is a stand alone solar thermal reactor. This system is sized to $135 \%$ of the daily hydrogen requirement to accommodate for daily variations in hydrogen production. This system is sized to refill one hundred fifty cars, half of the amount used in the other cases. This lower system rating is necessitated by the storage requirements that a three hundred car system requires. The capital costs of the storage system for three hundred cars make this system uneconomical in every location and in every case. In the other system orientations, the steam methane reformer eliminates the need for large amounts of storage, so they are sized to the three hundred car daily requirement.

Table 2. Sensitivity Analysis Base Case

\begin{tabular}{|c|c|c|c|}
\cline { 2 - 4 } \multicolumn{1}{c|}{} & Base Case & Rationale & Range \\
\hline Heliostat Cost & $\$ 130 / \mathrm{m}^{2}$ & $\begin{array}{c}\text { Reasonable unit price for } \\
\text { heliostats (Spath, 2002) }\end{array}$ & $\$ 50-\$ 250 / \mathrm{m}^{2}$ \\
\hline $\begin{array}{c}\text { Natural Gas } \\
\text { Cost }\end{array}$ & $\$ 3.72 / \mathrm{GJ}$ & $\begin{array}{c}\text { Current unit price for } \\
\text { natural gas (Spath, 2002) }\end{array}$ & $\$ 2.50-\$ 4.75 / \mathrm{GJ}$ \\
\hline $\begin{array}{c}\text { Carbon Black } \\
\text { Selling Price }\end{array}$ & $\$ 0.95 / \mathrm{kg}$ & $\begin{array}{c}\text { Current unit price for } \\
\text { mid-grade (N330) carbon } \\
\text { black (Degussa, 2002) }\end{array}$ & $\$ 0.00-\$ 1.90 / \mathrm{kg}$ \\
\hline $\begin{array}{c}\text { Load Fraction } \\
\text { Split }\end{array}$ & $60 \%$ SMR : & $\begin{array}{c}\text { Best trade off between } \\
\text { SMR economics and solar } \\
\text { benefits }\end{array}$ & $\begin{array}{c}40 \% \text { SMR : 60\% Solar (System 2) } \\
57 \% \text { SMR : 43\% Solar (System 3) } \\
73 \% \text { SMR : 27\% Solar (System 4) } \\
100 \% \text { SMR : 0\% Solar (System 5) }\end{array}$ \\
\hline
\end{tabular}

An analysis of the base case gives the hydrogen selling price required to produce a $15 \%$ internal rate of return for each of the three cities studied. The results of the base case analysis are shown in Table 3. 
Table 3. Base Case Hydrogen Prices

\begin{tabular}{|c|c|c|c|}
\hline \multirow[b]{2}{*}{ System } & \multicolumn{3}{|c|}{ Hydrogen Selling Price (/GJ) } \\
\hline & Phoenix & Miami & $\begin{array}{c}\text { New } \\
\text { Orleans }\end{array}$ \\
\hline $\begin{array}{c}1 \\
\text { 0\% SMR } \\
\text { 100\% Solar }\end{array}$ & $\$ 27$ & $\$ 59$ & $\$ 91$ \\
\hline $\begin{array}{c}2 \\
40 \% \text { SMR } \\
60 \% \text { Solar } \\
\end{array}$ & $\$ 26$ & $\$ 44$ & $\$ 60$ \\
\hline $\begin{array}{c}3 \\
57 \% \text { SMR } \\
43 \% \text { Solar } \\
\end{array}$ & $\$ 26$ & $\$ 39$ & $\$ 50$ \\
\hline $\begin{array}{c}4 \\
\\
73 \% \text { SMR } \\
27 \% \text { Solar } \\
\end{array}$ & $\$ 25$ & $\$ 34$ & $\$ 41$ \\
\hline $\begin{array}{c}5 \\
100 \% \text { SMR } \\
\text { 0\% Solar }\end{array}$ & $\$ 19$ & $\$ 19$ & $\$ 19$ \\
\hline
\end{tabular}

\section{Heliostat Analysis}

Due to the unique nature of the heliostat market, heliostat price is a highly uncertain cost. The manufacture of heliostats is a developing field, so mass production should help to lower the cost the units. Studies put the current cost of heliostats near $\$ 500 / \mathrm{m}^{2}$ (Weimer, 2002). A reasonable near-term future cost of $\$ 130 / \mathrm{m}^{2}$ is used as the base case. Previous studies used a range of heliostat costs varying between a minimum of $\$ 75 / \mathrm{m}^{2}$ and a maximum of $\$ 250 / \mathrm{m}^{2}$ (Spath, 2002). As the purpose of this report is to study the conditions under which the solar reactor is economically viable, the minimum heliostat price cost used in this report is somewhat lower, at $\$ 50 / \mathrm{m}^{2}$. This value is chosen as a potential value of heliostat prices upon mass production over the next decade.

The heliostat component is a significant percentage of the overall system cost. For the base case, the heliostat fixed capital cost comprises approximately $25 \%$ of the entire system cost. (The capital cost splits are detailed in Appendix A-5.) Therefore, variations in the heliostat cost significantly influence the economics of the system, especially at higher solar reactor system load fractions. As heliostat price decreases, the solar system becomes increasingly viable. At the lowest heliostat price in Phoenix, $\$ 50 / \mathrm{m}^{2}$, the solar-only system provides hydrogen almost as economically as the stand-alone SMR system can deliver. At higher heliostat costs, however, the solar reactor system price becomes uncompetitive. In the two locations with lower insolation, hydrogen selling price is more sensitive to the load fraction split, even at lower heliostat costs. In these two locations, hydrogen production is always cheaper at higher SMR load fractions. Figure 2 summarizes the results of varying heliostat costs for each of the three locations. 

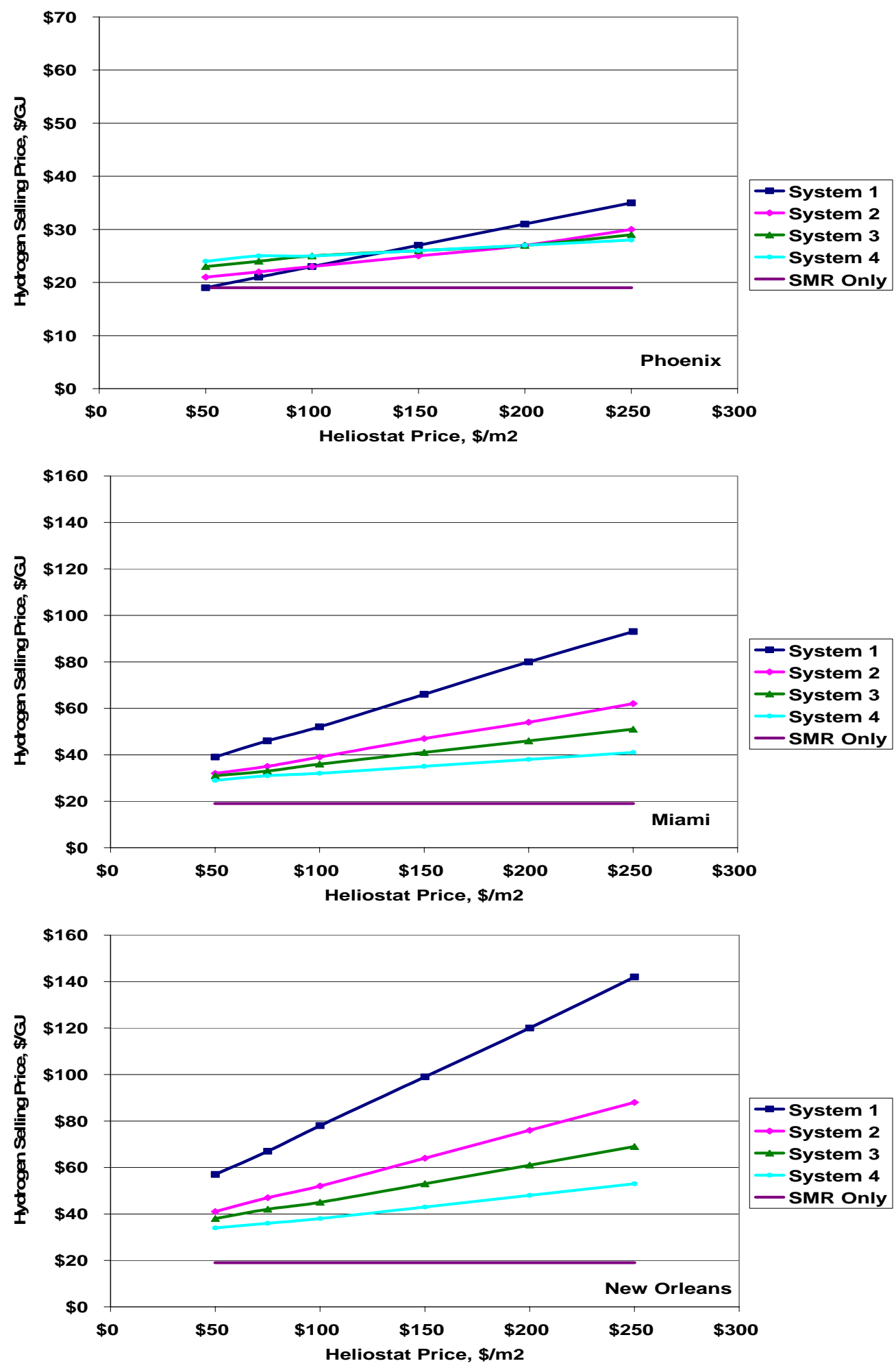

Figure 2. Heliostat Cost Analysis 


\section{Natural Gas Analysis}

Despite recent volatility in the natural gas selling price, a cost of $\$ 3.72 /$ GJ (Spath, 2002) is used. This cost is representative of the current price paid throughout the country and of the price projected in the near future. To accommodate future variations in price, the sensitivity analysis considers prices between a minimum of $\$ 2.50 / \mathrm{GJ}$ and a maximum of $\$ 4.75 / \mathrm{GJ}$.

An analysis of the effects of price of natural gas shows that the cost of the gas has little effect on the overall system economics. For all locations, a 90\% increase in the cost of natural gas results in an increase in the price of hydrogen of less than 15\%. Most hydrogen price increases fell far below this value. This effect is not unexpected, as both systems use natural gas, with the solar reactor consuming natural gas at only a slightly higher rate than the steam methane reformer. Also, the large capital cost of each system outweighs the relatively small cost of the natural gas. The results of this analysis are shown in Figure 3.

\section{Carbon Black Analysis}

The values for carbon black are the current prices for middle grade carbon black sold in bulk. The solar thermal reactor produces its maximum amount of carbon black when it is in the $40 \%$ SMR : $60 \%$ solar reactor configuration. This system split produces is approximately 900,000 kilograms of carbon black per year. This production level is not significant on the global level, as worldwide production levels are on the order of 7.9 million metric tons per year (Spath, 2002). The addition of less than 0.01 percent to the total global production capacity will not impact the market price of carbon black. Degussa, a major carbon black manufacturer, quoted the list price of middle grade carbon black, N330, as $\$ 0.4825 / \mathrm{lb}(\$ 1.06 / \mathrm{kg})$, with a bulk discount lowering the cost to approximately $\$ 0.4325 / \mathrm{lb}(\$ 0.95 / \mathrm{kg})$. Sid Richardson Company provided a bulk carbon black price of $\$ 0.3620 / \mathrm{lb}(\$ 0.80 / \mathrm{kg})$. Since the carbon black will most likely be sold in bulk, an approximate median price of $\$ 0.95 / \mathrm{kg}$ is assumed for the base price.

While the solar reactor system produces carbon black, the steam methane reformer does not. Therefore, the price of carbon black affects the system economics considerably. In every location, a high carbon black price can offset the high capital costs of the solar reactor and heliostats to make the solar reactor more economical. This result is the greatest in Phoenix, due to the advantageous climate in that region.

The analysis includes the case of no carbon black sales. This case demonstrates a strong preference toward the steam methane reformer, as the solar reactor is the only system that benefits from a high carbon black price. At the other extreme, that of the highest carbon black price, $\$ 1.90 / \mathrm{kg}$, the Phoenix hydrogen selling price is below the current market price for each case and the Miami selling price is comparable to the current market price. Therefore, a higher carbon black price pushes the system economics toward the solar reactor system. The complete carbon black analysis is provided in Figure 4. 

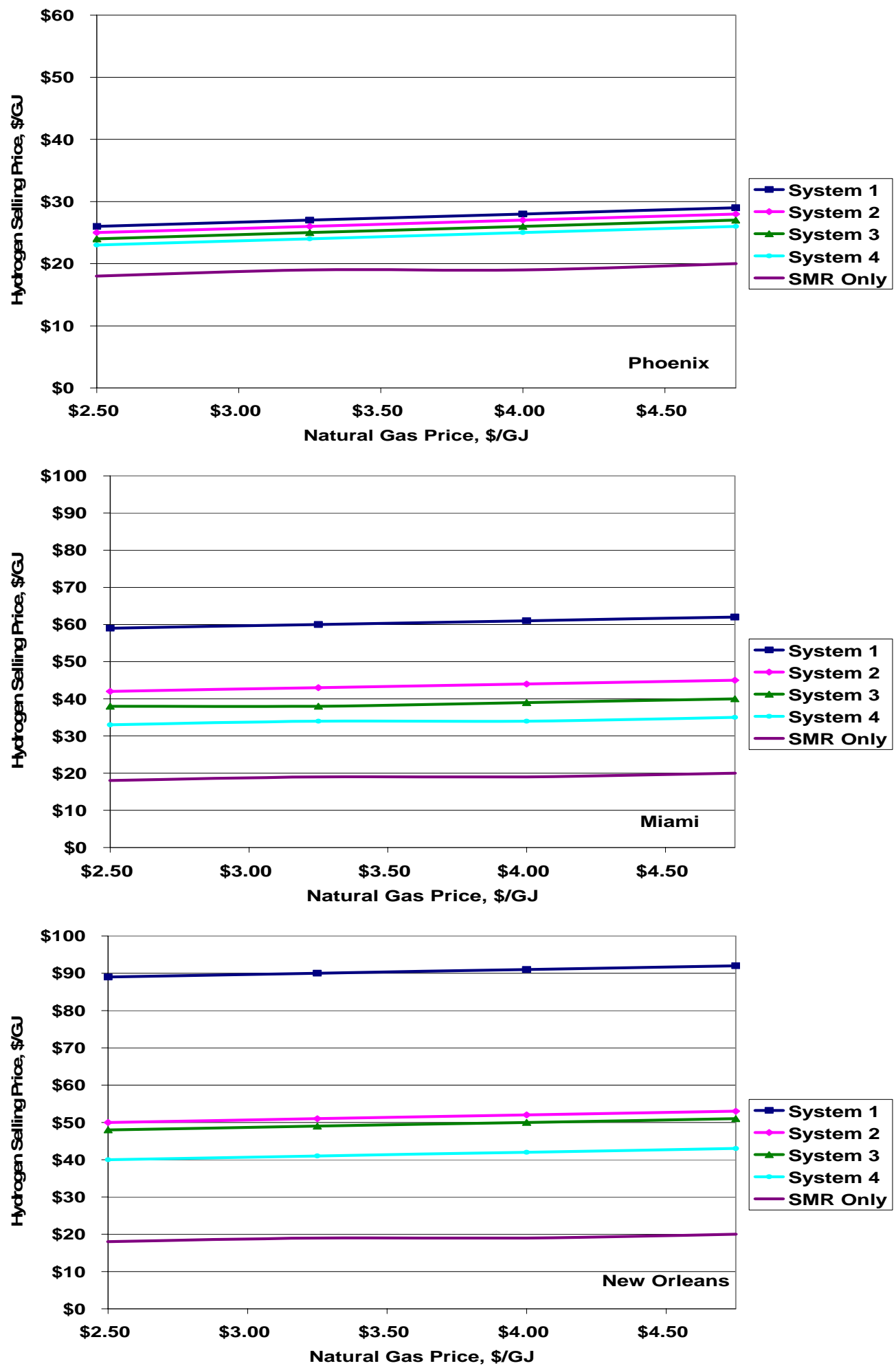

Figure 3. Natural Gas Cost Analysis 

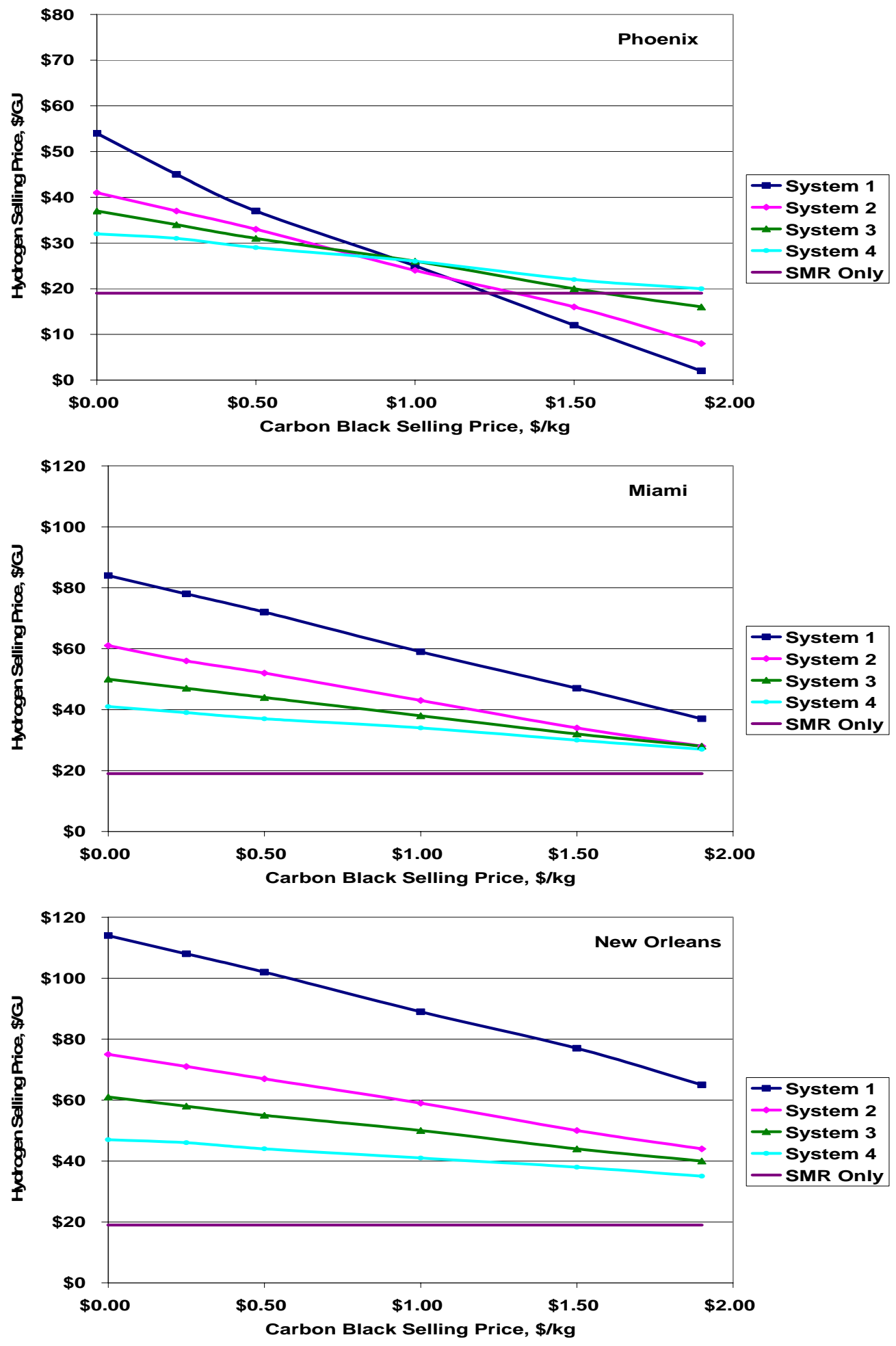

Figure 4. Carbon Black Analysis 


\section{Discussion of Results}

The solar reactor system is a viable option to traditional hydrogen production methods under certain circumstances. Hydrogen production from a steam methane reformer produces hydrogen at $\$ 19 / \mathrm{GJ}$ (calculations from Ogden, 1996). The solar reactor/SMR system should produce hydrogen at this price or lower in order to be a practical alternative for hydrogen production.

An analysis of the cost of hydrogen produced by a combined solar thermal reactor and steam methane reformer system shows at the current base case, increased solar load fractions result in an increased hydrogen selling price. In the Phoenix base case, the hydrogen selling price ranges from $\$ 27 / \mathrm{GJ}$ for the $27 \%$ solar / $73 \%$ SMR system to $\$ 27 / \mathrm{GJ}$ for the $100 \%$ solar reactor system. This relatively small increase in hydrogen price is due to the fact that in this high insolation area, hydrogen produced via the solar thermal reactor is only slightly more expensive than hydrogen produced via steam methane reforming. The cost differential is more profound in Miami and New Orleans. In Miami, the hydrogen price ranges from $\$ 34 / \mathrm{GJ}$ for the $27 \% / 73 \%$ system to $\$ 59 / \mathrm{GJ}$ for the solar-only system. In New Orleans, the price balloons to $\$ 41 / \mathrm{GJ}$ for the $27 \%$ / $73 \%$ system and $\$ 91$ for the solar-only system. The effects of varying heliostat cost are highlighted in Table 4.

\begin{tabular}{|c|c|c|}
\hline \multicolumn{3}{|c|}{ Hydrogen Price } \\
\hline & $100 \%$ Solar & $27 \%$ Solar : 73\% SMR \\
\hline Phoenix & $\$ 27 /$ GJ & $\$ 25 /$ GJ \\
\hline Miami & $\$ 59 /$ GJ & $\$ 34 /$ GJ \\
\hline $\begin{array}{c}\text { New } \\
\text { Orleans }\end{array}$ & $\$ 91 /$ GJ & $\$ 41 /$ GJ \\
\hline
\end{tabular}

Table 4. Hydrogen Price - Varying Load Fraction

The variability of other system parameters significantly affects the hydrogen selling price. Heliostat cost can affect the hydrogen selling price either negatively or positively. The general trend holds that the price of heliostats will decrease when they enter the mass production manufacturing stage. Should the price of heliostats drop to the minimum value considered in this report, $\$ 50 / \mathrm{m}^{2}$, the price of hydrogen produced by the system drops drastically. In the Phoenix $60 \% / 40 \%$ split, the hydrogen cost falls to $\$ 21 / \mathrm{GJ}$ at the lowest heliostat cost. Likewise, the hydrogen cost drops to $\$ 32 / \mathrm{GJ}$ in Miami and $\$ 41 / \mathrm{GJ}$ in New Orleans. The effects of varying heliostat cost are highlighted in Table 5 and detailed in Table A-1. 


\begin{tabular}{|c|c|}
\hline \multicolumn{2}{|c|}{ Hydrogen Price } \\
\hline & $60 \%$ Solar : $40 \%$ SMR \\
\hline Phoenix & $\$ 21 /$ GJ \\
\hline Miami & $\$ 32 /$ GJ \\
\hline $\begin{array}{c}\text { New } \\
\text { Orleans }\end{array}$ & $\$ 41 /$ GJ \\
\hline
\end{tabular}

\section{Table 5. Hydrogen Price $-\mathbf{\$ 5 0} / \mathbf{m}^{2}$ Heliostat Price}

The most important variable in the combined system appears to be the carbon black selling price. At higher carbon black selling prices, the economics of the system shift in the favor of a high solar reactor load fraction. Carbon black prices above $\$ 1.50 / \mathrm{kg}$ favor the solar reactor system over the steam methane reformer. At the highest carbon black selling price, $\$ 1.90 / \mathrm{kg}$, hydrogen sells for $\$ 8 / \mathrm{GJ}$ in the Phoenix $40 \%$ SMR / $60 \%$ solar reactor system. This price is significantly below the price of hydrogen produced via the SMR system. The preference toward the solar reactor is not as strong in Miami and New Orleans, with hydrogen selling prices of \$28/GJ and $\$ 44 / G J$, respectively, at the highest carbon black price. The high carbon black selling price is not enough in these two locations to overcome the significantly lower amount of carbon. The effects of varying carbon black selling price are highlighted in Table 6 and detailed in Table A-3.

\begin{tabular}{|c|c|}
\hline \multicolumn{2}{|c|}{ Hydrogen Price } \\
\hline & $60 \%$ Solar : $40 \%$ SMR \\
\hline Phoenix & $\$ 8 /$ GJ \\
\hline Miami & $\$ 28 /$ GJ \\
\hline $\begin{array}{c}\text { New } \\
\text { Orleans }\end{array}$ & $\$ 44 /$ GJ \\
\hline
\end{tabular}

Table 6. Hydrogen Price $-\mathbf{\$ 1 . 9 0 / k g}$ Carbon Black Price

Finally, we consider what we may call a "best case." In this scenario, we use our minimum for the heliostat cost, $\$ 50 / \mathrm{m}^{2}$, and a reasonable carbon black price of $\$ 1.25 / \mathrm{kg}$. The hydrogen selling price becomes very competitive with traditional production methods, as shown in Figure 5. At the base case load fraction, $60 \%$ solar production and $40 \%$ SMR production, the selling price of hydrogen is $\$ 16 / \mathrm{GJ}$ in Phoenix. Above $60 \%$ solar fraction, the price decreases further, to approximately $\$ 6 / \mathrm{GJ}$ at $100 \%$ solar production. The selling price is considerably higher in Miami, but at the higher solar load fractions, the hydrogen selling price is competitive. The best case analysis for New Orleans indicates that hydrogen production is more economical via steam methane reforming under all conditions. 


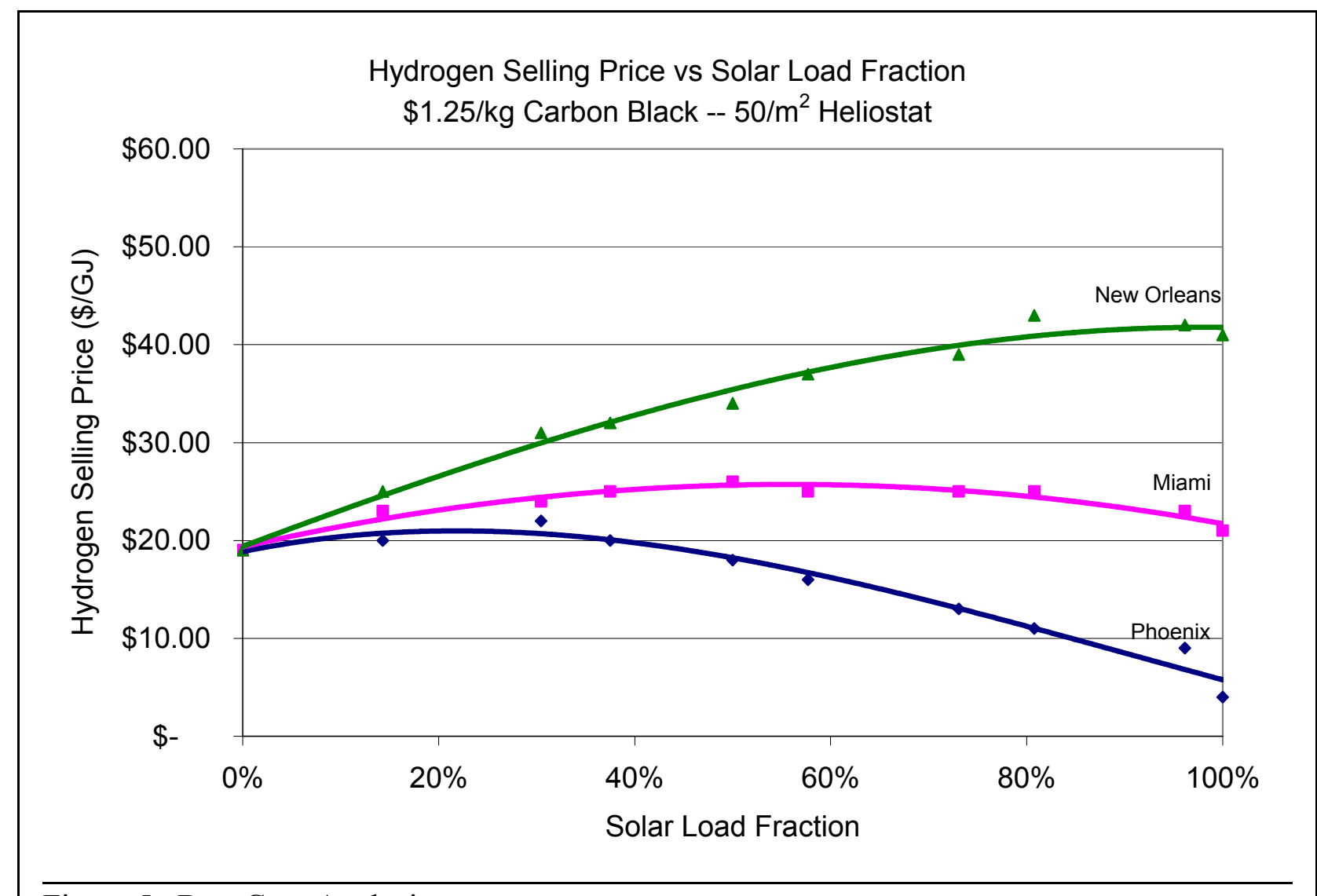

Figure 5. Best Case Analysis

While the solar reactor system does not currently produce hydrogen economically, it holds the potential for improvement. Highly variable parameters such as the price of heliostats and the price of carbon black can shift the economics toward the favor of the solar thermal reactor system. Another economic consideration is the possibility of carbon credits. The impact of increased carbon dioxide is currently under debate. If carbon dioxide emissions become regulated and quantified, the use of the solar reactor system would hold a strong advantage over the SMR system. 


\section{Acknowledgments}

The authors would like to thank Pam Spath and Wade Amos of the National Renewable Energy Laboratory in Golden, $\mathrm{CO}$ for their efforts in reviewing this analysis. 


\section{References}

Amos, Wade A. Costs of Storing and Transporting Hydrogen. National Renewable Laboratory, November 1998 NREL/TP-570-25106.

Bielger, Lorenz and Ignacio Grossman, Arthur Westerberg. Systematic Methods of Chemical Process Design. Prentice Hall PTR: New Jersey. 1997.

Degussa, Inc. Akron, OH. Personal Correspondence. May 2002.

Ogden, Joan and Thomas Kreutz, Margaret Steinbugler, Adam Cox, Jason White. "Hydrogen Energy Systems Studies", Proceedings of the 1996 U.S. DOE Hydrogen Program Review. National Renewable Energy Laboratory, 1996. Volume I, p. 125-137.

QuestAir Technologies, Inc. Personal Correspondence. Burnaby, BC, Canada. April 2002.

Renewable Resource Data Center. "The National Solar Radiation Data Base, Hourly Data Files." rredc.nrel.gov. March 2002.

Sid Richardson Company. Akron, OH. Personal Correspondence. May 2002.

Spath, Pamela and Wade Amos. Assessment of Natural Gas Splitting with a Concentrating Solar Reactor for Hydrogen Production. National Renewable Laboratory, April 2002. NREL/TP-510-31949.

Weimer, Alan and Allan Lewandowski. "Thermal Dissociation of Methane Using a Solar Coupled Aerosol Flow Reactor", Proceedings of the 2000 DOE Hydrogen Program Review. NREL/CP-570-28890. 


\section{Appendix 1: Detailed Compression and Storage}

The methodology for the sizing and costing of the hydrogen compression and storage systems is taken from "Costs of Storing and Transporting Hydrogen," by Wade Amos. Capital costs from this report are for the year 1995, and are updated using the Chemical Engineering Index as reported by Chemical Engineering Magazine to 2000 dollars. Certain assumptions, such as the cost of cooling water and electricity, are based on national average prices.

The amount of energy required by the compressor is based on the flow of hydrogen, and the inlet and output pressures:

$$
\begin{aligned}
& \text { Energy }=\text { Flow } \bullet \text { Compressor Power } \bullet \frac{\ln \left(\frac{P_{\text {out }}}{P_{\text {in }}}\right)}{\ln \left(\frac{20 \cdot 10^{6}}{0.1 \cdot 10^{6}}\right)} \\
& \text { Compressor Power }=1.0 \frac{\mathrm{kW} \cdot \mathrm{hr}}{\mathrm{lb}}
\end{aligned}
$$

Capital and operating costing follow a similar methodology:

$$
\begin{aligned}
& \text { Compressor Capital Cost }=\text { Comp Cost } \bullet \text { Comp Size } \bullet\left(\frac{\text { Energy }}{\text { Comp Size }}\right)^{0.8}\left(\frac{P_{\text {out }}}{\text { Comp Press }}\right)^{0.18} \\
& \text { Comp Cost }=\frac{\$ 1000}{k W} \\
& \text { Comp Size }=4000 \mathrm{~kW} \text { (Base Size) }
\end{aligned}
$$$$
\text { Cooling = Flow } \bullet \text { Comp Cool } \bullet \frac{\ln \left(\frac{P_{\text {out }}}{P_{\text {in }}}\right)}{\ln \left(\frac{20 \cdot 10^{6}}{0.1 \cdot 10^{6}}\right)}
$$

Comp Cool $=6.0 \frac{\mathrm{gal}}{\mathrm{lb}}$

Cooling Cost $=$ Cooling $\bullet$ Cooling Water Cost $\bullet$ Operating Factor

Cooling Water Cost $=\frac{\$ 0.055}{1000 \mathrm{gal}}$

Operating Factor $=0.9$

Energy Cost $=$ Energy $\bullet$ Electic Cost $\bullet$ Operating Factor

Electric Cost $=\frac{\$ 0.05}{k W}$ 
The tank sizing and costing are based on the amount of hydrogen stored, the length of storage, and the pressure at which it is stored.

Storage $=$ Hydrogen Flow $\bullet$ Storage Period

Tank CapitalCost $=($ Tank Cost $\bullet$ Tank Size $)\left(\frac{\text { Storage } \cdot \frac{\text { Tank Press }}{P}}{\text { Tank Size }}\right)^{0.75}\left(\frac{P}{\text { Tank Press }}\right)^{0.44}$

Tank Cost $=\frac{\$ 600}{\mathrm{lb}}$

Tank Size $=500 \mathrm{lb}$ (Base Size)

Tank Press $=20 \cdot 10^{6} \mathrm{~Pa}$ 


\section{Appendix 2: Detailed Sensitivity Analysis Data}

The following tables provide the values used in the heliostat, carbon black, and natural gas sensitivity analyses.

$\underline{\text { Table A-1. Heliostat Cost Analysis }}$

\begin{tabular}{|c|c|c|c|c|}
\hline \multirow{2}{*}{ System } & \multirow{2}{*}{$\begin{array}{l}\text { Heliostat } \\
\text { Cost }\end{array}$} & \multicolumn{3}{|c|}{$\begin{array}{c}\text { Hydrogen Selling Price } \\
\text { \$/GJ - 15\% IRR }\end{array}$} \\
\hline & & Phoenix & Miami & $\begin{array}{l}\text { New } \\
\text { Orleans }\end{array}$ \\
\hline \multirow{3}{*}{1} & $\$ 50$ & $\$ 19$ & $\$ 39$ & $\$ 57$ \\
\hline & $\$ 75$ & $\$ 21$ & $\$ 46$ & $\$ 67$ \\
\hline & $\$ 100$ & $\$ 23$ & $\$ 52$ & $\$ 78$ \\
\hline \multirow{3}{*}{$\begin{array}{l}\text { 0\% SMR } \\
\text { 100\% Solar }\end{array}$} & $\$ 150$ & $\$ 27$ & $\$ 66$ & $\$ 99$ \\
\hline & $\$ 200$ & $\$ 31$ & $\$ 80$ & $\$ 120$ \\
\hline & $\$ 250$ & $\$ 35$ & $\$ 93$ & $\$ 142$ \\
\hline \multirow{3}{*}{2} & $\$ 50$ & $\$ 21$ & $\$ 32$ & $\$ 41$ \\
\hline & $\$ 75$ & $\$ 22$ & $\$ 35$ & $\$ 47$ \\
\hline & $\$ 100$ & $\$ 23$ & $\$ 39$ & $\$ 52$ \\
\hline \multirow{3}{*}{$\begin{array}{l}40 \% \text { SMR } \\
60 \% \text { Solar }\end{array}$} & $\$ 150$ & $\$ 25$ & $\$ 47$ & $\$ 64$ \\
\hline & $\$ 200$ & $\$ 27$ & $\$ 54$ & $\$ 76$ \\
\hline & $\$ 250$ & $\$ 30$ & $\$ 62$ & $\$ 88$ \\
\hline \multirow{3}{*}{3} & $\$ 50$ & $\$ 23$ & $\$ 31$ & $\$ 38$ \\
\hline & $\$ 75$ & $\$ 24$ & $\$ 33$ & $\$ 42$ \\
\hline & $\$ 100$ & $\$ 25$ & $\$ 36$ & $\$ 45$ \\
\hline \multirow{3}{*}{$\begin{array}{l}57 \% \text { SMR } \\
43 \% \text { Solar }\end{array}$} & $\$ 150$ & $\$ 26$ & $\$ 41$ & $\$ 53$ \\
\hline & $\$ 200$ & $\$ 27$ & $\$ 46$ & $\$ 61$ \\
\hline & $\$ 250$ & $\$ 29$ & $\$ 51$ & $\$ 69$ \\
\hline \multirow[b]{2}{*}{4} & $\$ 50$ & $\$ 24$ & $\$ 29$ & $\$ 34$ \\
\hline & $\$ 75$ & $\$ 25$ & $\$ 31$ & $\$ 36$ \\
\hline \multirow{4}{*}{$\begin{array}{l}73 \% \text { SMR } \\
27 \% \text { Solar }\end{array}$} & $\$ 100$ & $\$ 25$ & $\$ 32$ & $\$ 38$ \\
\hline & $\$ 150$ & $\$ 26$ & $\$ 35$ & $\$ 43$ \\
\hline & $\$ 200$ & $\$ 27$ & $\$ 38$ & $\$ 48$ \\
\hline & $\$ 250$ & $\$ 28$ & $\$ 41$ & $\$ 53$ \\
\hline \multirow{2}{*}{$\begin{array}{c}5 \\
\text { 100\% SMR } \\
\text { 0\% Solar }\end{array}$} & & & & \\
\hline & & $\$ 19$ & $\$ 19$ & $\$ 19$ \\
\hline
\end{tabular}

Other system costs are held constant. These costs include:

- Carbon Black Selling Price: $\$ 0.95 / \mathrm{kg}$

- Natural Gas Price: \$3.72 / GJ 
Table A-2. Natural Gas Cost Analysis

\begin{tabular}{|c|c|c|c|c|}
\hline \multirow{2}{*}{ System } & \multirow{2}{*}{$\begin{array}{c}\text { Natural } \\
\text { Gas } \\
\text { Cost } \\
\text { \$/GJ }\end{array}$} & \multicolumn{3}{|c|}{$\begin{array}{c}\text { Hydrogen Selling Price } \\
\text { \$/GJ - 15\% IRR }\end{array}$} \\
\hline & & Phoenix & Miami & $\begin{array}{c}\text { New } \\
\text { Orleans }\end{array}$ \\
\hline \multirow{2}{*}{1} & $\$ 2.50$ & $\$ 26$ & $\$ 59$ & $\$ 89$ \\
\hline & $\$ 3.25$ & $\$ 27$ & $\$ 60$ & $\$ 90$ \\
\hline \multirow{2}{*}{$\begin{array}{l}\text { 0\% SMR } \\
100 \% \text { Solar }\end{array}$} & $\$ 4.00$ & $\$ 28$ & $\$ 61$ & $\$ 91$ \\
\hline & $\$ 4.75$ & $\$ 29$ & $\$ 62$ & $\$ 92$ \\
\hline \multirow{4}{*}{$\begin{array}{l}40 \% \text { SMR } \\
60 \% \text { Solar }\end{array}$} & $\$ 2.50$ & $\$ 25$ & $\$ 42$ & $\$ 50$ \\
\hline & $\$ 3.25$ & $\$ 26$ & $\$ 43$ & $\$ 51$ \\
\hline & $\$ 4.00$ & $\$ 27$ & $\$ 44$ & $\$ 52$ \\
\hline & $\$ 4.75$ & $\$ 28$ & $\$ 45$ & $\$ 53$ \\
\hline \multirow{2}{*}{3} & $\$ 2.50$ & $\$ 24$ & $\$ 38$ & $\$ 48$ \\
\hline & $\$ 3.25$ & $\$ 25$ & $\$ 38$ & $\$ 49$ \\
\hline \multirow{2}{*}{$\begin{array}{l}57 \% \text { SMR } \\
43 \% \text { Solar }\end{array}$} & $\$ 4.00$ & $\$ 26$ & $\$ 39$ & $\$ 50$ \\
\hline & $\$ 4.75$ & $\$ 27$ & $\$ 40$ & $\$ 51$ \\
\hline \multirow{2}{*}{4} & $\$ 2.50$ & $\$ 23$ & $\$ 33$ & $\$ 40$ \\
\hline & $\$ 3.25$ & $\$ 24$ & $\$ 34$ & $\$ 41$ \\
\hline \multirow{2}{*}{$\begin{array}{l}73 \% \text { SMR } \\
27 \% \text { Solar }\end{array}$} & $\$ 4.00$ & $\$ 25$ & $\$ 34$ & $\$ 42$ \\
\hline & $\$ 4.75$ & $\$ 26$ & $\$ 35$ & $\$ 43$ \\
\hline \multirow{4}{*}{$\begin{array}{r}100 \\
0\end{array}$} & $\$ 2.50$ & $\$ 26$ & $\$ 59$ & $\$ 89$ \\
\hline & $\$ 3.25$ & $\$ 27$ & $\$ 60$ & $\$ 90$ \\
\hline & $\$ 4.00$ & $\$ 28$ & $\$ 61$ & $\$ 91$ \\
\hline & $\$ 4.75$ & $\$ 29$ & $\$ 62$ & $\$ 92$ \\
\hline
\end{tabular}

Other system costs are held constant. These costs include:

- Carbon Black Selling Price: $\$ 0.95$ / kg

- Heliostat Price: $\$ 130 / \mathrm{m}^{2}$ 
Table A-3. Carbon Black Cost Analysis

\begin{tabular}{|c|c|c|c|c|}
\hline \multirow{2}{*}{ System } & \multirow{2}{*}{$\begin{array}{c}\text { Carbon } \\
\text { Black } \\
\text { Price } \\
\$ / k g\end{array}$} & \multicolumn{3}{|c|}{$\begin{array}{c}\text { Hydrogen Selling Price } \\
\text { \$/GJ - 15\% IRR }\end{array}$} \\
\hline & & Phoenix & Miami & $\begin{array}{c}\text { New } \\
\text { Orleans }\end{array}$ \\
\hline \multirow{3}{*}{1} & $\$ 0.00$ & $\$ 54$ & $\$ 84$ & $\$ 114$ \\
\hline & $\$ 0.25$ & $\$ 45$ & $\$ 78$ & $\$ 108$ \\
\hline & $\$ 0.50$ & $\$ 37$ & $\$ 72$ & $\$ 102$ \\
\hline \multirow{3}{*}{$\begin{array}{l}\text { 0\% SMR } \\
100 \% \text { Solar }\end{array}$} & $\$ 1.00$ & $\$ 25$ & $\$ 59$ & $\$ 89$ \\
\hline & $\$ 1.50$ & $\$ 12$ & $\$ 47$ & $\$ 77$ \\
\hline & $\$ 1.90$ & $\$ 2$ & $\$ 37$ & $\$ 63$ \\
\hline \multirow{3}{*}{2} & $\$ 0.00$ & $\$ 41$ & $\$ 61$ & $\$ 75$ \\
\hline & $\$ 0.25$ & $\$ 37$ & $\$ 56$ & $\$ 71$ \\
\hline & $\$ 0.50$ & $\$ 33$ & $\$ 52$ & $\$ 67$ \\
\hline \multirow{3}{*}{$\begin{array}{l}40 \% \text { SMR } \\
60 \% \text { Solar }\end{array}$} & $\$ 1.00$ & $\$ 24$ & $\$ 43$ & $\$ 59$ \\
\hline & $\$ 1.50$ & $\$ 16$ & $\$ 34$ & $\$ 50$ \\
\hline & $\$ 1.90$ & $\$ 8$ & $\$ 28$ & $\$ 44$ \\
\hline \multirow{6}{*}{$\begin{array}{l}57 \% \text { SMR } \\
43 \% \text { Solar }\end{array}$} & $\$ 0.00$ & $\$ 37$ & $\$ 50$ & $\$ 61$ \\
\hline & $\$ 0.25$ & $\$ 34$ & $\$ 47$ & $\$ 58$ \\
\hline & $\$ 0.50$ & $\$ 31$ & $\$ 44$ & $\$ 55$ \\
\hline & $\$ 1.00$ & $\$ 26$ & $\$ 38$ & $\$ 50$ \\
\hline & $\$ 1.50$ & $\$ 20$ & $\$ 32$ & $\$ 44$ \\
\hline & $\$ 1.90$ & $\$ 16$ & $\$ 28$ & $\$ 40$ \\
\hline \multirow{3}{*}{4} & $\$ 0.00$ & $\$ 32$ & $\$ 41$ & $\$ 47$ \\
\hline & $\$ 0.25$ & $\$ 31$ & $\$ 39$ & $\$ 46$ \\
\hline & $\$ 0.50$ & $\$ 29$ & $\$ 37$ & $\$ 44$ \\
\hline \multirow{3}{*}{$\begin{array}{l}73 \% \text { SMR } \\
27 \% \text { Solar }\end{array}$} & $\$ 1.00$ & $\$ 26$ & $\$ 34$ & $\$ 41$ \\
\hline & $\$ 1.50$ & $\$ 22$ & $\$ 30$ & $\$ 38$ \\
\hline & $\$ 1.90$ & $\$ 20$ & $\$ 27$ & $\$ 35$ \\
\hline \multirow{2}{*}{$\begin{array}{c}5 \\
\text { 100\% SMR } \\
\text { 0\% Solar }\end{array}$} & & & & \\
\hline & & $\$ 19$ & $\$ 19$ & $\$ 19$ \\
\hline
\end{tabular}

Other system costs are held constant. These costs include:

- Natural Gas Price: \$3.72 / GJ

- Heliostat Price: $\$ 130 / \mathrm{m}^{2}$ 
Table A-4. System Parameters

\begin{tabular}{|c|c|c|c|c|c|c|}
\hline \multirow[b]{2}{*}{ System } & \multicolumn{2}{|c|}{ Phoenix } & \multicolumn{2}{|c|}{ Miami } & \multicolumn{2}{|c|}{ New Orleans } \\
\hline & $\begin{array}{c}\text { Heliostat } \\
\text { Area } \\
\left(\mathbf{m}^{2}\right) \\
\end{array}$ & $\begin{array}{c}\text { Storage } \\
\text { Capacity } \\
\text { (kg) }\end{array}$ & $\begin{array}{c}\text { Heliostat } \\
\text { Area } \\
\left(\mathbf{m}^{2}\right) \\
\end{array}$ & $\begin{array}{c}\text { Storage } \\
\text { Capacity } \\
(\mathrm{kg})\end{array}$ & $\begin{array}{c}\text { Heliostat } \\
\text { Area } \\
\left(\mathbf{m}^{2}\right) \\
\end{array}$ & $\begin{array}{c}\begin{array}{c}\text { Storage } \\
\text { Capacity } \\
\text { (kg) }\end{array} \\
\end{array}$ \\
\hline $\begin{array}{c}1 \\
\text { 0\% SMR } \\
\text { 100\% Solar }\end{array}$ & 4,885 & 1,159 & 17,622 & 2,447 & 27,438 & 3,975 \\
\hline $\begin{array}{c}2 \\
40 \% \text { SMR } \\
60 \% \text { Solar }\end{array}$ & 5,428 & 1,131 & 19,580 & 2,365 & 30,487 & 3,458 \\
\hline $\begin{array}{c}3 \\
57 \% \text { SMR } \\
43 \% \text { Solar }\end{array}$ & 3,619 & 901 & 13,053 & 1,690 & 20,324 & 2,578 \\
\hline $\begin{array}{c}4 \\
73 \% \text { SMR } \\
27 \% \text { Solar }\end{array}$ & 2,171 & 496 & 7,832 & 954 & 12,195 & 1,491 \\
\hline
\end{tabular}


Table A-5. Capital Cost Breakdown - Phoenix

\begin{tabular}{|c|c|c|c|c|c|}
\hline & \multicolumn{5}{|c|}{ Phoenix } \\
\hline & System 1 & System 2 & System 3 & System 4 & System 5 \\
\hline \multicolumn{6}{|l|}{ SMR } \\
\hline Compressor & - & $3.0 \%$ & $4.1 \%$ & $5.5 \%$ & $10.2 \%$ \\
\hline SMR Capital Cost & - & $33.2 \%$ & $40.4 \%$ & $48.4 \%$ & $80.6 \%$ \\
\hline Total SMR \% & - & $36.1 \%$ & $44.6 \%$ & $53.8 \%$ & $90.8 \%$ \\
\hline \multicolumn{6}{|l|}{ Solar } \\
\hline Heliostats & $24.5 \%$ & $15.8 \%$ & $11.9 \%$ & $8.0 \%$ & - \\
\hline Tower & $6.4 \%$ & $3.9 \%$ & $3.6 \%$ & $3.1 \%$ & - \\
\hline Reactor & $5.2 \%$ & $3.4 \%$ & $2.5 \%$ & $1.7 \%$ & - \\
\hline Baghouse & $1.0 \%$ & $0.6 \%$ & $0.6 \%$ & $0.7 \%$ & - \\
\hline PSA Unit & $9.4 \%$ & $5.5 \%$ & $6.2 \%$ & $6.9 \%$ & - \\
\hline PSA Compressor & $13.5 \%$ & $8.5 \%$ & $7.0 \%$ & $5.2 \%$ & - \\
\hline $\mathrm{ZnO}$ Bed & $0.1 \%$ & $0.0 \%$ & $0.1 \%$ & $0.1 \%$ & $0.1 \%$ \\
\hline Total Solar \% & $60.1 \%$ & $37.7 \%$ & $31.8 \%$ & $25.8 \%$ & $0.1 \%$ \\
\hline \multicolumn{6}{|l|}{ Storage } \\
\hline Solar Compressor & $11.5 \%$ & $7.3 \%$ & $5.9 \%$ & $4.4 \%$ & $0.0 \%$ \\
\hline SMR Compressor & $0.0 \%$ & $2.7 \%$ & $3.7 \%$ & $4.9 \%$ & $9.1 \%$ \\
\hline Storage Tanks & $28.4 \%$ & $16.2 \%$ & $14.0 \%$ & $11.1 \%$ & $0.0 \%$ \\
\hline Total Storage \% & $39.9 \%$ & $26.1 \%$ & $23.6 \%$ & $20.4 \%$ & $9.1 \%$ \\
\hline Total Capital Cost & $\$ 3,708,798$ & $\$ 6,383,497$ & $\$ 5,666,506$ & $\$ \quad 5,041,078$ & $\$ 3,236,201$ \\
\hline
\end{tabular}


Table A-6. Capital Cost Breakdown - Miami

\begin{tabular}{|c|c|c|c|c|c|}
\hline & \multicolumn{5}{|c|}{ Miami } \\
\hline & System 1 & System 2 & System 3 & System 4 & System 5 \\
\hline \multicolumn{6}{|l|}{ SMR } \\
\hline Compressor & $0.0 \%$ & $1.9 \%$ & $2.9 \%$ & $4.2 \%$ & $10.2 \%$ \\
\hline SMR Capital Cost & $0.0 \%$ & $21.2 \%$ & $28.6 \%$ & $37.0 \%$ & $80.6 \%$ \\
\hline Total SMR \% & $0.0 \%$ & $23.1 \%$ & $31.6 \%$ & $41.2 \%$ & $90.8 \%$ \\
\hline \multicolumn{6}{|l|}{ Solar } \\
\hline Heliostats & $46.3 \%$ & $36.4 \%$ & $30.3 \%$ & $22.1 \%$ & $0.0 \%$ \\
\hline Tower & $6.4 \%$ & $4.7 \%$ & $4.8 \%$ & $4.6 \%$ & $0.0 \%$ \\
\hline Reactor & $2.7 \%$ & $2.1 \%$ & $1.8 \%$ & $1.3 \%$ & $0.0 \%$ \\
\hline Baghouse & $0.5 \%$ & $0.4 \%$ & $0.4 \%$ & $0.5 \%$ & $0.0 \%$ \\
\hline PSA Unit & $4.9 \%$ & $3.5 \%$ & $4.4 \%$ & $5.3 \%$ & $0.0 \%$ \\
\hline PSA Compressor & $7.1 \%$ & $5.5 \%$ & $4.9 \%$ & $4.0 \%$ & $0.0 \%$ \\
\hline $\mathrm{ZnO}$ Bed & $0.0 \%$ & $0.0 \%$ & $0.0 \%$ & $0.0 \%$ & $0.1 \%$ \\
\hline Total Solar \% & $67.9 \%$ & $52.6 \%$ & $46.7 \%$ & $37.8 \%$ & $0.1 \%$ \\
\hline \multicolumn{6}{|l|}{ Storage } \\
\hline Solar Compressor & $6.0 \%$ & $4.7 \%$ & $1.6 \%$ & $3.4 \%$ & $0.0 \%$ \\
\hline SMR Compressor & $0.0 \%$ & $1.7 \%$ & $2.6 \%$ & $3.8 \%$ & $9.1 \%$ \\
\hline Storage Tanks & $26.0 \%$ & $18.0 \%$ & $17.5 \%$ & $13.8 \%$ & $0.0 \%$ \\
\hline Total Storage \% & $32.1 \%$ & $24.3 \%$ & $21.7 \%$ & $21.0 \%$ & $9.1 \%$ \\
\hline Total Capital Cost & \$ 7,081,097 & $\$ 10,003,177$ & $\$ \quad 8,000,585$ & \$ $\quad 6,588,428$ & $\$ 3,236,201$ \\
\hline
\end{tabular}


Table A-7. Capital Cost Breakdown - New Orleans

\begin{tabular}{|c|c|c|c|c|c|}
\hline & \multicolumn{5}{|c|}{ New Orleans } \\
\hline & System 1 & System 2 & System 3 & System 4 & System 5 \\
\hline \multicolumn{6}{|l|}{ SMR } \\
\hline Compressor & - & $1.6 \%$ & $2.5 \%$ & $3.8 \%$ & $10.2 \%$ \\
\hline SMR Capital Cost & - & $18.1 \%$ & $24.6 \%$ & $33.6 \%$ & $80.6 \%$ \\
\hline Total SMR \% & - & $19.7 \%$ & $27.1 \%$ & $37.4 \%$ & $90.8 \%$ \\
\hline \multicolumn{6}{|l|}{ Solar } \\
\hline Heliostats & $54.3 \%$ & $48.5 \%$ & $40.5 \%$ & $31.3 \%$ & - \\
\hline Tower & $6.0 \%$ & $5.1 \%$ & $5.2 \%$ & $5.2 \%$ & - \\
\hline Reactor & $2.0 \%$ & $1.8 \%$ & $1.5 \%$ & $1.2 \%$ & - \\
\hline Baghouse & $0.4 \%$ & $0.3 \%$ & $0.4 \%$ & $0.5 \%$ & - \\
\hline PSA Unit & $3.7 \%$ & $3.0 \%$ & $3.8 \%$ & $4.8 \%$ & - \\
\hline PSA Compressor & $5.3 \%$ & $4.7 \%$ & $4.2 \%$ & $3.6 \%$ & - \\
\hline ZnO Bed & $0.0 \%$ & $0.0 \%$ & $0.0 \%$ & $0.0 \%$ & $0.1 \%$ \\
\hline Total Solar \% & $71.8 \%$ & $63.4 \%$ & $55.7 \%$ & $46.6 \%$ & $0.1 \%$ \\
\hline \multicolumn{6}{|l|}{ Storage } \\
\hline Solar Compressor & $4.5 \%$ & $4.0 \%$ & $3.6 \%$ & $3.1 \%$ & $0.0 \%$ \\
\hline SMR Compressor & $0.0 \%$ & $1.5 \%$ & $2.2 \%$ & $3.4 \%$ & $9.1 \%$ \\
\hline Storage Tanks & $28.2 \%$ & $20.5 \%$ & $20.6 \%$ & $17.6 \%$ & $0.0 \%$ \\
\hline Total Storage \% & $32.8 \%$ & $25.9 \%$ & $26.4 \%$ & $24.0 \%$ & $9.1 \%$ \\
\hline Total Capital Cost & $\$ 9,399,820$ & $\$ 11,683,221$ & $\$ 9,319,999$ & $\$ 7,250,359$ & $\$ 3,236,201$ \\
\hline
\end{tabular}




\section{Appendix 3: Sample Detailed Solar Insolation Data Sheet}

Phoenix, January 1, 1990

40\% SMR / 60\% Solar Thermal System

Table A-8. Hourly Solar Insolation Data Sheet

\begin{tabular}{|c|c|c|c|c|c|c|c|}
\hline Date/Time & $\begin{array}{c}\text { Direct } \\
\text { Normal } \\
\text { Radiation }\end{array}$ & $\begin{array}{c}\text { Power } \\
\text { Possible }\end{array}$ & $\begin{array}{l}\text { Power } \\
\text { Produced }\end{array}$ & $\begin{array}{c}\text { Max. } \\
\text { Instant. } \\
\mathrm{CH}_{4} \\
\text { Flow }\end{array}$ & $\begin{array}{c}\text { Max. } \\
\text { Natural } \\
\text { Gas } \\
\text { Consumed }\end{array}$ & $\begin{array}{l}\text { Natural } \\
\text { Gas } \\
\text { Recycled }\end{array}$ & $\begin{array}{c}\text { Max. } \mathrm{H}_{2} \\
\text { Produced }\end{array}$ \\
\hline & $\left(\mathrm{W} / \mathrm{m}^{2}\right)$ & $(\mathrm{kW})$ & $(\mathrm{kW})$ & $(\mathrm{mol} / \mathrm{s})$ & $(\mathrm{kg} / \mathrm{hr})$ & (kg/hr) & $(\mathrm{kg} / \mathrm{hr})$ \\
\hline 1/1/90 0:00 & 0 & 0 & 0 & 0 & 0 & 0 & 0 \\
\hline 1/1/90 1:00 & 0 & 0 & 0 & 0 & 0 & 0 & 0 \\
\hline 1/1/90 2:00 & 0 & 0 & 0 & 0 & 0 & 0 & 0 \\
\hline 1/1/90 3:00 & 0 & 0 & 0 & 0 & 0 & 0 & 0 \\
\hline 1/1/90 4:00 & 0 & 0 & 0 & 0 & 0 & 0 & 0 \\
\hline 1/1/90 5:00 & 0 & 0 & 0 & 0 & 0 & 0 & 0 \\
\hline 1/1/90 6:00 & 0 & 0 & 0 & 0 & 0 & 0 & 0 \\
\hline 1/1/90 7:00 & 106 & 199 & 199 & 2 & 65 & 28 & 23 \\
\hline 1/1/90 8:00 & 667 & 1249 & 1144 & 9 & 372 & 159 & 133 \\
\hline 1/1/90 9:00 & 850 & 1592 & 1144 & 9 & 372 & 159 & 133 \\
\hline 1/1/90 10:00 & 934 & 1749 & 1144 & 9 & 372 & 159 & 133 \\
\hline 1/1/90 11:00 & 973 & 1822 & 1144 & 9 & 372 & 159 & 133 \\
\hline $1 / 1 / 9012: 00$ & 980 & 1835 & 1144 & 9 & 372 & 159 & 133 \\
\hline 1/1/90 13:00 & 964 & 1805 & 1144 & 9 & 372 & 159 & 133 \\
\hline $1 / 1 / 9014: 00$ & 918 & 1719 & 1144 & 9 & 372 & 159 & 133 \\
\hline $1 / 1 / 9015: 00$ & 812 & 1521 & 1144 & 9 & 372 & 159 & 133 \\
\hline 1/1/90 16:00 & 328 & 614 & 614 & 5 & 200 & 86 & 71 \\
\hline $1 / 1 / 9017: 00$ & 38 & 71 & 0 & 0 & 0 & 0 & 0 \\
\hline 1/1/90 18:00 & 0 & 0 & 0 & 0 & 0 & 0 & 0 \\
\hline 1/1/90 19:00 & 0 & 0 & 0 & 0 & 0 & 0 & 0 \\
\hline 1/1/90 20:00 & 0 & 0 & 0 & 0 & 0 & 0 & 0 \\
\hline 1/1/90 21:00 & 0 & 0 & 0 & 0 & 0 & 0 & 0 \\
\hline 1/1/90 22:00 & 0 & 0 & 0 & 0 & 0 & 0 & 0 \\
\hline 1/1/90 23:00 & 0 & 0 & 0 & 0 & 0 & 0 & 0 \\
\hline
\end{tabular}




\section{Appendix 4: Sample Detailed Hydrogen Production Data Sheet}

Phoenix, January 1990

40\% SMR / 60\% Solar Thermal System

Table A-9. Daily Hydrogen Production Data Sheet

\begin{tabular}{|c|c|c|c|c|c|c|c|c|c|c|c|c|}
\hline Date & $\begin{array}{l}\text { Possible } \\
\text { Solar H2 }\end{array}$ & $\begin{array}{l}\text { Hydrogen } \\
\text { Sale from } \\
\text { Solar }\end{array}$ & $\begin{array}{l}\text { Hydrogen } \\
\text { Storage } \\
\text { from Solar }\end{array}$ & $\begin{array}{l}\text { Total H2 } \\
\text { Production } \\
\text { from Solar }\end{array}$ & $\begin{array}{l}\text { Hydrogen } \\
\text { Sale from } \\
\text { SMR }\end{array}$ & $\begin{array}{l}\text { Hydrogen } \\
\text { Storage } \\
\text { from SMR }\end{array}$ & $\begin{array}{c}\text { Total H2 } \\
\text { Production } \\
\text { from SMR }\end{array}$ & $\begin{array}{c}\text { Total } \\
\text { Production }\end{array}$ & $\begin{array}{c}\text { Filling } \\
\text { Station } \\
\text { Demand }\end{array}$ & $\begin{array}{c}\mathrm{H} 2 \text { Drawn } \\
\text { from } \\
\text { Storage }\end{array}$ & $\begin{array}{l}\mathrm{H} 2 \text { Added } \\
\text { to Storage }\end{array}$ & $\begin{array}{c}\text { Storage } \\
\text { Level }\end{array}$ \\
\hline & $(\mathrm{kg} / \mathrm{d})$ & $(\mathrm{kg} / \mathrm{d})$ & $(\mathrm{kg} / \mathrm{d})$ & $(\mathrm{kg} / \mathrm{d})$ & $(\mathrm{kg} / \mathrm{d})$ & $(\mathrm{kg} / \mathrm{d})$ & $(\mathrm{kg} / \mathrm{d})$ & $(\mathrm{kg} / \mathrm{d})$ & $(\mathrm{kg} / \mathrm{d})$ & $(\mathrm{kg} / \mathrm{d})$ & $(\mathrm{kg} / \mathrm{d})$ & 1131 \\
\hline 1/1/1990 & 1157 & 900 & 0 & 900 & 300 & 0 & 300 & 1200 & 1200 & 0 & 0 & 1131 \\
\hline 1/2/1990 & 414 & 414 & 0 & 414 & 600 & 0 & 600 & 1014 & 1200 & 186 & 0 & 945 \\
\hline 1/3/1990 & 1131 & 900 & 186 & 1086 & 300 & 0 & 300 & 1386 & 1200 & 0 & 186 & 1131 \\
\hline 1/4/1990 & 1129 & 900 & 0 & 900 & 300 & 0 & 300 & 1200 & 1200 & 0 & 0 & 1131 \\
\hline 1/5/1990 & 1147 & 900 & 0 & 900 & 300 & 0 & 300 & 1200 & 1200 & 0 & 0 & 1131 \\
\hline 1/6/1990 & 1169 & 900 & 0 & 900 & 300 & 0 & 300 & 1200 & 1200 & 0 & 0 & 1131 \\
\hline 1/7/1990 & 1080 & 900 & 0 & 900 & 300 & 0 & 300 & 1200 & 1200 & 0 & 0 & 1131 \\
\hline 1/8/1990 & 1122 & 900 & 0 & 900 & 300 & 0 & 300 & 1200 & 1200 & 0 & 0 & 1131 \\
\hline 1/9/1990 & 1153 & 900 & 0 & 900 & 300 & 0 & 300 & 1200 & 1200 & 0 & 0 & 1131 \\
\hline 1/10/1990 & 1173 & 900 & 0 & 900 & 300 & 0 & 300 & 1200 & 1200 & 0 & 0 & 1131 \\
\hline 1/11/1990 & 1177 & 900 & 0 & 900 & 300 & 0 & 300 & 1200 & 1200 & 0 & 0 & 1131 \\
\hline 1/12/1990 & 783 & 783 & 0 & 783 & 417 & 0 & 417 & 1200 & 1200 & 0 & 0 & 1131 \\
\hline 1/13/1990 & 944 & 900 & 0 & 900 & 300 & 0 & 300 & 1200 & 1200 & 0 & 0 & 1131 \\
\hline 1/14/1990 & 990 & 900 & 0 & 900 & 300 & 0 & 300 & 1200 & 1200 & 0 & 0 & 1131 \\
\hline 1/15/1990 & 889 & 889 & 0 & 889 & 311 & 0 & 311 & 1200 & 1200 & 0 & 0 & 1131 \\
\hline 1/16/1990 & 1099 & 900 & 0 & 900 & 300 & 0 & 300 & 1200 & 1200 & 0 & 0 & 1131 \\
\hline 1/17/1990 & 28 & 28 & 0 & 28 & 600 & 0 & 600 & 628 & 1200 & 572 & 0 & 559 \\
\hline 1/18/1990 & 159 & 159 & 0 & 159 & 600 & 0 & 600 & 759 & 1200 & 441 & 0 & 117 \\
\hline 1/19/1990 & 1139 & 900 & 239 & 1139 & 300 & 300 & 600 & 1739 & 1200 & 0 & 539 & 656 \\
\hline 1/20/1990 & 1174 & 900 & 274 & 1174 & 300 & 200 & 500 & 1674 & 1200 & 0 & 474 & 1131 \\
\hline 1/21/1990 & 1145 & 900 & 0 & 900 & 300 & 0 & 300 & 1200 & 1200 & 0 & 0 & 1131 \\
\hline 1/22/1990 & 0 & 0 & 0 & 0 & 600 & 0 & 600 & 600 & 1200 & 600 & 0 & 531 \\
\hline 1/23/1990 & 1154 & 900 & 254 & 1154 & 300 & 300 & 600 & 1754 & 1200 & 0 & 554 & 1085 \\
\hline 1/24/1990 & 1152 & 900 & 46 & 946 & 300 & 0 & 300 & 1246 & 1200 & 0 & 46 & 1131 \\
\hline 1/25/1990 & 1206 & 900 & 0 & 900 & 300 & 0 & 300 & 1200 & 1200 & 0 & 0 & 1131 \\
\hline 1/26/1990 & 1125 & 900 & 0 & 900 & 300 & 0 & 300 & 1200 & 1200 & 0 & 0 & 1131 \\
\hline 1/27/1990 & 1189 & 900 & 0 & 900 & 300 & 0 & 300 & 1200 & 1200 & 0 & 0 & 1131 \\
\hline 1/28/1990 & 1267 & 900 & 0 & 900 & 300 & 0 & 300 & 1200 & 1200 & 0 & 0 & 1131 \\
\hline 1/29/1990 & 1247 & 900 & 0 & 900 & 300 & 0 & 300 & 1200 & 1200 & 0 & 0 & 1131 \\
\hline $1 / 30 / 1990$ & 1112 & 900 & 0 & 900 & 300 & 0 & 300 & 1200 & 1200 & 0 & 0 & 1131 \\
\hline 1/31/1990 & 542 & 542 & 0 & 542 & 600 & 0 & 600 & 1142 & 1200 & 58 & 0 & 1073 \\
\hline
\end{tabular}




\section{Appendix 5: Sample Excel Spreadsheets for Calculation of Hydrogen Price Table A-10. Constants}

\begin{tabular}{|c|c|c|c|}
\hline \multicolumn{4}{|c|}{ Constants/Parameters } \\
\hline \multicolumn{2}{|c|}{ Heliostat Efficiency } & 0.69 & \\
\hline \multicolumn{2}{|c|}{$\begin{array}{l}\text { Solar Reactor } \\
\text { Efficiency }\end{array}$} & 0.5 & \\
\hline \multicolumn{2}{|c|}{ Solar Capacity Factor } & 0.4 & \\
\hline \multirow{2}{*}{\multicolumn{2}{|c|}{$\begin{array}{l}\text { Reactor Conversion } \\
\text { Heat of Reaction (298 } \\
\text { K) }\end{array}$}} & 0.7 & \\
\hline & & 75 & $\mathrm{~kJ} / \mathrm{mol} \mathrm{CH}_{4}$ \\
\hline \multicolumn{2}{|c|}{ Heat $\mathrm{CH}_{4}$ to $1800 \mathrm{~K}$} & 124 & $\mathrm{~kJ} / \mathrm{mol} \mathrm{CH}_{4}$ \\
\hline \multicolumn{2}{|l|}{ Hydrogen LHV } & 120022 & $\mathrm{~kJ} / \mathrm{kg}$ \\
\hline \multicolumn{2}{|c|}{ Natural Gas LHV } & 50824 & $\mathrm{~kJ} / \mathrm{kg}$ \\
\hline \multicolumn{2}{|c|}{ Hydrogen volume } & 424 & scf/kg \\
\hline \multicolumn{2}{|l|}{ Cars serviced } & 300 & cars/d \\
\hline Tank size & & 4 & $\mathrm{~kg} \mathrm{H}_{2}$ \\
\hline \multicolumn{2}{|l|}{ Heliostat cost } & 130 & $\$ / m^{2}$ \\
\hline \multicolumn{2}{|c|}{ LandArea:HeliostatArea } & 6 & \\
\hline \multicolumn{2}{|l|}{ Tower cost } & 7500 & $\$ / m$ \\
\hline \multicolumn{2}{|l|}{ SMR Efficiency } & 0.8 & \\
\hline \multicolumn{2}{|c|}{ Natural Gas Cost } & 3.72 & $\$ / G J$ \\
\hline \multicolumn{2}{|c|}{ Operating Factor } & 330 & days \\
\hline \multicolumn{2}{|c|}{ Electricity Cost } & $\$ 0.05$ & $/ \mathrm{kWh}$ \\
\hline \multicolumn{2}{|c|}{ Cooling Water Cost } & $\$ 0.06$ & /1000 gal \\
\hline \multicolumn{2}{|l|}{ Steam Cost } & $\$ 3.40$ & $\begin{array}{l}\text { /1000 lb @ } 150 \\
\text { psig }\end{array}$ \\
\hline \multicolumn{2}{|c|}{ Carbon Black Price } & $\$ 0.95$ & $/ \mathrm{kg}$ \\
\hline \multicolumn{3}{|c|}{ Annual Plant Cost Indexes } & \\
\hline Year & \multicolumn{2}{|c|}{$\begin{array}{l}\text { Composite CE } \\
\text { Index }\end{array}$} & \\
\hline 1996 & 381.7 & & \\
\hline 1997 & 386.5 & & \\
\hline 1998 & 389.5 & & \\
\hline 1999 & 390.6 & & \\
\hline 2000 & 394.1 & & \\
\hline
\end{tabular}


Table A-11. SMR Calculations

\begin{tabular}{|c|c|c|c|}
\hline \multicolumn{2}{|l|}{ SMR Load Fraction } & $50 \%$ & \\
\hline \multicolumn{2}{|l|}{ Maximum Production } & 600 & $\mathrm{~kg} /$ day \\
\hline \multicolumn{2}{|l|}{ Actual production } & 219000 & $\mathrm{~kg} / \mathrm{yr}$ \\
\hline \multicolumn{2}{|l|}{ Natural Gas Cost } & $\$ 51,757$ & \multirow[t]{2}{*}{$\$ / y r$} \\
\hline \multicolumn{2}{|c|}{ System Thermal Efficiency } & 0.8 & \\
\hline H2 Supply & SMR Size & $\begin{array}{l}\text { SMR } \\
\text { Capital }\end{array}$ & $\begin{array}{l}\text { SMR } \\
\text { Capital }\end{array}$ \\
\hline scf/d & $\max s c f / d$ & $(1996 \$)$ & $(2000 \$)$ \\
\hline 254,400 & 281,382 & $\$ 2,050,737$ & $\$ 2,117,358$ \\
\hline \multicolumn{4}{|l|}{ Operating Costs: } \\
\hline \multicolumn{2}{|l|}{ Steam/Methane Ratio: } & 2.0 & \\
\hline \multicolumn{2}{|l|}{ Steam Required: } & $4,357,110$ & $\mathrm{~kg} / \mathrm{yr}$ \\
\hline Cost of Steam: & & $\$ 32,659$ & /yr \\
\hline \multicolumn{4}{|l|}{ Compressor } \\
\hline \multicolumn{2}{|l|}{ Compressor Base Size: } & 4000 & \\
\hline \multicolumn{2}{|l|}{ Compressor Base Cost: } & $\$ \quad 4,000$ & \\
\hline \multicolumn{2}{|l|}{ Base Pressure: } & 20 & \\
\hline \multicolumn{2}{|l|}{ Sizing Exponent: } & 0.8 & \\
\hline \multicolumn{2}{|l|}{ Pressure Factor: } & 0.18 & \\
\hline \multicolumn{2}{|c|}{ Update Factor (1995-2000) } & 1.032 & \\
\hline Inlet Pressure & & 0.101 & \\
\hline \multicolumn{2}{|l|}{ Outlet Pressure } & 1.4 & \\
\hline Flow: & & 25.00 & $\mathrm{~kg} / \mathrm{hr}$ \\
\hline Energy: & & 27.38 & $\mathrm{~kW}$ \\
\hline \multicolumn{2}{|c|}{ Compressor Capital Cost: } & $\$ 189,873$ & \\
\hline \multicolumn{2}{|c|}{ Electrical Operating Cost: } & $\$ 10,844$ & /yr \\
\hline \multicolumn{2}{|l|}{ Cooling Operating Cost: } & $\$ \quad 71$ & /yr \\
\hline $\begin{array}{l}\text { Total Operating } \\
\text { Cost: }\end{array}$ & & $\$ 10,915$ & lyr \\
\hline
\end{tabular}


Table A-12. PSA Calculations

\begin{tabular}{|c|c|c|c|}
\hline Compressor Base Size: & & 4000 & $\mathrm{~kW}$ \\
\hline Compressor Base Cost: & $\$$ & 4,000 & $/ \mathrm{kW}$ \\
\hline Base Pressure: & & 20 & $\mathrm{MPa}$ \\
\hline Sizing Exponent: & & 0.8 & \\
\hline Pressure Factor: & & 0.18 & \\
\hline $\begin{array}{l}\text { Update Factor (1995- } \\
\text { 2000) }\end{array}$ & & 1.032 & \\
\hline Inlet Pressure & & 0.101 & $\mathrm{MPa}$ \\
\hline Outlet Pressure & & 1.4 & $\mathrm{MPa}$ \\
\hline Flow: & & 93.75 & $\mathrm{~kg} / \mathrm{hr}$ \\
\hline Energy: & \multicolumn{2}{|c|}{102.43} & $\mathrm{~kW}$ \\
\hline $\begin{array}{l}\text { Compressor Capital } \\
\text { Cost: }\end{array}$ & $\$$ & 545,537 & \\
\hline PSA Unit Capital Cost: & $\$$ & 350,000 & \\
\hline Total Capital Cost: & $\$$ & 895,537 & \\
\hline $\begin{array}{l}\text { Electrical Operating } \\
\text { Cost: }\end{array}$ & $\$$ & 16,225 & /yr \\
\hline Cooling Operating Cost: & $\$$ & 379 & /yr \\
\hline Total Operating Cost: & $\$$ & 16,605 & lyr \\
\hline
\end{tabular}


Table A-13. Solar Reactor Calculations

$\begin{array}{lccc}\text { Storage capacity } & 4 \text { days (1-4) } & \text { [BASIS] } & \\ \text { Minimum Daily Insolation } & 5865.8 \mathrm{Wh} / \mathrm{m}^{2} & & \\ & & & \\ & & & \\ \text { Total hydrogen produced } & 1200 \mathrm{~kg} / \mathrm{d} & \text { Reactor Specifications } \\ \text { Solar load fraction } & 75 \% & \text { Temp } & 2273 \mathrm{~K} \\ \text { Max solar production } & 900 \mathrm{~kg} / \mathrm{d} & \text { Pressure } & 101,325 \mathrm{~Pa} \\ \text { Actual production } & 305718 \mathrm{~kg} / \mathrm{yr} & \text { Volume } & 1.72 \mathrm{~m}^{3} \\ \text { Natural Gas used } & 1213286 \mathrm{~kg} / \mathrm{yr} & \text { Cost } & \$ 38,870 \$ \mathrm{~m}^{3} \\ \text { Natural Gas Cost } & \$ 229,390 \mathrm{\$} / \mathrm{yr} & & \\ \text { Max natural gas use } & 3572 \mathrm{~kg} / \mathrm{d} & & \\ \text { Max natural gas flow } & 9 \mathrm{~mol} / \mathrm{s} & & \\ \text { Reactor Power } & 1,144 \mathrm{~kW} & & \\ \text { Carbon Black produced } & 910,807 \mathrm{~kg} / \mathrm{yr} & & \end{array}$

\begin{tabular}{|c|c|c|c|c|c|c|c|c|c|c|c|c|}
\hline $\begin{array}{l}\text { Insolation } \\
\left(\mathrm{kWh} / \mathrm{m}^{2} / \mathrm{d}\right)\end{array}$ & $\begin{array}{l}\text { Insolation } \\
\left(\mathrm{kW} / \mathrm{m}^{2}\right)\end{array}$ & $\begin{array}{c}\text { Heliostat } \\
\text { Area } \\
\left(\mathrm{m}^{2}\right)\end{array}$ & $\begin{array}{c}\text { Heliostat } \\
\text { Purchase } \\
\text { Cost }\end{array}$ & $\begin{array}{c}\text { Heliostat } \\
\text { Fixed } \\
\text { Capital Cost }\end{array}$ & $\begin{array}{l}\text { Land } \\
\left(\mathrm{m}^{2}\right)\end{array}$ & $\begin{array}{l}\text { Tower } \\
\text { Height } \\
\text { (m) }\end{array}$ & $\begin{array}{c}\text { Tower } \\
\text { Purchase } \\
\text { Cost }\end{array}$ & $\begin{array}{c}\text { Tower } \\
\text { Fixed } \\
\text { Capital Cost }\end{array}$ & $\begin{array}{c}\mathrm{ZnO} \text { Bed } \\
\text { Cost }\end{array}$ & $\begin{array}{c}\text { Reactor } \\
\text { Cost }\end{array}$ & $\begin{array}{c}\text { Baghouse } \\
\text { Filter } \\
\text { Cost }\end{array}$ & $\begin{array}{c}\text { Total Capital } \\
\text { Cost }\end{array}$ \\
\hline$\overline{5.866}$ & $\overline{0.611}$ & $\overline{5,428}$ & 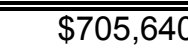 & $\overline{\$ \$ 1,009,065}$ & 32,568 & $\overline{23.3}$ & $\$ \$ \$ 174,736$ & \$249,872 & 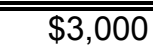 & $\$ 213,867$ & $\overline{\$ \$ 36,000}$ & 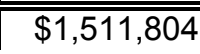 \\
\hline
\end{tabular}


Table A-14. Compression and Storage Calculations

\begin{tabular}{|c|c|c|c|c|c|c|c|c|c|}
\hline \multicolumn{3}{|l|}{ Solar Hydrogen Compressor } & \multirow[b]{2}{*}{$\mathrm{kW}$} & \multicolumn{2}{|l|}{ SMR Hydrogen Compressor } & \multirow[b]{2}{*}{$\mathrm{kW}$} & \multicolumn{2}{|l|}{ Combined Storage } & \multirow[b]{2}{*}{$\mathrm{kg}$} \\
\hline Compressor Base Size: & & 4000 & & Compressor Base Size: & 4000 & & Vessel Base Size: & 227 & \\
\hline Compressor Base Cost: & $\$$ & 2,000 & /kW & Compressor Base Cost: & $\$ 2,000$ & $/ \mathrm{kW}$ & Vessel Base Cost: & $\$ 1,323.00$ & $/ \mathrm{kg}$ \\
\hline Base Pressure: & & 20 & $\mathrm{MPa}$ & Base Pressure: & 20 & $\mathrm{MPa}$ & Base Pressure: & 20 & $\mathrm{MPa}$ \\
\hline Sizing Exponent: & & 0.8 & & Sizing Exponent: & 0.8 & & Sizing Exponent: & 0.75 & \\
\hline Pressure Factor: & & 0.18 & & Pressure Factor: & 0.18 & & Pressure Factor: & 0.44 & \\
\hline Update Factor (1995-2000) & & 1.032 & & Update Factor (1995-2000) & 1.032 & & & & \\
\hline Inlet Pressure & & 1.30 & $\mathrm{MPa}$ & Inlet Pressure & 1.00 & $\mathrm{MPa}$ & Tank Size: & 1131 & $\mathrm{~kg}$ \\
\hline Outlet Pressure & & 20.0 & $\mathrm{MPa}$ & Outlet Pressure & 20.0 & $\mathrm{MPa}$ & & & \\
\hline Flow: & & 132.88 & $\mathrm{~kg} / \mathrm{hr}$ & Flow: & 25.00 & $\mathrm{~kg} / \mathrm{hr}$ & & & \\
\hline Energy: & & 151.13 & $\mathrm{~kW}$ & Energy: & 31.16 & $\mathrm{~kW}$ & & & \\
\hline Compressor Capital Cost: & $\$$ & 600,898 & & Compressor Capital Cost: & $\$ 169,915$ & & Tank Capital Cost: & $\$ 1,033,809$ & \\
\hline Electrical Operating Cost: & $\$$ & 23,939 & lyr & Electrical Operating Cost: & $\$ 12,340$ & lyr & & & \\
\hline Cooling Operating Cost: & $\$$ & 395 & $/ y r$ & Cooling Operating Cost: & 74 & lyr & & & \\
\hline \multicolumn{4}{|c|}{ Total Compression and Storage Capital Cost: } & $1,804,621$ & & & & & \\
\hline \multicolumn{4}{|c|}{ Total Compression and Storage Operating Cost: } & 36,748 & lyr & & & & \\
\hline
\end{tabular}


Table A-15. Economic Calculations

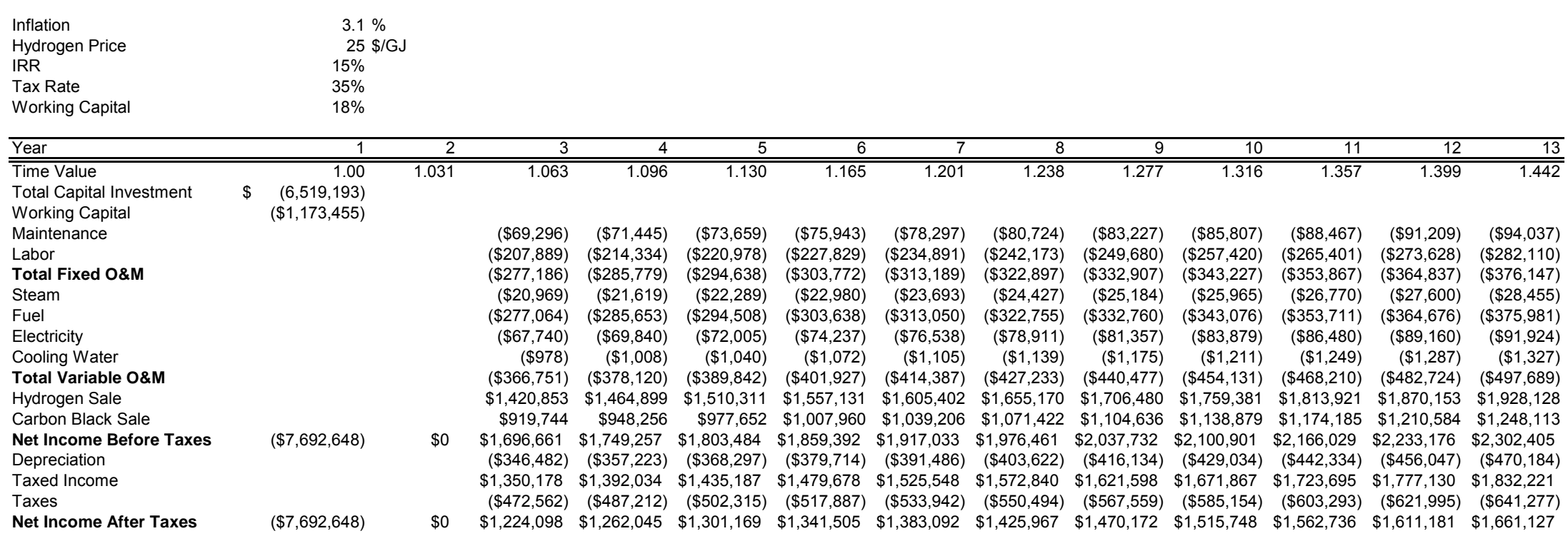




\title{
Comparative Analysis of Three Compressed Hydrogen Storage Systems
}

\author{
Prepared by \\ Edward G. Skolnik \\ Bryan G. Towns \\ Energetics, Inc. \\ Prepared for \\ US Department of Energy \\ In partial fulfillment of Contract No. DE-FC-00GO10602
}

September 18, 2002 


\section{Table of Contents}

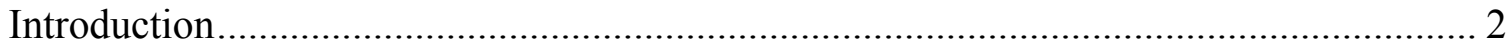

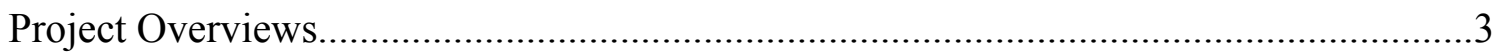

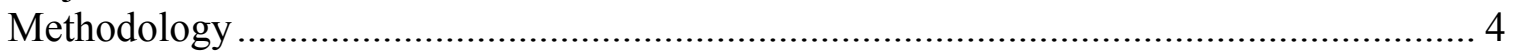

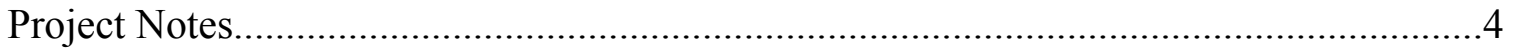

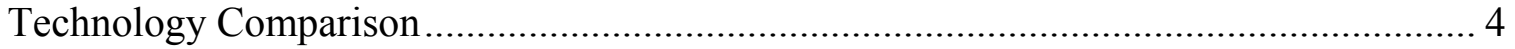

System Construction ..................................................................................... 4

Physical Parameters .......................................................................................... 7

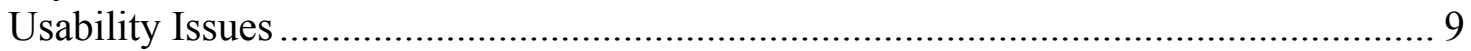

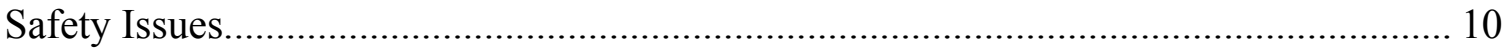

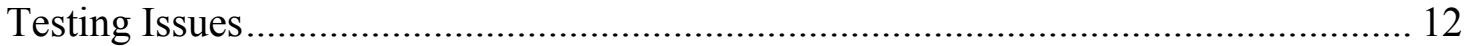

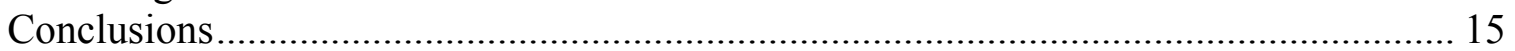

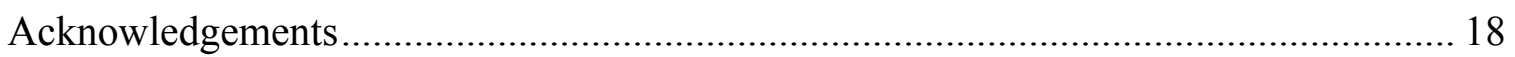

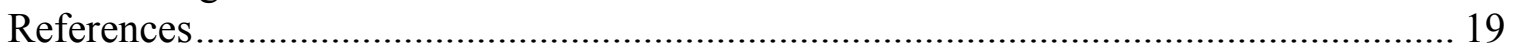

\section{Table of Tables}

Table 1. Project Overview Summary .................................................................. 3

Table 2. System Construction Summary …............................................................. 7

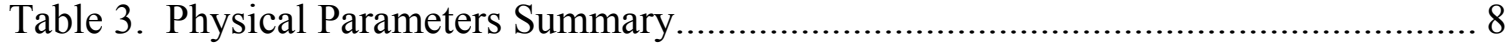

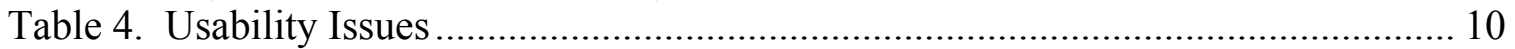

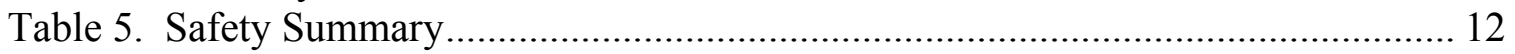

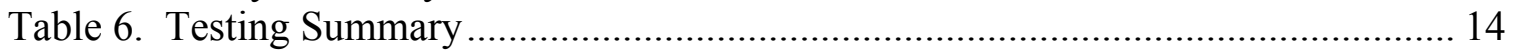

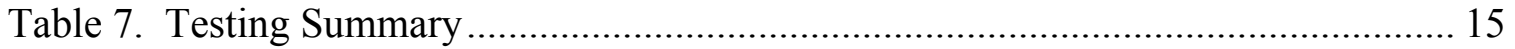

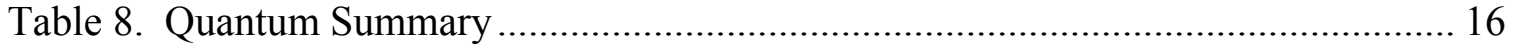

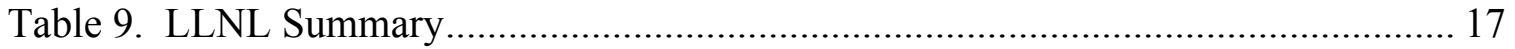

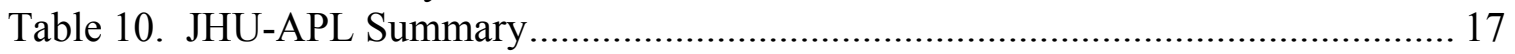




\section{Introduction}

One of the most formidable challenges to the development of hydrogen as a transportation energy carrier is the limitation of hydrogen storage. In the mid- and longterm, it is possible that hydrogen storage will include carbon structures and/or metal hydrides. Near-term hydrogen storage will almost certainly be physical, either as a liquid or as a compressed gas. Compression has received significant attention from research groups due to its potential to store hydrogen at high energy densities in the near future.

Although hydrogen contains a very high amount of energy on a unit weight basis, it is also the least dense element. Hydrogen's low density provides a great challenge to storage; it must be compressed to high pressures, higher than other gaseous fuels, to achieve the volumetric energy density required for practical transportation applications. The typical range required in traditional transportation applications is $400 \mathrm{~km}(250$ miles). A fuel cell vehicle capable of the gasoline equivalent of $34 \mathrm{~km} / \mathrm{L}(80 \mathrm{mpg})$ and a reasonable storage pressure, $34 \mathrm{MPa}(5000 \mathrm{psi})$, requires a storage volume of 235 liters (62 gallons) ${ }^{1}$.

Traditional storage cylinders capable of such a high pressure typically weigh too much to be utilized in a transportation application. Storage in steel cylinders is not possible, as hydrogen tends to embrittle steel. Therefore, current efforts favor lightweight composite materials, which offer the lowest weights with the highest pressure ratings, while limiting hydrogen interactions and permeation losses.

Compressed hydrogen storage is often compared to compressed natural gas (methane) storage. The technology for compressed natural gas $(\mathrm{CNG})$ systems is already in use in many transportation applications, such as in municipal bus systems. The use of compressed natural gas in vehicles helps to develop a foundation for hydrogen use in transportation applications. However, several significant differences exist between the storage requirements of the two gases. Hydrogen is considerably less dense than methane, with the energy content of a cylinder of hydrogen at 5000 psi roughly equivalent to the energy content of a cylinder of methane at $3000 \mathrm{psi}$. The diffusion coefficient of hydrogen is 3.8 times the diffusion coefficient of methane, making permeation and leakage much more serious concerns for hydrogen than for natural gas. Although many hydrogen storage projects are based on natural gas storage projects, the physical properties of hydrogen make its high-pressure storage significantly more difficult.

This report presents the results of an analysis of three compressed storage projects currently under development. Researchers at Quantum Technologies are developing a composite "Trishield" tank for hydrogen storage. Researchers at Lawrence Livermore National Laboratory (LLNL) are studying insulted pressure vessels that can contain

\footnotetext{
${ }^{1}$ A standard passenger vehicle requires storage of approximately $600 \mathrm{MJ}$ to travel $400 \mathrm{~km}$. The LHV of hydrogen is $120 \mathrm{MJ} / \mathrm{kg}$, equating to a storage need of $5 \mathrm{~kg}$. At room temperature and $34 \mathrm{MPa}$, the specific volume of hydrogen is approximately $0.047 \mathrm{~m}^{3} / \mathrm{kg}$. A volume of $235 \mathrm{~L}$ is required to contain $5 \mathrm{~kg}$ of gas with this specific volume (values calculated from Perry, 1997).
} 
cryogenic liquid or compressed hydrogen. A group at the Johns Hopkins University Applied Physics Laboratory (JHU-APL) is studying a compressed hydrogen integrated storage system.

\section{Project Overviews}

The Trisheild tank is being developed by Quantum Technologies, a commercial venture. Quantum is based in Irvine, CA and was formerly known as Impco, but is now a wholly owned subsidiary of Impco. Quantum is involved in several partnerships outside of their organization, including a joint development agreement with Thiokol and partial ownership by General Motors.

The Insulated Pressure Vessel for Vehicular Hydrogen Storage is under development at LLNL in Livermore, CA. LLNL's partnerships include Structural Composite Industries and the SunLine bus system.

Development of the Compressed Hydrogen Gas Integrated Storage System (CH2-ISS) is taking place at JHU-APL in Laurel, MD. The JHU-APL research group is partnered with General Dynamics Armaments \& Technical Products.

Collaborations with commercial firms are especially sound approaches to promoting the viability of the storage projects. Partnerships with firms like Thiokol and General Dynamics Armaments \& Technical Products provide technical synergies that can ease the development of storage systems. LLNL's partnership with SunLine and Quantum's work with General Motors bring practical operating expertise to the projects and are especially effective.

A summary of the administrative issues surrounding these three projects is presented in Table 6.

\begin{tabular}{|c|c|c|}
\hline \multicolumn{2}{|c|}{ Project Overviews } \\
\hline Technology & Manufacturer & Partners \\
\hline Trishield Tank & Quantum Technologies & $\begin{array}{c}\text { General Motors, } \\
\text { Thiokol }\end{array}$ \\
\hline $\begin{array}{c}\text { Insulated Pressure Vessels for } \\
\text { Vehicular Hydrogen Storage } \\
\text { Compressed Hydrogen Gas } \\
\text { Integrated Storage System }\end{array}$ & $\begin{array}{c}\text { Lawrence Livermore } \\
\text { National Laboratory } \\
\text { University - Applied } \\
\text { Physics Laboratory }\end{array}$ & $\begin{array}{c}\text { Structural Composite } \\
\text { Industries, SunLine } \\
\text { Transit Agency } \\
\text { Jenns Honnical Products } \\
\text { Armaments \& } \\
\text { (formerly Lincoln } \\
\text { Composites) }\end{array}$ \\
\hline
\end{tabular}

Table 6. Project Overview Summary 


\section{Methodology}

The three technologies provide certain benefits that are difficult to quantify. For example, although a pressure rating can easily be used to compare each of the three technologies, no simple parameter can allow for a direct comparison of the benefits of one composite shell material over another. Therefore, efforts are made to quantify system parameters in every case. If no metric is available, the system parameters are compared qualitatively.

The parameters of the three systems are broken down into five categories: system construction, physical parameters, usability, safety, and testing. Each of these five categories is discussed in depth later in this report.

Information collection is of paramount importance in this analysis, so sizeable efforts were made to collect comprehensive information on each project. Preliminary research focused on papers and presentations delivered by the principal investigators. Additional information was garnered by site visits performed by Dr. Edward Skolnik of Energetics at two of the research sites. These site visit reports contained detailed information on the status of the projects, as well as goals of the projects and any strengths and deficiencies in the projects. Further research required direct input from the investigators and their staffs. The sources of information for each project are detailed in the "References" section.

\section{Project Notes}

While LLNL and JHU-APL efforts have focused on one system geometry, Quantum offers different system sizes and orientations. In an effort to improve the ease of comparison between projects, a single system geometry was selected from the Quantum product line. Quantum offers tanks with hydrogen storage capacities between $0.77-3.9$ $\mathrm{kg}$ and mass fractions between $4.7-7.8 \%$. Quantum has also investigated systems with pressure ratings of up to $10,000 \mathrm{psi}$. In this analysis, a 5,000 psi, $3.9 \mathrm{~kg}$ capacity system is used, as its characteristics most closely match the parameters of the other projects.

The LLNL group has considered the use of 5000 psi cylinders in addition to $3600 \mathrm{psi}$ tanks. While a 5000 psi tank allows for a greater compressed hydrogen energy density, it diminishes the benefits of the cryogenic system. A higher-pressure system requires tanks with thicker walls, which adds to the cost of the system and decreases the energy density. This analysis uses parameters of the 3600 psi system, as recommended by LLNL's PI.

\section{Technology Comparison}

\section{System Construction}

\section{Hydrogen State}

Despite the common goal of high-pressure hydrogen storage, each project utilizes varying physical systems and methodologies to maximize energy density. While the Quantum 
and JHU-APL projects are meant for use in one operational mode, the LLNL insulated pressure vessel takes a significant departure from conventional operational methods. Its ability to operate at cryogenic temperatures allows the insulated pressure vessel to contain either cryogenic liquid or compressed hydrogen. Liquid hydrogen contains much more energy per unit of volume than hydrogen compressed at $5000 \mathrm{psi}$, so the liquid operational mode provides for a greater driving distance than compressed hydrogen ${ }^{2}$. The LLNL group intends for drivers to plan their automobile filling habits accordingly, using compressed hydrogen for day-to-day driving and liquid hydrogen for long trips. The LLNL system is designed to contain a single form of hydrogen at one time, so liquid hydrogen will not be filled into the tank until all compressed hydrogen has been emptied from the unit. Liquid hydrogen is not proposed as the only fuel for the LLNL tank because of its high cost relative to compressed hydrogen.

The filling procedures for the Quantum and JHU-APL projects are not as complicated. As compressed gas cylinders, these tanks will be filled from either centralized or distributed filling stations. The tanks are designed solely for use with compressed hydrogen, so the additional considerations required for the LLNL tank are not required for these two systems.

\section{System Components}

The basic construction of the three systems is very similar. Each includes a liner, a tank, and an outer protective shell, and each is constructed from some form of composite material. The construction is divided into three segments, with each segment providing a specific benefit to the system. The liner material, while not providing physical strength, prevents permeation of the hydrogen out of the system. The tanks, which are "sandwiched" between the liner and shell, provide much of the strength to counteract the pressure of containment. The outer shell provides the protection against puncture and environmental hazards.

Composite materials, consisting of a fiber within a resin matrix, are a large element of all three designs due to their high strength and low relative weight. Standard gasoline tanks are constructed from steel coated in terne, and more recently, automakers have used plastic gas tanks. However, steel is rapidly embrittled in the presence of hydrogen and plastics cannot provide the strength required for high-pressure compressed gas. In recent years, composites have gained attention for their high strength and low weight, making composite tanks ideal candidates for hydrogen storage. Composites offer several benefits over other materials, namely their resistance to corrosion, to leaking, and to fatigue creep.

The outer shell of the Quantum Trishield tank is composed of a fiber/resin shell with polymer end domes. The ratio of the dome mass to the straight wall mass is high, so higher energy mass densities are possible with longer tanks than with shorter tanks. Likewise, certain aspects of the JHU-APL project make longer cylinders more attractive. While the entire shell is constructed from the same material, bumpers are placed on either

\footnotetext{
${ }^{2}$ The density of liquid hydrogen is approximately $70.9 \mathrm{~kg} / \mathrm{m}^{3}$ and the density of compressed hydrogen at 34 MPa is approximately $21.3 \mathrm{~kg} / \mathrm{m}^{3}$. Using a LHV of $120 \mathrm{MJ} / \mathrm{kg}, 100 \mathrm{~L}$ of liquid hydrogen contains $851 \mathrm{MJ}$, while 100L of compressed hydrogen contains $256 \mathrm{MJ}$ (values calculated from Perry, 1997).
} 
end of the cylinders. A longer cylinder requires the same bumper mass as a short cylinder, thereby making longer cylinders more mass efficient. The LLNL exterior shell consists of stainless steel of uniform thickness, and does not experience any additional variations in the mass density, other than those resulting from geometry changes.

Considerable variation exists in the liner material of each of the projects. As the main purpose of the liner is to contain the hydrogen, the linear material must minimize the hydrogen permeation rate. The Quantum project utilizes a thermoplastic liner bonded to the composite tank wall. The JHU-APL project uses an eighth inch thick high-density polyethylene (HDPE) liner that is not bonded to the tank. The LLNL project uses aluminum as an inner liner due to the low temperatures that the cryogenic application entails. The selection of the liner material is largely a project specific application. Each project utilizes a unique material, but no single material presents a clear advantage over another. Rather, the material selection suits the specific physical constraints and parameters of each system.

\section{Insulation}

Due to its cryogenic applications, the LLNL project is the only design that requires thermal insulation. Although the Quantum and JHU-APL tanks offer a small amount of insulation inherent to their tanks and outer walls, neither project prioritizes insulation. The insulation on the LLNL design, named "multilayer vacuum superinsulation" (MLVSI), is aluminized Mylar contained within a vacuum. Each aspect of the insulation works to prevent a form of heat transfer; the Mylar prevents conduction, while the aluminum minimizes radiation, and the vacuum minimizes convection. The insulation prevents an increase in the hydrogen temperature, which minimizes the evaporation and permeation rates. The hydrogen permeation rate increases with temperature, so minimizing the permeation rate tends to improve the system economics. The MLVSI is an effective method of permeation reduction.

The construction of each system is summarized in Table 7.

\begin{tabular}{|c|c|c|c|c|c|}
\hline \multicolumn{6}{|c|}{ System Construction } \\
\hline Manufacturer & $\begin{array}{c}\text { Hydrogen } \\
\text { State } \\
\left(\mathrm{CH}_{2} / \mathrm{LH}_{2}\right)\end{array}$ & Liner Material & $\begin{array}{c}\text { Tank } \\
\text { Material }\end{array}$ & Shell Material & Insulation Material \\
\hline QUANTUM & $\mathrm{CH}_{2}$ & $\begin{array}{c}\text { proprietary } \\
\text { thermoplastic } \\
\text { liner }\end{array}$ & $\begin{array}{c}\text { composite } \\
\text { overwrap } \\
\text { (carbon- } \\
\text { epoxy) }\end{array}$ & $\begin{array}{l}\text { fiber/resin shell, } \\
\text { polymer end domes }\end{array}$ & none \\
\hline LLNL & $\mathrm{CH}_{2} / \mathrm{LH}_{2}$ & aluminum & $\begin{array}{l}\text { composite } \\
\text { (carbon- } \\
\text { epoxy or } \\
\text { aramid- } \\
\text { epoxy) } \\
\end{array}$ & stainless steel & $\begin{array}{c}\text { multilayer vacuum } \\
\text { superinsulation (most } \\
\text { effective under } \\
\text { vacuum below } 0.01 \\
\mathrm{~Pa} \text { ) }\end{array}$ \\
\hline
\end{tabular}




\begin{tabular}{|c|c|c|c|c|c|}
\hline JHU-APL & $\mathrm{CH}_{2}$ & $\begin{array}{c}\text { HDPE liner, } \\
0.125 \text { in thick }\end{array}$ & $\begin{array}{c}\text { composite } \\
\text { (carbon- } \\
\text { epoxy) }\end{array}$ & $\begin{array}{c}\text { plastic - compression } \\
\text { molding/SRIM }\end{array}$ & none \\
\hline
\end{tabular}

Table 7. System Construction Summary

\section{Physical Parameters}

The variation in system construction leads to variations in the physical parameters of each system. These variations are the most profound in the LLNL project, due to its dual operational modes and the requirements of a cryogenic system.

\section{$\underline{\text { System Limits }}$}

The service pressure for the LLNL tank is 3600 psi, while the service pressure for the Quantum and JHU-APL tanks is 5000 psi. Each tank offers a service life of approximately 15,000 cycles, or approximately 10 - 15 years of service. Aramids tend to age more rapidly than carbon fibers, so tanks utilizing carbon composites have a longer expected lifetime than tanks utilizing aramids.

The JHU-APL and Quantum systems have identical low temperature limits of $230 \mathrm{~K}$ (-40 C). The LLNL system, designed to work cryogenically, operates at temperatures as low as $20 \mathrm{~K}(-253 \mathrm{C})$. The high temperature limit of each system is somewhat higher than its operating temperature, mainly to allow for "fast fill" situations. Upon expansion, hydrogen increases in temperature through the reverse Joule-Thompson effect. Through this mechanism, hydrogen will become hotter as it expands into a hydrogen tank. Therefore, each system is designed to allow for the higher temperature that is expected when a tank is rapidly filled. The epoxy used in the tank construction is typically the most temperature sensitive component of the tanks; the carbon fiber and metal components of the tanks withstand much higher temperatures.

Likewise, the systems are designed to accommodate pressures slightly higher than their rated pressures. The pressure limit is a measure of the pressure that a tank can withstand on a constant basis. This value is generally $25 \%$ above the service pressure of the tank. The additional pressure capacity is to allow leeway for occasional overfill or increased pressure situations. The pressure limit should be considered a "safe" pressure rating, and is well below the burst pressure, which will be discussed later in this report.

A summary of the system limits is presented in Table 8 .

\section{Storage Density}

The per-unit quantity of hydrogen stored in a vessel is measured by two separate metrics: volume density and mass density. For transportation applications, the mass density of the systems is especially important, as a heavier storage system leads to decreased overall efficiency. Volume density is also an important concern, although the increased volume of hydrogen storage systems will be partially offset by the elimination of several traditional automotive systems, such as the emissions and transmission systems. 
The LLNL project, when operating in cryogenic mode, offers the highest mass density, $9 \%$. This effect is a result of the use of liquid hydrogen. Since the system operates at a lower pressure than the other systems, it does not require the thick walls of the other designs. Thinner walls create more flexibility in the design and enhance the mass density of the system. However, the mass density for this project under compressed mode is much lower, 2.1\%. The JHU-APL and Quantum systems offer mass densities of 5.7\% and $7.8 \%$, respectively. However, the JHU-APL system is significantly heavier than the Quantum system, at $73.8 \mathrm{~kg}$ empty mass to $49.7 \mathrm{~kg}$ empty mass, respectively, and holds more hydrogen, $4.2 \mathrm{~kg}$ vs. $3.9 \mathrm{~kg}$. This empty mass encompasses the mass of the basic storage system, not including the mass of any internal pressure regulation system. A pressure regulation system typically adds $1-5 \mathrm{~kg}$ to the mass of a system.

The external volume is a measure of the total displacement of the system. The Quantum and JHU-APL systems are the largest, with external volumes of $281 \mathrm{~L}$ and $266 \mathrm{~L}$, respectively. The external volume of the Quantum system is calculated as a rectangular envelope, so its actual displacement is somewhat smaller. The large volume of the JHUAPL system is partially due to the geometry of the system, as it is comprised of three tanks side-by-side. A single cylinder of equivalent internal volume would have a smaller external displacement. However, the side-by-side construction of the JHU-APL system reduces the diameter of each tank. Three lower-diameter tanks side by side effectively lower the system height, as opposed to the diameter of a larger cylinder. A single tank with a larger diameter encompasses a greater height, which could create clearance issues when the storage system is installed on the underbody of an automobile. The LLNL system consumes a much smaller volume, again due to its dual operational modes.

The volume density is a measure of the effective use of the storage space. The LLNL cryogenic operational mode offers the highest volume density, $60 \mathrm{~kg} / \mathrm{m}^{3}$. The LLNL compressed operational mode and Quantum and JHU-APL projects have volume densities between $13.8-15.8 \mathrm{~kg} / \mathrm{m}^{3}$.

The storage density parameters of each system are summarized in Table 8

\begin{tabular}{|c|c|c|c|c|c|c|c|c|c|c|c|c|c|}
\hline \multicolumn{14}{|c|}{ Physical Parameters } \\
\hline \multicolumn{2}{|c|}{ Manufacturer } & $\begin{array}{l}\text { Low } \\
\text { Temp }\end{array}$ & $\begin{array}{l}\text { High } \\
\text { Temp }\end{array}$ & $\begin{array}{l}\text { Service } \\
\text { Pressure }\end{array}$ & $\begin{array}{l}\text { Pres. } \\
\text { Limit }\end{array}$ & $\begin{array}{l}\text { Service } \\
\text { Life }\end{array}$ & $\begin{array}{l}\text { Empty } \\
\text { Mass }\end{array}$ & $\begin{array}{l}\text { Full } \\
\text { Mass }\end{array}$ & $\begin{array}{c}\text { Mass } \\
\text { Density }\end{array}$ & $\begin{array}{c}\mathrm{H}_{2} \\
\text { Storage } \\
\text { Capacity }\end{array}$ & $\begin{array}{l}\text { Internal } \\
\text { Volume }\end{array}$ & $\begin{array}{l}\text { External } \\
\text { Volume }\end{array}$ & $\begin{array}{l}\text { Vol } \\
\text { Dens }\end{array}$ \\
\hline \multicolumn{2}{|c|}{ QUANTUM } & $\begin{array}{c}233 \mathrm{~K} \\
(-40 \mathrm{C})\end{array}$ & $\begin{array}{l}361 \mathrm{~K} \\
(88 \mathrm{C})\end{array}$ & 5000 psi & $\begin{array}{c}6250 \\
\text { psi }\end{array}$ & $\begin{array}{c}15 \text { years } \\
(15,000 \\
\text { cycles) }\end{array}$ & $45.8 \mathrm{~kg}$ & $49.7 \mathrm{~kg}$ & $7.8 \%$ & $3.9 \mathrm{~kg}$ & $165 \mathrm{~L}$ & $\begin{array}{c}\text { approx. } \\
281 \mathrm{~L}\end{array}$ & $\begin{array}{c}13.9 \\
\mathrm{~kg} / \mathrm{m}^{3}\end{array}$ \\
\hline \multirow{2}{*}{ LLNL } & $\mathrm{LH}_{2}$ & \multirow{2}{*}{$\begin{array}{c}20 \mathrm{~K} \\
(-253 \mathrm{C})\end{array}$} & \multirow{2}{*}{$\begin{array}{c}373 \mathrm{~K} \\
(100 \mathrm{C})\end{array}$} & \multirow{2}{*}{3600 psi } & \multirow{2}{*}{$\begin{array}{c}4500 \\
\text { psi }\end{array}$} & \multirow{2}{*}{10 years } & \multirow{2}{*}{100 kg } & 109 kg & $9 \%$ & $9 \mathrm{~kg}$ & \multirow{2}{*}{$130 \mathrm{~L}$} & \multirow{2}{*}{$\begin{array}{c}\text { approx. } \\
150 \mathrm{~L}\end{array}$} & $\begin{array}{c}60 \\
\mathrm{~kg} / \mathrm{m}^{3}\end{array}$ \\
\hline & $\mathrm{CH}_{2}$ & & & & & & & $102.1 \mathrm{~kg}$ & $2.1 \%$ & $2.1 \mathrm{~kg}$ & & & $\begin{array}{c}13.8 \\
\mathrm{~kg} / \mathrm{m}^{3}\end{array}$ \\
\hline \multicolumn{2}{|c|}{ JHU-APL } & $\begin{array}{c}233 \mathrm{~K} \\
(-40 \mathrm{C})\end{array}$ & $\begin{array}{l}355 \mathrm{~K} \\
(82 \mathrm{C})\end{array}$ & 5000 psi & $\begin{array}{c}6250 \\
\text { psi }\end{array}$ & $\begin{array}{l}>15 \\
\text { years }\end{array}$ & $73.8 \mathrm{~kg}$ & $78 \mathrm{~kg}$ & $5.7 \%$ & $4.2 \mathrm{~kg}$ & $166 \mathrm{~L}$ & $266 \mathrm{~L}$ & $\begin{array}{c}15.8 \\
\mathrm{~kg} / \mathrm{m}^{3}\end{array}$ \\
\hline
\end{tabular}

Table 8. Physical Parameters Summary 


\section{Usability Issues}

The ultimate goal of the three systems is to store hydrogen for transportation applications efficiently. Although the hydrogen storage capacity and safety issues are of paramount concern, other factors affect the usability of the system. Storage systems must offer practical driving ranges and minimize permeation and loss rates.

\section{Driving Range}

The driving range of a vehicle is directly related to its hydrogen storage capacity. Presumably, each project is meant for use in personal transportation applications. Therefore, this analysis assumes a fuel cell vehicle fuel economy of 115 kilometers per kilogram of hydrogen (160 miles per pound of hydrogen). One kilogram of hydrogen holds the approximate energy equivalent of one gallon of gasoline ${ }^{3}$. With these assumptions, the LLNL liquid cryogenic system offers a range significantly longer than the other projects, 640 miles. The Quantum and JHU-APL systems have ranges of 280 miles and 300 miles, respectively. The LLNL compressed operational mode (3600 psi) offers the shortest range, 150 miles.

\section{Stage of Development}

The stage of development for the three systems indicates the approximate maturity of each system. Quantum has the unique advantage of being a commercial entity with the backing of a major automobile manufacturer. As a result, its product is in the most mature development stage. Its natural gas tanks have been in use for several years, and testing on its hydrogen storage system is nearing completion. The Quantum group classifies their product as being in the "commercial" phase. The two other products have not yet progressed to this stage. Both are past the "proof of concept" stage, but are not yet past the "development/testing" stage.

\section{Permeation and Leakage}

In order for a compressed storage system to be commercially viable, hydrogen losses must be minimized. The loss of hydrogen occurs mainly through the fittings of the tanks (James, 1996). Other sources of hydrogen loss are permeation and, in the case of the LLNL cryogenic operating mode, evaporation. These losses are much smaller than the losses that occur due to leaks in the tank fittings. In the case of the LLNL tank, permeation is of special concern, as permeation from the tank can destroy the vacuum insulation. The evaporation of the liquid is a concern, but LLNL tests indicate that evaporative losses increase as daily driving decreases. A lower daily mileage routine results in a longer hydrogen storage period, which results in a longer period for potential evaporative losses. LLNL tests indicate that their insulation prevents evaporation for driving distances above $5 \mathrm{~km} /$ day, which is well below the average daily driving distance in the United States. The PIs estimate their respective hydrogen loss rate as $0.16 \mathrm{scc} / \mathrm{hr} / \mathrm{L}$ for the LLNL project, as $0.15 \mathrm{scc} / \mathrm{hr} / 1$ for the Quantum project, and as $0.19 \mathrm{scc} / \mathrm{hr} / \mathrm{L}$ for the JHU-APL project. These values are the combined losses from all sources, including permeation and leaks from the fittings.

\footnotetext{
${ }^{3}$ The energy content of one kilogram of hydrogen is $120 \mathrm{MJ}$ (LHV), while the energy content of one gallon of gasoline is also approximately 120 MJ (values calculated from Perry, 1997).
} 


\section{$\underline{\text { Regulators }}$}

With system pressures as high as 5000 psi, all compressed hydrogen storage systems require some form of pressure regulation. Of the three storage systems, only the Quantum system includes an integrated pressure regulation system. The Quantum system is designed with an internal regulator to prevent the chances of rupturing the tank by detaching the regulator in a collision. This design complicates the system, and may create difficulties in repairing the regulator in the event of a failure. However, it provides for a safer and more complete storage system. The LLNL system does not include a pressure regulator system, and designing one for the dual operating modes may be a formidable obstacle. The low temperatures of the cryogenic mode and high pressures of the compressed mode impose additional constraints on the design of a regulator. A separate pressure regulation system may be required for each operating mode. The regulator for the JHU-APL project is intended to be completely external and separate from the storage system.

\begin{tabular}{|c|c|c|c|c|c|}
\hline \multicolumn{6}{|c|}{ Usability Issues } \\
\hline Manufacturer & Range & $\begin{array}{c}\text { Stage of } \\
\text { Development }\end{array}$ & $\begin{array}{l}\text { Hydrogen } \\
\text { Loss Rate }\end{array}$ & $\begin{array}{c}\text { Pressure } \\
\text { Regulator? } \\
(y / n)\end{array}$ & $\begin{array}{c}\text { Pressure } \\
\text { Regulator } \\
\text { Parameters }\end{array}$ \\
\hline QUANTUM & 450 km / 280 miles & commercial & $\begin{array}{c}0.15 \\
\mathrm{scc} / \mathrm{hr} / \mathrm{l}\end{array}$ & yes & $\begin{array}{l}\text { internal, } \\
\text { single or } \\
\text { double } \\
\text { stage, output } \\
100-400 \text { psi }\end{array}$ \\
\hline LLNL & $\begin{array}{l}1035 \mathrm{~km} / 640 \text { miles }\left(\mathrm{LH}_{2}\right) \\
240 \mathrm{~km} / 150 \text { miles }\left(\mathrm{CH}_{2}\right)\end{array}$ & developmental & $\begin{array}{c}0.16 \\
\text { scc/hr/l }\end{array}$ & no & $\begin{array}{l}\text { completely } \\
\text { external }\end{array}$ \\
\hline JHU-APL & 480 km / 300 miles & developmental & $\begin{array}{c}0.19 \\
\mathrm{scc} / \mathrm{hr} / \mathrm{l}\end{array}$ & no & $\begin{array}{l}\text { completely } \\
\text { external }\end{array}$ \\
\hline
\end{tabular}

Table 9. Usability Issues

\section{Safety Issues}

The public's sentiment on hydrogen safety remains mixed; the danger of hydrogen is exaggerated while general safety concerns about the dangers of the compression of any gas receive little attention. The greatest danger of any compressed gas system is its potential for bursting. Compressed gas cylinders can produce large amounts of energy upon bursting, creating dangerous projectiles. A compressed storage system for a transportation application carries the additional risks associated with high velocity collisions and punctures caused by road debris. Each of the three analyzed systems includes precautions to minimize the risk of a tank burst.

\section{Factor of Safety}

The factor of safety (FOS) of each system is an indication of the amount of additional pressure that a tank has been designed to handle. The factor of safety is a pressure 
multiple, typically between two and three, that a compressed pressure system can contain above its rated service pressure. The systems are not intended to be filled to this pressure routinely; doing so may affect the integrity of the tank. Each tank can contain a small amount of pressure above its service pressure on a regular basis, as indicated by its pressure rating. However, this value is well below its burst pressure. Various standards dictate different factors of safety, but a general DOT guideline is 2.25. Each of the systems in this analysis meets or exceeds 2.25. A tradeoff exists between the protection of a higher factor of safety and system mass and costs. While a higher factor of safety is generally preferred, higher strength materials are required at the higher factors. Therefore, those designs that most effectively maximize the factor of safety while minimizing the system cost and mass are desirable. Each of the three systems considered have effectively utilized advanced composite materials in an effort to improve the system safety and reduce the system cost.

\section{Pressure Relief Valve}

Compressed hydrogen systems for transportation applications should never reach their burst pressures or maximum rated temperatures under normal use. Even in fast fill or overfill situations, the hydrogen pressure and temperature will be well below the tank burst rating. More probable causes of tank failures are external fires, either caused by a collision or a fire while the vehicle is garaged. In these cases, a fire may heat the storage system to temperatures hot enough to cause the hydrogen pressure to increase considerably. In this scenario, the storage system requires a safety valve to release the hydrogen and prevent a tank rupture. Each of the three tanks includes a pressure relief valve.

The most reliable technique for pressure release is thermal activation. In a thermally activated pressure relief valve, a wax or plastic melts at a given temperature, thereby opening a valve and releasing the compressed hydrogen. This method is especially effective in a fire scenario, as the fire will heat the trigger well past its release pressure. Moreover, the probability of a thermal trigger failing in a fire is very slim, due to its simple construction. All three systems include thermally activated pressure relief valves. The Quantum system also includes pressure and temperature sensors, which can be tied into a central control system. Assuming these sensors do not significantly increase the cost of the system or severely complicate its manufacture, they can provide an important indication of the storage system's integrity. The LLNL system includes a pressure triggered relief valve, which is intended for use during cryogenic operation. A summary of the pressure relief features of each system is presented in Table 10.

\section{$\underline{\text { Standards }}$}

Compressed hydrogen storage systems fall under numerous regulations, both domestically and internationally. By fulfilling the requirements of one set of regulations, a storage system does not necessarily fulfill another set of regulations. While each storage system should generally fulfill the requirements of at least one set of regulations, the attainment of more than one standard allows for system adoption in more locations. The major regulations are as follows: 
- FMVSS-304: regulates the initial strength, durability, and pressure relief performance of compressed natural gas $(\mathrm{CNG})$ fuel cylinders, effective March 27, 1995. Predated by FMVSS-303 (U.S. Department of Transportation).

- NGV2-2000: in addition to FMVSS-304, it regulates the construction, performance, testing, inspection, and safe operation of vehicle on-board compressed natural gas storage cylinders, effective October 6, 2000. It is predated by NGV2-1996 (American National Standards).

- Draft EIHP: part of a larger code of practice for hydrogen systems manufacturers, dictates manufacturing and testing procedures as well as durability parameters. (European Integrated Hydrogen Project)

The codes and regulations pertaining to each system are listed in Table 10.

\begin{tabular}{|c|c|c|c|c|}
\hline \multicolumn{5}{|c|}{ Safety Issues } \\
\hline Manufacturer & Safety Factor & $\begin{array}{c}\text { Pressure } \\
\text { Relief Valve? } \\
(y / n)\end{array}$ & $\begin{array}{c}\text { Pressure } \\
\text { Relief } \\
\text { Valve } \\
\text { Parameters }\end{array}$ & Standards \\
\hline QUANTUM & 2.35 & yes & $\begin{array}{l}\text { thermally } \\
\text { activated, } \\
\text { integrated } \\
\text { temp and } \\
\text { pressure } \\
\text { sensors }\end{array}$ & $\begin{array}{c}\text { DOT } \\
\text { FMVSS304, } \\
\text { NGV2-2000, } \\
\text { Draft EIHP }\end{array}$ \\
\hline LLNL & 2.5 & yes & $\begin{array}{l}\text { pressure } \\
\text { and } \\
\text { thermally } \\
\text { activated }\end{array}$ & NGV2-2000 \\
\hline JHU-APL & 2.25 & yes & $\begin{array}{l}\text { thermally } \\
\text { activated }\end{array}$ & $\begin{array}{l}\text { NGV2-1996, } \\
\text { CAN/CGA- } \\
\text { B149.4 (g- } \\
\text { loads), DOT } \\
\text { FMVSS304 }\end{array}$ \\
\hline
\end{tabular}

Table 10. Safety Summary

\section{Testing Issues}

As each of the systems is currently in the development stage or in the early commercialization stage, testing procedures have previously been or are currently being performed upon the units. As with any storage technology, compressed storage systems must be rigorously tested for strength in construction, for dependable performance, and for compliance with safety regulations. In many cases, the PIs have tested their systems beyond the parameters stipulated by regulations.

An important consideration in the analysis of testing procedures is the gas used in the tests. In some cases, natural gas, helium, or nitrogen are used in place of hydrogen, due to a lack of resources or the difficulty in testing with hydrogen. Hydrogen is, of course, preferred to other gases as a testing medium. If other gases must be used, special effort must be made to ensure that reasonable results are attainable. Hydrogen's unique properties limit the effectiveness of substituting other gases in testing procedures.

\section{$\underline{\text { Cycle Test }}$}


Each of the three PIs indicates that they have completed cycle testing or that they are planning for such tests in the near future. Cycle testing establishes the number of drainrefill cycles that a system can endure. These tests are typically performed at $125 \%$ to $150 \%$ of the service pressure, and test for material deformation, or creep. Generally, composite materials do not suffer creep, so cycle testing is not an especially pertinent test of these materials. Nevertheless, the tests are significant in their certification of the durability of the systems, and must be performed on each of the systems. A summary of the cycle test parameters is presented in Table 6 .

\section{Burst Test}

The burst test establishes the maximum pressure that each system can contain. The burst pressure is typically a value greater than the service pressure multiplied by the factor of safety. Each of the three systems maintained its integrity up to and beyond its factor of safety. Each also burst at the expected location on the tank, at the mid cylinder. This test indicates that all three tanks can safely contain pressures up to a reasonable factor of safety. The tank burst pressures and locations are given in Table 6 .

Finite Element Analysis

A finite element analysis is the preliminary method of testing a compressed system, often completed prior to the fabrication of a tank. By modeling a physical system with a computer, designers can estimate their tank's performance under pressure and evaluate alternative designs. The process is not necessarily redundant with other tests, but sometimes produces similar results. For example, a finite element analysis may indicate that a vessel will burst at mid cylinder when it reaches a certain pressure, while an actual burst test will provide the same result. For this reason, the team at JHU-APL did not perform a finite element analysis. The JHU-APL team feels that the results of the burst test, as well as results of the other tests, render a finite element analysis unnecessary after the developmental stages. Each of the other two research teams did include a finite element analysis, the parameters of which are given in Table 11.

\section{Gunfire Test}

For a transportation application, the gunfire test provides an indication of a system's resistance to penetration and bursting. In a gunfire test, a bullet is expected to penetrate a tank, but not cause it to burst. The goal of the test is to evaluate the possibility of a tank rupture. A scenario in which a piece of road debris punctures a tank and causes a massive failure within the storage system is of special concern. Such a case can result in a potentially dangerous situation, as the pressure within the tank can propel pieces of the tank with great force in a burst situation. A gunfire test was performed on each of the three storage systems, and each maintained its structural integrity. A summary of the parameters of the test is presented in Table 11. 


\begin{tabular}{|c|c|c|c|c|c|c|c|c|c|}
\hline \multicolumn{10}{|c|}{ Testing } \\
\hline Manufacturer & $\begin{array}{l}\text { Cycle } \\
\text { Test? } \\
(\mathrm{y} / \mathrm{n})\end{array}$ & $\begin{array}{c}\text { Cycle Testing } \\
\text { Parameters }\end{array}$ & $\begin{array}{c}\text { Burst } \\
\text { Test? } \\
(\mathrm{y} / \mathrm{n})\end{array}$ & $\begin{array}{l}\text { Burst } \\
\text { Pressure } \\
\text { (psi) }\end{array}$ & $\begin{array}{c}\text { Burst } \\
\text { Location }\end{array}$ & $\begin{array}{c}\text { Finite } \\
\text { Element } \\
\text { Analysis } \\
(y / n)\end{array}$ & $\begin{array}{c}\text { Finite } \\
\text { Element } \\
\text { Analysis } \\
\text { Parameters }\end{array}$ & $\begin{array}{c}\text { Gunfire } \\
\text { Test? } \\
(y / n)\end{array}$ & $\begin{array}{l}\text { Gunfire Test } \\
\text { Parameters }\end{array}$ \\
\hline QUANTUM & yes & $\begin{array}{c}15,000 \text { to } 45,000 \\
\text { cycles at } 125 \% \\
\text { service pressure }\end{array}$ & yes & $\begin{array}{c}>11,750 \\
\text { psi }\end{array}$ & $\begin{array}{l}\text { mid cylinder } \\
\text { separation }\end{array}$ & yes & $\begin{array}{c}\text { service } \\
\text { pressure, } \\
150 \% \text {, burst } \\
\text { test }\end{array}$ & yes & $\begin{array}{l}0.50 \text { caliber at } \\
\text { service } \\
\text { pressure }\end{array}$ \\
\hline LLNL & yes & $\begin{array}{l}10000 \text { pressure } \\
\text { cycles; } 500 \\
\text { environmental } \\
\text { cycles; } 10000 \\
\text { thermal cycles }\end{array}$ & yes & $\begin{array}{l}13,657 \\
\text { psi }\end{array}$ & $\begin{array}{l}\text { hoop mid } \\
\text { cylinder } \\
\text { separation }\end{array}$ & yes & $\begin{array}{c}\text { mesh with } \\
4234 \\
\text { elements at } \\
6600 \text { psi }\end{array}$ & yes & $\begin{array}{l}0.30 \text { caliber } \\
\text { projectile at } \\
853 \mathrm{~m} / \mathrm{s} ; \\
\text { vessel at } \\
\text { service } \\
\text { pressure }\end{array}$ \\
\hline JHU-APL & $\begin{array}{c}\text { no - } \\
\text { planned } \\
\text { for } \\
\text { FY2003 }\end{array}$ & $\begin{array}{c}5000 \text { pressure } \\
\text { cycles at } 150 \% \\
\text { service pressure, } \\
13000 \text { pressure } \\
\text { cycles at service } \\
\text { pressure }\end{array}$ & yes & $\begin{array}{c}11,250 \\
\text { psi }\end{array}$ & $\begin{array}{l}\text { mid cylinder } \\
\text { separation }\end{array}$ & $\begin{array}{c}\text { not } \\
\text { planned }\end{array}$ & $\mathrm{n} / \mathrm{a}$ & yes & $\begin{array}{c}0.30 \text { caliber } \\
\text { projectile at } \\
823 \mathrm{~m} / \mathrm{s} ; \\
\text { vessel at } \\
\text { service } \\
\text { pressure }\end{array}$ \\
\hline
\end{tabular}

$\underline{\text { Table 11. Testing Summary }}$

\section{Drop Test}

A collision can also result in the loss of structural integrity. Tanks must be tested against structural failure when they are subjected to severe forces. Drop tests were performed on the tanks from varying heights. The angle at which each tank was dropped was also varied. Tanks were dropped on their sides, on the top of the domes, and on angles incident to the side of the domes. Again, the results from the tests were successful for each tank, with no tank suffering a release of pressure. The drop test parameters are summarized in Table 7.

\section{Environmental Test}

As the storage systems are intended for use on the underbodies or the trunks of automobiles, they are subjected to numerous environmental agents. Substances such as road salt, windshield washer fluid, gasoline, and methanol come in contact with a compressed storage system. The outer shell is responsible for protecting the storage system from these agents. Both the Quantum and JHU-APL groups have performed environmental testing on their tanks with positive results. The LLNL group has not tested their system against environmental hazards. SCI, their tank manufacturer, has performed acid testing on the tanks. However, these tests are limited only to the tanks, not the entire system. 


\section{Bonfire Test}

Bonfire tests are performed to test the integrity and function of both the storage system and its pressure relief valve. As was discussed earlier, a fire source external to the tank is much more likely than an internal tank fire. As is shown in Table 7, all three of the tanks have been successfully bonfire tested.

\section{$\underline{\text { Aging Test }}$}

A final set of procedures is aging testing. These procedures, performed at elevated temperatures or in the presence of moisture, simulate accelerated aging conditions. The tests help to warrant the durability and longevity of the storage systems. The Quantum aging tests are the most complete, which is partially due to the mature stage of that project. Results indicate that the Trishield tank does not lose significant performance qualities after an extended period. Results are similar for the LLNL and JHU-APL projects, although the testing procedures for those two systems are not as comprehensive. The parameters of the aging tests are summarized in Table 12 .

\begin{tabular}{|c|c|c|c|c|c|c|}
\hline \multicolumn{7}{|c|}{ Testing } \\
\hline Manufacturer & $\begin{array}{c}\text { Drop } \\
\text { Test? } \\
(\mathrm{y} / \mathrm{n})\end{array}$ & $\begin{array}{c}\text { Drop Test } \\
\text { Parameters }\end{array}$ & $\begin{array}{l}\text { Environmental } \\
\text { Testing }(\mathrm{y} / \mathrm{n})\end{array}$ & $\begin{array}{c}\text { Environmental Testing } \\
\text { Parameters }\end{array}$ & $\begin{array}{l}\text { Bonfire } \\
\text { Test }(y / n)\end{array}$ & Aging Tests \\
\hline QUANTUM & yes & $\begin{array}{l}1.8 \mathrm{~m}- \\
\text { multiple } \\
\text { angles }\end{array}$ & yes & $\begin{array}{c}\text { road splash }(\mathrm{NaCl}, \mathrm{CaCl} \text { and } \\
\left.\mathrm{H}_{2} \mathrm{SO}_{4}\right), \mathrm{H}_{2} \mathrm{SO}_{4}, \mathrm{NaOH} \\
\text { methanol/gasoline, } \\
\text { urea/ammonium nitrate, } \\
\text { windshield washer fluid }\end{array}$ & yes & $\begin{array}{l}\text { stress rupture } \\
\text { testing at elevated } \\
\text { temperature }\end{array}$ \\
\hline LLNL & yes & $\begin{array}{l}3 \mathrm{~m} \text { - } \\
\text { multiple } \\
\text { angles }\end{array}$ & yes, but limited & $\begin{array}{l}\text { acid testing performed by } \\
\text { tank manufacturer }\end{array}$ & yes & $\begin{array}{l}\text { stress rupture } \\
\text { testing at elevated } \\
\text { temperature }\end{array}$ \\
\hline JHU-APL & yes & $\begin{array}{c}1.8 \mathrm{~m} \text { - } \\
\text { multiple } \\
\text { angles }\end{array}$ & $\begin{array}{l}\text { yes, but only } \\
\text { on NG system }\end{array}$ & $\begin{array}{l}\text { sulfuric acid, sodium } \\
\text { hydroxide, methanol } \\
\text { gasoline, ammonium nitrate, } \\
\text { windshield washer fluid }\end{array}$ & yes & $\begin{array}{l}\text { accelerated testing } \\
\text { against moisture }\end{array}$ \\
\hline
\end{tabular}

Table 12. Testing Summary

\section{Conclusions}

The purpose of this analysis is not to rate the three systems against one another; rather, the goal is to present and analyze the significant aspects of three unique compressed hydrogen storage systems. However, certain strengths and weaknesses become evident when the projects are comprehensively examined.

The Quantum project's strengths are partially due to its mature development stage. Quantum has significant experience producing compressed gas systems, and the company's experience is evident in its design and testing protocols. The Trishield design is compact and augmented by the inclusion of an internal pressure regulation system. As 
with the other two projects, the project demonstrates both an effective use of composite materials and an acceptable hydrogen loss rate. A summary of the Quantum project's attributes is presented in Table 13.

\begin{tabular}{|l|l|}
\hline \multicolumn{2}{|c|}{ Quantum } \\
\hline \multicolumn{1}{|c|}{ Strengths } & \multicolumn{1}{c|}{ Drawbacks } \\
\hline $\begin{array}{l}\text { - System is in the advanced } \\
\text { commercialization stages }\end{array}$ & $\begin{array}{l}\text { • Difficulty of replacing internal } \\
\text { regulator in event of a failure }\end{array}$ \\
\hline $\begin{array}{l}\text { - Backing of strong corporate } \\
\text { partners, including GM }\end{array}$ & $\bullet$ Low volume density \\
\hline $\begin{array}{l}\text { - Compact design, including } \\
\text { integrated pressure regulation } \\
\text { system }\end{array}$ & \\
\hline $\begin{array}{l}\text { - Comprehensive testing } \\
\text { procedures, including thorough } \\
\text { aging tests }\end{array}$ & \\
\hline - High energy density possible & \\
\hline Acceptable gas loss rate & \\
\hline
\end{tabular}

Table 13. Quantum Summary

The operation of the Lawrence Livermore National Laboratory's project is complicated by its dual operating modes. This complexity may hinder its potential for adoption, as the public is accustomed to an "out-of-sight, out-of-mind" approach to vehicular filling procedures. The system may require a complete draining of the compressed system before it can be filled with cryogenic hydrogen. This process may be too complicated for the driving public to adopt. Also, the dual operation may complicate the design of a pressure regulation system. However, the dual system does allow for a more flexible system, and perhaps a more economical system. Those testing procedures that the LLNL researchers have performed have been successful, but not all have used hydrogen, which is of special concern. The group should also consider more comprehensive environmental testing on a complete system. A summary of the LLNL project's attributes is presented in Table 14. 


\begin{tabular}{|l|l|}
\hline \multicolumn{2}{|c|}{ Lawrence Livermore National Laboratory } \\
\hline \multicolumn{1}{|c|}{ Strengths } & \multicolumn{1}{c|}{ Drawbacks } \\
\hline $\begin{array}{l}\text { - Dual mode system allows for } \\
\text { maximum flexibility }\end{array}$ & $\begin{array}{l}\text { • Filling procedures difficult and } \\
\text { may be too complex }\end{array}$ \\
\hline - Acceptable gas loss rate & $\bullet$ Limited testing with hydrogen \\
\hline $\begin{array}{l}\text { - Effective insulation for cryogenic } \\
\text { operation }\end{array}$ & $\bullet$ High overall mass \\
\hline $\begin{array}{l}\text { - High volume energy density in } \\
\text { cryogenic mode }\end{array}$ & $\begin{array}{l}\text { ・ Low mass energy density in } \\
\text { compressed mode }\end{array}$ \\
\hline & $\begin{array}{l}\text { • Potential for shortened lifetime } \\
\text { if aramid fiber is used }\end{array}$ \\
\hline & $\begin{array}{l}\text { • Lack of a dual-mode pressure } \\
\text { regulator }\end{array}$ \\
\hline & $\begin{array}{l}\text { - Need for more comprehensive } \\
\text { environmental testing }\end{array}$ \\
\hline
\end{tabular}

Table 14. LLNL Summary

The Johns Hopkins University - Applied Physics Laboratory project integrates a comprehensive design with significant safety features. The system's greatest weakness is its large volume, which could hinder its integration into automotive systems. Its pressure release system is well designed, and the bumpers included on the system minimize the possibility of a serious rupture in a collision. A summary of the JHU-APL project's attributes is presented in Table 15.

\begin{tabular}{|l|l|}
\hline \multicolumn{2}{|c|}{ Johns Hopkins University - Applied Physics Laboratory } \\
\hline \multicolumn{1}{|c|}{ Strengths } & \multicolumn{1}{c|}{ Drawbacks } \\
\hline $\begin{array}{l}\text { - Urethane "bumpers" provide } \\
\text { maximum impact protection }\end{array}$ & • Low volume density \\
\hline - Acceptable gas loss rate & $\begin{array}{l}\text { - Testing procedures not entirely } \\
\text { complete }\end{array}$ \\
\hline $\begin{array}{l}\text { - Comprehensive pressure release } \\
\text { system }\end{array}$ & \\
\hline
\end{tabular}

Table 15. JHU-APL Summary 


\section{Acknowledgements}

The authors would like to thank Salvador Aceves of Lawrence Livermore National Laboratory, Neel Sirosh of Quantum Technologies, and John Wozniak of John Hopkins University - Applied Physics Laboratory for their input and assistance in the completion of this report. 


\section{References}

Johns Hopkins University - Applied Physics Laboratory

Wozniak, John. "Development of a Compressed Hydrogen Gas Integrated Storage System (CH2-ISS) for Fuel Cell Vehicles," Johns Hopkins University - Applied Physics Laboratory Report. 2002.

Wozniak, John. Personal Correspondence. Columbia, MD. July 2002.

Wozniak, John and Paul Wienhold, Rick Hildebrand, Norm Newhouse. "Development of a Compressed Hydrogen Gas Integrated Storage System (CH2-ISS) for Fuel Cell Vehicles," Peer Review Meeting Presentation. June 19, 2002.

Lawrence Livermore National Laboratory

Aceves, S.M. Personal Correspondence. Livermore, CA. July 2002.

Aceves, S.M. and J. Martinez-Frias, F. Espinosa-Loza. "Performance Evaluation of Insulated Pressure Vessels for Vehicular Hydrogen Storage," Lawrence Livermore National Laboratory Report. 2002.

Aceves, S.M. and J. Martinez-Frias, O. Garcia-Villazana. "Low Temperature and High Pressure Evaluation of Insulated Pressure Vessels for Cryogenic Hydrogen Storage," Proceedings of the 2000 Hydrogen Program Review. 2000. NREL/CP570-28890.

Quantum Technologies

Quantum Technologies Website. July 2002. www.qtww.com

Sirosh, Neel. "DOE Hydrogen Composite Tank Program,” Quantum Report. 2002.

Sirosh, Neel. Personal Correspondence. Irvine, CA. July 2002.

\section{$\underline{\text { All Projects/General }}$}

James, B. and G. Baum, F. Lomax, C.E. Thomas, I. Kuhn. "Comparison of Onboard Hydrogen Storage for Fuel Cell Vehicles.” Directed Technologies, Inc. May 1996. DOE DE-AC02-94CE50389.

Skolnik, Edward. "Compilation Of Site Visit-Based Technical Evaluations Of Hydrogen Projects 1996 - 2001.” Energetics, Inc. August 2002.

Perry, Robert H. and Donald W. Green. Perry's Chemical Engineer's Handbook. McGraw Hill Text. New York, 1997. 